


\author{
U. S. DEPARTMENT OF COMMERCE \\ JESSE H. JONES, Secretary \\ NATIONAL BUREAU OF STANDARDS \\ LYMAN J. BRIGGS, Director
}

CIRCULAR OF THE NATIONAL BUREAU OF STANDARDS C433

\title{
PHYSICAL PROPERTIES OF DENTAL MATERIALS
}

\author{
By \\ WILMER SOUDER and GEORGE C. PAFFENBARGER
}

[Issued February 6, 1942]

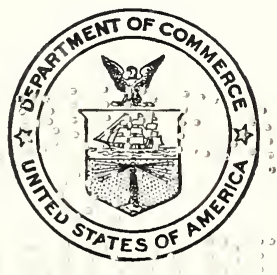

UNITED STATES

GOVERNMENT PRINTING OFFICE

WASHINGTON : 1942

For sale by the Superintendent of Documents, Washington, D. C. - - - - Price 75 cents 


\section{APR 1 ก 1942 \\ 53163}

\section{FOREWORD}

\section{NATIONAL BUREAU OF STANDARDS}

This publication on the physical and chemical properties of dental materials consummates twenty-three years of research at the National Bureau of Standards. The research developed out of a request by a Federal department for assistance in formulating a specification for dental amalgam. During 1919-1922 the Bureau carried on the work alone; from 1922-1928 the Weinstein Research laboratories cooperated; since 1928 the American Dental Association through its Research Commission has maintained a research staft' at the Bureau to cooperate in the program. Since 1919 more than a hundred reports of the work have been printed in various journals and in Bureau publications. The present publication is in reality a condensation and a résumé of all of these reports.

The cardinal purpose of the research program has been and now is (1) the formulation of specifications, (2) the investigations of the effect of dental technic upon the properties of the materials and (3) the translation of items (1) and (2) into dental practice. The latter has been, to a large extent, accomplished by publishing, through the American Dental Association, lists of materials which were certified by the manufacturers to conform to the specifications, and were found to so comply when tested at this Bureau. This compliance testing is done without charge to the manufacturers, the cost being assumed by the Bureatia aid the Lissociation."

The work has been efective because we nave bad the active assistance of the manufacturers of dentai supplies and the hearty cooperation of dentists throughout: the Inited States. Its value to the citizens of our country can hardly bę ovẹtemphasized. 


\section{AMERICAN DENTAL ASSOCIATION}

It was a fortunate day for the American Dental Association when Doctors Barber, Brown, and Volland of the Research Commission went to the National Bureau of Standards in 1927 to complete the details of the cooperative research, which has been so valuable to the dental profession.

We have been able to invest wisely our allocations to research in the physical sciences. Our associates have been wholeheartedly welcomed by the Bureau. Together we have, as this volume will show, pushed physical research to its highest point in the history of dentistry.

The supervision of the work, the assumption of responsibility for the data, and the complete publication of all findings by the Bureau have given us an authoritative position seldom possible in such fields of research.

Upon this foundation, we are able to issue lists of certified materials, backed by independent tests; criticize technics; and advise the profession accurately.

We hope to be able to maintain this cooperative relation with the National Bureau of Standards until all our mutual aims and benefits have been attained. 



\title{
PHYSICAL PROPERTIES OF DENTAL MATERIALS
}

\author{
By Wilmer Souder and George C. Paffenbarger*
}

\section{ABSTRACT}

This publication assembles pertinent data from numerous separate reports on dental materials and dental technics. It deals specifically with the restorative and accessory materials such as amalgam, gold alloys, denture base resins, cements, investments, and impression materials.

The details of test methods (many of which were developed at this Bureau), including illustrations and descriptions of testing equipment, will be of particular value to dental schools and research laboratories planning the installation of testing equipment.

Sufficient data from previous publications are included to document the conclusions stated and to justify the limits set in the specifications, which are reproduced in abstract form.

The data are, on numerous occasions, discussed under two headings, namely, theoretical significance and technical applications. This method necessitates a certain amount of repetition which, however, may be excused since it makes possible the addressing of two groups of readers in one publication. Furthermore, the combining of these two phases of the research gives greater clarity and unification to what might otherwise appear to be collections of data on unrelated materials.

The dentist will find explanations for some of the many difficulties which confront him daily, such as excessive expansion of amalgam, shrinkage of gold inlays, and solubility of cements. He will find technics suggested that will reduce the number of these difficulties and give him a greater confidence in his ability to render to his patients the best dental service possible under the present development of the science and art of restorative dentistry.

\section{CONTENTS}

Page

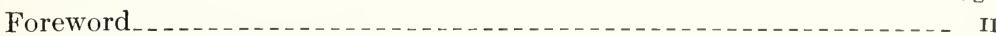

National Bureau of Standards $\ldots \ldots \ldots \ldots \ldots \ldots$ II

American Dental Association _..................... III

I. General introduction $\ldots \ldots \ldots \ldots$

II. Metals and alloys

1. Dental amalgam alloy _...

2. Dental mercury $\ldots \ldots \ldots$

3. Gold and its alloys in dentistry

4. Base metal alloys _...

III. Ceramic materials

1. Investments for gold alloys _.............. 80

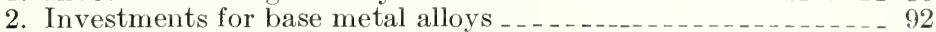

3. Cements $\ldots \ldots \ldots \ldots \ldots$

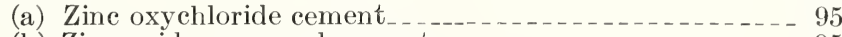

(b) Zinc oxide-eugenol cements

(c) Copper phosphate cements

(d) Zine phosphate cements _........................ 96

(e) Silicate cements_...

(f) Silicate zinc phosphate combination cements_._. _._. 136

* Research Associate at the National Bureau of Standards, representing the American Dental Association. 


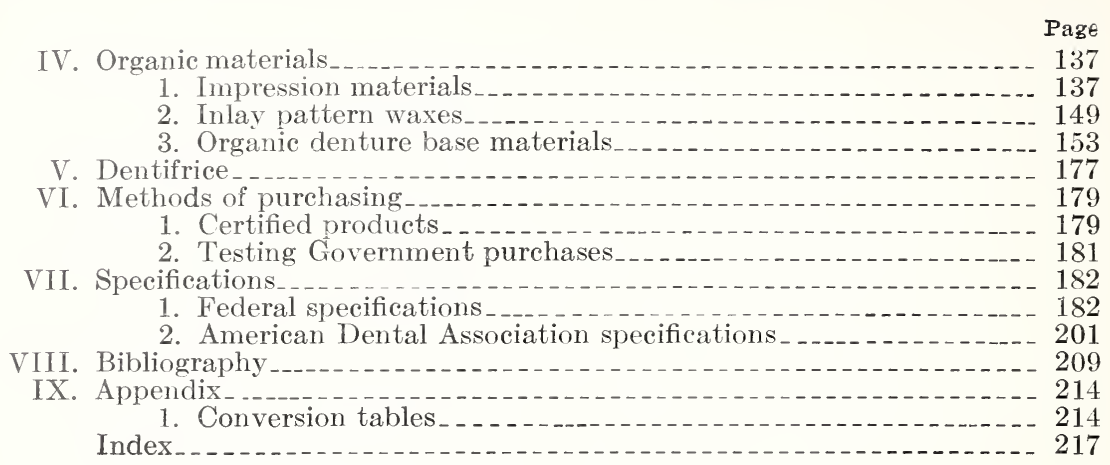

\section{GENERAL INTRODUCTION}

The dental research program at the National Bureau of Standards is a direct outgrowth of a dental amalgam investigation initiated in 1919 at the request of the War Department. The Bureau tested the amalgam alloys submitted at that time and showed serious deficiencies in most of them [1]. ${ }^{1}$ The investigation has been continued and extended to include additional materials until it now embodies a research of major proportions centering around restorative materials and technics [48].

This publication is offered as a compilation of information selected from the more than 100 separate publications (pages 209 to 213) on the various phases of dental research conducted at this Bureau. The difficulties encountered in securing the original reports, most of which are out of print, some of which are in foreign publications, and all of which are available in very few dental or technical laboratories, make it desirable to publish a summary at this time. Previous or contemporary researches in other laboratories (pages 213 to 214), except in rare instances, will not be discussed in this report.

Test data and details of testing methods will be presented in sufficient quantity to enable the student of dental materials to make an independent estimate of the significance of the data.

During the years 1922-28 the Bureau had the cooperation of the Weinstein Research Laboratories, whose research associates worked at the Bureau. From 1928 to date the research associates of the American Dental Association have continued the cooperation through its Research Commission. The personnel of the staff assigned to the dental research included: For the Government, Wilmer Souder, C. G. Peters, Peter Hidnert, Aaron Isaacs, N. D. Hawkins III, and I. C. Schoonover; for the Weinstein Research Laboratories, R. L. Coleman, Dorothy Snover, W. H. Swanger, and W. A. Poppe; for the American Dental Association, N. O. Taylor, Howard Berger, G. C. Paffenbarger, W. T. Sweeney, J. R. Beall, and H. J. Caul. The National Bureau of Standards has supplied standardized testing equipment, laboratory facilities, and consulting services as needed for the effective progress of the researches.

The cooperation of hundreds of active members of the American Dental Association, members of faculties of dental schools, and officers of the Government's military dental services has been of inestimable

1 Numbers in brackets indicate literature references in section VIII of this Circular. 
value in making clinical appraisals of the findings. The manufacturers of dental materials have maintained a friendly attitude toward the research and have been unusually helpful in giving the Bureau their assistance on problems of mutual interest.

The results of these various cooperative efforts are, first, a better understanding of the fundamental properties of dental materials; second, the formulation of specifications which point out high-quality materials; and third, the selection of the best technics to be employed in using these materials.

\section{METALS AND ALLOYS}

\section{Dental amalgam alloy}

Despite the many defects and dissatisfactions which have been registered against dental amalgam, there shine through the entire record numerous instances where it has approached perfection as a restorative material. These excellent restorations stimulated those of an investigative turn of mind to make efforts to find the explanations for the occasional apparent erratic behavior of dental amalgams. Many of the problems connected with dental amalgams have been solved, and today amalgam restorations are being placed with increasing assurance of satisfactory service.

As early as $1910 \mathrm{G}$. V. Black had discovered the effects of chemical composition and physical structure on dimensional change, strength, and flow of amalgam restorations. In fact, the Bureau was guided by his findings in its adoption of methods for testing this material [1]. Chemical composition, dimensional change on setting, flow under constant load, ultimate crushing strength, and technic were accordingly regarded as the chief factors to be controlled. Many amalgams were tested and shown to shrink as they crystallized. Others were found to be weak or soft. Such restorations yield under the stresses of mastication and impacts from opposing teeth. Preliminary tests indicated that instruments more accurate than those used by Black were desirable and that rigid uniformity in mixing technics would have to be observed if data free of contradictions were to be secured.

Chemical composition.- The chemical composition of a dental amalgam alloy is important, but composition alone is not sufficient to indicate all the properties of the finished amalgam. 'These properties are influenced by the size of the cut particle of alloy, the degree of cold-working imparted by the cutting tool, the heat treatment of the particles, the time and energy expended in mixing and packing the amalgam, and the amount of mercury which is permitted to combine with the alloy. These variables have such a profound effect upon the restoration that it is only through a rigid compliance with the manufacturers' instructions, verified by practical and laboratory tests, that the dentist can hope to develop the best qualities of these alloys.

The average composition of 51 alloys tested in 1938 [76], all of which passed the specification for dental amalgam (page 182), is as follows: Silver, 68.43 percent; tin, 26.33 percent; copper, 4.23 percent; and zinc, 1.04 percent. This formula has no special virtue. The variations of individual elements for these 51 alloys were as follows: Silver, 66.7 to 74.3 percent; tin, 25.3 to 27.7 percent; copper, 0 to 5.2 percent; and zinc, trace to 1.7 percent. The effects of these variations in composition were not sufficient to cause the alloys to fail in 
test. A few alloys having compositions near this average composi. tion (within less than $1 / 2$ percent) failed to meet the specification. Obviously items other than slight variations in chemical composition affect the behavior of dental amalgam alloys.

The chemical composition limits in the specification [10] first recommended by the Bureau were established after a study had been made of those alloys which were known to yield most consistently satisfactory restorations. The compositions appeared to be empirical in so far as metallurgical relations were concerned. The National Bureau of Standards has not, up to this time, attempted to explain the complex reactions that take place among the elements silver, tin, copper, zinc, and mercury during the mixing and setting of dental amalgam. Gayler [103] has made a definite contribution in this field. Perhaps the most important finding is her recommendation that the tin content of the alloy should be between 25 and 27 percent if the shrinking and expanding tendencies are to be kept at a minimum.

Confusion as to the relative amounts of silver in an alloy or in a restoration may be prevented by remembering that the word "alloy" refers to the unamalgamated particles and the word "amalgam" refers to the amalgamated material, that is, alloy plus incorporated mercury.

Many alloys have the approximate average formula given above. Those which are satisfactory are carefully cut, sifted, annealed, amalgamated, and tested for physical properties by their producers before they are placed on the market. Alloy filings carelessly prepared, unannealed, and of nonuniform sizes were frequently encountered 20 years ago, although seldom today.

Nontarnishing amalgam.-Nontarnishing amalgam has been sought for years. Precious metals, such as gold and platinum, have been added to dental amalgam alloys in attempts to eliminate or to minimize the tarnishing of amalgam restorations in the mouth. Clinical reports frequently do claim superior tarnish resistance for the special alloys. It is thought that the improved surface and the enthusiastic approvals of such special alloys arise from the extra care used in making the trial restoration. Naturally the cooperator making the trial restoration is careful to finish the margins properly and asks the patient to return after 24 hours for a final polish. This final polish, after 24 hours, is very important as it removes the bloom or frosty surface that appears soon after the amalgam sets. This should be removed from all amalgam restorations.

The Research Commission of the American Dental Association made tests on one of these special alloys [83]. Laboratory tests showed no difference in tarnish resistance between the special alloy and standard (specification) alloys. Individual packages of the two alloys were therefore prepared and sent to 50 cooperators, who placed trial restorations of these alloys designated as A and B. One was the so-called nontarnishing, and one was a standard alloy. The cooperators' reports showed no superiority whatever for the special alloy. Where the conditions were identical for alloy $\mathrm{A}$ and alloy $\mathrm{B}$, no difference was discernible. One alloy was said to contain small quantities (1.5 percent) of chromium and tungsten. The chemical analysis showed 71.6 percent of silver, 25.5 percent of tin, 0.2 percent of copper and lead, and 2.7 percent of zinc. Chromium and tungsten were not 

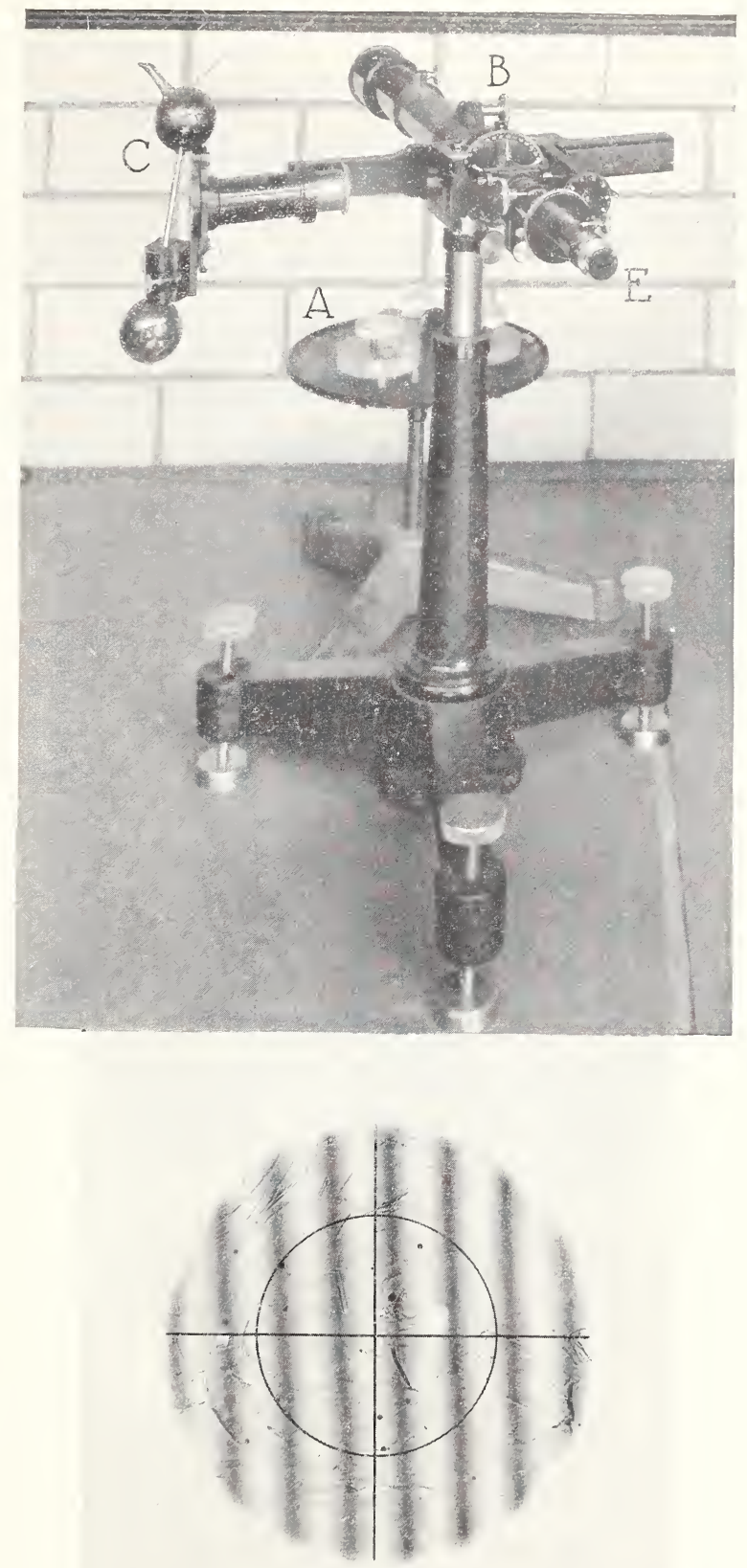

D

FiguRE 1.-Dental interferometer and viewing device.

$A$, battery of three interferometers on table. $B$, viewing deviee whieh collects light from helium-filled bulb, $C$. and transmits it to the interferometers, $A$. The fringe pattern, $D$, formed by the interference of the light wave train passing through various distances, is observed through eyepiee, $E$. When the amalgam specimen changes in length the number of lines (fringes) in the pattern ehanges.

The loss (or gain) of one fringe in the pattern, $D$, on this interferometer represents a ehange in length of the specimen of approximately one-quarter micron ( 0.00001 inch). 
present in appreciable quantities. Spectroscopic analysis indicated a trace of chromium, probably 0.001 percent, and no trace whatever of tungsten. Doubtless the promoters of this alloy were deceived by the reports from dentists who had given greater care to finishing and polishing the restorations of a new alloy.

Improvements in chemical composition, technics, or other items can readily be verified through accurate laboratory tests coupled with properly controlled clinical observations. Dentists should be wary of those mysterious claims of excellence which cannot be supported by reliable research institutions. Despite the determination of an operator to make an unbiased test, it is well to have a few tests made on materials whose trade names are not disclosed to the operator.

Dimensional change. - One of the advantages in the use of dental amalgam is the ease with which it can be prepared, condensed into irregular cavities, and carved during the plastic stage to exact dental anatomy. This advantage can, however, be offset by a shrinkage which may develop as the amalgam sets. Among those items which tend to promote shrinkage are excessive amounts of tin, finely cut particles, excessive grinding in mixing, and excessive packing pressures.

Many instruments have been devised for measuring dimensional changes in hardening amalgam. Glass tubes and dyes gave visual results when the amalgams shrank. If the amalgams expanded and the walls of the tubes were thin, the tubes were split by the expansion. Such results were little more than qualitative. The present day "air pressure" devices belong in the same category. 'The demand for quantitative data resulted in the development of multiplying lever systems, special microscopes and carriages, comparators, micrometers, mirrors and levers, multiplying gears and chains, and numerous other devices which might under special conditions give fairly accurate information on these changes in dimensions.

Dental interferometer and tests.-The National Bureau of Standards selected the interferometer as the most satisfactory instrument for measuring the dimensional changes in dental amalgams. The interferometer and viewing device are shown in figure 1 . This instrument functions with the minimum of contacts, levers, and adjustments. Its hysteresis or lag factor is a minimum. The measurements are recorded in terms of light waves, the most accurate standards of length known to science. The differential interferometer is very convenient and remarkably accurate for measuring changes in length of 1 to 25 microns, i. e., in the region of ten-thousand ths of an inch. The almost universal adoption of the interferometer by manufacturers, schools, and testing laboratories has reduced the contentions as to the accuracy with which tests on dental amalgam can be made. Figure 2 is a drawing of an adjustable differential interferometel.

This interferometer consists essentially of two flat plates, $A$ and $B$, of glass or fused quartz. The top plate $A$ is supported by the two permanent pins $C$ and $D$ and the specimen pin $E$. The interference phenomenon takes place between the light reflected from the bottom surface of plate $A$ and the light reflected from the top surface of plate $B$. Pins $C$ and $D$ are adjusted to the same height. The top of pin $E$ should be of nearly the same height. (If it is of exactly the same height the interference pattern will not be the desirable type for precision measurements of length changes taking place in the amalgam specimen, pin $E$.) With pin $E$ shorter (or longer) than pins $C$ and $D$, 

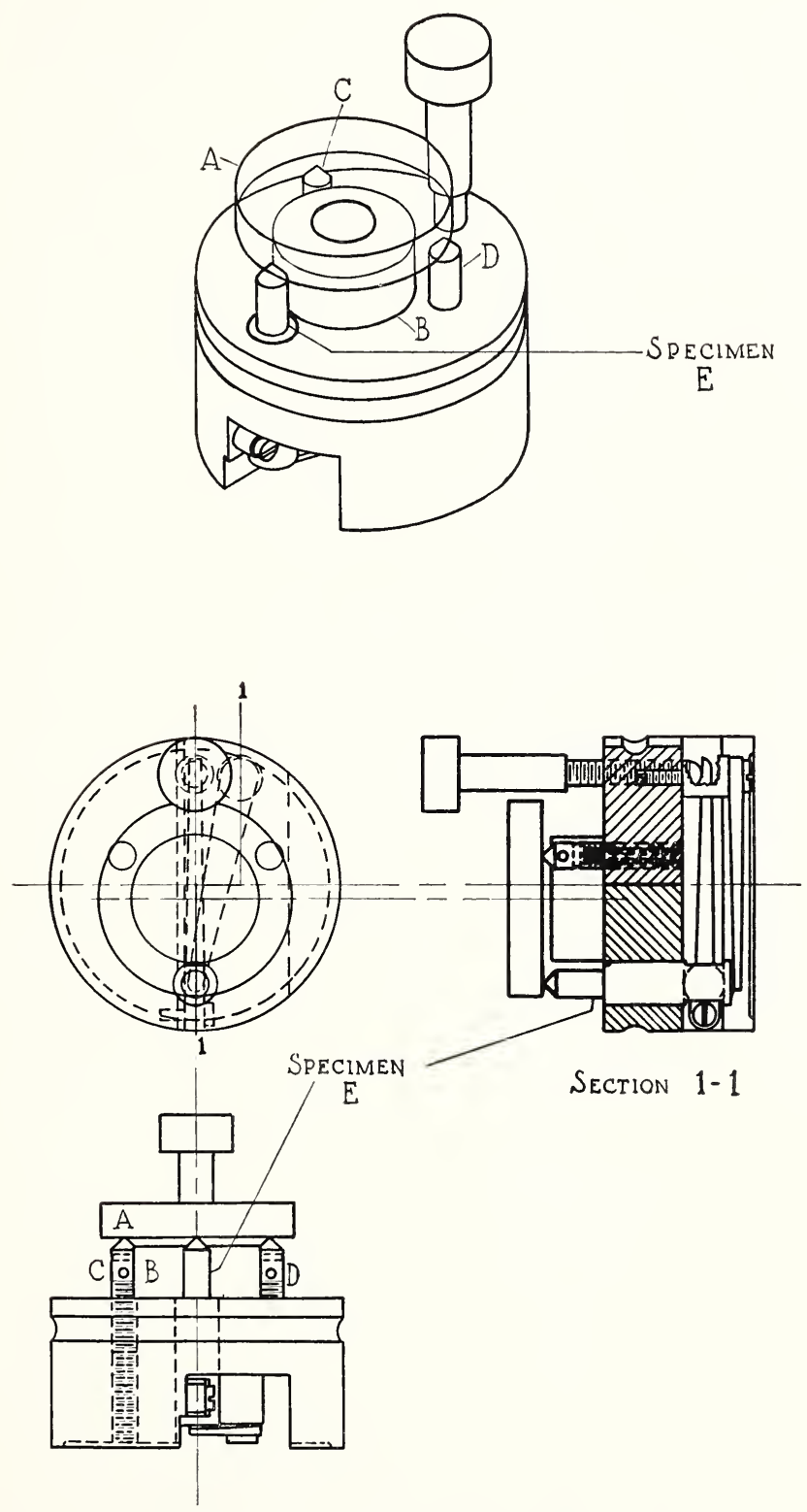

FiguRE 2.-Adjustable interferometer.

$A$, Top plate; $B$, bottom plate; $C$ and $D$, permanent pins; $E$, specimen which can be raised or lowered by the mechanism shown in section 1-1. 
the wedge-shaped air space between plates $A$ and $B$ will produce a line pattern of interference, as shown in figure $1, D$, when monochromatic light (that is, light of a single wavelength) is projected on these plates by the viewing device, reflected from the plates, collected by the viewing device, and passed to the eye. The difference in distance down and back through this wedge of air, at any adjacent lines shown in figure $1, D$, is equal to one wavelength of light. In other words, the wedge of air is thicker under one line of the pattern, by approximately $1 / 2$ wavelength of light, than it is under an adjacent line of the same pattern.

Translated to practical terms, the interferometer showing 10 fringes between the tops of pin $C$ or $D$ and pin $E$ indicates that the specimen $E$ is 5 light waves longer (or shorter) than pin $C$ or $D$. If this fringe pattern changes progressively to say 26 fringes during a period of 24

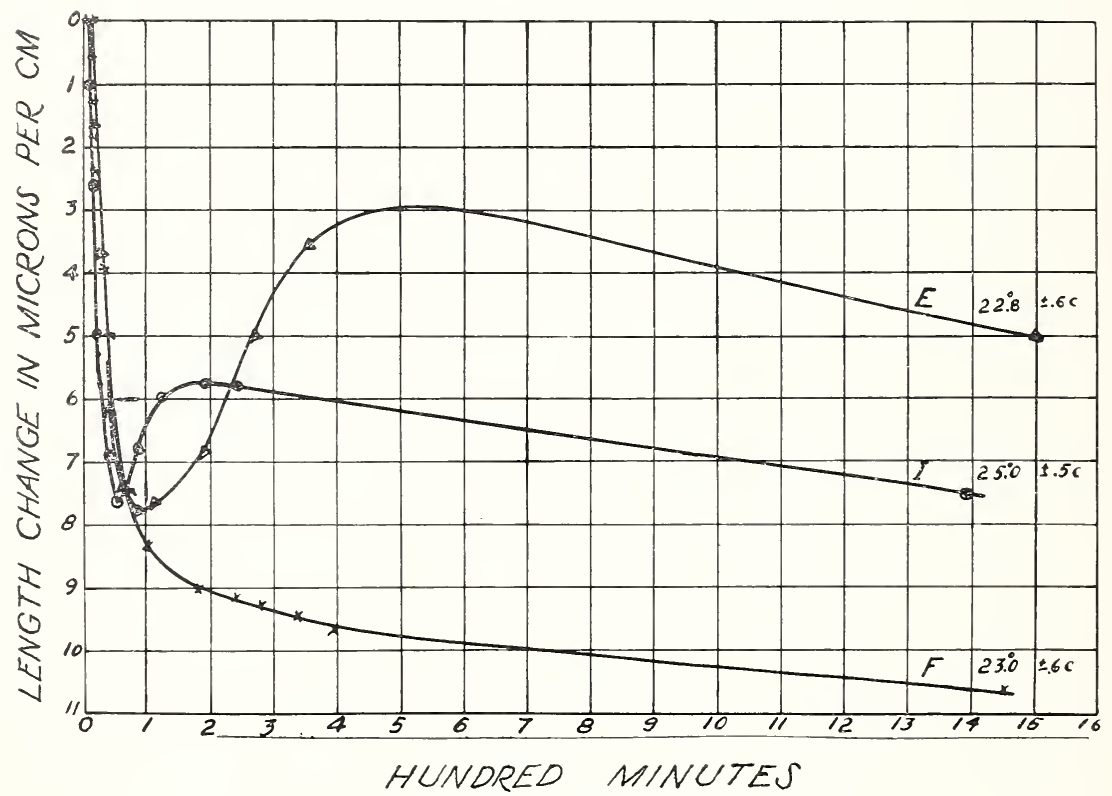

FigURE 3.- Shrinkage of amalgam during setting.

These curves, showing the shrinkage of three amalgams in current use in 1919, indicate by their shape that certain chemical and physical reactions are taking place during the setting of the amalgam. The precise nature of these reactions are not known and are difficult to investigate because most dental amalgams contain at least five elements. From the slope of the right-hand portion of the curves, it would appear that the shrinkage would continue with time.

hours, the specimen under test will have changed its length by 16 fringes, or 8 times the wavelength of the light used. 'The wavelength of the yellow helium radiation is 0.5876 micron. Roughly speaking, the loss or gain of each fringe indicates a change in length of the specimen of 1/100,000 inch. For further details relative to exact values, methods of adjusting the interferometer and interpreting the length changes, the reader should refer to a college text on optics.

The interferometer has not, as we shall see later (page 29), given concordant results in the hands of all operators. The differences in data submitted by different observers or by the same observer are not always chargeable to the instrument. They may result from the 
nonuniformity of the test specimens, contamination in mixing (see page 11), or from the failure of the operator to master the technic of handling the interferometer.

Inasmuch as the alloys selected by dentists as most satisfactory had expansions of the order of 5 to 10 microns per centimeter of length, the interferometer is the ideal instrument for testing dental amalgams.

The setting changes of 16 dental amalgams were determined in 1919 (table 1) [1].

Figure 3 shows the length of alloys $E, F$, and $I$ over a 24-hour period. Unfortunately, these alloys show shrinkages of from about 5 to over 10 microns per centimeter during a 24-hour period. In 1919 the use of such alloys was widespread, but since accurate methods and instruments for testing amalgam became available alloys having these shrinkages are practically obsolete in dental practice in the United States.

TABLE 1.-Test data on amalgams (1919)

[All tests on physical properties made at room temperature]

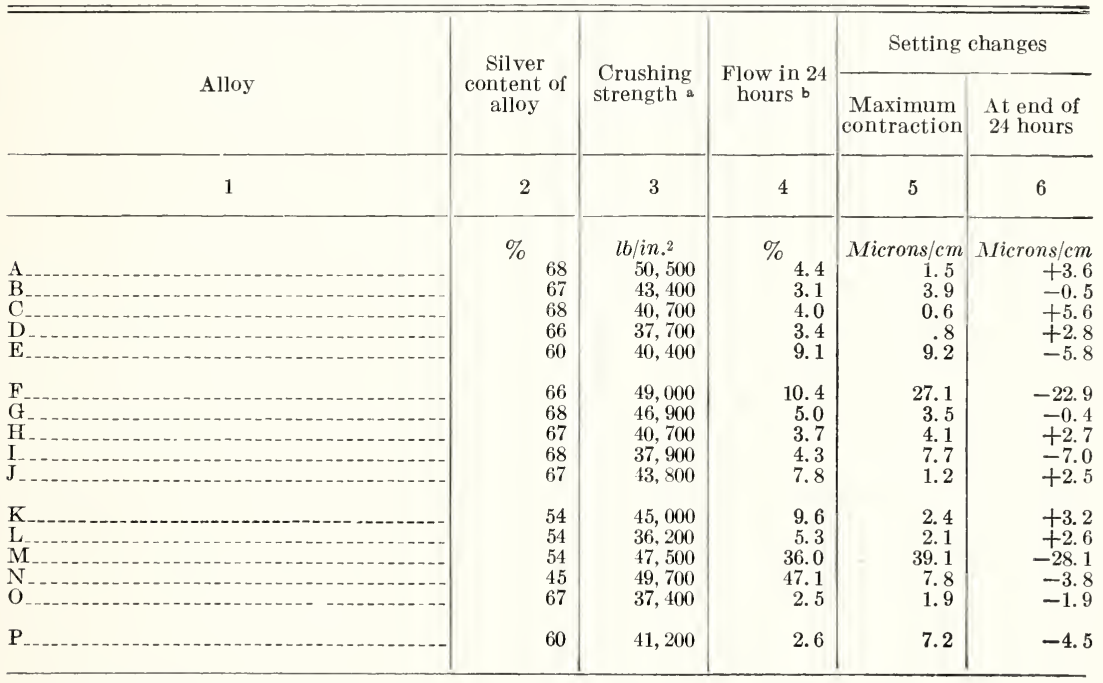

a Crushed 14 days after packing.

b Load applied 2 hours after packing.

The effect of time of trituration upon dimensional changes is shown in figure 4. In a series of experiments, one alloy, designated $\mathrm{C}$, figure 4, was amalgamated in approximately 3 minutes and packed in the usual manner. Another specimen of the same alloy (specimen C-4) was mulled in the hand for 35 minutes before packing. Mercury was added as needed to keep the mass plastic. 'The first specimen, $\mathrm{C}-1$, had a setting expansion of over 4 microns per centimeter at the end of 24 hours. Specimen number C-4 was rendered worthless as a filling material as it showed a 15 -micron contraction at the end of 24 hours. This induced shrinkage can be developed in practically all dental amalgam alloys, and in some it requires less than 5 minutes of over-trituration and mulling to produce it. Heavy grind- 
ing in a rough mortar for 3 minutes mar, with some allors, derelop shrinkage. Such dangers make it necessary for the manufacturer to prepare a trial technic for his alloy, test the alloy, and make such adjustments in the technic, or alloy, as are necessary to bring out the desired properties. Obviously, the dentist should follow this final technic.

The effects of testing an amalgam at mouth temperature instead of at room temperature are shown in figure $j$. Later tests on other alloys, following a more definite technic, gave somewhat irregular results. Some alloys appeared to expand slightly more at $37.5^{\circ} \mathrm{C}$

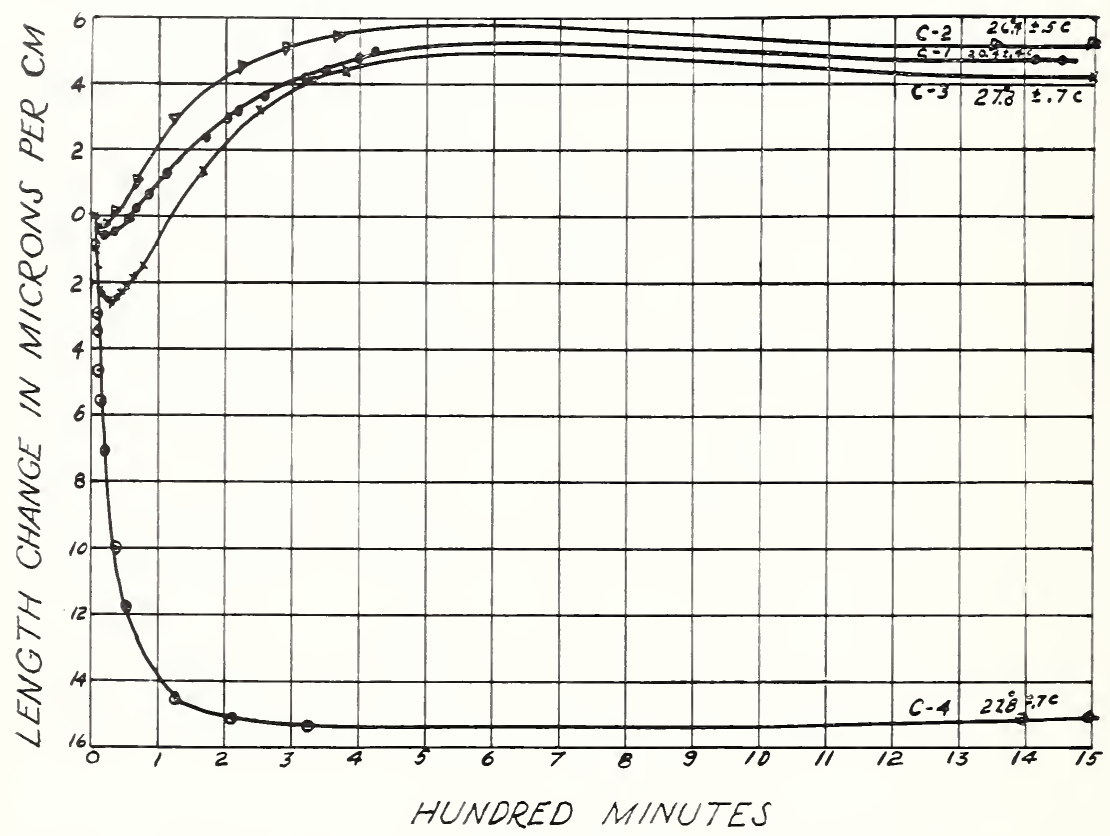

FIGURE 4.-Effect of certain variables upon the dimensional change which takes aceat during the setting of an amalgam.

Amalgam $C$ when mixed in the usual manner, that is, 1 minute of light trituration in the mortar and 2 minutes mulling in the hand gave a very farorable expansion of approximately 5 microns (curre $C-1$ ). The expansion of amalgam $C$ when mulled in the hand for only 1 minute was over 4 microns (curve $C-3$ ). This allor did not show large fluetuations in expansion that would be at tributable to reasonable variations in the mixing technic. However, when the amalgam was subjected to a long mulling (35 minutes) in the hand a large shrinkage occurred (curve $C-4$

The allor from which the amalgam was made appeared to be fully aged, because heating it for 3 hours at $120^{\circ} \mathrm{C}\left(248^{\circ} \mathrm{F}\right.$.) did not significantly change the expansion of the amalgam (curve $\left.C-2\right)$.

The approximate composition of amalgam $C$ was silver 68 percent; tin, 26 percent; copper, 5 percent; and zinc, 1 percent.

$\left(99.5^{\circ} \mathrm{F}\right)$ than at room temperature, while others appear to expand less at $37.5^{\circ} \mathrm{C}$.

Length changes that take place in an amalgam during a period of months or vears have been discussed frequently [129]. R. C. Angel and TI. S. Crowell. K. H. Strader, and E. IV. Skinner and J. R. Jarabak have demonstrated that "palming" (mulling in the hand) of a dental amalgam may cause excessive expansion with time (unpublished private comminications). Tests made at the National Bureau of Standards confirm this.

Three tests were necessary to locate definitely one or more of the 
causes of excessive expansion. The first or control test was made by amalgamating clean, dry alloy particles in a mechanical amalgamator, and condensing the test specimen in a steel mold without at at any time touching the amalgam with the hand. This specimen when tested in the interferometer showed the normal, expected, and desirable expansion of 8 microns per centimeter at the end of 24 hours. The specimen did not change so much as 0.5 micron during the next 30 days.

In the second test the same alloy and technic were employed, except that the amalgam was mulled in the palm of the hand, which was moist with perspiration. The expansion was near the normal during the first 24 hours when compared with that of the first speci-

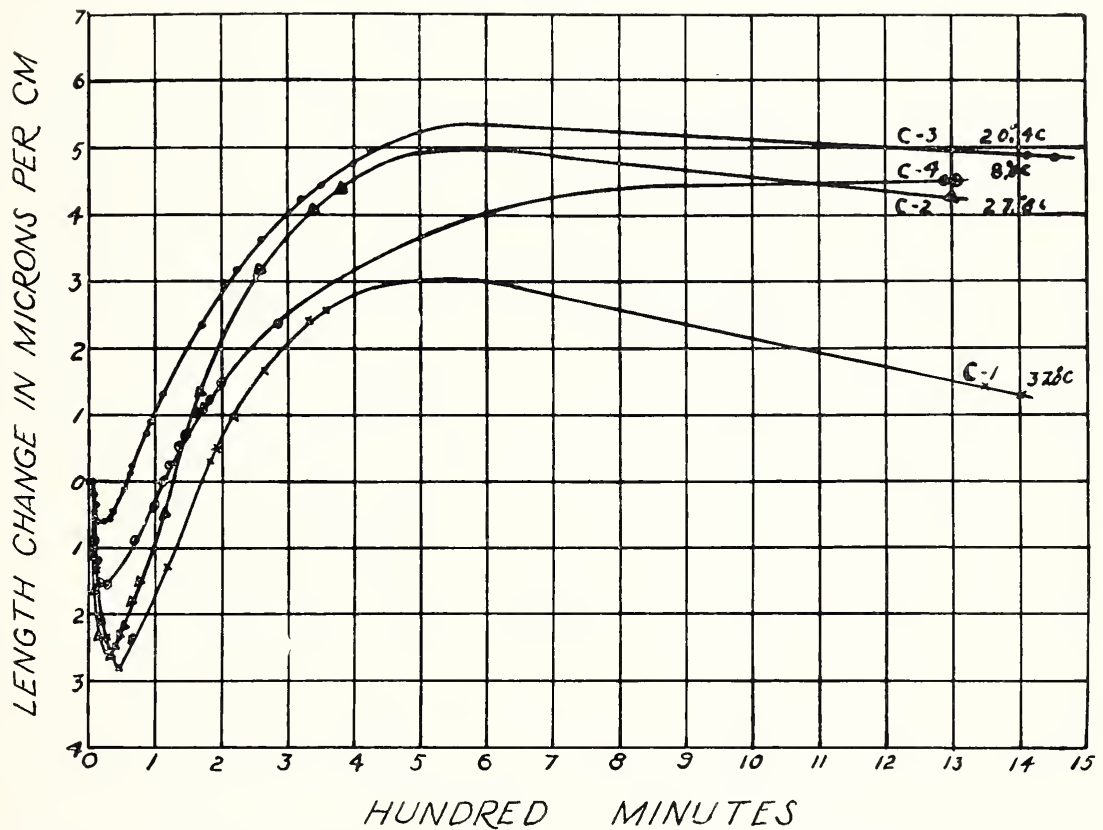

FIGURE 5.-Setting changes of amalgam $C$ when held at different temperatures.

men. The expansion of this contaminated amalgam continued each day thereafter at a fairly uniform rate for about 30 days, after which time the expansion appeared to have been completed at a total value of slightly more than 200 microns per centimeter.

The third test specimen was prepared in the same manner as the first except that a drop of saturated sodium chloride solution was added to the alloy and mercury before amalgamation. This specimen also expanded excessively; in fact, almost exactly the same amount as the palmed amalgam used in the second test. All the tests were made at $37^{\circ} \mathrm{C}$.*

Sodium chloride (common salt), an ingredient of perspiration, therefore appears to be one of the causes of excessive expansion. Precaution against this contamination is simple: use the mortar and

\footnotetext{
*Recent researches at this Burcau prove this excessive expansion develops from hydrogen gas generated when alloy containing zine is contaminated with salt solution during amalgamation. As the amount of gas increases, pressure pockets from which expand the specimen or cause blisters to appear on the surface. (Sce p. 24.)
} 
pestle or the mechanical amalgamator to amalgamate the allor, and do not mall it in the hand unless the hand has been freed of all foreign materials.

Qualitatire tests. - Thile manr dentists and studs clubs hare been interested in measuring the length changes taking place in dental amaloams. few have felt justified in spending sereral hundred dollars for an interferometer to be used in making the measurements. Qualitatire measurements of such length changes can be made by using specimens of amalgam, $1 \frac{1}{2}$ to 2 inches long and $1 / 8$ inch in diameter, formed in a split steel mold. and measured from time to time with a 1- to 2-inch micrometer caliper. The amalgam rod must be packed and remored from the mold not later than 15 minutes after trituration is started.

A steel taper mold is also used extensirely for these qualitative tests. A convenient size is a round flat plate $\overline{-1 / 2}$ millimeters in thickness haring a tapered hole 10.00 millimeters in diameter at the top. and 9.95 millimeters at the bottom. The mold should be attached to a flat base. The amalgam specimens should be packed flush with the top and bottom surfaces and pushed from the mold not later than 15 minutes after trituration is started. The specimens can be tried in the tapered carity at intervals to determine whether or not they are shrinking or expanding. Fifty microns contraction across the 1-centimeter diameter, will permit the specimen just to pass through the mold, while 50 microns expansion will just prevent it from entering the mold. Intermediate ralues of contraction or expansion may be estimated br the amount of projection through or elevation abore the mold. A change of 1 micron in diameter will thus cause a change of 150 microns in the position in which the plug will seat itself in the tapered carity. Obriously, the tapered carity of the mold must be reamed and polished rery accurately and the temperature must be the same for all measurements if reliance is to be put in the determinations. A specimen must not be left in the mold between measurements, as slight rariations in temperature or the expansion of the amalgam mar cause the specimen to stick and be distorted.

These qualitatire methods are not satisfactory for use in testing amalgams for compliance with specifications. Ther will. however, show the approximate length changes produced by undertrituration, orertrituration. and excessire amounts of mercury left in the specimen. Ther will disclose shrinking amalgams and excessirely expanding amalgams and will prove rerr instructive for study clubs. The tapered mold is an especially impressive demonstration instrument for use before students and clinics.

This moid has a further use in standardizing inlar technics. Tax patterns, prepared in the steel caritr. can be reproduced in gold through a number of rarring technics and the gold restorations referred back to the steel caritr for an approximate determination of the precision to be expected from the rarring technics.

Thermal expansivity.- Thermal expansions of teeth and amalgams were measured by the Bureau in 1919 [1] by the interferometer method. The specimens of teeth dried so rapidly that it was not possible to make satisfactory. or significant. measurements of the thermal expansion of fresh specimens of teeth in air. The interferometer and new specimens were therefore placed under water and the measurements made as the temperature of the water was in- 
creased. The wet specimen undoubtedly represents more accurately the normal condition of the tooth. The value of $8.6 \times 10^{-6}$ (sometimes written 0.0000086 ) per degree centigrade is thought to be a reasonably accurate average value for the thermal expansivity of human teeth.

Figure 6 and table 2 give additional test data. The figure shows a change in the root specimen when heated above $50^{\circ} \mathrm{C}\left(122^{\circ} \mathrm{F}\right)$. The change was smaller for the crown specimen. The demand for a restorative material having approximately the same expansion as the tooth can be met by the silicate cements, one of which had a coefficient of $7.6 \times 10^{-6}$ per degree centigrade. These cements are discussed in a later chapter (p. 110).

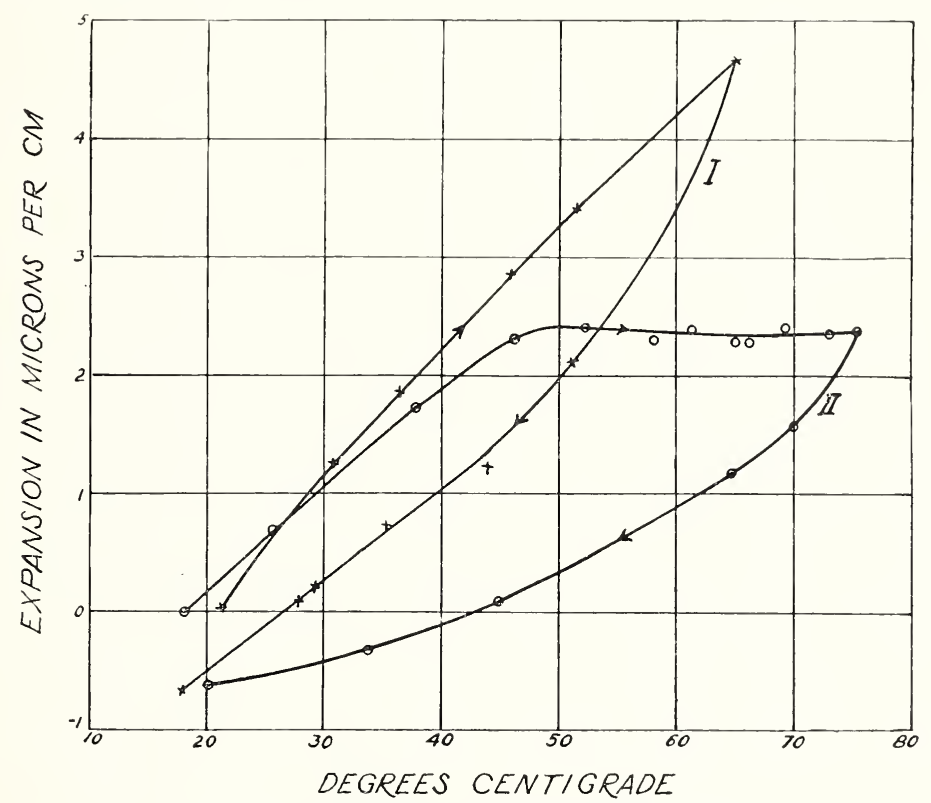

FIGURE 6.-Thermal expansion of teeth.

Curve $I$ was obtained for a specimen taken from the crown of a large molar; curve $I I$, for a specimen from the root of a cuspid.

TABLE 2.-Average coefficients of expansion of some materials used in dentistry [Range $20^{\circ}$ to $50^{\circ} \mathrm{C}\left(68^{\circ}\right.$ to $\left.122^{\circ} \mathrm{F}\right)$ ]

\begin{tabular}{|c|c|c|c|}
\hline Material & $\begin{array}{l}\text { Coeffi- } \\
\text { cient }\end{array}$ & Material & $\begin{array}{l}\text { Coeffi- } \\
\text { cient }\end{array}$ \\
\hline Tooth (root) & $\times 10^{-6}$ & Zine & $\begin{array}{r}\times 10^{-6} \\
29.2\end{array}$ \\
\hline Tooth (across crown) & 11.4 & Tin $\ldots$ & 22.3 \\
\hline Tooth (root and erown). & 7.8 & Copper & 16.8 \\
\hline Cement (dental-silicate) & 7. 6 & Aluminum & 23. 1 \\
\hline Amalgam (minimum) & 22.1 & Steel $\ldots \ldots$ & 11.0 \\
\hline Amalgam (maximum) & 28.0 & Rubber (maroon base) & 56.0 \\
\hline Porcelain (Bayeux) & 4.1 & Rubber (olive base) ... & 80.0 \\
\hline Gold & 14.4 & Resin-vinyl (denture) & 71. 0 \\
\hline Platinum & 9.0 & Resin-phenol-formaldehyde (denture) & 79.0 \\
\hline Silver & 19.2 & Methyl methacrylate resin & 81.0 \\
\hline Mercury (linear) & 60.6 & Celluloid & 135.0 \\
\hline
\end{tabular}

$406035^{\circ}-42-2$ 
Similar tests were made on specimens of dental amalgam. The amalgam specimens were not wet as there was no indication that atmospheric humidities affected the specimens. Nonzinc, high-silver, and low-silver alloys were used to make specimens. The average expansion for specimens several weeks old is given as $25.4 \times 10^{-6}$ per degree centigrade at or near mouth temperatures (fig. 7, and table 2). This value is approximately three times the value for the expansion of the tooth. This is one of the reasons why the dentist must use an amalgam which will expand slightly when it sets. Otherwise, as the tooth and amalgam restoration are cooled, the restoration will shrink away from the tooth. It is unfortunate that dental amalgam has a coefficient of thermal expansion approximately three times as great

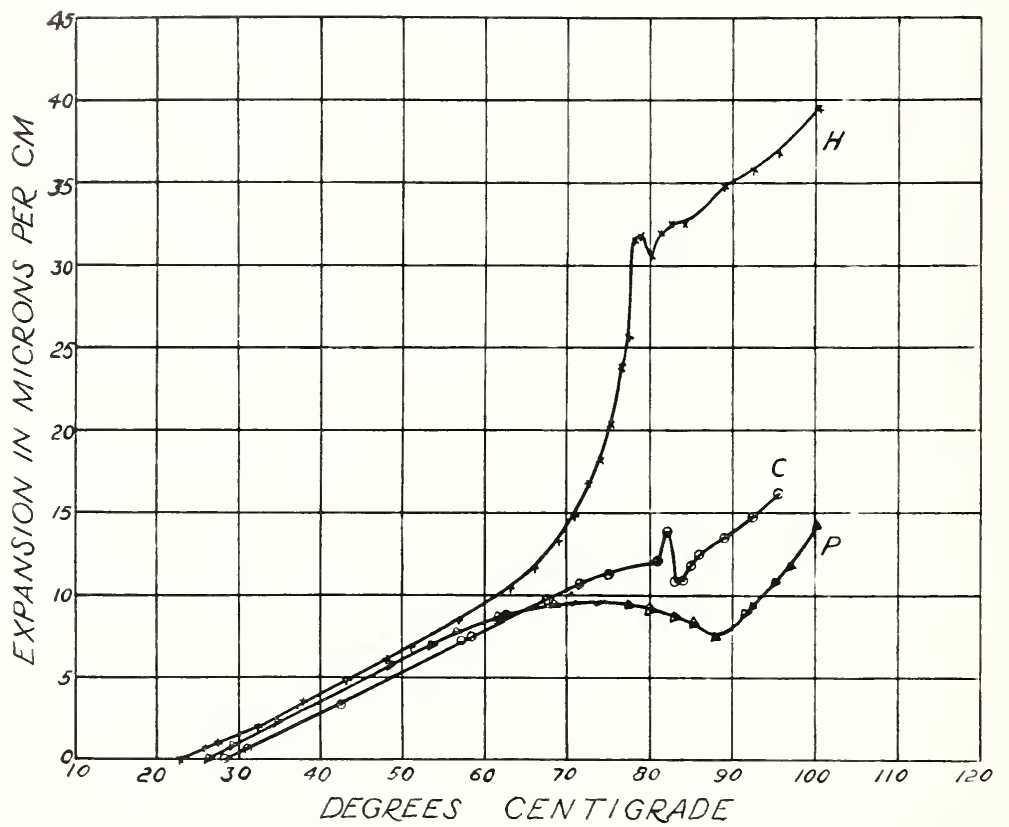

FIGURE 7.-Thermal expansion of amalgam.

The sudden change in contour of any of the curves indicates that the disintegration temperature of the amalgam has been reached. The irregular path of the curves around $80^{\circ} \mathrm{C}\left(176^{\circ} \mathrm{F}\right)$ is in part due to a surface crystal growth and therefore is not truly a thermal expansion.

as that of the tooth. Since the numerical coefficients for heating also apply for cooling, it is evident that dental amalgam will contract three times as much as the tooth if the tooth and restoration are cooled. This difierential expansion between the tooth and amalgam amounts to approximately 0.2 micron per centimeter per degree centigrade. It is thought that the effects of the contraction of a set amalgam, when cooled, can be compensated for through a definite setting expansion. This expansion may, as the amalgam hardens, push back the walls of the cavity and develop a resilient condition at mouth temperature so that the junction will not part when the tooth and amalgam are later cooled below body temperature.

Figure 7 shows typical curves for a few dental amalgams. From these it is evident that serious changes in the specimen took place 
after passing $60^{\circ} \mathrm{C}\left(140^{\circ} \mathrm{F}\right)$. This can be verified by examining the specimens after heating to about $80^{\circ} \mathrm{C}\left(176^{\circ} \mathrm{F}\right)$. Drops of mercury frequently are found on the surfaces of the specimens. A drop of mercury, should it exude from the specimen within the area of contact with the interferometer plate, will tend to lift the plate and indicate a false expansion. The lack of similarity of the expansion curves, after passing $70^{\circ} \mathrm{C}\left(168^{\circ} \mathrm{F}\right)$, can be explained by this phenomenon. Since amalgam restorations stand little chance of ever being heated to $60^{\circ} \mathrm{C}\left(140^{\circ} \mathrm{F}\right)$ in service, further discussion of this phase of the subject may be abandoned.

Flow.-Unfortunately dental amalgams have at least one property in common with plastics. Light loads, say one-tenth that necessary to crush the test specimen, will cause it to shorten or flow. Instruments selected for use in measuring flow are shown in figures 8 and 9 . They consist essentially of loaded vertical shafts, under which specimens of amalgam may be placed, and to which accurate dial indicators are attached to measure the flow of the specimens after the loads are applied. One of the two instruments shown (fig. 8) supports the load above the specimen. Care must be taken in using such instruments to level them accurately and to apply the load concentrically to prevent errors in the effective load applied. In the other instrument (fig. 9), the load is suspended below the specimen. Here also the instrument must be properly leveled so that the shaft is vertical and the load must be suspended on knife-edge bearings

The dial micrometer should be read at frequent time intervals and a graph prepared showing the length changes which have taken place while the load was applied. Such graphs show a maximum of flow during the first few hours after packing. The flow decreases with succeeding hours but never entirely ceases. Measurements made during the first 2 to 5 hours after mixing are unquestionably combined with changes in length which result from the incompleteness of set of the amalgam, and might be more properly labeled flow-set data.

In figure 10 are shown the flow curves and the compositions of three amalgams of the so-called high-silver type. These data were obtained during the routine testing of amalgams to determine whether they complied with the American Dental Association specification No. 1 for dental amalgam alloy. (This specification as well as other ADA specifications, agrees with the respective Federal specification except on certain demands on labeling, etc.). Other data are given in table 1.

The test results shown in figure 11 represent an attempt made in 1919 [1] to establish a flow-test so that measurements of flow would not be confused with length changes incident to setting.

It was found that the flow during the first hour of test (from the second to the third hour after amalgamation) was very much greater than the flow during succeeding hours. The 1926 specification [10] took account of this fact and set the time to begin flow tests as 3 hours after amalgamation. Increasing this starting time to 4 , or say 10 hours after amalgamating, would tend to make the test more truly a flow-test, but it is thought that it might eliminate a test on a much needed properly, namely, a fairly definite set within 3 hours. Values more nearly respresenting the true flow of set amalgam can be secured by taking readings for several days, plotting the curve, and then projecting the curve back to the ordinate, disregarding as much of the early part of the curve as may be necessary to eliminate the effects of 

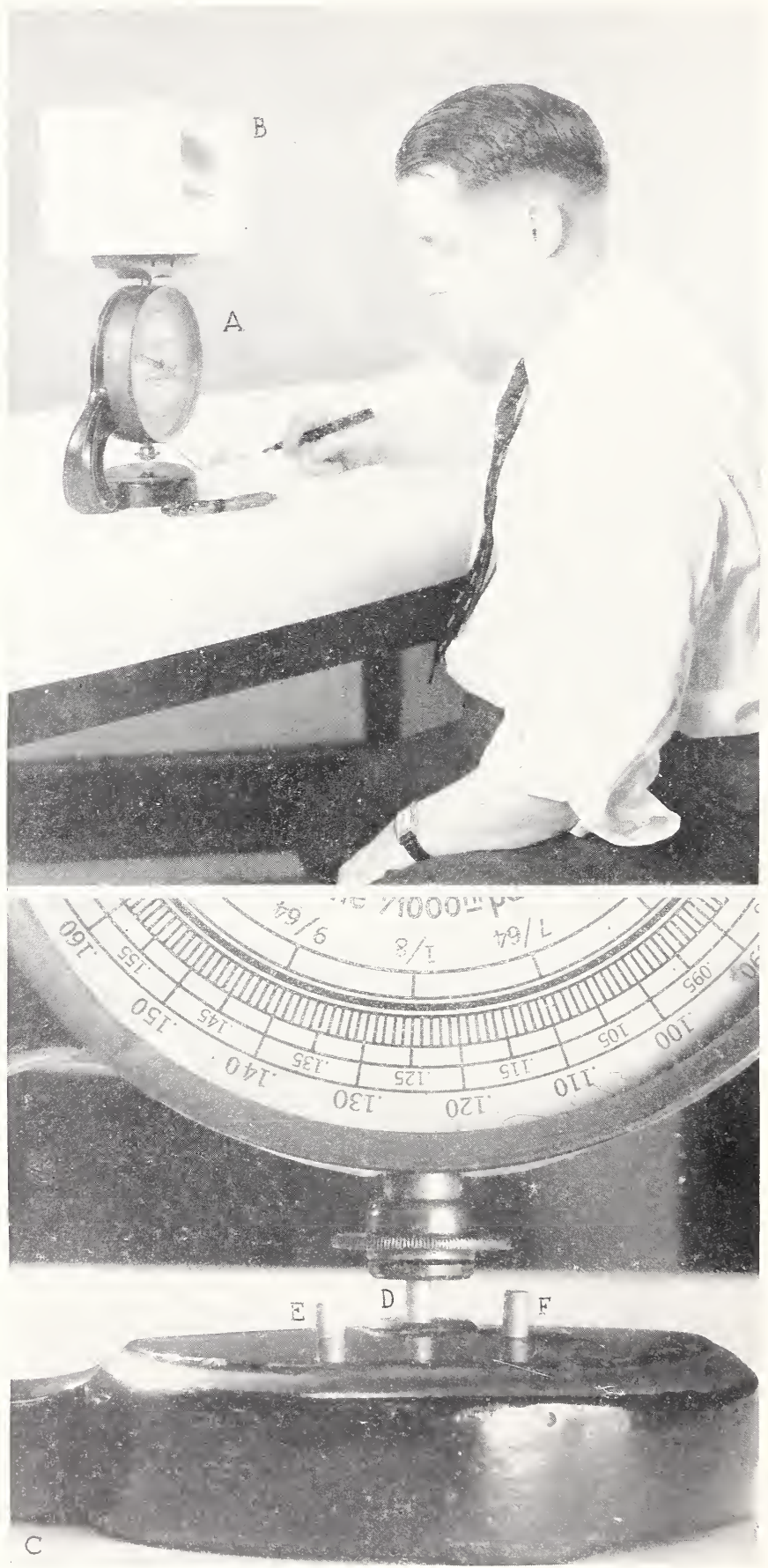

FIGURE 8.- Automatic micrometer used in measuring flow of amalgam. $A$, Micrometer; $B$, weight; $C$, enlarged section of the lower part of the micrometer. Note $D$, specimen in position for testing; $E$. specimen which flowed excessively; and $F$, specimen which had a low flow. 
set. The slope of the projected curve will represent more nearly true flow values.

Regardless of whether or not the results of the specification test represent flow, the test seems necessary and well selected. Compliance with the specification does guarantee sufficient rigidity within 3 hours to maintain contact points, gingival margins, exposed edges, and anatomy, and to withstand limited occlusal stresses which may accidentally be applied soon after the restoration is completed. Alloys rated as satisfactory clinically by representative dentists of the American Dental Association do pass the flow test as it is now

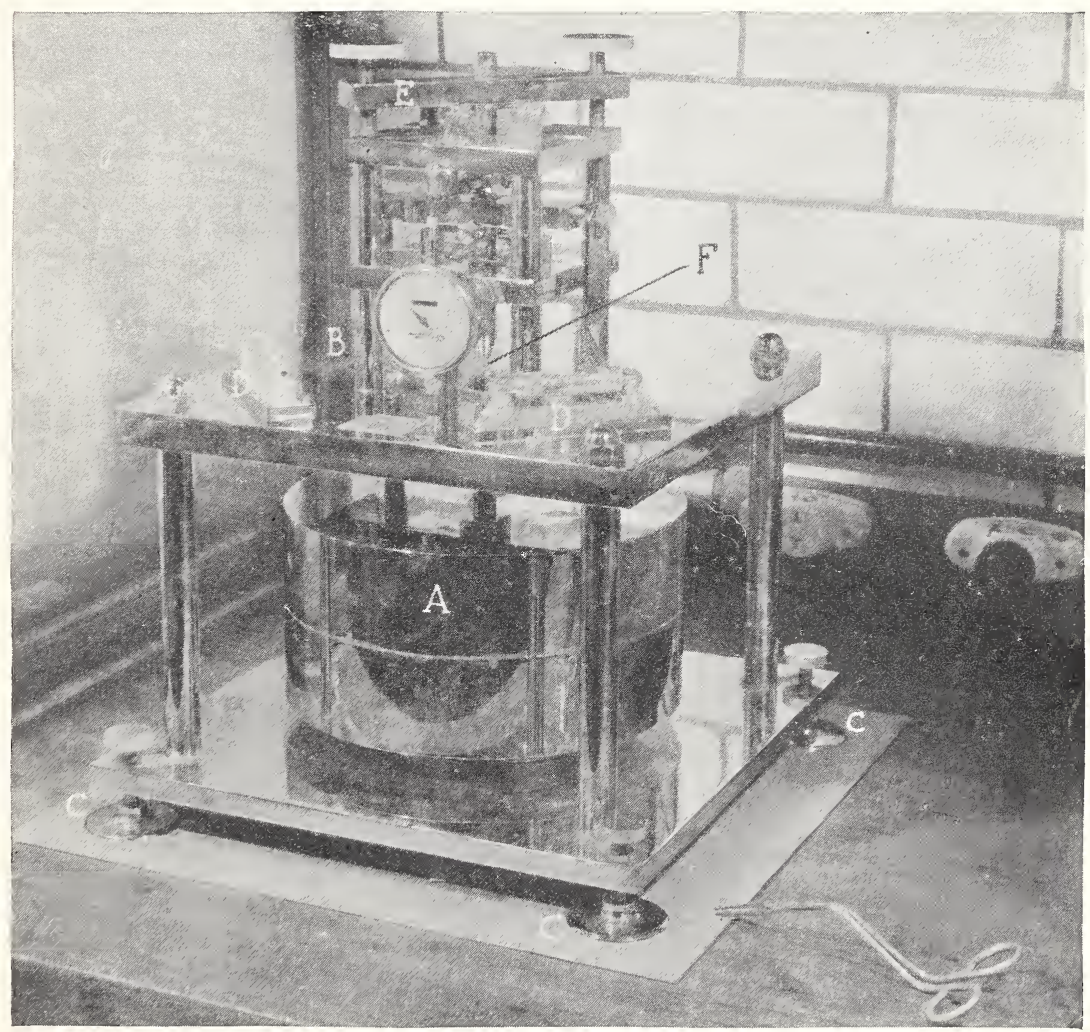

FiguRE 9.-Instrument used to measure flow of amalgam.

$A$, Weight suspended below specimen; $B$, dial gage; $C$, leveling screws; $D$, levels; $E$, screw jack assembly used to apply and remove the load on specimen $F$.

empirically established (page 182). The 1926 specification permitted 5 percent flow but improvements in alloys liave made it possible to reduce the value to 4 percent.

Flow can be kept to a minimum by eliminating as much mercury as possible from the restoration. The use of small sized pluggers, the addition of small amounts of amalgam and heavier thrusts in packing will give the minimum flow. However, each of these precautions has limitations beyond which it cannot be carried.

Flow of an amalgam can be one of the handicaps to its use. The dentist must recognize this and take such measures as are available to 
evade small contact areas, thin edges and heavy occlusal stresses in unprotected areas. The flow undoubtedly is negligible in carefully amalgamated and carefully placed restorations. In fact, it is difficult to demonstrate in service the flow of amalgams made from alloys complying with the specification.

Tests on flow and setting changes are made at temperatures between $20^{\circ}$ and $25^{\circ} \mathrm{C}\left(68^{\circ}\right.$ and $\left.77^{\circ} \mathrm{F}\right)$. Suggestions that tests should be made at mouth temperatures are occasionally received. This change can be made without serious inconvenience. The only added work

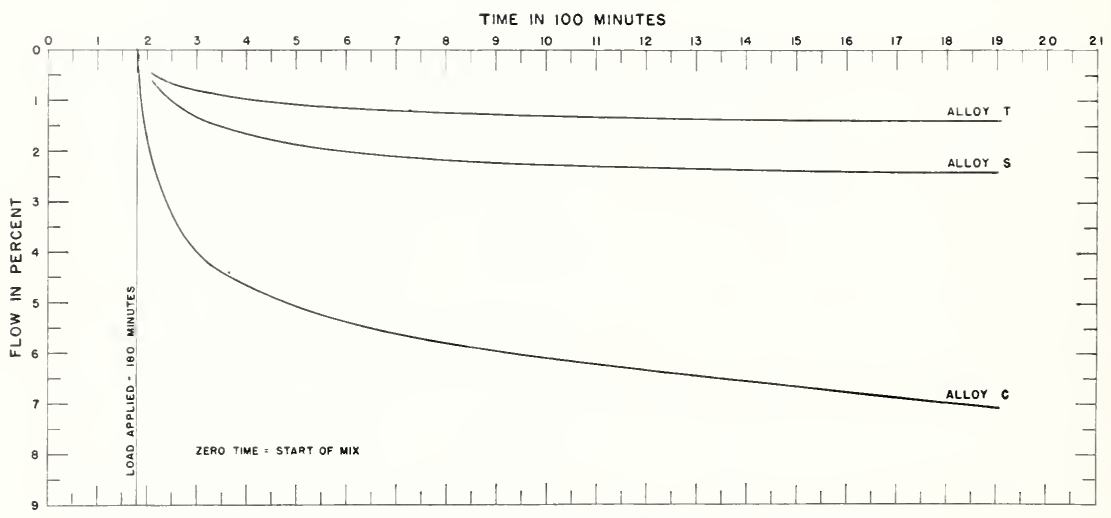

FIGURE 10. - Flow of high silver content amalgam alloys.

The specimens from which these data were obtained were 3 hours old when a load of $250 \mathrm{~kg} / \mathrm{cm}^{2}$ was applied. It will be noted most of the flow occurred in the first 2 hours that the load was applied. The compositions of alloys $T, S$, and $C$ are:

\begin{tabular}{|c|c|c|c|c|}
\hline Alloy & Silver & Tin & Copper & Zine \\
\hline $\begin{array}{l}T \\
S \\
C\end{array}$ & $\begin{array}{l}\% \\
70.2 \\
69.2 \\
69.8\end{array}$ & $\begin{array}{l}\% \\
25.6 \\
25.7 \\
25.0\end{array}$ & $\begin{array}{r}\%^{2} \\
2.4 \\
4.4 \\
4.9\end{array}$ & $\begin{array}{r}\% \\
1.8 \\
1.1 \\
0.4\end{array}$ \\
\hline
\end{tabular}

Even though the compositions are about the same, the flow varied from approximately 1.5 to 6.5 percent. From this it is evident that there are other factors aside from composition that determine the degree of flow.

necessary would be to test a sufficiently large number of representative alloys now known to be satisfactory and substitute for the present $20^{\circ}$ to $25^{\circ} \mathrm{C}\left(68^{\circ}\right.$ to $\left.77^{\circ} \mathrm{F}\right)$ values those found at $37^{\circ} \mathrm{C}\left(99^{\circ} \mathrm{F}\right)$. This would make it necessary to place the interferometer and flow meter in a thermostated chamber and secure corresponding data for the changes in testing conditions. Changes can be made if requested by the profession or manufacturers and agreed upon by both interests. The Bureau sees no urgent need for changes to be made at this time.

Ultimate compressive strength.-Dental amalgam alloys develop a remarkable ability to withstand crushing (table 1). They develop a strength several times as great as that of the dental cements, and are perhaps adequate for all needs in this respect. Localized stresses along thin sections may cause failures; but such failures are usually the result of improper marginal design. Much attention was given to determinations of ultimate compressive strength of amalgam alloys when the research was inaugurated at the National Bureau of Standards. The value $35,500 \mathrm{lb} / \mathrm{in}^{2}{ }^{2}$ was set in 1926 as the minimum safe 
limit. This was derived from tests on amalgams which were recommended by dentists as being satisfactory. The manufacturers have since improved their alloys, and the average value for those now in general use has increased to about $45,000 \mathrm{lb} / \mathrm{in}^{2}$

When the data on compressive strength, expansion, flow, and composition were correlated, it was observed that all amalgams passing the flow, composition, and expansion tests had uniformly high crushing values. The specification value was therefore not increased to 45,000

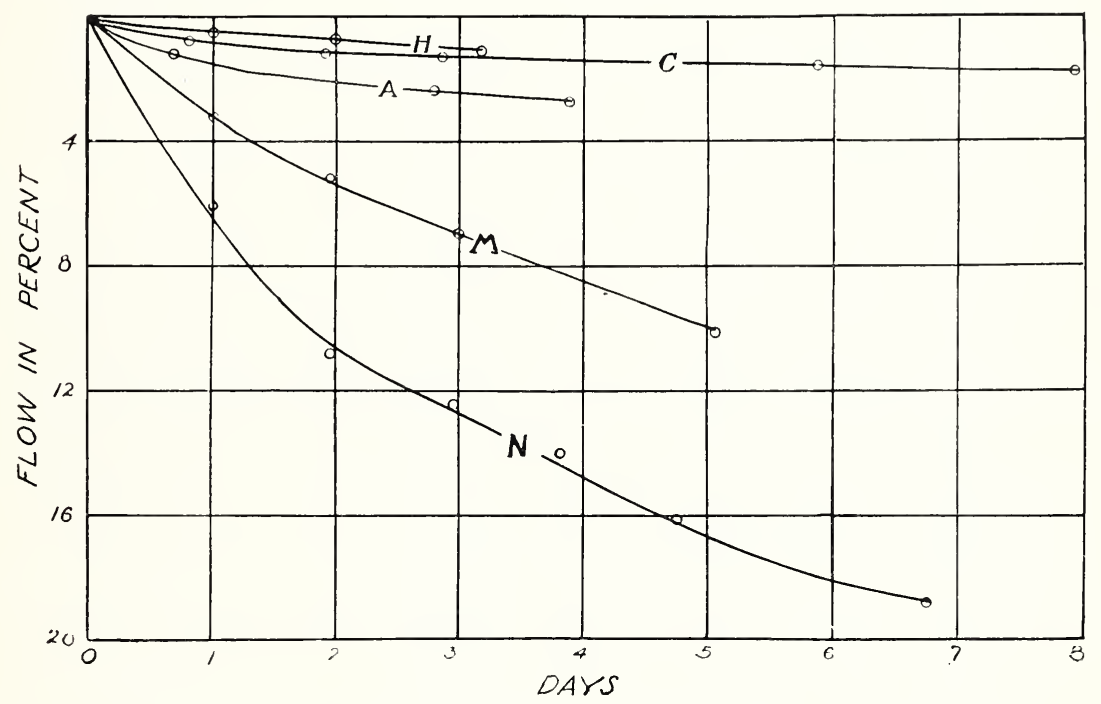

FIGURE 11.-Flow of amalgam alloys.

The specimens from which these data were obtained were 48 hours old when a load of $250 \mathrm{~kg} / \mathrm{cm}^{2} \mathrm{was}$ applied. The compositions of the alloys are as follows:

\begin{tabular}{|c|c|c|c|c|}
\hline Alloy & Silver & Tin & Copper & Zine \\
\hline $\begin{array}{l}A_{C} \\
C_{H} \\
M \\
N_{1}\end{array}$ & $\begin{array}{l}\% \\
68.0 \\
68.2 \\
66.9 \\
54.0 \\
44.6\end{array}$ & $\begin{array}{l}\% \\
27.0 \\
26.1 \\
27.1 \\
43.7 \\
50.9\end{array}$ & $\begin{array}{l}\% \\
5.0 \\
4.8 \\
5.0 \\
1.6 \\
2.5\end{array}$ & $\begin{array}{r}\% \\
0.9 \\
1.0 \\
.5 \\
2.0\end{array}$ \\
\hline
\end{tabular}

The comparatively high-tin-content alloys, $M$ and $N$, show the greatest flow.

$\mathrm{lb} / \mathrm{in.}^{2}$ but was deleted from the specification, as all amalgams which passed the other requirements of the specification passed the strength tests. Furthermore, to increase the strength requirement to $45,000 \mathrm{lb} / \mathrm{in}^{2}{ }^{2}$ might tend to overemphasize this property above its true importance and could easily encourage efforts to further increase the strength at the expense of other desirable properties.

The practice of condensing amalgam by using small-surfaced instruments and heavy thrusts is an example wherein the operator seeks to improve the crushing strength.

Tensile strength.- Tensile strength has been considered a desirable property and some have advocated that it should be included in a specification for dental amalgam. Figure 12 shows specimens and 
orips used in making tensile tests of dental amalgam. The tensile Talues [19] of specification trpe allors are rerr low. about one-tenth the crushing ralues. The allors of high-tin content have high tensile strength amounting to from one-eighth to one-sixth of their compressive strengths. While the increase in tin may have a further beneficial effect in reducing the brittleness of the alloy, additions berond 27 percent introduce dangers of contraction and in general mar reduce the crushing strength and increase the flow. The flow and dimensional changes appear to be of oreater importance than tensile strength in that the permissible rariations in flow and dimensional changes will not admit of changes in composition or technic sufficient to make appreciable differences in crushing or tensile strengths.

Reamalgamating and reworking a partially set mass of amalgam is
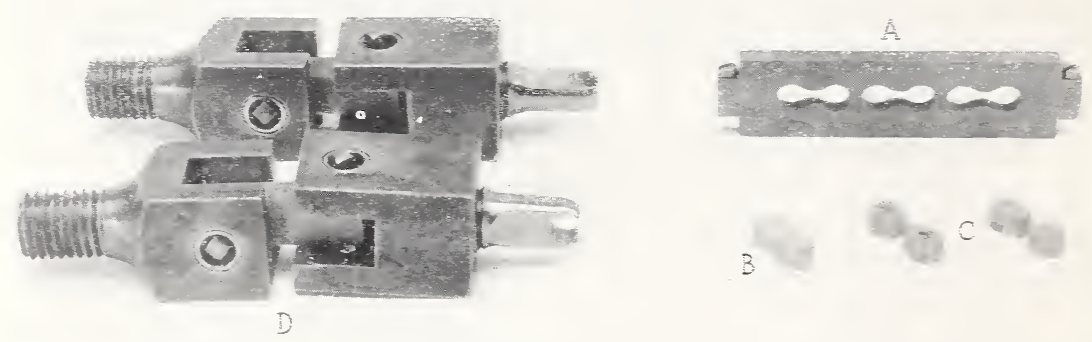

Figtre 12.- Apparatus used in testing amalgam in tension.

1. mold: $B$, specimen; $C$, broken specimens: $D$, alining grips for holding specimens in testing machine.

a dangerous practice which reduces the strength and should not be practiced under any conditions. In fact, if 1 drop of mercury is added to a partially set mix of the arerage size. the compressire strength of the resulting amalgam will be about one-tenth of the normal strength [21].

Attempts to improre the tensile strengths, to reduce the tarnish. or to decrease the brittleness of dental amalgams are suitable subjects for fundamental research.

Adaptation.-Many discussions on the possible defects of dental amalgams hare centered around the indefinite question of adaptation, i.e., ability to mold accurately to all contours and to fill completely all crevices in the cavity. Proof of the degree of adaptation of an amalgam restoration is difficult to displar. One of the most popular methods offered for this purpose is the air-pressure derice. So strong have been the endorsements of pressure tests that it is not unusual to find individuals quite willing to make this the one and only test for acceptance of an amaloam.

The air-pressure test is made by packing amalgam into a carity in a steel block, then applying air under pressure through an opening 
at the bottom of the "filling." 'The steel cavity and filling are usually immersed in water so that air escaping between the amalgam and steel surfaces may be detected as bubbles.

The method is defective for several reasons. Excess mercury in the first pieces of amalgam packed in the bottom of the cavity is very effective in preventing the passage of air. This result has led many to advocate the thin mix or "sloppy" amalgam technic. The excess mercury will cause reactions in the alloy to continue much longer than they should. These reactions may cause erratic behavior in the restoration, such as excessive expansion and movement at the margins. Such technics undoubtedly contribute to the pain experienced so frequently in large amalgam fillings having extensive under cuts. This condition has been reported by Romnes and Skinner [104].

The test is unnatural, as no sustained air pressures are developed in teeth. The rigid cavity of the steel block will, by virtue of its expansivity coefficient, compress and distort the amalgam filling if an increasing temperature cycle is encountered. The expansion (and contraction) of steel is about one-half that of dental amalgam (table 2). Information secured from restrained or distorted specimens is not as definite and convincing as that secured from unrestrained specimens such as are tested in the interferometer. Adaptation tests can undoubtedly be made and interpreted with greater ease and with less chance of deception by packing the amalgam in a cavity in a split mold. Usually there will be tool marks on the walls of the split mold, or a design may be engraved on the wall if necessary. The degree to which these are reproduced in the amalgam can be used as an approximate measure of the adaptability of the amalgam in question. Alloys which develop the smooth plastic amalgam in 3 minutes, as demanded by the specification, have relatively small particles and develop this smoothness because of proper surface solubility of the particles in mercury. Solubility sufficient to give smoothness to the amalgamated mass when spread in the palm of the hand should be sufficient to give all necessary adaptation, if the amalgam is properly packed in the cavity. Under the circumstances outlined above, the National Bureau of Standards has not seen fit to use the air-pressure test beyond the experimental or informative stage. There are indeed no objections to its use by any research laboratory, provided the limitations of its usefulness are recognized.

Mechanical amalgamators.--These machines can undoubtedly be built, standardized, and operated to render considerable aid to the dentist. It has been known for many years that the behavior of an amalgam on setting can be greatly influenced by the time and energy used in amalgamating the alloy. Mechanical amalgamators of various forms have been offered the profession from time to time.

Three types of mechanical amalgamators, two of which are shown in figure 13, were tested and the data were intercompared and also compared with data from specimens amalgamated by hand with the usual mortar and pestle equipment [15]. Type $A$ amalgamator consisted of a motor and vibrating attachment. 'The alloy and mercury were placed in a capsule which fitted the vibrating attachment. The time and speed of vibration were left to the pleasure of the operator. Type $B$ was similar to the mortar and pestle type except that it was smaller and attached to the dental engine. Type $C$ was a sort of 
centrifugal and tumbling derice operated on the end of a motor shaft. It was not manufactured commercially and is not shown in figure 13.

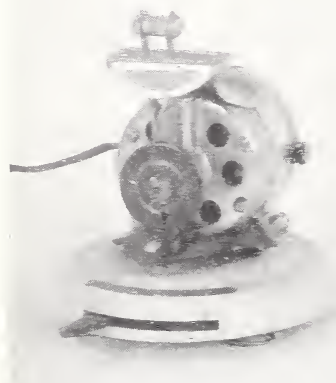

A

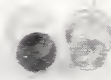

B

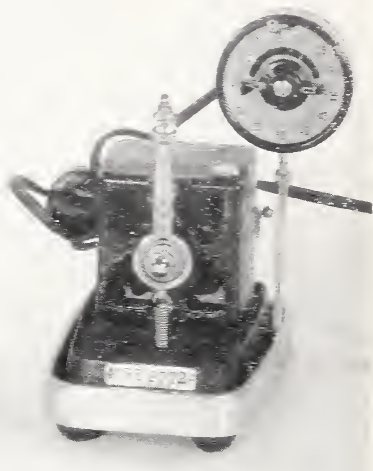

D

FIGTRE 13.- Types of mechanical amalgamators.

-1 and $D$ are ribrating types: $B$ is mortar and pestle type.

TABLE 3.-Effects of different amalgamations

\begin{tabular}{|c|c|c|c|c|c|}
\hline \multirow{2}{*}{ Phrsical properts tested } & \multirow{2}{*}{$\begin{array}{l}\text { Hand mix- } \\
\text { ed accord- } \\
\text { ing to man- } \\
\text { ufacturer"s } \\
\text { directions }\end{array}$} & \multicolumn{2}{|c|}{$\begin{array}{c}\text { Trpe } 1 \text { amalga- } \\
\text { mator: }\end{array}$} & \multicolumn{2}{|c|}{$\begin{array}{c}\text { Trpe } C \text { amalga } \\
\text { mator }\end{array}$} \\
\hline & & $15 \mathrm{sec}$ & $60 \mathrm{sec}$ & $15 \mathrm{sec}$ & $60 \mathrm{sec}$ \\
\hline
\end{tabular}

ALIOI WHICH MEI THE FEDERAI SPECIFICAIION: [10]

Lenoth change in microns (at end of 24 hours

Flow in pereent ( 3 to 21 hours

Tltimate crushing strength in $1 \mathrm{~b} / \mathrm{in}{ }^{2}$ (at end of 5 days

$\begin{array}{rrrrr}-5.0 & -17.0 & -4.0 & -2.7 & -0.6 \\ 3.2 & 3.2 & 5.9 & 3.2 & 5.2 \\ 46.700 & 15.100 & 53.500 & 54.200 & 51.900\end{array}$

ALLOI WHICH FAILED TO MEET THE FEDERAL SPECIFICATION 3 [10]

Tength change in microns lat end of 24 hours Flow in percent ( 3 to 21 hours

Tlimate crushing strength in $1 \mathrm{~b} / \mathrm{in}$. (at end of 5 days

$\begin{array}{rr}-1.2 & -3.5 \\ 2.5 & 2.0 \\ 45.500 & 45.200\end{array}$

\begin{tabular}{|c|}
\hline $\begin{array}{r}-7.5 \\
3.1\end{array}$ \\
\hline 2. 700 \\
\hline
\end{tabular}

Note figure 13

Alloy composition, in percent: silver, 0.7 ; tin. 26.1 ; copper, 5 ; zinc, 0.2.

3 Alloj composition, in percent: $11 \mathrm{l}$ rer, 66.1 ; tin, 25.2 ; copper, $1.9 ;$ zine, 0.3 .

The data in table 3 show the necessity for standardizing the instrument and technic in terms of the individual allor. Fariations in dimensional changes are shown of an acceptable alloy (when amalgamated according to the manufacturers' instructions) which cause it to be rejected for excessire expansion when amalgamated on trpe A amalgamator or cause it to be rejected for shrinkage and flow) when amalgamated on trpe $C$ amalgamator. Data on trpe $B$ amalgamator are not included in table 3. 
Obviously, this situation suggests the possibility of adjusting a technic or set of directions so that an alloy amalgamated according to the directions will pass the specification. This is frequently possible and proper. The rule works both ways. Without a definite set of directions, it would be possible in many instances to amalgamate an alloy in such a manner as to make it fail on one test and to make it pass on another test. The directions for amalgamating and packing should be observed. They protect the manufacturer and guide the operator. They must be complied with if they are reasonable and feasible in dental practice. Alloys submitted for test on Government purchases are not accepted unless directions are included in each package of alloy. An important requirement of the Federal and ADA Specifications for amalgam is that accurate and adequate instructions must accompany each package of alloy which is guaranteed to comply with the specifications.

It is possible for manufacturers of mechanical amalgamators to combine their production efforts with the actual laboratory testing of amalgamated specimens and to furnish definite instructions for the operation of the amalgamator. The manufacturers of alloy should furnish instructions for amalgamating their alloy in one or more of the standardized mechanical amalgamators. (One such amalgamator is now available to the profession, fig. $13, D$ ). Unless this is done, the mechanical amalgamator is a liability to those members of the dental profession who attempt to use it.

Electrode potentials.-Electrode potentials were measured [1] to determine the electromotive forces that might be expected to develop between amalgam and gold restorations and between different types of amalgams. The value found ( $1 / 2$ volt between amalgam and gold) was definite and nearly constant regardless of the type of dental amalgam alloy tested. It did not appear to be influenced by the absence or presence of zinc up to 5 percent in the dental amalgam alloy (table 4). These data were secured by the use of the normal calomel half-cell and potentiometer. Since the prospects for reducing this potential difference between amalgam and gold are not encouraging, and since $1 / 2$ volt is sufficient to produce unpleasant conditions in the mouth, the dentist must take the necessary precautions to insulate or isolate gold from amalgam restorations or other electrically dissimilar combinations that are to be placed in the mouth. Such combinations may develop unpleasant conditions and may cause serious injuries to the health of the patient.

TABLE 4.-Electrode potentials of dental amalgam

\begin{tabular}{|c|c|c|c|c|}
\hline \hline \multicolumn{3}{|c|}{ Silver alloy composition } & \multirow{2}{*}{ emf 1} \\
\cline { 1 - 2 } Silver & Tin & Copper & Zine & \\
\hline & & & & \\
\hline Percent & Percent & Percent & Percent & 1 olts \\
68 & 27 & 5 & 0 & -0.54 \\
54.3 & 29.8 & 15.9 & 0 & -.52 \\
66.9 & 27.1 & 5.0 & 1 & -.52 \\
60 & $(2)$ & $(2)$ & 5 & -.51 \\
\hline
\end{tabular}

1 In normal sodium chloride solution.

2 Complete composition not known. 
Additional electrode potentials are given in table 5 . The order of the elements indicates their tendencies to react or to go into solution under standard conditions. These potentials rary with the trpe and concentration of the solution used. In fact. by changing the solutions. it is sometimes possible to change the order of the elements from that shown in the table. Table 4 gires a lower value for gold than that giren in table 5. This is the result of using a weaker solution (approximately oral fluid) in testing the gold and amalgam combinations. Had the gold and amalgam been tested in standard solutions, the voltage interval would undoubtedly have been much greater. These effects will be elaborated under the more specific heading of tarnish and corrosion.

TABLE 5. Electrode potentials of some metals ${ }^{1}$

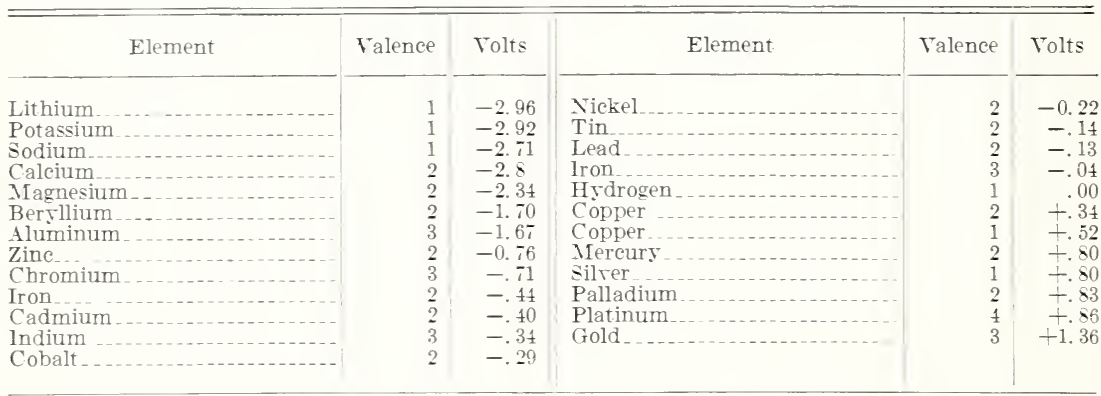

1 Data are from rarious sources, such as International Critical Tables, handbooks, and texts.

Tarnish and corrosion [100]. - The following types of corrosion are considered under this subject: Solubility, tarnish, two-metal galranic action, and concentration cells. The discussions on galranic action and concentration cells have a possible connection with the subject of physiological effects and will therefore be considered in this section.

The solubility of amalgam alloys in mouth fluids is known to be in many instances extremely small. After years of service there is scarcely a perceptible loss of exposed surfaces. The edges. which should be the first to show eridences of solution, may not deteriorate. The metallic taste which usually discloses the presence of metals in solution is seldom detected in the mouth containing properly placed amalgam restorations.

Tarnish, which, in the case of amalgam restorations, indicates a chemical reaction producing adhering salts, is frequently a source of dissatisfaction. Specimens of amalgam become tarnished when placed in a hydrogen sulfide atmosphere. Specimens suspended in a 1-percent solution of sodium chloride will, after a few months, show loss of surface finish because of a film of oxide or chloride or both though no appreciable solution may have occurred. Some specimens after a few months in the salt solution derelop blisters trpical of galranic action and concentration-cell corrosion. (See footnote, p. 11.)

Then two metals having a sufficiently large difference in electrode potential are in contact in an electrolyte, the metal which is the more electropositive of the two will be corroded at a more rapid rate than if contact is not maintained. (If one consider's the internal circuits or reduction potentials, all plus and minus signs in tables 4 and 5 must 
be reversed; e. g., lithium is electropositive and gold is electronegative to hydrogen. Lithium will therefore corrode more rapidly than gold.)

Specimens of amalgam in contact with dental gold alloys were attacked when immersed in 1-percent sodium chloride solution. During a 6-months immersion in this solution, the amalgam was badly pitted and a heavy precipitate was formed. Analysis showed this precipitate to be mostly tin with only traces of silver, copper, and zinc. Mercury was not detected. This pitting suggests a lack of homogeneity throughout the amalgam and is apparently a general manifestation of the reaction responsible for the blister-like spots mentioned previously. Lack of homogeneity of structure of an amalgam furnishes the elements necessary for local galvanic action. A tarnished surface of amalgam is different in galvanic properties from a polished surface. The thoroughly amalgamated particles of alloy are different from those added during the last stages of amalgamation. This may account for some of the inhomogeneity and consequent difficulties encountered in keeping certain amalgam restorations polished.

Concentration-cell corrosion displays a similar effect and arises from differences in concentrations of an electrolyte. The products arising from debris and food decay between two adjacent teeth are different from normal saliva. Therefore, it is possible to have one type of electrolyte at the gingival margin of a restoration and a different type of electrolyte at the occlusal surface. This may start concentration-cell corrosion. The resulting changes in surfaces will more than likely produce galvanic dissimilarities in the two surfaces and lead to further deteriorations.

The means for preventing the difficulties are:

1. The amalgamation must be thorough, incorporating every particle at the beginning of trituration.

2. The restorations must be contoured for self-cleansing between the teeth.

3. The restorations must be kept polished.

4. Dissimilar metals in contact constitute a hazard and must be observed for evidences of corrosion of the metals and for lesions in the adjacent tissues.

5. Since some individuals wear gold appliances in contact with amalgam restorations without appreciable injury while others are not able to do so, the question of allergy of the individual arises. The corrosion products of gold and amalgam in contact being principally tin, this would seem to be the logical ion to test for first in a differential diagnosis to determine whether or not a lesion was the result of goldamalgam electrolysis.

6. One of the dissimilar metals must be removed. Pitting and excessively tarnishing amalgams should be replaced by a more nearly homogeneous amalgam.

Poisoning from amalgam.- The mercury content of a dental amalgam filling is approxmiately 50 percent [33]. The possibility of a health hazard developing through loss of mercury from the restoration is an important question. Losses of mercury have been claimed to occur from vapors of mercury given off at the surface of the amalgam; from mercury oozing or dissolved from the restoration; or from particles abraded or broken from it. 
With the derelopment of equipment suitable for measuring the presence of extremelr small amounts of mercurr rapor in the air. and with added information on the amounts of mercurt necessart to produce toricity. quantitative tests Tere made on the amalgams to determine how much mercurt rapor. metallic mercurt or dissolved mercurs Tas lost br trpical restorations [3:3].

Analrses of new amalgams and of restorations of the same amalgam 10 rears old shomed no definite differences in the relative amounts of mercurt present [3.3] table $b^{3}$ ). This prored that mercurr was not being liberated or dissolred in appreciable quantities from the amalqams. Mercury can be and doubtless is. lost from the restoration through abrasion. Experience shows that the losses through abrasion and chipping at the edges. for a mouth haring many amalgam restorations. amount to not more than a few grains during an entire rear. This material. if soluble in bodr fluids. could scarcels hare a serious effect on the bodr as the therapeutic dose for the most poisonous salts of mercury is about 0.1 grain daily. Furthermore, mercury combined with tin. copper. and zinc is not soluble in bodr fluids. "These elements are electropositive to mercurr and retard the solution of mercure as long as ther are in the amalgam. This is easilr prored br placing set amalgam in a s-percent solution of hrdrochloric acid for a few hours and then testing for mercurr in solution. Amalgam was heated to $s 0^{\circ} \mathrm{C}\left(176^{\circ} \mathrm{F}\right.$ for 50 hours in a solution of hrdrochloric acid. The solution contained no appreciable amount of mercurt.

TABLE 6.-Chemical composition of long service and reu amalgams

\begin{tabular}{|c|c|c|c|c|c|c|}
\hline $\begin{array}{l}\text { Sample } \\
\text { number }\end{array}$ & S:1re: & Tin & Conper & Zine & $\begin{array}{l}\text { Mercuss } \\
\text { br dif- } \\
\text { ference }\end{array}$ & Remarks \\
\hline 3. & $\begin{array}{l}3.1 \\
32.3 \\
32.2 \\
32.3\end{array}$ & $\begin{array}{l}13.1 \\
11.1 \\
12.2 \\
12.2\end{array}$ & $\begin{array}{l}2.5 \\
\frac{2}{2} .0 \\
2.5\end{array}$ & $\begin{array}{l}0.7 \\
.9 \\
. \frac{1}{3} \\
.3\end{array}$ & $\begin{array}{l}\$ 1.6 \\
5.6 \\
5.6 \\
52.2\end{array}$ & $\left\{\begin{array}{l}\text { Samples remorei from teeth after } \\
\text { more than } 10 \text { rears service. } \\
\text { samples analyzei a tem dars after con- } \\
\text { densing. }\end{array}\right.$ \\
\hline
\end{tabular}

TABLE 7.-Elemente expresed with mercury

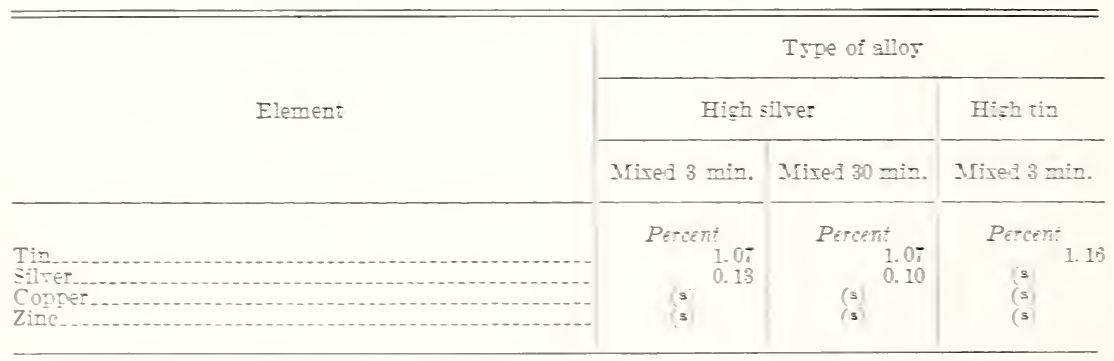

s lot detected. The remainder was mercurs.

If exces mercurt should be left in a restoration through inadequate pressure in packing and should later escape. for some unknown reason. it is thought that no salts or soluble compounds of mercure will be formed. because the escaping mercurr carries tin and silver with it. The material expressed through chamois shin from standard mixes of 
amalgam was found to have the compositions shown in table 7 . These expressed residues were heated overnight on a steam bath in 5-percent hydrochloric acid. Mercury was not detected in the solution. Tin was found in the solution.

That mercury from an amalgam restoration will be dissolved by liquids in the body or in foods is not borne out by experiments. The ratio of mercury in new and old amalgams being the same makes untenable the claim that any large quantity of mercury is lost.

There remains the possibility of losses of minute quantities of mercury as vapor. Exposed clean mercury does give off vapor which is poisonous. By the use of the mercury vapor detector (fig. 14), it

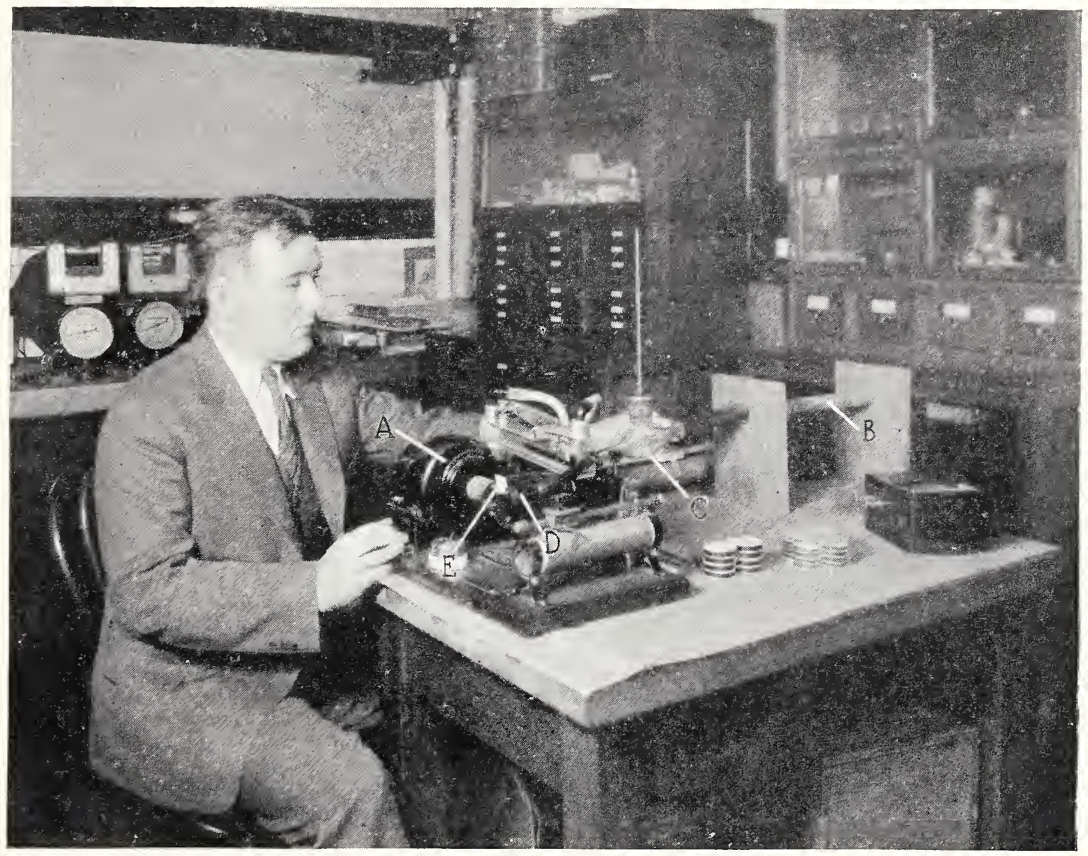

Figure 14.--Mercury-vapor detector.

By means of a motor-driven fan, $A$, air warmed to body temperature by a resistance coil, $B$, was passed over amalgam specimen, $C$, and then conducted to chamber, $D$, which contained a strip of paper, $E$, coated with selenium sulfide. The relative darkening of the paper was the index used to measure the concentration of mercury vapor in air.

was shown that air taken at a distance of $1 / 2$ inch above a mercury surface had a content of 1 volume of mercury vapor to $3,000,000$ volumes of air. 'The detector will reveal 1 part of mercury in 200,000,000 parts by volume of air. The presence of mercury is revealed by the reaction which takes place when the vapor is driven against selenium sulfide paper. Disks of amalgam about the size of a 25 cent coin and having an area of approximately 1,150 square millimeters were formed in a mold under compression. These disks were then inclosed in a chamber over which a constant stream of air at body temperature flowed for 1 hour. The tests were repeated for 4 hours also at $37^{\circ} \mathrm{C}\left(99^{\circ} \mathrm{F}\right)$, as shown in table 8 .

The only vapor detected was from the copper amalgam. This amount was small and tended to decrease rapidly with time. The 
danger limit on mercury vapor in air appears to be at about 0.01 milligram of mercury per cubic meter of air. The normal intake of air into the lungs is 10 cubic meters per day. This gives for the above concentration 0.1 milligram of mercury taken into the lungs each day when the individual breathes air contaminated to the extent of 0.01 milligram per cubic meter. With a mercury vapor content of 0.025 cubic centimeter (see copper amalgam, table 8, approximately 0.22 milligram) to 1 cubic meter of air for 1,150 square millimeters of surface, and, assuming an amalgam filling to have 25 square millimeters of surface, two copper amalgam fillings would be sufficient to give 0.1 milligram of mercury during the second day after condensing. However, this amount soon falls to one-half this value. These values represent the maximum under most favorable conditions. Fortunately, these favorable conditions are never met outside of the laboratory.

TABLE 8.-Mercury vapor from dental amalgams

\begin{tabular}{|c|c|c|}
\hline \multirow{2}{*}{ Type of amalgam } & \multicolumn{2}{|c|}{$\begin{array}{c}\text { Cubic centimeters of mercury vapor s in each } \\
\text { cubic meter of air }\end{array}$} \\
\hline & 1 hour at $37^{\circ} \mathrm{C}\left(99^{\circ} \mathrm{F}\right)$ & $\begin{array}{c}4 \text { hours at } 37^{\circ} \mathrm{C} \\
\left(99^{\circ} \mathrm{F}\right)\end{array}$ \\
\hline $\begin{array}{l}A \text { (copper) } \\
B \text { (copper) } \\
C \text { (copper) } \\
D \text { ("'high silver") } \\
F \text { ("high tin') } \\
F \text { (nonzine) }\end{array}$ & $\begin{array}{c}\mathrm{cm}^{3} / \mathrm{m}^{3} \\
0.031 \\
.025 \\
\text { None detected }\end{array}$ & $\begin{array}{l}0.025^{c m^{3} / m^{3}} \\
.017 \\
.031 \\
\text { None detected. } \\
\text { Do. } \\
\text { Do. }\end{array}$ \\
\hline
\end{tabular}

s $1 \mathrm{~cm}^{3}$ of mercury vapor under normal conditions equals 8.5 milligrams or 0.14 grain.

Any serious damage which might arise through the inhaling of mercury vapor from copper amalgams may be dismissed from the present study, as mercury vapor escapes from clean, dry surfaces only. When covered with saliva, the escape into the air ceases. Observers in this Bureau have in general found that mercury spilled over the floor ceases to give vapor in appreciable quantities if contaminated or if covered by a dressing material such as floor polish.

The danger arising from mixing amalgams in the hand and thus forcing mercury through the skin into the system must not be ignored. Such effects have been encountered. The intestinal discomfort, the changes in oral tissues, including discolorations and other familiar symptoms of poisoning, should give the dentist sufficient warning to enable him to protect himself from serious danger in those instances where special susceptibility exists.

While the Bureau is not qualified to speak with authority on medical subjects or to express an opinion on the poisoning effects of dental materials, it is thought that the claims of poisoning from amalgam restorations through vapor or solution have been highly exaggerated. The question of electrode potentials between amalgam and other noninsulated metallic restorations and appliances obviously is not included in the above statement. These effects and the means for their prevention are discussed elsewhere (page 23).

Intercomparison tests.-Questions regarding the precision and reproducibility of test data are always in order. The interferometer, used in testing length changes of dental amalgams, has a degree of 
precision many times higher than is necessary. The same is true of the dial indicator and load used in measuring flow. The reproduction of identical values on amalgam specimens, prepared and tested as duplicates, is seldom accomplished because of the nonuniformity of the specimens.

In 1935 the National Bureau of Standards arranged a series of cooperative tests which were participated in by 18 laboratories outside of the Bureau. The cooperating laboratories were: (1) Dental schools.University of Southern California, Columbia University, Georgetown University, Northwestern University, University of Pittsburgh, and Western Reserve University; and (2) Manufacturers.-Ackerman Dental Mfg. Co., The L. D. Caulk Co., Crescent Dental Mfg. Co., Garhart Dental Specialty Co., Hammond Dental Mfg. Co., The Minimax Co., The J. M. Ney Co., Patterson-Hettinger, Precious Metals Refining Works, San Diego Smelting \& Refining Co., S. S. White Dental Mfo. Co., Wildberg Smelting \& Refining Co. A standard lot of amalgam alloy was prepared. Samples were sent to each of the cooperating laboratories with instructions to make two or more tests for flow and dimensional change on setting. The instructions for preparing the test specimens were exacting and detailed. Mercury-alloy ratio, type of mortar, time and thrust for amalgamation, number of triturations in the mortar, amounts of alloy to be used in packing,

TABLE 9.-Intercomparison tests on amalgam

\begin{tabular}{|c|c|c|c|c|c|c|c|c|c|}
\hline \multirow{2}{*}{ Cooperator } & \multicolumn{4}{|c|}{ Expansion * } & \multicolumn{4}{|c|}{ Flow \& } & \multirow{2}{*}{$\begin{array}{l}\text { Tem- } \\
\text { pera- } \\
\text { ture }\end{array}$} \\
\hline & 1 & 2 & 3 & Average & 1 & 2 & 3 & $\begin{array}{l}\text { A ver- } \\
\text { age }\end{array}$ & \\
\hline $\begin{array}{l}A \\
B \\
C \\
D \\
E \\
F \\
G \\
H \\
I \\
\\
K \\
L \\
M \\
N \\
O \\
P \\
Q \\
R\end{array}$ & $\begin{array}{c}\text { Microns/cm } \\
5.5 \\
5.5 \\
5.8 \\
9.1 \\
0.2 \\
5.3 \\
6.0 \\
5.2 \\
2.0 \\
2.0 \\
4.0 \\
3.8 \\
10.7 \\
2.1 \\
3.0 \\
3.8 \\
2.0 \\
3.3\end{array}$ & \begin{tabular}{|r|} 
Microns/cm \\
5.5 \\
7.8 \\
4.3 \\
13.4 \\
0.8 \\
5.9 \\
6.0 \\
4.7 \\
2.0 \\
2.0 \\
2.0 \\
4.1 \\
12.7 \\
1.9 \\
4.0 \\
4.4 \\
2.0 \\
3.6
\end{tabular} & $\begin{array}{r}\text { Microns/cm } \\
5.7 \\
5.4 \\
15.4 \\
6.8 \\
5.3 \\
5.9 \\
5.6 \\
1.9 \\
2.0 \\
3.0 \\
2.6 \\
13.0 \\
1.5 \\
3.5 \\
3.6 \\
3.0 \\
3.3\end{array}$ & $\begin{array}{r}\text { Microns/cm } \\
5.5 \\
6.3 \\
5.2 \\
12.6 \\
2.6 \\
5.5 \\
6.0 \\
5.2 \\
2.0 \\
2.0 \\
3.0 \\
3.5 \\
12.1 \\
1.8 \\
3.5 \\
3.9 \\
2.3 \\
3.4\end{array}$ & $\begin{array}{l}\% \\
2.9 \\
4.7 \\
1.9 \\
1.8 \\
2.2 \\
3.1 \\
4.7 \\
1.3 \\
3.0 \\
3.0 \\
3.0 \\
1.9 \\
2.9 \\
3.5 \\
2.6 \\
1.9 \\
3.0 \\
3.5\end{array}$ & $\begin{array}{l}\% \\
3.7 \\
5.2 \\
2.1 \\
2.3 \\
2.3 \\
2.6 \\
4.9 \\
1.8 \\
2.5 \\
3.1 \\
3.1 \\
2.0 \\
3.6 \\
3.2 \\
2.4 \\
2.7 \\
2.8 \\
2.2\end{array}$ & $\begin{array}{l}\% \\
4.5 \\
2.1 \\
2.0 \\
2.2 \\
2.4 \\
6.0 \\
1.6 \\
3.0 \\
3.1 \\
2.8 \\
1.9 \\
3.9 \\
3.5 \\
2.3 \\
2.3 \\
2.9 \\
2.8\end{array}$ & $\begin{array}{l}\% \\
3.3 \\
4.8 \\
2.0 \\
2.0 \\
2.2 \\
2.7 \\
5.2 \\
1.6 \\
2.8 \\
3.1 \\
3.0 \\
1.9 \\
3.5 \\
3.4 \\
2.4 \\
2.3 \\
2.9 \\
2.8\end{array}$ & $\begin{array}{l}\circ \mathrm{F} \\
80 \pm 2 \\
80 \pm 5 \\
77 \pm 2 \\
73 \pm 2 \\
72 \pm 5 \\
78 \pm 2 \\
78 \pm 5 \\
85 \pm 3 \\
70 \pm 1 \\
74 \pm 6 \\
72 \pm 3 \\
85 \pm 7 \\
70 \pm 4 \\
70 \pm 1 \\
75 \pm 3 \\
81 \pm 1 \\
73 \pm 3 \\
76 \pm 4\end{array}$ \\
\hline Grand a & & & & 4.8 & & & & 2.9 & \\
\hline
\end{tabular}

TESTS AT NATIONAL BUREAU OF STANDARDS

\begin{tabular}{|c|c|c|c|c|c|c|c|c|c|}
\hline $\begin{array}{l}1 \\
2 \\
3 \\
4\end{array}$ & $\begin{array}{l}5.0 \\
4.0 \\
4.6 \\
4.2\end{array}$ & $\begin{array}{l}5.2 \\
3.5 \\
3.8 \\
6.7\end{array}$ & $\begin{array}{r}4.2 \\
4.9\end{array}$ & $\begin{array}{l}5.1 \\
3.9 \\
4.4 \\
5.4\end{array}$ & $\begin{array}{r}2.7 \\
2.3 \\
-\end{array}$ & $\begin{array}{r}3.1 \\
2.5\end{array}$ & $\begin{array}{r}-1.2 \\
-\cdots\end{array}$ & $\begin{array}{r}2.9 \\
2.3 \\
-\end{array}$ & $\begin{array}{l}73 \pm 3 \\
73 \pm 3 \\
73 \pm 3 \\
73 \pm 3\end{array}$ \\
\hline Grand averas & & & & 4.7 & & - & & 2.6 & 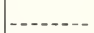 \\
\hline
\end{tabular}

a The expansion and flow values in columns 2 and 3 are values for repeat tests. Composition of alloy (in percent): Silver, 68.0 ; copper, $4.7 ; \mathrm{tin}, 26.5 ;$ zinc, 0.8 .

$406035^{\circ}-42-3$ 
packing tools, and packing pressures were specified in detail. The data from these tests indicate the accuracy and reproducibility with which amalgams were being tested at that time. Table 9 gives the values obtained by these 18 laboratories and by 4 workers at the Bureau.

In reporting these data to the cooperators, the Bureau offered the following comments:

The Bureau workers do not insist that their values for setting expansion (4.7 microns) and for flow (2.6 percent) are exact. They do feel, howerer, that deriations from these values of more than 1.5 microns on setting and 0.75 percent on flow should cause the operators to strive for a better mastery of the testing operations. The preliminary analysis of this cooperative experiment shows that most of the testing laboratories are making fairly accurate tests of dental amalgam and that they can follow an arbitrary technic. These two items * * * were the purpose of this experiment. Some of the cooperators have shown exceptional expertness in their handling of the tests.

From the ralues shown in table 9 it appears that individual operators can, in a few instances. make tests which will agree to about 1 micron on dimensional change and 0.5 percent on flow. The values which are uniformly high or uniformly low undoubtedly resulted from failures to follow the technic outlined. It is noteworthy, that the manufacturers' laboratories reported data much nearer the presumably correct (or arerage NBS) values than did the university laboratories. The manufacturers supply directions with each bottle of allor. These directions should be followed to the letter when their products are tested. Where such meticulous care in testing according to directions is exercised by the manufacturer and followed by the testing laboratory, there should be no disagreements on acceptance of allor, especially if the manufacturer has kept his product some distance from the outer limits of the specification. The value of 8 microns \pm 5 microns per centimeter for dimensional change on setting (see specification $\mathrm{U}-\mathrm{A}-451 \mathrm{a}$. p. 182) seems to furnish ample tolerance for all variables of manufacturing and testing.

Changes in quality.- Table 1 gives a summary of test data arailable for a few of the dental amalgams which were in use by the dentai profession in 1919. Complete chemical analyses were not made at that time. Less than one-half of these allors would meet the requirements of the specification [10] set up by the Gorernment in 1926. A small number would pass the 1938 specification [10]. The inprovements in allors are evident when we refer to the large list [101] of allors which in 1939-41 were found to comply with a specification far more rigid than the 1926 specification. Most of the 1919 brands had been improved. The list of 51 alloys offered the dentist in 1941 [101] constitutes an excellent guide for use in making selections.

The a verage silver content for 11 of the higher silver alloys in 1919 was 66.5 percent. By 1938 the arerage for all certified alloys was 68.4 percent. This increase in silver has not increased the setting expansion or produced harsh working alloys. The finer cut allors now so much in evidence permit increases in silver content without the development of excessive expansion or too rapid setting. 
The maximum flow limit permitted in the specification was recently reduced from 5 percent to 4 percent. For many alloys the flow is below 3 percent. Manufacturers have found little difficulty in meeting this more strict requirement.

A few alloys still show a tendency to blacken when amalgamated. The greatest difficulty in the blackening problem seems to be to produce zinc-free alloys that will not blacken when amalgamated. These zinc-free alloys are demanded by certain dentists though their definite superiority has not been established.

Efforts to secure in one amalgam alloy the many improvements which one can suggest will perhaps never be successful. Dentists, recognizing the defects and shortcomings of amalgam, take such steps as are available to mitigate them. The tarnishing of the amalgam surfaces can to some degree be prevented by a high polish. Cavity design and distribution of the loads of mastication will aid in eliminating the effects of flow.

Dental cement has low thermal conductivity and when used as a lining in cavities will reduce the thermal shocks which frequently accompany the use of amalgan in deep cavities. Proper isolation from dissimilar metals and alloys should reduce the galvanic effects.

Too many defective teeth have been restored to function and these restored teeth have given entire satisfaction over too many years for us to lose interest in or to abandon, in any respect whatever, this excellent material in those selected instances where standardized amalgam can give such remarkable service.

Improvements in the quality of other dental materials are equally impressive and have usually followed the developments of cooperative research.

Technic.-Amalgam technics must be rated with respect to effective sealing of the cavity, minimum flow (maximum permanence of form), and degree of surface finish. Satisfactory sealing of the cavity demands careful packing and the elimination of excess mercury. A slight expansion of the packed amalgam assists in keeping the cavity sealed. Amalgams containing excessive amounts of mercury may tend to expand and to sweat or lose mercury when stored in the laboratory. It is thought that the same defects develop from fillings overloaded with mercury.

The effective packing of amalgam requires instruments of different sizes and shapes which will fit into the angles of the cavity. Small additions of, say, one-eighth of the total amount of amalgam to be used enable the operator to remove excess mercury and secure satisfactory uniformity in the restoration.

A slight excess of mercury in the amalgamation may not be as serious as one might believe. The excess mercury, when expressed through a chamois skin or cloth will contain approximately 1 percent of tin and 0.1 percent of silver. Since the excess mercury is not likely to exceed 20 percent of the total mass, the amount of tin removed from the amalgam is not over 0.2 percent. The loss of this small amount of tin should not seriously affect the service value of an amalgam restoration.

Trituration must be systematic.-In the roughened glass or steel mortars the mixing must proceed according to the manufacturers' directions. (In the absence of specific directions for roughening the surfaces of the mortar and pestle, it is proper to grind a quantity of 
2F carborundum powder occasionally to prevent the derelopment of smooth surfaces.) During amalgamation, the mortar should be inclined, rotated, or jarred if necessary so that every alloy particle will be promptly incorporated in the plastic mass. Raw filings, if added to the amalgamated mass at the last instant. contribute toward nonhomogeneity and may be a disturbing factor when the attempt is made to polish the restoration. If the mechanical amalgamators are used, their operation must be standardized for the alloy selected. Few brands of alloy are accompanied by directions for mechanical amalgamation. Some mechanical amalgamators give excellent uniformity of amalgam, but a few seconds excessive trituration in the mechanical amalgamator may change an expanding alloy into a shrinking allor. The same defect can be produced in the mortar, but the time required will usually be many times greater for hand mixing than for the mechanical mixing. Mechanical amalgamators without second timers and tables showing the number of seconds necessary to properly amalgamate the different brands of alloys are apt to prove to be liabilities rather than assets. Properly standardized and used according to directions, they should be found quite satisfactory.

The advisability of mulling in the cleaned palm is left to the manufacturer's wishes as expressed in the directions for the alloy. The soiling of the palm in mulling some alloys and not in others may arise from the presence of foreign materials in the alloy. The formation of some trpes of these foreign materials can be prevented br the use of a. scarenger, such as zinc.

Flow will be at a minimum when the amalgams are handled according to instructions and will perhaps never cause trouble in the arerage restoration. A critical period of 2 to 5 hours exists immediately after packing the restoration. Contact points may be flattened during this period unless the teeth have been separated sufficiently to prevent the adjacent tooth from touching the soft amalgam. Occlusion from sharp cusps in opposing teeth during this hardening period can also injure the restoration.

The incorporation of metallic particles, plates, and bars in a restoration is of questionable value. Amalgams are usually sufficiently strong in the massive sections of the alloy (approximately 45,000 $\mathrm{lb} / \mathrm{in}^{2}$ ) to match the dentin (approximately 30,000 lb/in. ${ }^{2}$ crushing strength). The weak spots on the amalgain restoration are at the edges and along thin sections. Reinforcements are potential sources of difficulty. If they are exposed, they may set up a galranic action between the metal reinforcement and the amalgam. (See page 24.) If they are not deeply imbedded in the amalgam, they may, by reason of the weakness of the bond between the amalgam and the reinforcement, cause chipping or flaking of the amalgam from the reinforcing plate. The chipping of feather edges (and in fact any edge) of amalgam is one of its inherent defects and a certain amount of chipping is to be expected. The introduction of reinforcing plates must not be expected to prevent this; in fact, they may be expected to increase it. The weakness of the bond of amalgam to a silver or other reinforcing plate can be disclosed by attempting to weld two plates of clean silver by the use of a film of amalgam pressed between them. The bond is readily broken, and the amalgam will chip off in flakes 
if the plates are distorted. Reinforced fillings should be watched for these defects.

There should be no criticism of those who line cavities with cement if this is not extended to the outer margins of the cavity. Cement is an excellent protection against thermal shock and may be of assistance in preventing the dark stain which so frequently develops within the cavity around the amalgam.

The restoration should be polished after it has hardened sufficiently to retain the polish. This will be after 24 hours. Many dentists have failed to grasp the importance of this polishing operation and especially over the interproximal spaces. The polish tends to prevent local galvanic action (corrosion), adherent deposits or stains, and the discrepancy in color relations which are so much emphasized by dark amalgam restorations in white teeth.

Partially set amalgam must not be reworked by the addition of more mercury to make it sufficiently plastic for use in completing a large time-consuming operation. It is necessary to arrange for a second mix to be completed at the halfway point of the packing operation. Reworked alloys contain excessive amounts of mercury and are very weak [24].

Questions of apparent allergy and irritations supposedly due to the presence of amalgam should be studied carefully to make certain that the difficulty is not caused by mechanical defects such as rough surfaces, jagged edges or overhanging ledges. The possibility of a psychological phobia, induced by an unfounded suspicion that amalgams might be poisonous, should not be overlooked.

\section{DENTAL MERCURY}

Large quantities of mercury are used in the amalgamation of silver alloy filings to produce the plastic amalgam filling. The finished amalgam may contain nearly 50 percent of mercury [33]. The demands for permanence of amalgam restorations, under all types of service requirements, make it necessary that no extraneous reactions take place during the amalgamation and setting of the alloy. Small amounts of impurities or foreign elements may cause serious depreciations of the alloys. Since mercury will unite with many other metals and carry these metals in solution, it is necessary that some standards of purity be established for the dental mercury used to amalgamate the alloy filings.

Unfortunately, "pure," “chemically pure," "distilled," "redistilled," "triple distilled," and similar terms have no significance as to the degree of purity of mercury. The term "U. S. P." when applied to mercury is definite and indicates that the mercury has no surface contamination and less than 0.02 percent of nonvolatile residue.

Mercury displays its contamination and impurities to a surprising degree [35]. The mirror or reflecting properties of a mercury surface are seriously depreciated by the incorporation of base metal impurities, dirt, grease, and other contaminating materials. The base metals after dissolving in the mercury appear to oxidize and float on the surface. These surface contaminations destroy the sphericity of mercury droplets and cause them to spread, or "tail," as they are rolled over a flat surface. 
Amounts as little as 0.001 percent of copper, zinc, tin, lead, bismuth, cadmium, and antimony (and doubtless many other elements), added to mercury, will disclose their presence as surface contaminations. Since this small amount of an impurity in mercury introduced into an almost equal amount of silver alloy may be regarded as harmless, it is not likely that dental amalgam alloys will unknowingly be injured by the use of impure mercury if a risual inspection is given the mercury before it is used. Arsenic, when heated with mercury, does not combine but floats on the surface. The impurities which float can readily be remored by filtering the mercury through a pinhole or through a chamois skin or a selected cloth. The noble metals such as gold and silver do not reveal their presence so definitely as do the base metals. For such contaminations it is sufficient to determine the nonvolatile residue as outlined in the specification. Tests for nonvolatile residue should be carried out under the usual precautions, as the vaporization of mercury into the laboratory atmosphere constitutes an extreme health hazard.

Tests of mercury, purchased from various sources, indicate that all samples secured were satisfactory for use in the amalgamation of dental alloys. Few rejections have been encountered in the testing of dental mercury for compliance with the ADA specification (page 202) over a period of years. Most of the rejections have been on the container rather than on the quality of the mercury. A glass container is necessary for the greater convenience in making the visual inspection.

\section{GOLD AND ITS ALLOYS IN DENTISTRY}

The pure gold foils, the casting gold alloys, solders and the wrought gold alloys represent the more important forms in which gold is used in dentistry. Each has its particular applications and corresponding superiorities.

Foil can be malleted (cold welded) into a strong, hard mass approximately duplicating in hardness the 22 -carat casting gold alloys. The adaptation, fit, permanence, and freedom from future disturbances make it one of the best filling materials available to the dentist.

The cast restorations can be prepared to protect weaker portions of a tooth. Strengths can be selected to satisfy any normal need of the dentist. Two types of defects are responsible for many failures where casting golds are used to restore lost portions of teeth. Many dentists have failed to master the art of producing accurately fitting inlays. Secondly, poorly fitting inlays, seated with a cement which is slowly soluble, are headed for failure.

Wrought gold alloys yield the maximum in mechanical properties. The cold-working incident to swaging, drawing, and rolling produces a refinement in the grain structure. Greater strength, hardness, and elastic properties are obtained in the wrought than in the cast form.

There are three methods recognized by metallurgists for hardening metals-cold-working, alloying, and heat treatment. Pure gold foil as used in dentistry illustrates admirably the first method as 24carat metal is not alloyed and does not harden by heat treatment. The other two methods of hardening alloys will be elaborated later in this report (pp. 35 and 51).

Gold foil.-The problems connected with the use of 24-carat gold foil are those of art in mastering the technic. The purity of the foil 
and the welding properties are practically assured when the foil is produced. Impurities in the original ingot would harden the gold and reduce its malleability to such an extent that it could not be beaten to satisfactory thinness and uniformity of structure.

The density and hardness of six gold foil fillings are listed in table 10. The fillings numbered 1 to 6 were made by six members of the dental profession, all recognized leaders in this field. The densities are included but have little significance except in specimen 3 , where it is evident from the density and hardness values that the operator did not weld the foil properly. Such imperfections would doubtless result in the loss of a contact or in leakage permitting the invasion of bacteria. These however should not be charged against the use of foil as a filling material. Brinell hardness numbers are of much greater value than density in predicting the service to be expected from a foil restoration or in exposing poor operative technic. The
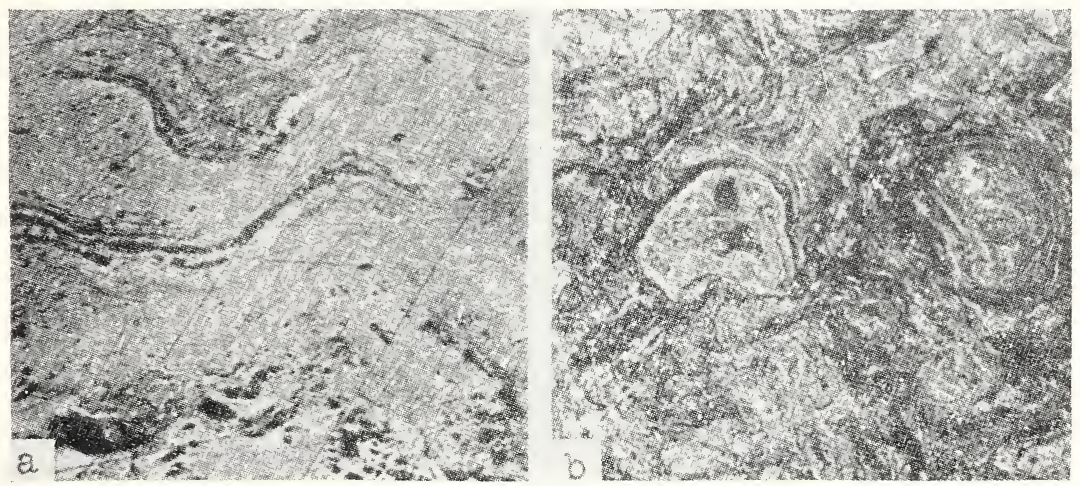

FIGURE 15.-Micrographs of gold-foil fillings, etched with aqua regia, $\times 90$.

$A$, Section parallel to the direction of packing; $b$, section perpendicular to the direction of packing. Note the laminated structure and voids due to incomplete condensation.

increase in hardness of the 24-carat foil over the hardness of 24-carat cast gold (from 27 to 61 ) is attributable to cold-working. The microstructures of two gold foil fillings are shown in figure 15.

TABLE 10.-Properties of foil fillings and soft gold alloys for inlays

\begin{tabular}{|c|c|c|c|c|}
\hline \multicolumn{3}{|c|}{ Foil fillings } & \multicolumn{2}{|l|}{ Cast-inlay gold alloys } \\
\hline Sample No. & Density & $\begin{array}{c}\text { Brinell } \\
\text { hardness } \\
\text { number }\end{array}$ & Material & $\begin{array}{c}\text { Brinell } \\
\text { hardiness } \\
\text { number }\end{array}$ \\
\hline $\begin{array}{l}1 \\
1 \\
3 \\
4 \\
5 \\
6 \\
6\end{array}$ & $\begin{array}{r}g / \mathrm{cm}^{3} \\
17.0 \\
17.3 \\
14.2 \\
16.8 \\
18.2 \\
19.0\end{array}$ & $\begin{array}{r}136 \\
50 \\
218 \\
51 \\
61 \\
60\end{array}$ & \multirow[t]{2}{*}{$\begin{array}{l}\text { 24-carat gold }{ }^{3} \\
\text { Alloy XXV1I: } 22 \text {-carat gold ( } 91.7 \text { gold, } 7.8 \text { silver, } \\
\text { and } 0.5 \text { percent cepper). } \\
\text { Alloy XXV111; 22-cart gold (91.7 gold, } 4.6 \\
\text { silver, and } 3.7 \text { percent of copper). }\end{array}$} & $\begin{array}{l}27 \\
32 \\
54\end{array}$ \\
\hline Average & 17.1 & 46 & & \\
\hline
\end{tabular}

1 Brinell hardness of different spots varied from 22 to 46 .

2 Brinell hardness of different spots varied from 13 to 26.

3 Density of 24-carat cast gold is $19.3 \mathrm{~g} / \mathrm{cm}^{3}$ (Smithsonian Physical Tables, 7th ed., p. 110). 
Technic.-Technics for gold foil restorations are largely the development of personal skill. The operator may on occasions be very positively reminded, as the partially completed filling tumbles out of the cavity, that he has not mastered the art of cold welding gold foil. There are practically no explanations of failure, other than lack of skill. The foil, if uniform and thin, must be of high purity and the welding is, when expertly done, very effective. The restoration must grow or spread from an initial roll of foil condensed into a protected retaining angle or corner. Further rolls must be welded to the mass without dislodging any previously welded portion. This makes it necessary for the successful operator to visualize or in some manner to correctly judge the magnitude and directions of resultant forces before each welding blow is struck. The student, after studying textbooks and observing instructors, will probably adopt his personal interpretation of these technics and will by trial and error acquire an ability to judge the correctness and effectivness of each blow by the "feel" of the instruments.

Gold-foil restorations have many advantages over all other types of restorations. Dentists must master the technic of placing foil restorations if they are to give their patients the most effective and complete dental service.

Gold alloys.- The cast gold alloy gives service under as many as four distinct headings. It can be used to restore lost parts of a tooth. It can be used to protect a tooth in a cap or crown restoration. Its third use is as an anchor abutment or support for appliances. A fourth use for cast alloys is found in the cast appliance.

The softer alloys, high in gold content, meet the needs for the simplest inlay in a protected location. 'These alloys can be swaged and burnished to an exact fit and should give unlimited service. The exposed inlay and three-quarter crown require a harder, stronger gold. The inlay used as a bridge abutment or pontic must have greater strength. The single-piece appliance terminating in a clasp, occlusal rest or facing for the attachment of a porcelain tooth demands the utmost in strength and resiliency.

A study of the specifications (p. 188) for these four or more types of alloys will reveal the unusual success with which the manufacturers can supply alloys to meet the specific needs of the dental profession, as outlined in the four or more types of restorations discussed above.

The effects of alloying elements to produce metals of unusual properties are well illustrated in these alloys. Gold, silver, and copper can be combined to produce an alloy far superior in strength to any one of these metals alone. Further improvements can usually be imparted to the alloy by drawing or swaging it. 'This improvement will be discussed in the next section.

As previously stated, the wrought alloys in their cold-worked condition offer the maximum in physical properties. If heated, they usually lose in strength, proportional limit, and hardness. Part of this loss may, in some instances, be restored by a careful heat treatment, which will be discussed in a later section.

Chemical composition.-Analytical methods. The publication by the National Bureau of Standards of the compositions of dental gold alloys of many types, together with the methods used in analyzing them $[8,80]$, created a wholesome atmosphere, which had far-reaching influence. 
Gold alloys for cast inlays.- The chemical compositions and hardness numbers of representative casting gold alloys, for use primarily as inlays and crowns, are listed in table 11 . These analyses were made in 1931 [34]. It will be noted that the soft inlay group is comprised primarily of ternary alloys of gold, silver and copper. The large percentage of gold is neccessary in the soft inlay group to produce a tarnish-resistant alloy which is also soft and plastic enough to burnish easily. Small amounts of zinc are added to make the alloy, according to general belief, more fluid when molten and also to deoxidize or reduce any metallic oxides during melting.

Gold alloys for cast inlays of medium hardness and the hard type are essentially four-element alloys consisting of gold, copper, silver, and platinum, modified by slight additions of other metals principally zinc (table 11).

TABLE 11.-Chemical composition and hardness of gold alloys for cast inlays

\begin{tabular}{|c|c|c|c|c|c|c|c|}
\hline Alloy & Gold & Silver & Copper & $\begin{array}{l}\text { Plati- } \\
\text { num }\end{array}$ & Zinc & Nickel & $\begin{array}{c}\text { Brinell } \\
\text { hardness } \\
\text { numbers }\end{array}$ \\
\hline & $\begin{array}{l}\% \\
97.0\end{array}$ & & $\%$ & $\%_{3.0}$ & $\begin{array}{c}\% \\
0.03\end{array}$ & $\%$ & 34 \\
\hline $\begin{array}{l}2-10 \\
32-1\end{array}$ & $\begin{array}{l}95.0 \\
87.8\end{array}$ & $\begin{array}{r}4.0 \\
11.2\end{array}$ & $\begin{array}{l}1.0 \\
1.0\end{array}$ & & & & $\begin{array}{l}34 \\
38\end{array}$ \\
\hline
\end{tabular}

SOFT INLAYS

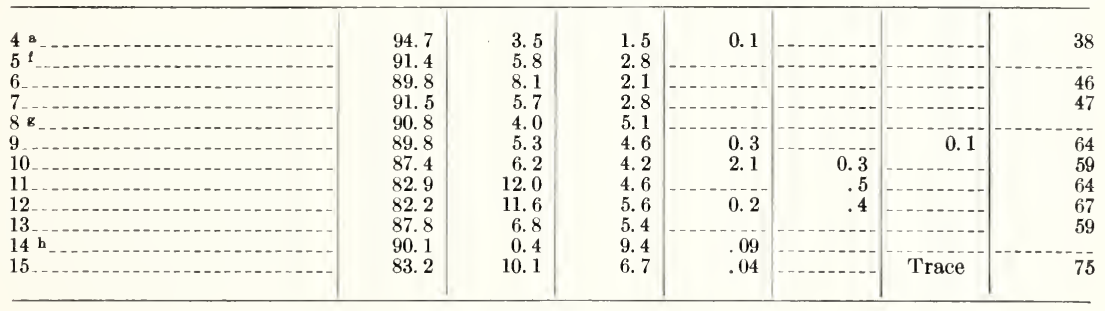

MEDIUM INLAYS

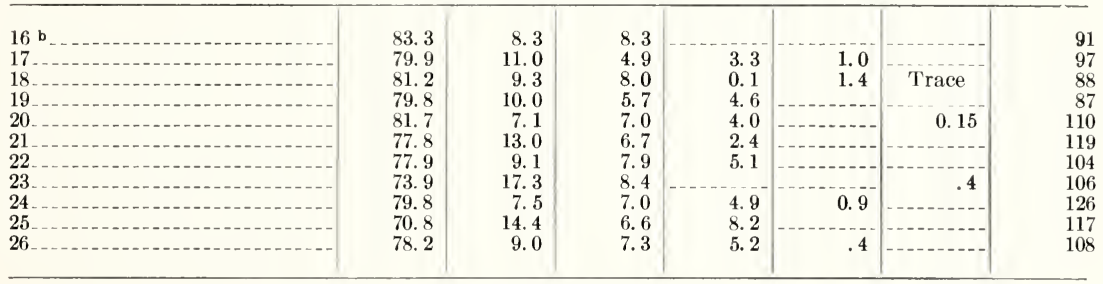

HARD INLAYS

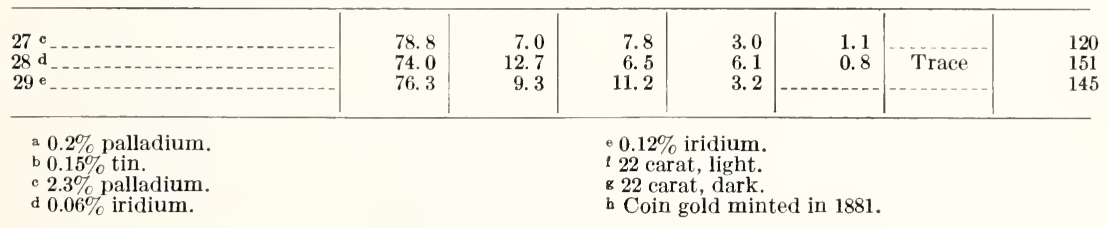


Gold alloys for partial dentures. clasps, bars. etc.-The compositions of four denture trpe allors are giren in table 12. Allors IT-D and T-D are of the so-called "Four" trpe, which were rel'r popular about 10 rear's ago. and eren now are used to a considerable extent. Ther differ from the customary allors of this trpe in that they contain appreciable amounts of nickel and zinc. Nost modern denture allors contain appreciable amounts of palladium. In some of the allors designated as "white golds" the palladium content may exceed 12 percent.

TABLE 12.-Chemical composition of gold alloys for dentures and clasps

\begin{tabular}{|c|c|c|c|c|c|c|c|c|c|}
\hline Allo5 & Gold & $\begin{array}{l}\text { Sil- } \\
\text { Ter }\end{array}$ & $\begin{array}{l}\text { Cop- } \\
\text { per }\end{array}$ & $\begin{array}{l}\text { Plati- } \\
\text { num }\end{array}$ & Nickel & Zine & $\begin{array}{l}\text { Irid- } \\
\text { ium }\end{array}$ & Tin & Remarks \\
\hline $\begin{array}{l}\mathrm{I}-\mathrm{D}[14] \\
\mathrm{IV}-\mathrm{D}[1 \mathrm{H}]\end{array}$ & $\begin{array}{c}c_{c} \\
7 i .3 \\
71.4\end{array}$ & $\begin{array}{l}\widetilde{c} \\
\because .1 \\
6.0\end{array}$ & $\begin{array}{c}\tau_{c} \\
9.9 \\
15.6\end{array}$ & $\begin{array}{c}\tau \\
\tau_{c} \\
10.6 \\
2.5\end{array}$ & $\frac{\tau_{c}}{2.0}$ & $\begin{array}{l}\widetilde{c}_{c} \\
0.05 \\
2.4\end{array}$ & $\begin{array}{c}\widetilde{c}_{c} \\
0.14\end{array}$ & $\begin{array}{c}\widetilde{F}_{c} \\
0 . \$ 3\end{array}$ & \multirow{3}{*}{$\begin{array}{l}\text { For casting clasps, bars. } \\
\text { For clasps. saddles, arches and } \\
\text { bars. } \\
\text { For clasps. saddles, bars. etc.; } \\
\text { one piece castings. } \\
\text { Primarily for casting dentures. }\end{array}$} \\
\hline$V-D[11] \ldots \ldots$ & 62.5 & 13.9 & 15.9 & & 2.6 & 2.0 & & & \\
\hline$X \times X-D[31] \ldots$ & 70.5 & 9.4 & 14.1 & 5.0 & 0.5 & 0.5 & & & \\
\hline
\end{tabular}

Wrought gold alloys for wirt.-The compositions of wrought gold wire allors are giren in table 13 [40]. The allors are listed according to the decreasing order of their content of gold plus metals of the platinum group. These allors are rers complex and sometimes contain as high as nine elements. Naturally, with so large a number of elements, it is rirtualle impossible to explain the role of each. This sugeests that the compositions are to a large extent empirical. Nerertheless. such compositions produce, as will be shown later, allors haring remarkable phrsical properties. From 1924 to 1931 there occurred some changes in the composition of wrought gold allor wires, which appeared to be reflected in improred mechanical properties. These changes include a reduction of the gold content of the 1924 wires. together with an increase in the copper, platinum. and zinc content $[11,40]$.

TABLE 13.-Composition of dental urought gold alloys

[Percentage br weight]

\begin{tabular}{|c|c|c|c|c|c|c|c|c|c|c|c|}
\hline Allos number & Gold & silver & $\begin{array}{l}\text { Cop- } \\
\text { per }\end{array}$ & $\begin{array}{l}\text { Plati- } \\
\text { num }\end{array}$ & $\begin{array}{l}\text { Palla- } \\
\text { dium }\end{array}$ & Nickel & Zine & Iron & $\begin{array}{l}\text { Irid- } \\
\text { ium }\end{array}$ & $\begin{array}{l}\text { Man- } \\
\text { ganese }\end{array}$ & Tin \\
\hline $\begin{array}{l}\mathrm{A}-2 \\
\mathrm{~B}-2 \\
\mathrm{C}-2 \\
\mathrm{D}-2 \\
\mathrm{E}-2 \\
\mathrm{~F}-2\end{array}$ & $\begin{array}{l}57.6 \\
64.3 \\
58.9 \\
54.5 \\
60.0 \\
54.6\end{array}$ & $\begin{array}{l}\text { 4. } 3 \\
5.2 \\
7.0 \\
6.2 \\
7.5 \\
7.1\end{array}$ & $\begin{array}{l}11.7 \\
10.5 \\
13.3 \\
13.0 \\
12.8 \\
12.3\end{array}$ & $\begin{array}{l}17.2 \\
16.7 \\
16.5 \\
17.7 \\
16.0 \\
17.2\end{array}$ & $\begin{array}{l}5.9 \\
2.2 \\
4.4 \\
7.2 \\
1.5 \\
7.3\end{array}$ & & $\begin{array}{l}0.10 \\
1.00 \\
0.05 \\
1.20 \\
0.06 \\
1.50\end{array}$ & $\begin{array}{r}0.02 \\
.02 \\
.06\end{array}$ & $\begin{array}{r}0.13 \\
.20 \\
-2 .\end{array}$ & & 0.11 \\
\hline $\begin{array}{l}\mathrm{G}-2 \\
\mathrm{H}-2 \\
\mathrm{I}-2 \\
\mathrm{~J}-2 \\
\mathrm{~K}-2 \\
\mathrm{~L}-2\end{array}$ & $\begin{array}{l}66.2 \\
50.5 \\
54.3 \\
50.3 \\
60.4 \\
60.1\end{array}$ & $\begin{array}{r}11.1 \\
5.5 \\
7.9 \\
7.5 \\
15.2 \\
10.2\end{array}$ & $\begin{array}{r}9.0 \\
12.9 \\
12.5 \\
11.1 \\
9.0 \\
13.9\end{array}$ & $\begin{array}{l}10.5 \\
17.3 \\
17.0 \\
16.2 \\
15.5 \\
5.0\end{array}$ & $\begin{array}{l}1.9 \\
2.6 \\
7.1 \\
3.5 \\
2.5\end{array}$ & & $\begin{array}{l}1.00 \\
1.20 \\
0.06 \\
\cdots\end{array}$ & & .20 & & 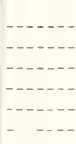 \\
\hline $\begin{array}{l}\mathrm{M}-2 \\
\mathrm{D}-2 \\
\mathrm{O}-2 \\
\mathrm{P}-2 \\
\mathrm{Q}-2 \\
\mathrm{R}-2\end{array}$ & $\begin{array}{l}54.9 \\
63.1 \\
74.5 \\
63.2 \\
61.9 \\
63.2\end{array}$ & $\begin{array}{r}14.3 \\
9.1 \\
14.9 \\
13.0 \\
12.4\end{array}$ & $\begin{array}{r}10.1 \\
13.5 \\
1.9 \\
11.3 \\
12.5 \\
14.9\end{array}$ & $\begin{array}{r}14.5 \\
6.9 \\
10.6 \\
7.9 \\
4.3\end{array}$ & $\begin{array}{l}5.2 \\
4.9 \\
3.9 \\
4.5\end{array}$ & $\begin{array}{l}0.04 \\
2.0 \\
15.4\end{array}$ & $\begin{array}{r}.74 \\
.53 \\
4.30 \\
0.70 \\
.60\end{array}$ & .20 & 10 & 0.4 & (1... \\
\hline
\end{tabular}


Chemical composition of gold solders.-As will be noted from table 14 [14], solders for 18- and 20-carat gold alloys are five-element alloys, consisting of gold, silver, copper, zinc, and tin. The designation "solder for 18-carat" (16- or 20-carat) should not be misinterpreted. It means only that the solder is proper for use in joining or building up 18-carat gold alloy inlays and appliances and does not indicate the carat of the solder. It will be seen in table 14 that solder for use with 18-carat alloys is roughly 16 carat, and that solder for use with 20-carat alloy may be from 17.5 to 19.4 carat in fineness.

TABLE 14.-Composition of gold solders

\begin{tabular}{|c|c|c|c|c|c|c|}
\hline Solder & Gold & Silver & Copper & Zine & Tin & \\
\hline 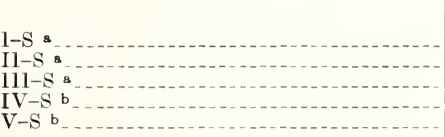 & $\begin{array}{r}\% \\
65.4 \\
66.1 \\
65.0 \\
72.9 \\
80.9\end{array}$ & $\begin{array}{r}\% \\
15.4 \\
12.4 \\
16.3 \\
12.1 \\
8.1\end{array}$ & $\begin{array}{r}\% \\
12.4 \\
16.4 \\
13.1 \\
10.0 \\
6.8\end{array}$ & $\begin{array}{l}\% \\
3.9 \\
3.4 \\
3.9 \\
3.0 \\
2.1\end{array}$ & $\%$ & $\begin{array}{l}\text { 3. } 1 \\
\text { 2. } 0 \\
\text { 1. } 7 \\
\text { 2. } 0 \\
\text { 2. } 0\end{array}$ \\
\hline
\end{tabular}

a Solder for 18-carat plate.

b Solder for 20-carat plate.

Segregation of constituents [14].-Much is heard about the dangers of segregations in dental alloys through carelessness in melting or casting technics. Segregations are undoubtedly possible in certain combinations of the metals used in producing dental gold alloys. The successful manufacturers of these alloys have carefully avoided the ratios of metals likely to develop segregations. Tests were made to determine to what extent these effects are likely to occur in the ordinary dental casting process. A cylindrical casting 10 millimeters in diameter and about 20 millimeters long was made of an alloy relatively high in platinum and palladium. Chemical analyses were made of the outside and center of this casting to determine whether or not there was a difference in the compositions of these parts of the casting. The results of the analyses are given in table 15 . No significant difference was found.

TABLE 15.- Segregation in casting alloy ${ }^{1}$

\begin{tabular}{|c|c|c|c|c|c|c|c|c|c|c|}
\hline \multirow{3}{*}{ Element ${ }^{2}$} & \multicolumn{2}{|c|}{$10 \mathrm{~mm}$ easting } & \multicolumn{4}{|c|}{ Cast at moderate temperature ${ }^{3}$} & \multicolumn{4}{|c|}{ Cast at high temperature } \\
\hline & \multirow{2}{*}{ Outside } & \multirow{2}{*}{ Inside } & \multicolumn{2}{|c|}{ Air pressure } & \multicolumn{2}{|c|}{ Centrifugal } & \multicolumn{2}{|c|}{ Air pressure } & \multicolumn{2}{|c|}{ Centrifugal } \\
\hline & & & Top & Bottom & Top & Bottom & Top & Bottom & Top & Bottom \\
\hline $\begin{array}{l}\text { Gold } \\
\text { Silver } \\
\text { Copper-..- } \\
\text { Zine }\end{array}$ & $\begin{array}{c}\% \\
59.9 \\
10.9 \\
8.8 \\
0.76\end{array}$ & $\begin{array}{c}\% \\
60.4 \\
10.9 \\
8.5 \\
0.78\end{array}$ & $\begin{array}{r}\% \\
59.9 \\
10.9\end{array}$ & $\begin{array}{l}\% \\
59.9 \\
11.0\end{array}$ & $\begin{array}{r}\% \\
59.8 \\
10.9\end{array}$ & $\begin{array}{l}\% \\
60.1 \\
10.9\end{array}$ & $\begin{array}{c}\% \\
60.3 \\
11.0\end{array}$ & $\begin{array}{l}\% \\
60.4 \\
11.0\end{array}$ & $\begin{array}{r}\% \\
60.4 \\
11.0 \\
8.6\end{array}$ & $\begin{array}{l}\% \\
60.6 \\
11.1 \\
8.8\end{array}$ \\
\hline $\begin{array}{l}\text { Zinc } \\
\text { Platinum }\end{array}$ & $\begin{array}{r}0.76 \\
12.9\end{array}$ & $\begin{array}{l}0.78 \\
13.4\end{array}$ & 0.72 & 0.76 & 0.77 & 0.67 & 0.56 & 0.56 & 12.9 & 12.3 \\
\hline Palladium. & & & & & & & & & 5.9 & 5.8 \\
\hline
\end{tabular}

${ }^{1}$ Composition: gold, $60.0 \%$; silver, $11.0 \%$; copper, $8.8 \%$; platinum, $13.1 \%$; palladium, $5.94 \%$; zinc, $0.72 \%$ and tin, $0.14 \%$

${ }_{2}$ As these analyses were made for comparison only, determinations of all the constituent metals were not made.

${ }^{3}$ The term "moderate temperature" is used to designate a temperature slightly above the minimum at which castings could be made with the alloy in question. 1t is obvious that this temperature will vary for different alloys, depending upon their melting points, and, possibly to some extent, on other factors. "The term "high temperature" is used to designate a temperature markedly higher than the moderate temperature defined above. 
Two series of castings of the same alloy were then made with both an air-pressure and a centrifugal casting machine. For one series the gold was heated to a moderate casting temperature with a hydrogenair blowpipe. For the other series the gold was heated to much higher temperature with an oxygen-gas blowpipe. The castings were rods approximately $1 / 8$ inch in diameter by $1 \frac{11}{2}$ inches long and were made in investment molds at a temperature of about $250^{\circ} \mathrm{C}\left(480^{\circ} \mathrm{F}\right)$ to $300^{\circ} \mathrm{C}\left(570^{\circ} \mathrm{F}\right)$. Chemical analyses were made of the top, or residue button, and the bottom of each of these castings. The results of these analyses are given in table 15 . In no case was any significant difference between the composition of the top and that of the bottom of a casting found.

The freezing range of this alloy is very long, there being a difference of more than $160^{\circ} \mathrm{C}\left(288^{\circ} \mathrm{F}\right)$ between the temperature at which freezing begins and that at which solidification is completed. This and the size of the castings and, in one series of castings, the high temperature of the gold, are conditions much more favorable to segregation than those usually encountered in dental practice. Since no segregation was detected even under these conditions, it may be concluded that, in general, this effect is not likely to be serious in dental castings.

Unbalancing alloys during remelting [14].- The extent to which the composition of an alloy may be changed by the burning out of certain constituent metals during the casting process was determined by another series of tests. A section $3 / 4$ inch long was cut out of the center of a cast bar $3 / 8$ inch in diameter and 6 inches long. This center section was cut into three parts which were analyzed, one after being remelted with hydrogen and air and held at a moderate temperature for 2 minutes, one after being remelted with gas and oxygen and held at a very high temperature (approximately $1,600^{\circ} \mathrm{C}\left(2,900^{\circ} \mathrm{F}\right)$ ) for 5 minutes, and one without remelting. During the remeltings, borax flux was used freely. The analyses are given in table 16.

The remelting and holding at a moderate temperature for 2 minutes is a more severe treatment than the gold would ordinarily receive if cast only once. It may be considered as equivalent to remelting and casting at least twice. Yet it will be noted from table 16 that no significant change in composition resulting from this treatment was found. Heating to the excessively high temperature and holding this temperature for 5 minutes is very much more severe, both as to the temperature and the length of time this temperature was held, than is likely to occur in ordinary dental practice. This treatment was so severe that during the entire 5 minutes small particles were flying off

TABLE 16.-Change in composition of casting alloy ${ }^{1}$ due to remelting

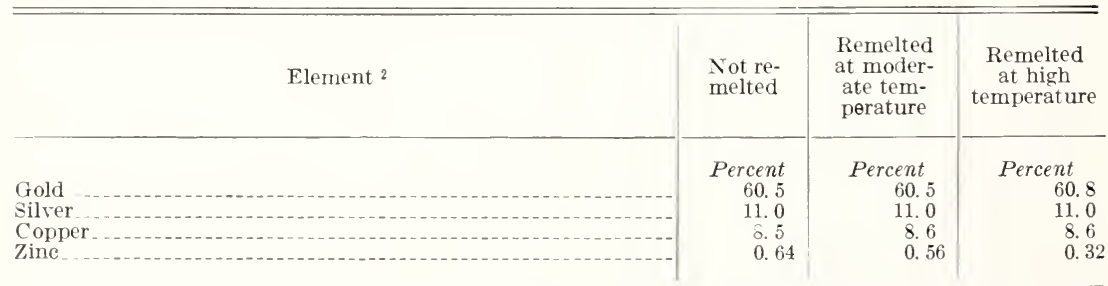

${ }_{1}^{1}$ Composition: gold $60.0 \%$; silver, $11.0 \%$; copper, $8.8 \%$; platinum, $13.1 \%$; palladium, $5.94 \%$; zinc, $0.72 \%$; and tin, $0.14 \%$.

${ }^{2}$ Platinum, palladium, and tin were not determined. 
from the molten metal, and the total loss of metal was approximately one-half of the original weight. As will be seen from table 16, the only change in composition of the alloy subjected to this treatment was the loss of about 50 percent of the original zinc content.

In order that the conditions of test with respect to the grade of alloy used might be as severe as any likely to be encountered in practice, the tests were repeated using low-grade alloys (approximately 15-carat gold) containing a large percentage of base metals. These alloys were very similar to alloy $\mathrm{V}-\mathrm{D}$, which was the lowest in precious metal content of the alloys analyzed (table 12). Since alloy $\mathrm{V}-\mathrm{D}$ has been criticized as being too low in precious metals to be used in the mouth with safety, it is thought that the low-grade alloys used in these tests represent the extreme in this respect. The results of these tests were very similar to those described previously (table 16), except that at the very high temperatures the loss of base metals was slightly greater. Castings made from such excessively heated alloys may, however, display unusually poor physical properties by reason of (1) dissolving of oxides in the alloy; (2) disintegration of the investment when struck by the superheated alloy; and (3) an injurious heat treatment incident to the slow cooling from an excessive temperature in the investment mold. Burned-out dental investments are excellent insulators and tend to retard the loss of heat from castings.

The conclusions to be drawn from these results may be stated briefly as follows: Gold alloys such as those tested in this investigation when remelted and cast with reasonable care are not expected to undergo any serious "unbalancing" or change in the proportions of their constituent metals, even if remelted and cast two or three times. This is true even of alloys so low in precious metal content as to be of doubtful value in the mouth. If due precautions are taken to prevent contamination from oxidation or the inclusion of foreign substances, such treatment should not seriously alter the mechanical properties of these alloys. If, however, the alloys are heated to excessively high temperatures loss of base metals is likely to occur.

Tarnish resistance.-A study of the compositions of dental gold alloys reveals that gold and platinum metals are usually present to the extent of 75 percent or more. A few alloys and solders show lower percentages. Silver is not regarded as a precious metal or tarnishresisting element in the further discussions of this subject.

Isaacs [62] showed that available alloys having a precious-metal content below 65 percent were not sufficiently resistant to tarnish from sulfide vapors to make their usage acceptable to all dentists. The test used by Isaacs is as follows:

Saturate 100 milliliters of ammonium hydroxide with hydrogen sulfide gas. Then add another 100 milliliters of ammonium hydroxide and dilute to 500 milliliters. Place clean strips of alloy in a vertical position beside a beaker containing the solution, in a closed desiccator. After 96 hours of exposure, wash the strips in carbon disulfide, then with acetone, and dry. Compare the color of the exposed strip with a control strip not exposed to the vapors. If the original color no longer predominates, the alloy shall be rejected.

The results of this test indicate a possible danger when alloys for bridge abutments, pontics, saddles, etc., having a noble metal content below 65 to 75 percent are used. Solders for these alloys are usually produced by additions of larger percentages of base metals. With a 
lower limit of 65 percent of precious metal for the solders it is necessary to adopt the above lower limit of 75 percent for the basic alloys. Additional research on the part of manufacturers may possibly enable them to produce nontarnishing alloys with a lower content of precious metal. Changing the specification to admit such alloys need not be a difficult procedure when they are available.

Microstructure [14].- Studies in microstructure may furnish important information on the properties of dental alloys. Differences between cast and wrought alloys may be shown. Microscopic defects incident to casting or mechanical working may be revealed. The final criteria are physical and chemical properties, however, and the information gained from studies of microstructure should be evaluated to these criteria.

Figure 16 (a) shows the "tree-like," or dendritic, pattern of the primary crystals formed during solidification from the molten state. This is characteristic of pure metals and many alloys. Crystallites formed initially at a number of different centers have intermeshed into the pattern shown in the figure. In some metals these crystals can be transformed into equiaxed grains such as are shown in figure 17, by annealing. In wrought metals, the original cast structure is effectively broken up by forging, rolling and wire drawing to produce the fibrous structure shown in figure 16 (c) and (d). The primary crystals are elongated in the direction of the principal elongation of the wire. If the elongating operations are conducted at a sufficiently high temperature, an equiaxed instead of the fibrous structure is obtained. A similar equiaxed structure may be obtained from the fibrous structure by suitable heat treatment after cold deformation. The strength and ductility of a metal in the wrought form, if not damaged by incorrect working practice, are superior to those of the metal in the cast condition. The breaking up of the dendrites must not be regarded as a destructive operation. This can be understood, to some degree, if a study is made of the figure 18. Two alloys were cast as dental appliances. Sections were cut from the castings, polished (not etched), and examined under the microscope. Two types of porosity are shown. The voids in figure 18 (a) are irregular in shape and appear to be the result of localized shrinkage. These voids have bright side walls and are free of tarnish or foreign materials. Remelting this alloy in a vacuum to remove all gas and allowing it to cool did not eliminate this type of porosity. Figure 18 (b) illustrates the shapes of the voids in the gas-free alloy. It does not, however, illustrate properly the bright, flashy surface walls within these voids. Figure 18 (c) illustrates the second type of porosity. The roundness of these voids suggests occluded gases or foreign material of some sort. Remelting in vacuum removes these rounded voids and leaves the alloy with the typical minute pores (fig. 18 (d)). It is not difficult to conceive of a welding taking place, as rolling or drawing operations collapse these porous spots and press clean metal against clean metal and thus improve the mechanical properties of the alloy.

Attempts to roll or draw an alloy having inclusions of the type shown in figure 18 (c) would result in internal seams or streaks in the wrought plate or wire. These are sources of weakness.

No evidence of serious porosity, caused by the inclusion of metallic oxides, was found when the usual precautions of melting with a reduc- 

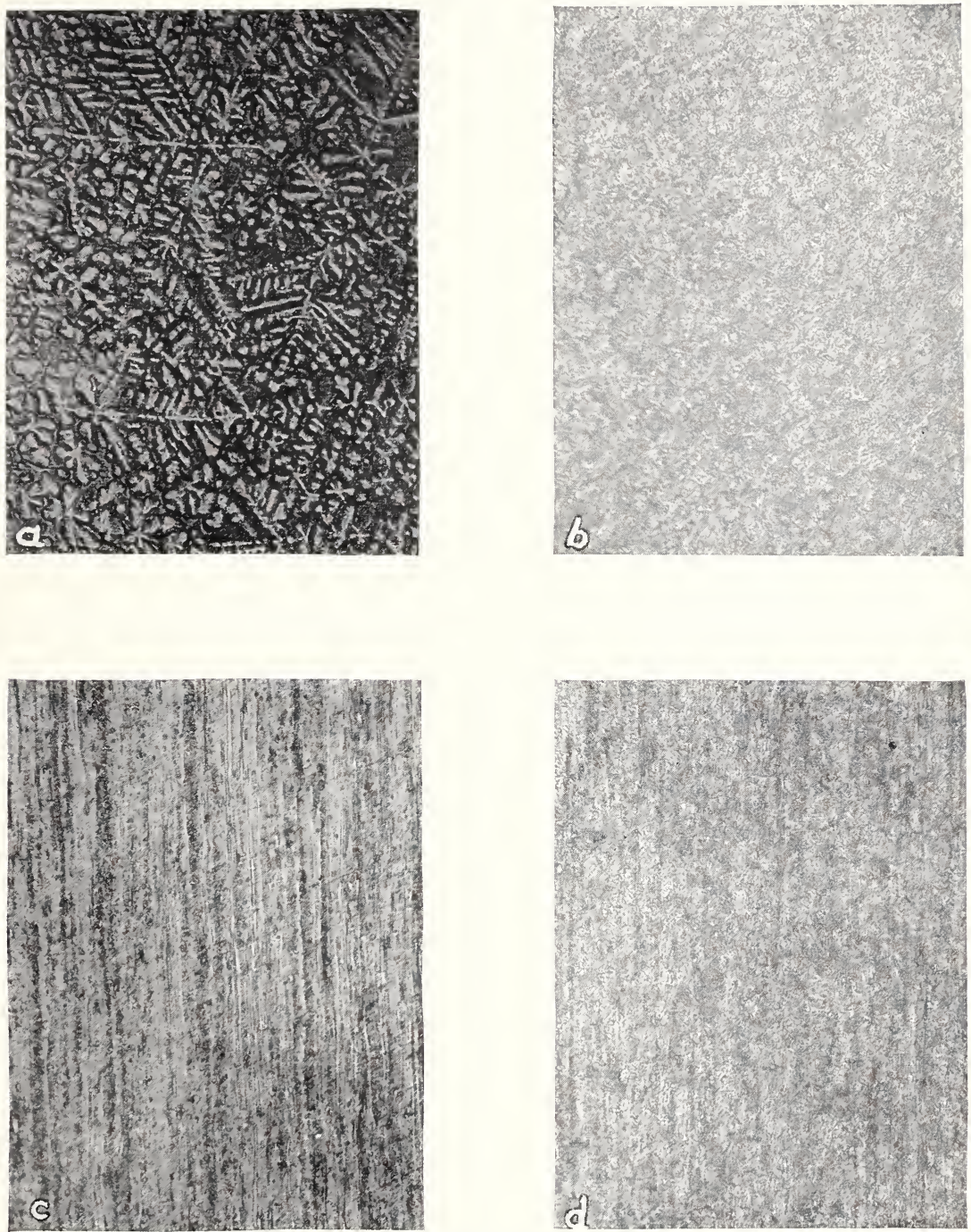

FIgURE 16.- Microstructure of a dental gold alloy.

Composition: gold, 64.5 percent; platinum, 17.6 pereent; copper, 10.4 pereent; silver, 5.1 pereent; palladium, 2.1 percent; and zinc, 0.8 percent.

$a$, Cast and slowly cooled. The dendritic structural pattern (light colored) represents the highest freezing constituents and is charaeteristic of pure metals and many alloys.

$b$, Cross-sectional structure of the same alloy drawn into a wire and then given a hardening heat treatment.

c. Longitudinal section showing strueture of wire after subjecting it to a softening heat treatment.

$d$. Longitudinal section showing structure of wire after hardening.

Note that the dendrites in $a$ have been ruptured and elongated in $c$ and $d$, where they appear as lightcolored portions elongated in the direction of the drawing operation of the wire. 
ing flame and using a protective flux, such as fused borax or borax and charcoal, were taken. It is now believed that porosity in dental castings is the result of occluded gas, of localized shrinkage, or a combination of both. The inclusion of gases can be minimized by care in melting, and the use of a flux when allors susceptible to gas inclusions are melted. The roids can be coaxed from the essential part of the casting by attaching a mass of wax around the sprue immediately abore the inlay or appliance (fig. 34 (c)). If sereral sprues are used, each of them should be loaded with a block of wax to provide reservoirs of molten gold near the appliance. These reserroirs will supply molten gold to the solidifying and shrinking inlay or appliance. The reservoirs will solidify last and many of the roids and porous structures which would hare dereloped in the appliance derelop in the reservoir instead. The use of such reservoirs is in accordance with good foundry practice. The reservoir to be most

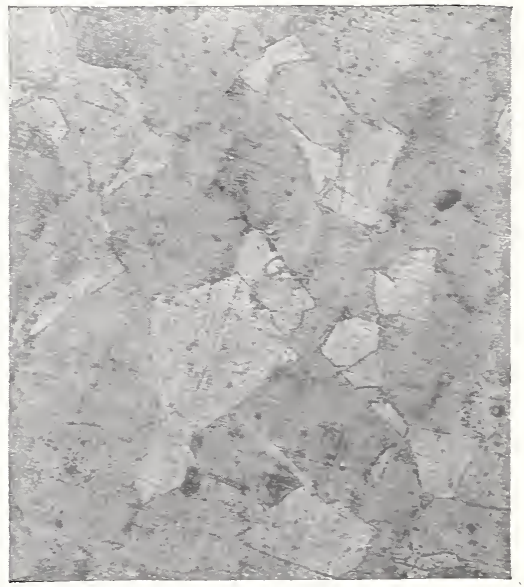

FigURE 17.-Photomicrograph of casting alloy etched with potassium cyanide.

The composition of this alloy is gold, 91.7 percent; silver, 4.6 percent; copper, 3.7 percent. Note the general type of crystal structure.

effective must be of such size and so placed that it will remain molten until every part of the appliance has solidified (fig. 34 (c)); otherwise, the reservoir may, if it solidifies first, draw molten alloy from the appliance.

Melting temperatures [14, 34].-Melting temperature is an important item in casting alloys, which must all be melted before castings can be made. High-melting alloys require special fuels. Low-melting alloys must not be orerheated. Wrought appliances and many cast appliances are soldered at some stage during their fabrication and, if an allor melts below a standard minimum temperature the hazard is introduced of melting the basic alloy at the time the solder is melted.

Complex alloys seldom have a single. definite melting temperature. as the pure metals have, but usually have a melting range or temperature interral within which part of the allor is in the liquid and part is in the solid state. The allor begins to melt at the temperature of the lower limit of the range but is not completely melted until the 

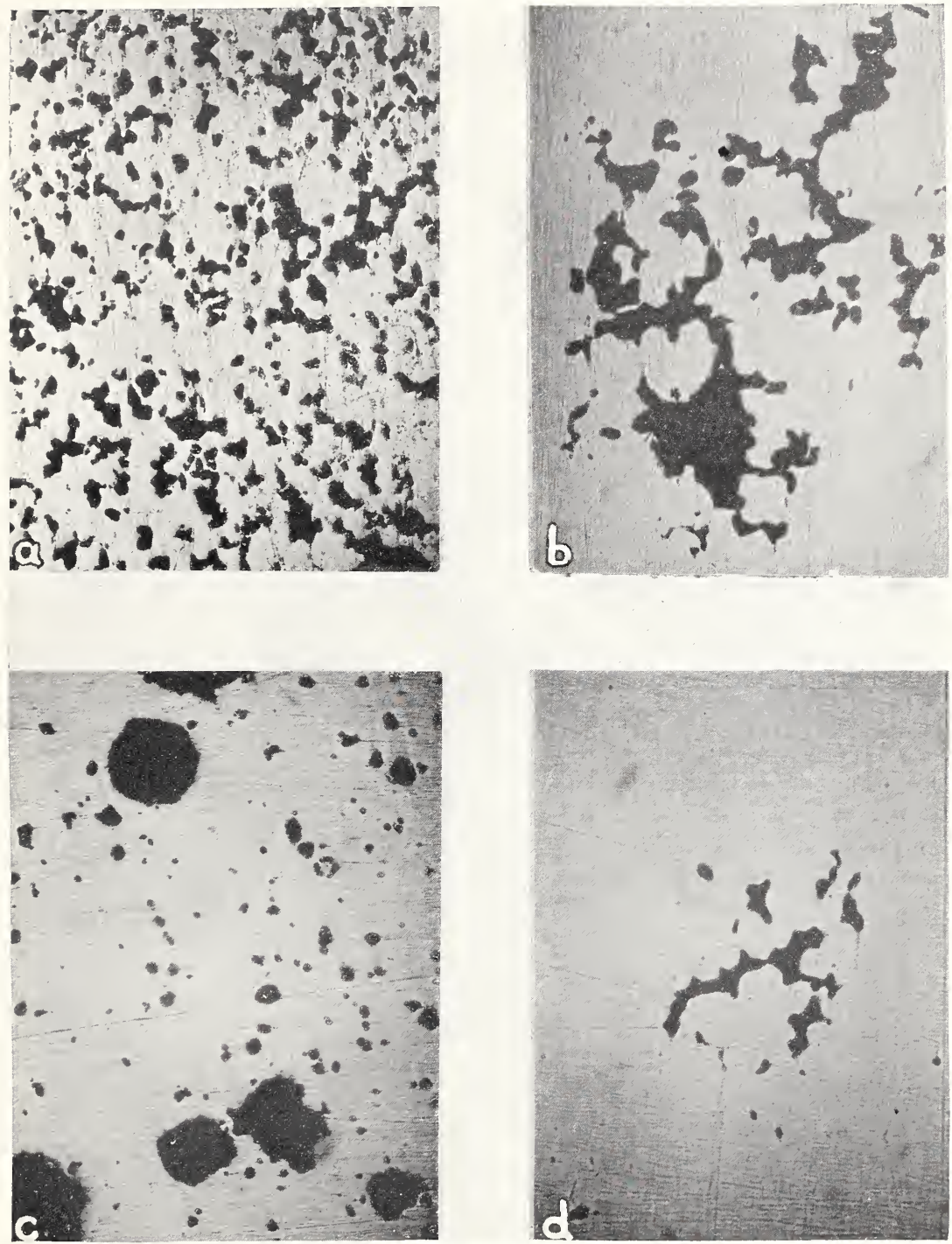

Figure 18.-Porosity in dental castings.

All sections polished but not etrhed.

$a$, A type of porosity which appears to be due to localized shrinkage. This alloy if etched would show the normal dendritic structure.

$b$, Section of the same alloy as in $a$ after remelting in vacuum.

$c$, Another type of porosity which appears to be due to occluded gas

$d$, Section of the same alloy as in $c$ after remelting in vacuum. 
temperature of the upper limit is reached. Table 17, giving the melting points of some of the metals used in dental alloys and the melting ranges of a binary alloy of each of these metals with gold, is included to illustrate this and for reference purposes. It will be noted

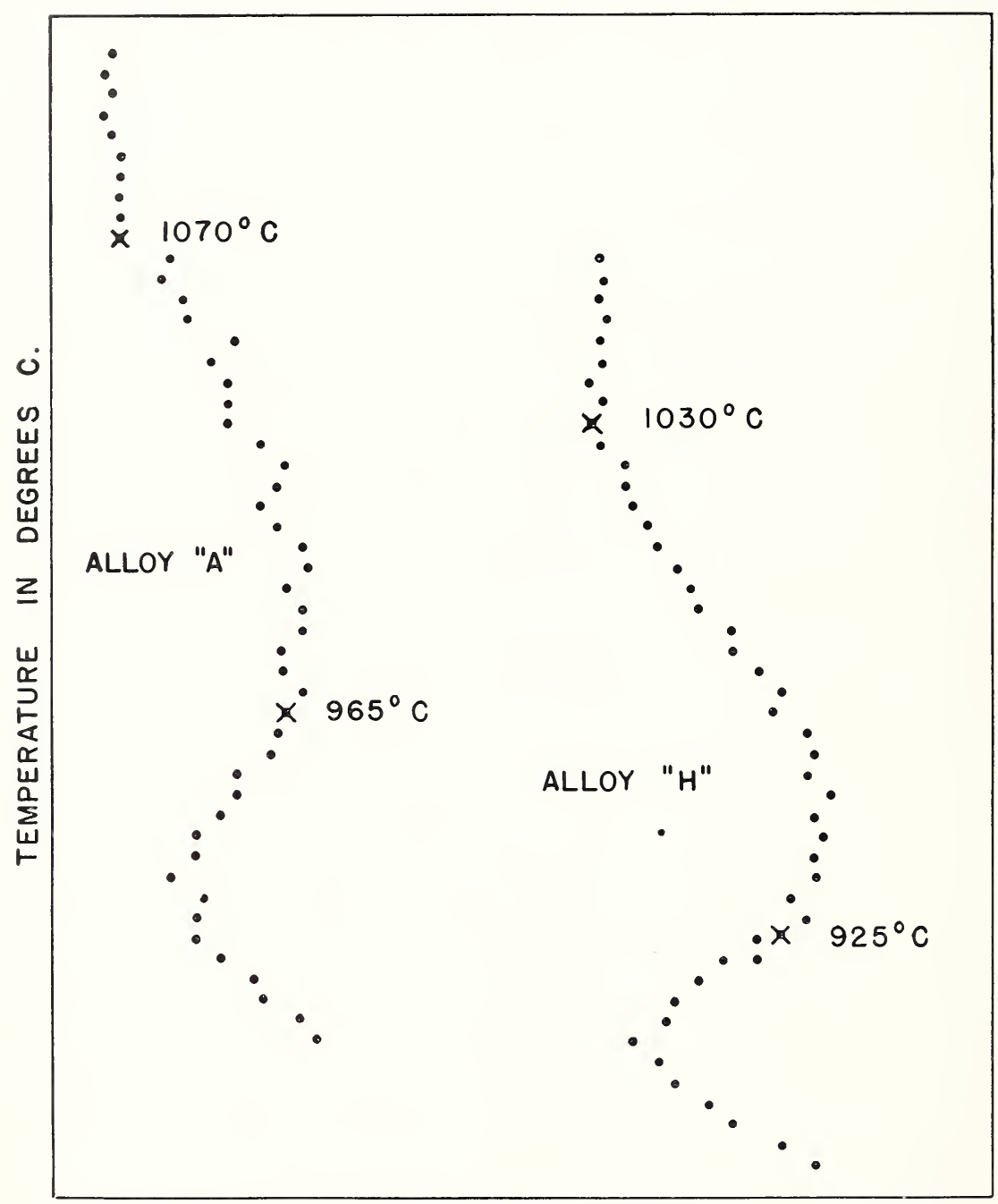

TIME IN SECONDS

Figure 19.-Cooling curves for alloys $A$ and $H$

The time required for the alloy to cool equal temperature intervals is plotted against temperature. This is known as the inverse-rate method and locates the freezing range. The teinperature at which the molten alloy begins to freeze is indicated by a decrease in the rate of cooling: $1,070^{\circ} \mathrm{C}\left(1,958^{\circ} \mathrm{F}\right)$ i or alloy $A$ and $1,030^{\circ} \mathrm{C}\left(1,886^{\circ} \mathrm{F}\right.$ for alloy $H$. Solidification of the alloy is complete when the rate of cooling shows a sudden increase; $965^{\circ} \mathrm{C}\left(1,769^{\circ} \mathrm{C}\right)$ for alloy $A$ and $925^{\circ} \mathrm{C}\left(1,697^{\circ} \mathrm{F}\right)$ for alloy $H$. Compositions are given in table 22 .

that the length of the melting range of an alloy varies widely, depending upon its composition. The range for an alloy containing 90 percent of gold and 10 percent of silver is only $6^{\circ} \mathrm{C}\left(11^{\circ} \mathrm{F}\right)$, while that of an alloy containing 90 percent of gold and 10 percent of 
platinum is nearly $130^{\circ} \mathrm{C}\left(234^{\circ} \mathrm{F}\right)$. Some of the complex alloys used in dentistry have melting ranges even longer than this. Such temperature ranges are usually determined by observing changes in the rate of cooling of the alloy as it passes from the liquid to the solid state. Two determinations of this kind are illustrated in figure 19.

TABLE 17.-Melting points and ranges of a few metals used in dentistry and some of their binary alloys

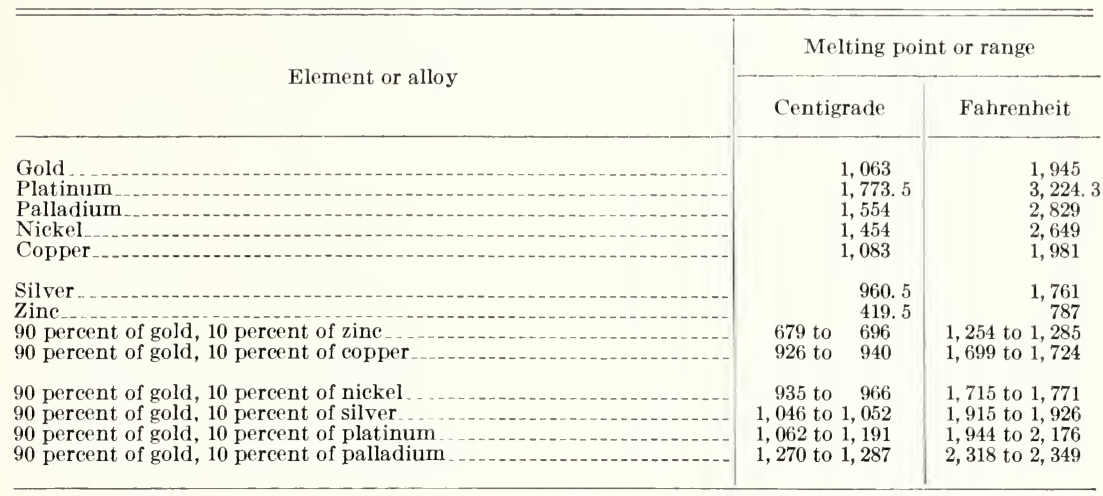

For the most intelligent use of the casting alloys it is necessary to know not only the maximum temperatures at which they are sufficiently rigid and cohesive to be soldered, bent, or otherwise manipulated with safety, but also the minimum temperatures at which they are sufficiently fluid to be cast or, in the case of solders, flowed. For this reason it was necessary to determine the melting ranges of the alloys of this group. The lower limit of the melting range, or the temperature at which fusion begins, is an index of the maximum temperature at which the alloy may be manipulated with safety, and the upper limit, or the temperature at which fusion is completed, is an index of the minimum temperature at which the alloy may be cast or flowed in the case of a solder. The melting ranges determined are given in table 18. By referring to this table, it will be noted that the melting ranges of some of the alloys of this group are quite long, in some cases extending over $100^{\circ} \mathrm{C}\left(180^{\circ} \mathrm{F}\right)$.

In a wrought alloy the upper limit of the melting range is of little practical importance to the user, since he seldom has occasion to completely melt the alloy. However, it is important to know the maximum temperature at which the alloy may be soldered, bent, or otherwise manipulated with safety. For the purpose of locating this temperature it was felt that sufficient data could be secured by determining a point within the melting range by means of the "wire" method [105]. A brief description of this method, as employed in these tests, follows. A short piece of the alloy (from 3 to $4 \mathrm{~mm}$ long), the fusion point of which was to be determined, was welded between the wires of a platinum and platinum-rhodium thermocouple to form the hot junction. After connecting this thermocouple to a potentiometer, the hot junction was inserted in an electric furnace at a temperature somewhat below the fusion temperature of the alloy 
TABLE 18.-Welting range and fusion points of dental gold alloys

Gold alloys for cast inlars

(Composition given in table 11)

\begin{tabular}{|c|c|c|c|c|}
\hline Alloy & Melti & range & Fusio & int \\
\hline $\begin{array}{l}{ }_{8}^{8}{ }_{9} \\
19 \\
22 \\
26 \\
29\end{array}$ & $\begin{array}{lr}{ }^{\circ} C & \\
\text { sse to } & 928 \\
955 \text { to } & 9 \mathbf{s 9} \\
944 \text { to } & 1.022 \\
929 \text { to } & 999 \\
929 \text { to } & 999 \\
921 \text { to } & 997 \\
902 \text { to } & 946\end{array}$ & $\begin{array}{l}\circ F \\
1.627 \text { to } 1.702 \\
1.751 \text { to } 1.812 \\
1.731 \text { to } 1.872 \\
1.704 \text { to } 1.830 \\
1.701 \text { to } 1.830 \\
1.690 \text { to } 1.827 \\
1.656 \text { to } 1.735\end{array}$ & $\begin{array}{l}\circ C \\
899 \\
970 \\
978 \\
956 \\
942 \\
957 \\
923\end{array}$ & $\begin{array}{l}{ }^{\circ} F \\
1,6 \\
1,7 \\
1,7 \\
1.7 \\
1,7 \\
1,7 \\
1,6\end{array}$ \\
\hline
\end{tabular}

Gold alloys for dentures, clasps, etc.

(Composition giren in table 12)

\begin{tabular}{|c|c|c|c|c|}
\hline 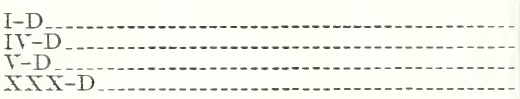 & $\begin{array}{l}910 \text { to } 1.010 \\
8 \leq 5 \text { to } 955 \\
820 \text { to } 870 \\
900 \text { to } 949\end{array}$ & $\begin{array}{l}1.670 \text { to } 1.850 \\
1.625 \text { to } 1.505 \\
1.505 \text { to } 1.595 \\
1,652 \text { to } 1.740\end{array}$ & 906 & 1,663 \\
\hline
\end{tabular}

Gold solders

(Composition given in table 14)

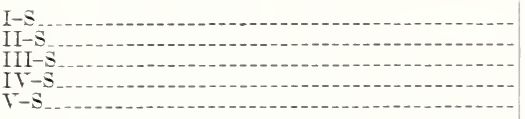

$7 \pm 5$ to
750 to
765 to
755 to
$\$ 20$ to

\begin{tabular}{l|}
755 \\
$\$ 05$ \\
500 \\
535 \\
570
\end{tabular}

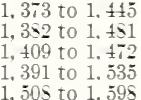

under test and the temperature raised at a uniform rate not exceeding $5^{\circ} \mathrm{C}\left(9^{\circ} \mathrm{F}\right)$ per minute. The temperature was indicated by the potentiometer. Care was taken to prerent a temperature gradient across the sample that might cause serious error in the indicated temperature. The fusion of the sample, causing a break in the connection between the wires of the thermocouple, was indicated by the potentiometer registering an open circuit. Additional details are to be found in the specifications for these allors (pp. 1S8, 190, 202).

Both limits of the melting range were determined by the cooling curve method for a few wrought allows, and it was found that ther were of no more practical value than the temperatures determined by the "wire" method and. perhaps, not so reliable in indicating the temperature at which failure could be expected. The "wire" method was, therefore, adopted. The fusion temperatures, as determined by this method, are giren in table 20, columns 3 and 4 .

No comments are offered as to the most appropriate working temperature for such allors. Certainly soldering. heat treating. or manipulating should not be attempted above the fusion temperature. For most purposes the temperature should be kept below this point. The nearness to which the fusion temperature may be approached with safety will depend upon the skill of the operator, the control of the furnace or flame, the quality of the solder used, and other factors. The temperature given mar be taken as a maximum which should never be exceeded in ans operation.

Heat treatment. - At the time the original investigation was begun some data had been published on the subject of the heat treatment of dental gold alloys, but it was found impossible to coordinate the 
findings of the different observers. The devices and methods for heat treatment recommended by most lecturers and clinicians were so general in their nature and lacked so much in detail that it was decided to make an independent investigation of this subject.

Preliminary experiments indicated that these alloys could be softened by heating to a temperature of about $700^{\circ}$ to $800^{\circ} \mathrm{C}\left(1,292^{\circ}\right.$ to $1,472^{\circ} \mathrm{F}$ ) and quenching in water, and that some, though not all of them, could be hardened by heating to the same temperature and cooling slowly. It was necessary to determine the proper temperatures and times or rates of cooling to produce these results efficiently under the practical working conditions of the dental laboratory.

Attempts to determine these constants by changes in cooling curves and thermal expansivity, induced by different heat treatments, were not conclusive. The most promising method appeared to be that of determining changes in thermal electromotive force. By making

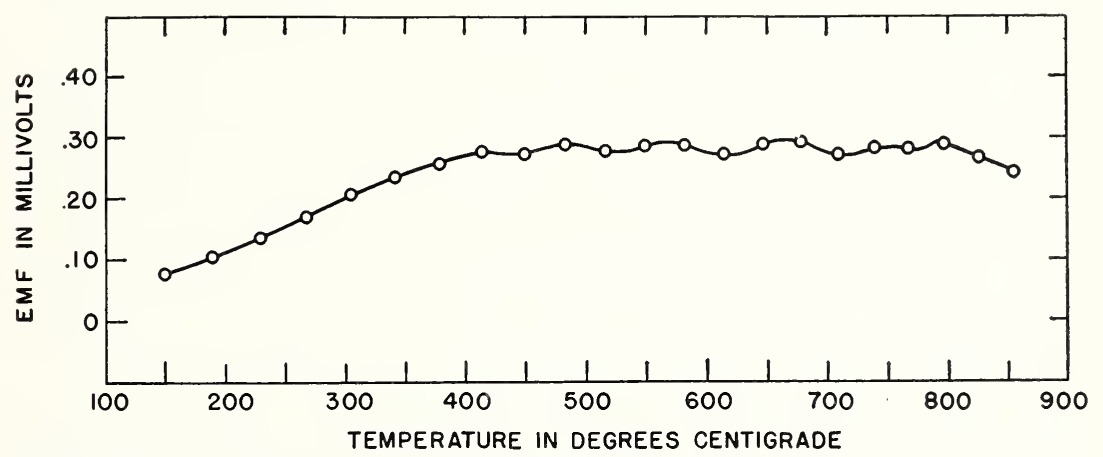

FIGURE 20.--Temperature-emf-relation for a thermocouple made of two wires of the same chemical composition but given different heat treatments.

thermocouples of heat-treated and untreated wires, and of wires subjected to different heat treatments, and observing the emf values at increasing temperatures, it was found that changes in the thermoelectric properties were taking place within certain temperature ranges. Careful tests with wires prepared in the manner indicated by these first approximate findings served to narrow the range of temperature and time.

Figure 20 represents a typical curve obtained by this method. The values plotted in this figure were obtained from a thermocouple made of two alloy $A$ wires (composition given in table 22). Both wires had previously been quenched in water from $700^{\circ} \mathrm{C}\left(1,292^{\circ} \mathrm{F}\right)$, and one was used in the quenched condition, and the other after it had been reheated to $700^{\circ} \mathrm{C}\left(1,292^{\circ} \mathrm{F}\right)$ and cooled slowly. One end of the couple was placed in a furnace, the temperature raised at a rate of approximately $13^{\circ} \mathrm{C}\left(23.4^{\circ} \mathrm{F}\right)$ per minute, and the emf of the alloy $A$ couple corresponding to various temperatures was recorded. It will be noted that the emf increases as the temperature is raised to about $425^{\circ} \mathrm{C}\left(797^{\circ} \mathrm{F}\right)$ and then remains approximately constant, which indicates that a transformation has occurred and that the portions of the two wires inside the furnace are now in the same condition. The indicated emf does not drop to zero, as might be expected after the furnace has reached the temperature at which the 
transformation is completed, because the wires extend outside the furnace and pass through a temperature zone which is just below that at which the transformation is completed: hence, as the temperature inside the furnace is raised the indicated emf becomes approximately constant at the maximum value.

The temperature at which this transformation is completed, in this case approximately $425^{\circ} \mathrm{C}\left(797^{\circ} \mathrm{F}\right)$, was recognized as that at which the maximum change in the mechanical properties of the alloy was most likely to occur. Similar tests on this and other alloys, using thermocouple elements that had been subjected to various heat treatments, indicated that for these alloys the maximum softening effect could be secured by quenching from a temperature ranging from $700^{\circ}$ to $800^{\circ} \mathrm{C}\left(1,292^{\circ}\right.$ to $\left.1,472^{\circ} \mathrm{F}\right)$, and the maximum hardening effect by prolonged heating at a temperature ranging from $400^{\circ}$ to $450^{\circ} \mathrm{C}\left(752^{\circ}\right.$ to $\left.842^{\circ} \mathrm{F}\right)$ or by slow cooling from a temperature within or slightly above this range. 'These tests also indicated that varying degrees of hardening could be secured by prolonged heating at, or slow cooling from, temperatures both above and below the range specified and by varying the length of time the temperature was maintained or by varying the rate of cooling. It was also found that the time required to produce a given degree of hardening was practically the same whether the alloy was held at a constant temperature or allowed to cool slowly. For example, cooling the alloy from $450^{\circ} \mathrm{C}$ $\left(842^{\circ} \mathrm{F}\right)$ to $250^{\circ} \mathrm{C}\left(482^{\circ} \mathrm{F}\right)$ in 30 minutes produced practically the same effect as heating at $450^{\circ} \mathrm{C}\left(842^{\circ} \mathrm{F}\right)$ for 30 minutes. These findings were verified by tests of the various mechanical properties. A description of these tests and further details of the effects of heat treatment are given in a following section on mechanical properties (p. 53; see also p. 69).

From the standpoint of practical application in the dental laboratory the method of hardening by slow cooling has two very marked advantages in that, when this method is employed, it is not necessary to know so precisely the temperature most suitable for hardening a given alloy nor to measure the temperature of the work very accurately during the heat treatment. This method was therefore adopted as standard for this investigation and used for all alloys except those for which special heat treatments were recommended by their manufacturers. The rate of cooling found most efficient for this purpose was the rate obtained by allowing the specimen to cool at a constant rate from $450^{\circ} \mathrm{C}\left(842^{\circ} \mathrm{F}\right)$ to $250^{\circ} \mathrm{C}\left(482^{\circ} \mathrm{F}\right)$ in 30 minutes.

There has been some ambiguity in the terms used in the dental literature to describe the heat treatments of gold alloys. The quenching operation, by which these alloys are softened, has often been referred to as "annealing," although, as generally used, this term implies a slow rate of cooling, and the hardening treatment has been called "tempering," a term which, as applied to steel, means a slight softening of the hardened alloy by heating. In order to avoid such ambiguity, the terms "softening heat treatment" and "hardening heat treatment" are used throughout this paper and are defined as follows:

Softening heat treatment.-The heating of the specimen to $700^{\circ} \mathrm{C}$ $\left(1,292^{\circ} \mathrm{F}\right)$ and quenching in water. In the case of specimens of the size used in dentistry, this treatment will soften the alloy whether 
it has been hardened by mechanical working or by previous heat treatment.

Hardening heat treatment.-The cooling of the specimen from $450^{\circ} \mathrm{C}\left(842^{\circ} \mathrm{F}\right)$ to $250^{\circ} \mathrm{C}\left(482^{\circ} \mathrm{F}\right)$ at a constant rate over a period of 30 minutes.

In the case of certain alloys, variations from these rates of cooling are permissible and sometimes produced more desirable properties.

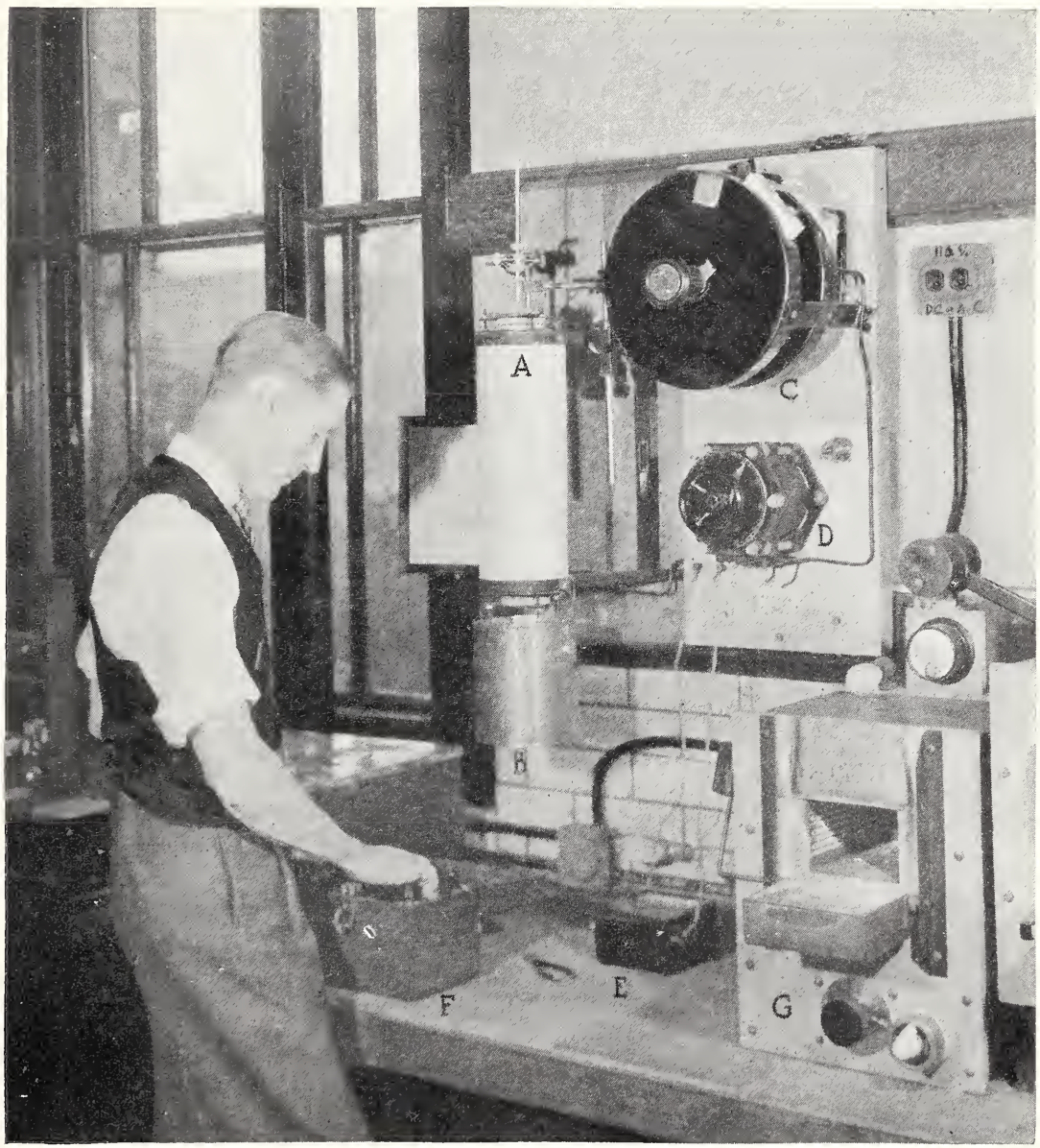

Figure 21.- Apparatus used in heat treating long test specimens.

$A$, tube furnace; $B$, bucket of water for quenching specimens; $C$, rheostat; $D$, variable transformer; $E$ ammeter; $F$, potentiometer: $G$, box-type furnace designed by the National Bureau of Standards for dental laboratory use.

Thus, for some alloys air cooling from $700^{\circ} \mathrm{C}\left(1,292^{\circ} \mathrm{F}\right)$ will produce a condition almost as soft as that produced by quenching, while for others air cooling will produce a marked hardening effect. Those alloys that are decidedly hardened by air cooling may become quite brittle if cooled from $450^{\circ} \mathrm{C}\left(842^{\circ} \mathrm{F}\right)$ to $250^{\circ} \mathrm{C}\left(482^{\circ} \mathrm{F}\right)$ in 30 minutes, and greater ductility may be obtained by cooling at a faster rate. However, for practical purposes the maximum softening and harden- 
ing effects for most allors may be obtained by the treatments specified abore.

For small pieces of wire or plate, such as are ordinarily used in the construction of dental appliances, the heating preliminary to quenching for the softening treatment mar be done successfully orer a gas flame. provided care is taken to heat the work as uniformly as possible and to aroid orerheating. An experienced technician may judge the temperature with sufficient accuracr by observing the color of the work. Howerer, a much safer and more reliable method is to use a properly designed electric furnace prorided with a prrometer. For the hardening heat treatment. which requires that the work be held at a definite temperature for a definite length of time or that it be cooled at a definite rate, the open flame is obriously inadequate. The inclosed box-trpe oren is quite satisfactorr. "Further adrantages of such a derice are that it can readily be equipped with a rheostat for temperature control and a prrometer or other suitable derice for measuring the temperature. Such a heating derice when properly equipped and standardized has proved rerr satisfactory for hardening short specimens. For heat treating long test specimens. the equipment shown in figure 21 was used. The temperature in this furnace is rery uniform and can be measured and controlled accurately.

Probably the most conrenient and at the same time the least expensive equipment suitable for heat treating dental appliances is a salt bath. For many rears rarious mixtures of salts have been used in industry for this purpose. Potassium nitrate $\left(\mathrm{KNO}_{3}\right)$, and sodium nitrate $\left(\mathrm{NaNO}_{3}\right)$ when mixed in equal proportions by weight, melt to a straw-colored liquid at approximatelr $205^{\circ} \mathrm{C}\left(401^{\circ} \mathrm{F}\right)$. The only additional equipment necessary is a Bunsen bumer, a tripod, a heary metal pan for holding the salts, and a short-stemmed mercury thermometer which will read to $400^{\circ} \mathrm{C}\left(752^{\circ} \mathrm{F}\right)$. One distinct adrantage in the use of this bath is the prevention of oxidation of the appliance during the heat treatment. It can be used repeatedly without deterioration. Certain precautions must be observed in its use. The appliance must be absolutely dre when placed in the hot liquid as any moisture introduced with it will form steam, spraring the hot liquid with explosire riolence. All organic materials such as waxes must be kept awas from the bath because of danger of an explosion. Aside from these two precautionary measures, the material is almost mistakeproof. The equipment can be procured from a laboratory supply company and some dental supply houses and is inexpensive.

It should be noted that the purpose of this inrestigation of the heat treatment of dental gold allors was to develop efficient and practicable methods. No attempt was made to derelop a theoretical explanation of the effects produced on the mechanical properties. Sereral authors of articles appearing in dental journals have stated that the hardening of these allors br heat treatment is caused br the formation of intermetallic compounds of gold and copper [106. 130]. Thile it seems probable that these statements are at least partly correct, it should be borne in mind that most of the dental gold allors contain metals other than gold and copper. and that in some cases these other metals appear to have a marked influence on 
the hardening effect. A thorough investigation of the cause or causes of the hardening of the complex dental gold alloys, resulting in authoritative information on this subject, would be a valuable contribution to the science of dental metallurgy.

The practical significance of this investigation on heat treatment arises from the possibilities for the dentist to adjust clasps, swage or spin the margin of an inlay, shape a bar or arch wire from softened alloy having abundant ductility, and then to fix permanently the appliance to the adjusted state by hardening it. Many alloys show remarkable improvements in hardness and strength when given proper heat treatments.

Mechanical properties. - The mechanical properties of a dental alloy are the most important properties to be considered in deciding which one of a number of apparently similar alloys is to be selected for use by the dentist. The properties of major importance are hardness, elastic limit, ultimate tensile strength, and elongation. Additional items of importance are resistance to repeated stresses, modulus of elasticity, and modulus of resiliency. For the wrought alloys, little difficulty is encountered in securing satisfactory specimens on which these tests can be made as the wire, band, or bar may be tested in the "as purchased" condition. Definite heat treatments must be applied and the responses by the alloys must be accurately measured.

Tests on the casting alloy in the shapes received from the supply house are not satisfactory. Some brands are furnished in the rolled or wrought form and others in the form of chilled shot. Since the alloy is to be melted and cast by the dentist, it is preferable that test specimens be prepared which will accurately represent in size and technic of preparation the sizes and technics employed by the dentist.

Considerable time was spent in the initial approach to this phase of the research. Flat bars and round rods of different dimensions were cast in dental investment. Other's were poured in hard carbon molds. Some were cast in air-pressure machines, others were cast in centrifugal machines. Rods having diameters as large as $1 / 8$ inch and lengths of $5 \frac{3}{4}$ inches were poured and tested. The net results of all these preliminary tests indicated that round specimens, cast in dental investment, having diameters of 0.080 inch and sufficiently long to permit measurements of elongation over a 2-inch gage length, were quite satisfactory.

The data presented in this report are from several types of specimens. Some of the early data are from specimens $1 / 8$ inch in diameter. It is believed that these data are comparable with those secured from the smaller specimens. No effort will be made to designate differences in the sizes of the test specimens where data thought to be representative of both sizes are presented.

Hardness. - To define accurately what is meant when the term hardness is used is very nearly impossible. Hardness has been used in a mechanical sense to define resistance to abrasion or penetration. There are numerous types of instruments and systems designed to measure hardness. Among these are the 10 steps of the Mohs-scale, ranging from talc to diamond, the file, the rebounding hammer (scleroscope), and various types of indenting tools. Many of the quantitative tests for hardness employ an indenter which is pressed into 
the alloy under fixed conditions of time and load. Three types of indenters have been used at this Bureau for measuring the indentation hardness of dental gold alloys. These are the spherical steel ball (Brinell), the square-base pyramid (Vickers), and the diamondsection pyramid (Knoop) [107]. The baby Brinell instrument (fig. 22) presses a hardened steel ball 1.6 millimeter $(1 / 16$ in.) in diameter in to the flat surface of the alloy under a load of 12.6 kilograms (27.8 lb.). The
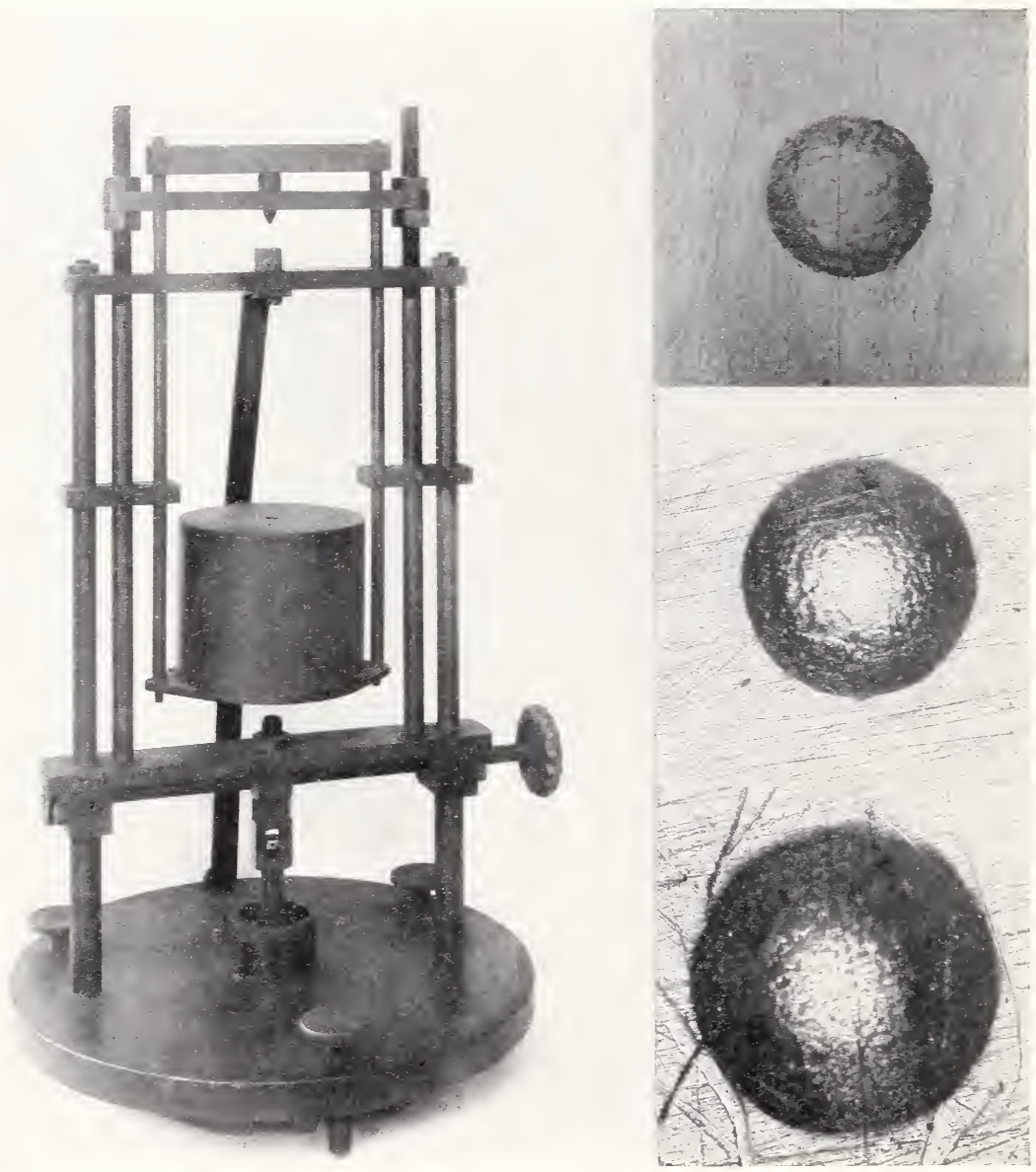

Figure 22.-Baby Brinell instrument for determining hardness of small samples. Insets: Indentations in gold alloys. Top, cast clasp BHN 192; center, hard inlay BHN 90; bottom, soft inlay BHN 48.

Vickers hardness tester (fig. 23) presses the apex of a square-based, 136-degree diamond pyramid, into the flat surface of the alloy under a load of 5 to 120 kilograms. The Knoop indenter (fig. 24) differs from the Vickers, in that the diamond pyramid is so formed that a cross section of the indentation is an equilateral parallelogram having diagonals of different lengths (fig. 56). The ratios of these diagonals may run as high as 10 to 1 . The increased accuracy of the Knoop indenter arises from the ability to determine very accurately (from the length of the major diagonal) the exact projected area of the indentation. 
The hardness numbers in the Brinell and Vickers types of indenting tests is the quotient of the load in kilograms divided by the total area in square millimeters of the surface which supports this load. The mathematical expression of this ratio for spherical indenting tools is:

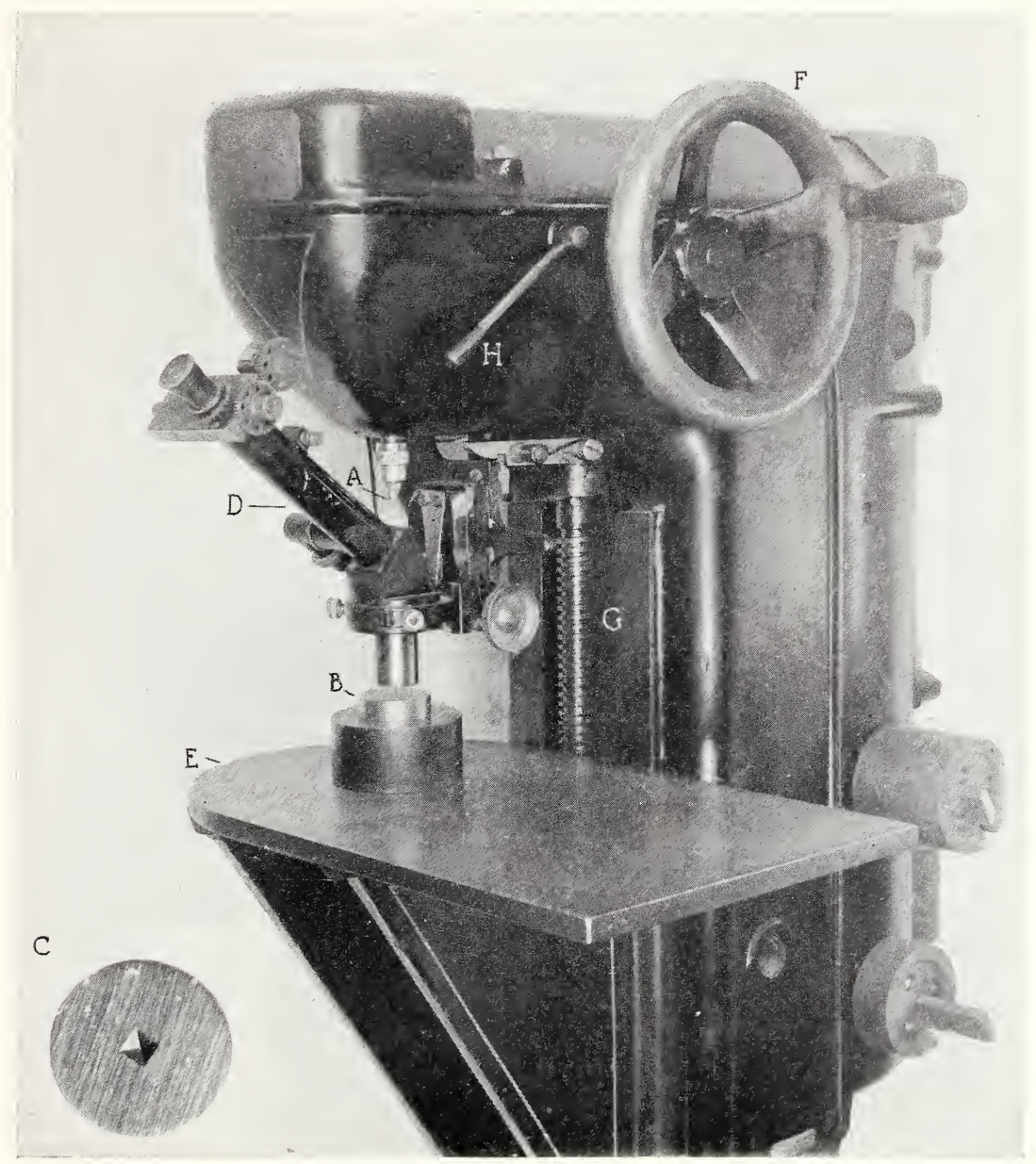

FIGURE 23.-Vickers hardness instrument.

A diamond pyramid, $A$, when pressed into a specimen, $B$, makes an indentation, as shown in $C$. This indentation was made in a cross section of an 0.040-in. orthodontia wire. The lenoths of the diagonals of $C$ are determined with the measuring microscope assembly, $D$, which is in reading position. When an indentation is made, the microscope assembly, $D$, is thrown sideways on a hinge and the platform, $E$, is raised into position by turning wheel, $F$, which actuates the serew, $G$. When the switch lever, $H$, is thrown the load is automatically applied for a definite interval.

Brinell hardness number $=\frac{\text { load }}{\text { area }}=\frac{P}{\frac{\pi D}{2}\left(D-\sqrt{\left.D^{2}-d^{2}\right)}\right.}$,

where

$P=$ load in kilograms

$D=$ diameter of indenting sphere in millimeters

$d=$ diameter of indentation in millimeters. 
Tables are available in handbooks showing the hardness numbers for various diameters of indentations, where standard spheres are used as indenters. Similar tables can be computed for the pyramidal or other simple types of indenters.

Obviously, the harder the material the smaller will be the area of indentation and consequently the larger the numerical value of the quotient, which is designated as the hardness number. Conversion ratios for the various hardness numbers are necessary if comparisons of materials tested on different types of instruments are to be made. These ratios do not hold over an extended range of hardness. A general idea of the relative hardnesses (Knoop method [107]) of typical

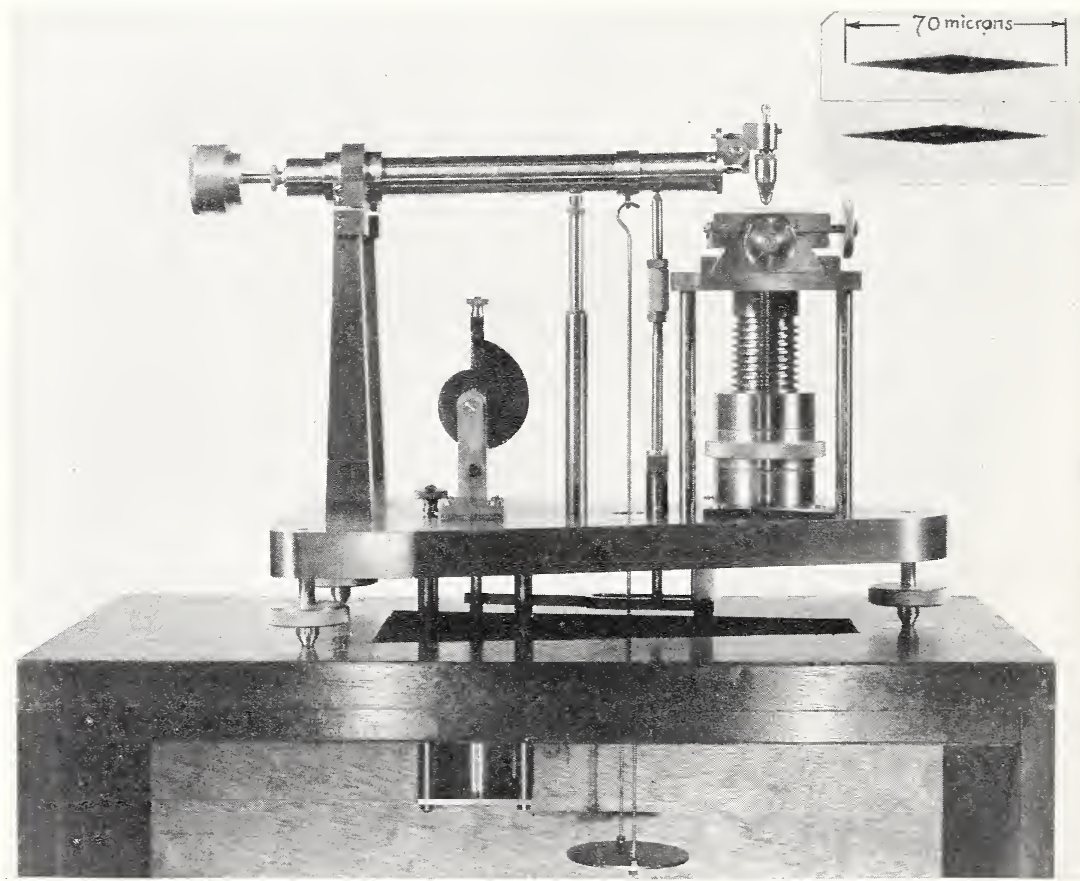

Figure 24.-Mardness tester, using Knoop indenter.

Inset: Two indentations in highly polished tooth enamel.

items may be secured from table 50. The Brinell numbers for casting gold alloys are given in table 19, columns 2 and 3, those for solders, in table 21. The Vickers numbers of wrought gold wire alloys are found in table 20 , columns 5 to 8 .

Tensile properties.-The mechanical properties which were determined in tension included proportional or elastic limit, strength, and elongation, in the order named. Most of the tests were conducted in the Amsler pendulum-type testing machine (fig. 25). Details of the extensometer assembly are shown in figure 26.

Proportional and elastic limits.-Proportional limit, in tension, has been defined as the stress beyond which extension ceases to be proportional to the load applied and elastic limit as the maximum 
TABLE 19.- Physical properties of gold alloys for casting

\begin{tabular}{|c|c|c|c|c|c|c|}
\hline \multirow{2}{*}{ Alloy } & \multicolumn{2}{|c|}{ Brinell hardness } & \multirow{2}{*}{$\begin{array}{l}\text { Tensile strength } \\
\text { (softened) }\end{array}$} & \multirow{2}{*}{$\begin{array}{l}\text { Elastic limit }{ }^{4} \\
\text { (softened) }^{1}\end{array}$} & \multirow{2}{*}{\multicolumn{2}{|c|}{$\begin{array}{l}\text { Elongation in } \\
2 \text { inches } \\
\text { (softened) }^{1}\end{array}$}} \\
\hline & $\begin{array}{l}\text { Sof- } \\
\text { tened } 1\end{array}$ & $\begin{array}{l}\text { Hard- } \\
\text { ened } 2\end{array}$ & & & & \\
\hline 1 & 2 & 3 & 4 & 5 & 6 & \\
\hline $\begin{array}{l}1 \\
1 \\
2 \\
3\end{array}$ & $\begin{array}{r}\text { No. } \\
33 \\
32 \\
39\end{array}$ & $\begin{array}{r}\text { No. } \\
34 \\
34 \\
38\end{array}$ & $\begin{array}{r}l b / \text { in } .^{2} \\
16,000 \\
16,500 \\
25,500\end{array}$ & $\begin{array}{r}\text { lb } / \text { in }^{2}{ }^{2} \\
3,000 \\
3,500 \\
4,500\end{array}$ & Percent & $\begin{array}{l}18.5 \\
14.5 \\
25.5\end{array}$ \\
\hline
\end{tabular}

SOFT INLAYS

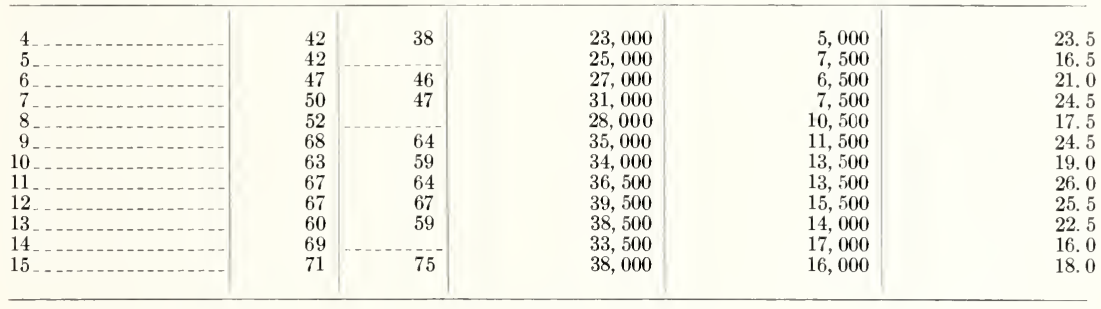

MEDIUM INLAYS

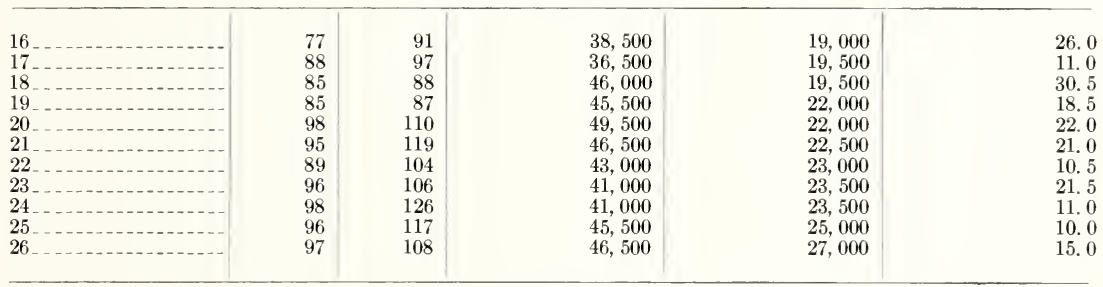

HARD INLAYS

\begin{tabular}{l|l|l|l|l|l}
\hline 27 & 101 & 120 & 48,000 & 25,500 & 16.5 \\
28 & 116 & 151 & 51,500 & 30,500 & 30,500 \\
129 & 145 & 47,500 & 1.5 \\
\hline
\end{tabular}

DENTURES, CLAPS, SADDLES, ETC.

\begin{tabular}{|c|c|c|c|c|c|c|c|c|}
\hline & & & $\begin{array}{c}\text { Sof- } \\
\text { tened }\end{array}$ & $\begin{array}{l}\text { Hard- } \\
\text { ened }{ }^{2}\end{array}$ & $\begin{array}{c}\text { Sof- } \\
\text { tened } 1\end{array}$ & $\begin{array}{l}\text { Hard- } \\
\text { ened } 2\end{array}$ & $\begin{array}{c}\text { Sof- } \\
\text { tened } 13\end{array}$ & $\begin{array}{c}\text { Hard- } \\
\text { ened } 23\end{array}$ \\
\hline $\mathrm{I}-\mathrm{D}_{-}$ & 154 & 195 & 64,500 & 84,000 & 50,000 & 61,000 & 1.0 & \\
\hline $\mathrm{IV}-\mathrm{D}$ & 145 & 249 & 69,000 & 108,000 & 53,500 & 94,500 & 4. 0 & \\
\hline$V-D_{\ldots} \ldots \ldots$ & 149 & 214 & 70,000 & 103,000 & 46,000 & 73,000 & 10.0 & 1. 0 \\
\hline $\mathrm{X} X \mathrm{X}-\mathrm{D} \ldots$ & 149 & 205 & 57,000 & 94,000 & 41,000 & 69,000 & 5.5 & 1. 0 \\
\hline
\end{tabular}

1 Softened-Specimen quenched in water at $700^{\circ} \mathrm{C}\left(1,292^{\circ} \mathrm{F}\right)$.

2 Hardened-Specimen gradually cooled from $450^{\circ} \mathrm{C}\left(842^{\circ} \mathrm{F}\right)$ to $250^{\circ} \mathrm{C}\left(482^{\circ} \mathrm{F}\right)$ over a period of $30 \mathrm{minutes}$.

${ }^{3}$ Elongation in 3 inches except for alloy XXX-D, on which a 2-inch gage length was used. Values less than 1 percent are not recorded.

${ }_{4}^{4}$ That stress at which the deformation rate was 1.25 times the initial rate of deformation. In alloys $\mathrm{I}-\mathrm{D}$, II-D, and V-D, 1.1 times was used in establishing the elastic limit. 
stress to which a specimen can be subjected and then return to its original dimensions upon release of the load. Experiments have shown that neither of these limits actually exists in commercial metals. Small deviations from an exact proportionality of deformation to load

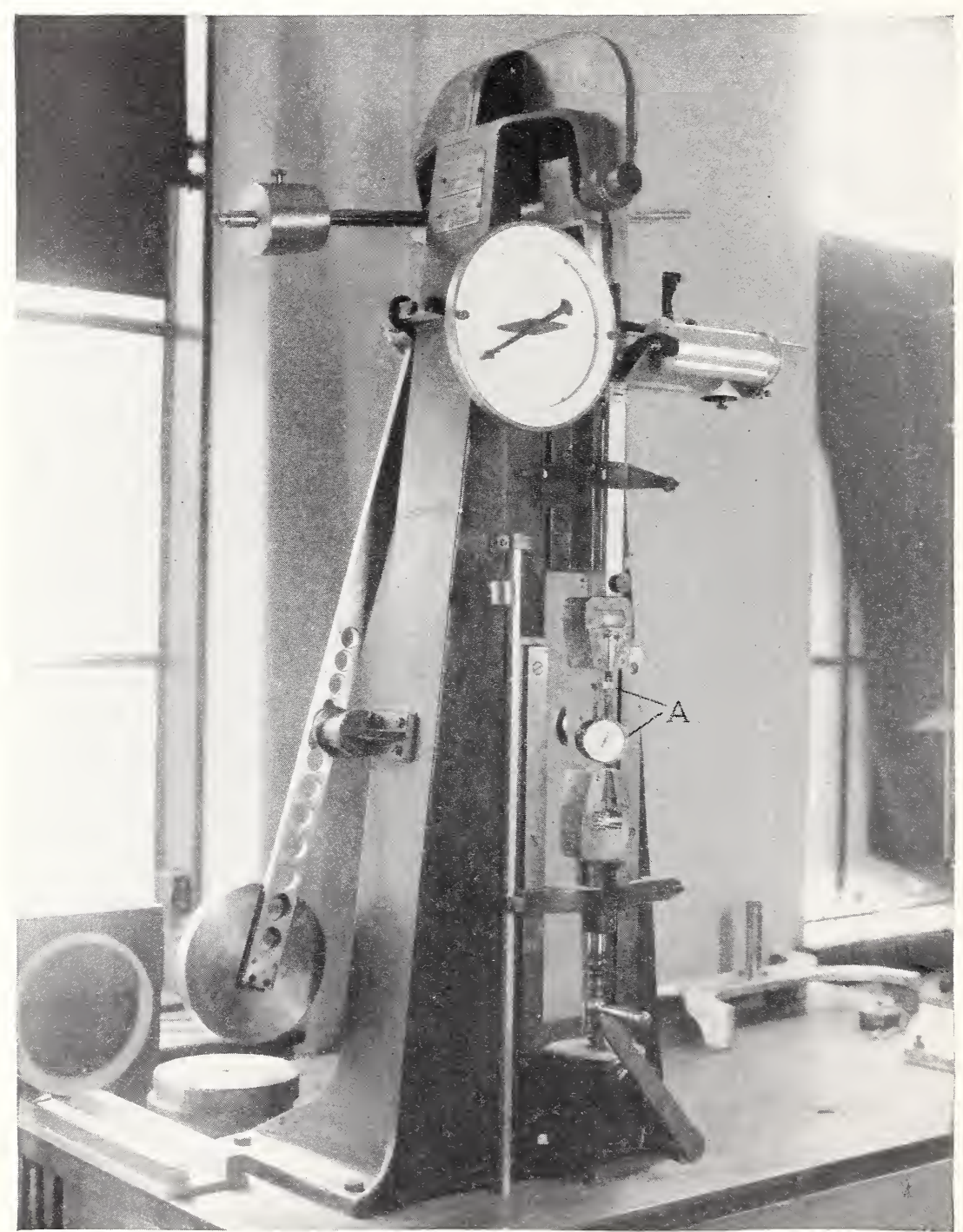

FIGURE 25.-Amsler testing machine and averaging extensometer, A, used in determining tensile properties of gold alloys.

(strain to stress) and small permanent deformations are found at all stresses, if the measuring instruments are sufficiently sensitive. A practical expedient is to determine the stress at which is obtained a deviation from the exact proportionality or straight-line relation of stress to strain (or permanent set) no greater than a specified amount. 

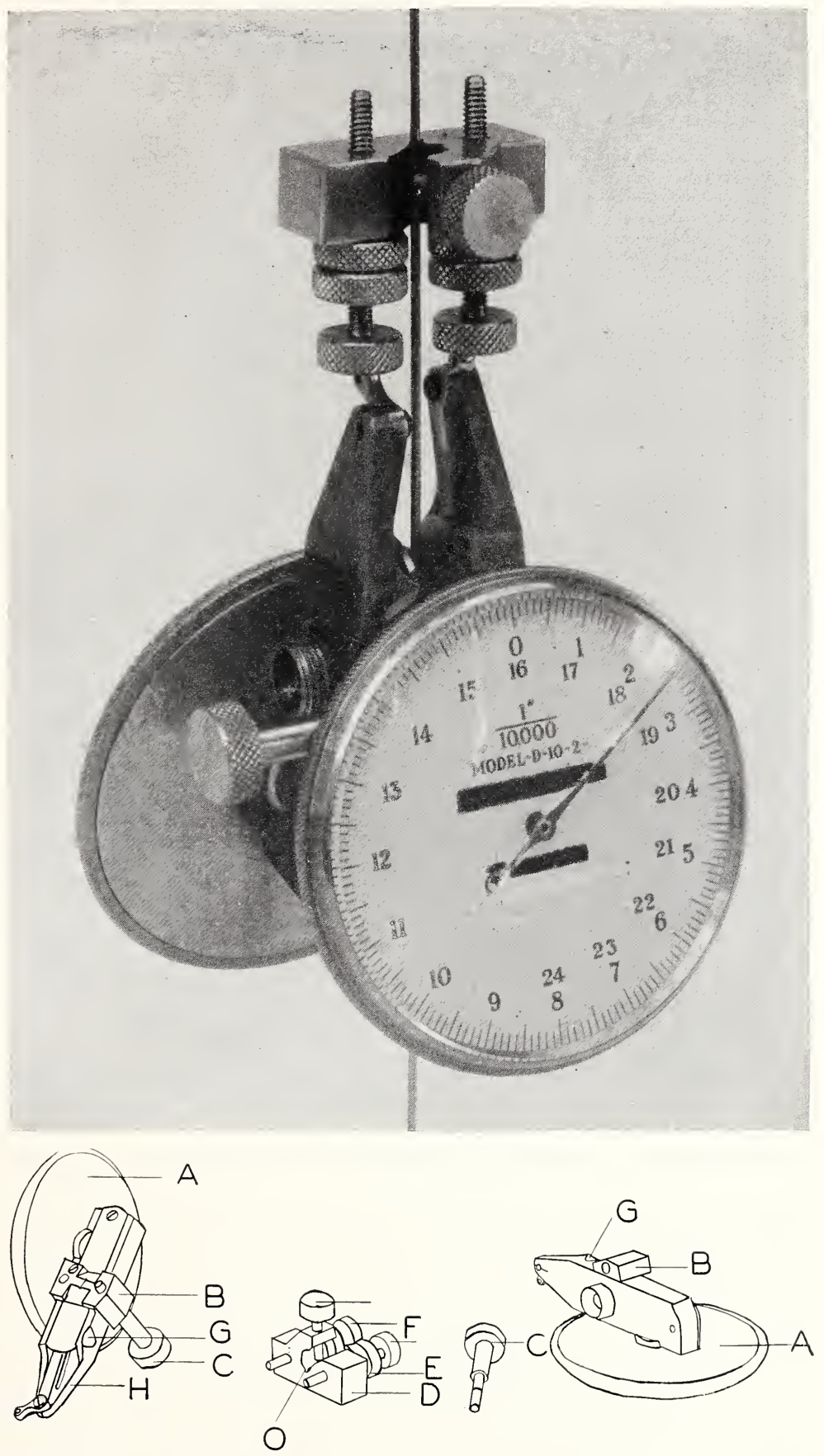

Figure 26.-Averaging extensometer used in determining stress-strain relationships. Gage length, 2 inches. Component parts: $A$, indicator dials; $B$, grips to hold samples; $C$, clamping screws to hold sample; $D$, upper clamp; $E$, lock nuts to adjust gage length: $F$, set screws to reset extensometer; $G$, notch in body in indicator, $H$, to accommodate the opposite dial; $O$, notch for specimen. 


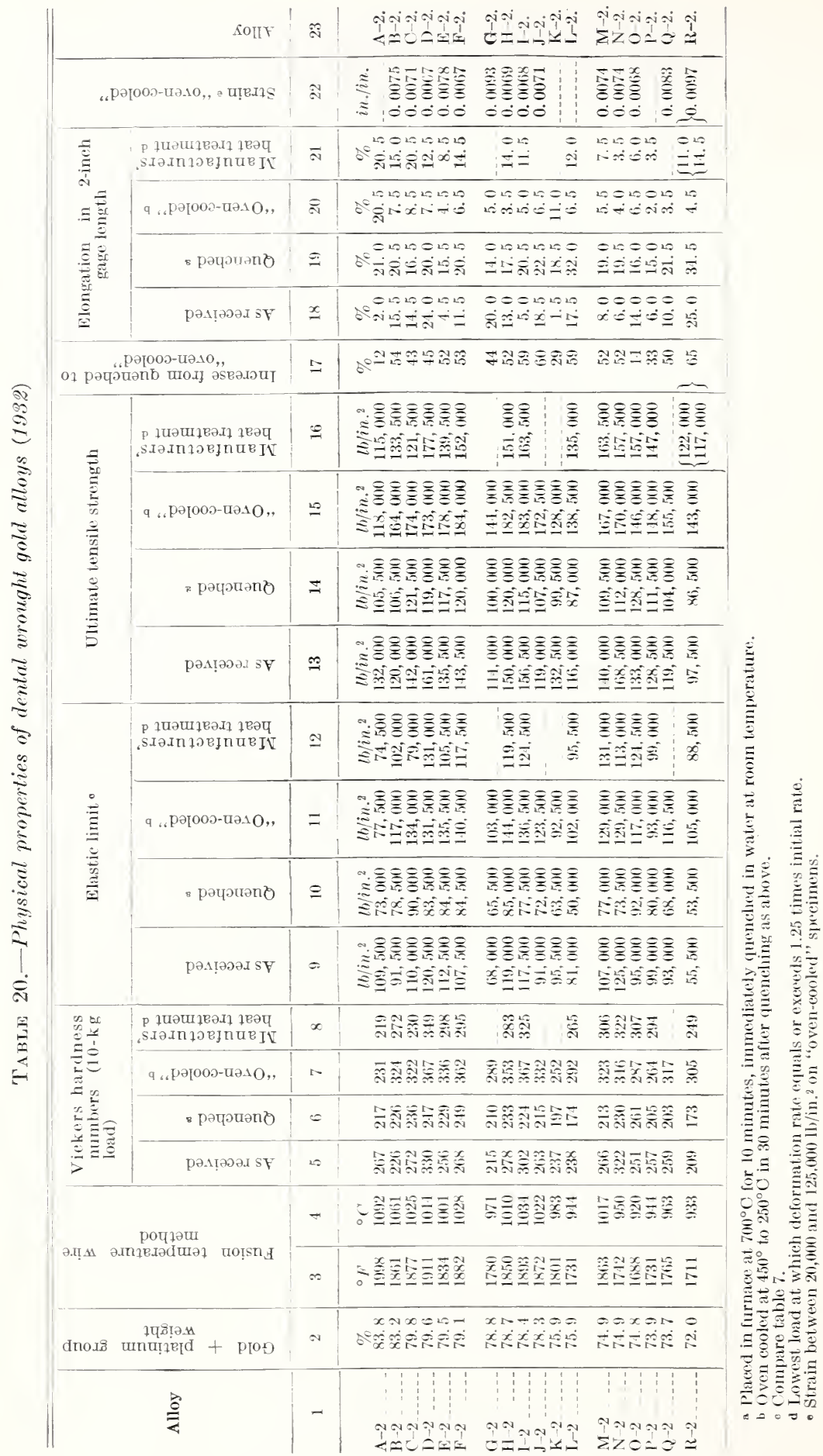


For the types of gold alloys described here, it was found satisfactory to take the level of stress at which the increase in strain (extension in inches per inch of gage length) for a given increase in stress became from 1.1 to 1.25 times the increase in strain for an equal stress increase, at stresses up to this level. This sharp break in the stress-strain curves is shown in figure 27. For practical purposes, the stress at which this break begins can be regarded as the limit below which significant permanent deformation will not occur. Therefore, in this résumé

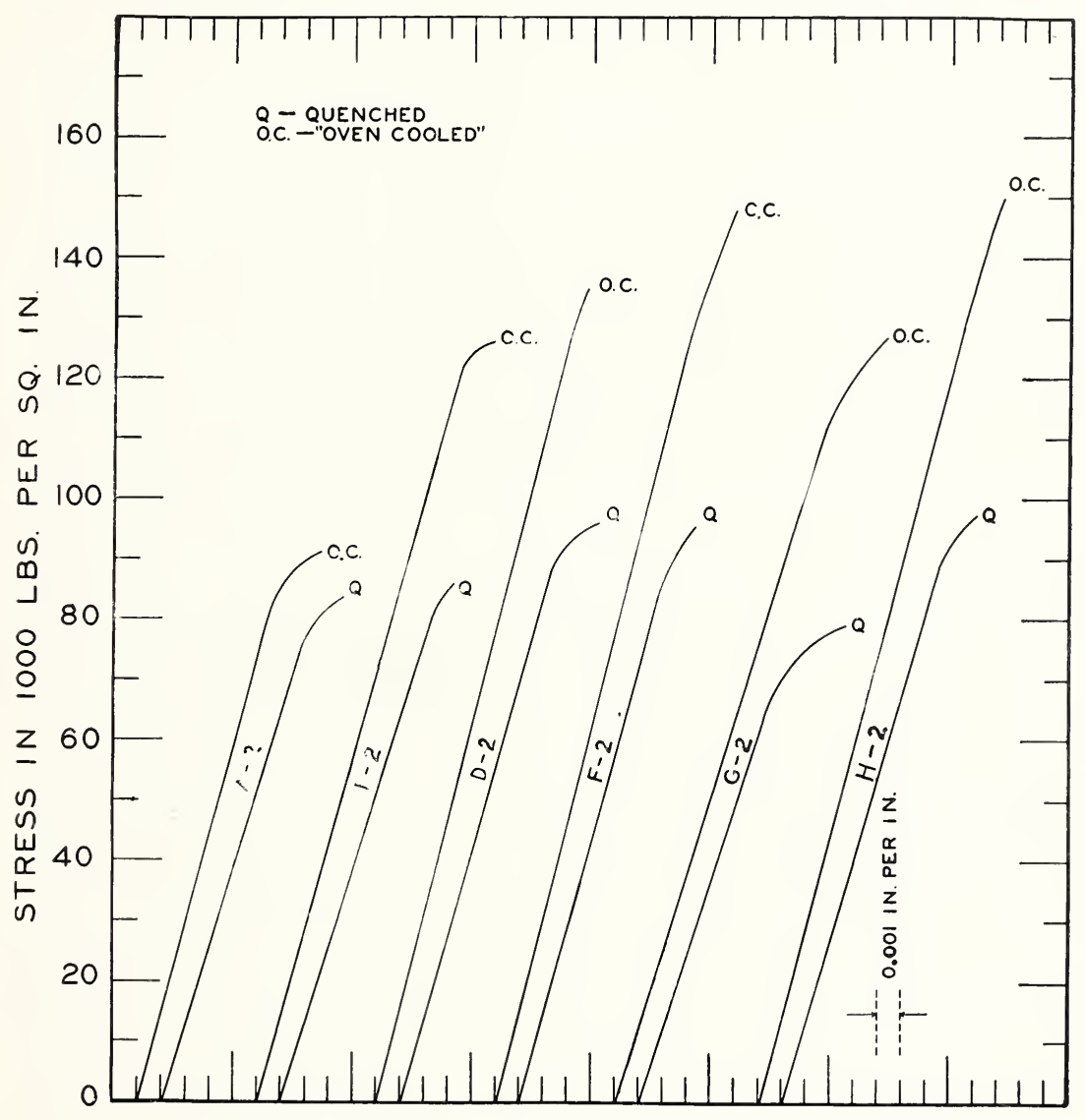

STRAIN

FIGURE 27.-Stress-strain curves of six wrought-gold wire alloys (compositions are in table 13).

the stress at which the rate of deformation became 10 or 25 percent more than the rate of deformation, observed in the first few increments of load, was designated as elastic limit or proportional limit. In the earlier work [14] 10 percent was used; in later work [34, 40] 25 percent. These are noted in the tables of data. Since a clasp, bar, or similar appliance may be distorted or bent out of its proper shape 
by the forces to which it is subjected in use (certain parts of the appliance are subjected to tensile stress), it is readily seen that the elastic limit of the material of which the appliance is made is an index of the ability of the appliance to maintain its proper shape in service. It is equally true that the elastic limit is an index of the resistance of the material to forming or adjusting to the desired shape.

The values for elastic limit on gold alloys are given in tables 19 , 20,21 , and 22. The stress-strain relationship for a series of wrought gold wires is shown graphically in figure 27. The effect of heat treatment is here strikingly depicted, as well as proof of the value of heat treatment.

TABLE 21.-Physical properties of gold solders

\begin{tabular}{|c|c|c|c|c|c|c|c|c|}
\hline \multirow{2}{*}{ Solder } & \multicolumn{2}{|c|}{ Brinell hardness } & \multicolumn{2}{|c|}{$\begin{array}{l}\text { Ultimate tensile } \\
\text { strength }\end{array}$} & \multicolumn{2}{|c|}{ Elastic limit 1} & \multicolumn{2}{|c|}{$\begin{array}{l}\text { Elongation }{ }^{2} \text { in } \\
3 \text { inches }\end{array}$} \\
\hline & Softened & Hardened & Softened & Hardened & Softened & Hardened & Softened & Hardened \\
\hline 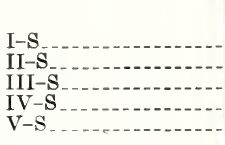 & $\begin{array}{r}\text { No. } \\
111 \\
103 \\
111 \\
103 \\
78\end{array}$ & $\begin{array}{r}\text { No. } \\
185 \\
193 \\
199 \\
180\end{array}$ & $\begin{array}{c}l b / i n .^{2} \\
42,500 \\
44,500 \\
44,000 \\
36,000 \\
37,500\end{array}$ & $\begin{array}{r}\text { lb/in. }{ }^{2} \\
63,000 \\
83,500 \\
92,000 \\
70,000\end{array}$ & $\begin{array}{c}\text { lb/in. }{ }^{2} \\
27,000 \\
29,500 \\
30,000 \\
24,000 \\
20,500\end{array}$ & $\begin{array}{r}\text { lb/in. } .^{2} \\
55,000 \\
77,500 \\
77,000 \\
61,500\end{array}$ & $\begin{array}{r}\text { Percent } \\
14 \\
12 \\
9 \\
7 \\
18\end{array}$ & ${ }^{2}$ Percent \\
\hline
\end{tabular}

1 Elastic limit-that stress at which the deformation rate was 1.1 times the initial rate of deformation. 2 Elongations of less than 1 percent were not recorded.

Cltimate tensile strength.-The stress causing rupture of the specimen in tension. This is an index of the stress an appliance will withstand without failure due to breakage. The tensile strengths of gold alloys are given in tables $19,20,21$, and 22 .

Elongation.-Elongation is the increase in length measured after rupture expressed in percentage of the original gage length. The elongation is an index of the extent to which the material may be permanently stretched or bent before failure. This properly is related to the suitability of materials for making appliances that must be bent, swaged, or burnished to shape. Tables 19, 20, 21, and 22 contain data on this property.

Modulus of elasticity.-The ratio of stress within the elastic limit to the corresponding strain or deformation is known as the modulus of elasticity. It is a measure of stiffness or of the force required to produce a given elastic deformation. Reference to figure 27 will show that the modulus of elasticity, on alloy B-2 quenched, is roughly 13,000,000 $\mathrm{lb} /$ in. $^{2}$ As the slope of all of the curves in figure 27 is somewhat similar, it will be seen that the modulus will not vary greatly in any of the alloys there shown. The heat treatment does appear to affect appreciably the modulus as the slope of the curves of the hardened specimens is always steeper than the slopes of the softened ones. 
TABLE 22.-Flexure tests, tensile properties, and composition of eight wrought wires of gold alloys [14] (1924)

RESULTS OF FLEXURE LIFE TESTS: NUMBER OF REVERSALS TO CAUSE FAILURE 1

\begin{tabular}{|c|c|c|c|c|c|c|c|c|}
\hline \multirow{2}{*}{ Heat treatment } & \multicolumn{8}{|c|}{ Alloy } \\
\hline & $\mathbf{A}$ & B & $\mathrm{C}$ & D & $\mathrm{E}$ & $\mathrm{F}$ & G & H \\
\hline $\begin{array}{l}\text { Softened } \\
\text { Hardened }\end{array}$ & $\begin{array}{l}15,000 \\
75,000\end{array}$ & $\begin{array}{r}4,000 \\
15,000\end{array}$ & $\begin{array}{l}23,500 \\
88,500\end{array}$ & 23,500 & 18,000 & 25,000 & $\begin{array}{l}19,000 \\
24,000\end{array}$ & $\begin{array}{l}41,000 \\
58,000\end{array}$ \\
\hline
\end{tabular}

1 A verage of several tests given to nearest 500 .

TENSILE PROPERTIES

\begin{tabular}{|c|c|c|c|c|c|c|c|}
\hline \multirow[t]{2}{*}{ Alloy } & \multicolumn{2}{|c|}{ Elastic limit 4} & \multicolumn{2}{|c|}{ Ultimatestrength } & \multirow{2}{*}{$\begin{array}{c}\text { Elonga- } \\
\text { tion in } \\
8 \text { inches } \\
\text { Percent } \\
12.5\end{array}$} & \multirow{3}{*}{$\begin{array}{c}\begin{array}{c}\text { Modulus } \\
\text { of } \\
\text { elasticity }\end{array} \\
\begin{array}{ll}l b / \text { in } .^{2} \\
17,000,000\end{array}\end{array}$} & \multirow{3}{*}{$\begin{array}{r}\begin{array}{r}\text { Modulus } \\
\text { of } \\
\text { resiliency }\end{array} \\
\text { in.lb/in. } .^{3} \\
147\end{array}$} \\
\hline & $\begin{array}{c}\text { Pounds } \\
68\end{array}$ & $\begin{array}{l}l \text { b/in. } .^{2} \\
71.000\end{array}$ & $\begin{array}{c}\text { Pounds } \\
104\end{array}$ & lb/in.2 & & & \\
\hline A $\left\{\begin{array}{l}\text { sottened } \\
\text { Hardened }\end{array}\right.$ & $\begin{array}{r}68 \\
106\end{array}$ & $\begin{array}{r}71,000 \\
110,000\end{array}$ & $\begin{array}{l}104 \\
148\end{array}$ & $\begin{array}{l}108,000 \\
153,000\end{array}$ & & & \\
\hline S Softened & 62 & 64,000 & 90 & 94,000 & 11.0 & $17,000,000$ & 119 \\
\hline $\mathrm{B}\left\{\right.$ Hardened ${ }^{2}$ & 84 & 87,000 & 119 & 124,000 & 3.6 & $17,000.000$ & 2 \\
\hline $\mathrm{C}\{$ Softened & 81 & 84,000 & 119 & 124,000 & 9.6 & $18,000,000$ & 193 \\
\hline 'THardened. & 128 & 133,000 & 168 & 175,000 & 4. 6 & $19,000,000$ & 473 \\
\hline & 71 & 74,000 & 104 & 108,000 & 8.8 & $14,000,000$ & \\
\hline (Hardened ${ }^{3}$ & & 96,000 & 132 & 138,000 & 1.0 & $17,000,000$ & 278 \\
\hline $\mathrm{E}\left\{\begin{array}{l}\text { Softened - } \\
\text { Hardened }\end{array}\right.$ & 61 & 63,000 & 97 & 102,000 & 10.2 & $16,000,000$ & 122 \\
\hline "i Hardened. & 73 & 76,000 & 118 & 123,000 & 6.8 & $17,000,000$ & \\
\hline $\mathrm{F}\left\{\begin{array}{l}\text { Softened } \\
\text { Hardened }\end{array}\right.$ & $\begin{array}{l}66 \\
75\end{array}$ & 69,000 & 98 & 102,000 & 9. 2 & $17,000,000$ & $\begin{array}{l}138 \\
187\end{array}$ \\
\hline (nardento. & 10 & $7 x, 000$ & 113 & 118,000 & 6.0 & $16,000,000$ & 187 \\
\hline $\mathrm{G}\{$ Softened - & 77 & 80,000 & 121 & 126,000 & 2.9 & $20,000,000$ & 162 \\
\hline "Y Hardened. & 79 & 82,000 & 118 & 123,000 & 3.2 & $21,000,000$ & $\begin{array}{l}162 \\
186\end{array}$ \\
\hline $\mathrm{H}\{$ Hardened & 76 & 79,000 & 109 & 113,000 & 10.6 & $17,000,000$ & 18 \\
\hline $\mathrm{H}\left\{\begin{array}{l}\text { Hardened }{ }^{2} \\
\text { Hardened }\end{array}\right.$ & 83 & 86,000 & 125 & 130,000 & 8.4 & $16,000,000$ & 228 \\
\hline |Hardened... & 116 & 121,000 & 169 & 176,000 & .5 & $18,000,000$ & 402 \\
\hline
\end{tabular}

1 All wires of 0.035 -inch diameter.

2 A ir cooled from $700^{\circ} \mathrm{C}$

310 inches total length; 6 inches gage length.

4 Deformation rate was 1.1 times initial rate.

CHEMICAL COMPOSITION (PERCENTAGE BY WEIGHT)

\begin{tabular}{|c|c|c|c|c|c|c|c|c|}
\hline Alloy & Silver & Gold & $\begin{array}{l}\text { Plati- } \\
\text { num }\end{array}$ & $\begin{array}{l}\text { Palla- } \\
\text { dium }\end{array}$ & Copper & Zinc & Nickel & Iridium \\
\hline$A^{1}$ & 5. 1 & 64.5 & 17.6 & 2.1 & 10.4 & 0.8 & & \\
\hline $\mathrm{B}^{2} 2$ & 36.4 & 41.7 & & 8.3 & 9.4 & .3 & & 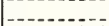 \\
\hline $\mathrm{C}_{-} \ldots \ldots$ & 7. 7 & 59.3 & 18.3 & 1. 6 & 13.0 & & & 0.2 \\
\hline D. & 15. 2 & 62.6 & 10.4 & .2 & 11.8 & & & . \\
\hline$E_{\ldots} \ldots \ldots$ & 15.0 & 59.5 & 15.2 & & 8.8 & $-\ldots$ & 1.3 & $-\ldots$ \\
\hline $\mathrm{F}_{--}$ & 15.4 & 60.9 & 16.0 & .2 & 6.7 & .3 & & .5 \\
\hline $\mathrm{G} \ldots \ldots$ & .2 & 66. 2 & 13. 3 & 19.4 & .2 & .1 & 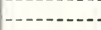 & .5 \\
\hline H & 9.9 & 61.9 & 16.0 & ----- & 12. 1 & .1 & $----1--$. & \\
\hline
\end{tabular}

1 Tin, 0.16 percent.

2 Manganese, 3.8 percent; magnesium, 0.1 percent. 
Modulus of resiliency.-The potential energy stored up in unit volume of material. stressed to the elastic limit, is defined as the modulus of resiliency. The value depends upon the elastic limit and the modulus of elasticity and is a measure of the work the material can do with safety when used as a spring. Such a property is important in eraluating wires for use in orthodontia. If the value for elastic limit is increased br a hardening heat treatment, then the value for the modulus of resiliener will increase. For instance, allor F-1 (table 20) has a resiliency modulus of $250 \mathrm{in.lb} \mathrm{in.}{ }^{3}$ in the softened or quenched and $650 \mathrm{in.lb} \mathrm{in}^{3}$ in the hardened state. Alloy $\mathrm{F}-1$ will therefore,

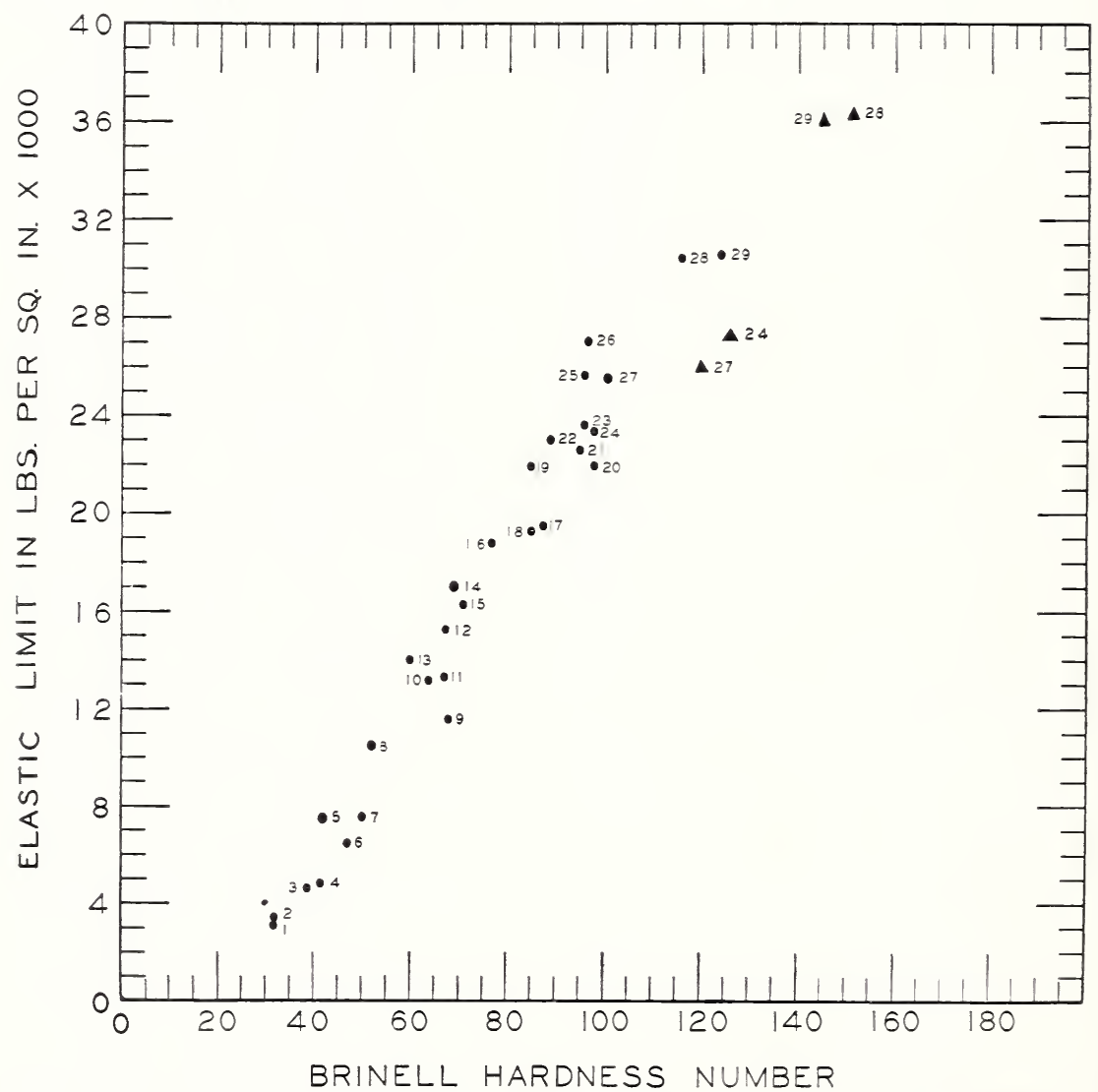

FIGLRE 28.-- Relation of values for Brinell hardness number and elastic limit of gold alloys for cast inlays.

Circles represent quenched or softened allors; triangles, heat treated or hardened alloys (compositions are in table 11).

in the hardened state, do twice the work when used as a spring, as it will do in the softened or quenched state. Other values are given in table 22.

Relationship among properties.-The relation between hardness and elastic limit is shown for a few dental alloys (fig. 28). The relation for ultimate tensile strength is also shown (fig. 29). The ralues for elongation and hardness are plotted in figure 30 . but the relation is so indefinite that one must not attempt to select a strong alloy on its 
hardness value alone, especially if ductility is an item of major importance.

The more satisfactory relationship is between hardness and ultimate tensile strength. For all practical purposes, one can halve the Brinell (or Vickers) hardness number and obtain the approximate tensile strength in $1,000 \mathrm{lb} / \mathrm{in}^{2}{ }^{2}$ For instance, if the Brinell number of a gold casting alloy is 100 , the tensile strength will be in the neighborhood of $50,000 \mathrm{lb} / \mathrm{in}^{2}$

The relationship between tensile strength and hardness of the cast specimens was as definite as that of the wrought specimens. This

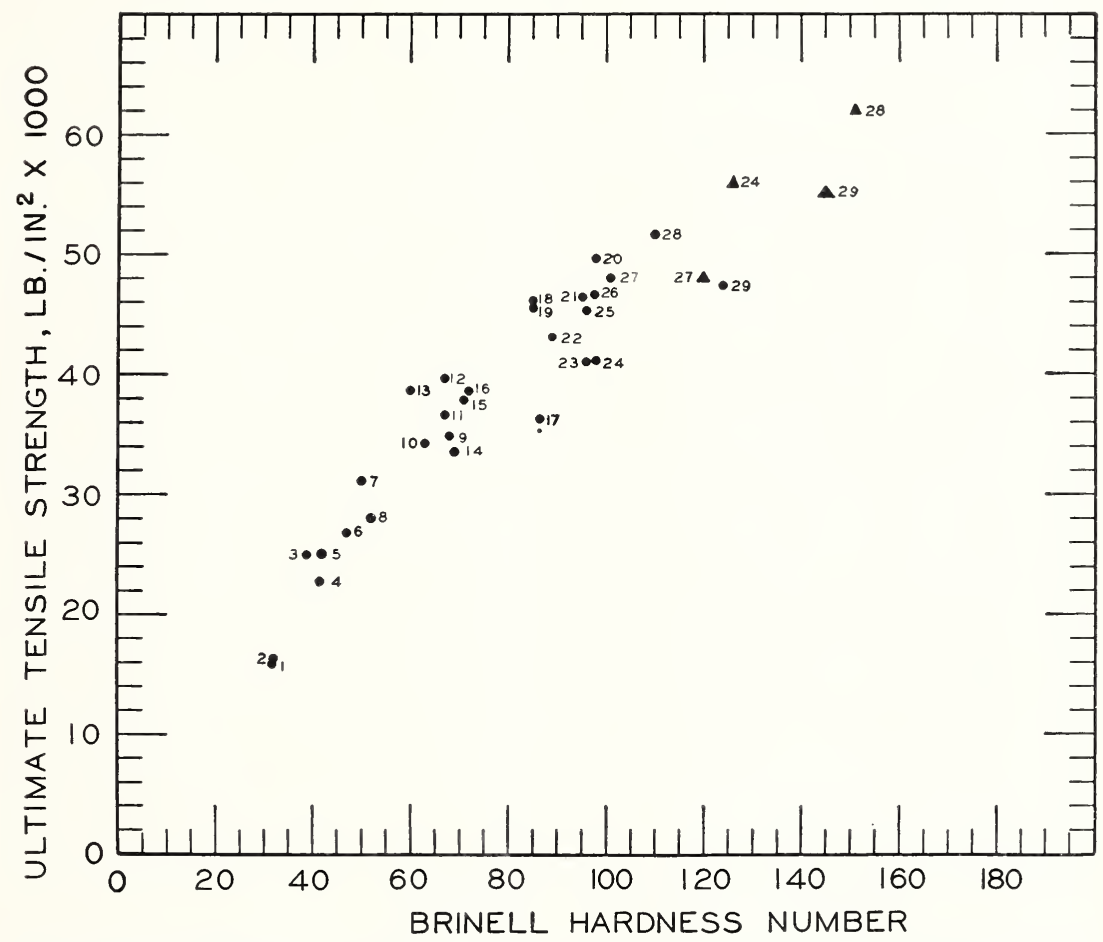

FIGURE 29.-Relation of values for Brinell hardness number and ultimate tensile strength of gold alloys for cast inlays.

Circles represent quenched or softened alloys; triangles, heat treated or hardened alloys (compositions are in table 11).

leads one to assume that the cast specimens were reasonably sound and uniform.

Testing irregular shaped specimens.-The mechanical properties are readily determined on straight specimens. On curved or irregular shaped specimens such as lingual bars and clasps a difficulty is encountered which makes it necessary to make indirect tests for certain properties such as elongation. One method of test is to bend or wrap the material around a mandrel or form of definite radius. In the case of lingual bars (p. 190), the bends are made over the jaws of a vise having radii of 0.05 inch. A bar which will bend from vertical to horizontal over one jaw then back through vertical and to 
horizontal over the other jaw should be satisfactory for all practical needs. Clasps may not require this amount of ductility. However, the same method of test can be used to compare clasps made from different alloys or subjected to different heat treatments.

Hardness tests may be made with the instruments described on pp. 54-56. On thin strips the loads applied to press the indenter into the strip must not be large enough to produce an indentation which shows through to the back of the thin specimen. Otherwise, the hardness number secured will be a value representing the combined hardnesses of the specimen and the supporting anvil. The Knoop indenter (fig. 24) is admirably suited for use on thin specimens, as the depth of the penetration need be but a few microns.

Repeated stresses.-It is well-known to many dentists that clasps

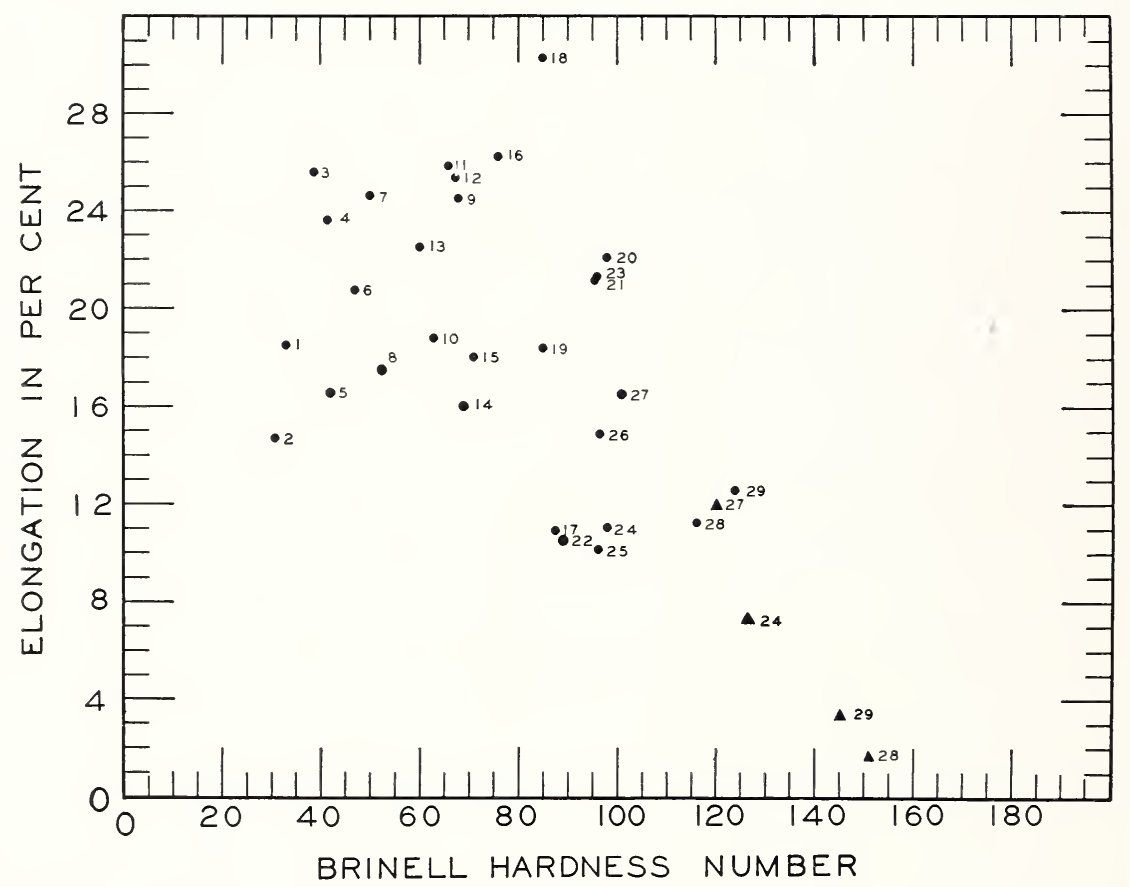

Figure 30.- Relation of values for Brinell hardness number and elongation in gold alloys for cast inlays.

Circles represent quenched or softened specimens; triangles, heat treated or hardened specimens (compositions in table 11).

(both wrought and cast), orthodontia spring wires, and other appliances that are subjected to repeated stresses, such as those induced by mastication or the removal and insertion of the appliance in the mouth, often give good service for a time but eventually fail, from breakage, even when there is no evidence that the appliance has been subjected to abnormal use or abuse. Such failures have been attributed to "crystallization" and numerous other causes, but are now generally recognized as being due to the effect of stress applied a great number of times. It appeared desirable, therefore, to obtain some data on the relative resistance of the various dental gold alloys to repeated stresses. 
A machine was built to apply definite stresses to rods in an attempt to secure data on this subject (fig. 31). A brief description of the operation of this machine follows. The specimen under test is supported in a horizontal position between a pair of holders. A yoke is placed over the specimen midway of the holders, and cords fastened to either side of the yoke pass over pulleys and support weights. These weights are lifted alternately by means of a rocker arm driven by a motor. As the weight on one side is lifted the one on the other side is allowed to hang suspended from the specimen under test.

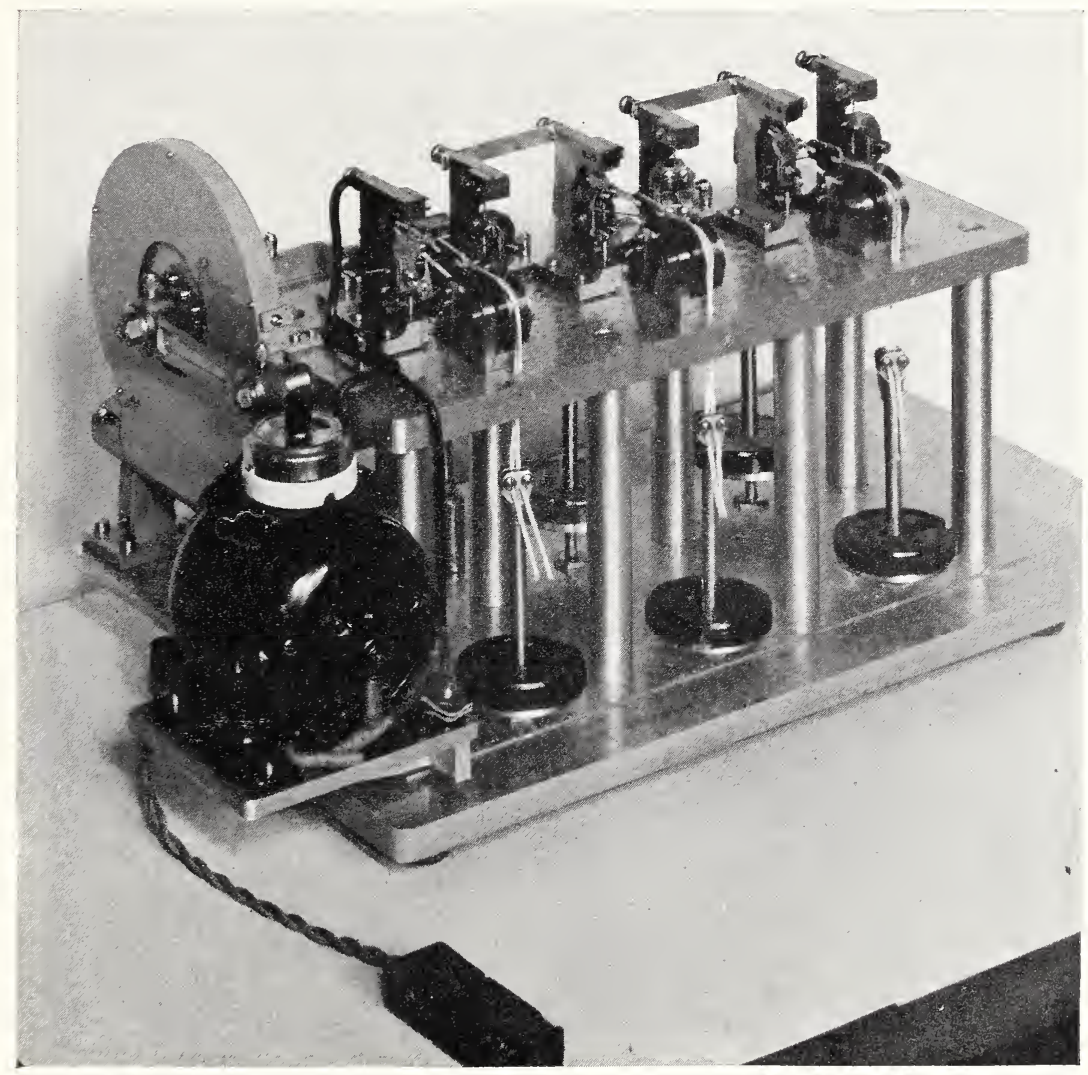

FigURE 31.-Dead-load flexure machine for making tests of the relative life of alloys subjected to repeated stresses.

Thus the specimen is subjected to a bending stress first in one and then in the opposite direction. The magnitude of the stress and the stress range can be varied at will by adjusting the weights. The number of applications of stress is recorded by means of a revolution counter, and the operation is continued until the specimen fails.

The maximum stress which a specimen will endure for any number of repetitions is generally called the fatigue limit.

In order to determine this value it is necessary to test specimens at each of a number of stresses, a procedure which would require a great deal of time, especially with a low-speed machine, such as the 
one used in this investigation. For this reason it was decided to use as an index of the endurance, or life, of the dental gold alloys of this group, the number of alternations of a definite stress necessary to cause fracture. Accordingly, a stress was selected that would cause failure of most of the alloys between 10,000 and 100,000 reversals. These figures are somewhat arbitrary, though they do have some relation to the number of times a removable appliance is stressed over a period of years by normal removals and insertions.

The specimens used were round wires 0.035 inch in diameter, accurately sized by drawing through a diamond die. The length of the specimen between supports was 2 inches, and the load used was 14 ounces. With this combination the theoretical maximum fiber stress set up in the test specimen was calculated to be approximately

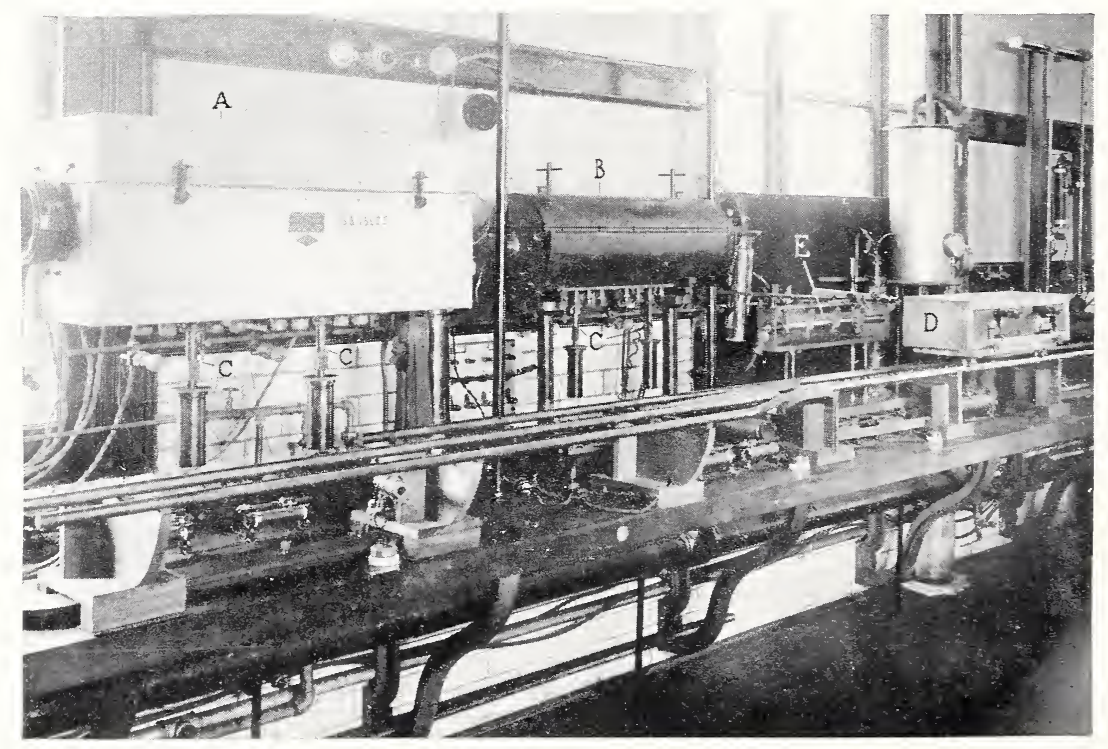

Figure 32.-Apparatus for determining the linear thermal expansion of solids.

Electric furnaces for heating the specimen are shown at $A$ and $B$. The specimen is placed in the furnace in a horizontal position and may be supported throughout its length. Very fine wires are passed over the ends of the specimen and allowed to hang through the tubes, $C$, in the bot tom of the furnaces. Length changes, which are transmitted to the wires. are measured with micrometer microscopes mounted on a movable carriage, $D$. The distance between microscopes is compared before readings by reference to a fused-quartz standard, $E$. The furnace temperature is measured with thermocouples and a potentiometer.

$100,000 \mathrm{lb} / \mathrm{in}^{2}$. The selection of a markedly different stress value will undoubtedly change slightly the relative arrangement or order of failure, but such changes as are necessary to produce an arrangement differing appreciably from that reported do not appear to be justified from service conditions. At least three duplicate specimens of each material were tested and the average value was reported. The values obtained are given in table 22 along with tensile properties and the composition of eight wrought wire alloys in use in 1924 [14]. These indicate a marked variation in the life, or length of service, to be expected of the different materials.

The arbitrary adjustment of the machine to apply a fiber stress of approximately $100,000 \mathrm{lb} / \mathrm{in}^{2}$ obviously favored some of the alloys. It is not unfair, however, in testing this class of alloys, to use the 
high stress value, which, if accompanied by sufficient ductility, is desirable for the best quality of dental appliance.

Tests for repeated stresses are not included in the specifications for dental gold alloys. It is thought that the tensile values, including elongation, and the hardness values if properly selected will give the maximum in service life.

It will be noted that for all alloys, except alloy $G$, tested in both the softened and hardened conditions, the service value is greatly increased by the hardening heat treatment. As the other mechanical properties of alloy $\mathrm{G}$ were not susceptible to improvement by heat treatment, it was not expected that the treatment would greatly affect its service value. In the case of alloy $A$, however, the service was increased fivefold. This furnishes a very striking example

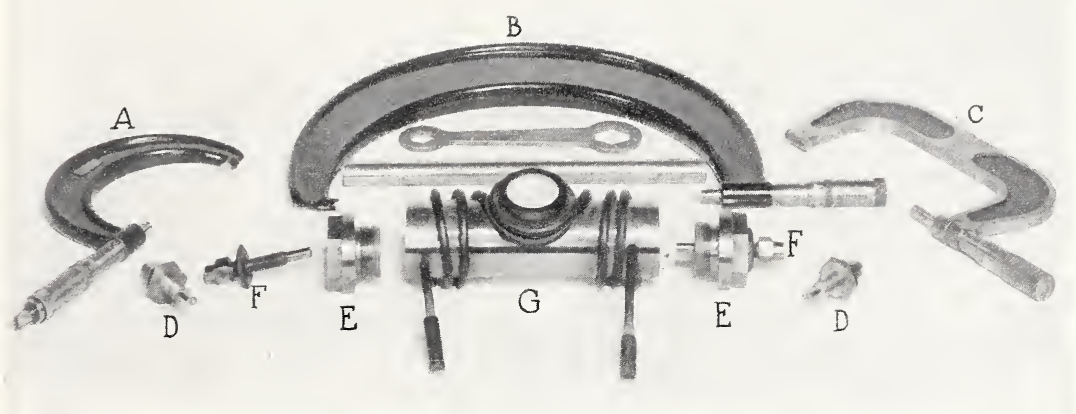

FIGURE 33.- Apparatus used in determining the casting shrinkage of gold casting alloys.

$A, B$, and $C$ are micrometer calipers. $D$, hollow plugs which are fastened in eaps $E$. $F$, solid plugs which were used to replace $D$ after investment was poured into form $G$.

of the benefits to be derived from proporly heat treating alloys of this character.

Casting shrinkage [14].--The casting shrinkage of gold may be divided into three parts: (1) The contraction of the liquid metal on cooling from the temperature at which it enters the mold to the freezing point, (2) the contraction of the metal on changing from the liquid to the solid state at constant temperature $\left(1,063^{\circ} \mathrm{C}\left(1,945^{\circ} \mathrm{F}\right)\right.$ for pure gold), and (3) the contraction of the solid gold on cooling from the freezing point to room temperature.

A search of the literature failed to reveal any reliable value for part (1). Price [108] in his classical experiment, using a fusedquartz mold, determined values for parts (2) and (3). These values he reported to be 1.46 percent linear contraction due to change of state without change of temperature and 2.20 percent linear contraction from the freezing point, $1,063^{\circ} \mathrm{C}\left(1,945^{\circ} \mathrm{F}\right)$ to $0^{\circ} \mathrm{C}\left(32^{\circ} \mathrm{F}\right)$. Price concluded that under favorable conditions all of the contraction of the gold, except that which occurs after the metal has solidified, is compensated for by the addition of liquid gold from the crucible. 
It was thought adrisable to rerift this conclusion and determine the net casting shrinkage (or that which affects the dimensions of the casting for some of the allors of gold. The thermal contraction of the metal in the solid state was determined for 24-carat gold and some of its binarr allors. The apparatus [109] used in making these determinations was that regularly used at the National Bureau of standards for determining the thermal expansion of solids. A photograph of the instruments, with a brief description. is presented in figure 32. The specimens were rods 30 centimeters long and approximately 1 centimeter in diameter. The temperature range for these tests was from the maximum temperature at which the sample was sufficiently rigid to maintain its shape without sagging, to room temperature. From the ralues determined in this manner the total contraction from the melting point to room temperature was calculated by extrapolation. The ralues are giren in table 23.

TABLE 23.- Thermal contraction of golds

\begin{tabular}{|c|c|c|c|c|c|c|}
\hline Material & $\begin{array}{c}\text { Masimur } \\
\text { ature }\end{array}$ & $\begin{array}{l}\text { temper- } \\
\text { test }\end{array}$ & $\begin{array}{l}\text { Ohserved con- } \\
\text { traction from } \\
\text { maximum tem- } \\
\text { perature to }\end{array}$ & Melting & point 1 & $\begin{array}{l}\text { Computed } \\
\text { contraction } \\
\text { irom melting }\end{array}$ \\
\hline 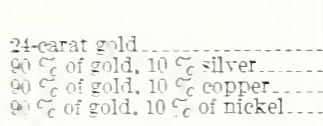 & $\begin{array}{l}{ }^{\circ} \mathrm{C} \\
1.014 \\
973 \\
830 \\
895\end{array}$ & $\begin{array}{l}\circ F \\
1,55 \\
1,2=3 \\
1,507 \\
1,627\end{array}$ & $\begin{array}{r}\text { Percent } \\
1.71 \\
1.70 \\
1.45 \\
1.55\end{array}$ & $\begin{array}{l}{ }^{\circ} \mathrm{C} \\
1.033 \\
1.040 \\
0.25 \\
035\end{array}$ & $\begin{array}{l}\circ F \\
1.04 \% \\
1.915 \\
1,599 \\
1.715\end{array}$ & $\begin{aligned} & \text { Petcent } \\
& 1.73 \\
& 2.03 \\
& 1.62 \\
& 1.91\end{aligned}$ \\
\hline
\end{tabular}

"In this table, "melting pcint" is used to designate that temperature at which solidification is completed.

The apparatus used for measuring the net casting shrinkage is shown in figure 3.3. The test procedure was as follows: The large caps $(E)$ were screwed tightly into the ends of the flash $(G)$ and the small hollow plugs $(D)$ were screwed into the caps $(E)$ and locked in position with lock nuts. A metal rod. inserted through and supported br the hollow plugs $(D)$. serred as the pattern. The sprue was attached to the pattern with wax, the crucible former placed in position and the flask $G$ filled with inrestment. After the inrestment has set. the crucible former. sprue, and pattern rod were remored. The hollow plugs $(D)$ were replaced with the solid plugs $(F)$. thus forming a mold. the length of which is determined solelr by the distance between the inside faces of the solid plugs. The flask was then placed in an oren and "burned out" at the desired temperature. The casting was made with an air-pressure machine in the ordinary manner.

The metal parts of the apparatus were made of an oxidationresisting steel. the coefficient of thermal expansion of which is known. The temperatures of various parts of the flask were measured with small thermocouples and a potentiometer. The length. at room temperature. of each of the solid plugs was accurately determined. The distance between the outside faces of the solid plugs was measured with a micrometer. From these ralues the distance between the inside faces of the solid plugs. or the length of the mold. Was computed. 
After the casting had cooled to room temperature, it was removed from the mold and its length measured with a micrometer caliper. The difference between the length of the casting and the length of the mold is the net shrinkage of the casting. The castings were approximately $3 \frac{1}{4}$ inches long and $1 / 8$ inch in diameter.

The temperature of the molds in which the castings were made was varied from approximately $300^{\circ} \mathrm{C}\left(572^{\circ} \mathrm{F}\right)$ to slightly above room temperature. The temperature of the metal was varied from the lowest at which a casting could be made to the maximum temperature obtainable with a good blowpipe, using hydrogen and compressed air. The casting pressure was varied from 5 to $20 \mathrm{lb} / \mathrm{in}^{2}$

A complete series of tests, table 24, was made for one alloy, coin gold (90\% gold, $10 \%$ copper). A few tests by this method on other alloys and rougher measurements of the shrinkage of a large number of castings made for tensile test specimens indicated that no large variations from these values, due to variations in composition of the alioy, are to be expected for gold alloys within the range of composition commonly employed in dentistry.

It will be noted that the variations in the casting conditions had little, if any, effect, and that in every case the effective shrinkage was less than that of the solid metal from its melting point to room temperature. The average of the values for net casting shrinkage given in table 24 is 1.25 percent, whereas the contraction of the solid metal is 1.62 percent.

TABLE 24.-Casting shrinkage of a gold-copper alloy (90\% gold, 10\% copper)

\begin{tabular}{|c|c|c|c|}
\hline Temperature of mold (approximate) & Casting temperature of alloy & $\begin{array}{l}\text { Casting } \\
\text { pressure }\end{array}$ & $\begin{array}{l}\text { Net casting } \\
\text { shrinkage }\end{array}$ \\
\hline $\begin{array}{l}40^{\circ} \mathrm{C}\left(104^{\circ} \mathrm{F}\right) \\
40^{\circ} \mathrm{C} \\
300^{\circ} \mathrm{C}\left(572^{\circ} \mathrm{F}\right) \\
300^{\circ} \mathrm{C}\end{array}$ & $\begin{array}{l}\text { Moderate } \text { do } \text { do } \\
\text { High }\end{array}$ & 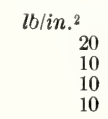 & $\begin{array}{r}\text { Percent } \\
1.24 \\
1.24 \\
1.26 \\
1.28\end{array}$ \\
\hline
\end{tabular}

Two possible explanations of this difference are suggested: (1) There may be sufficient friction or interlocking between the casting and the walls of the mold to hold and stretch the casting while it is cooling through that range of temperature within which the metal is very soft or weak, thus preventing the full normal shrinkage, and (2) the compensation of part of the total shrinkage of the solid metal may be dependent upon a difference in the rates of cooling of different parts of the casting. If part of the metal in the mold solidifies and cools to some temperature below the melting point before the metal in the sprue freezes, the shrinkage due to the cooling of this solid metal may be compensated by the addition of metal from the crucible.

The shrinkage of the liquid metal before the sprue freezes obviously would be compensated by the addition of metal from the crucible if the casting pressure were maintained. If a crust of solid metal forms around the entire outside surface of the casting before the central part of the casting freezes, the shrinkage of this central portion as it cools to the freezing point may produce voids or porosity sometimes referred to as localized shrinkage in the casting. Such localized shrinkage would not affect the outside dimension of the casting. 
A studr was made of the effects of the sizes and shapes of castings to see whether the amount and distribution of the gold allor in the casting would affect the ralue previouslr announced. "Tar patterns were inrested between the parallel jaws of a tarnish-resisting steel gage block figure 34). The block. with the pattern in place. was sprued. invested. burned out. and placed in the casting machine,
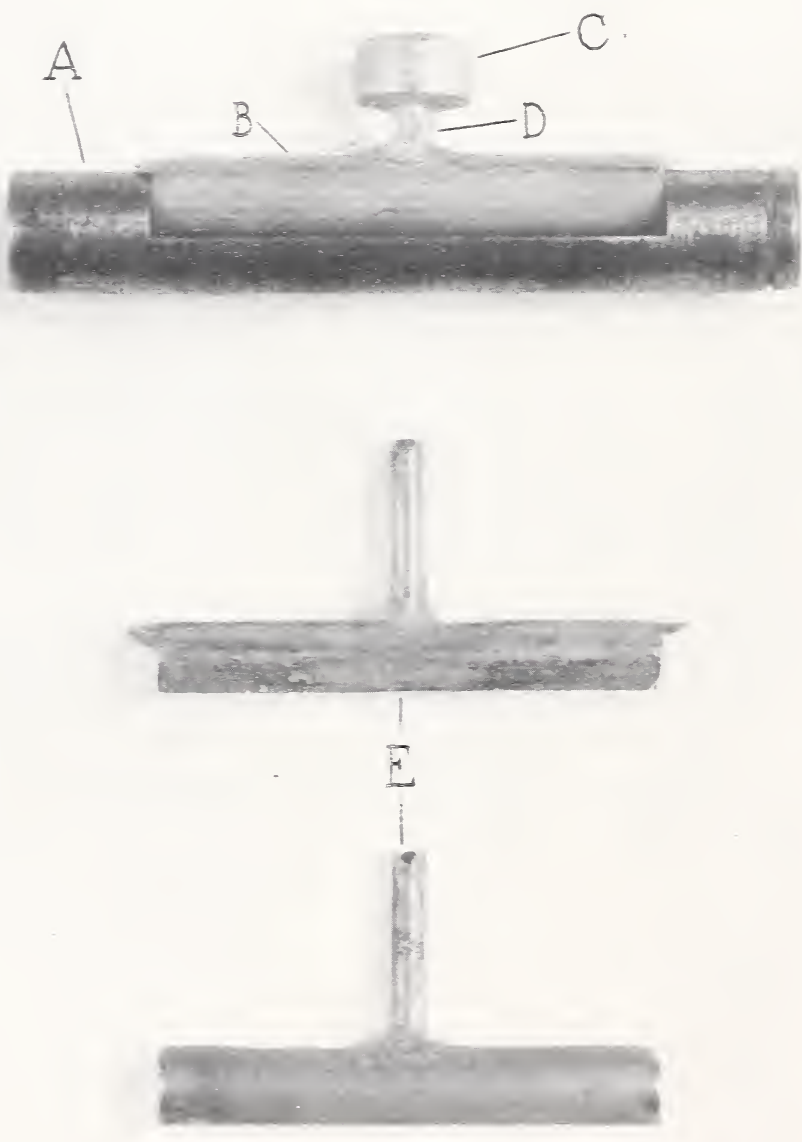

FIGCRE 34.--Simple apparatus ior determining the casting shrinkage of gold alloys when a variety of pattern designs are employed.

-1. metal mold made of oxidation-resisting alior. B. casting in place; nte the reseroir buttn. C. on spr.le. This entrols localized shriniage in the area where the sprue. D, joins the casting. $B$. E. castirgs remored from mold.

wher a casting was made in accordance with regular dental methods. The block and casting were then taken from the investment. The castings were alwars found shorter than the space between the jaws of the block. The patterns included spirals, spheres with projections 
to touch the jaws of the block, and rods large and small, some of which had anchoring wings at each end. The method was not regarded as so precise as that shown in figure 33, from which the value 1.25 percent was obtained; however, the data did show that despite what are believed to be instrumental inaceuracies the value 1.2 percent \pm 0.2 percent would cover all variations. Doubtless there are alloys now used by the profession having casting shrinkages differing from this average value. However, for the typical gold alloy of the period when these determinations were made, the value 1.25 percent is representative.

Time required to cast [45]. - An experimental procedure was arranged to measure the time consumed in casting molten alloy into a pattern cavity. A window was cut on one side of a casting ring. This window was then closed with a fused-quartz plate (fig. 35). Wax pat-

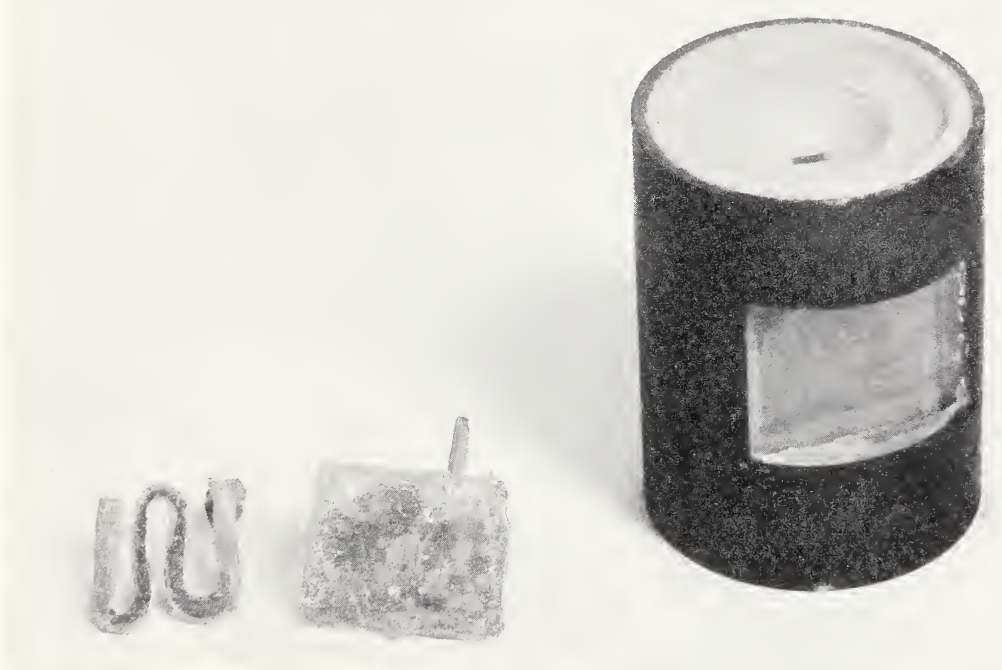

FIGURE 35.-Casting ring with fused-quartz window in place.

To the left are two castings made against this window.

terns were placed against the quartz plate, sprued, and invested according to the usual dental technic. The flat plate was cast from a wax pattern 18 by 22 by 1.5 millimeters through a rectangular sprue 1.5 by 2 millimeters. The double $U$-shaped bar' had a length of 50 millimeter's.

The invested patterns were heated to remove moisture and wax. The casting operation was completed on a casting machine and using 10 pounds air pressure. During the act of casting, a motion-picture camera was operated to record the entry of the molten alloy into the cavity (fig. 36). The best estimates of the time consumed in filling these cavities indicated that it was of the order of $0.1 \pm 0.05$ second.

Technic Casting golds. - The dentist will find, in the certified lists of gold alloys [101], types of alloys suitable for most of his casting gold needs. The fact that these alloys have been cast into small rods 4 to 6 inches in length and that these rods have strengths equal 


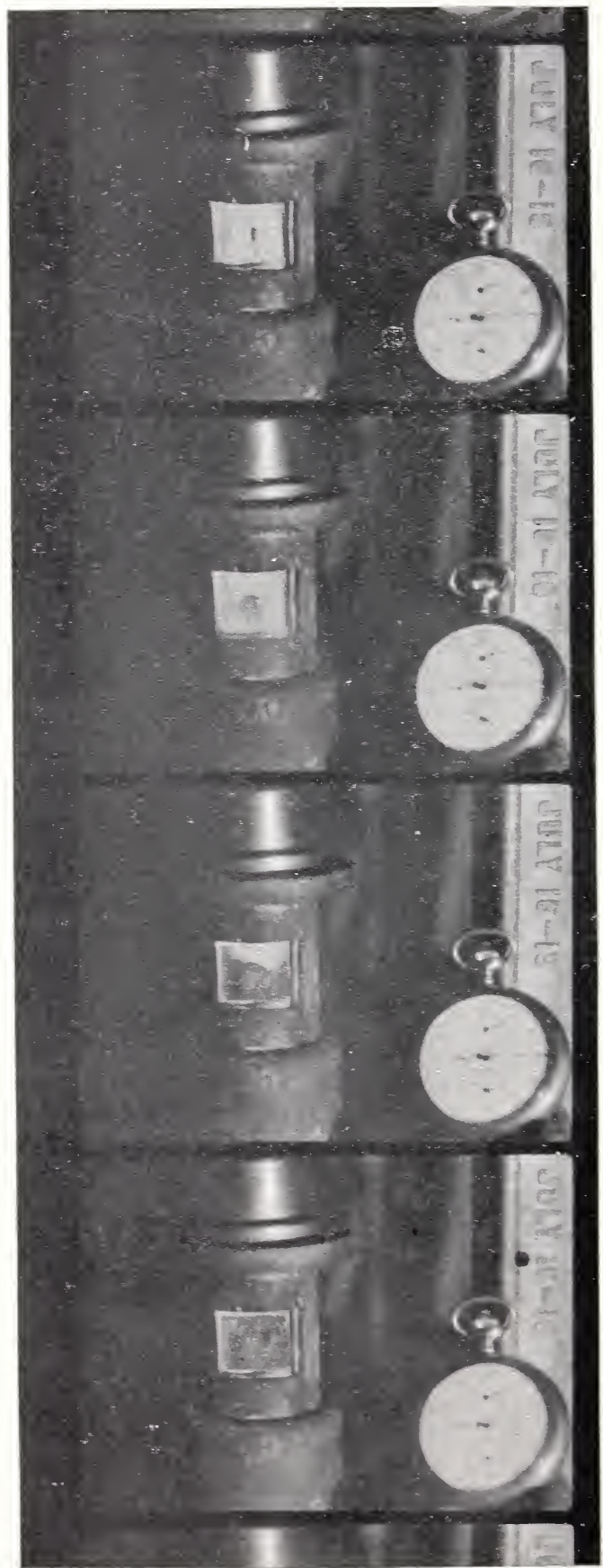

FIGLRE 36.-Casting a gold alloy against a fused-quartz window. 
to the specification requirement indicate that these alloys should be satisfactory for the needs of the dentist. Little difficulty need be anticipated in casting into corners or to thin sections such as may be necessary for dental needs.

It is not necessary to overheat these alloys when casting sharp angles or thin sections. It was observed that test rods cast at temperatures only slightly above the melting point usually gave test specimens of better quality than those cast at the higher temperatures. The discovery came as a result of observations in casting a series of test rods. When the alloy was heated to a high temperature so that the entire lot of five or more rods were cast on the first attempt, frequently there were rods in the lot which failed to pass the specification. When the casting temperature was lower, so near the melting range that one or more of the rods failed to cast, usually all the cast rods passed the specification. Casting at the lower temperatures was adopted as the most satisfactory technic.

Hydrogen and air mixtures are excellent fuels for melting gold alloys. There is not the danger of overheating that is present when oxyacetylene or oxyhydrogen flames are used. Blowpipes should be selected to give the type of flame desired. The large brush flame is wasteful. The flame should spread over the alloy being melted and can be used to cause the button of molten gold to spin and thereby uniformly mix the different elements just before casting. This is accomplished by moving the flame to the side of the melt. Partially molten metal will not spin. The oxyhydrogen flame can be very severe for gold alloys and if used must be watched closely to prevent overheating. The inner blue oxygen cone of the flame must not be permitted to touch the alloy as it will tend to chill the metal.

Electric melting furnaces are used by some operators. They are usually slower in melting the alloy. In some general tests, specimens of gold alloys cast from electrically melted metal failed to show any superiority over similar specimens cast from gas-melted metal.

Comparisons of test specimens cast by compressed air (method shown in fig. 37), air reductions (racuum), and centrifugal force failed to show any advantage in the physical properties of the specimens for any one of these methods over the others. The selection of a casting machine may well be made on the basis of economy and convenience. For the larger castings a centrifugal machine will be more convenient. It requires considerable skill to construct sprues for the air-pressure or vacuum type of casting machine which will pass the molten gold when, and not before, the air pressure or vacuum is applied.

The time required for the molten gold to flow into a cavity of average dimensions, through an average sized sprue is of the order of 0.1 second. The gold doubtless remains molten for some time after' entering the cavity and pressure should be maintained until the casting has solidified.

A cold mold, which would undoubtedly hasten the solidification of the molten allov, would be undersize and would introduce additional shrinkage defects or misfits which would off set any convenience accluing from the use of cold molds.

The greatest gains in technics are to be realized from the heat treatment of the cast alloy. One must not hope to be able to develop in cast restorations those properties which are readily obtainable in 
wrought alloys of identical chemical composition. In the harder types of alloys it usually is possible to improve the strength, elastic limit, hardness, and similar properties by a properly conducted heat treatment. The details for the best heat treatment for the alloy and its anticipated use should be supplied by the manufacturer.

Electric ovens equipped with temperature-measuring devices are quite satisfactory for heat-treating appliances. Mixtures of salts, such as sodium and potassium nitrates, having proper melting points can be used, but these introduce the danger of explosions unless precautions are taken.

Cleaning or pickling solutions are usually recommended by the manufacturers. Dilute solutions of sulfuric acid are frequently used. The gold alloy may be heated and dropped into the solution. If the

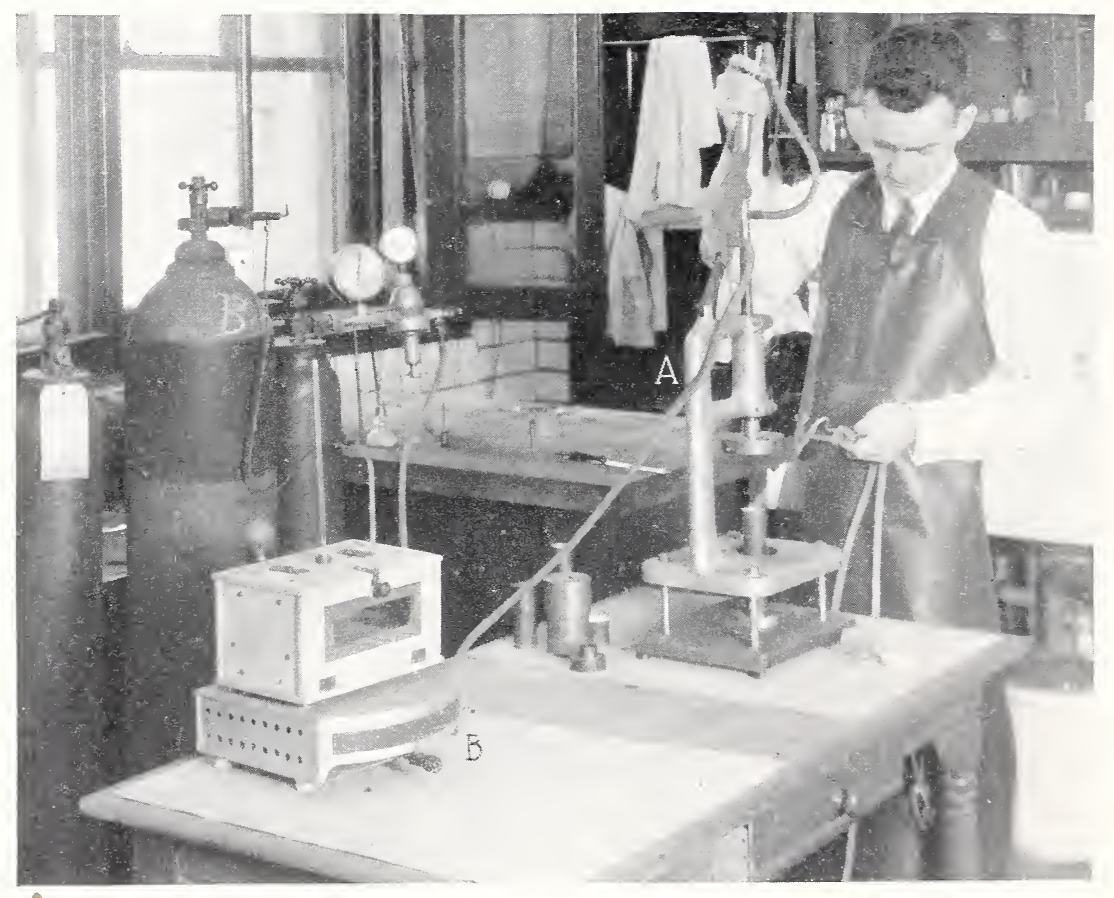

FIGURE 37.-Casting test specimen by compressed air.

$A$, Casting machine; $B$, furnace suitable for heat-treatment procedures.

heat treatment has been completed, the alloy can be heated in the boiling diluted acid, but in a flame it may unintentionally be heated high enough to destroy the effect of heat treatment.

Polishing is quite important for appearance, satisfaction to the patient, and the prevention of deposits or stains.

Casting to an exact dimension requires mathematical computations for the expansions of waxes and investments. Combinations of various amounts of expansion can be arranged as shown in the technic chart (fig. 38). The first castings made to a predetermined, computed exactness are shown in figure 39. (Dentists had made castings to an exact fit by empirical methods.) Holding the dimension and pre- 
venting local shrinkages and shrinkage pipes from injuring a casting can be achieved by using a short sprue and a surplus of gold so large that the reserve gold will not solidify until after the casting has solidified. A better method is to place a reservoir button on the sprue. The molten gold in this button will feed the shrinkage pipe as it starts to develop in the casting.

Surface defects usually reveal their origin if carefully studied. Etched and uniformly rough surfaces, apparently attacked by the investment, may have resulted from the disintegration of an investment by excessively hot alloy. Pimples or nodules usually result from an incorporation of air in the investment. Failure of the investment to adhere to the wax pattern may give various types of surplus

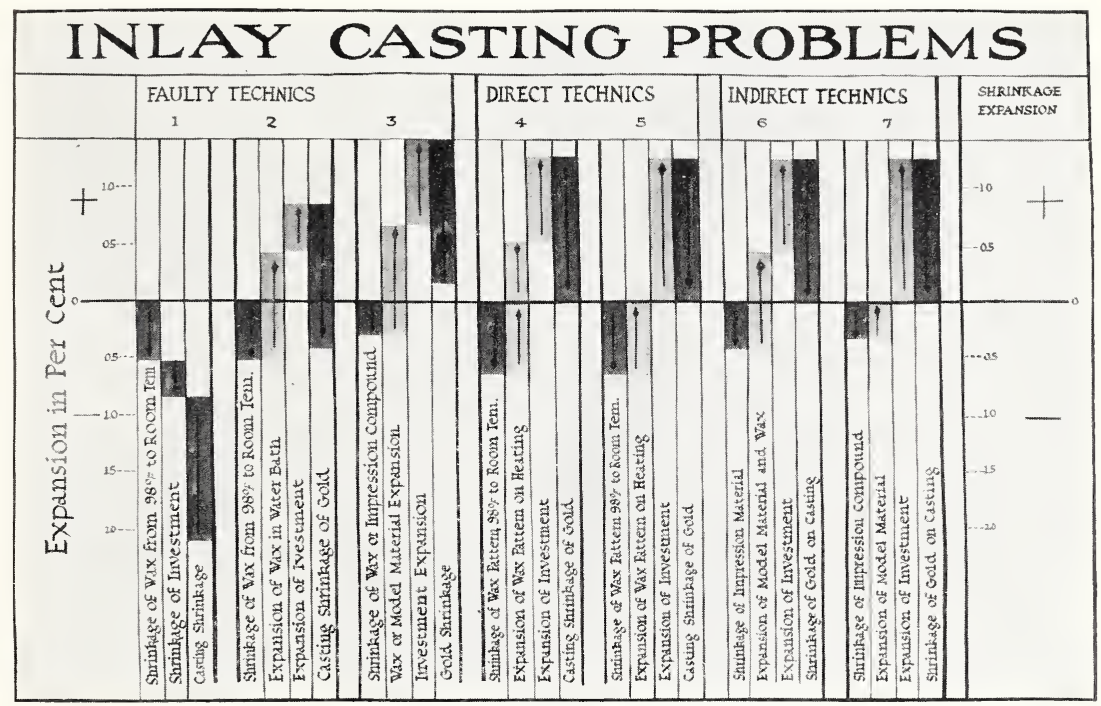

FIGURE 38.-Inlay casting problems.

The effect of direct and indirect technies, both faulty and good, upon the size of the casting is shown graphically.

designs or patterns on the surface of the gold casting. Wax patterns moved during the hardening of the investment may show a general mat surface. This is the result of the formation of a water layer between the wax pattern and setting investment. Thin fins attached to a casting reveal a cracked investment, apparently heated too rapidly on the burn-out.

Deficiencies of gold or failures to cast completely can result from gases developed when the molten gold strikes particles of wax not completely eliminated, flux accidentally blown into the cavity, or gases generated from the investment in contact with superheated gold. Chips of investment blown off by too rapid heating can usually be identified. The cavity from which the chip came and the chip itself as it floats on the molten gold will be recorded on the casting.

Wrought materials.-Little need be offered on this subject beyond the reminder that heating (soldering and similar operations) usually softens wrought gold alloys. This is likewise true for the wrought

$406035^{\circ}-42-6$ 
stainless steels of certain compositions. The properties of some gold alloys can be partially restored by heat treatment. Directions for heat treatment may be supplied with the alloy or may be taken from the instructions for the hardening heat treatment in specification number 7 (page 202).

Clasps and other attachments should be shaped and adjusted after the wrought alloy has been softened. When all adjustments have been completed the entire appliance should be hardened according to the directions supplied by the manufacturer. For some gold alloys heat treatment may restore 50 percent or more of the strength or hardness taken away by the quenching, or soldering heating.

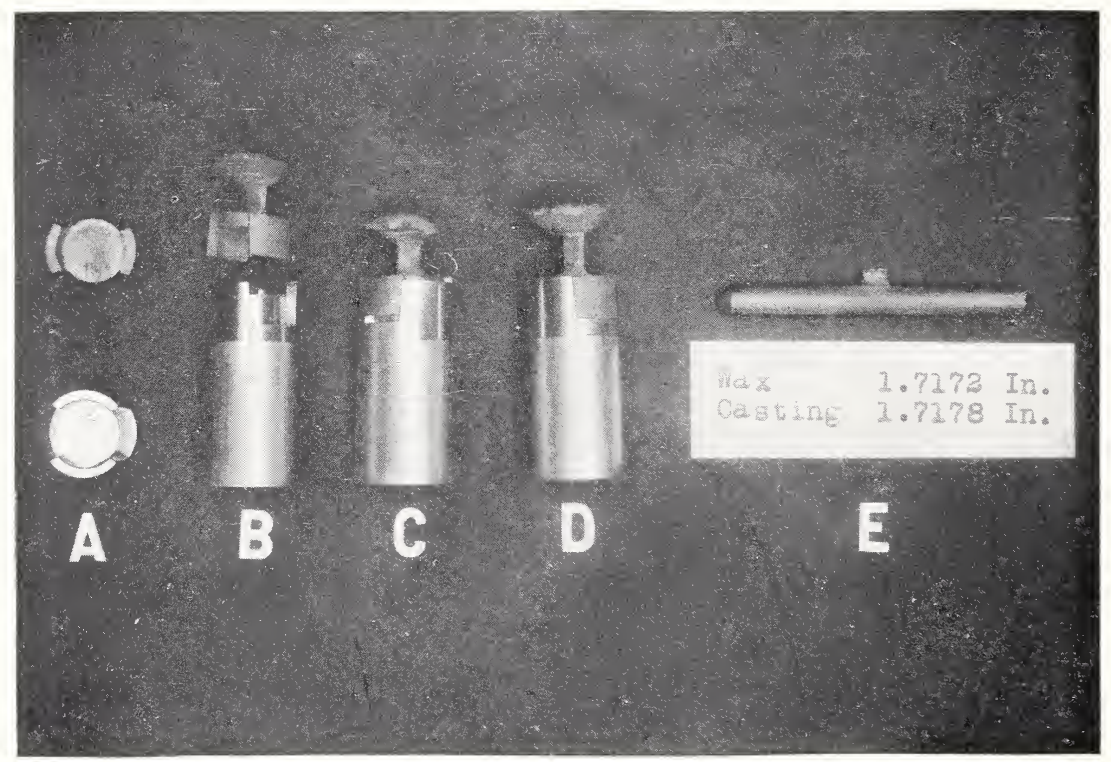

Figure 39.- Steel model and gold castings.

$A$, Top view of model; $B$, side view of model and casting; $C$, showing lack of dimensional accuracy in a asting made according to a popular technic; $D$, casting made by the methods described; $E$, showing the dimensional accuracy of castings made by these methods.

\section{BASE METAL ALLOYS}

Various types of base metal alloys have been tried for inlay and bridge castings but have been with few exceptions entirely discarded. Among the alloys which were not satisfactory are included (1) coppernickel alloys, and copper-aluminum alloys, (2) nickel-chromium alloys, (3) tin-antimony alloys, one brand of which contamed 72.5 percent of tin and 27.5 pereent of antimony, and (4) silver-rich alloys. 'Two types of base metal alloys have been successfully used in dentistry. These are the stainless stecls which are used in the wrought state and the Stellite type alloys which are used in the cast state.

Stainless steels are alloys of iron with at least 12 percent of chromium. The type most suitable for dental use is the alloy containing 16 to 20 pereent of chromium and 7 to 10 percent of nickel, commonly known as "18-8". Many orthodontists regard stainless steel as superior to precious metal alloys, especially as far as discoloration is concerned. Friedrich Hauptmeyer, chief of the Krupp Dental Clinic 
in Essen, Germany, utilized this material in 1919 in constructing dental appliances and appears to have pioncered the dental use of stainless steel.

The physical properties of the stainless steels, particularly the $18-8$ variety, are well known. Data showing the relative mechanical properties of 18-8 type stainless steels and various grades of wrought gold wire alloys are given in table 25. From these values it will be seen that the two types of alloys could be used for orthodontia or prosthetic appliances. One advantage of the gold alloys is that they can be softened, adapted, and fabricated while soft and then behardened by an appropriate heat treatment. The 18-8 type of stainless steel hardened by cold-drawing, if softened by soldering or by cooling from $1,100^{\circ} \mathrm{C}\left(2,012^{\circ} \mathrm{F}\right)$, cannot be rehardened except by cold-working-an impractical process in fabricated dental appliances. Ingenious mechanical methods of making appliances of stainless steel without soldering and hence without lowering the hardness imparted by cold-working have been developed and have made the 18-8 type of stainless steel a valuable dental alloy.

Reference to table 25 will show that the stainless steel is very tough, that is, it has a high tensile strength in combination with an extremely high elongation. It is this toughness which makes the 18-8 type of stainless steel the most suitable material for tie wire in fracture cases and in orthodontia.

TABLE 25.-Mechanical properties of 18-8 type of stainless steel and a wrought gold alloy wire

18-8 STAINLESS STEEL

(Softened by cooling from $1,100^{\circ} \mathrm{C}\left(2,012^{\circ} \mathrm{F}\right)$ )

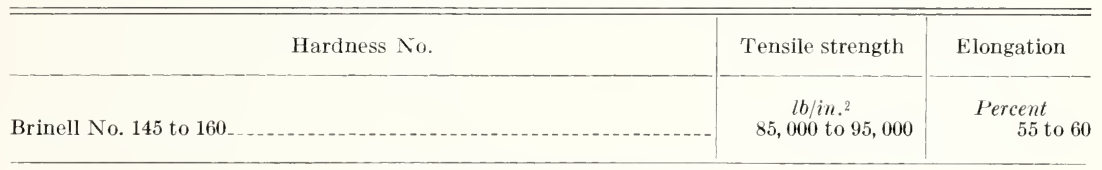

(Hardened-only by cold-working)

Up to $400 \ldots$ Up to $300,000 \mid$ to 50

WROUGHT GOLD ALLOYS

(Softened by quenching from $700^{\circ} \mathrm{C}\left(1,292^{\circ} \mathrm{F}\right)$ )

Vickers No. 170 to 260

85,000 to 120,000

15 to 35

(Hardened by gradual cooling from $450^{\circ}$ to $250^{\circ} \mathrm{C}\left(842^{\circ}\right.$ to $482^{\circ} \mathrm{F}$ ) in 30 minutes)

250 to 370

130,000 to 185,000

2 to 20

In cast dentures, particularly cast partial dentures, gold alloys have to a considerable extent been replaced with base metal alloys having a cobalt-chromium base. In fact, alloys of this type have been the only successful competitors of the casting gold alloys for dentures. Compositions of four prominent alloys are given in table 26 . It will be seen that alloy D-B in this table is essentially a Stellite type of alloy, being composed principally of cobalt, chromium, and molybdenum. Alloy B-B is in the Stellite class too, even though it does have ap- 
proximately 4.5 percent of nickel. All of the alloys contain chromium, which is probably the element largely responsible for the nontarnishing characteristics of the alloys.

TABLE 26.-Composition of base-metal alloys used in cast dentures

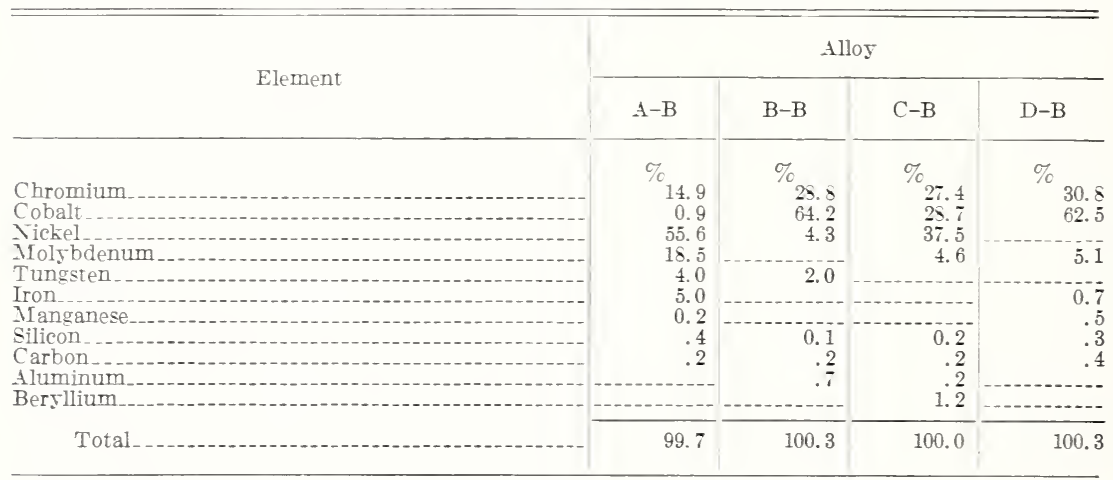

The "freezing temperatures" of such allors are high ranging from about $1.395^{\circ} \mathrm{C}\left(2.543^{\circ} \mathrm{F}\right)$ for alloy $\mathrm{D}-\mathrm{B}$ (table 26$)$ to $1.290^{\circ} \mathrm{C}\left(2,354^{\circ}\right.$ F) for alloy C-B. These determinations were made by $\mathrm{W}$. F. Roeser in the Prrometry Section of this Bureau. Additional work on these alloys is in progress.

\section{CERAMIC MATERIALS}

\section{INVESTMENTS FOR GOLD ALLOYS}

Description and behavior.-The art of reproducing wax designs in metal has been practiced for centuries. Its application to dentistry came during the last quarter of the nineteenth century and enabled the profession to supply entirely new types of restorations such as the dental inlay and cast crown. These can be made to restore and protect badly mutilated and weakened teeth more effectively than any other type of restoration.

The inlay or crown is first designed in wax. It is then reproduced in gold through the use of an intermediate material designated as an investment. The commonly used investment is a mixture of a refractory material, usually silica in the form of quartz or cristobalite or both, and a binder, calcined gypsum (plaster of paris) in varying proportions. When water is added to the mixture a paste is formed in which the wax pattern is imbedded. Upon hardening the investment accepts the design of the frail wax pattern. Later the wax and water are eliminated by heat, learing a carity within the mold into which molten alloy is forced.

The investment expands on hardening because of the changing of the calcined grpsum $\left(\mathrm{CaSO}_{4} \cdot 1 / 2 \mathrm{H}_{2} \mathrm{O}\right)$ to grpsum $\left(\mathrm{CaSO}_{4} \cdot 2 \mathrm{H}_{2} \mathrm{O}\right)$. The investment also expands when heated because of the thermal expansion of the quartz or cristobalite and because of the crrstalline change from alpha to beta quartz or, in the case of cristobalite, from alpha to beta cristobalite. Methods of measuring these changes are given on pages 92, 152. Both types of expansion of the investment vary with the composition used. "In modern practice the composition is adjusted so that the combined setting and thermal expansion will be 
$1.3 \pm 0.2$ percent on the linear basis. This amount of expansion compensates very closely for the casting shrinkage of the gold alloy $(1.25 \pm 0.05$ percent $)$ and the shrinkage which the wax pattern undergoes when it cools from mouth to room temperature. If the investment material develops the proper amount of expansion, it is not necessary to expand the wax pattern.

In addition to exhibiting a proper degree of expansion, a satisfactory investment should set within a few minutes. Upon setting, the material should have a fine enough structure to reproduce minute details of the wax pattern and should be strong enough not to crack or break when the molten alloy is forced into it.

The setting of the investment is caused by the reaction of water with the calcined gypsum in it to form a crystalline mass of gypsum which serves as a binder for the silica. The investments in common use contain 25 to 35 percent of calcined gypsum. Formerly the calcined gypsum used was ordinary plaster of paris, but at this time another form of this compound, known as hydrocal, is almost universally employed. An investment containing hydrocal requires less water to make a paste of the preferred consistency than one containing ordinary plaster of paris. On setting, the mixture containing the smaller amount of water is the stronger and also exhibits more thermal expansion.

Hydrocal is also used in making dental model materials which are usually referred to as artificial stone in current dental practice.

When the set investment in which the wax pattern is imbedded is heated to drive out the wax and water, the gypsum is again calcined and therefore tends to shrink. However, this shrinkage is more than offset by the expansion of the silica particles which comprise the larger proportion of the investment. If only the crystalline form of silica known as quartz is used in the investment mixture, the net expansion is not enough to compensate for the casting shrinkage. Since 1930 another form of crystalline silica known as cristobalite has been used to a considerable extent, in place of quartz. The thermal expansion of cristobalite is greater than that of quartz and investment mixtures in which it is used show a nearly constant amount of expansion over a considerable temperature range. These advantages are shown in figure 40.

Although investment materials are composed mainly of calcined gypsum and silica, they often contain other constituents in small quantities. Among them is sodium chloride which, in amounts up to almost 1 percent, decreases the shrinkage of the gypsum when the wax is burned out, and thereby increases the expansion of the investment. The middle curve in figure 40 represents the thermal expansion of an investment containing sodium chloride, in contrast to the lower one which does not, but whose composition is similar in other respects. It will be seen that the investment containing quartz and sodium chloride has an expansion nearly as great as that of the one containing cristobalite, but that the temperature range over which the expansion is practically constant is smaller. It should be noted that when investments containing sodium chloride are heated in an electric oven damage is likely to result to the chromium-nickel alloys used as heating elements.

Another minor constituent is boric acid, which serves to produce a harder investment and to remove metallic oxides from the surface 
of the alloy during solidification. Highly refractory oxide powders are sometimes used, probably as coloring materials to enable a manufacturer to identify his product.

If a precious metal alloy is imbedded in the investment, along with a wax pattern, corrosion of this alloy often occurs when the investment is heated. The attack may be serere or only superficial but in either case it prevents a satisfactory union between the cast alloy and the imbedded piece. This type of corrosion is thought to be caused by

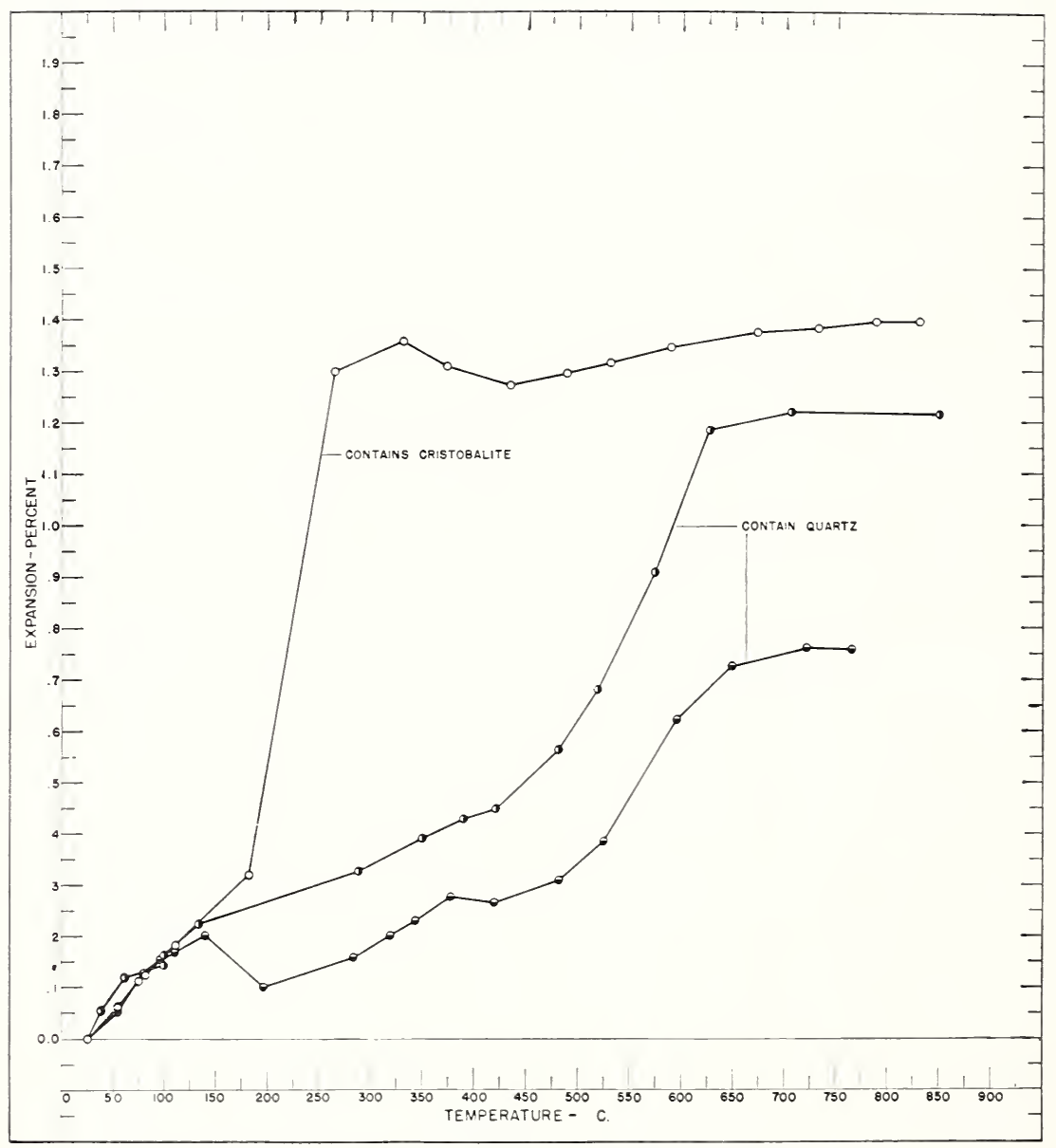

FIGURE 40.- Thermal expansion of three inlay investments.

the sulfur-containing gases originating from the breaking down of the calcium sulfate in the investment during heating. To prevent the corrosion, certain substances, such as graphite (carbon) or powdered copper, are added. The latter is especially effective.

Relationship between the thermal expansion of investments and the dimensional accuracy of castings.-As was previously stated, the combined setting and thermal expansion of an investment should be $1.3 \pm 0.2$ percent on a linear basis in order to compensate for the shrinkage of the wax pattern and of the cast alloy. 
One of the unique features of the cristobalite type of investment is its almost constant linear expansion of about 1.3 percent between $300^{\circ}$ and $900^{\circ} \mathrm{C}\left(572^{\circ}\right.$ and $\left.1652^{\circ} \mathrm{F}\right)$. Thus restorations can be cast to exact dimensions at any temperature within the range. Figure 41 , A, shows the result obtained with an experimental investment

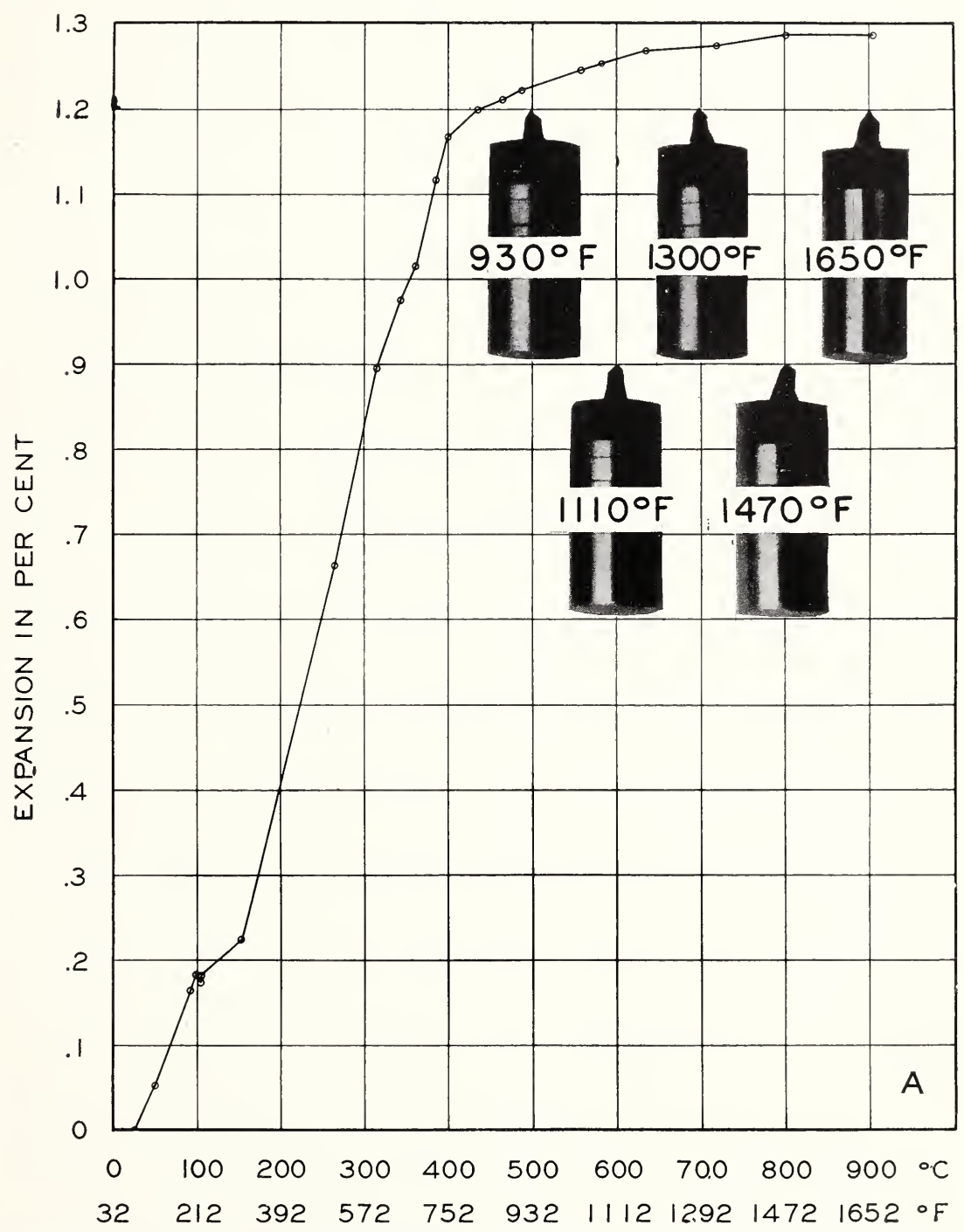

Figure 41, A.- Thermal-expansion curve of an experimental cristabolite investment.

The series of castings were made at the designated temperatures. All fit reasonably well.

containing silica in the form of cristobalite. It will be observed that all of the M-O-D inlays cast in cristobalite investment at or above $500^{\circ} \mathrm{C}\left(932^{\circ} \mathrm{F}\right)$ fit equally well. This is a real advantage because elaborate temperature-measuring equipment is not required. If the investment is heated only high enough to eliminate the water and 
wax, it will expand about 1.3 percent, or if it is heated to a bright cherry red, the expansion will still be about 1.3 percent.

The amount of water used in an investment also affects its thermal expansion. This is illustrated in figure 41, B. 'The solid line shows

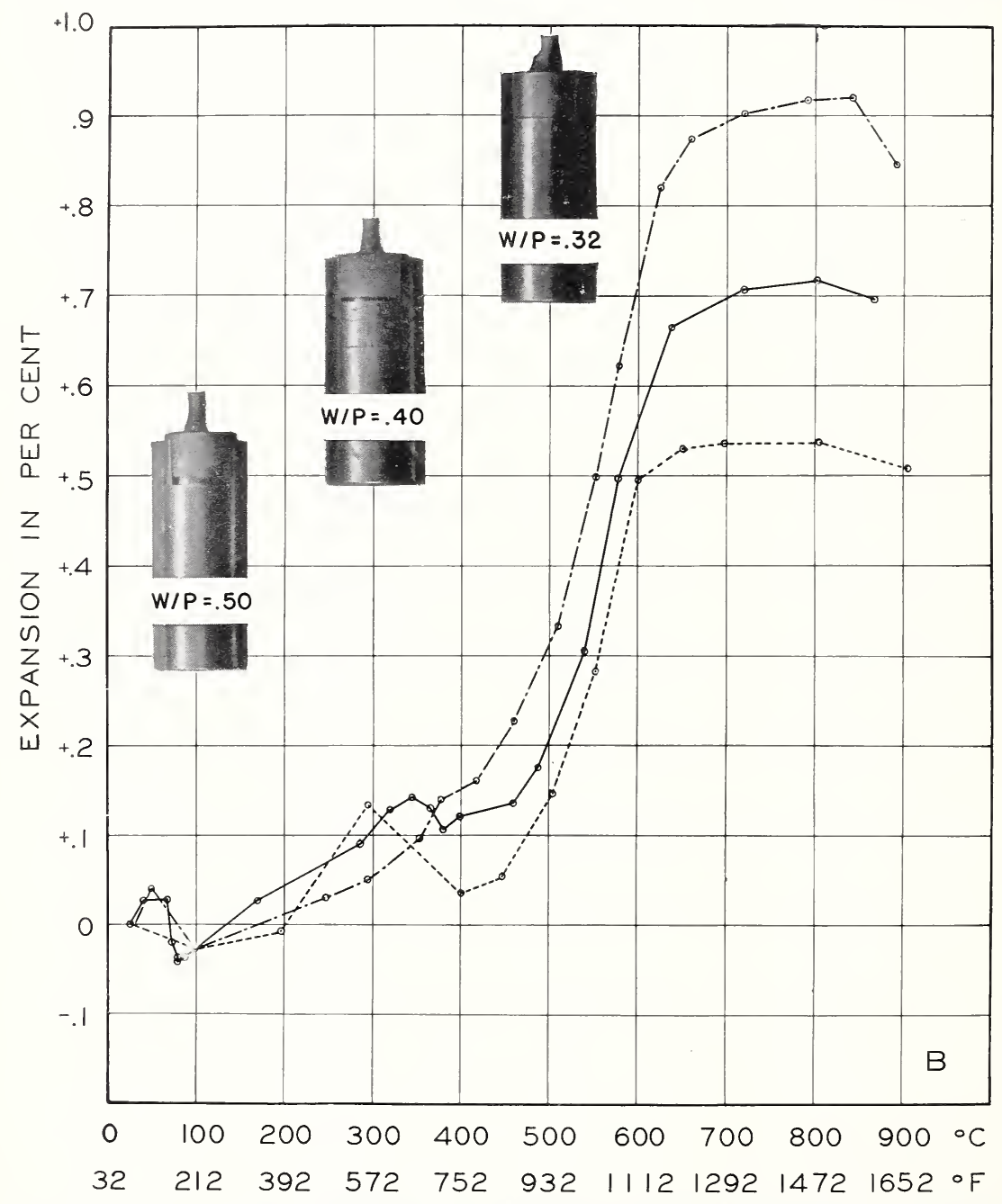

FIGURE 41, B.- Effect of varying the water-powder ratio upon the thermal expansion of a 20 -percent plaster, 80-percent quartz investment.

$32 \mathrm{ml}$ of water to $100 \mathrm{~g}$ of investment

$40 \mathrm{ml}$ of water to $160 \mathrm{~g}$ of investment

$50 \mathrm{ml}$ of water to $100 \mathrm{~g}$ of investment

the typical thermal expansion of an average plaster of paris-quartz investment when heated. The two broken lines show the effects of increasing and decreasing the water content in mixing the investment. The M-O-D castings shown in figure 41, B, were made in an identical manner except that the water-powder ratio of the investing material was varied as indicated. The fit of the castings on the dies demon- 
strates again how the dimensional changes occurring in the investment are reflected in practice.

A thermal expansion curve of plaster of paris (fig. 41, C) proves the previously made statement that plaster of paris is the shrinking component in dental investments. Castings can be made in plaster

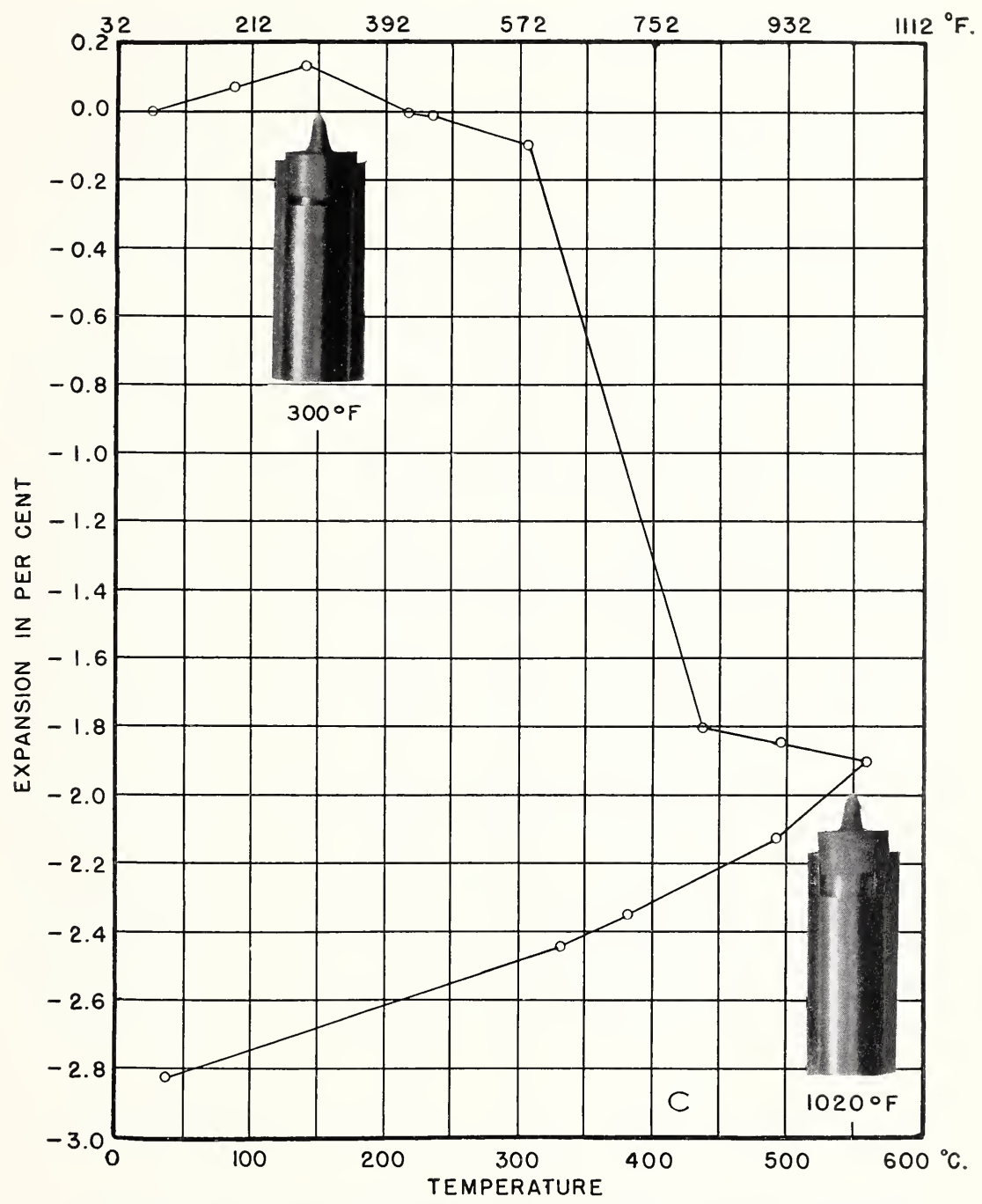

FIGURE 41, C.-Thermal-expansion curve of plaster of paris and castings.

but they are of course unsatisfactory because they are too small (inserts in fig. 41, C).

The effect of casting upon a model made of a shrinking investment, which was surrounded by an investment that expanded on heating, is illustrated in figure 42 . $B$ is a model prepared from a shrinking investment. The wax pattern, $A$, was formed on the model and then 

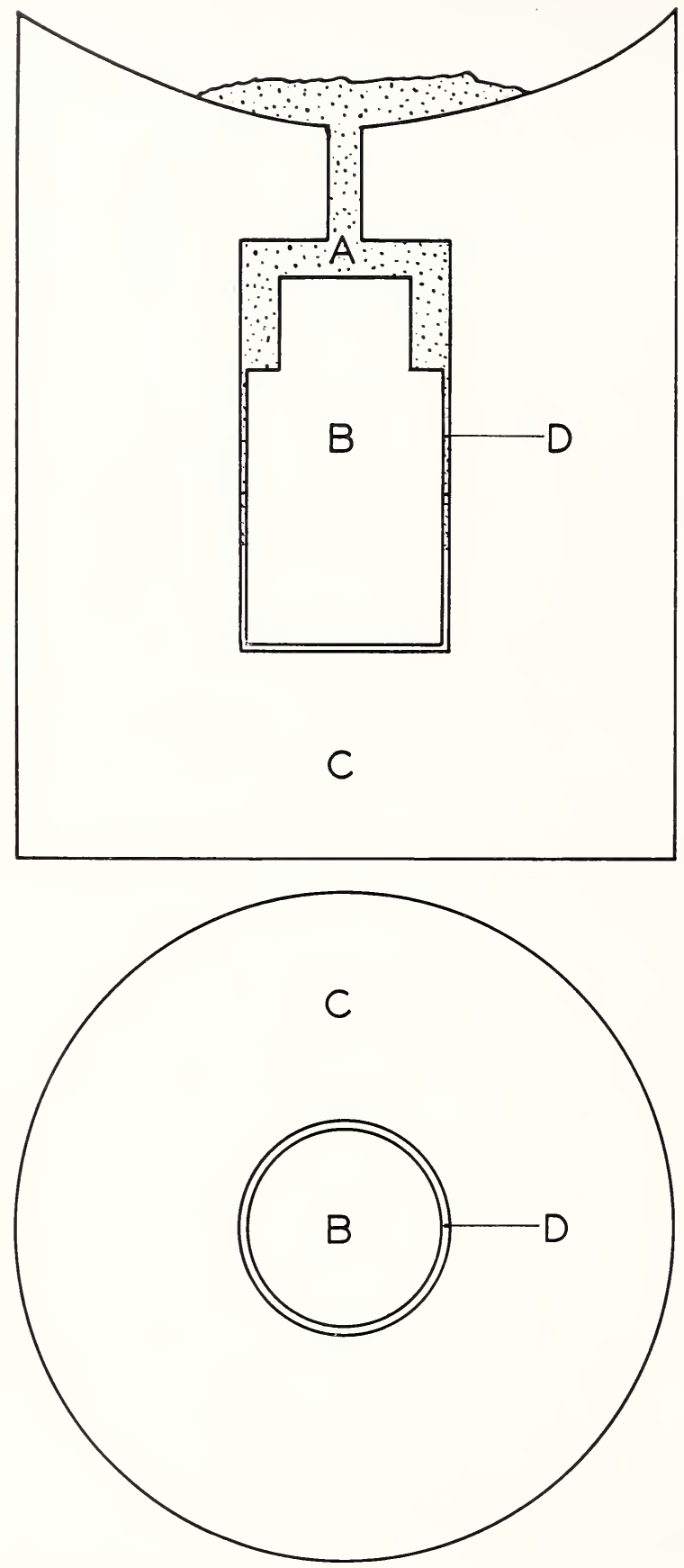

FIGURE 42.-Effect of casting upon a model made of a shrinking investment surrounded by an expanding investment.

$A$, Casting; $B$, model made of shrinking investment (shrinkage 0.4 percent); $C$, outer expanding investment (expansion 0.85 percent); $D$, space caused by the shrinkage of $B$ and expansion of $C$. This space was filled with gold as indicated. 
invested in an expanding investment $C$. The combination was carried through the usual inlay procedure and a casting made from a dental gold alloy. The separation between $B$ and $C$ was so great that a skirt of gold cast around the model, well down the side.

Compressive strength. - The apparatus used in determining the compressive strength was a universal testing machine of 2,000 pounds capacity. In order to make tests on specimens at elevated temperatures, the equipment shown in figure 43 was used. The heating device

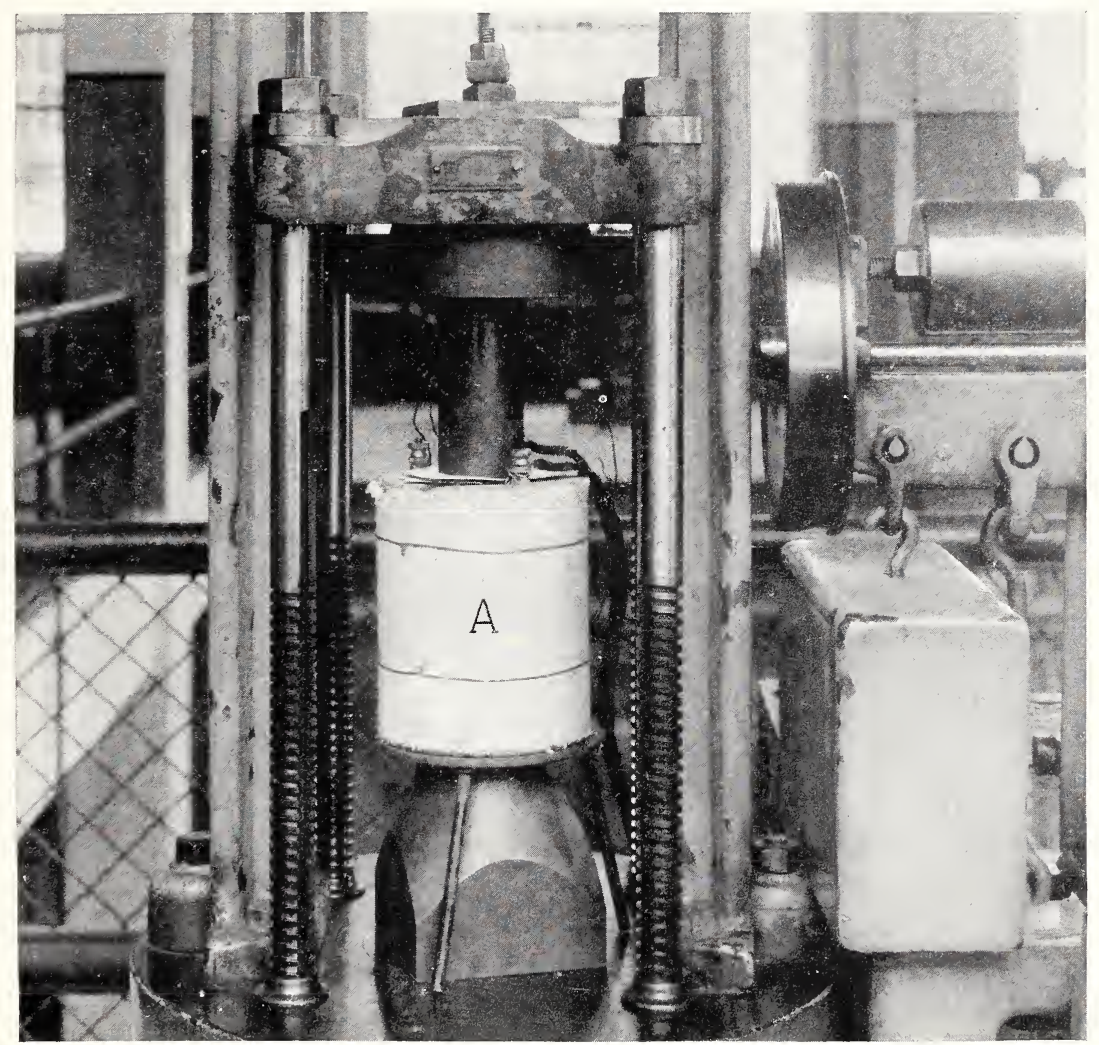

FIGURE 43.- Apparatus for determining compressive strength of investments at elevated temperatures.

Investment specimen is inclosed in the electrically heated furnace, $A$.

was a chromel-wound, vertical-tube electric furnace with rheostats or a voltage regulator for controlling the temperature. Two steel cylinders with their ends ground flat and parallel, and projecting into the ends of the furnace, provided means of applying load to the specimen.

The specimens were cylinders 1.3 inches in diameter and 2 inches long. They were prepared with parallel faces in the mold shown in figure 44. The type of fracture obtained, also illustrated in figure 44, indicates that the loading was axial.

The compressive strengths of a plaster of paris and of two inlaycasting investments containing 30 percent of plaster each at temperatures up to $800^{\circ} \mathrm{C}\left(1,472^{\circ} \mathrm{F}\right)$ and at room temperature, after being 
heated to rarious temperatures and allowed to cool, are giren in table 27. The ralues are the arerages of sereral tests. The strengths of two of the materials in the green state, that is, before heating, are included for comparison.

It will be noted that the strength of investment No. 7 (approximate composition 30 percent of plaster and 70 percent of quartz) dropped from about $300 \mathrm{lb}$ in. ${ }^{2}$ for the green material. 3 hours old, to 160 lb in. ${ }^{2}$ when heated to $150^{\circ} \mathrm{C}\left(302^{\circ} \mathrm{F}\right)$. As the temperature was raised to $400^{\circ}$ or $500^{\circ} \mathrm{C}\left(752^{\circ}\right.$ or $\left.932^{\circ} \mathrm{F}\right)$ the strength increased. At $600^{\circ} \mathrm{C}\left(1,112^{\circ} \mathrm{F}\right)$ the strength dropped to about $200 \mathrm{lb} / \mathrm{in}^{2}$, but at $700^{\circ} \mathrm{C}\left(1.292^{\circ} \mathrm{F}\right)$ and $800^{\circ} \mathrm{C}\left(1,472^{\circ} \mathrm{F}\right)$ was again near the maximum, which was only slightly below the strength of the green material. 3 hours old. When this investment was allowed to cool to room temperature, after being heated to the rarious temperatures indicated, the decrease in strength was very marked. It was thought that this

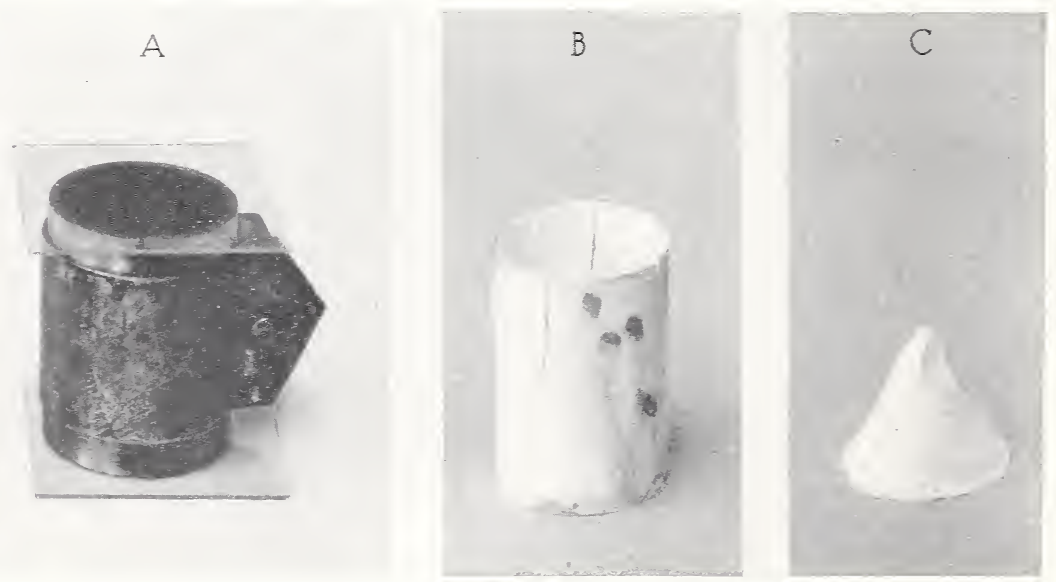

FIGLRE 11. - Mold for forming specimen of investment used in compressive test and crushed specimen.

$A$, Nold for forming specimen; $B$, broken specimen; $C$, cone from top of broken specimen.

decrease in strength might have been due to cracking caused br too rapid cooling, but tests on specimens allowed to cool slowly in the furnace over a period of several hours showed that the slower rate of cooling caused a still greater loss of strength.

The behavior of pure plaster or plaster without ans added quartz was similar to that of investment No. 7 . The strength dropped from $825 \mathrm{lb}$ in. $^{2}$ for the green material 3 hours old, to $52 \%$ lb in. ${ }^{2}$ when heated to $200^{\circ} \mathrm{C}\left(392^{\circ} \mathrm{F}\right)$. The strength increased slightly at the higher temperatures until, at $600^{\circ} \mathrm{C}\left(1,112^{\circ} \mathrm{F}\right)$, there was a marked loss in strength. At $700^{\circ} \mathrm{C}\left(1,292^{\circ} \mathrm{F}\right)$ the strength rose to 662 lb in $^{2}$, which was the maximum value obtained for plaster crushed hot. When specimens of pure plaster were cooled from $500^{\circ} \mathrm{C}$ $\left(932^{\circ} \mathrm{F}\right)$ or higher, they invariably cracked and fell to pieces.

The effect of varying the proportion of water used with investment No. 7 is shown in table 27 . When the amount of water was increased 25 percent, the strength at $400^{\circ} \mathrm{C}\left(752^{\circ} \mathrm{F}\right)$ dropped from 286 to $93 \mathrm{lb}$ in'. Decreasing the amount of water 25 percent increased the strength to $513 \mathrm{lb}$ in ${ }^{2}$. 
$\mathrm{T}_{\mathrm{ABLE}}$ 27.-Compressive strength of investment materials

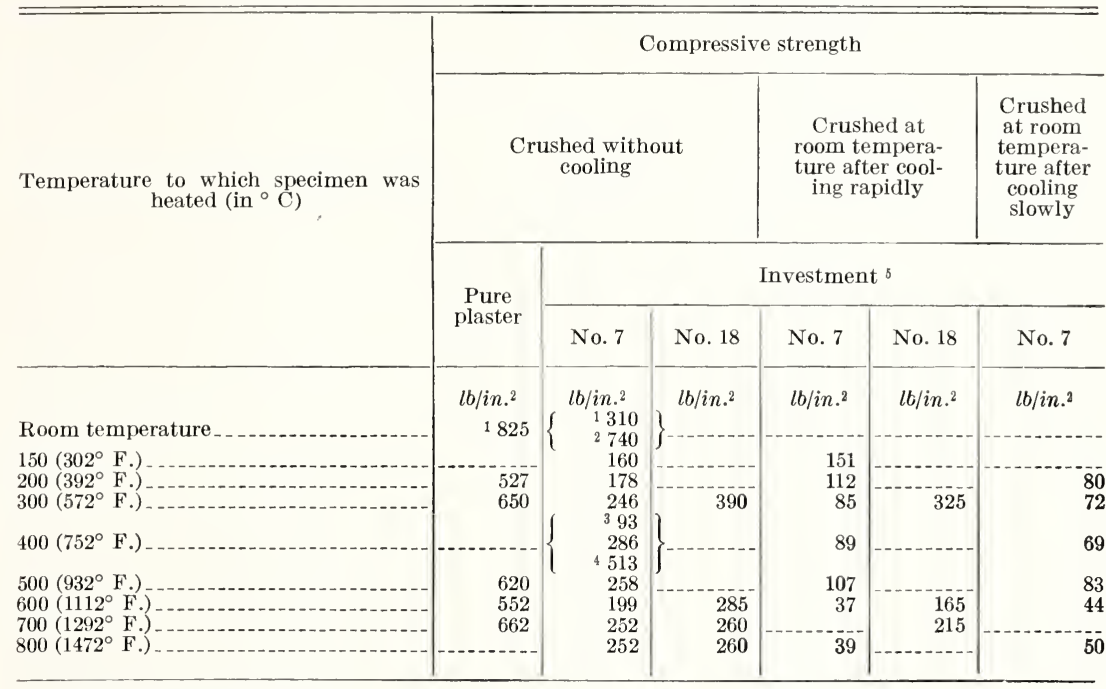

1 Crushed 3 hours after mixing.

2 Crushed 6 days after mixing.

3 Mixed with 25 percent more than normal amount of water.

4 Mixed with 25 percent less than normal amount of water.

5 Composition of investments:

\begin{tabular}{|c|c|c|}
\hline & No. 7 & No. 18 \\
\hline Calcined gypsum. & $\begin{array}{r}\text { Percent } \\
30\end{array}$ & \multirow{3}{*}{$\begin{array}{r}\text { Percent } \\
26 \\
72 \\
1 \\
1\end{array}$} \\
\hline Quartz & 68 & \\
\hline Coloring matter and impurities & 2 & \\
\hline
\end{tabular}

From the results of these tests it may be stated that when the usual inlay casting investment, consisting of about 30 percent of plaster and 70 percent of silica in some form, is heated to drive off the moisture and eliminate the wax pattern, the loss of strength is comparatively small. If, however, the investment is allowed to cool, the mold becomes weak and is likely to be distorted by the impact or pressure as the molten gold enters.

Technic.-Adequate directions for using investments usually appear on the package, but it may be desirable to point out several precautions which should be taken to avoid defects such as fins, mat surfaces, nodules, localized shrinkages, distortions, porosities, and incomplete castings.

Air bubbles in the investment result in nodules on castings; they can usually be traced to faulty mixing. The mixing of investments by hand with a whipping motion should be avoided because it introduces air bubbles into the mix. A less energetic technic, keeping the spatula in the mix, using a spreading motion around the mixing bowl, and taking care to prevent the flowing investment from enfolding quantities of air, should minimize the incorporation of air in the mix. Vibrating the investment helps to eliminate the larger bubbles of entrapped air. A certain amount of vibration aids in effect- 
ing contact while painting the pattern, but ribrating an invested pattern after filling the ring may cause stray bubbles of air to rise and attach themselves to the under side of the pattern.

Mechanical spatulators are available which will rield an investment mixture free of bubbles of appreciable size. An experiment to test one's mixing and investing ability can be performed by applying investment to two sides of a sheet of wax held in a vertical position. Hand-spatulated inrestments should be placed on one side and mechanically spatulated on the other. After the wax is burned out the two surfaces will separate and air bubbles incorporated in the mixes will be visible. Figure 45 shows the two surfaces of investments poured against such a sheet of wax. after the wax was burned out. The many air bubbles in surface $H$ (hand-mixed) show the usual results of a too rigorous hand spatulation. The other surface, $T$, was mixed in a racuum to eliminate all bubbles. However, it is possible to duplicate the $T$-surface either by careful hand or mechanical spatulation.

Morement of the wax pattern after it is placed in the unset inrestment may cause water to collect at the wax-investment surface.
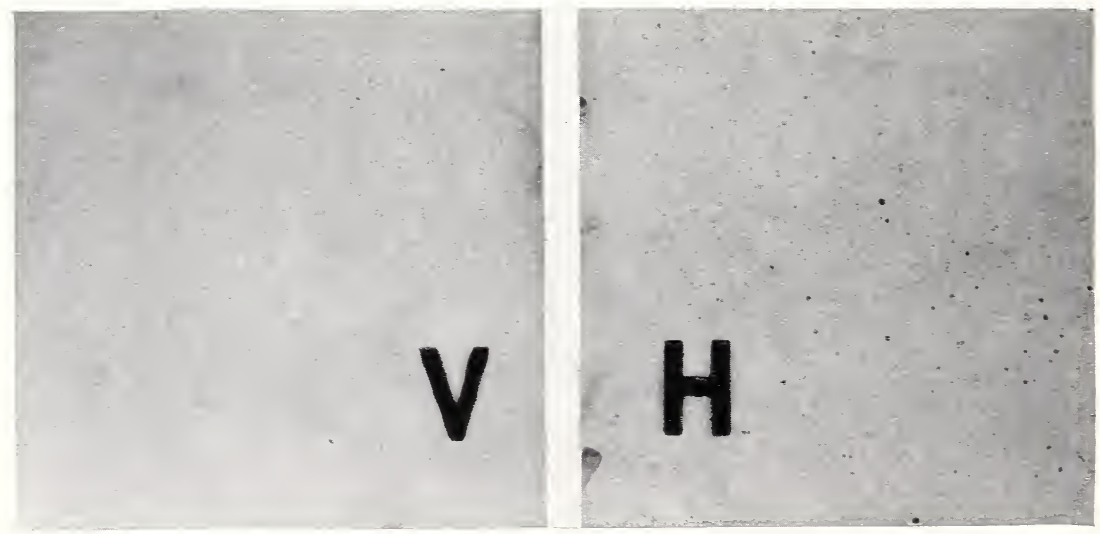

FIGURE 45.-Surfaces of investment mixed in a vacuum $V$ and by hand $H$. Observe the numerous small roids in the hand-mixed material. Inrestment mixed in a mechanical mixer gives surfaces similar to $V$.

thus producing a mat surface or a fin on the casting. Excess water at the wax-investment surface can be remored br dusting the inrested pattern with dry powder. This dry powder will abstract water from considerable distances beneath the surface of the wet investment.

Too rapid burning out mas develop a number of defects. Water rapidly changed to steam may push flakes of inrestment from the walls of the carity. Rapidly emerging water may carry salts to the surface of the carity and leare these as deposits as the water eraporates. The unequal heating of the inrestment mas cause fractures of the mass. Too rapid heating of the invested case may also cause fractures because of the great difference in the coefficient of thermal expansion of the wax and investment in the range from room temperature to $100^{\circ} \mathrm{C}\left(212^{\circ} \mathrm{F}\right)$. The wax pattern has a high thermal expansion and is almost entirelr inclosed in the investment. which has a much lower expansion. The heating if not done very 
gradually will cause the wax pattern to enlarge so much and so rapidly that it cannot escape through the sprue hole and consequently cracks the investment. These broken sections usually separate slightly and permit a fin of gold to flow into the crevice.

A gypsum-bonded investment should not be heated much above $700^{\circ} \mathrm{C}$ as the plaster of paris begins to break down and to give off sulfur-containing gases which may injure the casting. Further, it has been observed that the casting of an overheated alloy in an overheated mold may cause disintegration of the surface of the investment.

Attempts to cast in damp cavities or in cavities containing residues of wax or flux (accidentally dropped or blown in during the melting of the gold) will develop explosions from the vapors which are quickly generated through contact with the molten alloy. These explosions may injure the mold or drive the alloy back and prevent completion of all details of the casting.

If the setting expansion of an investment is restricted by confining it in a continuous inlay casting ring, distortion of the wax pattern may result. This is especially important when hydroexpansion technics [110] are used. A continuous ring may also prevent the free thermal expansion of the investment. If a thin open ring is used, it will spread as the investment expands, both during the setting and the subsequent heating. Another method, first used at this Bureau, of preventing the improper confinement of the investment, is to line a closed ring with wet asbestos paper. The wet lining is soft enough not to restrict the expansion caused by setting and shrinks enough when it dries out during heating to make room for the thermal expansion of the investment.

The enlargement of the cavity which occurs when the investment expands on heating may not be clearly understood by all who employ the investment expansion technic. A simple case of this kind and exactly the same in principle, is seen when a machinist shrinks a metal band on a cylinder or a blacksmith puts a heated metal tire on a wagon wheel. The inside diameter of the band or tire increases as it is heated in exactly the same proportion as the outside diameter. Even when a disk or plate of metal or some other solid has an irregular hole in it, all the dimensions of the hole are enlarged proportionally when the disk or plate is heated. The same thing happens to the irregular dimensions of the wax pattern chamber within the investment when the mold is heated. This illustration helps to visualize what takes place when dental investments surrounding wax pattern cavities are heated.

Testing.-The tests which are used to determine whether dental investment materials meet the requirements of the Federal spccification are included in the text of the specification (page 184). All of the tests must be made on specimens prepared from mixes of the specified consistency, since differences in the consistency of the mixes will affect the results of the tests.

The changes in length which occur during setting are easily measured with a simple form of microscope comparator. This instrument consists of two rigidly connected micrometer microscopes mounted above a $\mathrm{V}$-shaped trough. Into this trough are placed two triangular blocks about 40 centimeters apart. These form the ends of the mold and retain the unset investment in place. The mold is lined with 
wax paper to keep the investment from sticking to the metal surface. The investment is then mixed at the specified consistency and poured into the mold. Before setting begins, two small silver plates with fine lines ruled across their surfaces are put in place near the ends of the specimen and about 30 centimeters apart. Prongs on the under surfaces of the silver plates anchor them in the investment. As setting proceeds, the changes in length are followed with the micrometer microscopes.

The equipment used to measure thermal expansion is shown in figure 46. It is described in detail in another of the Bureau's publications [109]. The long cylindrical specimens $(1.5 \times 20 \mathrm{~cm})$ are made by pouring the unset investment into a split brass tube the inner surface of which has been lubricated with vaseline. This specinen is mounted in the fused quartz tube as shown in figure 46 . The
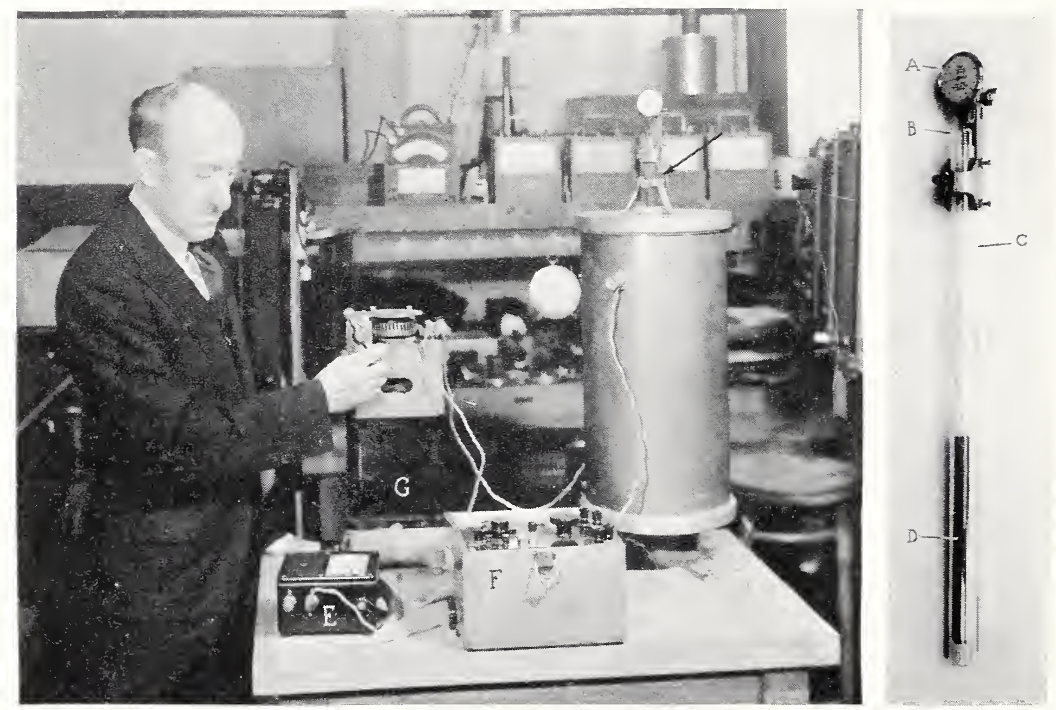

Figure 46. Fused-quartz assembly used to measure the thermal expansion of dental investments.

$A$, Dial indicator is in eontaet with hollow fused-quartz $\operatorname{rod} B$ whieh is inelosed in fused-quartz tube $C$. The fused-quartz rod $B$ rests upon the specimen of investment $D$. This whole assembly is mounted in a tube furnaee, as indieated by the arrow. The auxiliary equipment eonsists of ammeter $E$, potentiometer $F$, and voltage regulator $G$.

removal of the vapors which are given off during the heating of the specimen may be accomplished (1) by drilling two small holes in the fused quartz tube, one near the bottom of the tube and the other at the place on the tube where it emerges from the furnace; and (2) by attaching a vacuum line to the upper hole. A quartz tube so altered cannot be used as a support for a specimen if a liquid bath is to be used for heating or cooling.

The tests for time of setting and compressive strength are described in sufficient detail in the specification (p. 184).

\section{INVESTMENTS FOR BASE METAL ALLOYS}

The base metal alloys used in prosthesis usually have such high melting points that special investments are required. The composi- 
tion of some of the alloys also prevents the use of the customary quartz-plaster investments. The Stellite type of alloys are cast into a unique investment. The powder of the investment is quartz and the essential ingredient of the liquid is ethyl silicate. Such investments are weaker and set more slowly than the ordinary type and consequently must be handled more carefully. The conventional quartz-plaster investment is successfully used with some of the alloys if special precautions are used in heating the investment and in casting the alloy.

\section{CEMENTS}

Today, cements hold an important position among the therapeutic agents at the command of the dentist. In fact cement restorations comprise approximately 10 percent of all fillings [111]. If one considers their use for auxiliary purposes, such as bases for the metallic fillings, pulp capping, and so forth, it has been estimated that cements in some form are used in 50 percent of all dental restorations.

They are used extensively because of certain definite practical advantages held over metallic filling materials such as (1) a natural appearance; (2) greater speed of manipulation than metals and alloys; and (3) lower heat conductivity.

Even though cements are used so extensively, they are generally considered to be the least permanent of the available materials for restorative dentistry. This is because they are relatively soft and soluble and shrink during setting.

Classification by composition.--The grouping of dental cements into classes (table 28) based largely upon composition will be convenient in the study of their properties. In class I the cement powders are primarily zinc oxide. The liquid of the zinc oxychloride cement is a saturated solution of zinc chloride.

TABLE 28.-Classification of dental cements

\begin{tabular}{|c|c|c|c|}
\hline \multirow{2}{*}{ Class } & \multirow{2}{*}{ Cement } & \multicolumn{2}{|l|}{ Use } \\
\hline & & Primary & Secondary \\
\hline I.-. & $\left\{\begin{array}{l}\text { Zinc oxychloride } \ldots \ldots \\
\text { Zinc oxide-eugenol }\end{array}\right.$ & $\begin{array}{l}\text { \{avity lining } \\
\text { Root canal filling } \\
\text { Sealing in treatments } \\
\left\{\begin{array}{l}\text { Base for metallic filling } \\
\text { Pulp capping } \\
\text { Short-life fillings }\end{array}\right.\end{array}$ & $\left\{\begin{array}{l}\text { Temporary cementing me- } \\
\text { dium. } \\
\text { Root canal filling. }\end{array}\right.$ \\
\hline II.-. & $\left\{\begin{array}{l}\text { Copper phosphate } \\
\text { Zinc phosphate }\end{array}\right.$ & $\left\{\begin{array}{l}\text { Short-life fillings where anti- } \\
\text { septic properties are desired } \\
\text { Cementing appliances in place }\end{array}\right.$ & Base for metallic fillings. \\
\hline III--- & $\left\{\begin{array}{l}\text { Class I and II plus silver, } \\
\text { copper, or mercury salts. }\end{array}\right.$ & $\left\{\begin{array}{l}\text { Temporary fillings in deciduous } \\
\text { teeth. } \\
\text { All fillings where antiseptic } \\
\text { properties are desired. }\end{array}\right.$ & $\begin{array}{l}\text { Root canal filling. } \\
\text { Base for metallic filling. }\end{array}$ \\
\hline IV & $\left\{\begin{array}{l}\text { Silicate } \\
\text { Zinc phosphate-silicate }\end{array}\right.$ & Semipermanent fillings...... & Cementing medium. \\
\hline
\end{tabular}

The powders of the class II cements are the oxides of zinc, magnesium, bismuth, or copper in various combinations. The above oxides are not all usually present in the same cement. In many instances small amounts of silver, copper, or mercury salts may be 


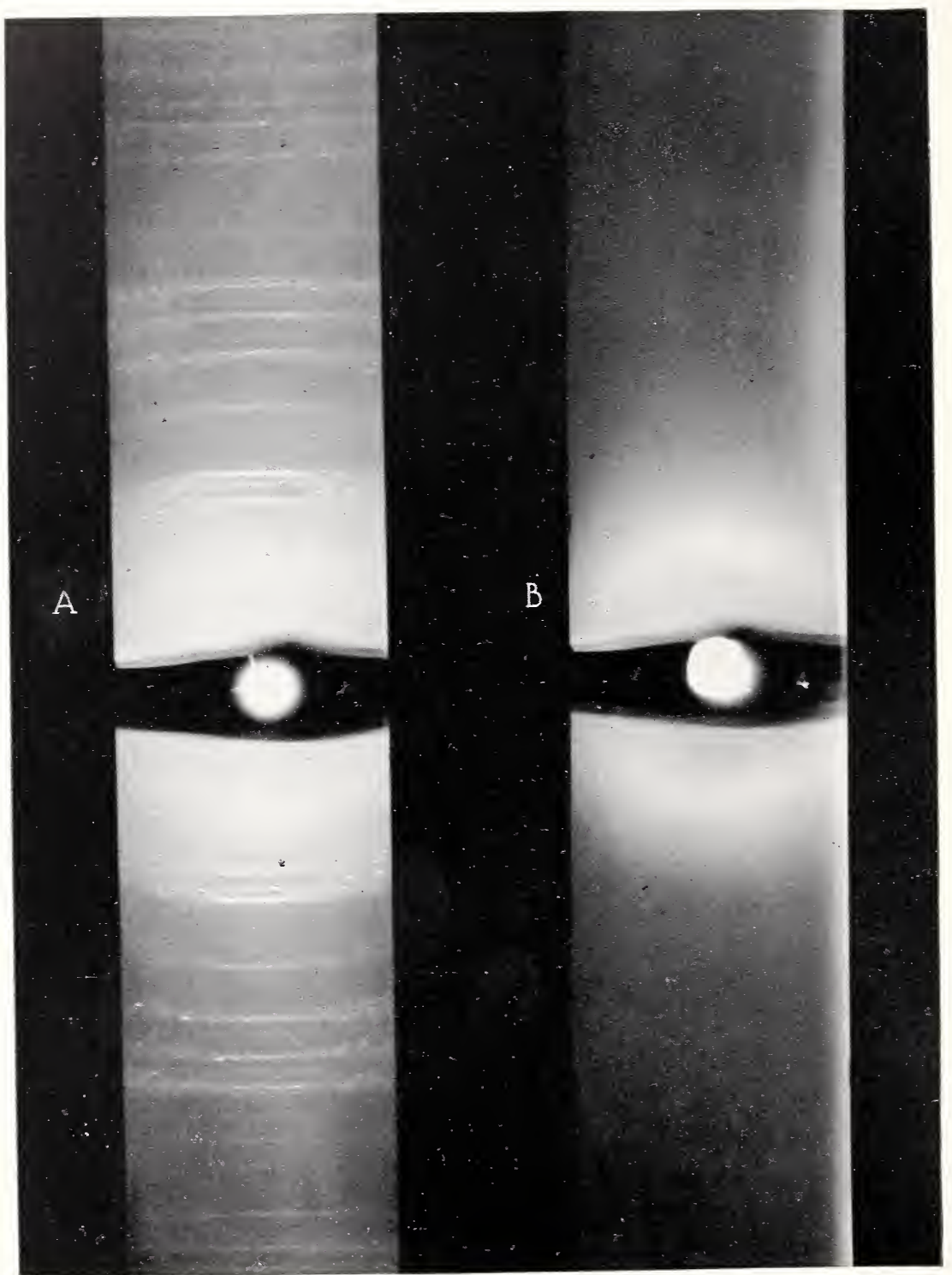

FIGURE 47.-X-ray diffraction patterns of dental cements.

$A$, zinc phosphate cement pattern which shows crystalline structure. B. silicate cement pattern which shows a nonerystalline structure. 
added to classes I and II cements to give antiseptic or germicidal properties. thus making them class III cements. The powder of silicate cement (class IV) is a complex mixture of aluminum silicates containing calcium, sodium, fluorides, phosphates and sometimes zinc and beryllium, as major constituents. The liquids of the cements of classes II, III, and IV are invariably aqueous solutions of phosphoric acid modified by the addition of zinc or aluminum salts, or both. The silicate cements differ from all other dental cements in that they are apparently noncrystalline, judging by their X-ray diffraction pattern (fig. 47).

\section{(a) ZINC OXYCHLORIDE CEMENT}

Zinc oxychloride cement is hardly ever used because it disintegrates very readily and the products of disintegration are corrosive. For these reasons the cement cannot be used in contact with soft tissues. Its use is limited to cavity linings and root canal fillings and even for these purposes another type of cement may be preferable.

\section{(b) ZINC OXIDE-EUGENOL CEMENTS}

The use of a mixture of zinc oxide and eugenol as a temporary cement and as a pulp-capping material dates from about 1894 [112].

The compositions of four commercial zinc oxide-eugenol cements [113] are given in table 29. The setting time, compressive strength, and resistance to disintegration of the four cements were determined (table 30) according to the methods of testing specified in the American Dental Association specification No. 9 for dental silicate cement (p. 204). It will be seen that cements I and III are better than the other two.

TABLE 29.-Zinc oxide-eugenol formulas a

\begin{tabular}{|c|c|}
\hline Powder & Liquid \\
\hline \multicolumn{2}{|c|}{ FORMULA I } \\
\hline $\begin{array}{l}\text { Zinc oxide } \\
\text { Zinc acetate }\end{array}$ & Eugenol \\
\hline \multicolumn{2}{|c|}{ FORMULA II } \\
\hline $\begin{array}{l}\text { Zinc oxide } \\
\text { White rosin } \\
\text { Zinc stearate } \\
\text { Zinc acetate }\end{array}$ & $\begin{array}{l}\text { Eugenol } \\
\text { Olive oil } \ldots 1\end{array}$ \\
\hline \multicolumn{2}{|c|}{ FORMULA III } \\
\hline $\begin{array}{l}\text { Zinc oxide } \\
\text { Hydrogenated rosin } \\
\text { Zinc acetate }\end{array}$ & $\begin{array}{l}\text { Eugenol } \\
\text { Olive oil }\end{array}$ \\
\hline \multicolumn{2}{|c|}{ FORMULA IV c } \\
\hline Thymol oxide & $\begin{array}{l}\text { Eugenol } \\
\text { Rosin } \\
\text { Menthol } \\
\text { Oleic acid } \\
\text { Phenol }\end{array}$ \\
\hline
\end{tabular}

a Reference [113].

b All percentages of both powder and liquid are by weight.

c Formula $1 \mathrm{~V}$ (liquid) was compounded as parts by weight. 
(c) COPPER PHOSPHATE CEMENTS

The two types of copper phosphate cement in most common use today are the so-called red and black copper cements, which derive their names from the presence of either red cuprous oxide or black cupric oxide. The copper phosphate cements are used chiefly for their antiseptic value. The properties of two copper cements when mixed to a consistency suitable for fillings are given in table 30 . The marked difference in the properties of the two cements may not be characteristic of all cements of these types.

\section{(d) ZINC PHOSPHATE CEMENTS}

Because of their greater importance the zinc phosphate cements will be treated in detail, as will the silicate cements in a later section.

TABLE 30.-Physical properties of different types of dental cements ${ }^{\text {a }}$

\begin{tabular}{|c|c|c|c|c|c|c|}
\hline Type & Chemical classification & $\begin{array}{l}\text { Powder- } \\
\text { liquid } \\
\text { ratio } \\
\text { (powder } \\
\text { in } 0.4 \mathrm{ml} \\
\text { of liquid) }\end{array}$ & $\begin{array}{l}\text { Time of } \\
\text { setting } \\
\text { at } 37^{\circ} \mathrm{C}\end{array}$ & $\begin{array}{l}\text { Compres- } \\
\text { sive } \\
\text { strength } \\
\text { at } 7 \text { days }\end{array}$ & Opacity at 7 days & $\begin{array}{l}\text { "Solu- } \\
\text { bility"a } \\
\text { and dis- } \\
\text { integration } \\
\text { during } \\
\text { first } 7 \\
\text { days }\end{array}$ \\
\hline I. & $\begin{array}{l}\text { Formula 1, zinc oxide- } \\
\text { eugenol. }\end{array}$ & ${ }^{g} 2.2$ & $\begin{array}{r}\text { Minutes } \\
5.5\end{array}$ & $\begin{array}{r}l b / \text { in }^{2} \\
2,000\end{array}$ & $\begin{array}{c}C_{0.70} \\
\text { Practically } \\
\text { opaque. }\end{array}$ & $\begin{array}{l}\text { Percent } \\
\quad 0.1\end{array}$ \\
\hline $\mathrm{I}_{\ldots-\ldots}$ & $\begin{array}{l}\text { Formula } 2, \text { zinc oxide- } \\
\text { eugenol. }\end{array}$ & 6.0 & 19.0 & 2,000 & $\ldots$ do $\ldots \ldots \ldots \ldots . . . . . . .4$ & .1 \\
\hline I & $\begin{array}{l}\text { Formula } 3 \text {, zinc oxide- } \\
\text { eugenol. }\end{array}$ & 8.5 & 9.0 & 5,500 & $\ldots$ do_..... & .02 \\
\hline I & $\begin{array}{l}\text { Formula } 4 \text {, zinc oxide- } \\
\text { eugenol. }\end{array}$ & 2.0 & $>30$ & Not set & _... do & .1 \\
\hline II $\ldots . .$. & Red ropper phosphate & 1.8 & 3.5 & 21,000 & $\ldots$ do & .05 \\
\hline II & Black copper phosphate & 1. 4 & 5.5 & 9,000 & $\ldots$ do $\ldots . . . . . .$. & 3.7 \\
\hline
\end{tabular}

a Methods used are described in ADA specification No. 9 for dental silicate cement (p. 204).

Powder.-In table 31 it will be seen that the powders can be roughly grouped into three classes depending upon composition. Class I are almost 100 percent zinc oxide. In class II zinc and magnesium oxides are in the approximate ratio of 9 to 1 . The third class is more complex as here, in addition to the zinc and magnesium oxides, there are other constituents such as barium sulfate, bismuth oxide, silica, etc. It is a significant fact that on the whole cements of class II have superior physical qualities.

It might be well to point out that chemical composition in itself is not sufficient to establish definitely the properties of a cement. The fineness of and treatment accorded the powder are almost as significant as the composition.

Liquid.-The liquids are always composed of phosphoric acid and aluminum phosphate. In most instances zinc phosphate is present (table 32). The phosphates in solution in the liquid temper the reaction between the powder and liquid during mixing and to a large extent control the rate of reaction. The water content of each of the liquids is within the range $33 \pm 5$ percent. 
TABLE 31.-Composition of zinc phosphate cement powders

[Percentage by weight]

\begin{tabular}{|c|c|c|c|c|c|c|}
\hline Sample & $\mathrm{ZnO}$ & $\mathrm{MgO}$ & $\mathrm{SiO}_{2}$ & $\mathrm{R}_{2} \mathrm{O}_{3}$ & $\mathrm{Bi}_{2} \mathrm{O}_{3}$ & Miscellaneous \\
\hline $\begin{array}{l}\mathbf{A}_{1} \\
\mathrm{~B}_{\mathrm{C}} \\
\mathrm{C} \\
\mathrm{D}\end{array}$ & $\begin{array}{r}100.0 \\
99.7 \\
98.0 \\
99.4\end{array}$ & 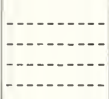 & $\begin{array}{c}0.05 \\
.1 \\
.6\end{array}$ & $\begin{array}{c}0.05 \\
.1 \\
.1\end{array}$ & $\begin{array}{r}1.9 \\
.04\end{array}$ & $\mathrm{CaO}, 0.1$ \\
\hline $\begin{array}{l}\mathrm{E}_{\mathrm{H}} \\
\mathrm{F} \\
\mathrm{G} \\
\mathrm{H} \\
\mathrm{I} \\
\mathrm{I} \\
\mathrm{J}_{\mathrm{K}} \\
\mathrm{K}\end{array}$ & $\begin{array}{l}92.4 \\
90.3 \\
90.2 \\
89.9 \\
89.5 \\
89.3 \\
88.0\end{array}$ & $\begin{array}{l}7.5 \\
8.2 \\
9.4 \\
9.1 \\
9.4 \\
9.4 \\
9.4\end{array}$ & $\begin{array}{r}.1 \\
1.4 \\
.4 \\
.4 \\
.3 \\
.3 \\
.8\end{array}$ & $\begin{array}{l}.06 \\
.1 \\
.07 \\
.5 \\
.1 \\
-1 .-\end{array}$ & 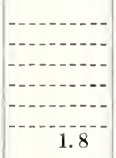 & $\begin{array}{l}\mathrm{BaCrO}_{4}, 0.8 \\
\mathrm{CuO}, 0.02 ; \mathrm{BaCrO}_{4}, 1.0\end{array}$ \\
\hline 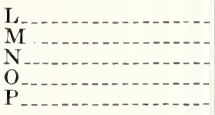 & $\begin{array}{l}89.1 \\
82.2 \\
83.1 \\
84.0 \\
74.9\end{array}$ & $\begin{array}{r}4.0 \\
9.0 \\
7.2 \\
7.2 \\
13.0\end{array}$ & $\begin{array}{r}1.8 \\
3.0 \\
.1 \\
4.9 \\
1.3\end{array}$ & $\begin{array}{l}.5 \\
.9 \\
.04 \\
1.0 \\
2.6\end{array}$ & 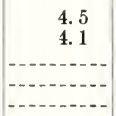 & $\begin{array}{l}\mathrm{CuO}, 0.8 \\
\mathrm{BaSO}_{4}, 8.2 ; \mathrm{BaO}, 1.3 \\
\mathrm{CaF}_{2}, 2.7 \\
\mathrm{CaO}, 2.2 ; \mathrm{B}_{2} \mathrm{O}_{3}, 5.1\end{array}$ \\
\hline
\end{tabular}

Cement.-What compounds are formed as a result of the reaction between the powder and liquid is not definitely known, but they are generally considered to be essentially one or more of the zinc phosphates. They are crystalline in structure, as shown by the X-ray diffraction pattern (fig. 47).

TABLE 32.-Composition of zinc phosphate cement liquids

[Percentage by weight]

\begin{tabular}{|c|c|c|c|c|c|c|c|c|}
\hline \multirow{2}{*}{ Sample } & \multicolumn{4}{|c|}{ Analysis } & \multicolumn{4}{|c|}{ Calculations } \\
\hline & $\mathrm{PO}_{4}$ & Al & $\mathrm{Zn}$ & $\mathrm{Mg}$ & $\begin{array}{c}\text { Free } \\
\mathrm{H}_{3} \mathrm{PO}_{4}\end{array}$ & $\underset{\mathrm{H}_{3} \mathrm{PO}_{4}}{\text { Combined }}$ & $\begin{array}{c}\text { Total } \\
\mathrm{H}_{3} \mathrm{PO}_{4}\end{array}$ & $\begin{array}{l}\text { Phos- } \\
\text { phate }\end{array}$ \\
\hline $\begin{array}{l}\mathrm{A} \\
\mathrm{B} \\
\mathrm{C} \\
\mathrm{D}\end{array}$ & $\begin{array}{l}57.4 \\
55.2 \\
64.3 \\
57.3\end{array}$ & $\begin{array}{l}1.8 \\
3.4 \\
2.7 \\
2.1\end{array}$ & $\begin{array}{r}10.0 \\
3.1 \\
10.0\end{array}$ & & $\begin{array}{l}42.8 \\
41.6 \\
56.8 \\
41.7\end{array}$ & $\begin{array}{r}16.6 \\
15.5 \\
9.8 \\
17.6\end{array}$ & $\begin{array}{l}59.4 \\
57.1 \\
66.6 \\
59.3\end{array}$ & $\begin{array}{l}27.8 \\
21.5 \\
12.2 \\
29 .\end{array}$ \\
\hline $\begin{array}{l}\mathrm{E} \\
\mathrm{F} \\
\mathrm{G} \\
\mathrm{H} \\
\mathrm{I} \\
\mathrm{J} \\
\mathrm{K}\end{array}$ & $\begin{array}{l}64.6 \\
52.6 \\
59.9 \\
59.7 \\
57.9 \\
61.1 \\
64.0\end{array}$ & $\begin{array}{l}2.7 \\
2.5 \\
2.9 \\
2.1 \\
2.8 \\
2.8 \\
3.2\end{array}$ & \begin{tabular}{l}
1.6 \\
7.1 \\
2.0 \\
4.1 \\
\hdashline..-
\end{tabular} & 0.3 & $\begin{array}{l}55.5 \\
38.2 \\
49.4 \\
50.1 \\
48.9 \\
53.1 \\
54.7\end{array}$ & $\begin{array}{l}11.4 \\
16.2 \\
12.6 \\
11.7 \\
11.0 \\
10.2 \\
11.6\end{array}$ & $\begin{array}{l}66.9 \\
54.4 \\
62.0 \\
61.8 \\
59.9 \\
63.3 \\
66.3\end{array}$ & $\begin{array}{l}15.4 \\
25.3 \\
17 . \\
17 . \\
13 . \\
12 . \\
14 .\end{array}$ \\
\hline $\begin{array}{l}\mathrm{L} \\
\mathrm{M} \\
\mathrm{N} \\
\mathrm{O} \\
\mathrm{P}\end{array}$ & $\begin{array}{l}64.2 \\
67.2 \\
64.9 \\
54.6 \\
53.4\end{array}$ & $\begin{array}{l}2.7 \\
3.0 \\
2.9 \\
2.3 \\
2.7\end{array}$ & \begin{tabular}{c}
.9 \\
\hdashline 10.3 \\
\hdashline..--
\end{tabular} & & $\begin{array}{l}55.8 \\
58.7 \\
56.6 \\
37.8 \\
45.5\end{array}$ & $\begin{array}{r}10.7 \\
10.9 \\
10.6 \\
18.7 \\
9.8\end{array}$ & $\begin{array}{l}66.5 \\
69.6 \\
67.2 \\
56.5 \\
55.3\end{array}$ & $\begin{array}{l}14 . \\
13 . \\
13 . \\
30 . \\
12 .\end{array}$ \\
\hline
\end{tabular}

Consistency.- It is common knowledge among the users of cements that, to produce mixes of the same consistency, the amount of powder required for a given quantity of liquid will vary with different cements. If the relative merits of cements are to be compared satisfactorily, it is necessary that all the test specimens be prepared from mixes of the same consistency.

The method for measuring consistency is a modified "shump" test in which a definite quantity $(0.5 \mathrm{ml})$ of mixed but unset cement is pressed between two flat plates under a constant load (120 g) for a definite time $(10 \mathrm{~min}$.). The soft cement slumps or spreads into a disk. The diameter of the disk is used as a measure of the consistency. The apparatus used to measure consistency is shown in figure 48 . 
The method of determining the consistency is as follows: Trial amounts of powder are mixed with $0.5 \mathrm{ml}$ of liquid. One-half cubic centimeter of the soft cement is deposited on a slab. A flat glass plate $(20 \mathrm{~g})$ and a weight $(100 \mathrm{~g})$ are placed (parallel to the bottom plate) upon the cement 3 minutes after the mixing is started. The soft cement spreads out into a disk between the glass plates. Ten minutes after the mixing is started, the diameters of the disk are measured. Different consistencies of mixed cement produce disks of varying sizes. This relationship between the consistencies and powder-liquid ratios on cements $F, L$, and $K$ is shown in figure 49 .

The standard testing consistency which was adopted (fig. 49) is the average consistency used by approximately 200 practicing dentists
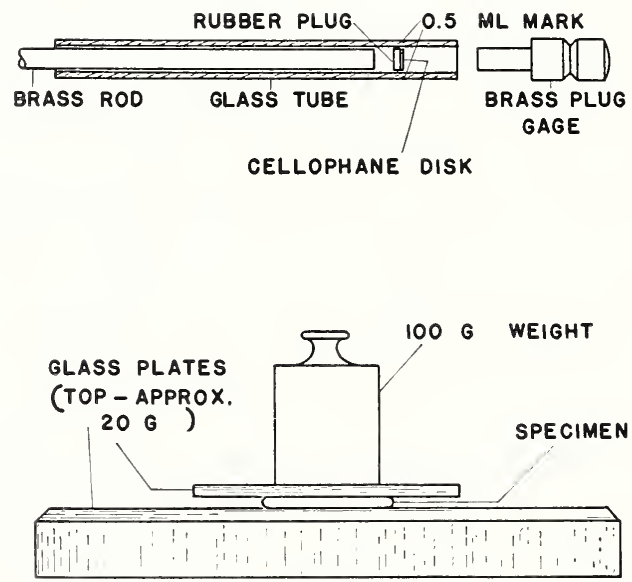

FIGURE 48.-A pparatus for consistency tests on zinc phosphate cements.

who reported the amounts of powder which they were mixing in a definite quantity $(0.5 \mathrm{ml})$ of liquid.

Time of setting. - The setting time is very important in the practical use of the cements. Sufficient time must elapse between the mixing and setting of the cement to permit the placement of the appliance or restoration.

The setting time of any dental cement can be conveniently determined by filling a small brass ring with the mixed but unset cement and applying a Gillmore needle to the cement surface. When the needle fails to make an indentation on the surface, the cement is set. The setting time is the interval between the beginning of the mixing and the completion of the initial hardening.

A reasonable setting time would be $7 \pm 4$ minutes at mouth temperature (table 33, column 3). Practically all of the currently used cements come within this range. The time of setting can be decreased by using a warm slab, by incorporating the powder rapidly (table 34 ), by increasing the amount of powder in the mix (table 35), by grinding the powder finer, or by increasing the amount of water in the liquid (table 36). The time of setting may be increased by using a mix of thinner consistency, by mixing on a cold slab, by incorporating the powder slowly and over a long mixing time, by using a coarser powder, or by decreasing the amount of water in the liquid. 


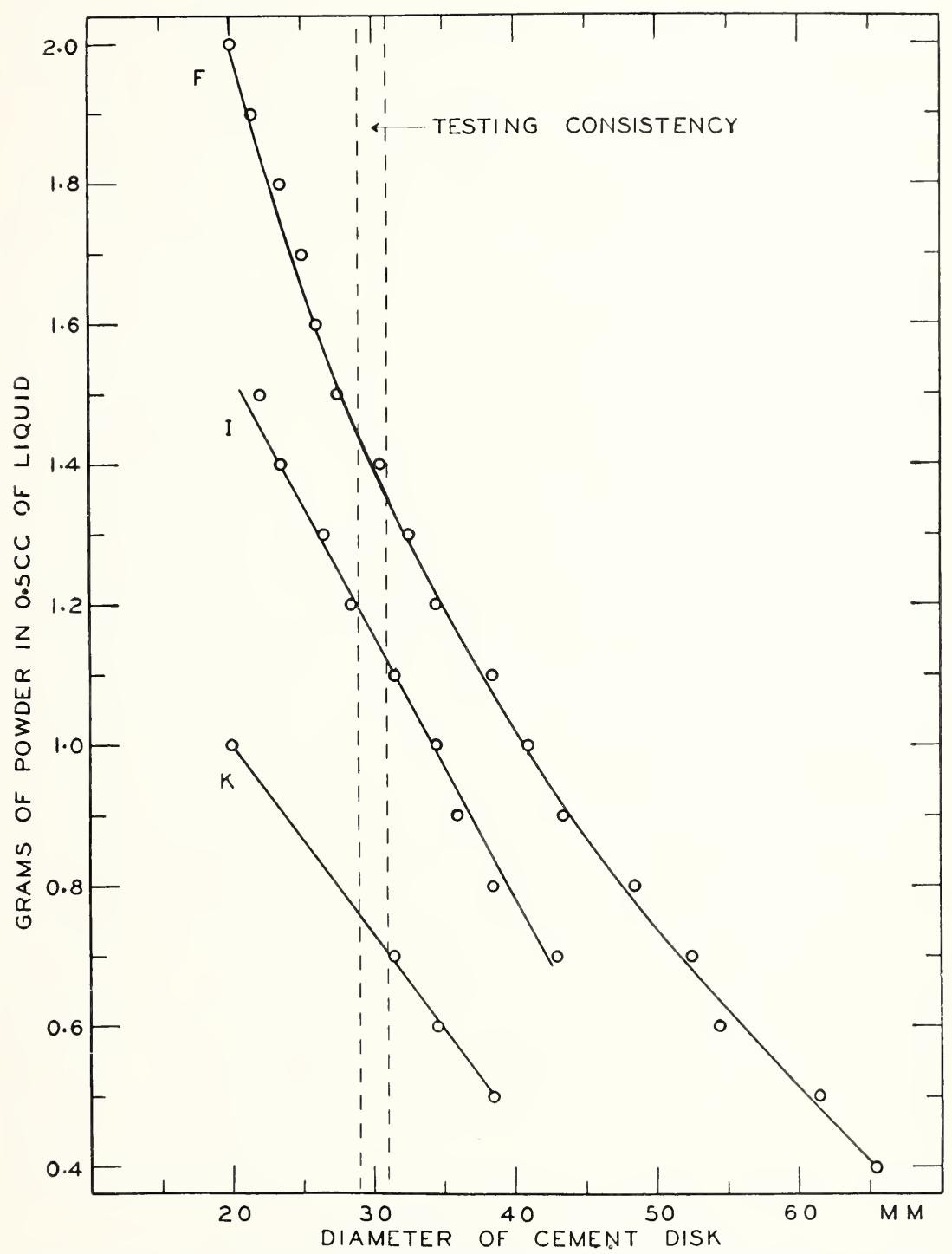

FIGURE 49.-Relationship between consistency and powder-liquid ratios on zinc phosphate cements $F, I$, and $K$ (compositions are in tables 31 and 32). 
TABLE 33.-Physical properties of certified zinc phosphate cements $\mathrm{s}$

\begin{tabular}{|c|c|c|c|c|c|}
\hline Cement & $\begin{array}{l}\text { Powder in } \\
0.5 \mathrm{ml} \text { of } \\
\text { liquid to } \\
\text { produce } \\
\text { standard } \\
\text { consistency }\end{array}$ & $\begin{array}{c}\text { Setting } \\
\text { time at } \\
\text { mouth } \\
\text { tempera- } \\
\text { ture }\end{array}$ & $\begin{array}{l}\text { Compres- } \\
\text { sire } \\
\text { strength } \\
\text { at } 1 \text { week }\end{array}$ & $\begin{array}{c}\text { Film } \\
\text { thickness }\end{array}$ & $\begin{array}{l}\text { "Solubil- } \\
\text { it } 5 " \text { and } \\
\text { disintegra- } \\
\text { tion during } \\
\text { first } 7 \text { days }\end{array}$ \\
\hline 1 & 2 & 3 & 4 & 5 & 6 \\
\hline 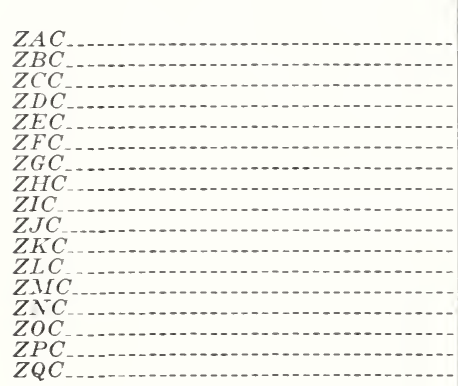 & $\begin{array}{r}g \\
1.20 \\
1.00 \\
1.00 \\
1.00 \\
0.95 \\
1.00 \\
0.95 \\
.85 \\
1.30 \\
1.30 \\
1.30 \\
0.95 \\
1.20 \\
1.25 \\
1.35 \\
1.20 \\
1.25\end{array}$ & $\begin{array}{r}\text { Minutes } \\
8 \\
6 \\
8 \\
8 \\
9 \\
7 \\
8 \\
6 \\
10 \\
9 \\
10 \\
10 \\
8 \\
7 \\
7 \\
8 \\
7\end{array}$ & $\begin{array}{l}\text { lb/in. }{ }^{2} \\
12,000 \\
13.500 \\
12.500 \\
12,500 \\
12,500 \\
13,500 \\
12.000 \\
12,000 \\
12,500 \\
13,500 \\
13,000 \\
12,000 \\
15,500 \\
12,000 \\
12,500 \\
14,500 \\
13,500\end{array}$ & $\begin{array}{r}\text { Microns } \\
40 \\
30 \\
25 \\
30 \\
35 \\
30 \\
40 \\
40 \\
30 \\
25 \\
25 \\
40 \\
40 \\
40 \\
35 \\
40 \\
35\end{array}$ & $\begin{array}{r}\text { Percent } \\
0.20 \\
.10 \\
.10 \\
.15 \\
.15 \\
.10 \\
.05 \\
.05 \\
.20 \\
.10 \\
.20 \\
.10 \\
.15 \\
.05 \\
.05 \\
.05 \\
.05\end{array}$ \\
\hline
\end{tabular}

- Methods used are described in Federal specification UC211 (p. 191).

TABLE 34.-Effect of rate of addition of powder on setting time

\begin{tabular}{|c|c|c|c|c|c|}
\hline \multicolumn{2}{|r|}{ Powder } & \multirow{2}{*}{$\begin{array}{c}\text { Mixing } \\
\text { time }\end{array}$} & \multicolumn{3}{|c|}{$\begin{array}{l}\text { Setting time of cements }\left(70^{\circ} \mathrm{F} \text { and }\right. \\
65 \text { percent relative humidity) }\end{array}$} \\
\hline Portions & Rate of addition & & $C$ & $I$ & $K$ \\
\hline 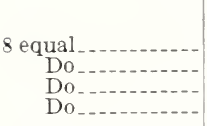 & $\begin{array}{l}15 \text {-second intrerals } \\
10-\text { second intervals } \\
5 \text {-second interrals } \\
3 \text {-second intervals }\end{array}$ & $\begin{array}{r}\text { Minutes } \\
2.0 \\
1.5 \\
1.0 \\
0.5\end{array}$ & $\begin{array}{r}\text { Minutes } \\
31 \\
25 \\
14 \\
9\end{array}$ & $\begin{array}{r}\text { Minutes } \\
17 \\
14 \\
10 \\
7\end{array}$ & $\begin{array}{r}\text { Minutes } \\
34 \\
30 \\
24 \\
9\end{array}$ \\
\hline
\end{tabular}

TABLE 35.-Effect of powder-liquid ratio on setting time of cements

\begin{tabular}{|c|c|c|c|c|c|c|}
\hline \multirow{2}{*}{$\begin{array}{l}\text { Amount of } \\
\text { powder }\end{array}$} & \multirow{2}{*}{$\begin{array}{l}\text { Amount of } \\
\text { liquid }\end{array}$} & \multicolumn{5}{|c|}{ Setting time of cements- } \\
\hline & & $C$ & $F$ & $I$ & $K$ & $M$ \\
\hline $\begin{array}{l}9 \\
1 \\
1 \\
1\end{array}$ & $\begin{array}{c}m l \\
0.25 \\
.50 \\
1.00\end{array}$ & $\begin{array}{c}7 \\
21 \\
120^{3}\end{array}$ & $\begin{array}{r}7 \\
15 \\
26\end{array}$ & $\begin{array}{r}8 \\
16 \\
29\end{array}$ & $\begin{array}{c}5 \\
16 \\
120^{\mathrm{s}}\end{array}$ & $\begin{array}{c}7 \\
12 \\
100^{\circ}\end{array}$ \\
\hline
\end{tabular}

a Cements were not completely set.

TABLE 36.-Effect of dilutions of liquids on setting time of cement

\begin{tabular}{|c|c|c|c|c|c|}
\hline \multirow{2}{*}{$\begin{array}{l}\text { Dilution } \\
\text { by volume }\end{array}$} & \multicolumn{5}{|c|}{$\begin{array}{c}\text { Setting time of cement }\left(70^{\circ} \mathrm{F} \text { and } 65 \text { percent relative }\right. \\
\text { humidity) }\end{array}$} \\
\hline & $C$ & $F$ & $I$ & $K$ & $M$ \\
\hline $\begin{array}{r}\% \\
0 \\
10\end{array}$ & $\begin{array}{c}\text { Minutes } \\
21 \\
8\end{array}$ & $\begin{array}{c}\text { Minutes } \\
15 \\
12\end{array}$ & $\begin{array}{c}\text { Minutes } \\
16 \\
11\end{array}$ & $\begin{array}{c}\text { Minutes } \\
16 \\
10\end{array}$ & $\begin{array}{c}\text { Minutes } \\
12 \\
9\end{array}$ \\
\hline
\end{tabular}


In the older zinc phosphate cements the setting time would often vary with the color because the colors were obtained by subjecting the powder to different degrees of calcination.

Lltimate compressive strength.-The compressive strengths of representative zinc phosphate cements, shown in table 33, column 4, were obtained by the method outlined in the Federal specification (page 191).

When considering the strength of these cements it is pertinent also to consider the strength of some of the tooth tissues. The compressive strength of human dentine has been determined as about 30,000 $\mathrm{lb} / \mathrm{in}^{2}$. For different types of teeth and with different orientations of the specimen this value may vary considerably. The rod-like structure of enamel makes it difficult to prepare test specimens which will give dependable data on its strength. However, from comparisons of the hardness of dentine and enamel it appears safe to assume that the ultimate strength of sound, strong enamel may exceed $100,000 \mathrm{lb} / \mathrm{in}^{2}$. An approximate crushing strength of 13,000 pounds for a representative zinc phosphate cement is therefore only two-fifths that of dentine and less than one-sixth that estimated for enamel. Manifestly these cements must not be expected to restore lost tooth structures to the degree now possible by amalgams which have crushing strengths around $45,000 \mathrm{lb} / \mathrm{in}^{2}$.

Cements when properly protected by gold inlays, crowns and similar restorations are quite satisfactory and may never fail from lack of strength. The compressive strength varies with the powderliquid ratio (table 37 ), with time (table 38 ), with the media in which the cement specimens are stored (table 39), and with the color especially if the colors are obtained by calcining the powder differently (table 40). The compressive strengths of current cements are shown in table 33 , column 4 .

TABLE 37.-Effect of powder-liquid ratio on compressive strength of zinc phosphate cements

\begin{tabular}{|c|c|c|c|}
\hline \multirow{2}{*}{ Powder } & \multirow{2}{*}{ Liquid } & \multicolumn{2}{|c|}{ Compressive strength } \\
\hline & & Cement $F^{a}$ & Cement $I^{b}$ \\
\hline $\begin{array}{l}g \\
0.50 \\
.75 \\
1.00 \\
1.25 \\
1.50 \\
1.75 \\
2.00 \\
2.50 \\
3.00\end{array}$ & $\begin{array}{c}m l \\
0.50 \\
.50 \\
.50 \\
.50 \\
.50 \\
.50 \\
.50 \\
.50 \\
.50\end{array}$ & $\begin{array}{r}l b / i n .{ }^{2} \\
5,500 \\
8,000 \\
9,000 \\
13,000 \\
14,500 \\
14,000 \\
15,000 \\
16,000 \\
16,500\end{array}$ & $\begin{array}{l}l b / \text { in. } .^{2} \\
\\
12,000 \\
13,500 \\
18,000 \\
17,500 \\
19,000 \\
19,500 \\
19,000\end{array}$ \\
\hline
\end{tabular}

a Specimens immersed in distilled water for 24 hours.

$b$ Specimens immersed in distilled water for 2 weeks. 
$\mathrm{T}_{\mathrm{ABLE}}$ 38.-Compressive strength of zinc phosphate cements with time

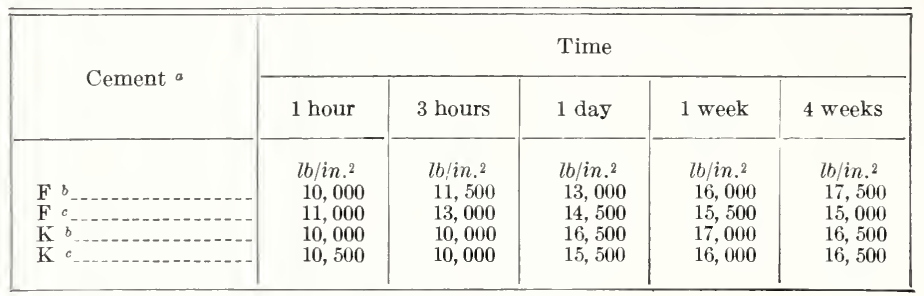

a Mixes made with $1.50 \mathrm{~g}$ of powder to $0.50 \mathrm{ml}$ of liquid.

$b$ Specimens were immersed in liquid petrolatum.

$c$ Specimens were immersed in distilled water.

TABLE 39.-Compressive strength of zinc phosphate cements

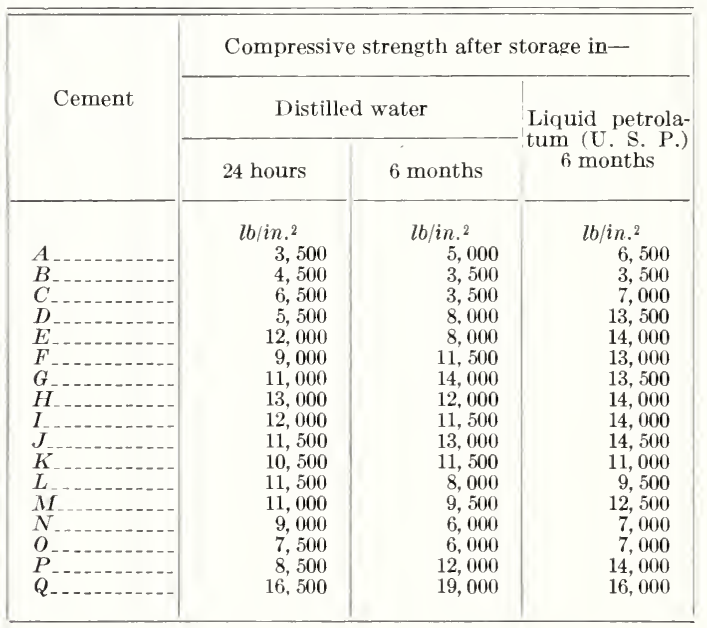

TABLE 40.-Compressive strength of zinc phosphate cements with color

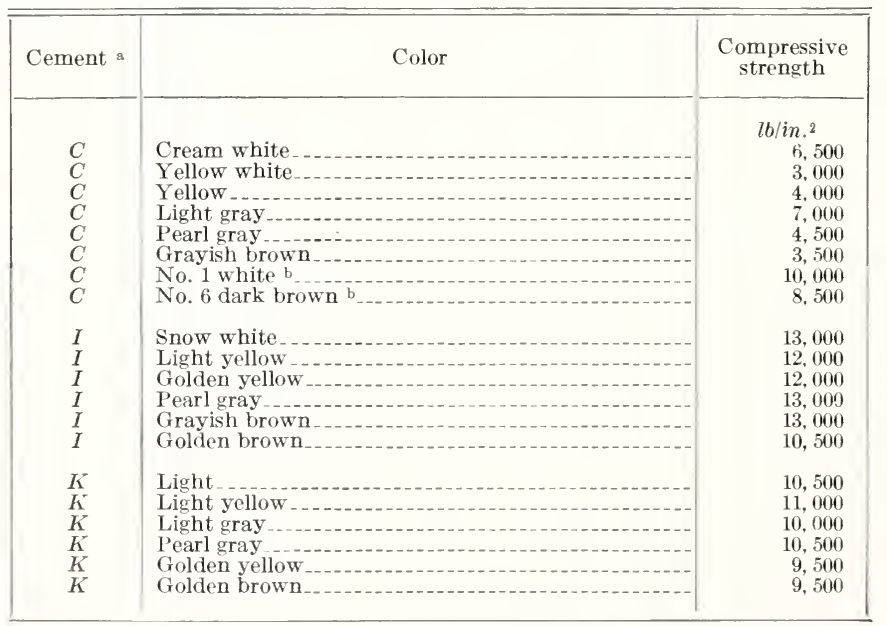

a Specimens immersed in distilled water for 24 hours.

b Special inlay cement of the same brand. 
"Solubility" and Disintegration.-One of the main defects of zinc phosphate cement is its solubility in the mouth. To measure the relative rate of disintegration the simple test described on page 192 was used. Data on currently used cements are shown in table 33, column 6. Earlier surveys of cements showed disintegration up to 14 percent. Fortunately cements of this kind are not extensively used today; in fact, they are disappearing from the market.

Thermal Conductivity.-The dental cements, because of their low thermal conductivity, can be used to prevent or decrease the thermal shock which occurs when metallic fillings are placed near the pulp. The transmission of heat by fillings may not only cause discomfort but may result in serious involvement of the pulp. Tests made at this Bureau on the conductivity of dental cements showed them to be between one one-hundredth and one two-hundredths as conductive as alloys akin to those used in making inlays [132]. A cement lining of sufficient thickness in a deep cavity is therefore an effective thermal insulator giving definite protection to the pulp. Table 41 lists values on thermal conductivity which will be of interest to dentists.

TABLE 41.-Thermal conductivity

\begin{tabular}{|c|c|}
\hline Material & $\begin{array}{c}\text { Thermal } \\
\text { Conductivity a }\end{array}$ \\
\hline $\begin{array}{l}\text { Gold } \\
\text { Platinum } \\
\text { Gold alloy (10 percent platinum) } \\
\text { Gold alloy (12 percent copper) } \\
\text { Stainless steel (18 chromium, } 8 \text { nickel) } \\
\text { Glass (window) } \\
\text { Cement (zinc phosphate) [132] } \\
\text { Hard rubber } \\
\text { Cork board }\end{array}$ & $\begin{array}{c}\text { Milliwatts/cm }{ }^{2} \\
{ }^{\circ} \mathrm{C} / \mathrm{cm} \\
2940.0 \\
696.0 \\
690.0 \\
600.0 \\
145.0 \\
10.5 \\
4.8 \\
1.6 \\
0.4\end{array}$ \\
\hline
\end{tabular}

a Values other than [132] and [133] were taken from Int. Critical Tables.

Adhesiveness.-Claims for adhesiveness of cements are not uncommon. Tests of the adhesiveness of a cement for uniting two flat sections of teeth showed that its adhesiveness was negligible. The set cement separated from the sections before the test could be completed. In a more carefully planned test two blocks of ivory were inserted in the ends of two brass rods $(B)$, as shown in figure 50. These ivory blocks were surfaced flat and perpendicular to the axis of the rods. The rods were inserted in the tube $(A)$ and the two ivory surfaces were cemented together. The tube protected the rods and cement during setting and made it possible to apply tensile forces without bending components. After hardening, the cement, with the tube and rod assembly, was immersed in water for 24 hours. The bond between the ivory and cement was so weak that the cement came loose before an appreciable tensile force could be applied. A further test was made using a truncated cone fitted to a cavity $(C)$ of figure 50 . This form, having a maximum diameter of 10 millimeters, was selected as representative of a crown restoration. The length or depth of the cone was 15 millimeters. These rods were placed in the guide $(A)$ and cemented. After 24 hours in water, a 1,300-pound tension was necessary to separate the cone. A control test was then made with only 


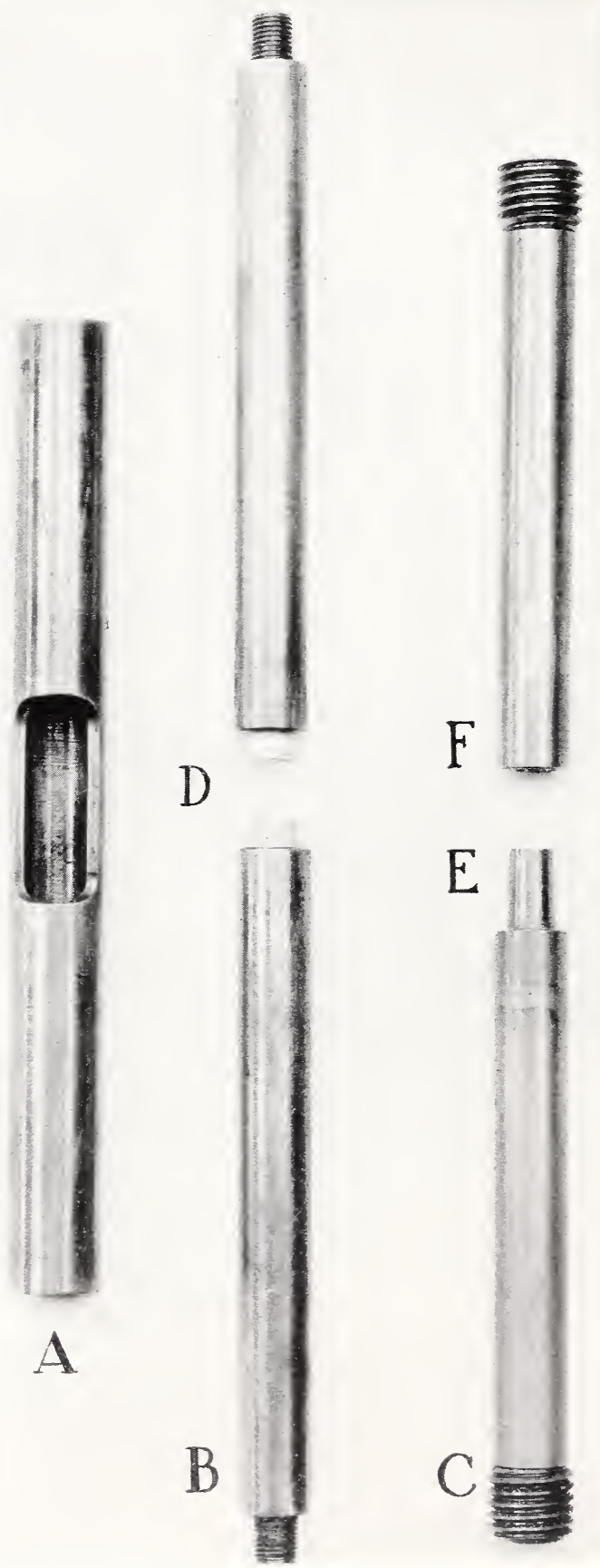

FIGURE 50.-Apparatus used in determining the adhesiveness of cements. $A$, assembly sleeve which was used in alining the parts of $B$ and $C . \quad D$, ivory cylinders, between which film of cement was placed. $E$, metal truncated cone which was cemented into tube, $F$. 
cement powder and water to unite the cone. About 1,300 pounds was necessary to separate this combination. From these experiments it appears that the adhesion of cement is indeed very small and of little practical significance. The forces holding restorations are mechanical in their nature and depend upon either the mechanical interlocking of material in roughened surfaces or upon the frictional resistance of surfaces between which irregular sand-like particles have been placed. This indicates that the difficulty encountered in removing an inlay or appliance is not the result of an adhesiveness of the cement used. It is rather a function of the crushing strength of sections of the cement at the undercut areas between the surface of the tooth and the surface of the restoration.

$\mathrm{T}_{\mathrm{ABLE}}$ 42.-Weight changes in zinc phosphate cement liquids after exposure to air

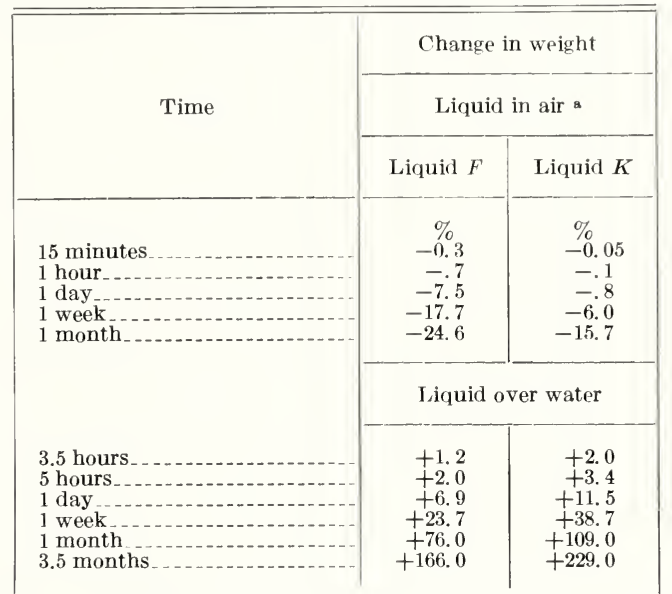

a Temperature varied between $70^{\circ}$ and $80^{\circ} \mathrm{F}$, relative humidity, between 25 and 50 percent.

Contact with water.-Minute traces of moisture in a cavity should have no serious effects upon a zinc phosphate or silicate cement. Extreme desiccation of a cavity may cause more injury than could be caused by a trace of moisture left in it. The changes caused by the trace of water abstracted from a cavity will be confined to a thin bottom layer of cement and will be covered with additional layers of normal cement. The effects of moisture at the surface layer of cement, prior to complete set is, however, a serious matter. The phosphoric acid of dental cements has the property of giving off water or absorbing water from the surroundings depending upon the concentration of the phosphoric acid in the cement. Plastic cement, in contact with water prior to the completion of the chemical reactions, will not develop a smooth, hard, glossy surface. The water absorbed by the phosphoric acid causes it to take on a dull, soft, and relatively soluble surface layer. Claims that any brand of cement (either zinc phosphate or silicate) will set in contact with water are quite true but they should be accepted with the reservations noted above.

It is assumed that each manufacturer has adjusted the water content of his liquid and has specified the exact ratio of powder to liquid to secure the maximum in desirable properties including a minimum 
solubility. Exposed liquids in unstoppered bottles or spread on mixing slabs will abstract moisture from the air if the humidity is high. Most of the liquids lose water if exposed to air of low humidity. Therefore the safe procedure is to keep the bottle tightly stoppered at all times except when liquid is being withdrawn. Table 42 shows what mas happen to some of these liquids when exposed to the air. This subject will be further dereloped in the section on
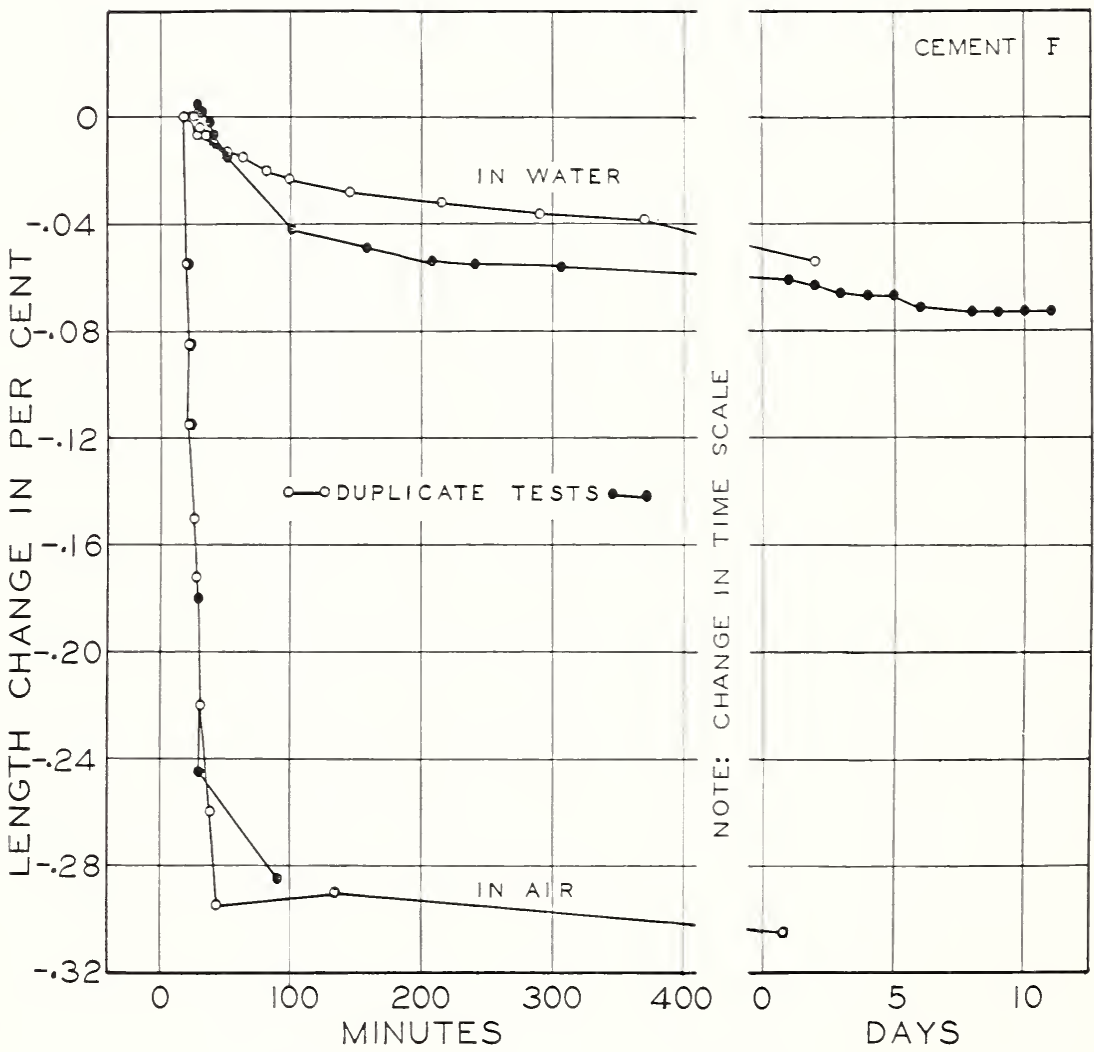

TIME

FIGCRE 51.-Dimensional change of zinc phosphate cement $F$ during setting (composition is in tables 31 and 32).

silicate cements (page 131). The set cement, howerer, must be kept moist or it will shrink and crack.

Temperature rise.-The increase in temperature produced by the chemical reactions between the powder and liquid during mixing and setting depend upon the rate of reaction of the phosphoric acid, the size of the mix and the abstraction of heat by the mixing slab. Zinc oxide powder and concentrated phosphoric acid produce rather violent reactions and intense heat when mixed. The partially neutralized acid used in mixing some of these cements may, in a cylindrical specimen, 1/2-inch long and $1 / 4$-inch in diameter, supported in a hard 
rubber mold having a $7 / 16^{-i n c h}$ wall, cause a rise of as much as $13^{\circ} \mathrm{C}$ $\left(23^{\circ} \mathrm{F}\right)$ above the surrounding temperature. This amount of cement, if spread extensively over a chilled slab, would be several degrees below mouth temperature when carried to the cavity or applied to the restoration. The rise in temperature which is manifest in from 3 to 8 minutes under such mixing technics should not be injurious to pulps.

Shrinkage.- It is not difficult to show that dental cements shrink. A glass tube filled with cement and placed in a colored liquid after the cement has set will show penetration of the color between the cement and wall of the tube.

Figure 51 displays the typical behavior of a specimen of zinc phosphate cement tested in the amalgam interferometer. The first specimen was kept under water during the test. 'The shrinkage is much greater when the cement is exposed to the air. While it is true that all of the zinc phosphate cements which were tested shrank, it is fortunate that the shrinkage is so small that it may not be of major importance. For instance let it be assumed that the cement line on an inlay is as large as 0.2 millimeter and the shrinkage is 0.1 percent. 'Then the actual shrinkage is only 0.2 micron. Hence no great consideration was given to this factor. However, the subject of dimensional changes in dental cements will be given a more thorough treatment in a later section when tests on the silicate cements are reported (page 124). Equipment and methods for measuring dimensional changes will be explained more completely.

Film thickness. - Many inlays are cast so accurately that a cement containing large particles would prevent their proper seating. 'Therefore the thickness of the film of cement between the inlay and the cavity walls is of practical importance. The method of measuring the film thickness outlined in the specification on page 192 appears to be consistent and satisfactory for present needs.

One of the factors affected by the size of the powder particles is the film thickness. When examined microscopically some of the cements were found to have a uniformly fine-grained powder (cement $I$, fig. $52)$. Others were mixtures of fine and coarse grains (cement $K$, fig. 52). 'The large particles of cement $P$, figure 51, were obtained by water flotation. There is a general trend indicating that the film thickness is based upon the particle size of the powder. This trend is termed general as the irregularities of the particles, the uncertainties of orientation of the particle selected, and other limitations connected with such measurements introduce an element of uncertainty in the results obtained. It appears safe to say that few powders will show particles having any linear dimension greater than 75 microns. 'This maximum size would appear on first thought to be serious when attempting to seat a close-fitting inlay having very slight tapers.

Two factors tend to mitigate these difficulties. 'The larger particles may be fractured sufficiently in grinding to cause them to crush readily upon the application of pressure upon the inlay. 'The attack by the phosphoric acid reduces these particles and removes the sharp corners very effectively. In fact, from experiments made to determine the nearness to which two flat glass plates can be made to approach each other when separated only by a quantity of freshly mixed cement, it was found that the separation was much less than the maximum particle dimension. From these tests it was found that 
a cement made from a powder having one or more particles apparently 75 microns in dimension caused a separation of less than 35 microns.

The specification limitation on film thickness (p. 192) is thought to be proper for all dental needs. Demands for further reductions in

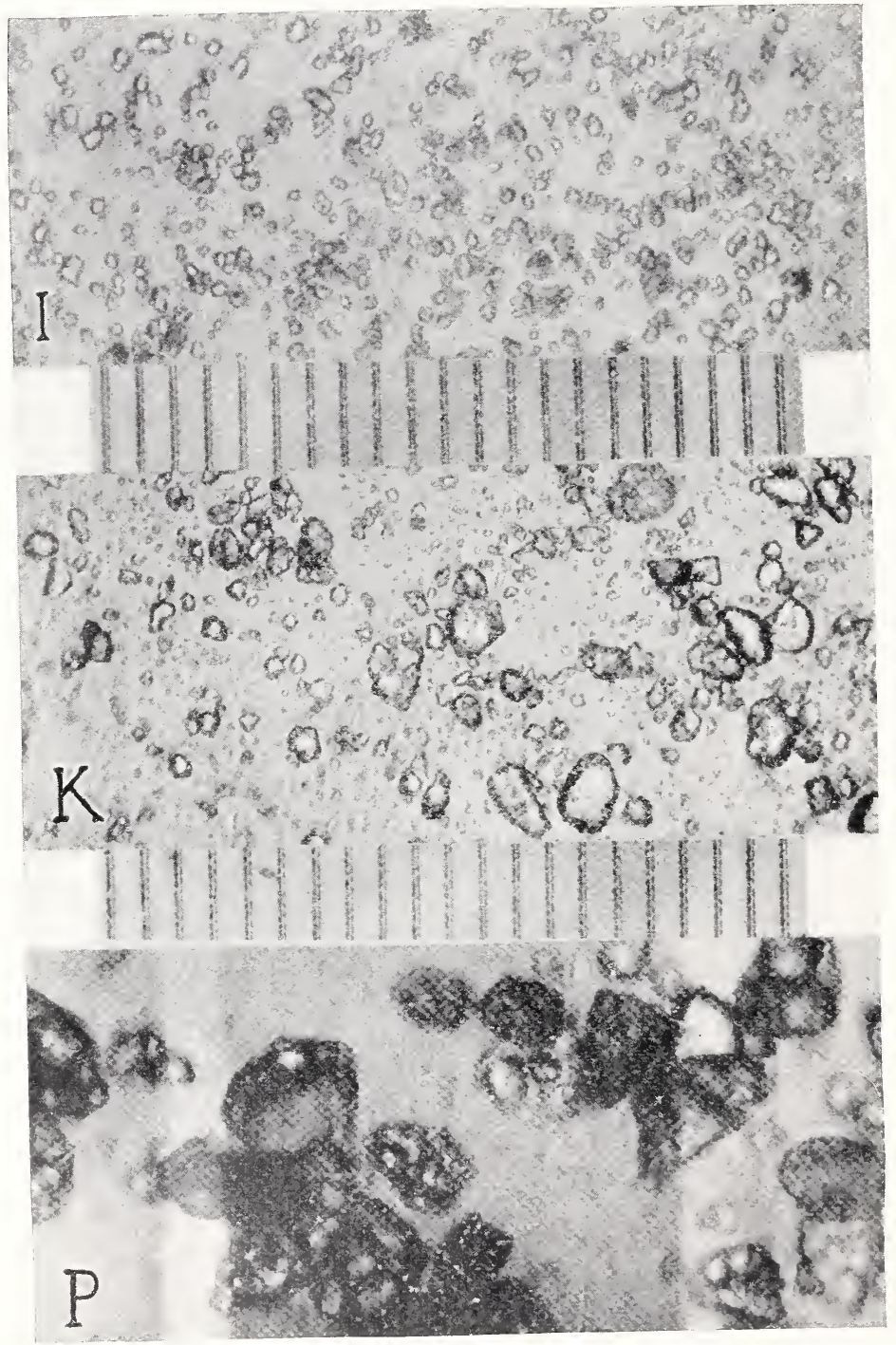

FIGURE 52.- Particle size of zinc phosphate cement powders.

$I$ is a uniformly fine-grained powder; $K$ is a mixture of fine- and medium-sized particles; $P$, large particles of a cement powder separated by water floating. Each seale division equals 10 microns (0.0004 in.).

film thickness, if made, will make desirable a different type of testing equipment. A graph of the relations between maximum size of particle and film thickness indicates that with the complete solubility of all particles there would still be a film thickness of about 10 microns. The present method of test under these conditions therefore obviously approaches a measurement of the riscosity of the cement. 
Density. - The true density of cement powders has frequently been associated erroneously with quality, and the porosity of the set cement has often been confused with its density. The cements having dense powders were thought by some to be stronger and less soluble than cements having powders of lesser density. However, the denser powders, which were practically pure zinc oxide, produced cements which were much inferior in strength and more soluble than those containing less dense powder's; for example, those consisting chiefly of a mixture of zinc and magnesium oxides.

Arsenic and pulp irritation.-The arsenic content of the presentday zinc phosphate cements is very small, being usually less than 0.0002 percent or 1 part in 500,000 parts of cement. It is believed that this limited quantity of arsenic is not sufficient to produce devitalization when one considers the long duration of their satisfactory use clinically. There has been little or no evidence presented to show that this very minute amount of arsenic is available. If the arsenic is in an available form then only that in the surface of the cement next to the dentine will be potent as a pulp devitalizer.

Technic.-The zinc phosphate cements react to form a crystalline material. The silicate cements form a colloidal material (fig. 47). These facts give the keys to the two technics which should be adopted to secure the maximum service from these types of dental cements.

The powders should be weighed and the liquids measured to an exact predetermined ratio before the mixing is started. Unfortunately a very small percentage of dentists have realized the importance of this basic principle. The remainder continue to guess on the amounts of powder necessary, adding bit after bit of raw powder to a reacting and setting mass which already should have been placed in the cavity so that it could complete its final reaction without being broken up or otherwise disturbed.

The bottle containing the liquid should be kept tightly stoppered at all times except when withdrawing the amount of liquid needed. The specification provides for a 20 percent excess in the amount of liquid supplied with a given amount of powder. This remaining 20 percent is to be discarded when the unit of powder has been used up. The cumulative changes in concentration of liquid, resulting from repeated opening and closing of the container, increase more rapidly as the ratio of the exposed surface of liquid to its total volume increases. For the last 20 percent this ratio of exposed surface to volume is 5 times as great as it is for the full bottle.

The retention of gold inlays, by the cement appears to be of a mechanical nature. Well-fitting inlays, bridge abutments, ete., will usually stay in place for days with the use of the weak wax-like cements, or gutta percha. The regular inlay cements brace and support restorations rather than glue them in place. Retention may be enhanced by cutting slight grooves in the tooth opposite similar grooves in the restoration. The mass of cement solidifying in these two grooves forms a solid, continuous key of cement which will lock the inlay securely until the key is crushed or the tooth is split.

Zinc phosphate cement should be manipulated in accordance with the following technic:

1. Use the maximum powder content possible for the operation at hand. This will tend to keep the solubility of the cement low and 
the compressive strength high. The ratio of powder to liquid should be established from previously weighed amounts of powder and measured quantities of liquid standardized to the consistency preferred by the operator.

2. The mixing may be prolonged slightly by incorporating small amounts of powder at first if such a technic is preferred. The growth of the crystalline structure may be disturbed up to a certain extent, without serious permanent injury.

3. The mixing slab should be cooled to a temperature slightly above the dew point as this delays the setting reaction and enables the operator to incorporate the maximum amount of powder before serious stiffening or setting of the mix prevents the addition of the total weight of powder.

4. The liquid must not be exposed unnecessarily to the air.

5. Hold the inlay, abutment or other restoration in place until the cement has set. Then anticipate no retentive forces other than mechanical locking.

6. Remember that the zinc phosphate cements are excellent insulators against the thermal conduction of heat to or from the pulp.

\section{(e) SILICATE CEMENTS}

It has been estimated [97] that roughly $11,000,000$ silicate cement fillings (popularly and improperly referred to as porcelain fillings) are made yearly in the United States, a clear indication of their general acceptance in operative dentistry. This widespread use is based upon first, the natural appearance of the silicate cement filling, and second, the ease with which the cement can be introduced into the cavity and shaped to the contour of the tooth. These two favorable properties are frequently overshadowed by some very serious faults such as solubility, shrinkage during setting, and staining. In fact silicate cements are the least permanent of the so-called permanent filling materials.

Perhaps the most important distinction between silicate cements and the phosphate cements is the nature of the reactions which occur during setting. The setting of phosphate cements involves the formation of crystalline compounds. The silicate cements undergo a very different type of reaction when they set. The exact nature of the reaction is not known, but it is well understood that a type of substance known in chemistry as a "gel" is formed when the complex silicate which constitutes the cement powder is mixed with the cement liquid, the essential ingredient of which is phosphoric acid. The behavior of sodium silicate (water glass) toward an acid such as phosphoric acid can be considered as a simple case of the same type of reaction. When the two substances are mixed in the proper proportion, there is formed within a few minutes a semitransparent, stiff, jelly-like mass which may contain as much as 95 percent of water.

The way in which the silicic acid molecules which are set free by the phosphoric acid may combine to form the very large molecules which comprise the gel has been explained by Hurd [115]. 'The mechanism which he suggests is shown in part in figure 53. The reaction between the $\mathrm{OH}$ groups may go on almost indefinitely to form long chainlike molecules and also to cross-link them by chains with other similar molecules.

The silicate cements are much more complex than sodium silicate and may therefore be expected to undergo much more complex 
reactions with phosphoric acid, but the type of reaction is the same. That the product of the reaction has a noncrystalline structure can be seen clearly by comparing the photograph of the X-ray diffraction pattern of a set silicate cement (fig. 47) with the accompanying photograph of a zinc phosphate cement. The matter of importance, however, is that gels have very different characteristics from crystalline solids. In the subsequent discussion it will be seen that the differences in characteristics have very much to do with the manipulation of the silicate cements and with their behavior in the completed restoration.
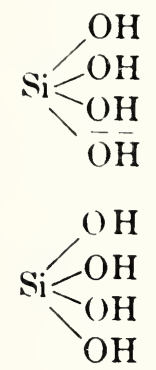

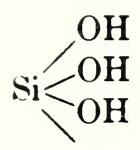

()

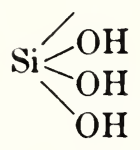

$+\mathrm{H}_{2} \mathrm{O}$

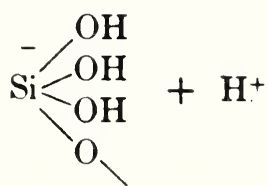

or

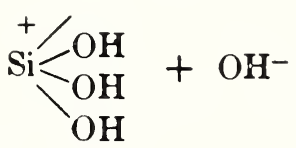

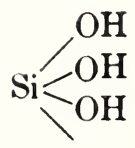

O

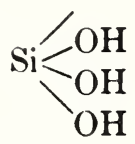

$+\mathrm{H}_{2} \mathrm{O}$

FigURE 53.-Diagram [115] of theoretical reactions thought to occur during the setting of silica gel (Hurd).

The chemical reactions associated with the mixing and setting of a silicate cement can perhaps be explained by outlining the steps in producing the cement and by comparing the reactions with the theoretical reactions of a typical silicate.

A hypothetical silicate cement powder and liquid mixed to form a restoration, can be thought of as undergoing the following general changes:

\section{POWDER}

Silica, 40 percent; alumina, 30 percent; lime, 10 percent; flux, 20 percent.

Cement powders are produced from fused glass-like mixtures which have been chilled or crazed, and ground to very fine dimensions. In some instances zinc and other oxides are added to the powder before it is packaged.

\section{LIQUID}

Phosphoric acid, 50 percent; water, 40 percent; aluminum and zinc salts, 10 percent.

Mix the powder and liquid to a plastic mass.

\section{PLASTIC MASS}

Surfaces of the powder particles are partially dissolved, forming a gel surface over each particle.

The gel unites throughout the mass and usually sets when less than 20 percent of the solid particles has been dissolved. 
A solid mass, 60 to 70 percent of which is undissolved powder surrounded by the set gel.

For the dental silicate cements there are in addition to silicate ions, those of aluminum, calcium, zinc and possibly lithium, sodium, beryllium, and magnesium. The nature and relative amounts of metallic ions will have an important bearing on the properties of the cement, in particular, its solubility. The more nearly insoluble the final molecular combinations are the more insoluble will be the cement. (Ground cement powder which makes up a large percentage of the set cements is relatively insoluble in water.)

Just what happens to the water given off by the reactions described above is not clear. The chaining and linking reactions are thought to extend through the mass and to leave a capillary or fiber-like structure which would provide excellent means for water storage. The theory of a capillary or fibrous structure is given added weight by the Liesegang ring phenomenon, which is likewise interesting in dentistry because of its visualization of the effects of the migrations of ions through these gels. To display this phenomenon one may add to the silicic acid solution, mentioned previously, before it sets, 0.01 percent of gold chloride. After it sets, pour an oxalic acid solution over the hard gel. Rings will appear in the gel. These rings are shown in figure 54, and represent the results of migration of gold ions to positions where they are reduced by the oxalate ions to metallic gold. Such migrations demand paths of movement and reaction between the oxalate and gold ions. The capillary structure, the surplus water within the network of capillaries and the chemical affinities of the elements concerned are sufficient to make the above explanation a logical if not a true one.

The above experiment, showing migrations into and within the colloidal gel is well worth performing before students. It can be duplicated to a small degree in the silicate cements. The large amount of unattacked cement powder in the gel matrix of the cement undoubtedly retards the migrations and reduces the speed and depth of penetration.

Chemical composition. - The complex composition of silicate cements is shown by tables 43 and 44, in which are given the analysis of 12 cement powders and the corresponding liquids, respectively. The presence in the cements of many minor constituents is shown by the results of spectrochemical analyses given in table 45 .

It will be noted that the calcium and sodium in some instances are reported as the oxides (table 43 , columns 3 and 6 ); in others, as the elements (table 43 , columns 4 and 7 ), because the analysis indicated that, in those cements containing fluorine, the calcium and sodium were present as fluorides and not as oxides.

Cement SH has an unusual amount of phosphorus pentoxide, from almost three to twelve times that of the other phosphorus-containing cements. This unusual amount of phosphorus pentoxide may account for the relatively high solubility and low strength of this cement. 


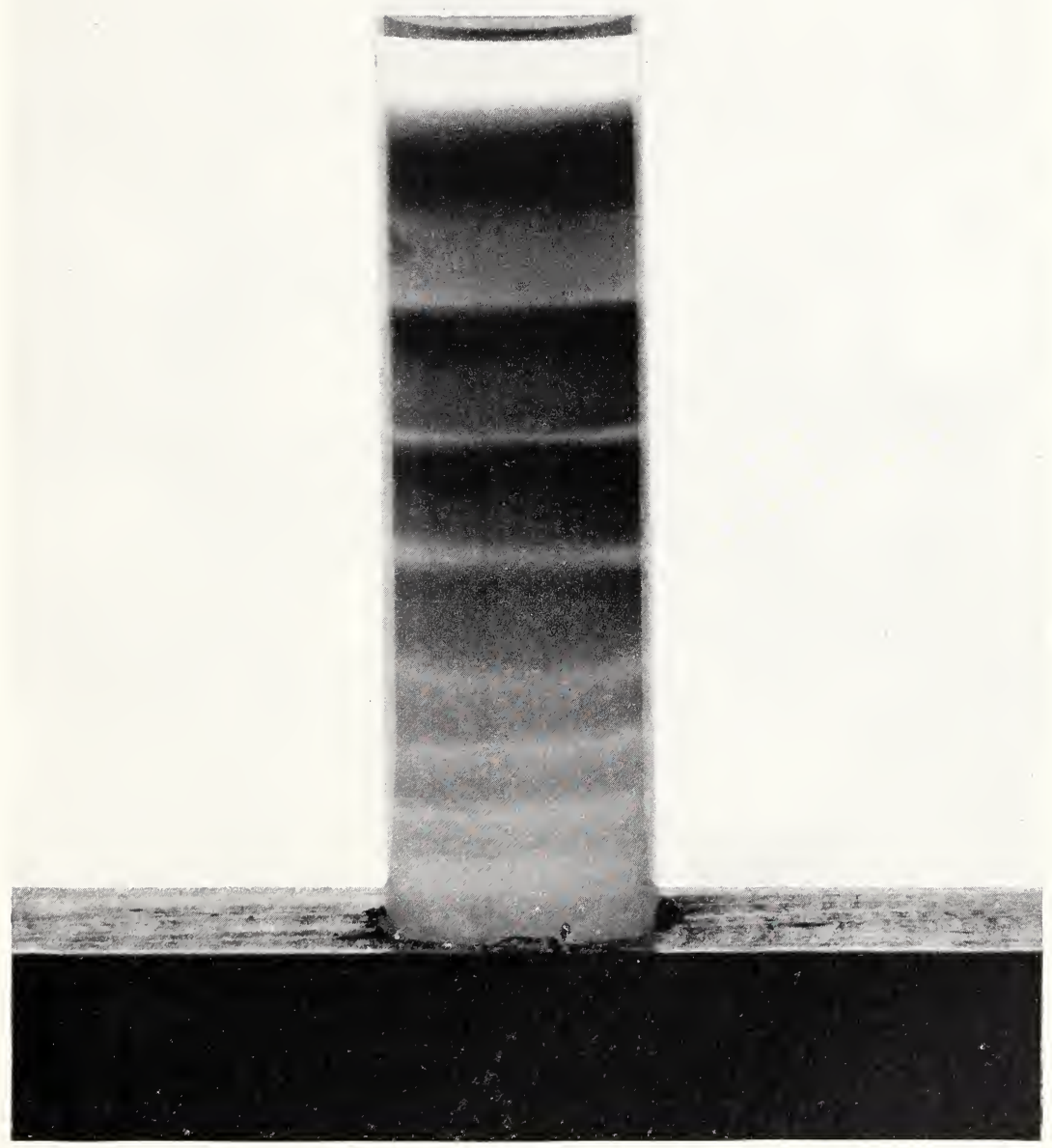

FigURE 54.-Liesegang ring phenomenon which demonstrates the migration of ions in silica gel. 
TABLE 43.-Composition of silicate cement powders (percentage by weight)

\begin{tabular}{|c|c|c|c|c|c|c|c|c|c|c|}
\hline Column & 1 & 2 & 3 & 4 & 5 & 6 & 7 & 8 & \multicolumn{2}{|l|}{9} \\
\hline Cement powder* & $\begin{array}{l}\text { Siliea } \\
\left(\mathrm{SiO}_{2}\right)\end{array}$ & $\begin{array}{c}\text { Alu- } \\
\text { mina } \\
\left(\mathrm{Al}_{2} \mathrm{O}_{3}\right)\end{array}$ & $\begin{array}{l}\text { Cal- } \\
\text { eium } \\
\text { oxide } \\
(\mathrm{CaO})\end{array}$ & $\begin{array}{l}\text { Cal- } \\
\text { cium } \\
(\mathrm{Ca})\end{array}$ & $\begin{array}{l}\text { Fluor- } \\
\text { ine } \\
\text { (F) }\end{array}$ & $\begin{array}{c}\text { Sodium } \\
\text { oxide } \\
\text { (Na2 } \mathrm{O} \text { ) }\end{array}$ & $\underset{(\mathrm{Na})}{\text { Sodium }}$ & $\begin{array}{l}\text { Phos- } \\
\text { phorus } \\
\text { pent- } \\
\text { nxide } \\
\left(\mathrm{P}_{2} \mathrm{O}_{5}\right)\end{array}$ & \multicolumn{2}{|c|}{$\begin{array}{l}\text { Loss on } \\
\text { ignition }{ }^{3}\end{array}$} \\
\hline $\begin{array}{l}\text { SA } \\
\text { SB b } \\
\text { SC } \mathrm{e} \\
\text { SD } \\
\text { SE d- } \\
\text { SF e } \\
\text { SG } \\
\text { SH } \mathrm{P} \\
\text { SI } \mathrm{g} \\
\text { SJ } \\
\text { SK } \\
\text { SL } \mathrm{h}\end{array}$ & $\begin{array}{c}\text { Percent } \\
47.2 \\
44.0 \\
32.0 \\
39.9 \\
35.1 \\
14.6 \\
37.7 \\
29.7 \\
41.7 \\
39.7 \\
40.1 \\
36.5\end{array}$ & $\begin{array}{c}\text { Percent } \\
33.1 \\
21.4 \\
29.5 \\
27.7 \\
29.9 \\
15.6 \\
31.7 \\
23.1 \\
28.1 \\
35.8 \\
29.8 \\
26.3\end{array}$ & $\begin{array}{c}\begin{array}{c}\text { Percent } \\
10.4 \\
13.6 \\
\end{array} \\
5.8 \\
\end{array}$ & $\begin{array}{r}\text { Percent } \\
8.6 \\
5.9 \\
7.9 \\
3.2 \\
6.2 \\
-6.7 \\
3.2 \\
6.6 \\
5.9\end{array}$ & $\begin{array}{r}\text { Percent } \\
14.3 \\
15.4 \\
14.2 \\
5.9 \\
12.9\end{array}$ & $\begin{array}{c}\text { Percent } \\
8.7 \\
2.6 \\
- \\
7.6 \\
\end{array}$ & $\begin{array}{r}\text { Percent } \\
7.3 \\
6.6 \\
7.3 \\
2.9 \\
7.4\end{array}$ & $\begin{array}{r}\text { Percent } \\
7.6 \\
5.8 \\
4.0 \\
5.4 \\
2.1 \\
3.3 \\
24.0 \\
2.2 \\
3.9 \\
3.2 \\
3.2\end{array}$ & 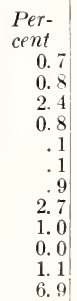 & $\begin{array}{l}{ }^{\circ} C . \\
900 \\
120 \\
850 \\
110 \\
120 \\
120 \\
900 \\
900 \\
900 \\
110 \\
900 \\
900\end{array}$ \\
\hline
\end{tabular}

a Ignition losses at $900^{\circ} \mathrm{C}$. on those cements containing fluorides may be in error because of the volatilization of some silieon tetrafluoride $\left(\mathrm{SiF}_{4}\right)$.

$b$ Contained 9.8 pereent of beryllium oxide $(\mathrm{BeO})$ and 0.3 percent of niekel oxide $(\mathrm{NiO})$.

- Contained 0.3 percent of strontium (Sr).

d Contained 0.2 pereent of ferrie oxide $\left(\mathrm{Fe}_{2} \mathrm{O}_{3}\right)$.

e Contained 53.2 pereent of zine oxide $(\mathrm{ZnO}) ; 2.3$ percent of magnesia $(\mathrm{MgO})$, and 0.1 pereent of ferric oxide $\left(\mathrm{Fe}_{2} \mathrm{O}_{3}\right)$. Not a true silieate, but a silicate-zine phosphate combination.

1 Contained 4.1 pereent of zinc oxide $(\mathrm{ZnO}) ; 2.9$ percent of beryllium oxide (BeO), and 0.2 percent of magnesia ( $\mathrm{MgO})$.

g Contained 0.5 percent of lithium oxide $\left(\mathrm{Li}_{2} \mathrm{O}\right)$.

h Contained 9.4 percent of zinc oxide ( $\mathrm{ZnO}$ ) and 0.5 percent of magnesia $(\mathrm{MgO})$. Therefore a silicate-zinc phosphate combination.

*Analyses of powders A, D, E, F, H, I, J, K and L were made by the late Aaron Isaacs.

Methods of analysis are given in referenee [114].

The powder of cement $S F$ contained over 53 percent of zinc oxide, making the cement a hybrid between a dental silicate and dental zinc phosphate cement. A microscopical examination of the powder showed that the fusion was incomplete.

TABLE 44.-Composition of silicate cement liquids (percentage by weight)

\begin{tabular}{|c|c|c|c|c|c|c|c|c|}
\hline \multirow[t]{2}{*}{ Column } & 1 & 2 & 3 & 4 & 5 & 6 & 7 & 8 \\
\hline & \multicolumn{4}{|c|}{ Analyses } & \multicolumn{4}{|c|}{ Calculations } \\
\hline Cement liquid* & $\mathrm{PO}_{4}$ & $\mathrm{Al}$ & $\mathrm{Zn}$ & $\mathrm{Mg}$ & $\begin{array}{c}\text { Free } \\
\mathrm{H}_{3} \mathrm{PO}_{4}\end{array}$ & $\begin{array}{c}\text { Com- } \\
\text { bined } \\
\mathrm{H}_{3} \mathrm{PO}_{4}\end{array}$ & $\begin{array}{c}\text { Total } \\
\mathrm{H}_{3} \mathrm{PO}_{4}\end{array}$ & Water a \\
\hline 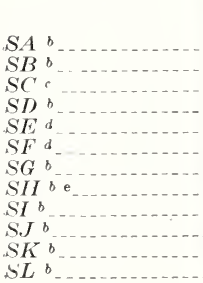 & $\begin{array}{r}\text { Percent } \\
60.1 \\
52.3 \\
56.8 \\
47.4 \\
56.1 \\
55.7 \\
48.6 \\
51.9 \\
51.7 \\
48.6 \\
48.1 \\
48.1\end{array}$ & $\begin{array}{r}\text { Percent } \\
1.9 \\
2.1 \\
2.1 \\
2.3 \\
2.4 \\
2.4 \\
\\
3.3 \\
2.5 \\
1.9 \\
1.9\end{array}$ & $\begin{array}{r}\text { Percent } \\
7.7 \\
6.2 \\
2.5 \\
5.6 \\
3.1 \\
3.1 \\
9.1 \\
\\
5.8 \\
8.9 \\
4.4 \\
4.4\end{array}$ & $\begin{array}{r}\text { Percent } \\
0.1 \\
.7 \\
.8 \\
.7 \\
\end{array}$ & $\begin{array}{r}\text { Percent } \\
47.6 \\
39.8 \\
46.5 \\
35.0 \\
44.1 \\
43.6 \\
41.1 \\
41.7 \\
37.6 \\
41.3 \\
38.3 \\
38.3\end{array}$ & $\begin{array}{r}\text { Percent } \\
14.5 \\
14.2 \\
12.1 \\
13.8 \\
13.8 \\
13.9 \\
9.1 \\
11.8 \\
15.7 \\
8.9 \\
11.3 \\
11.3\end{array}$ & $\begin{array}{r}\text { Percent } \\
62.1 \\
54.0 \\
58.6 \\
48.8 \\
5.9 \\
57.5 \\
50.2 \\
53.5 \\
53.3 \\
50.2 \\
49.6 \\
49.6\end{array}$ & $\begin{array}{r}\text { Percent } \\
28.3 \\
37.6 \\
36.1 \\
43.3 \\
35.8 \\
36.3 \\
40.7 \\
43.2 \\
38.4 \\
40.9 \\
44.1 \\
44.1\end{array}$ \\
\hline
\end{tabular}

a Water content ealculated by difference.

$b$ Contained less than 0.0002 percent of arsenic.

$c$ Contained 0.0002 percent of arsenic.

$d$ Contained 0.0005 percent of arsenic.

- Contained 0.3 percent of calcium.

*Analyses of liquids $S K$ and $S L$ were made by the late Aaron Isaaes. 
The powder of cement $S L$ is a mechanical mixture of silicate and zinc phosphate cement powders in the approximate ratio 9 to 1 . Where a cement is desired which has some characteristics of both silicate and zinc phosphate types, this kind of mixture appears to have in general superior physical qualities.

Table 44 gives the composition of the liquids, which are placed in the table in the same order as the powders in table 43 ; i.e., liquid $A$ is supplied for use with cement $A$, etc.

The silicate cement liquids are aqueous solutions of phosphoric acid $\left(\mathrm{H}_{3} \mathrm{PO}_{4}\right)$ to which are added aluminum or zinc or salts of both. They are very similar in composition to the zinc phosphate cement liquids, but, in general, are higher in water and lower in acid content.

From the analyses, certain calculations (table 44, columns 5, 6, 7, and 8) were made. Column 7 , "Total $\mathrm{H}_{3} \mathrm{PO}_{4}$ ", was derived from the experimentally determined phosphate content of the liquid (column 1), irrespective of whether it was present as phosphoric acid or as a salt of phosphoric acid. Column 6, "combined $\mathrm{H}_{3} \mathrm{PO}_{4}$ ", indicates the quantity of phosphoric acid needed to react with the zinc, aluminum and magnesium content (columns 2, 3, and 4) to form the neutral phosphates. Column 5, "free $\mathrm{H}_{3} \mathrm{PO}_{4}$ ", obtained by subtracting column 6 from column 7 , indicates the total amount of uncombined phosphoric acid present. The percentage of water (column 8) was obtained by deducting the sum of $\mathrm{Al}, \mathrm{Mg}, \mathrm{Zn}$, and "Total $\mathrm{H}_{3} \mathrm{PO}_{4}$ " (columns 2, 3, 4 , and 7) from 100.

TABLE 45.-Spectrochemical analysis of silicate cement powders and liquids

\begin{tabular}{|c|c|c|}
\hline Cement powders & Major constituents & Minor constituents and traces $a$ \\
\hline $\begin{array}{l}S A \\
S B C \\
S D \\
S E \\
S E \\
S G \\
S H \\
S I \\
S I_{1} \\
S L\end{array}$ & $\begin{array}{l}\text { Al, Ca, Na, Si } \\
\text { Al, Be, Ca, Na, Ni, P, Si } \\
\text { Al, Ca, F, Na,P, Si, Sr. } \\
\text { Al, Ca, F, Na, P, Si... } \\
\text { Al, Ca, F, Fe, Na, P, Si } \\
\text { Al, Ca, F, Fe, Mg, Na, P, Si, Zn } \\
\text { Al, Ca, F, Na, P, Pb, Si } \\
\text { Al, Be, Ca, Mg, Na, P, Si, Zn } \\
\text { Al, Ca, F, Li, Na, P, Si } \\
\text { Al, Ca, F, Na, P, Si } \\
\text { Al, Ca, F, Na, P, Si } \\
\text { Al, Ca, F, Mg, Na, P, Si, Zn }\end{array}$ & $\begin{array}{l}\text { Ba, Cr, Fe, Ga, K, Li, Mg, Mn, Mo, Pb, Sr, U, V. } \\
\text { Cr, Fe, Ga, K, Mg, Mn, Pb, Sr, Ti. } \\
\text { Cr, Fe, Ga, K, Mg, Mn, Pb, Ti, V. } \\
\text { Ba, Cr, Fe, Ga, K, Li, Mg, Pb, Sr, V. } \\
\text { B, Ba, Cr, Ga, K, Li, Mg, Mn, Mo, Pb, Sr, V. } \\
\text { Ba, Cr, Ga, K, Li, Mn, Pb, Sr, V. } \\
\text { Cr, Fe, Ga, K, Mg, Mn, Ni, Sr, Ti, V, Zn. } \\
\text { Ba, Cr, Fe, Ga, K, Li, Mn, Mo, Pb, Sr, U, V. } \\
\text { Ba, Cr, Fe, Ga, K, Mg, Mn, Pb, V. } \\
\text { Cr, Fe, Ga, K, Li, Mg, Ni, Pb, V. } \\
\text { Cr, Fe, Ga, K, Li, Mg, Pb, V. } \\
\text { Cr, Fe, Ga, K, Li, Pb, V. }\end{array}$ \\
\hline Cement liquids & & \\
\hline $\begin{array}{l}S A \\
S B \\
S B\end{array}$ & $\begin{array}{l}\text { Al, P, } \mathrm{Zn} \\
\text { Al, Ca, Mg, P, Zn } \\
\text { Al, Mg, P, Zn } \\
\text { Al, P, Zn }\end{array}$ & $\begin{array}{l}\mathrm{Ba}, \mathrm{Ca}, \mathrm{Cr}, \mathrm{Fe}, \mathrm{Ga}, \mathrm{Mg}, \mathrm{Pb}, \mathrm{Si}, \mathrm{Sr} . \\
\mathrm{Fe}, \mathrm{Si}, \mathrm{Sr} . \\
\mathrm{Ca}, \mathrm{Fe}, \mathrm{Pb}, \mathrm{Si} . \\
\mathrm{Ba}, \mathrm{Ca}, \mathrm{Fe}, \mathrm{Ga}, \mathrm{Mg}, \mathrm{Pb}, \mathrm{Si}, \mathrm{Sr} .\end{array}$ \\
\hline $\begin{array}{l}S E \\
S F \\
S G_{2} \\
S H_{2}\end{array}$ & $\begin{array}{l}\text { Al, Mg, P, Zn } \\
\text { Al, Mg, P, Zn } \\
\text { P, Zn } \\
\text { Al, Ca, P. }\end{array}$ & $\begin{array}{l}\mathrm{Ba}, \mathrm{Ca}, \mathrm{Fe}, \mathrm{Ga}, \mathrm{Ni}, \mathrm{Pb}, \mathrm{Si}, \mathrm{Sr}, \mathrm{V} \text {. } \\
\mathrm{Ba}, \mathrm{Ca}, \mathrm{Fe}, \mathrm{Ga}, \mathrm{Ni}, \mathrm{Pb}, \mathrm{Si}, \mathrm{Sr}, \mathrm{V} \text {. } \\
\mathrm{Al}, \mathrm{Ca}, \mathrm{Cu}, \mathrm{Fe}, \mathrm{Mg}, \mathrm{Pb}, \mathrm{Si} . \\
\mathrm{Fe}, \mathrm{Mg}, \mathrm{Pb}, \mathrm{Si}, \mathrm{Sr}, \mathrm{Zn} \text {. }\end{array}$ \\
\hline $\begin{array}{l}S I \\
S J \\
S K \\
S L\end{array}$ & $\begin{array}{l}\mathrm{Al}, \mathrm{Li}, \mathrm{P}, \mathrm{Zn} \\
\mathrm{P}, \mathrm{Zn} \\
\mathrm{Al}, \mathrm{P}, \mathrm{Zn}\end{array}$ & $\begin{array}{l}\mathrm{Ca}, \mathrm{Mg}, \mathrm{Pb}, \mathrm{Si} . \\
\mathrm{Al}, \mathrm{Ca}, \mathrm{Fe}, \mathrm{Mg}, \mathrm{Pb}, \mathrm{Si}, \mathrm{Sr} . \\
\mathrm{Ca}, \mathrm{Fe}, \mathrm{Mg}, \mathrm{Pb}, \mathrm{Si} . \\
\mathrm{Ca}, \mathrm{Fe}, \mathrm{Mg}, \mathrm{Pb}, \mathrm{Si} .\end{array}$ \\
\hline
\end{tabular}

- These elements are present in amounts less than 0.1 percent. 
Traces of arsenic are frequently found in the cement powders and sometimes in the liquids. It is extremely difficult to remove all traces of arsenic from the powder since it may appear as an impurity in one or more of the powder components. It does not appear to impose a hardship to demand liquid and powder to a standard of purity of less than two parts of water-soluble arsenic to one million parts of cement. Methods for determining water-soluble arsenic are described in the specification for silicate cements which appears in a later section of this summary (item $\mathrm{K}-1$, p. 206).

Mixing technic.--It is a well known fact that the technic used in mixing a cement profoundly affects its properties. Manifestly then, in order to compare and evaluate dental cements, it is necessary to treat them in an identical manner. The following technic was adhered to in the preparation of test specimens. (1) The amount of powder used in 0.4 milliliters of liquid was determined by a consistency test hereinafter described (page 205). (2) Mixes were made for one minute at $21^{\circ} \mathrm{C}\left(70^{\circ} \mathrm{F}\right)$ and at 65 percent relative humidity. (3) The mixing schedule was: one-half of the powder was placed in the liquid during the first 15 seconds, one-fourth during the following 15 seconds and the remainder during the last 30 seconds. (4) Clean glass slabs 3 inches wide, 6 inches long, and 1/8 inch thick were used.

Consistency.-Details of the test for consistency are given in the specification for silicate cement on page 205, item $\mathrm{F}-2$. The test though simple is effective not only in determining consistency but in detecting differences among different batches of the same cement, and is used sometimes as a laboratory control of plant production. The standard consistency selected was the average of the consistencies used by a committee of cooperating dentists and represents the number of grams of powder which can be incorporated in 0.4 milliliters of liquid to produce a disk having a diameter of $25 \pm 1$ millimeters under the test conditions. Data are given in table 46 , column 2.

Let it be emphasized that this may not be the optimum consistency or the consistency which will produce the best physical properties. It represents the consistency found in practical use.

TABLE 46.-Physical properties of certified silicate cements ${ }^{\text {a }}$

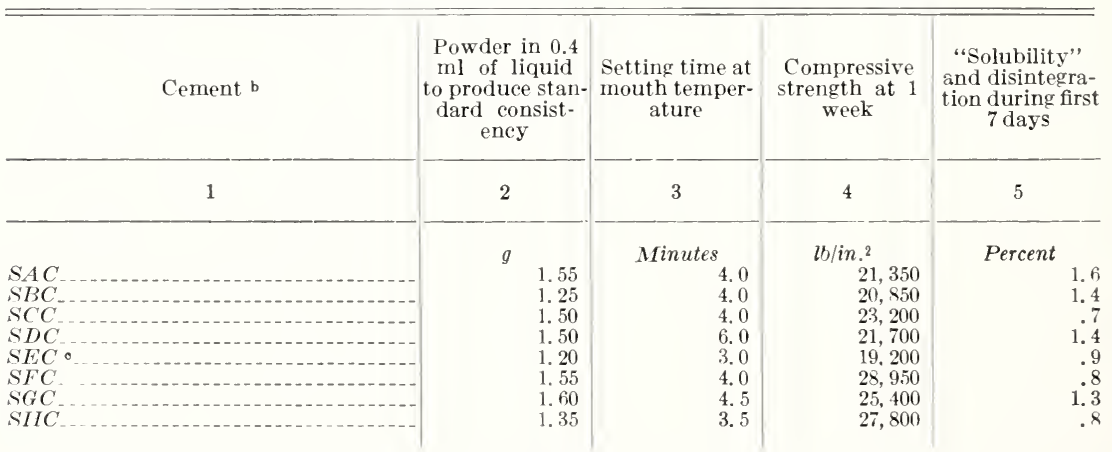

a Methods used are described in A. D. A. specification (p. 204)

b The arsenic content of all cements was less than 0.0002 percent. The opacity of all cements was between 35 and 55 percent.

c Discontinued by replacement of an improved material.

Time of setting.- The method of determining the time of setting is identical with that described in the section on zinc phosphate 
except that the silicate cement, because of the shorter mixing time, is transferred to the test chamber at the end of 2 instead of 3 minutes (ADA specification No. 9, item G, p. 205).

Most of the present-day silicate cements set rapidly (table 46 , column 3) when mixed to standard consistency.

There are many factors which modify the setting time of a silicate cement. Some of these are controlled by the manufacturer, who adjusts the composition, treatment and fineness of the powder, and the composition of the liquid. Many other factors the dentist can control. For instance, the time of setting may be increased by lengthening the mixing time and by reducing the powder-liquid ratio. Neither of these should be resorted to as a long mixing time causes the cement to be weaker and more soluble and a reduction of the powder in a given amount of liquid causes the cement to be weaker, to stain more, to be more soluble, and to shrink more than a cement mixed quickly and with a normal powder-liquid ratio. The setting time may be decreased by increasing the temperature of the mixing slab. The setting time may also be slightly reduced in some silicate cements by adding the powder all at one time instead of in 6 equal portions at 10 -second intervals.

Compressive strength.- Silicate cement is a little weaker than dentine, about two-thirds as strong as the zinc phosphate cement and about one-half as strong as amalgam. The average strength of the most popular cements is roughly $24,000 \mathrm{lb} /$ in. $^{2}$ (table 46 , column 4 ). But there are other factors that must be considered. One of the most important of these is brittleness, a property which silicate cements exhibit to a considerable degree. Therefore, even though silicate cement is almost as strong as dentine, the cement will not absorb shock as dentine does and hence chips and fails under service conditions that dentine might easily survive.

ТАВLE 47.-Compressive strength of silicate cements

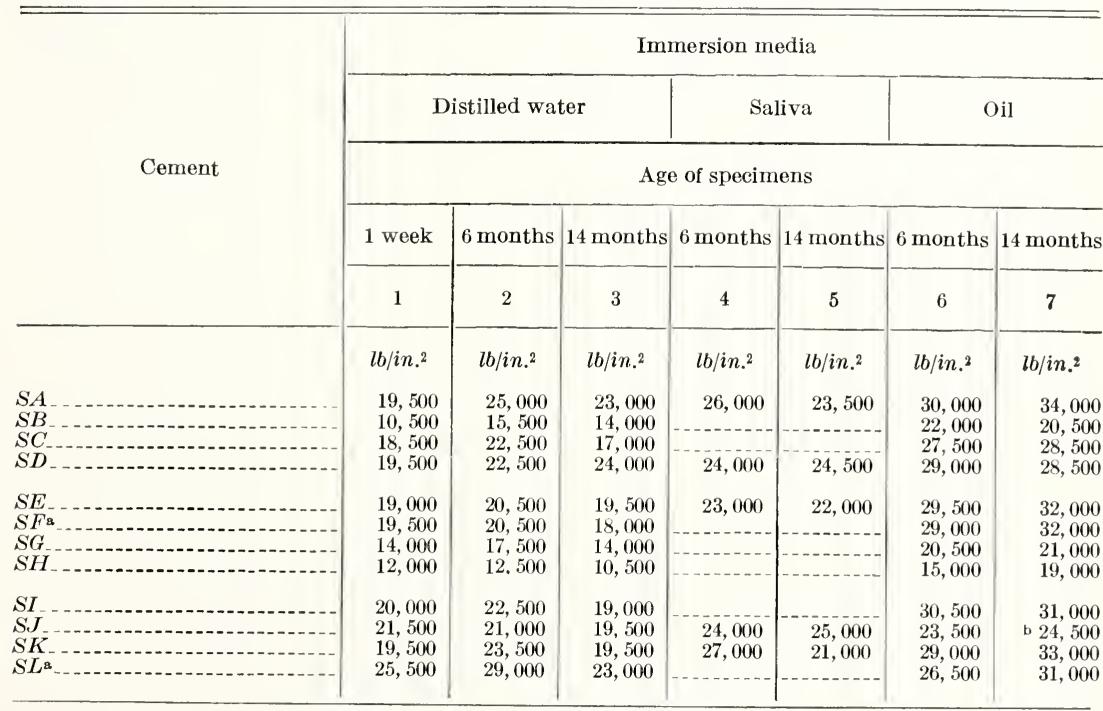

a Cements $S F$ and $S L$ are silicate-zinc phosphate combinations.

b A verage of 2 specimens. 
The size, preparation and treatment accorded test specimens are given in A.D.A. specification No. 9, item H, page 205.

In this specification it will be noted that the requirement for compressive strength is set at a minimum value of $18,000 \mathrm{lb} / \mathrm{in}^{2}{ }^{2}$ at the end of 1 week in distilled water at mouth temperature. In order to select a proper value for compressive strength as determined by an accelerated test in distilled water, rather extended tests were conducted on specimens stored in distilled water, saliva and mineral oil. Data on these tests are given in table 47 .

A comparison of the strengths of the 6 months old specimens in water, saliva and oil (columms 2,4 and 6 , table 47 ) shows that the silicate cements were strongest when stored in oil and weakest when stored in water. Those stored in saliva were stronger than those specimens which were stored in water. Therefore distilled water can be considered a satisfactory immersion medium. By making the tests over short and long periods of time a relationship was noted between the strength at the end of 1 week and after 14 months. With such data at hand a logical short-time test was developed for the specification (item G, page 205).

To illustrate that the powder-liquid ratio affects the compressive strength of silicate cements, refer to the value of $19,500 \mathrm{lb} / \mathrm{in} .^{2}$ for cement $S D$ (table 47, column 1) which was obtained on specimens containing 1.3 grams of powder to 0.4 milliliters of liquid. When this ratio was raised to 1.5 grams $/ 0.4$ milliliters the strength increased to $24,500 \mathrm{lb} /$ in. $^{2}$. Contrariwise, when the ratio was lowered to 0.8 grams $/ 0.4$ milliliters, the strength fell to $16,500 \mathrm{lb} / \mathrm{in}^{2}$.

The rate of reaction between the powder and liquid can be roughly determined by compressive strength tests. For example, specimens of cement $S D$, which were 15 minutes old, developed a strength of $10,000 \mathrm{lb} /$ in. $^{2}$, about 40 percent of their strength at 14 months. At 3 hours the strength had risen to $15,000 \mathrm{lb} /$ in. $^{2}$ or about 60 percent of their strength at 14 months. In 1 week it was 80 percent of the 14-month value. These data indicate that at least 3 hours and preferably 1 week should elapse between the placement and the polishing of a filling, because its surface should not be disturbed until the reaction between the powder and liquid has been largely completed.

"Solubility."-Because of its tendency to dissolve and disintegrate in the mouth silicate cement should really be designated as a temporary filling material. Black [116] maintained that his records showed that the effective life of the silicate cement filling of his day was no more than 2 years. The fillings would usually fail to maintain the contact point, or contour, or would stain. The average life expectancy of a silicate cement filling of today is, according to the group of cooperating dentists, no longer than $4 \frac{1}{2}$ years [97]. It would seem therefore that an investigation of the "solubility" was perhaps the most important single property which was reported in the original paper [74].

The method used is described in detail in ADA specification No. 9, item J, page 206. Data on certified cements are given in table 46, column 5. In addition to the 1-week test there given, tests were continued over a period of 5 weeks (table 48).

It will be noted that cements $S A, S B$, and $S H$, which do not contain fluorine (table 43), had the highest "solubility" (table 48). This 
might indicate that the presence of fluorine tends to reduce the "solubility." The unusually high "solubility" of cement SH may be caused by the large amount of phosphate in it (table 43).

There is a very rough relationship between "solubility" (table 48) and compressive strength (table 47). Notice that cement $S D$, the least soluble, was also the strongest at the end of 14 months (table 47 , column 3 ) and that cement $S H$, the most soluble, was also the weakest.

In table 48 is also given the "solubility" of a zinc phosphate cement $Z N$. This is very low-much lower than that of the silicates, which is inconsistent with the durability of the two kinds of cement in clinical service. Factors other than straight "solubility" are involved. Among these factors one may cite resistance to abrasion (the silicate cements are much harder and more resistant to scratching) and the effects of hydrogen sulfide (the zinc phosphate cements deteriorate rapidly in the presence of hydrogen sulfide whereas the silicate cements are very little affected). However, in each class of cements the solubility test appears to be indicative, but it cannot be effectively used to compare the clinical life of different types of cement with their respective solubilities.

In the mouth most silicate cement fillings are polished and do not therefore possess the smooth glossy surface which was imparted to them by the matrix. To determine the influence of the surface condition upon the "solubility," disks of cement $S D$ were roughened with No. 150 carborundum powder. The "solubility" of these roughened disks was not significantly different from that of the smooth-surface disks.

Disks of cement $S D$ were reduced to a powder which would pass a No. 200 sieve. The rate of solution of the powder under the stated conditions was approximately four times (2.3 percent) that of the disk (0.6 percent). The increase is of course attributable to the comparatively large surface area of the powder which is exposed to the action of the solvent. Powdered human tooth enamel had a "solubility" of 0.8 percent when subjected to the same test.

TABLE 48.- "Solubility" and disintegration of silicate cements in distilled water

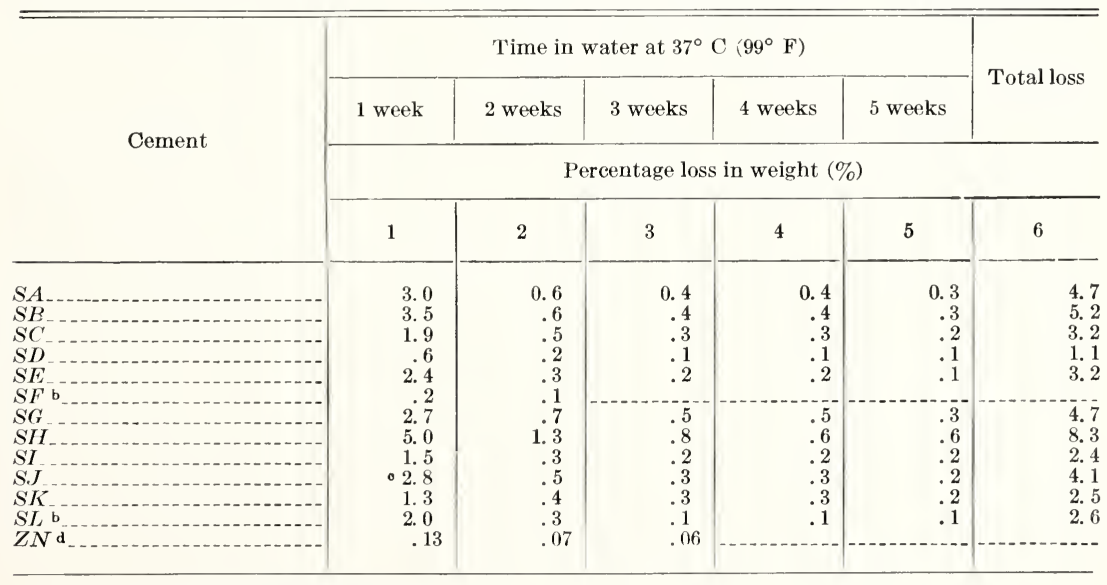

a Methods used are given on p. 206.

b Not a true silicate cement, (table 43 ).

c Other values on different batches ranged from 1.5 to 0.9 percent.

d Zinc phosphate cement. 
The "solubility" of cement powder SA was determined because it was thought that if the powder was soluble it might account for the high solubility of the cement (3.0 percent); also by leaching the soluble constituent out of the powder a cement might be prepared having a low solubility.

In the testing procedure, about $3 \mathrm{~g}$ of cement powder $S A$ was placed in a platinum dish and digested in $100 \mathrm{ml}$ of distilled water for 1 hour on a steam bath. The mixture was then filtered and the filtrate dried at $120^{\circ} \mathrm{C}\left(248^{\circ} \mathrm{F}\right)$ to constant weight. The loss in weight of the sample amounted to only 0.4 percent. Since the weight loss of cement $S A$ at the end of the first week was 3.0 percent, it is apparent that the 0.4 percent solubility of the powder does not explain the 3.0 percent solubility of the cement. In considering this unexpected result one must remember that the powder presented a much greater area for attack by the solvent than did the cement disk. Also the powder was digested just below $100^{\circ} \mathrm{C}\left(212^{\circ} \mathrm{F}\right)$. while the cement disk was digested for 1 week at $37^{\circ} \mathrm{C}\left(99^{\circ} \mathrm{F}\right)$.

Acid ty.-Pulp irritation under silicate cement fillings has long been blamed upon the claim that acid substances which are protoplasmic poisons are released by the cement continually for a long period of time. To test this theory Crowell [117] after intensive investigations of the $\mathrm{pH}$ of solutions of various kinds of cements reported that, after 7 dars, the leachings of three different brands of cement had $\mathrm{pH}$ values of $5.6,5.8$, and 5.5 .

In the present work the degree of acidity or alkalinity (pH value) was determined on the powder. the liquid and the cement (both set and plastic). All measurements were made at $25^{\circ} \mathrm{C}\left(77^{\circ} \mathrm{F}\right)$ on (1) solutions prepared by mixing 1 gram of cement powder in 25 milliliters of distilled water: (2) solutions made by adding 0.4 milliliters of cement liquid to 25 milliliters of distilled water; and (3). solutions prepared by immersing 0.5 milliliters of the mixed cement in 25 milliliters of distilled water.

Under the above conditions of testing all of the powders. except that of cement $S H$. were slightly alkaline $(\mathrm{pH} 7.5$ to 7.6$)$. The powder of cement $S H$ which contained much phosphate (table 43) was acid (pH 5.3). The phosphoric acid liquids (table 44) had $\mathrm{pH}$ ralues running from 1.9 to 2.3. The data on the partially hardened and the set cements of four types of composition (table 43) are given in table 49. At the end of 15 minutes the cement solution is decidedly acid. This acidity slowly decreases until. at the end of 24 hours. most of the cements are approaching neutrality. This means that when the plastic cement is first introduced into the cavity, its acidity is relatively high. and it is probably at this time that the greatest injury to the pulp is liable to occur. This is especially true if the dentine has been sererely dried and so has rapidly absorbed some of the liquid portion of the rerr acid unset cement. The need of rarnishing the caritr floor and walls to prerent or retard the penetration of such acid substances toward the pulp is rerr evident. At the end of 24 hours (table 49 ) the cement solutions were approaching the $\mathrm{pH}$ of the distilled water $(5.6$ to 6.0$)$ used in making up the solution. Cement SH which had the high phosphate content was more acid than the other cements in table 49 . 
TABLE 49.-Change of $\mathrm{pH}$ of silicate cements with time a

\begin{tabular}{|c|c|c|c|c|c|c|c|c|}
\hline \multirow{2}{*}{ Cements } & \multirow{2}{*}{ Powder } & \multicolumn{7}{|c|}{ pH value ${ }^{\circ}$ at - } \\
\hline & & $\begin{array}{c}15 \\
\text { minutes }\end{array}$ & $\stackrel{20}{\text { minutes }}$ & $\stackrel{1}{\text { hour }}$ & $\stackrel{2}{\text { hours }}$ & $\begin{array}{c}4 \\
\text { hours }\end{array}$ & $\begin{array}{c}6 \\
\text { hours }\end{array}$ & $\begin{array}{c}24 \\
\text { hours }\end{array}$ \\
\hline $\begin{array}{l}S A \\
S D \\
S H \\
S J\end{array}$ & $\begin{array}{r}\text { Grams b } \\
0.90 \\
1.30 \\
0.80 \\
1.20\end{array}$ & $\begin{array}{r}\text { pH } \\
3.5 \\
3.6 \\
2.8 \\
3.7\end{array}$ & $\begin{array}{r}\text { pH } \\
3.9 \\
5.0 \\
3.3 \\
4.6\end{array}$ & $\begin{array}{r}\text { pH } \\
4.4 \\
5.5 \\
3.9 \\
4.7\end{array}$ & $\begin{array}{r}\text { pH } \\
4.7 \\
5.4 \\
4.2 \\
4.6\end{array}$ & $\begin{array}{r}\text { pH } \\
4.9 \\
5.5 \\
4.5 \\
4.8\end{array}$ & $\begin{array}{r}\text { pH } \\
5.3 \\
5.6 \\
4.8 \\
4.9\end{array}$ & $\begin{array}{r}\text { pH } \\
5.5 \\
5.8 \\
4.8 \\
5.6\end{array}$ \\
\hline
\end{tabular}

* Age of specimen calculated from the beginning of the mixing.

b Grams of powder mixed with 0.4 milliliter of liquid to produce a mix of standard consistency.

- The distilled water used as the solvent had a pH of 5.6 to 6.0 .

Opacity and refractive index.-The optical properties of the silicate cements, including color or shade, account for their popularity. The careful operator can blend the shades to a satisfactory visual match for the natural tooth. The opacity, if properly standardized, will come so near to matching the opacity of enamel and dentine combined that the refractive effects of the cement and the adjacent tooth structure will not be discernible to the unaided eye. For complete concealment of the restoration the index of refraction of the cement should match that of the tooth. The index of enamel is near 1.60 and of dentine near 1.56. The index of the silicate powder is between 1.47 and 1.60 . The cementing substance (matrix representing the product of the reaction of powder and liquid which unites the partially dissolved particles of powder) has an index between 1.45 and 1.48 .

As inferred above and as is well known, enamel and dentine are not perfectly transparent. Using the inverse term (opacity), we can say that they are partially opaque. The opacity of specimens of enamel 1 millimeter thick ranged from 21 percent to 67 percent. The opacity of dentine ranged from 50 percent to 91 percent. The average opacity of enamel was 39 percent and of dentine 70 percent. The opacity of silicate cements depended upon the brand, shades, etc., and ranged from 23 percent to 57 percent. These percentages were determined from data taken on the Priest-Lange reflectometer [118].

It is practically impossible for any operator to secure exact matches in opacity for all restorations. The usual differences in opacity between enamel and dentine would require two grades of silicate for a single restoration. One does not notice small differences in these optical properties, especially when restorations are placed on irregular surfaces or in partially concealed spots.

In general it will be found sufficient to match the shade of the tooth and select the cement from brands having opacities between the limits set by the specification for silicate cements. Laboratory tests of opacity may be made using specimens of the cements and comparing these with standardized samples of alabaster glass. Figure 55 shows three samples of glass of different opacities. Cements are compared with these glass standards by placing water-covered cement specimens (1 mm thick) and the standards over a variegated black and white background and by matching the distinctness of the background pattern as seen through the standards and specimens. 
Comparisons should not be made on freshly mixed cements as these usually become less opaque in a few hours, just as restorations in the mouth usually become less opaque, i. e.. slightly more translucent, a few days after they are completed. The zinc phosphate cements are 100 percent opaque when subjected to the abore test. This is one of the reasons why they are so easily detected when used as filling materials.

Hardnes. - Hardness is a broad term. It is necessary to define the type of hardness to be considered. The resistance to indentation has been used as a measure of the hardness of dental gold allors and appears to be well suited for measuring teeth and cements. This type of hardness testing discloses the amount of penetration and permanent injury sustained by a specimen when an object (spherical ball, knife edge or pointed instrument) is pressed against it. The difficulties encountered in measuring. br this method. the hardness of brittle material such as enamel have been overcome by an instru-
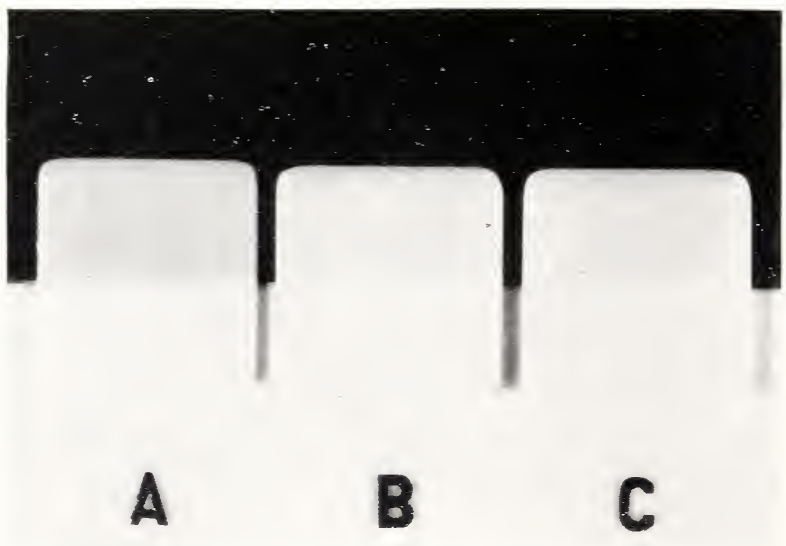

FIGURE 5̃.- - Alabaster glass standards used in determining opacity of silicate cements photographed on a black-and-white background.

$A, B$, and $C$ are 35,50 , and 55 percent opaque, respectirely. Notire the sharpness of the border line between the black and white sections when riewed througb each standard.

ment (fig. 24) invented by Knoop [107]. This instrument produces the indentation by pressing the apex of a small four-sided diamond prramid into the specimen under test. The impressions resemble the impressions made by the sharp edge of an axe when driven into a flat surface, except that the diamond pyramid is shaped to leave a rhomboidal impression on the surface of the specimen (fig. 56). The precision with which the indentation, at maximum load, can be determined with this new instrument makes it superior to any other instrument available for measuring the hardness of dental enamel and substances of similar properties. Table 50 gives numerical values which represent the relative hardness of a number of items, most of which are familiar to the dentist. These hardness numbers, as indicated at the top of the column, represent the ratio of the load applied to the cross-sectional or projected area of the indentation. In the simplest terms the hardness number represents the load in kilograms supported by 1 square millimeter of cross-sectional area 


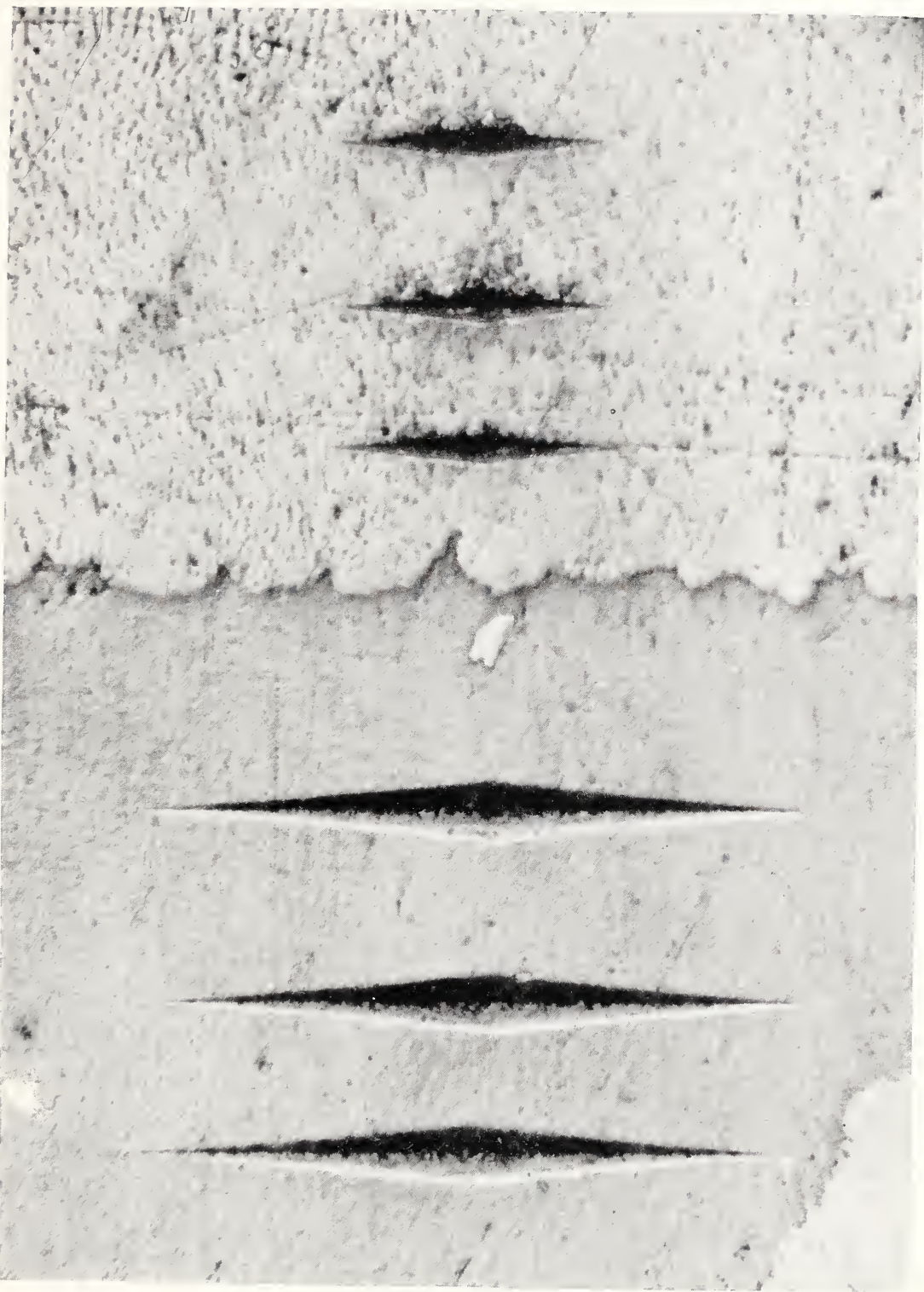

Figure 56. - Indentation marks made by the Knoop indenter (see fig. 24).

Transverse section of the crown of a lower first molar near the dento-enamel junction. The long marks are in dentin. The short marks are in enamel. The ename! fractured around the marks, not because of It is difficult to polish but because of the condition of the enamel surface which was not adequately polished. because of their polish adjacent dentine and enamel at the same time and maintain them on the same level because of their great difference in hardness. Indentation marks in highly polished enamel are shown in
figure 24 . 
of the indenting tool. According to the shape of the indenting tool (spherical, pyramidal or other design) numbers differing from those given in table 50 may be obtained, but there should be no differences in the relative orders of the items.

\section{TABLE 50.-Indentation hardness (average values)}

[Knoop method]

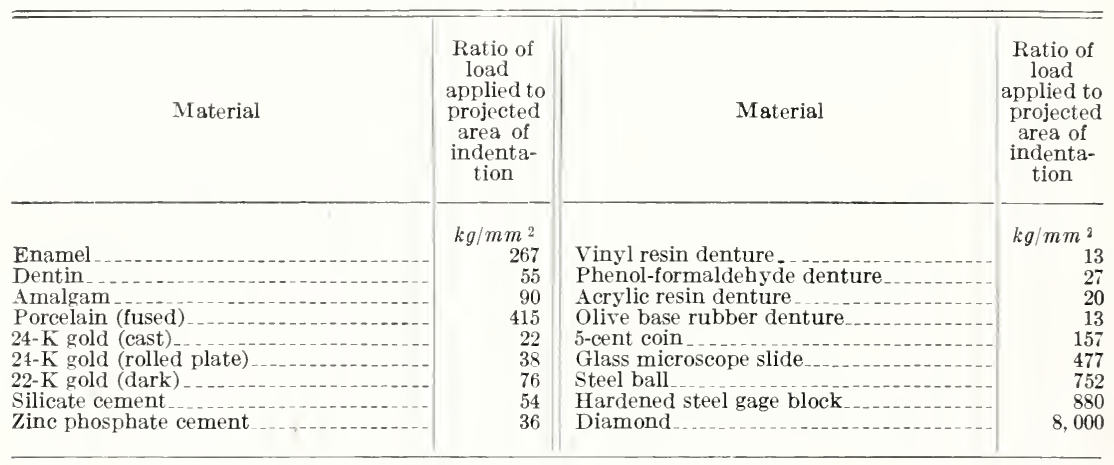

It is evident from the value 54 given in the table that silicate cement is approximately equivalent, in relative hardness, to dentine, but this does not necessarily mean that the two materials would show the same resistance to wear in service.

Dimensional change.-The thermal expansion of the human tooth is about 8 parts per million per degree centigrade [1]. This happened to be very nearly the same as the thermal expansion of a silicate cement which was measured at the same time. The thermal expansion of dental amalgam was also measured and found to be about three times that of the tooth. Table 2 gives values for these and a few other materials. Since the expansivities of teeth and silicate cement are approximately the same, thermal changes should not introduce disturbances at the margins of a silicate filling. Neither should temperature variations develop pressure against the pulpal wall of a deep cavity. In this respect the silicates are ideal filling materials.

For years confusion has existed over the question of what dimensional changes take place as a silicate cement hardens or sets. Supposedly simple tests have been developed to show expansion. Strang ? enough some of these tests may with slight variations of teckiles show expansion with one mix and shrinkage with another mix of ine same brand of cement.

In the cooperative research with the American Dental Association an extensive study of the length changes taking place during the setting of these cements was made. It is a well-known fact that a set cement exposed to air will shrink. Silicates in service must be kept moist and must be protected from air. The loss of water from the capillary structures injures the cement.

An item of great significance in making tests on dimensional changes in silicate cements is the selection of the time at which the measurements shall begin. In making restorations, pressure is maintained against the cement during the plastic period of from 3 to 8 minutes. Practically all satisfactory cements set in a rather short interval. 


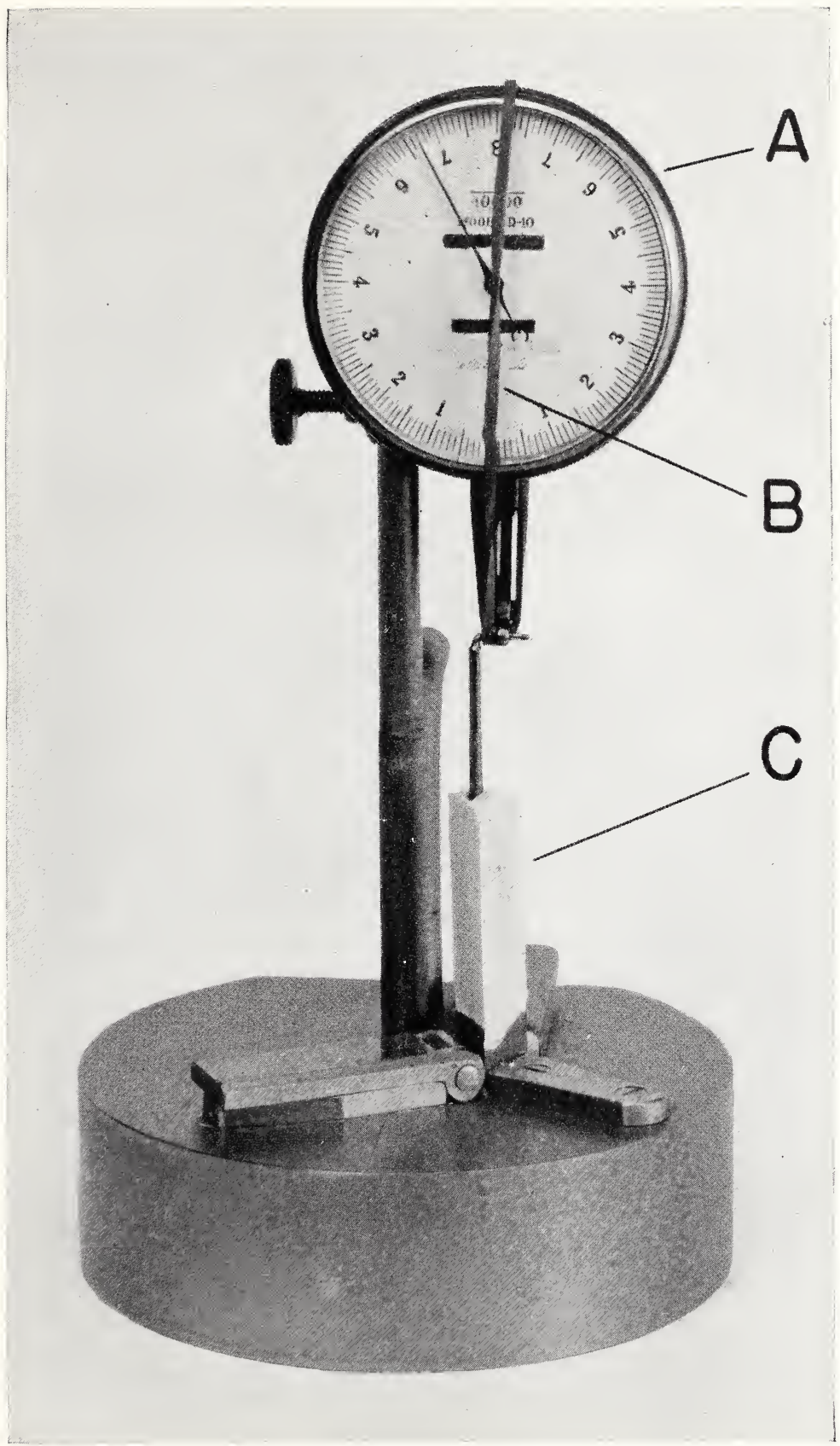

FIGURE 57.-One type of instrument used in determining linear dimensional change of silicate cement during setting.

$A$, dial gage; $B$, rubber band adjusted to balance the load exerted by the dial-gage mechanism; $C$, tri$A$, dial gage; $B$, rubber band adjusted to balance the load everted by the dial-gage mechanism; $C$, trict
angular-shaped specimen, the ends of which were securely fastened in the contacting parts of the instrument $406035^{\circ}-42-9$ 
The set is usually sharp and easily determined. After the set takes place the cement itself, rather than applied pressure, determines the dimensional changes which take place. Therefore it is evident that measurements of changes in length should begin at or near the time of set. Since the set cement must not be exposed to air, it is necessary to immerse it in water or in oil, or to coat it with a protecting varnish. Either method of protection may interfere with the precision of the measurements. Varnish and oil layers may change in thickness as they dry out. Water may react with the surface layer of the cement gel and dissolve off part of it, or may soak in and puff the surface. The first might show unreal or excessive shrinkage and the second unreal or excessive expansion. It is therefore very important that the general change in volume of the cement shall not be obscured or lost entirely by superficial or surface reactions.

Three methods of measurement were employed before the abovepictured chaotic situation was completely cleared up. In all the tests, unless a statement to the contrary appears, the specimens were placed in water at the time of set, and readings started at once. Five brands of cement were tested in the dental amalgam interferometer (fig. 1 and 2) using specimens 10 millimeters long. All the specimens showed shrinkage (table 51). New specimens were prepared having a length of 2 millimeters. Two of these showed expansion, one showed less shrinkage than before, and two showed no definite difference in length change between the 10-millimeters and 2-millimeters specimens. This suggests, for three of the brands tested, that surface effects, which in small specimens quite definitely predominate over volume effects, were responsible for their behavior. The next test was designed to eliminate the surface effect suspected in two or more of the brands tested above. Specimens 25 millimeters long were prepared, with rods incorporated in and extending from each end. These rods were anchored near the end surfaces of the specimens by means of plates attached to the ends of the rods (fig. 57). These anchor plates were completely covered with the plastic cement as the specimens were formed. When this method of mounting the specimens in the testing device is employed the surface reactions between the water and cement cannot affect the measurements. (See fig. 58, which shows the effect of premature exposure to water). Movements of the rods therefore represent actual expansion or contraction of the inner mass of cement. Six brands were tested. All showed shrinkage (table 51). The values for these six tests are thought to represent definitely and with a fair degree of accuracy the normal behavior of the interior mass of a silicate cement.

As a final test to verify the surface reaction and to separate it from the volume or mass reaction, a third experiment was performed. Approximately 2.5 grams of mixed cement was pressed into a disk 0.4 millimeters in thickness. The diameter was about 50 millimeters. A duplicate mix was formed into a sphere having a diameter of about 10 millimeters. The specimens were suspended in water at the time of set. The change in volume was followed by recording changes in density as indicated on a magnetically damped density balance.

The volumes of the disk and sphere were about equal but the surface area of the disk was about 25 times that of the sphere. Two brands of cement were tested. Both brands showed large permanent expansions for the disk specimens. The spherical specimens showed a 
TABLE 51.-Effect of size and shape of specimen on dimensional change on setting of silicate cements (a)

\begin{tabular}{|c|c|c|c|c|c|c|c|}
\hline \multirow{3}{*}{ Cement } & \multicolumn{3}{|c|}{ Length of specimen } & \multirow{3}{*}{ Cement } & \multicolumn{3}{|c|}{ Length of specimen } \\
\hline & $2 \mathrm{~mm}(\mathrm{~b})$ & $10 \mathrm{~mm}(\mathrm{c})$ & $25 \mathrm{~mm}(\mathrm{~d})$ & & $2 \mathrm{~mm}(\mathrm{~b})$ & $10 \mathrm{~mm}(\mathrm{c})$ & $25 \mathrm{~mm}(\mathrm{~d})$ \\
\hline & \multicolumn{3}{|c|}{ Linear change at end of 24 hours } & & \multicolumn{3}{|c|}{ Linear change at end of 24 hour } \\
\hline $\begin{array}{l}S A \\
S C \\
S D\end{array}$ & $\begin{array}{r}\text { Percent } \\
+0.18 \\
+.66 \\
-.25\end{array}$ & $\begin{array}{r}\text { Percent } \\
-0.04 \\
-.10 \\
-.23\end{array}$ & $\begin{array}{r}\text { Percent } \\
-0.03 \\
-.08 \\
-.24\end{array}$ & $\begin{array}{l}S E \\
S J \\
S K\end{array}$ & $\begin{array}{c}\text { Percent } \\
+1.52 \\
-0.005 \\
-.14\end{array}$ & $\begin{array}{r}\text { Percent } \\
-.16 \\
-.17\end{array}$ & $\begin{array}{r}\text { Percent } \\
-.21 \\
-.13 \\
-.25\end{array}$ \\
\hline
\end{tabular}

a All specimens were immersed in water at the time of setting.

b Specimens were small cylinders about 2 millimeters $(0.08$ inch) in diameter and 5 millimeters (0.2 inch) long. Measurements were made parallel with the diameter.

c Specimens were small cylinders about 5 millimeters $(0.2$ inch) in diameter and 10 millimeters $(0.4$ inch) long. The top surface of the cylinder was conical. Measurements were made parallel with the axis.

d Specimens were triangular in cross-section. Each side of the triangle was approximately 10 millimeters (0.4 inch) long. The length of the specimens was approximately 25 millimeters (1 inch). Measurements were made on the 25 -millimeter dimension.

slight initial expansion but at the end of 1 hour had returned to a volume approximately the same as that at the time of set. 'This was accepted as conclusive proof that the net dimensional change taking place in a silicate cement restoration is composed of at least two parts. One of these is a small internal volume shrinkage which takes place throughout those parts of the mass of cement which are protected from moisture. The second reaction appears to be an expansion which takes place when moisture reaches the cement. This is naturally most pronounced at the surfaces of the cement. As the varnish or protective medium applied to a new silicate restoration begins to disintegrate and the moisture reaches the surface of the cement an expansion is to be expected. In shallow dental restorations it may extend to a depth sufficient to include a major portion of the mass of cement incorporated in the restoration. The immediate or too early application of moisture to silicate cement may develop the surface expansion so effectively and so rapidly that, as in the case of the thin disks suspended in water, no shrinkage whatever will be manifested. Such early admissions of moisture will unfortunately cause the cement to develop a soft or spongy layer which will be detrimental to the dental restoration. Moisture coming in contact with the surface after the set is more nearly completed, as for instance when the protective coating wears away, does not impair the surface appreciably and may conceivably tend to cause a slight, helpful expansion of the cement.

The surface defects resulting from the early contact with water were shown in a very conclusive manner by an experiment which can be duplicated in any dental office or laboratory. Disks of cement prepared in the usual manner were dropped into water a few minutes before the set had taken place. One-half of each disk was covered with cellophane prior to dropping it into the water. A few minutes after the setting time had elapsed the cellophane was removed from the protected halves of the disks. The disks were then left in the water 1 week. Figure 58 shows the surface of the two halves of such a disk. The exposed surfaces are much softer. This is proved by the depth and width of the lines produced by drawing a scratch-hardness tool across the surfaces. The prematurely wetted surface has a mat 
surface such as is produced by etching. In fact the surface is etched as well as swollen. Neither condition is desirable.

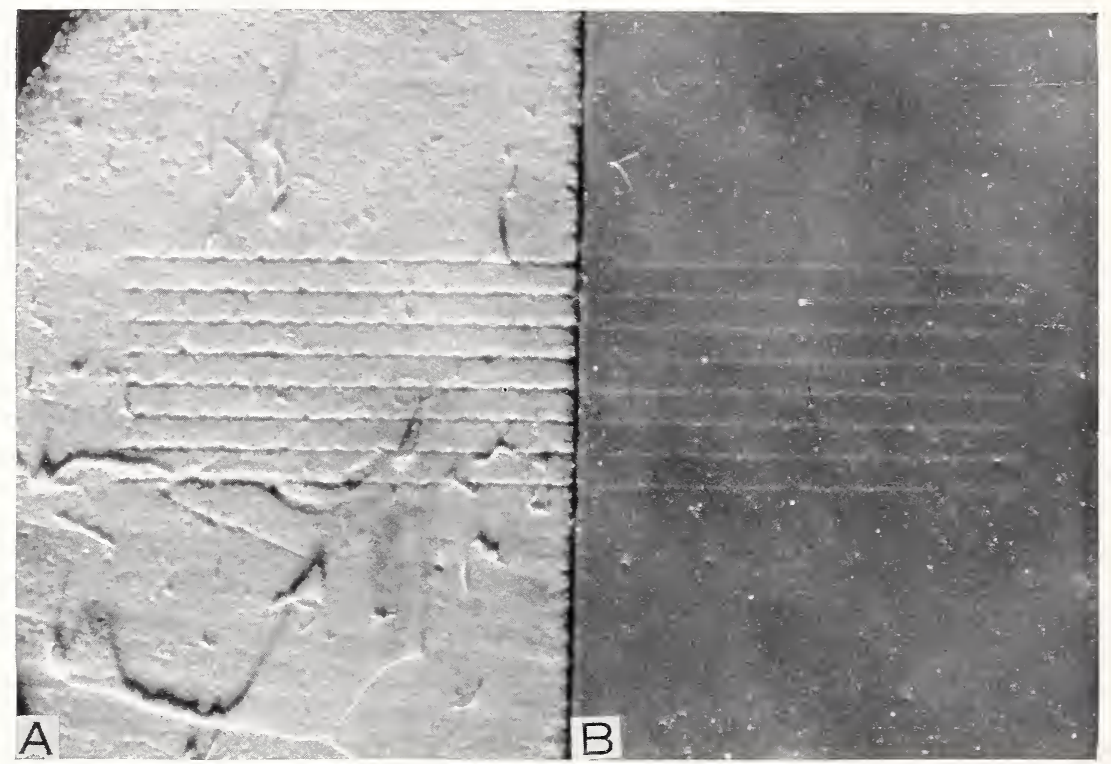

Figure 58. - Section of a disk of silicate cement $K$.

$A$ was immersed in water 2 minutes prior to the time of setting, $B$ was immersed in water 4 minutes after the time of setting. The series of parallel lines ruled across the surface of the specimen show the apparent differences between the two surfaces. The surface of $B$ did not seem to be seriously affected by the water contact.

Lining or varnishing the cavity and protecting the surface are essential. The tooth tissues are thus protected from the effects of possible free acid in the new, unset cement and the exposed surfaces of the restoration are permitted to develop the necessary and most satisfactory physical properties. Such a technic is logical. Experience has shown that it is not impossible to place silicate fillings which will last 10, 20, or more years. Such fillings can be made with cements that comply with the specification requirements when used as directed by the manufacturer (item L-2, p. 206).

An unsatisfactory test for dimensional changes in silicate cements appeared some years ago. A small amount of cement was packed in the center section of a small tube. Mercurochrome was then poured into the tube. The ends of the tube were closed with corks to prevent the escape of the colored liquid. If no color penetrated between the cement and the wall of the glass tube the cement was said to be free of shrinkage. On some very slow-setting cements the water in the mercurochrome will react with the plastic or semi-set cement and cause it to expand. Whether or not the dye enters between the cement and glass depends upon the chemical reaction between the dye and cement. Free acid in these partially set cements will precipitate the color component of the mercurochrome and thus tend to prevent its penetration between the walls of the tube and the plug of cement. Dyes dissolved in water-free solvents such as benzine or absolute alcohol penetrate between the plug of cement and walls of the tube 
and disclose shrinkage which may not have been disclosed by the aqueous solution of mercurochrome. The mercurochrome test is deceptive and need not be followed further in its many variations.

Staining and discoloration.-Previous discussions have touched upon the loss of water by the silicate cements when exposed to the air and the absorption of water when they are immersed in water. These changes are typical of hydrogels of colloidal materials. Porosity and

\begin{tabular}{|c|c|c|c|c|c|c|c|}
\hline CEMENT & SHADE & UNEXPOSED & EXPOSED (2) & CEMENT. & SHADE & UNE XPOSED & Exposed 0 \\
\hline$S A$ & No. 2 & & & SJ & NO. 6 & & \\
\hline SB. & NO. $2 B$ & & & SK & No. 1 & & \\
\hline sc & NO. 2 & & & SK & No. 3 & & \\
\hline SD & No. 3 & & & SK & NO. 6 & & \\
\hline SD & No. 6 & & & SK & NO. 12 & & \\
\hline SE & No. 2 & & & $\mathrm{SK}^{(3)}$ & No: 3 & & \\
\hline SE & No. 6 & & & SK 0 & $\begin{array}{l}\text { No. } 3 \\
\text { No. } 6\end{array}$ & & \\
\hline SF & No. 1 & & & SK ${ }^{6}$ & NO. 3 & & \\
\hline$S F$ & No. 3 & & & SL & No. 3 & & \\
\hline SG & No. 3 & & & SM & No. 3 & & \\
\hline $\mathrm{SH}$ & No. 2 & & & $2 N^{(1)}$ & & & \\
\hline 51 & No. 4. & & & $20^{\circ}$ & & & \\
\hline $8 \mathrm{~J}$ & No. : : & & & & & & \\
\hline
\end{tabular}

FIGURE 59.-Discoloration of silicate cements in a hydrogen sulfide atmosphere.

1 Zine phosphate cements.

2 Exposed to hydrogen sulfide fumes for 24 hours at $20^{\circ}$ to $25^{\circ} \mathrm{C}\left(68^{\circ}\right.$ to $\left.77^{\circ} \mathrm{F}\right)$

3ith Durosim.

With 5-percent prtrolatum.

5 With castor oil and aluminum phosphate

staining of the restoration are at once suggested when these changes take place.

The change in the surface shade of some of these cements, when exposed to sulfides, is well known (fig. 59). It will be noted that cements $S E, S F$ and $S G$ darkened the most. Reference to table 45 will show that cements $S E$ and $S F$ contained considerable amounts of iron while cement $S G$ had lead as a major impurity. It is believed that the degree of freedom from such impurities is an index of the degree of freedom from discoloration in hydrogen sulfide. The presence of antiseptic materials such as copper compounds will also 
cause discoloration. This effect is shown by the zinc phosphate cement $Z O$, figure 59, which contained copper silicate.

The zinc phosphate cements softened and disintegrated badly in the hydrogen sulfide atmosphere. The silicate cements were little affected as the original glossy surface of the disk appeared to be present after the test. There may be some connection between the behavior of the two types of cements in hydrogen sulfide and their solubilities in clinical service as small amounts of hydrogen or other sulfides are in the mouth when sulfur-bearing proteins decompose.

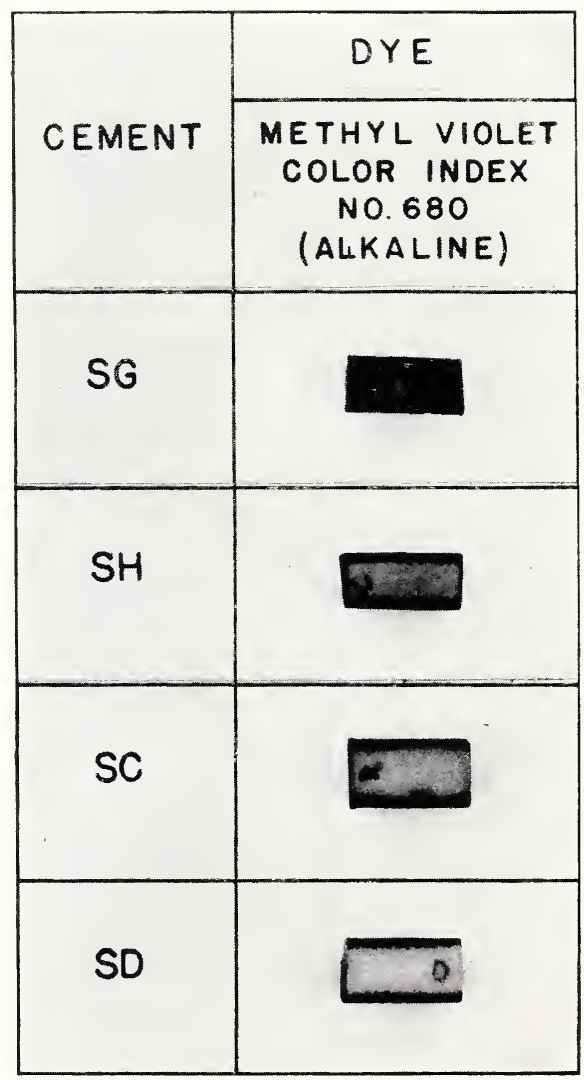

FIGURE 60.--Staining of silicate cements.

For years dyes have been used to test the permeability or staining characteristics of dental cements. The criteria used in evaluating the cement by the dye test were usually the brilliance and the depth of penetration of the dye. Some dyes like mercurochrome are precipitated by the cement liquid and should not be used. In testing silicate cements a dye having a slightly alkaline reaction should be selected because of the faint acidity of the cements. Methyl violet is a suitable dye of this type and is fairly selective as shown in figure 60. The small cylinders were immersed in a 0.2 pereent aqueous solution of the dye and stored for one month at $37^{\circ} \mathrm{C}\left(99^{\circ} \mathrm{F}\right)$. The specimens were then removed from the dye solution and a tangential 
section was planed on each cylinder to disclose the amount of penetration of the dye.

Effect of humidity on the cement liquid.-Recall that the liquids used in making the mixes are essentially aqueous solutions of phosphoric acid containing dissolved phosphates (table 44). Such solutions are not stable as they tend to come into equilibrium with the

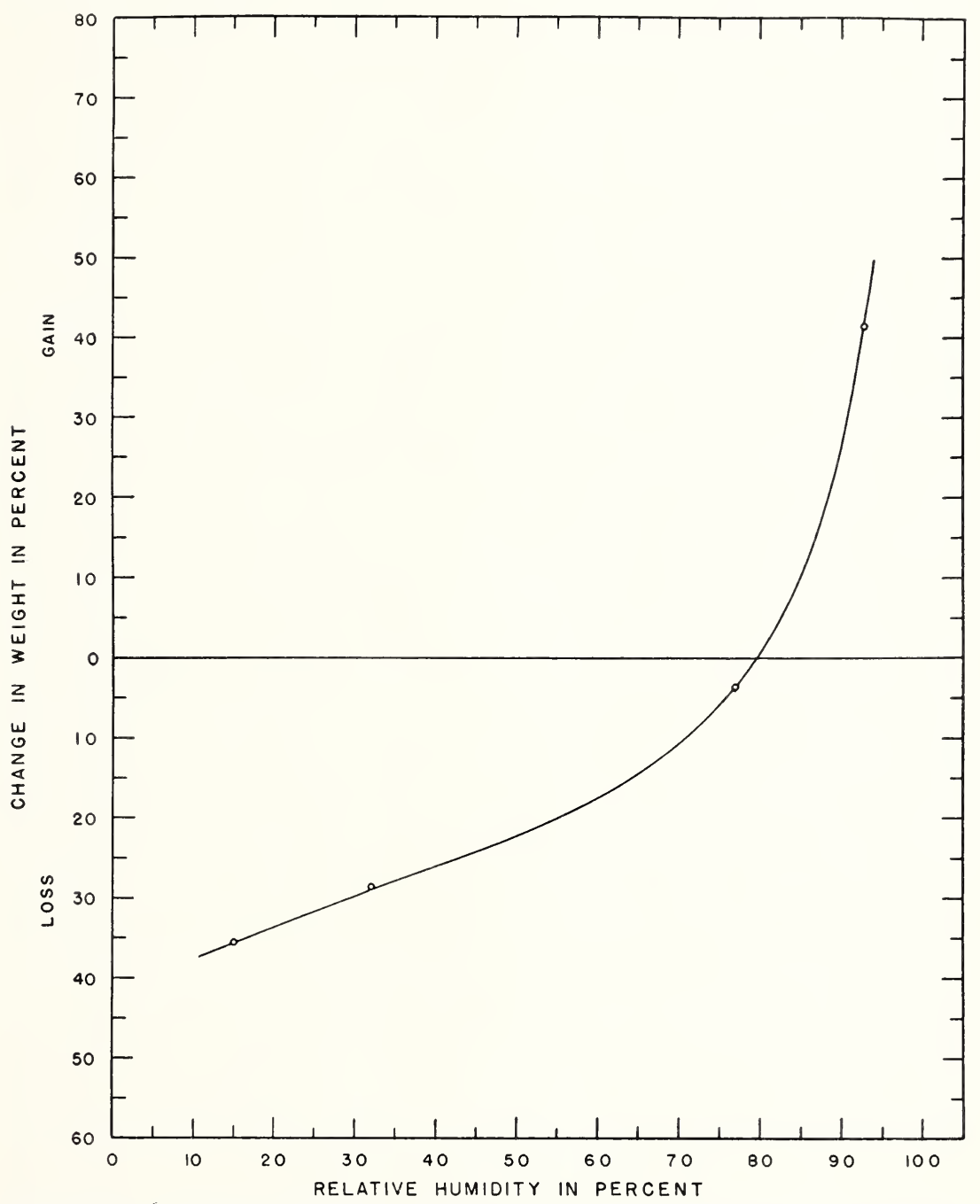

FIGURE 61.-Change in weight of cement liquid SD after storing for 200 days at different humidities.

water vapor of the air and in so doing change their water content. If the liquids are exposed to dry air they lose water; in moist air they gain water. Reference to figure 61 will show this phenomenon on cement liquid $S D$. In this case the liquid is in equilibrium with air having a relative humidity of 80 percent. When such liquids are 
exposed to air having a higher humidity water is rapidly absorbed. At humidities lower than 80 percent this particular liquid rapidly lost water. To illustrate the practical effect of such a condition the setting time of cement $S D$ was determined with (1) the normal liquid, (2) the normal liquid less 3 percent of its water. (3) the normal liquid less 10 percent of its water. The setting times were 6,9, and more than 30 minutes, respectively. The normal liquid may lose water when exposed to air having a low humidity. This is the cause of the frequent complaints regarding the slow setting of silicate cement during the winter months.

The matter of preserving the liquid is therefore of real practical importance. Any or all of the following suggestions will help. Never leave the stopper out of the bottle longer than is necessary to withdraw the liquid. The liquid should be placed upon the slab imme-
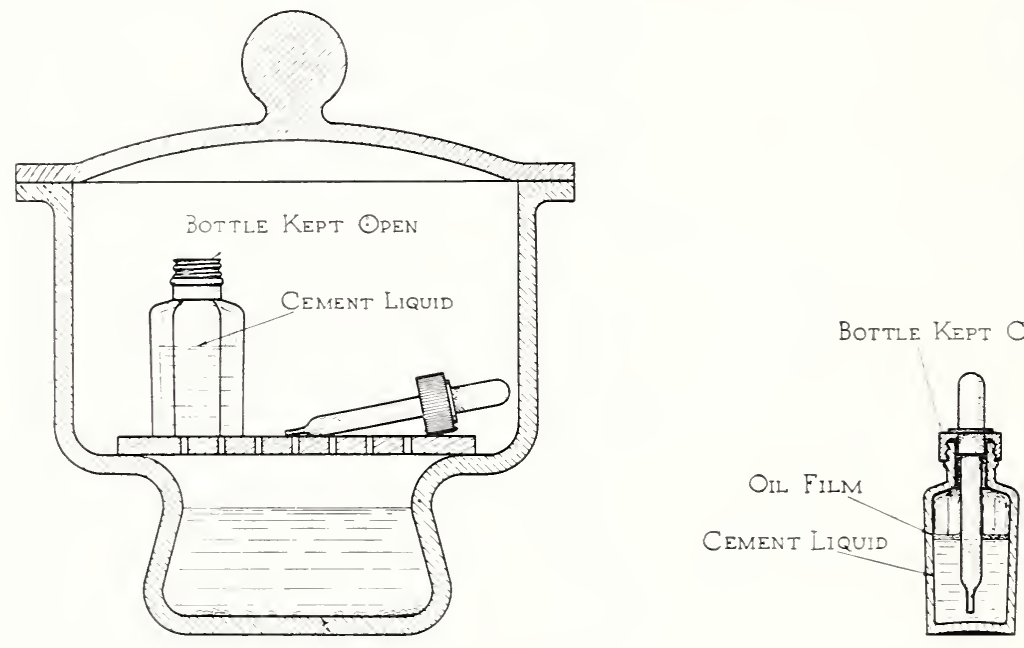

Saturated SALT SOLUTiON TO CONTROL HUMIDITY IN JAR

FIGURE 62.-Two methods of protecting the cement liquid from gain or loss of water due to atmospheric conditions.

diately before the mixing is started and there must be no delay in completing the mixing. Two methods of protecting the liquids are shown in figure 62. The method emploving the protective oil film seems quite practicable. Light liquid petrolatum U. S. P. was used for this purpose. In practical use, the dropper should be inserted beneath the oil film before any liquid is drawn into the dropper. The outside of the tube of the dropper should also be wiped off after it is withdrawn from the liquid. Laboratory tests showed that the small amount of oil which might contaminate the mix had no ill effects upon the phrsical properties of the mix. Nerertheless if one desires to try this method one should first place some experimental fillings, as the laboratory tests may not have detected some fault which may be exposed by clinical tests.

Another suggestion (fig. 62) is to place the unstoppered bottle in a closed container having the air humidity in equilibrium with cement 
liquid. Various humidities may be maintained in such a closed space by placing solutions of different saturated salts in the bottom of the jar as shown in figure 62. For example, cement $S D$ liquid was found to be stable at 80-percent relative humidity (fig. 61). To produce and maintain this humidity a saturated solution (there must be some undissolved crystals in the solution) of ammonium chloride $\left(\mathrm{NH}_{4} \mathrm{Cl}\right)$ is kept in the bottom of the jar. Different cement liquids would require different degrees of humidity to maintain a constant weight. Information about the equilibrium humidity of each cement liquid should be obtained from the manufacturer.

Modifying agents.-The effective life of silicate cement is sometimes short, consequently all dentists may reasonably expect to encounter a number of failures at one time or another when using them. At such times the dentist may be susceptible to appeals to try one of the modifying preparations which have been recommended from time to time as necessary to improve the properties of silicate cements. Certain special oily, soapy and grease-like preparations have been offered for incorporation in the cement during the mixing procedure with the assurance that the properties of the restoration would be enhanced. So far no American manufacturer has been convinced that the modifying agents advocated do materially improve the cements. In tests conducted in the Bureau's laboratory, the addition of 5 percent by weight of petrolatum to the powder of cement $S K$ increased the powder-liquid ratio for a given consistency but also increased the solubility in water and the opacity. The time of setting and acidity were not appreciably affected. The specimens containing petrolatum were 30 percent weaker than the normal cement. The shrinkage of these specimens in air was about 40 percent less than the shrinkage of the normal cement under like conditions of test. However there was no significant difference in the shrinkages when the tests were conducted in water at mouth temperature. All in all one can say that the addition of petrolatum did neither definite harm nor good to the cement. Its use should certainly be confined to experimental fillings. There is always the danger that these added ingredients may break down in a few months and cause serious discolorations. The same may be said of soap and other agents which, when added to a silicate cement, are said to improve it.

Variation in batches or lots produced by manufacturers.-In the case of cement $S F$ a definite difference was noted between different batches or lots as measured by the consistency test (ADA specification No. 8, item F-2, page 205). 1.3 grams of powder (first purchase) could be incorporated in 0.4 milliliter of liquid to produce a mix of standard consistency; while only 1.1 grams of powder of the second purchase would be necessary. 'The disintegration and "solubility," and the shrinkage of the second purchase $(1.1 \mathrm{~g} / 0.4 \mathrm{ml})$ would be appreciably more than those of the first purchase $(1.3 \mathrm{~g} / 0.4 \mathrm{ml})$. The strength would be less.

It is customary to send to each manufacturer data obtained on his product during the survey of materials prior to the formulation of a specification. In one instance, cement SJ, the manufacturer's data did not agree with those of the Bureau. Subsequent work disclosed that the disagreement was caused by variation among batches of powder and liquid. The differences among batches of the liquid are demonstrated in table 52. Undoubtedly these variations are pro- 
duced by the exposure of the liquid to the air during preparation and bottling:

TABLE 52.-Tariation in batches of silicate cement liquid $S J$

\begin{tabular}{c|c|}
\hline \hline $\begin{array}{c}\text { Liquid (batch } \\
\text { number) }\end{array}$ & $\begin{array}{c}\text { Percentage loss in } \\
\text { weight of liquid } \\
\text { when exposed } \\
\text { for } 1 \text { week at } 32- \\
\text { percent relative } \\
\text { humidity }\end{array}$ \\
\hline & $\begin{array}{c}\text { Perctrt } \\
223\end{array}$ \\
232 & 14.6 \\
249 & 14.4 \\
250 & 12.4 \\
\hline
\end{tabular}

The rariations among batches of powder are disclosed in table 53. Here it will be noted powder batch 707 , in combination with liquid batch 250, produced a cement of high "solubility" (2.8 percent). In another combination (powder 647 and liquid 223) the "solubilitr" was low $(0.9$ percent). The manufacturer of this cement was not aware of the situation. When it was brought to his attention it was corrected and he is now controlling his production by tests.

TABLE 53.- Tariation in physical properties among batches of silicate cement $S J$

\begin{tabular}{|c|c|c|c|c|}
\hline $\begin{array}{c}\text { Powder } \\
\text { (batch Xo.) }\end{array}$ & $\begin{array}{l}\text { Liquid } \\
\text { (batch No.) }\end{array}$ & $\begin{array}{l}\text { Powder li- } \\
\text { quid ratio }\end{array}$ & $\begin{array}{l}\text { Time of } \\
\text { setting }\end{array}$ & $\begin{array}{l}\text { "Solubility" } \\
\text { and disin- } \\
\text { tearatinn } \\
\text { during first } \\
\text { i days }\end{array}$ \\
\hline $\begin{array}{l}707 \\
716 \\
718 \\
647 \\
647\end{array}$ & $\begin{array}{l}250 \\
250 \\
223 \\
250 \\
223\end{array}$ & $\begin{array}{c}\text { Grame } 1 \\
1.20 \\
1.35 \\
1.35 \\
1.10 \\
1.15\end{array}$ & $\begin{array}{c}\text { Minutes } \\
4.0 \\
4.0 \\
4.0 \\
6.5 \\
3.5\end{array}$ & $\begin{array}{c}\text { Percent } 3 \\
2.5 \\
1.5 \\
1.1 \\
1.1 \\
0.9\end{array}$ \\
\hline
\end{tabular}

1 Grams of pow der used in $0.4 \mathrm{ml}$ of liquid to produce a mix of standard consistener. $\therefore$ Tests conducted at $21^{\circ} \mathrm{C}\left(75^{\circ} \mathrm{F}\right)$.

3 Br weight.

Pulp irritation.-The results of clinical experiments on the irritation of the pulp br various trpes of cement are inconclusive. To illustrate how far apart professional opinions are regarding the toxic effects of silicate cement on the pulp one has only to reriew the replies to the following question submitted to a group of 106 dentists who were cooperating with the ADA Research Commission in a studr of silicate cements [97]. Question: Do rou beliere that the silicate cements are more irritant to the pulp than are other restorative materials? Approximatels 45 percent of the cooperators replied "No," 45 percent replied "Yes," and the remaining 10 percent were undecided. In other words clinical experience has failed to provide a definite answer to the question.

Effect of varying consistency.-As has been pointed out earlier the properties of a silicate can be modified to a remarkable degree br changing the relative amounts of powder and liquid used in making the cement. To illustrate this there are given in table 54 data on the phrsical properties of cement $S K$ determined at three different 
ratios. The standard testing consistency, 1.4 grams of powder to 0.4 milliliter of liquid, was varied by adding 0.2 gram of powder to the standard to make a stiffer mix $(1.6 \mathrm{~g} / 0.4 \mathrm{ml})$ and by using 0.2 gram less powder than the standard to make a thinner mix (1.2 $\mathrm{g} / 0.4 \mathrm{ml}$ ). Note (table 54) that the thicker mix sets in a shorter time, is stronger, is less soluble, and shrinks less than the thinner mix. This is to be expected as the thicker mix contains relatively more powder and less binder than the thinner mix. It has been repeatedly pointed out that the binder or matrix material is responsible for most of the inferior qualities of silicate cement. One should therefore always use the thickest mix which the operation at hand will permit.

As before stated, the standard consistency, that is, the average consistency used by a group of representative practitioners, is not necessarily the best. A stiffer or heavier consistency is preferable. With few exceptions, such as the placing of a temporary jacket crown, there is certainly no need of a thinner than standard consistency.

TABLE 54.-Effect of varying powder-liquid ratio on physical properties of silicate cement $S K$ a

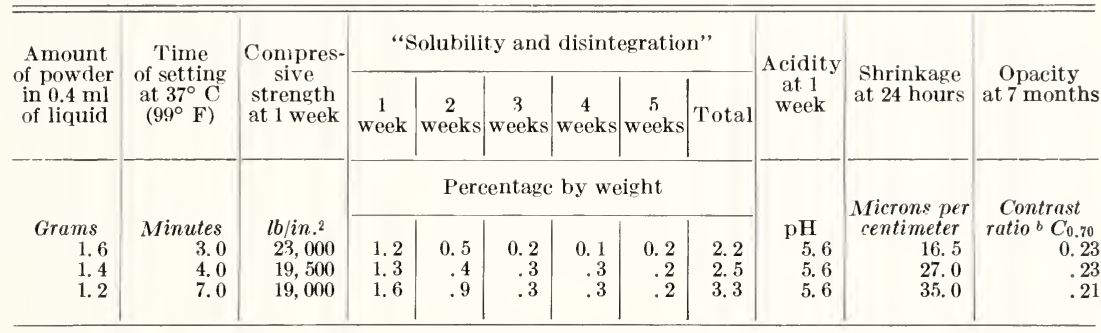

a Methods user are described in A. D. A. Specification No. 9 (p. 205).

$b$ The ratio is obtained by dividing the apparent daylight reflectance of light from a specimen $1 \mathrm{~mm}$ thick when placed against a black backing by the apparent daylight reflectance obtained when the specimen is placed over a white backing, with an apparent daylight reflectance relative to that of $\mathrm{MgO}$ of 70 percent.

Specification.-The specification for dental silicate cements (page 204) has definite requirements or limitations for consistency of mix, time of setting, compressive strength, opacity, solubility and disintegration, and arsenic content.

Objections have been raised to the testing of all cements at a standard consistency. The makers of these cements want their products tested at the consistency they recommend, which is invariably heavier than the standard. In connection with this view several elements should be considered. First, no logical comparisons of physical propperties can be made among cements when the same consistency of mix is not used (table 54). Second, the standard consistency of mix represents average service conditions. Third, it is not contended that the standard mix is the optimum one, in fact, it usually is not. Fourth, if the consistency requirement in the specification was changed so that a heavier mix was required the resulting properties of all of the cements would be improved, and this would necessitate a general upward revision of the specification requirements. This, however, would not make the specification more restrictive than it now is. Fifth, if the cement will not withstand variations in treatment and still comply with the specification it may be too critical for general use. 
Technic.-The silicate cements should be manipulated in accordance with the following technics:

1. Use an exact ratio of powder to liquid. This ratio should represent the maximum of powder it is possible to use so as to keep the amount of gel in the restoration at a minimum.

2. Nix the liquid and powder on a chilled slab. (Dew must not form on the slab.) The lowered temperature of the slab aids the operator to wet each powder particle with the liquid before any appreciable amount of the chemical reactions have taken place, thus minimizing the injurt to the gel.

3. The mixing should be speedy and the restoration completed quickly so that the setting reactions may take place undisturbed in the carity. Restorations placed according to this technic should have phrsical properties decidedly superior to those mixed without definite technics.

4. Wherever possible the restoration should be molded to correct anatomy. Attempts to cut or polish the finished restoration will expose hard particles of powder embedded in a gel matrix. It is very difficult to polish this nonhomogeneous material.

5. The carity should be lined. except at the outer edge. and the restoration rarnished to prevent migrations of ions to or from the reacting cement. These migrations may, if not prevented, take place between the cement and pulp. and between the cement and oral fluids. In addition to this these cements must not be permitted to dry out during the first few hours. or in fact at any time after the reaction between the powder and liquid has formed the gel bonding material.

6. The water content of the liquid must not be permitted to change.

The mixing technics to be used in preparing specimens for testing are definitely set forth in the specification for silicate cement (p. 204).

If for any reason the mixing technics are changed as indicated below, the corresponding changes in properties may be expected. Decreasing the amount of powder increases the time of set. the "solubility". and the shrinkage and reduces the strength. Increasing the time of mixing increases the time of set and the "solubility." Increasing the temperature of the mixing slab decreases the time of set and the power-liquid ratio. Decreasing the amount of water in the liquid increases the time of set and the "solubility."

\section{(f) SILICATE-ZINC PHOSPHATE COMBINATION CEMENTS}

It was not long after the successful use of silicate cement that there appeared what might be termed hrbrid cements which were basically of the silicate trpe modified br the addition of zinc oxide alone or in combination with magnesium oxide. Sometimes the powder is a mechanical mixture of silicate and zinc phosphate cement powders. Cement $S L$ is of this kind (table 43). It is a mechanical mixture of silicate and zinc phosphate powders in the ratio of about 9:1. Other times the cement powder has had the zinc oxide fused into it as is the case with cement $S F$ (table 43) which contained orer 53 percent of zinc oxide and almost 2.5 percent of magnesia.

The phrsical properties of these two cements and one other of this trpe when tested according to the specification for silicate cement are given in table 5.5. 
Extravagant claims have been made for some of these mixtures, claims that they are as enduring as enamel and that they can be used to replace amalgam. A glance at table 55 will show that their strength is less than half that of amalgam. Furthermore, they in common with all dental cements are very brittle. This combination of weakness and brittleness limits their effective use to small protected cavities. The specific use of the cements is as a translucent cementing medium.

$\mathrm{T}_{\mathrm{ABLE}}$ 55.-Physical properties of silicate-zinc phosphate cements ${ }^{\text {a }}$

\begin{tabular}{|c|c|c|c|c|}
\hline Cement & $\begin{array}{c}\text { Powder in } \\
0.4 \text { ml of } \\
\text { liquid to } \\
\text { produce } \\
\text { standard } \\
\text { consistency }\end{array}$ & $\begin{array}{c}\text { Setting } \\
\text { time at } \\
\text { mouth } \\
\text { tempera- } \\
\text { ture }\end{array}$ & $\begin{array}{l}\text { Compres- } \\
\text { sive } \\
\text { strength } \\
\text { at } 1 \text { week }\end{array}$ & $\begin{array}{l}\text { “Solubil- } \\
\text { ity" and } \\
\text { disinte- } \\
\text { gration } \\
\text { during } \\
\text { first } 7 \text { days }\end{array}$ \\
\hline 1 & 2 & 3 & 4 & 5 \\
\hline $\begin{array}{l}S F \\
S L \\
S P\end{array}$ & $\begin{array}{l}g \\
1.3 \\
1.5 \\
1.1\end{array}$ & $\begin{array}{r}\text { min. } \\
7.0 \\
4.0 \\
8.0\end{array}$ & $\begin{array}{c}\text { lb/in. } .^{2} \\
19,500 \\
25,500 \\
22,000\end{array}$ & $\begin{array}{l}\% \\
0.2 \\
2.0 \\
0.7\end{array}$ \\
\hline
\end{tabular}

a Methods used are described in A DA specification 9 (p. 204).

\section{ORGANIC MATERIALS}

\section{IMPRESSION MATERIALS}

Three important types of materials are used in taking impressions. These may be classified as rigid, plastic, and elastic. Quick-setting plaster of paris with or without organic modifiers represents the rigid type. The waxes and resins (impression compound) which may be softened by heating and hardened by cooling represent the plastic type. The third is a type new in dental technics and consists primarily of an elastic (hydrocolloidal) material known as agar.

The trays in which these materials are carried to the mouth and supported during the setting or chilling are shaped to the approximate contours of the tissues to which the material is to be molded. This is obviously an economical arrangement, but it has a still greater significance. The setting changes, contractions on cooling, dimensional changes resulting from loss or gain of water content, and distortions during the pouring of a model are kept to a minimum by this rigid tray of metal or of the harder wax and resin tray compounds.

The elastic impression matcrials would be of little value without the stiff walls of the tray. In fact, it is necessary to anchor the material by forcing it into numerous holes in the tray in such a manner that it is keyed in position.

A trial impression in a plastic compound is frequently followed by a second impression wherein only a thin layer of soft plaster, softer wax, cement, or heated wax has been applied. 'This second impression, made in a form approximately fitting the tissues, reduces further the chances of distortion. Skillful operator's are able to soften designated parts of these primary impressions or to add materials of different degrees of plasticity, and thus cause compressions of parts of the soft tissues to an extent that produces a desired effect when the appliance is processed and seated. 
Rigid type.-Plaster of paris, a ceramic material, is considered here because of its use as an impression material. The plaster of paris impression is limited in its use by undercuts and similar irregularities. Some operators use the setting plasters where there are undercuts and break the impression before removing it from the mouth. The parts of the impression are then assembled in the tray and the model is poured. Resins and starches are often added to plaster to modify its properties.

Our interest in standards for this type of impression material can be limited to very simple tests. The time of set is important for the comfort of the patient. This should be between 2 and 4 minutes. Plasters having longer or shorter times of set will be rejected by most dentists without the necessity of a formal test or report by the research laboratory. The plaster should not shrink during the setting period as subsequent operations such as casting or vulcanizing are usually productive of shrinkage. A fine grain is necessary for satisfactory surface detail.

Plastic type.-The resinous, waxlike compounds are farorites with many operators. They can be preformed, flamed, or coated with softer wax in order to obtain finer detail in the impression. Ther can be rapidly chilled and removed. They give excellent detail; sufficient to permit their use in taking impressions for indirect inlay or bridge restorations.

One of the most exacting requirements is that the direct-impression materials shall soften decidedly at slightly above body temperature and shall develop definite rigidity as ther cool below body temperature. The tray compounds are for use at the higher temperatures and are not. strictly speaking mouth-impression compounds. Several tests were made to determine which instrument would most satisfactorily define the hardening and softening temperatures of plastic compounds. The instrument shown in figure 63 is used to apply loads to a test cylinder of the compound as required in the specification tests (page 187). The tests are made on cylinders 10 millimeters in diameter and 6 millimeters long, which are immersed in water at the temperature of the test for at least 20 minutes prior to loading. The load of 2,000 grams is applied for 10 minutes. Figure 64 indicates the flow values for six impression compounds. These compounds were supplied 15 vears ago. Values for present-day materials are given in table 56 . The working range represents those temperatures at which the compound will take a detail impression of fine lines. The highest temperature for direct-impression compounds must not be above that which can be tolerated by oral tissues.

Practical tests indicate that a compound will register tissue detail if it will flow 85 percent under the conditions specified in the previous paragraph. This value of 85 percent minimum flow at the maximum temperature of $45^{\circ} \mathrm{C}\left(113^{\circ} \mathrm{F}\right)$, arbitrarily established as the highest temperature permissible for oral comfort, gives us a compound which will register the desired details and not injure the tissues. At the other extreme of temperature we must have a rigidity which will maintain these details. The limit on maximum flow at low temperatures accordingly is set at not more than 6 percent at $37^{\circ} \mathrm{C}\left(99^{\circ} \mathrm{F}\right)$. The demand for 20 -percent flow at $40^{\circ} \mathrm{C}\left(104^{\circ} \mathrm{F}\right)$ has been added to prevent the use of compounds which fail to soften appreciably at this temperature. 
Tray compounds.-Tray compounds are those used in making preformed trays or for taking impressions outside of the mouth. The temperature and flow limits are listed in the specification on page 187. Naturally, higher temperature ranges are permissible for the tray compounds. Flow values for a number of present day compounds are

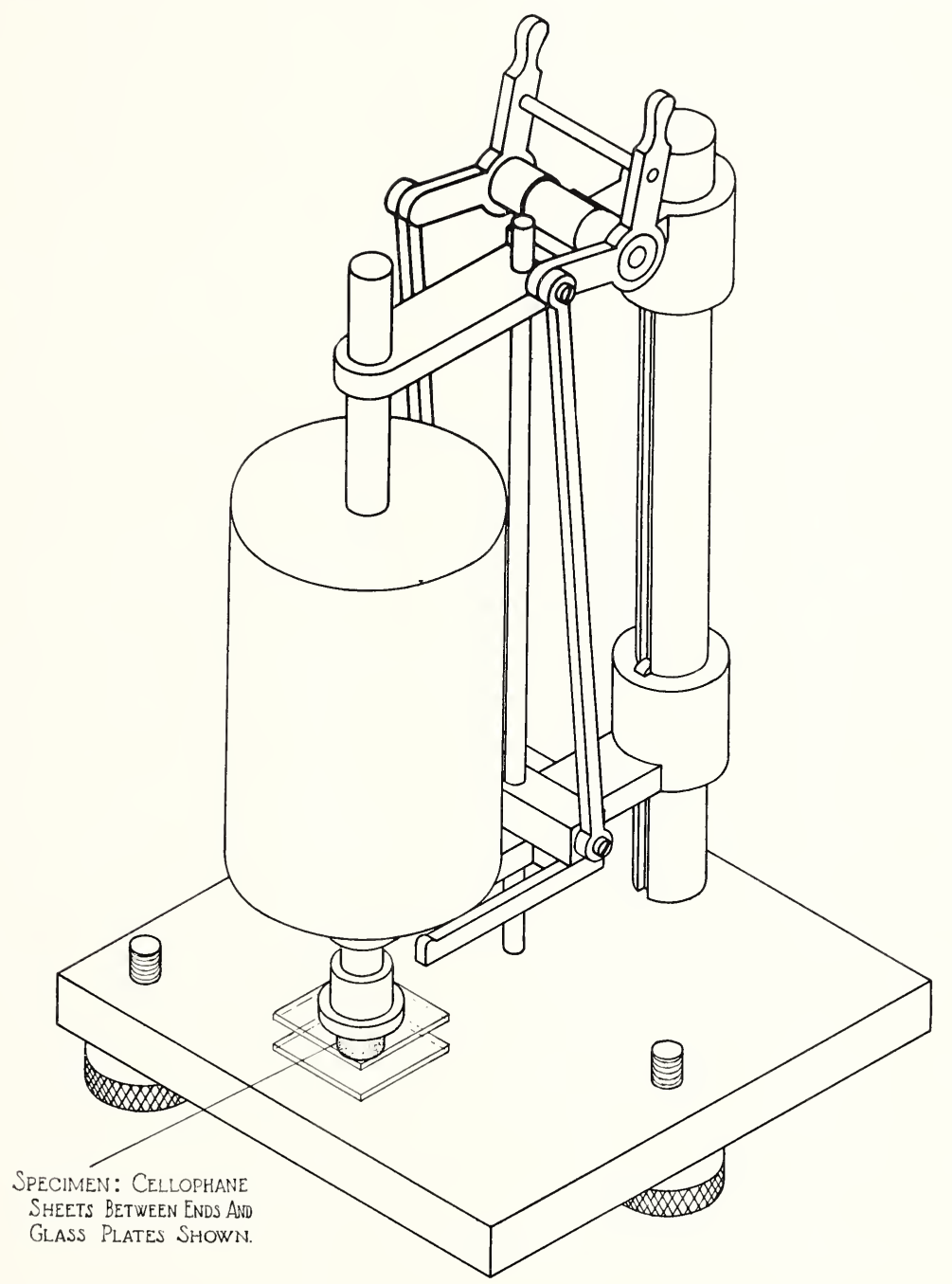

FIGURE 63.-Instrument used in measuring the flow of impression compounds and waxes.

listed in table 56. Compounds $A, B, C$, and $D$, are direct-impression compounds. $E, F, G, H$, and $I$, are tray compounds.

Doubtless some operators can use tray compounds as regular or direct-impression compounds and not encounter serious difficulties. An attempt to reproduce the detail of the test block shown in figure 65 , 
using temperatures comfortable to the mouth should convince one that he can take better impressions with those compounds which are classified by the flow test as impression compounds. See specification U-M-506 for details of the impression test (page 186).

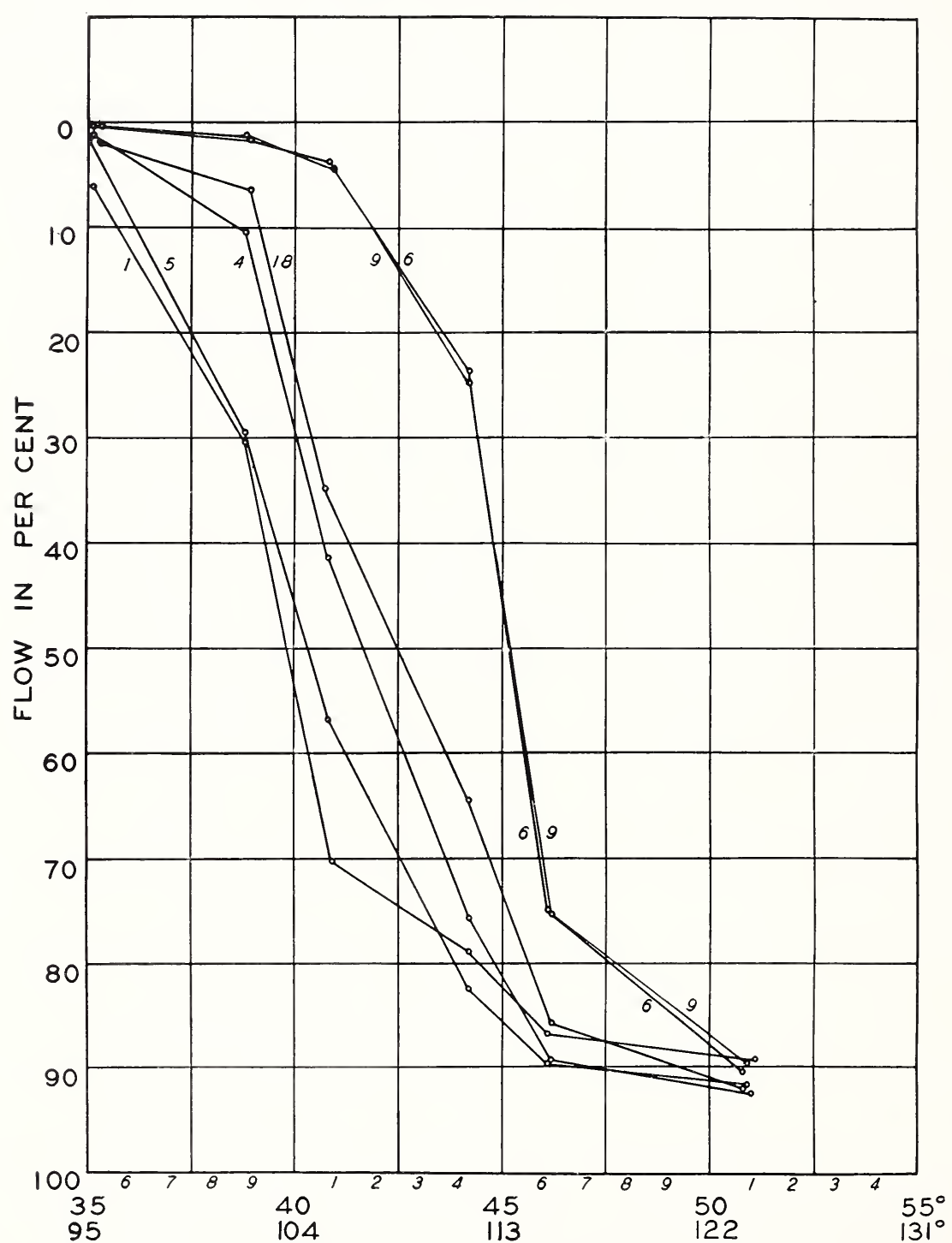

Figure 64.-Flow of impression compounds under pressure.

Specimens were 10 millimeters in diameter and 6 millimeters high. Cylinders were under a load of 2,000 grams.

Additional requirements for plastic compounds are homogeneity, smooth surfaces after flaming, and firm smooth margins after trimming.

The average linear thermal expansion between $25^{\circ}$ to $40^{\circ} \mathrm{C}\left(77^{\circ}\right.$ to $104^{\circ} \mathrm{F}$ ) of 18 impression compounds is 0.43 percent, which is approxi- 
TABLE 56. Flow of plastic impression compounds

\begin{tabular}{|c|c|c|c|c|}
\hline \multirow{2}{*}{ Compound } & \multicolumn{4}{|c|}{ Flow, in percent, at- } \\
\hline & $\begin{array}{c}37^{\circ} \mathrm{C} \\
\left(99^{\circ} \mathrm{F}\right)\end{array}$ & $\begin{array}{c}40^{\circ} \mathrm{C} \\
\left(104^{\circ} \mathrm{F}\right)\end{array}$ & $\begin{array}{c}45^{\circ} \mathrm{C} \\
\left(113^{\circ} \mathrm{F}\right)\end{array}$ & $\begin{array}{c}50^{\circ} \mathrm{C} \\
\left(122^{\circ} \mathrm{F}\right)\end{array}$ \\
\hline \multicolumn{5}{|c|}{ TYPE I-DIRECT } \\
\hline $\begin{array}{l}A \\
B \\
C \\
D\end{array}$ & $\begin{array}{l}2.4 \\
1.4 \\
2.0 \\
5.5\end{array}$ & $\begin{array}{l}29.1 \\
51.1 \\
35.5 \\
39.4\end{array}$ & $\begin{array}{l}88.2 \\
91.0 \\
91.2 \\
89.9\end{array}$ & $\begin{array}{l}95.3 \\
93.2 \\
98.0 \\
95.2\end{array}$ \\
\hline \multicolumn{5}{|c|}{ TYPE II-TRAY } \\
\hline $\begin{array}{l}E \\
F \\
G \\
H \\
I\end{array}$ & $\begin{array}{l}2.1 \\
0.7 \\
0.9 \\
2.3 \\
0.9\end{array}$ & $\begin{array}{r}9.0 \\
9.5 \\
11.4 \\
11.0 \\
3.1\end{array}$ & $\begin{array}{l}70.5 \\
80.5 \\
86.4 \\
82.0 \\
75.0\end{array}$ & $\begin{array}{l}86.3 \\
91.6 \\
93.8 \\
93.8 \\
93.8\end{array}$ \\
\hline
\end{tabular}

mately one-half that of 12 inlay waxes ( 0.79 percent). 'The effects of thermal expansion and shrinkage are shown in figure 66 [18]. An impression of the two metal posts, $A-1$ and $A-2$, in the flat plate, $A$, was taken by applying the compound in a tray. An excessively large mass of warm compound was applied and chilled. The depression in the face of the impression, $B$, between the pockets produced by the

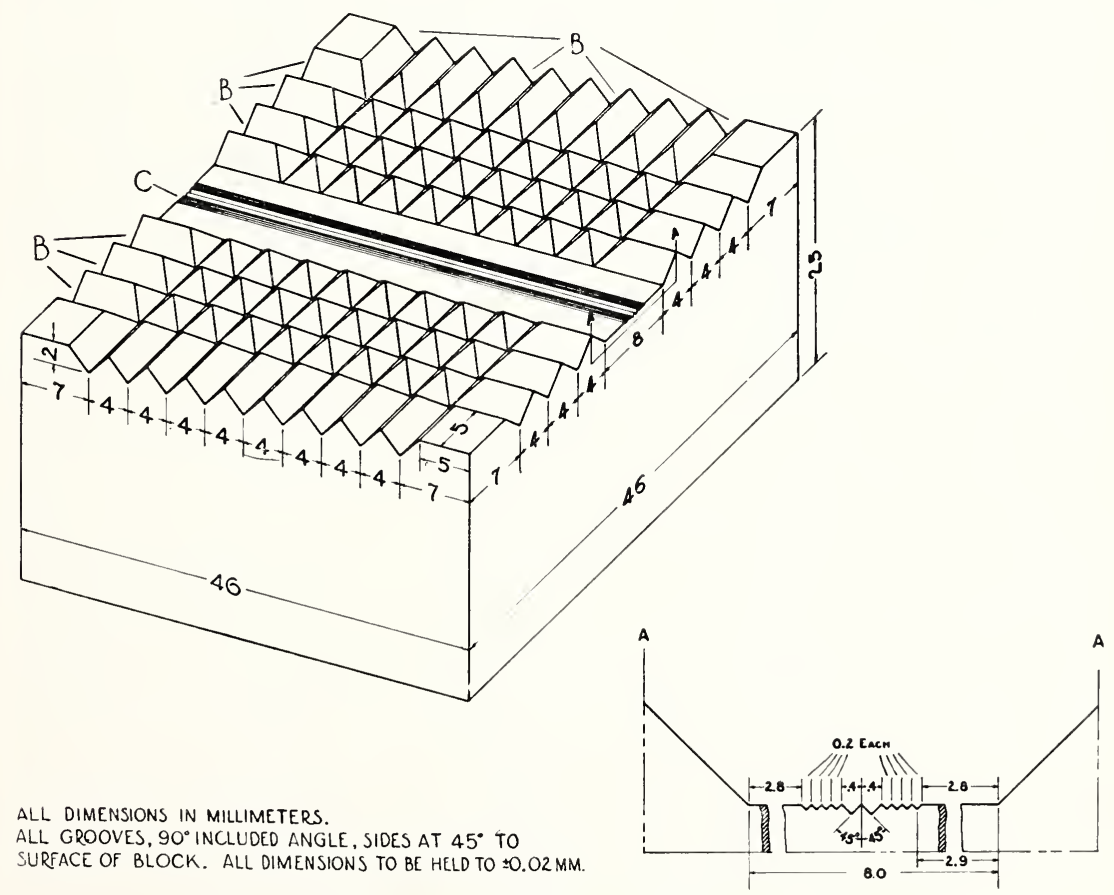

FigURE 65.-Test block for dental impression compound. $406035^{\circ}-42-10$ 
pins, represents part of the thermal shrinkage of the compound. Further defects are evident in the pockets produced by the pins. These impressions of pins $A-1$ and $A-2$ are not round but elliptical, which shows a drag of the compound horizontally on cooling, toward a shrinking central point. The operator wishing to verify the accuracr of his impression technic can do so by attempting to take an impression of a flat plate containing two or more pins. He will soon discorer that he must shape his tray to the minimum dimensions and not have the compound too hot if he wishes the most nearly exact reproduction.

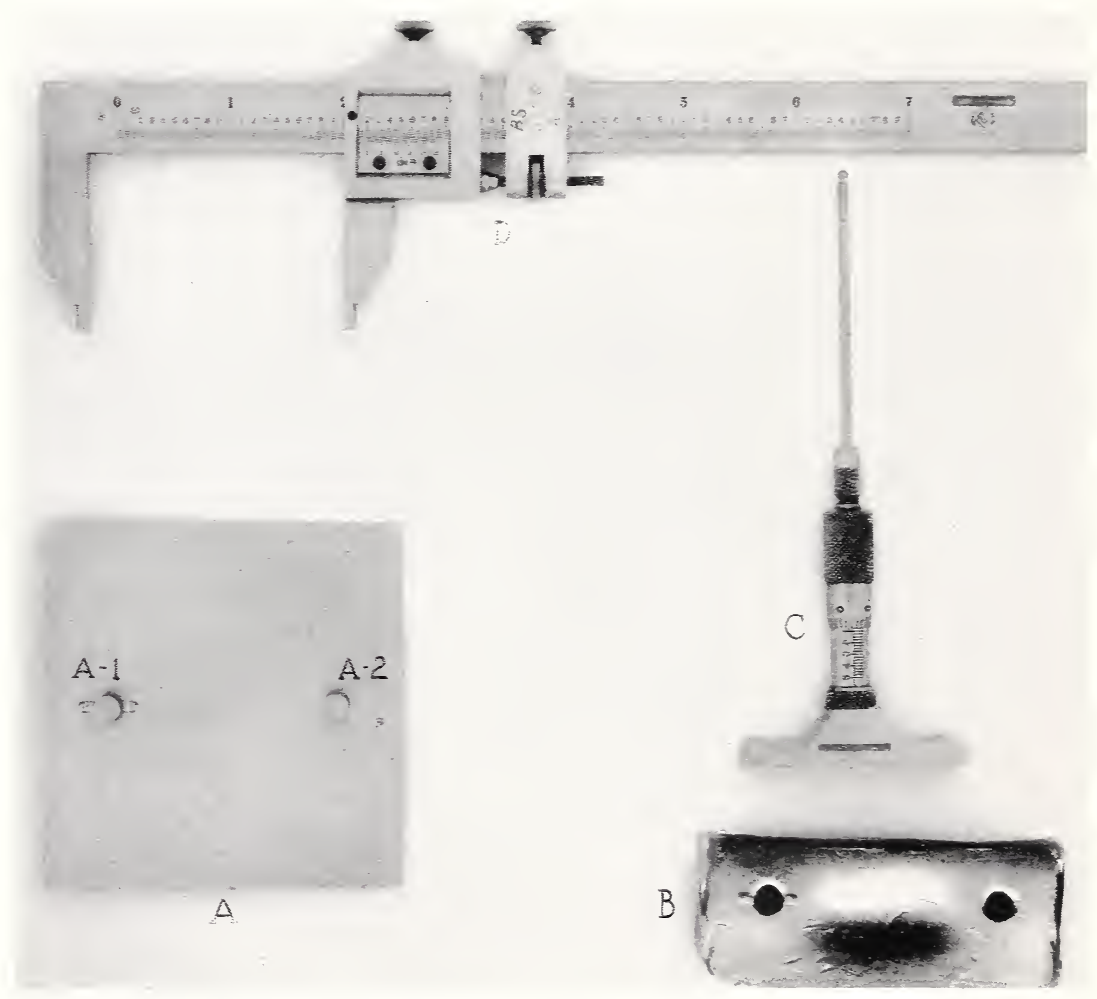

FigLRE 66. - Wethod of demonstrating the shrinkage of impression compound. $A$ is a flat steel plate on the face of which are two crlindrical pins, $A-1$ and $A-2$. An imprescion of the pins and surrounding surface is obtained by apolying a tray of rompound to them. The resulting impression, $B$, shows a large shrinkage area. The depte of the depression can be measured with a depth micrometer $C$. The rernier caliper, $D$. was used to measure distances between the pins on $A-1$ and $A-2$ and between the impression of the pins on $B$

The experience gleaned from taking an impression of the flat steel plate will also convince one of the excellence of the technic in which a trial impression is taken and chilled, its surface resoftened by flaming. and another impression taken. The shrinkage, by this technic, will be relatively small because it principally occurs on the thin surface layer and not throughout the body of the impression.

Elastic type.-Elastic impression materials are frequently selected for use where undercuts would prevent withdrawal of the impression in one piece or cause distortion or breakage if the rigid or plastic impression materials were used. W ith proper tray support, experience, 
and care in pouring the model this type of impression material is satisfactory for many operations. Some have attempted to use it for inlay impressions. Only the more skillful individuals can hope for satisfactory inlays by this method. Such use in not generally recommended by manufacturers of elastic impression materials.

The original development of agar as an impression material appears to have been done by Dr. Poller [119] of Vienna, a criminologist, who used it in taking impressions of human faces [131]. Models were poured against the impressions, tinted to lifelike colors and used for criminal identification. Its use was extended to other criminal fields such as the production of replicas of perishable objects, wounds, and minor details of massive objects needed as exhibits or evidence in court. Paul Gross has published a general formula for use by those wishing to make impressions of parts of the body [120]. This formula is:

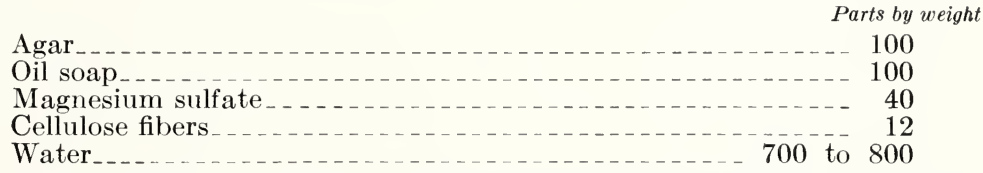

This can be used for masks but as will be shown later it is not satisfactory for dental uses (material $A$ in table 57).

Agar for dental uses must be selected from the best grade of raw product. According to the report of two Japanese investigators [121] the "square" and "thin" agar obtained from southern Japanese seaweed should be most suitable for dental impressions.

Physical properties.-Many peculiar properties appear to be associated with the agar compounds. An apparent decrease in deformation by cold-working, an apparent elastic recovery with time, the amount of water accepted or released, depending upon previous treatments, the enormous elongations for sudden distortions, and the sol-gel temperature hysteresis are a few of the properties which are not readily explained.

TABLE 57.- Physical properties of hydrocolloidal impression materials

\begin{tabular}{|c|c|c|c|c|c|c|c|c|c|c|c|}
\hline \multirow{2}{*}{ Code letter } & \multirow{2}{*}{$\begin{array}{l}\text { Wa- } \\
\text { ter } \\
\text { con- } \\
\text { tent }\end{array}$} & \multirow{2}{*}{\multicolumn{2}{|c|}{$\begin{array}{l}\text { Gel forma- } \\
\text { tion tem- } \\
\text { perature }\end{array}$}} & \multicolumn{3}{|c|}{ Tensile properties a } & \multicolumn{4}{|c|}{ Compressive properties b } & \multirow{2}{*}{$\begin{array}{l}\text { Stiffness } \\
\text { factor d }\end{array}$} \\
\hline & & & & \multicolumn{2}{|c|}{ Strength } & Elonga- & \multicolumn{2}{|c|}{ Strength } & Defor- & Set $\mathbf{c d}$ & \\
\hline$A_{-}$. & $\begin{array}{l}\% \\
90.5\end{array}$ & $\begin{array}{c}{ }^{\circ} C \\
36\end{array}$ & $\begin{array}{c}\circ F \\
97\end{array}$ & $\mathrm{~g} / \mathrm{cm}^{2}$ & lb/in..$^{2}$ & $\%$ & $\begin{array}{c}g / \mathrm{cm}^{2} \\
500\end{array}$ & $\begin{array}{r}l b / i n .^{2} \\
7.1\end{array}$ & $\begin{array}{l}\% \\
9.6\end{array}$ & $\%$ & $\begin{array}{r}\text { Stress } / \text { strain } \\
4,600\end{array}$ \\
\hline$B$ & 73.4 & 36 & 97 & & & & $\left\{\begin{array}{l}1,300 \\
(1,100)\end{array}\right.$ & $\begin{array}{r}18.5 \\
(15.6)\end{array}$ & 8.0 & & 13,800 \\
\hline$C_{--}$ & 80.0 & 38 & 100 & 700 & 9.9 & 3 & 1,700 & 24. 2 & 8.8 & & 15,700 \\
\hline$D$ & 78.6 & 41 & 106 & 1,300 & 18.5 & 13 & $\left\{\begin{array}{c}2,300 \\
(2,100)\end{array}\right.$ & $\begin{array}{r}32.7 \\
(29.9)\end{array}$ & 18.6 & (2.4) & 11,700 \\
\hline$E_{-}$ & 76.5 & 41 & 106 & 1,000 & 14.2 & 4 & 2,700 & 38.4 & 14.4 & & 17,100 \\
\hline$F_{--}$ & 80.3 & 36 & 97 & & & & $\left\{\begin{array}{l}2,700 \\
(2,800)\end{array}\right.$ & $\begin{array}{r}38.4 \\
(39.8)\end{array}$ & 17.0 & $(0.6)$ & 16,700 \\
\hline $\begin{array}{l}G \\
H_{-} \\
\end{array}$ & $\begin{array}{l}84.6 \\
76.5\end{array}$ & $\begin{array}{l}44 \\
40\end{array}$ & $\begin{array}{l}111 \\
104\end{array}$ & & & & $\begin{array}{r}2,800 \\
3,100\end{array}$ & $\begin{array}{r}39.8 \\
44.1\end{array}$ & $\begin{array}{l}14.3 \\
11.6\end{array}$ & & $\begin{array}{l}17,500 \\
24,700\end{array}$ \\
\hline$I_{\ldots} \ldots$ & 72.7 & 40 & 104 & 1,000 & 14. 2 & 4 & $\left\{\begin{array}{c}3,800 \\
(2,600)\end{array}\right.$ & $\begin{array}{c}54.0 \\
(37.0)\end{array}$ & 13.9 & $(0.8)$ & 28,100 \\
\hline
\end{tabular}

a $50-\mathrm{mm}$ gage length. Measurements made prior to rupture.

b Values in parcntheses are for small cylinders 0.50 inch in diameter and $0.75 \mathrm{inch}$ long.

c This value indicates the shortening of the smaller cylinders after the following cycle of loading, 50, $1,000,0$, and $50 \mathrm{~g} / \mathrm{cm}^{2}$ were applied for 1 -minute intervals in the foregoing scquence.

$\mathrm{d}$ These data are from large cylinders 1.50 inches in diameter and 2.75 inches long. 
The enormous hrsteresis, or lag. associated with these compounds accounts for their usefulness in the arts. When heated to the temperature of boiling water for a few minutes they become quite fluid and remain so until ther hare cooled nearly to bodr temperature. As ther approach or cool below bodr temperature ther pass rather abruptly from the fluid or sol state to a more nearly solid or gel state (table $5 \%$ ). This gel state is fairly permanent at ordinarr temperatures if the humiditr is kept high. The crcle is reversible and br again heating to the temperature of boiling water the gel will change to the sol or liquid state.

The temperature of gelation was determined br a method illustrated in figure 67 [88]. The heated material was poured into a

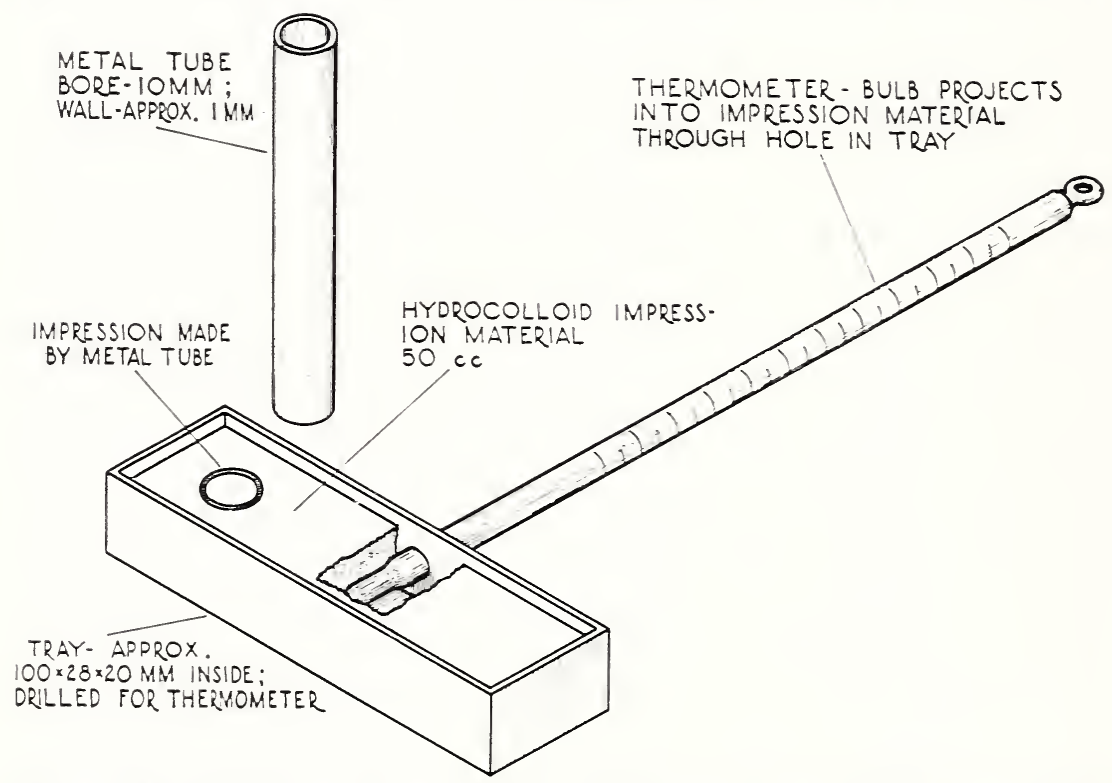

FIGURE 67.--Equipment for determining gelation point of hydrocolloidal impression materials.

tray haring a thermometer inserted through one side. A metal tube was pressed into the cooling material and remored periodically. The temperature at which the tube could be withdrawn and leave a definite core. well defined br two concentric circles and separate from the mass of material filling the trar, was recorded as the temperature of gel formation. Obviously this temperature should not be far from mouth temperature if the compound is to be used as a dental impression material. Naterials hardening at high temperatures would tend to solidify as ther came in contact with the oral tissues and would not mold into the finer contours. Materials hardening at low temperatures would require colder water or more time for chilling to temperatures at which the impression could be safelr withdrawn.

The curres shown in figure 68 represent data from crlindrical specimens tested in compression as illustrated in figure 69 . The cylinders were 1.50 inches in diameter and 2.75 inches long. Later 
work indicated that smaller specimens 0.50 inch in diameter and 0.75 inch long could be used without sacrificing appreciably the precision of the data obtained. The data reported include, in a few instances, values from both sizes of specimens.

Materials like $H$ and $I$ having a high steep curve (fig. 68 ) will be found to have relatively high stiffness and strength. Materials like $F$ and $D$ are more flexible and will stand more distortion. Material $A$ (Gross formula) with the flattest slope will accept large distortions for very small loads. It is too weak, however, to be of value in the usual dental operations.

Tensile tests were made on specimens shaped and clamped as illustrated in figure 70 . The cross section of the central part of the specimen was 5 millimeters square.

The values obtained in tension, compression, and stiffness tests

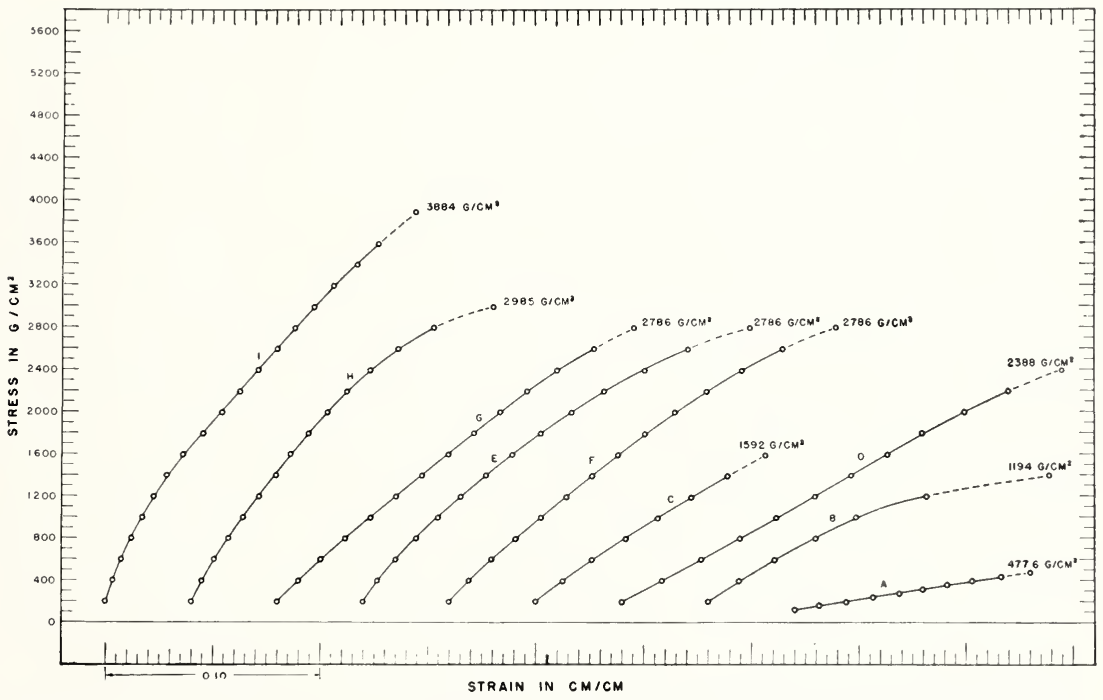

FigURE 68.- Representative stress-strain diagrams of hydrocolloidal impression materials in compression.

Figures at the ends of curves are values for compressive strengths.

shown in table 57 and in figure 68 were secured from 8 trade brands and one lot of material made according to the formula given earlier in this chapter.

Intercomparisons to show the effect of water content on the temperature at which gel forms will lead to confusion. The same is true of other items in the table. Some of this confusion undoubtedly results from the variations in the type of agar used, the formula, and the methods of combining the ingredients.

Practical tests. - It was decided to supplement the specification for physical properties with a practical test, using the metal model shown in figure 71. Practical tests are always appropriate when they can be concluded in a reasonable time. The illustration, with dimensions, gives a definite idea of what can be expected of satisfactory elastic impression materials. 
It must be possible to reproduce the metal model in dental "stone" with all posts and undercuts showing smooth surfaces. The metal model presents an apparent contradiction in that it demands an elongation of approximately is percent for an impression around the stem of post $B$, figure 71 , to pass orer the hemisphere mounted on

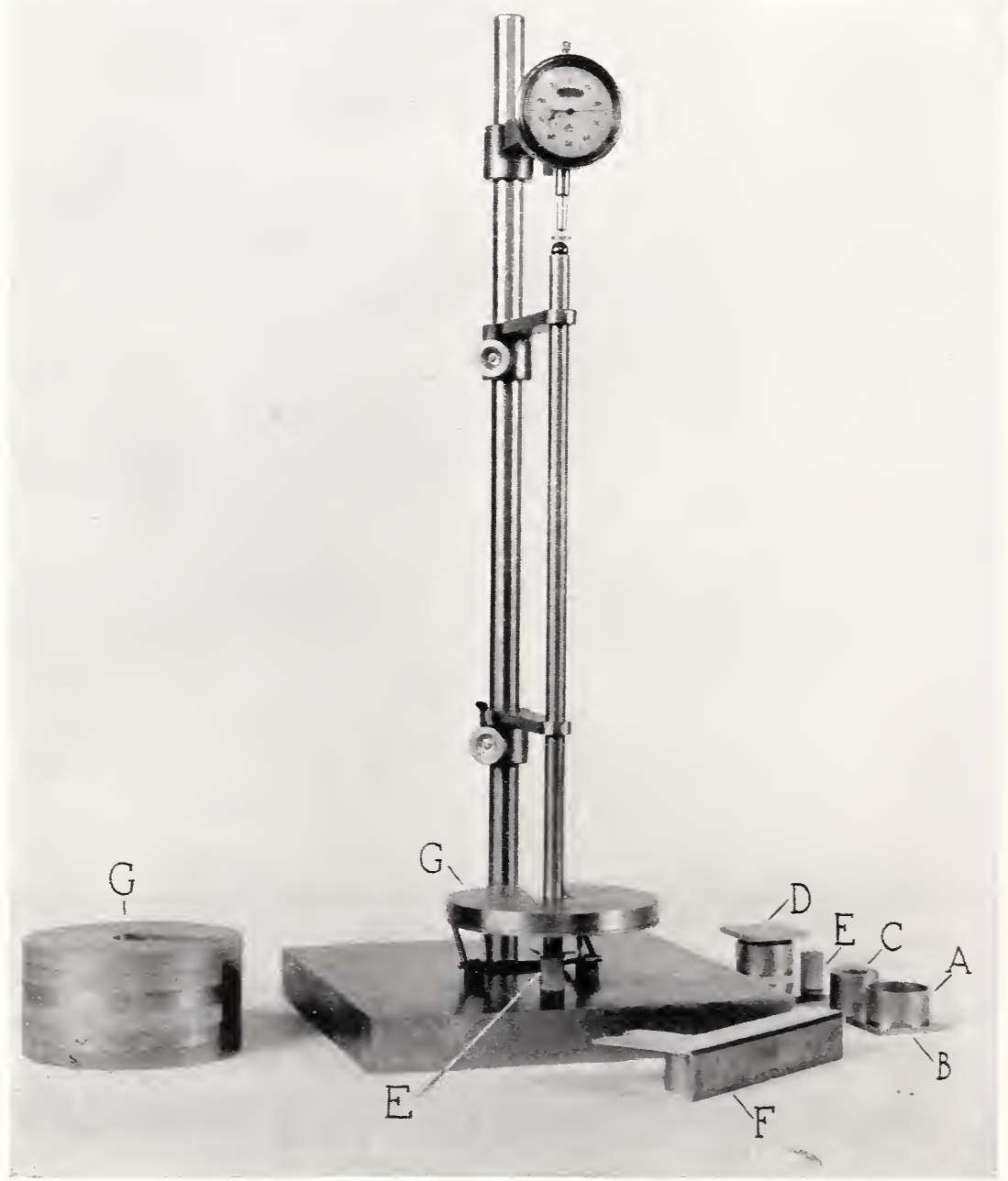

FIGLRE 69.- Apparatus used to form specimens and to determine the properties of hydrocolloidal impression materials in compression.

The ring, $A$, on flat glass plate, $B$, is slightly more than half filled with the softened material. Mold, $C$, is forced into $A$ until $C$ is more tban filled. Glass plate, $D$. is placed on top oi $C$ to remore excess material. Thus specimens $E$ are formed $F$, jig for centering specimen, $E$, under calibrated weight. $G$

the top of the post. In other words a 4.5-millimeter canal must pass an 8-millimeter object without rupture. Table 57 shows elongations from 3 to 13 percent which are thought to be representative values. These brands will separate from the metal model without injury. The separation must, however, be made rapidly. An attempt to 
slowly separate the metal model from the elastic impression will cause rupture of the impression material. The percentage elongations reported in table 57 are low because of the 10 or more minutes required to make the elongation tests. The dental significance of this anomaly is-remove an impression with a quick pull which will cause the separation to take place as rapidly as safety will permit.

Technic.- The operator must make his selection of materials in

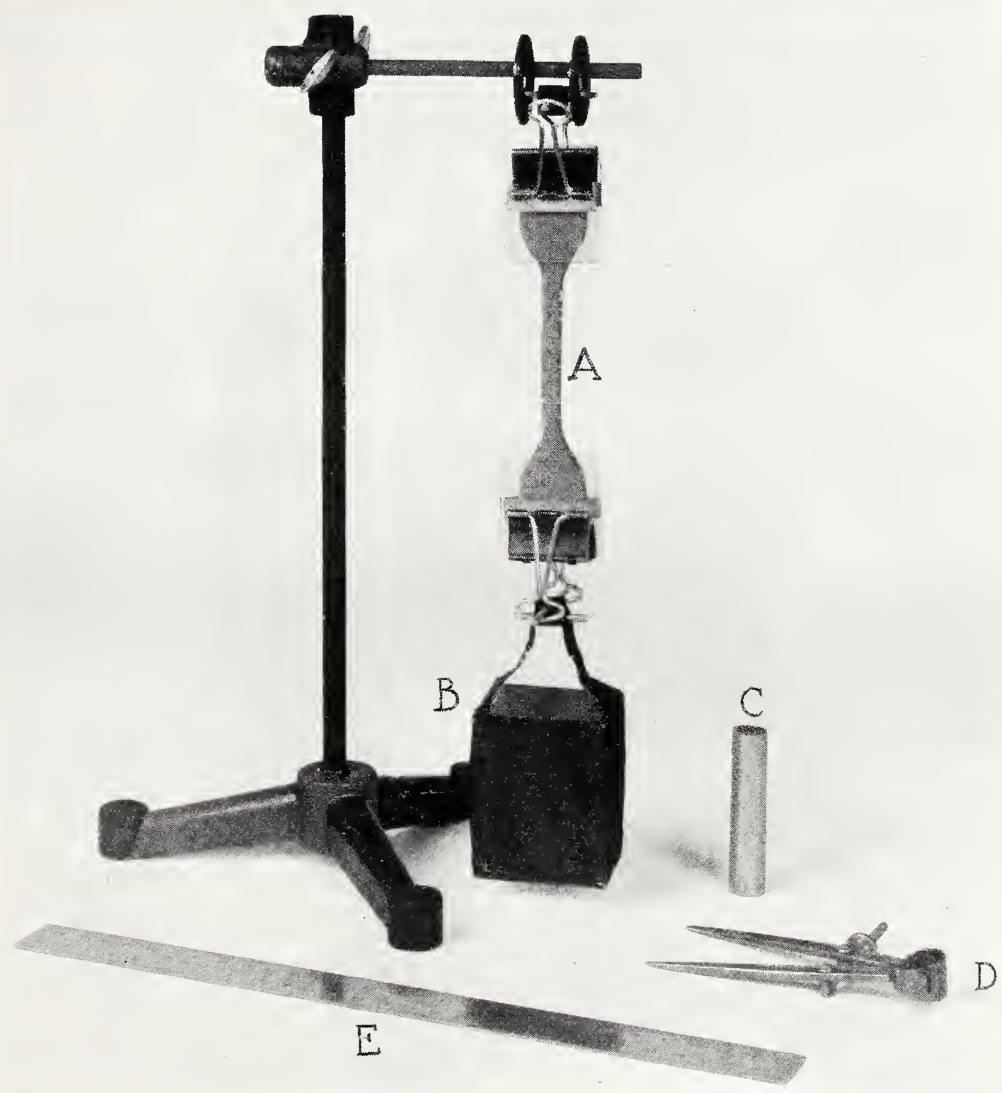

Figure 70.-Apparatus for determining the properties of the hydrocolloidal impression material in tension.

$A$, Specimen; $B$, bucket for receiving shot; $C$, container for measuring shot: $D$, caliper; $E$, steel scale

accordance with the conditions encountered. Undercuts call for sectional impressions or for the use of the flexible materials.

Reproduction of detail, angles and surfaces is possible only when the viscosity of the material and the applied pressure are correctly balanced. Reproduction of over-all dimensions depends upon the setting, chilling or otherwise production of rigidity of the plastic material without shrinkage or expansion due to thermal chemical or other changes. The rigid tray shaped to a semblance of a fit over the parts to be modeled reduces important sources of error to a minimum. 
This makes it possible to use small quantities of the material most likely to become distorted, and also to quickly cool small amounts of warmed plastic impression materials.

Flaming the surfaces of impression compounds to soften them to a very shallow depth is an art and if practiced must be mastered by each operator. The addition of thin layers of soft wax on an initial impression will enable many operators to improve their impression technic.

In taking an impression of an extensive cavity for which an inlay is to be prepared by the indirect technic, it is necessary that the copper
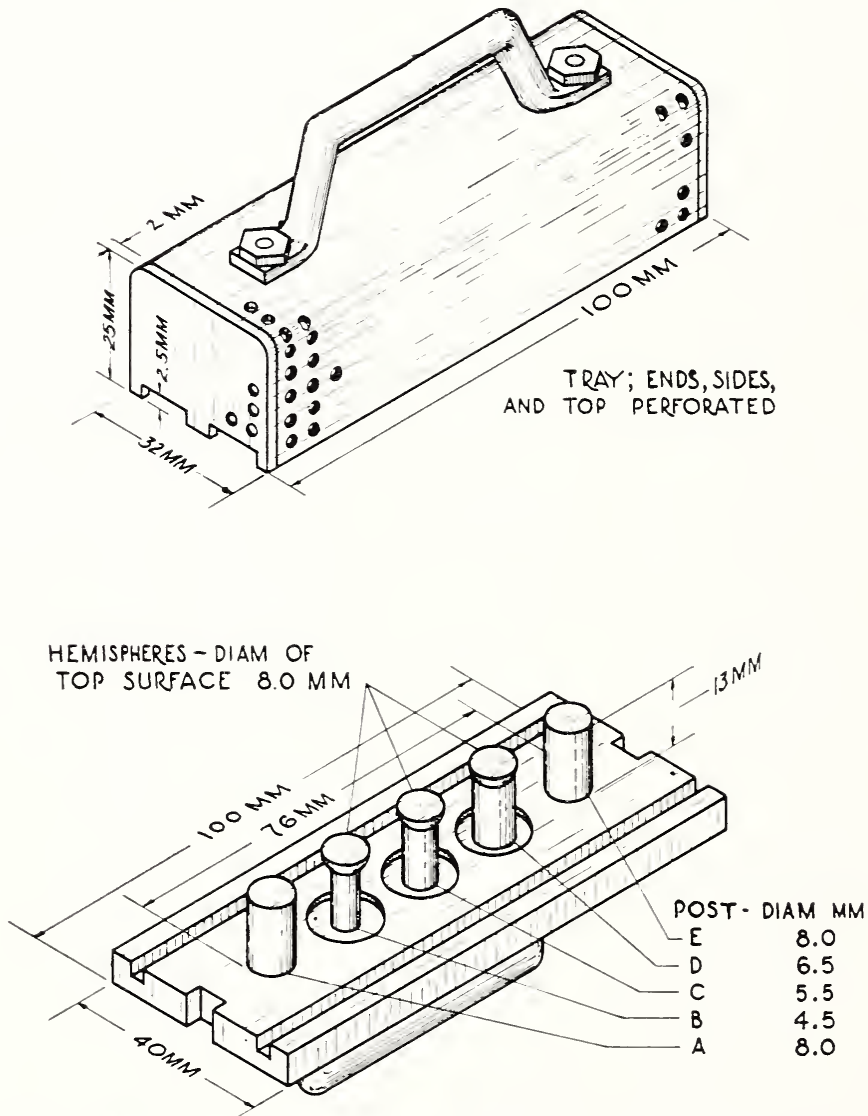

FIGURE 71.-Master metal model for testing hydrocolloidal impression materials.

band or other retaining form be so shaped that the impression material will be forced into every pocket and margin of the carity.

Impression materials of the agar type are not primarily suitable for inlay technic. They are, however, suitable for many other types of impressions. These flexible materials must be rendered plastic by heating. For the agar type this may require boiling for several minutes. The agar-hydrocolloidal impressions should, after they have been sufficiently chilled, be removed from the teeth as rapidly 
as safety will permit. Impressions removed slowly are more liable to rupture in passing undercuts. The model should be poured promptly. If the agar impression has to be shipped or stored for some hours before the model can be poured it should be kept moist.

Plaster of paris models poured with a base only 3 millimeters thick warped badly. When the base was 10 millimeters thick the plaster of paris reproduction of the metal model (fig. 71) was much more satisfactory in respect to flatness along the base or post support and across the top surfaces of the two end posts and three hemispheres which, on the metal model, are ground to the same height.

The following precautions are important if best results are to bc secured in the use of the hydrocolloid types of impression materials.

1. The mass must be heated until it is uniformly fluid throughout.

2. The material must be well supported by the tray. The tray should be shaped to approximate the size of the object to be impressed so that large thick masses of elastic material will not appear in any part of the impression.

3. The surface of the impression and all cavities in it should be cleared of drops of water or exudates before the plaster model is poured. The surface of the plaster model can be injured by this surplus water or salt solution.

4. The model should be poured promptly before the exposed impression material loses an appreciable amount of water and shrinks.

5. If the model cannot be poured promptly the impression should be stored in water. This storage in water will however tend to change the surface texture of the impression compound as it absorbs water and releases some of its soluble salts. These changes will be evident in the surface appearance of the model.

\section{INLAY PATTERN WAXES}

Of the many materials used in the inlay casting process none is more important than the pattern wax. Any defect or impairment in the pattern will carry through to the gold inlay.

The cavity in the tooth or model is easily filled with the softened wax; but margins, contacts, and anatomical form must be given to the wax and retained by it until every detail of the pattern is incorporated in the investment. The wax must mold to the cavity at temperatures comfortable to the tooth for direct work and be convenient to the technic selected for indirect work. It must carve readily to sharp margins without pitting or flaking. It must be decidedly rigid at or near body temperature and should accept small additions of melted wax when these are necessary. A color in contrast with that of the oral tissues facilitates carving in the mouth. Finally, the wax must be eliminated from the investment when heated to the usual temperatures.

However, with all the above properties present in the most favorable degrees, there is one other factor, shrinkage, which, unless carefully controlled, will prevent the production of a satisfactory pattern. This disturbing factor can be shown by attempting to make a wax pattern which will exactly fit a tapered eavity. This tapered cavity is worth constructing as it makes an excellent piece of lecture-demonstration equipment. The simplest form consists of a tapered hole of approximately dental dimensions reamed in a flat bar of brass. 
The hole should be covered at the narrow end by another flat bar of brass attached to the first bar by screws. Fill the taper cavity with the warm plastic wax and carve it flat to the top of the cavity. Now remove the base of the cavity and observe that the cold wax pattern is too small, and that it will project beyond the bottom of the cavity if pressure is applied to it at the top. The shrinkage of the wax, as it cools and solidifies, is responsible for this discrepancy in reproducing the dimensions of the cavity in the wax pattern.

While a wax having a low coefficient of thermal expansion would be welcomed by all dentists, there is little likelihood that it will be available for some years if it is ever available. Under such circumstances the dentist must recognize this source of error in handling inlay waxes and should take such steps as are possible to minimize

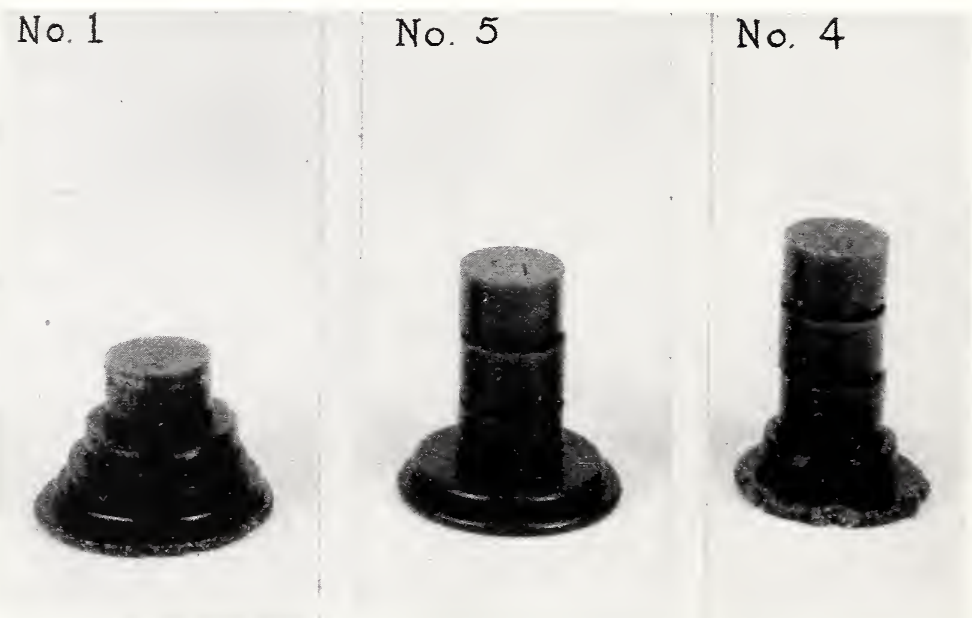

FiguRE 72.-Results of flow tests on a soft wax (No. 1), a medium wax (No. 5) and $a$ hard wax (No. 4).

The top cylinder in each stack was tested at $34^{\circ} \mathrm{C}\left(93^{\circ} \mathrm{F}\right)$. The remaining cylinders from top to bottom were tested at $36.5^{\circ} \mathrm{C}\left(98^{\circ} \mathrm{F}\right) ; 39^{\circ} \mathrm{C}\left(102^{\circ} \mathrm{F}\right) ; 42^{\circ} \mathrm{C}\left(107.5^{\circ} \mathrm{F}\right)$; and $47.5^{\circ} \mathrm{C}\left(117.5^{\circ} \mathrm{F}\right)$, respectively. In the wax with medium flow (No. 5) notice the abrupt flow on the specimen tested at $42^{\circ} \mathrm{C}$. compared with the specimen tested at $39^{\circ} \mathrm{C}$. Refer to Figure 73 for the graphical data on flow.

or to correct for the dimensional changes caused by temperature variations in the wax pattern.

Van Horn [122], Lane [123], and others early recognized the effects of wax contraction and expansion and were able to turn it to an asset by expanding the wax pattern during its investing so as to correct not only the wax shrinkage but also to compensate for part or all of the casting shrinkage of the gold alloy used in producing the inlay. The fact that it is now possible to compensate completely the shrinkage of the alloy by using improved investments detracts nothing from the basic analytical technics developed by these men.

Flow.-The flow of inlay waxes at the higher temperatures indicates their tendency to mold to and take the exact shape of the cavity; at and below mouth temperatures it measures their ability to retain, undistorted, that shape during removal from the cavity and to withstand the distorting tendencies encountered during investing. Flow is measured on small cylinders (fig. 72), which are held at the test 
temperature for a definite time under a specified load in much the same manner as when testing impression compounds. (Details of the test are given in ADA Specification No. 4 on page 201).

Figure 73 gives flow data on a soft (No. 1), a medium (No. 5) and a hard (No. 13) wax. Wax 5 exhibits an almost ideal flow or softening range. At mouth temperature it is practically rigid, having a flow of only 0.8 percent. A wax as rigid as this will not be distorted appre-

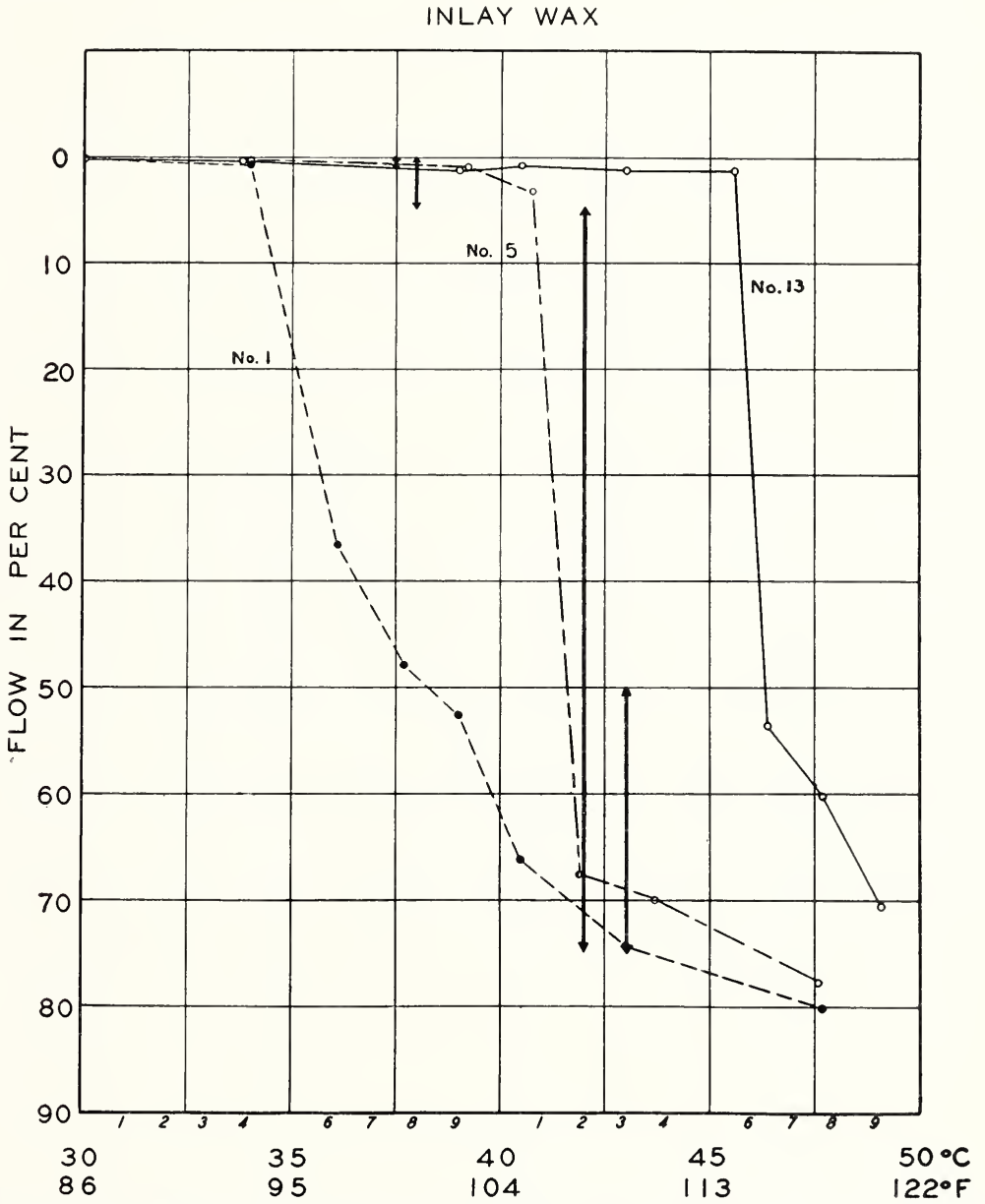

FigURe 73.-Flow of a soft (No. 1), a medium (No. 5), and a hard (No. 13) inlay wax.

The bars with the arrowheads on each end indicate the specification limits for flow.

ciably when withdrawn from the cavity. Another excellent feature is the great flow, approximately 68 percent, which takes place about $4^{\circ} \mathrm{C}\left(7.2^{\circ} \mathrm{F}\right)$ above mouth temperature. This wax will therefore take a fine impression without undue heating. Also the temperature range between its rigid and plastic conditions is narrow. The shorter this range, the less the shrinkage of the wax. Wax 5 is of the speci- 
fication type and shows these advantages. The flow curve of wax 13 , figure 73 , indicates that it is too hard for the average dentist to use successfully. Another disadvantage of such a hard wax is the long cooling range between its plastic and rigid states.

The specification limits for flow are indicated in figure 73 by the bars with arrows on each end. To comply with the flow requirements of the specification, a wax must have a flow curve which intersects each bar.

Thermal expansion.-Most of the measurements of the thermal expansion of wax were made by means of the comparator microscopes (fig. 74). A density method has also been successfully used to measure thermal expansion.

All of the popular inlay waxes have a very high thermal expansion, as will be noted in figure 75 , which, as previously pointed out, is a

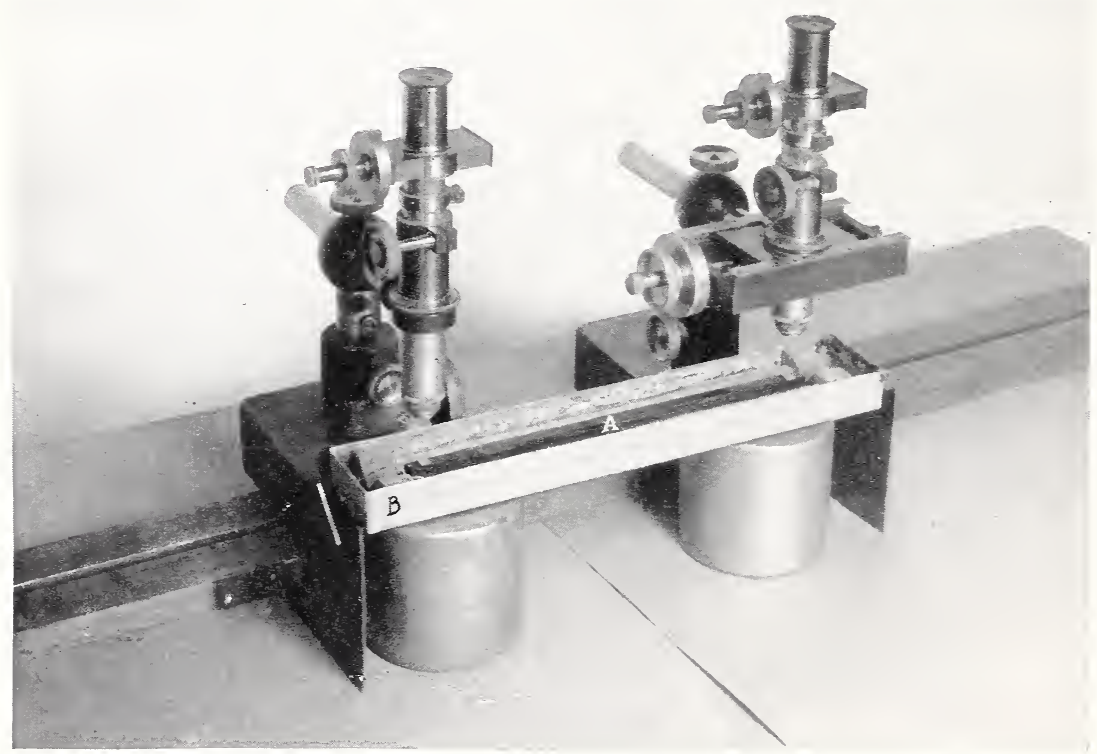

Figure 74.-Comparator used to measure the thermal expansion of waxes and compounds.

Note the specimen, $A$, in the water bath, $B$.

fact that must be coped with in handling them. Of course, in the wax expansion technics, most of which are obsolescent, the thermal expansion was utilized to partially compensate for the shrinkage of the gold. It is important to know the exact contraction of the wax pattern from mouth to room temperature so that it can be allowed for in devising a feasible technic where one wishes to cast a restoration to an exact dimension. Reference to figure 75 will show that it will be in the neighborhood of $0.7 \pm 0.2$ percent for the temperature ranges commonly used in inlay technics. Wax 5 (specification type) has a comparatively low shrinkage. 


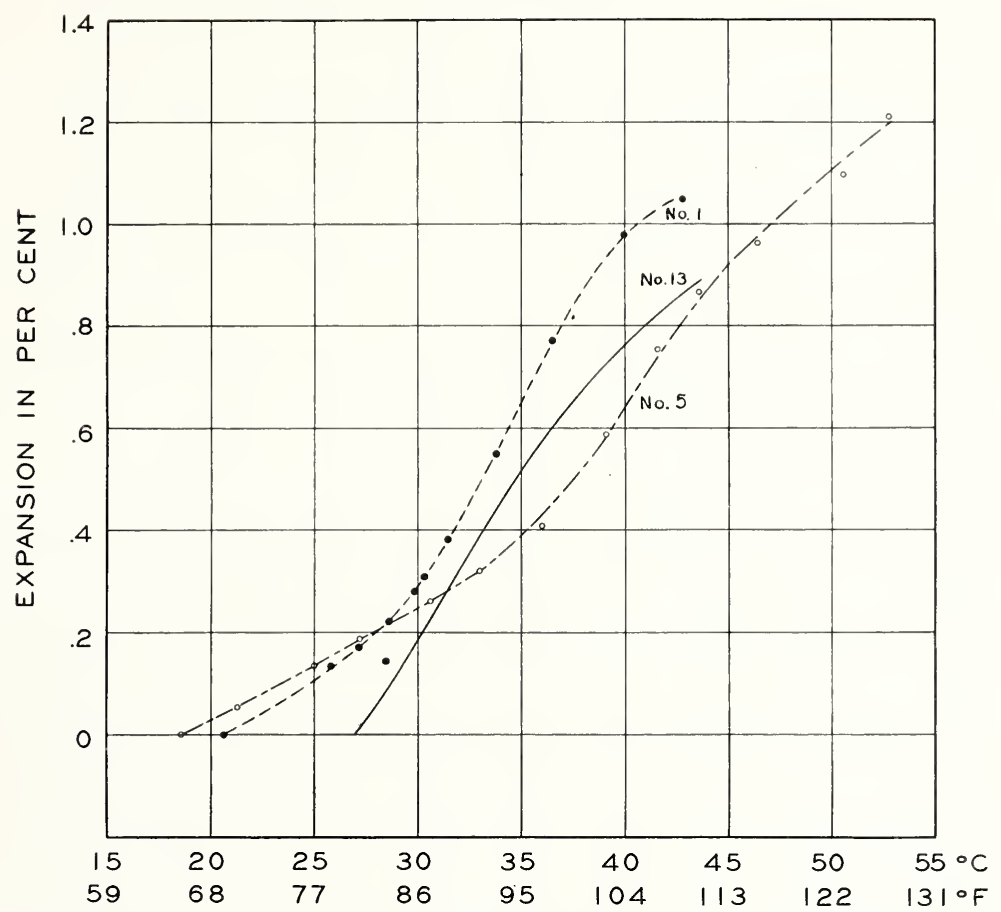

FigURE 75.-Thermal expansion of a soft wax (No. 1), a hard wax (No. 13), and a medium wax (No. 5) of the specification type.

\section{ORGANIC DENTURE BASE MATERIALS}

The making of a satisfactory artificial denture is a distinct accomplishment. It involves a long chain of procedures each of which must be carefully controlled. An important link in this chain is the selection of a proper base. Another and no less important link is the appropriate use of the selected material. It shall therefore be the purpose of this section to compare the physical and chemical characteristics of the various types of organic materials which are used as denture bases and to show how these properties can be affected by the methods used in processing.

Before a direct comparison of properties is made among the various types of materials it would be well to outline what properties an ideal denture base should possess. The first essential is that it must be compatible with and not injurious to the oral tissues. It must be strong, hard, tough, durable, physically and chemically stable, light in weight and insoluble in the oral fluids. It must take and retain a high polish. It must have a lifelike appearance and be relatively easy to process and to repair. It must not have an offensive taste or odor and should be a good thermal conductor. These are the more important requisites of an ideal denture base material. Such a material is of course not available, but some of those on the market today are certainly much more desirable than others. 
To withstand the rigors of the oral environment to which a denture base is subjected it is necessary to emplor either an allor. a ceramic material such as porcelain, or organic plastics like rubber and the srnthetic resins. Onls the organic plastics are here considered.

Chaotic condition.-The desire for a tissue-colored denture base material has existed since the invention of the rubber plate. Announcements of "natural-colored" dentures have, during recent rears, been perennial and have until the late 1930 's been followed br failures and disappointments.

This condition continued until about 1935. shortly after a research was reported br Barber [52] in which methods were indicated for testing these newer denture base materials. Their properties were compared with those of rubber and thus the inferior properties of manr of these materials were revealed.

Classification.- It is convenient to divide the organic denture base materials into two large classes; thermosetting and thermoplastic. To the thermosetting class belong rubber and phenol-formaldehyde resins. These materials harden when heat is applied to them in the soft uncured state, hence the name thermosetting. Some form of chemical reaction has occurred, either by the formation of a chemical compound, as is the case in rubber. or br a condensation as in the phenol-formaldehyde resin. The thermoplastic type of resin which softens and can be molded upon the application of heat and pressure is represented in the denture field br the celluloids, vinyl resins and methyl methacrylate. Methrl methacrylate resin appears in this category because after it undergoes polymerization and hardens it is thermoplastic. Vulcanite (hard rubber) is likewise thermoplastic to a limited extent.

Mixtures or copolymers of thermoplastic resins are now used for denture bases. An example is the mixture of rinyl and methyl methacrylate resins.

Chemical properties.-The chemical properties of complex materials of fairls recent synthesis like the present-dar plastics are not nearly as well known as are the properties of less complicated substances. The same can be said of the physical and in particular the mechanical properties of the materials. This incompleteness of knowledge about the plastics and their application in diverse circumstances has certainly been reflected by the chaotic situation resulting from their use as denture base materials.

Molecular structure.-The molecular structure of organic substances of such high molecular weight as rubber or the srnthetic resins or mixtures containing them is extremely difficult and often impossible to obtain.

Denture rubber consists essentially of rubber hydrocarbon. sulfur, fillers, pigments and usually an accelerator. In the so-called olive base type the rubber content may be as high as 62 percent; the sulfur content mar be almost 30 percent. These amounts are reduced proportionally to each other in such other rubber bases as those of the general-purpose trpes, and especially the reneer types. As the rubber and sulfur content decreases there is an increase in the amount of inert matter. For instance olive base rubber has only 8.5 percent of inert matter while some reneer rubber may contain as much as 36 percent.

The rinyl resins used for dentures are said to be copolymers of rinyl chloride and rinyl acetate. In this research no effort was made 
to determine the relative amounts of the chloride or acetate present. However the polymer distribution (size of molecules) was determined by a fractional solubility method [124]. By this method it was shown that the vinyl resins as supplied for denture bases were by no means uniform in molecular distribution. Since the physical properties of the vinyl resins are affected by the distribution of polymers of different chain length or (molecular weight) it is logical to assume that some of the failures of the vinyl resins could be attributed to their nonuniformity of composition. In fact this was demonstrated when

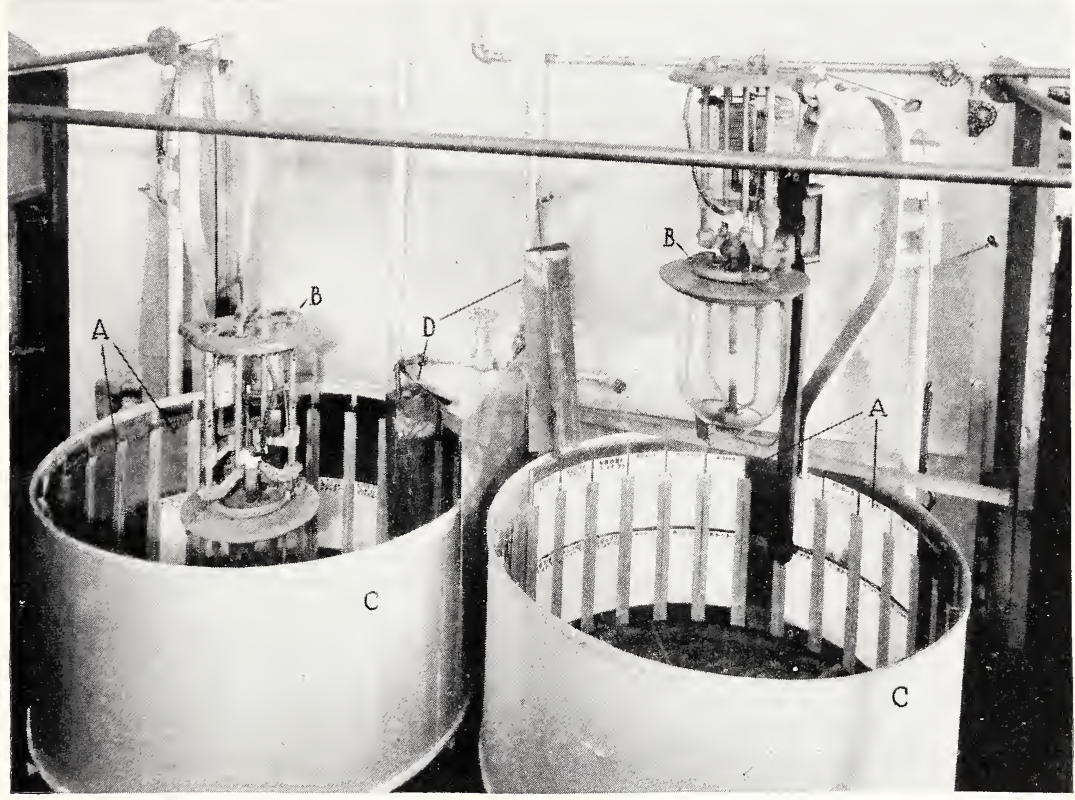

Figure 76.-Apparatus used in test for color stability.

$A$, Specimens; $B$, carbon-are light; $C$, revolving drum; $D$, water spray.

See P. H. Walker and E. F. Hickson, Accelerated tests of organic protectue coatings, BS J. Research 1, 1 (1928) RP1, for a description of this apparatus.

attempts were made to use the same molding technic on lots of nonuniform resins, which had different molecular distributions.

Color stability. - The color of a resin should be stable under the conditions of processing and service. Unfortunately not all denture resins meet this basic requirement, as was discovered through clinical experience. Some dentures changed from the original tissue-pink to orange, red, or brown. Such changes may be caused by two factors; the instability of the resin itself and nonpermanence of the dye or pigment. In the case of the vinyl and phenol-formaldehyde resins it was found that the resins themselves were not light-stable.

The resins were exposed to the radiation of a regulated carbon arc to determine their color fastness (fig. 76). This test gives a fair index of the color stability of the denture bases and rates them from the best to poorest in the following approximate order: (1) methyl methacrylate, (2) rubber, vinyl-acrylic copolymers and celluloses, and (3) phenol-formaldehyde, and vinyl. 
Shelf-life. - A material which does not cure or harden during storage or shipping has, other things being equal, a distinct practical advantage. In this regard the thermo-plastic type of resin is excellent as it is fully cured before molding. Methyl methacrylate in the powderliquid form, if properly made, has a satisfactory shelf-life. However, this resin in the plastic cake form has a short shelf-life unless it is stored at a low temperature. The same holds true for the phenolformaldehyde resins. Unless they are kept cool they soon become unsatisfactory for use.

As a specific example of a currently used resin with a short shelf-life one can cite methyl methacrylate in the plastic cake or gel form. This material when stored for one day at $43^{\circ} \mathrm{C}\left(109^{\circ} \mathrm{F}\right)$ becomes too hard for use. When stored at $37^{\circ} \mathrm{C}\left(99^{\circ} \mathrm{F}\right)$ the resin could not be used after one week; at $25^{\circ} \mathrm{C}\left(77^{\circ} \mathrm{F}\right)$ after 15 days; but at $5^{\circ} \mathrm{C}$ $\left(41^{\circ} \mathrm{F}\right)$ the material could be used after storage for a year.

TABLE 58. Change in weight, water sorption, and dimensional change of denture base materials

\begin{tabular}{|c|c|c|c|c|c|c|}
\hline 1 & 2 & 3 & 4 & 5 & $6^{s}$ & 75 \\
\hline Type & Resin & $\begin{array}{l}\text { Change } \\
\text { in } \\
\text { weight }\end{array}$ & $\begin{array}{l}\text { Water } \\
\text { sorption }^{2}\end{array}$ & $\begin{array}{l}\text { Linear } \\
\text { dimen- } \\
\text { sional } \\
\text { change } 3\end{array}$ & $\begin{array}{l}\text { Linear } \\
\text { curing } \\
\text { shrink- } \\
\text { age }\end{array}$ & $\begin{array}{l}\text { Net } \\
\text { linear } \\
\text { change }\end{array}$ \\
\hline Methyl methacrylate & 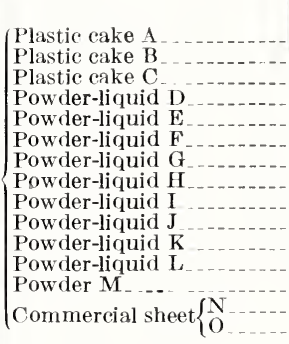 & $\begin{array}{r}m g \\
-5 \\
-9 \\
-3 \\
-9 \\
-7 \\
-27 \\
--9 \\
\end{array}$ & $\begin{array}{r}\mathrm{mg} / \mathrm{cm}^{2} \\
0.56 \\
.54 \\
.57 \\
.45 \\
.52 \\
.53 \\
.48 \\
.49 \\
.53 \\
.49 \\
.56 \\
.58 \\
.55 \\
.55\end{array}$ & $\begin{array}{r}\% \\
+0.9 \\
+.8 \\
+1.1 \\
+.8 \\
+.7 \\
+.9 \\
\end{array}$ & $\begin{array}{r}\% \\
0.40 \\
.30 \\
.45 \\
.45 \\
.25 \\
.30 \\
.35 \\
-.40 \\
.40 \\
.35 \\
.45 \\
.40 \\
.25 \\
-. .\end{array}$ & $\begin{array}{r}+0.50 \\
+.50 \\
+.65 \\
+.35 \\
+.35 \\
\end{array}$ \\
\hline $\begin{array}{l}\text { Acrylic-styrene copoly- } \\
\text { mer. }\end{array}$ & Powder-liquid P.......... & -8 & .50 & +0.5 & .35 & +.15 \\
\hline Acrylic-vinyl copolymer & $\left\{\begin{array}{l}\text { Stiff blank Q } \\
\text { Powder-liquid R } \\
\text { Plastic cake S } \\
\text { Plastic cake T. }\end{array}\right.$ & $\begin{array}{l}-3 \\
-5 \\
-5\end{array}$ & $\begin{array}{l}.16 \\
.26 \\
.19\end{array}$ & $\begin{array}{r}+0.3 \\
+.3 \\
+.2\end{array}$ & $\begin{array}{l}.20 \\
.20 \\
.35 \\
.25\end{array}$ & $\begin{array}{l}+.10 \\
+.10 \\
+.15\end{array}$ \\
\hline Cellulose compounds & $\left\{\begin{array}{l}\text { Stiff blank U } \\
\text { Powder V } \\
\text { Stiff blank W } \\
\text { Stiff blank X } \\
\text { Stiff blank Y }\end{array}\right.$ & $\begin{array}{r}-32 \\
-721 \\
-260 \\
-842\end{array}$ & $\begin{array}{l}2.14 \\
2.47 \\
1.49 \\
2.01 \\
6.26\end{array}$ & $\begin{array}{l}+1.0 \\
+3.4 \\
+1.4 \\
-2.0\end{array}$ & - & 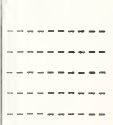 \\
\hline Rubber & $\left\{\begin{array}{l}\text { Base }\left\{\begin{array}{l}Z \\
\mathrm{~A} A\end{array}\right. \\
\text { All-purpose }\left\{\begin{array}{l}\mathrm{BB} \\
\mathrm{C} C\end{array}\right. \\
\text { Veneer }\left\{\begin{array}{l}\mathrm{DD} \\
\mathrm{EE}\end{array}\right.\end{array}\right.$ & $\begin{array}{r}+13 \\
+13 \\
+15 \\
+5\end{array}$ & $\begin{array}{r}0.06 \\
.08 \\
.16 \\
.08 \\
.07 \\
.28\end{array}$ & $\begin{array}{r}-0.1 \\
-.2 \\
-.3 \\
-.6 \\
\end{array}$ & $\begin{array}{l}.20 \\
.25 \\
.05 \\
.15 \\
.10\end{array}$ & $\begin{array}{l}-.30 \\
-.45 \\
-.35 \\
-.75 \\
-\end{array}$ \\
\hline
\end{tabular}

1 Change in weight of dentures after two 6-week cycles of wetting and drying.

2 Specimen size: disks $50 \pm 1 \mathrm{~mm}$ in diameter and $3.2 \pm 0.2 \mathrm{~mm}$ thick. (See p. 207 for new thickness.)

3 Change in dimension of dentures (tuberosity to tuberosity) after two 6-week cycles of wetting and drying.

${ }_{4}^{4}$ Colunin 5 plus column 6 (algebraic addition).

5 The values in columns 6 and 7 are relative only as no length corrections have been made for the differential expansion of the mold and resin. 
Sorption.-At one time it was thought that the sorption of water by a denture material might be an index of its fouling characteristics in service. This idea has been discarded because rubber which becomes foul in the mouth has a rather low water sorption. Methyl methacrylate has a high water sorption yet remains comparatively clean in the mouth. However all things being equal a material having a low water sorption is preferable because other factors, such as dimensional changes, are affected by water sorption. This will be demonstrated subsequently (p. 166).

The new method used in determining water sorption is given on page 207 (specification 12, for acrylic resins). The values obtained by the old method [99] are given in table 58, column 4.

Change in weight.- The solubility of a denture resin in water or saliva should be practically nil. Unfortunately this has not been the case in some instances as will be discovered by reference to table 58 , column 3. These values represent weight changes of dentures which were carried through two cycles of (1) immersing in water for about 3 weeks followed by (2) drying for about 3 weeks in air having a relative humidity of 32 percent. The rubber dentures after the drying operation showed a slight increase in weight because some of the absorbed water was retained. The cellulose-compound dentures contain ingredients which are appreciably soluble, which confirms the remarks of users of dentures of this type that they can taste the material. In the methyl methacrylate and the acrylic copolymers the solubility is too slight to be of consequence.

Physical properties.-In this section certain physical properties such as density, plasticity, softening temperature, curing temperature, thermal conductivity, porosity, and dimensional change of each type of resin will be discussed and intercomparisons made among the various types of materials. Some other physical properties commonly grouped under mechanical properties will be discussed in a subsequent section.

Density.-Density is of secondary importance in evaluating a denture material. However a denture which is light in weight is more desirable than a heary one. Those resins which can be successfully used as denture materials do not differ greatly in density. The range is from roughly 1.36 grams per cubic centimeter for vinyl resin and some of the celluloses to about 1.17 grams per cubic centimeter for methyl methacrylate resin. In other words a cubic centimeter of methyl methacrylate resin would weigh about 0.2 gram less than a cubic centimeter of vinyl resin. The heaviest organic material used in dentures is veneer rubber, which may have a density as high as about 2.5 grams per cubic centimeter. Thus a denture made of veneer rubber (disregarding the weight of the teeth) would be twice as heavy as one made of methyl methacrylate.

Plasticity and packing qualities.-During the time that vinyl resins were used extensively for dentures, tests were made in this Bureau which showed that the plasticity or, perhaps better said, the pressing characteristics of diffcrent samples of vinyl resins when heated were by no means uniform. The primary cause of this variance was undoubtedly the difference in composition hereinbefore mentioned. Nevertheless, the same processing technic was recommended by the manufacturer for all the samples processed at the Bureau. It was 
found that suitable test specimens could not be obtained with some of the samples by an identical pressing technic which had given satisfactory specimens with other samples. Also the test showed that if the temperature of pressing was increased sufficiently to obtain a satisfactory working plasticity the resin darkened so much that it was unfit for use. Manifestly the resin was not color-stable at the optimum pressing temperature. Possibly this explains why the manufacturer's specified pressing temperature was kept below a point which would insure an appropriate plasticity. The end result, as will be shown later, was the development of internal strain to a high degree.
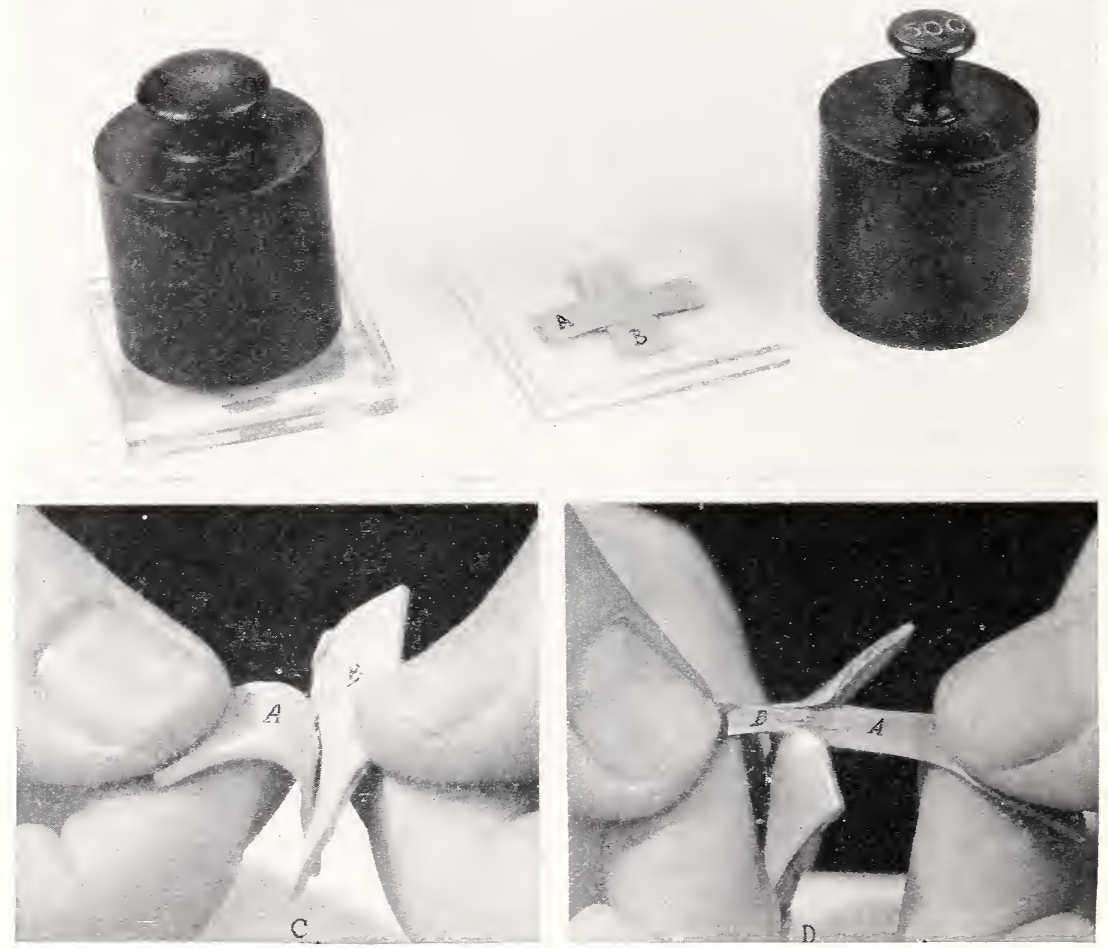

FIGURE 77.- Packing test for denture rubber.

$A$ and $B$, specimens of denture rubber; $C$, unsatisfactory cohesion; $D$, satisfactory cohesion.

This was undoubtedly one of the major factors in the almost universal failure of the vinyl resin dentures in service.

In the investigation of denture rubber it was necessary to specify two tests which would give an index of the working qualities of the unvulcanized materials. One, a packing test, the details of which are given in item $\mathrm{F}-2$ of the specification for denture rubber (page 195), shows whether the strips of rubber will cohere when packed against each other (fig. 77 ). The second, a plasticity test. (item E-1d, page 194) specifies that the rubber shall flow sufficiently to conform properly to the mold. The plasticity of the reneer and base types must be so adjusted that the reneer rubber will not flow as easily as 
the base rubber. Otherwise the veneer rubber might be displaced by the base while closing the flask.

In addition to the foregoing, a packing test was developed for determining the pressing qualities of methyl methacrylate resin. A description of the test method and apparatus is given in item F-2 of the specification 12 for acrylic resins, page 208. This shows whether the resin will be plastic enough to fill the mold completely under moderate pressure. Resin which has partially hardened during shipping or during storage is eliminated by the test. Resin which becomes too stiff for pressing and molding shortly after the powder and liquid are mixed is also eliminated.

Vulcanization of rubber.--The vulcanization of rubber is a process of combining sulfur and rubber hydrocarbon $\left(\mathrm{C}_{5} \mathrm{H}_{8}\right)_{x}$. Therefore the

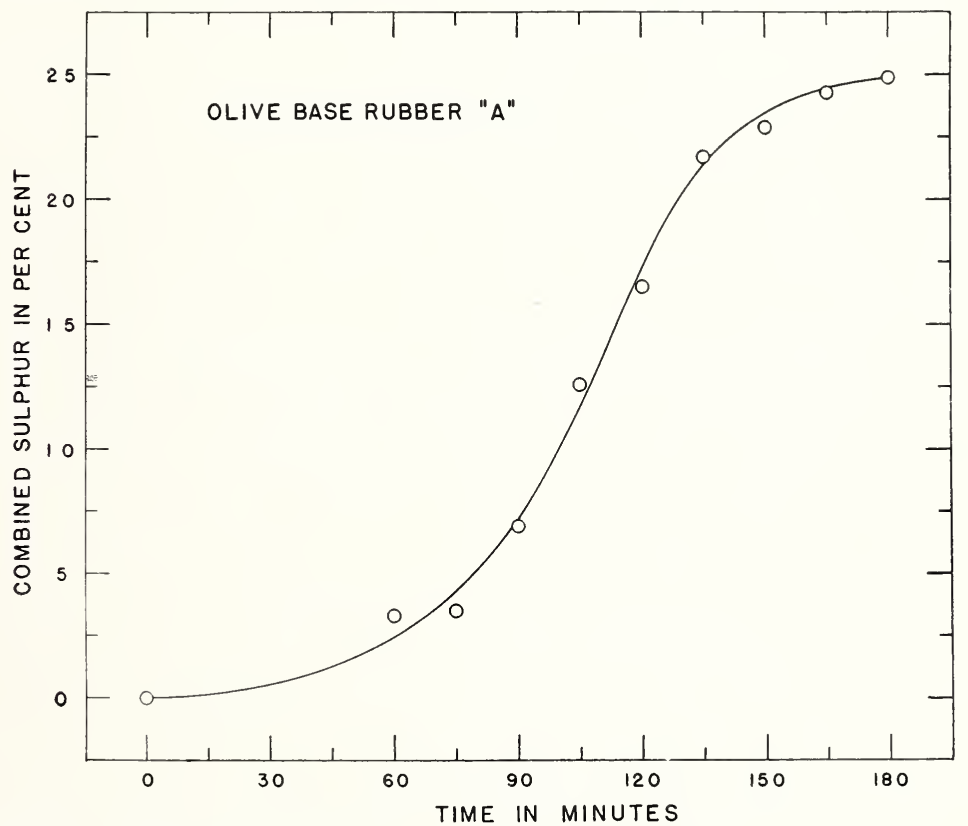

FIGURE 78.-Rate of combination of sulfur with rubber hydrocarbon during vulcanization.

amount of combined sulfur is an index of the degree of vulcanization. This is shown in figure 78 , the data of which were obtained from an olive base rubber which was brought to $160^{\circ} \mathrm{C}\left(320^{\circ} \mathrm{F}\right)$ in 60 minutes, and was sampled for analysis then and at 15-minute intervals thereafter until 3 hours had elapsed from the beginning of the vulcanization. Note that the combined sulfur increased from roughly 3.5 percent to over 16 percent during the first hour at $160^{\circ} \mathrm{C}$. It gradually increased after this time, but as will be seen in figure 78 the main part of the vulcanization was over in approximately 1 hour after a temperature of $160^{\circ} \mathrm{C}$ was reached. This rate of vulcanization holds, of course, only for the time-temperature relationship given. If the temperature is raised $10^{\circ} \mathrm{C}\left(18^{\circ} \mathrm{F}\right)$ the rate will increase approximately twofold [125]. This shows the importance of controlling the time- 
temperature relationship which should be precisely determined by each manufacturer for his indiridual product.

Thermal conductivity.-Dental literature reminds us repeatedly that a denture base which is a good thermal conductor is preferable. This statement is based upon the clinical observation that tissue health is supposed to be better where heat is conducted readily to and from the tissues through the denture base. Unfortunately rubber and resins are extremely poor conductors of heat in comparison with metals and alloys. Attempts have been made to increase the thermal conductivity of rubber by the addition of metallic powders as in the case of the so-called "gold-dust" rubbers. The same type of mixture has recently been introduced by adding powdered gold leaf to methyl methacrrlate.

Thermal conductirity measurements were made on 6 denture base materials. The instrument and method used are described elsewhere [126]. In addition to the data on rubber and resins given herein (table 59) information is also included on other materials used in dentistry. The metal-filled base rubber has for all practical purposes the same conductivity as have the other resins. This particular rubber was advertised as haring a comparatively high heat conductivity. It is believed that each particle of metal powder is enreloped in a film of rubber so that the contact of metal particles with each other is not continuous and therefore the conductivity is not increased appreciably.

TABLE 59.-Thermal conductivity of denture base materials

\begin{tabular}{|c|c|c|c|}
\hline Material & Conductivits & Material & Conductivity \\
\hline & Milliwatts $/ \mathrm{cm}^{2}$ & & Milliuatts $/ \mathrm{cm}^{2}$ \\
\hline $\begin{array}{l}\text { Olire base rubber } \\
\text { Metal filled base rubber } \\
\text { Maroon rubber }\end{array}$ & $\begin{array}{r}{ }^{\circ} \mathrm{C} / \mathrm{cm} \\
\\
1.6 \\
1.5 \\
1.7\end{array}$ & $\begin{array}{l}\text { Vincl resin } \\
\text { Phenol-formaldehyde resin } \\
\text { Cellulose nitrate compound }\end{array}$ & $\begin{array}{rr}{ }^{\circ} \mathrm{C} / \mathrm{cm} & \\
& 1.5 \\
& 2.3 \\
& 2.0\end{array}$ \\
\hline
\end{tabular}

Porosity.-The gross structure of a cross section of an improperly cured denture taken through its thicker portions reminds one of bone structure in that there is a dense cortical layer with a spongy cancellous interior. This condition, usually found only in thermosetting materials, is caused primarily by too rapid curing. For instance, if a block of rubber approximately 10 millimeters thick, 30 millimeters wide and 70 millimeters long is vulcanized by raising it from $20^{\circ}$ to $100^{\circ} \mathrm{C}\left(68^{\circ}\right.$ to $\left.212^{\circ} \mathrm{F}\right)$ in 20 minutes, from $100^{\circ}$ to $160^{\circ} \mathrm{C}\left(212^{\circ}\right.$ to $\left.320^{\circ} \mathrm{F}\right)$ in 40 minutes, and by holding it at $163^{\circ} \mathrm{C}\left(325^{\circ} \mathrm{F}\right)$ for 2 hours, porosity will develop, as shown in figure 79 . In the case of rubber the porosity is caused by the rapid erolution of hydrogen sulfide which occurs when the sulfur and the rubber hydrocarbon combine too rapidly and at an excessive temperature.

The theory, used until recently in dentistry to account for the condition shown in figure 79 , was that the outer sections of the specimen would cure first, and thus trap the gas in the interior. Taylor [127] proved this to be erroneous when he demonstrated that the interior of the specimen became rery hot during rulcanization, much hotter than the outer sections, because of the heat generated 
when the sulfur and the rubber hydrocarbon combined. The interior then vulcanized very rapidly, which caused the porous condition. This can easily be prevented by a slower rate of heating during vulcanizing.

To guard against this condition in practical use there has been inserted in the specification for dental rubber a test (item D-3,

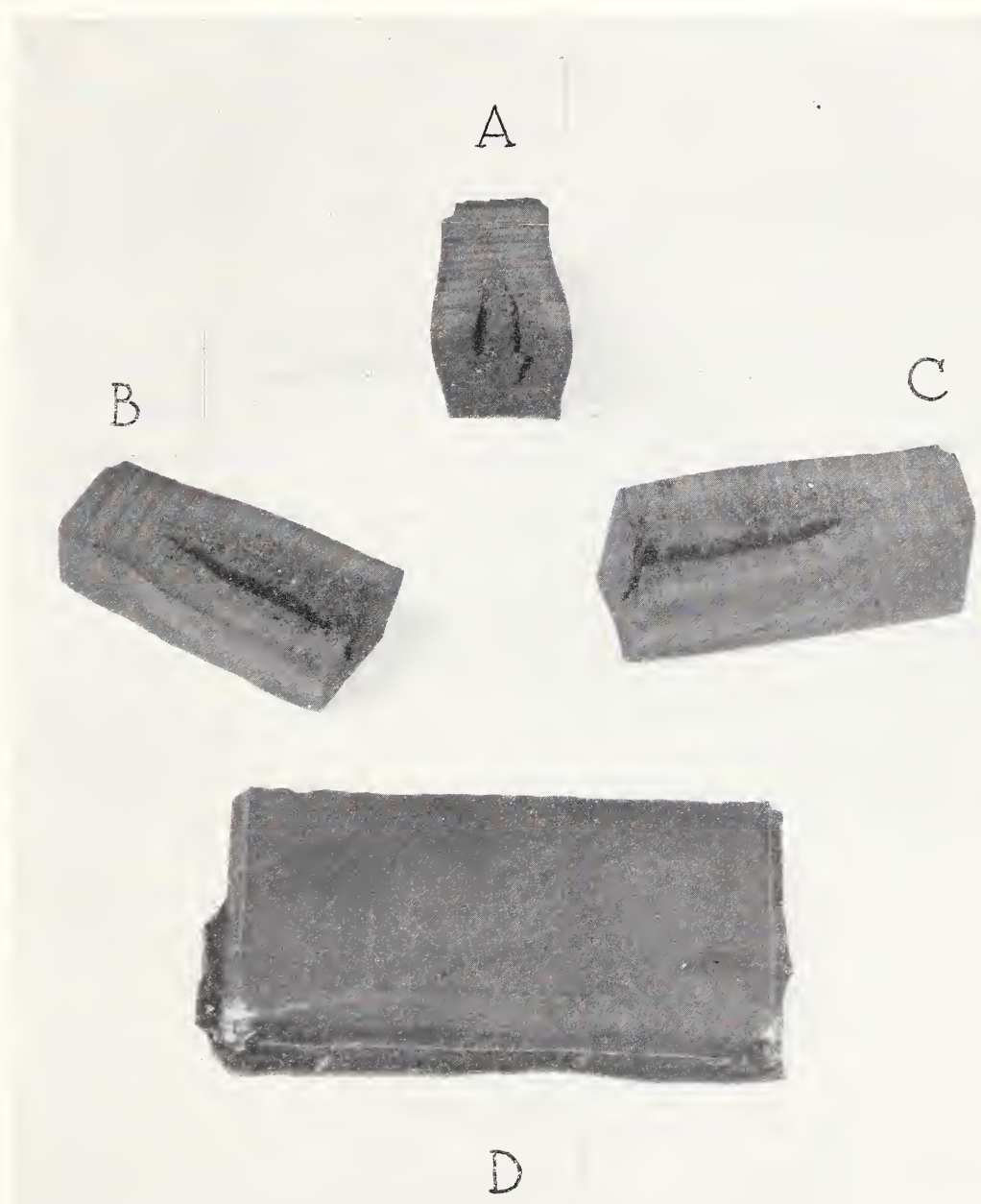

Figure 79.-Porosity in dental hard rubber, olvve base type

$.1, B$, and $C$ are sections taken from block similar to $D$.

page 194) requiring that a specimen 6 millimeters in thickness shall not develop porosity when cured according to the directions on the package.

Frequently during the processing of a powdered phenol-formaldehyde resin, when it is placed in the flask and then heated, air will 
be trapped and will appear in the denture. If the resin is heated very slowly so that it will melt uniformly in the flask, this will not occur. However, if the case is heated too rapidly, the top layer of resin will melt first and form a very viscous layer through which some of the underlying air can not escape, hence the bubbles in the denture.

In the methyl methacrylate resins there are several conditions which cause gas bubbles to form inside of the specimen during curing. If the specimen is cured at a high temperature, some of the monomer (liquid) is vaporized and trapped before it is completely polymerized, and thus causes porosity. A thick specimen of resin can easily and inadvertently be cured too rapidly because in addition to the external heat applied there is also considerable heat evolved during polymerization. The amount of heat developed will depend upon the size and shape of the specimen. As the resin is a poor thermal con-

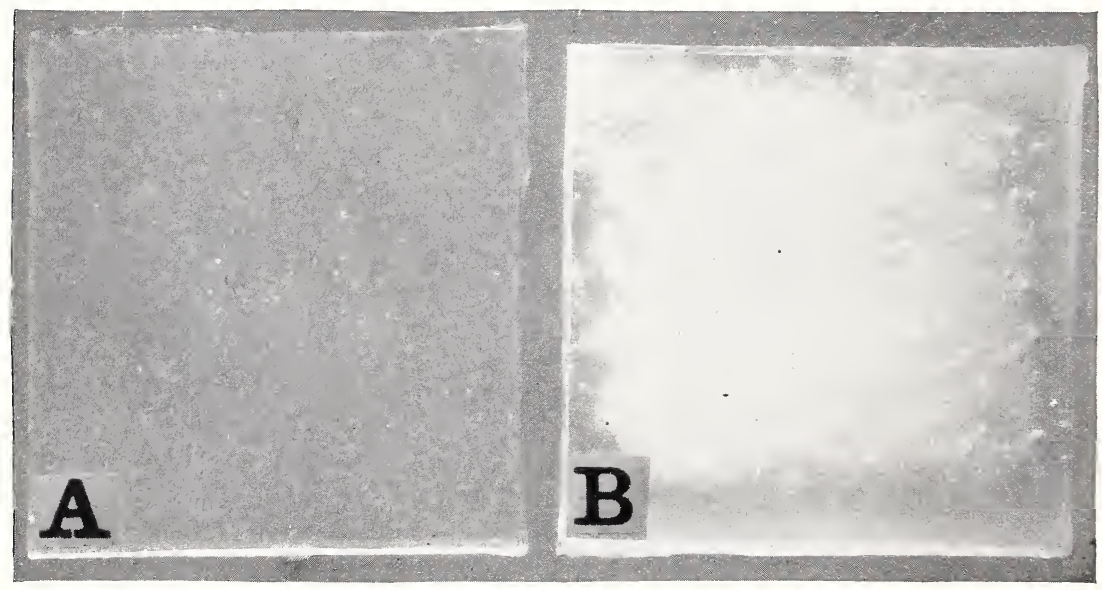

FIGURE 80.-Porosity in methyl methacrylate resin caused by improper mixing. $A$, Clear cake in which the powder and liquid were mixed for 5 minutes prior to packing the mold. The small white dots are protrusions from the surface which were formed when the resin was forced into the irregularities of the plaster mold.

$B$, Cloudy cake in which the powder and liquid were mixed for only 1 minute prior to packing the mold.

ductor the heat formed during polymerization cannot readily escape. Consequently, the interior of the specimen becomes much hotter than the temperature of the water bath or vulcanizer. Some of the monomer will be vaporized and trapped in the resin, whose plasticity is rapidly decreasing. Bubble formations of this type may be avoided by holding the resin at from $70^{\circ}$ to $80^{\circ} \mathrm{C}\left(158^{\circ}\right.$ to $\left.176^{\circ} \mathrm{F}\right)$ for 1 hour and then gradually raising to $100^{\circ} \mathrm{C}\left(212^{\circ} \mathrm{F}\right)$.

If the powder and liquid (polymer and monomer) are not mixed long enough prior to packing in the mold, bubbles will also be formed. This is convincingly illustrated in figure 80 . Here are shown two squares ( 65 by 60 by $4 \mathrm{~mm}$ ) which were cured at the same time in the same pan of water. One square is filled with bubbles, the other is clear. The only variable introduced into the experiment consisted in changing the mixing time of the powder and liquid. In the clear cake the mixing was carried on for 5 minutes before the resin was packed into the mold. When the powder and liquid were mixed 
for only 1 minute the cloudy cake was formed upon heating to the curing temperature.

Sometimes insufficient pressure on the flask or insufficient material in the mold will cause bubble formation in the resin, apparently from the monomer vapor. These bubbles in the cured resin are under reduced pressure. A partial vacuum exists in them. This was verified when a drop of dye solution was placed above a bubble and a small hole was drilled under the dye through the resin to the bubble. The dye rushed into the bubble space, thus showing a reduced pressure within the bubble. Bubbles in a block of cured methyl methacrylate can be eliminated by sufficient heating and pressure on the block. By observing the foregoing precautions, one should not be troubled by porosity in methyl methacrylate resin.

Dimensional changes.-The dimensional changes which occur in the making of a denture and in its subsequent life are of real import

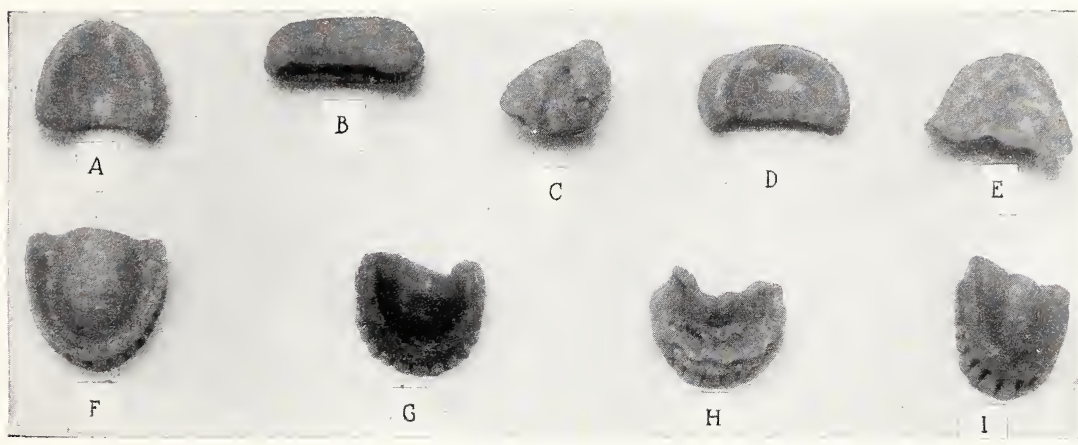

Figure 81.-Distortions in denture blanks and in dentures of vinyl resin caused by internal strain.

$A$, Blank used in forming denture.

$B, C, D$, and $E$ duplicates of $A$, which were heated at $130^{\circ} \mathrm{C}\left(266^{\circ} \mathrm{F}\right)$ in an oil bath for 30 minutes.

$\mathrm{F}$, Vinyl resin denture after polishing, and ready for insertion in the mouth.

$G, I I$, and $I$ dentures similar to $F$, which were heated at $130^{\circ} \mathrm{C}\left(266^{\circ} \mathrm{F}\right)$ in an oil bath for 30 minutes.

and are not any too well understood. These changes in size or shape of a denture can be attributed to a number of causes among which are: (1) Internal strain developed during processing. This may be relieved in time by the warpage, distortion, or even the fracture of the denture; (2) the giving up or taking on of water, or both, which in some materials may cause a linear change of over 3 percent; (3) chemical changes during curing which are manifested more in some directions in the denture than in others, depending of course on the shape of the mold in which the resin is processed; (4) continued curing of the resin at mouth temperature, which occurs over a several months' period and may cause a linear shrinkage of perhaps 2 percent; (5) change in temperature, which gives the expected thermal expansion or contraction (table 2).

Distortions caused by internal strain.-As was stated in the section on plasticity and packing qualities, the vinyl resins usually acquired a considerable amount of internal strain during processing, because the resin blank had to be molded at a low temperature. In other words the resin was not plastic enough to mold without excessive pressure. Consequently, when a denture such as shown in figure 81, 


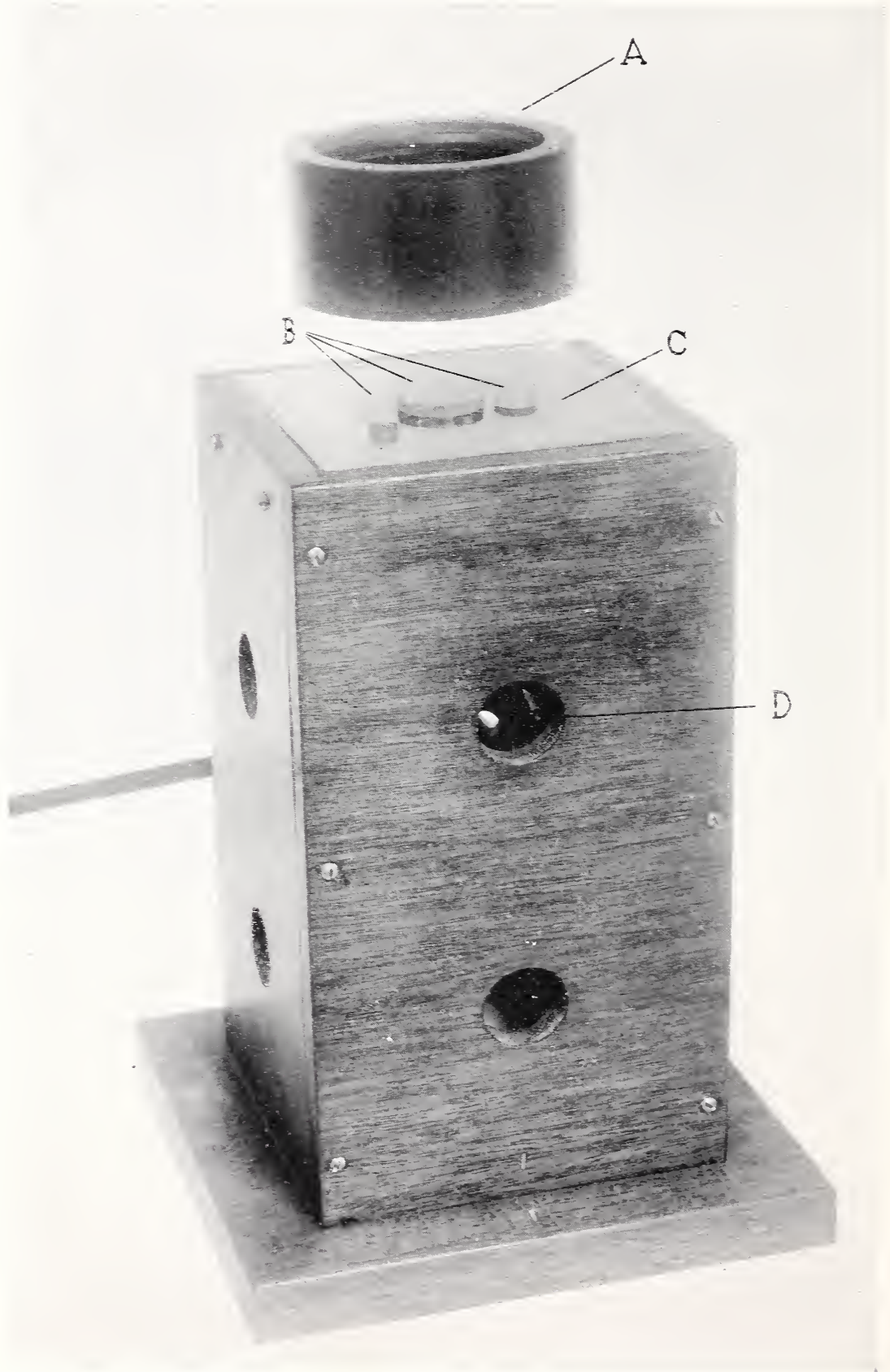

FigCRE 82.-Instrument used to view specimens of resin in polarized light. $A$, Analyzer; $B$, specimens; $C$, polarizer; $D$, light source. 
item $F$, was heated for 30 minutes at $130^{\circ} \mathrm{C}\left(266^{\circ} \mathrm{F}\right)$ in an oil bath, these strains were released and caused distortions of varying degree (fig. 81, items $G, H$, or $I$ ) depending of course upon the amount of strain. At lower temperatures these strains may be only partially released and cause distortions of a lesser degree.

The vinyl resin blanks (fig. 81, item $A$ ) used in making the dentures were also highly strained when received, because severe distortions (fig. 81, items $B, C, D$, and $E$ ) resulted when they were heated in oil as described above. Part of this strain in the blanks was undoubtedly carried into the finished denture. This contributed to the failure of vinyl resin dentures.

If methyl methacrylate resin is processed in an injector type of flask, some internal strain may be developed. In the ordinary processing technic no appreciable amount of strain can be detected.

If the resin is not transparent or not very translucent, internal strain may be detected by heating the specimen. Strain may be

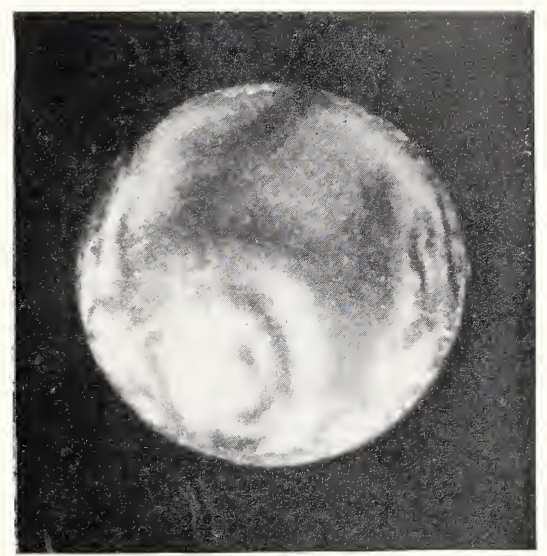

FIGURE 83.- Specimen of vinyl resin showing strain pattern.

exposed in clear or translucent resins of uniform flat section by the use of polarized light. Such a method is depicted in figure 82. The specimens, $B$, lying between the analyzer, $A$, and polarizer, $C$, (films of Polaroid) will if strained distort the plane of polarization of the light. The amount of this distortion is proportional to the intensity of the strain. Figure 83 shows the strain pattern of a vinyl resin disk. When examined visually the pattern is colored, and the order of the color also is related to the degree of strain. Strain-free resins will transmit polarized light without distortion and the resin will be uniformly light or dark, depending upon its orientation between the polarizer and analyzer.

Distortions caused by absorption or loss of water.-As pointed out previously (table 58, column 4) the organic denture base materials absorb water. This water absorption is invariably associated with changes in dimensions, as are shown in table 58, column 5. The ma- 
terials having the greatest water absorption also show the greatest changes in dimensions and conversely. The data in column 5 represent the changes in length across the posterior palatal portion of dentures. A measuring microscope was used to determine the distances between reference lines placed on the resin just posterior to the second molars.

In some materials like the cellulose products the changes assume alarming proportions ranging from +3.4 to -2.0 percent according to the type or brand of product. The methyl methacrylates are the next worst offenders, as in them a growth of from 0.7 to 1.1 percent is encountered. Their water absorption is also comparatively high and parallels the dimensional changes to a remarkable degree (fig. 84). Here it is well to point out that on a denture made of methyl methacrylate the expansion may amount to as much as 0.5 millimeter on

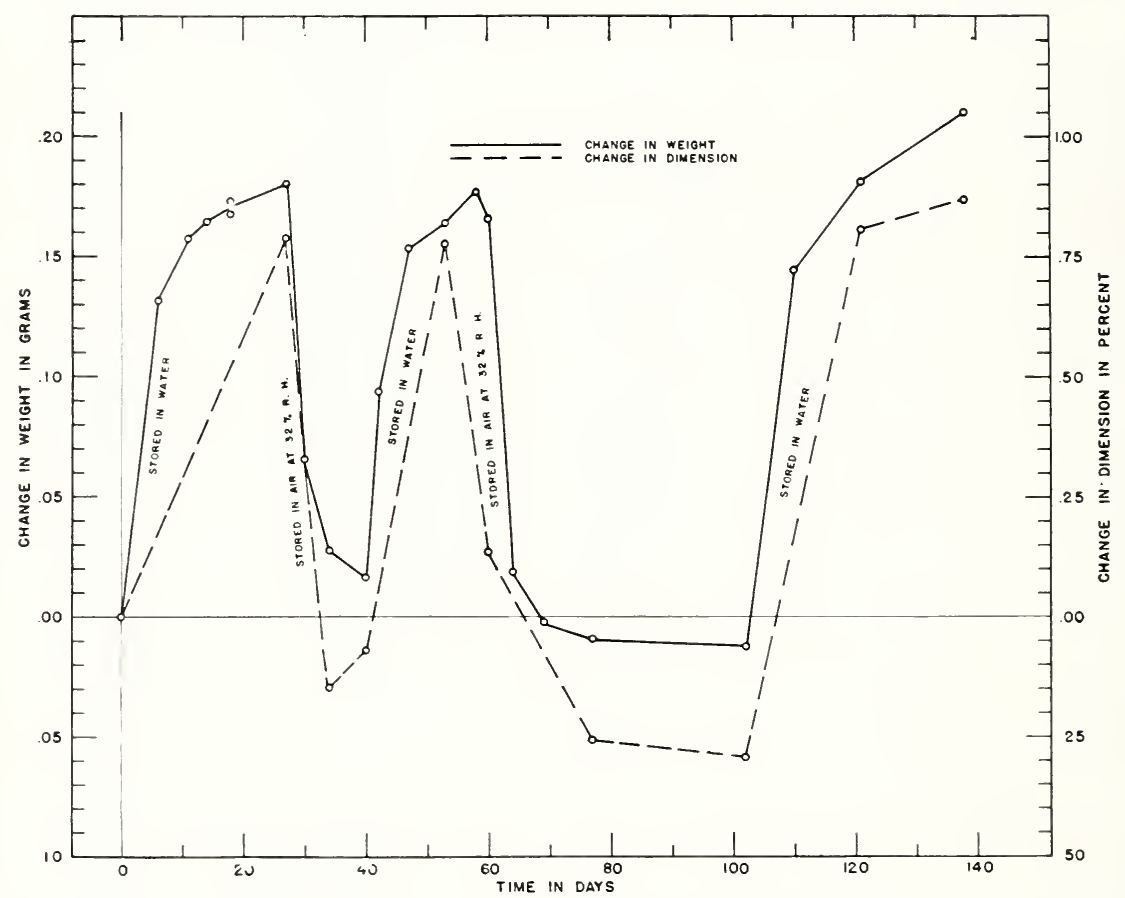

Figure 84.-Effect of water on a methyl methacrylate denture at $37^{\circ} \mathrm{C} .\left(99^{\circ} \mathrm{F}\right.$.).

a 50-millimeter span from molar to molar. Manifestly a change of such magnitude cannot be ignored in adjusting occlusion. In fact during processing and polishing the denture should not be allowed to dry out and should immediately after polishing be placed in water until put in service. The patient should also be instructed to keep the denture in water when it is not in use. If the denture has dried out for several days it should be soaked in water several days before an occlusal adjustment is attempted. The curve of case 5 (fig. 85) shows the behavior of two clinical cases over a period of almost 3 years. Notice that case 5 (methyl methacrylate) reached equilibrium in approximately 4 months. The 0.5 percent expansion in this case amounted to a change of approximately 0.25 millimeter. 
The acrylic-vinyl copolymers and rubber have the lowest water absorption and consequently the least dimensional change therefrom. This change amounts to only 0.3 percent growth in the case of the acrylic-vinyl copolvmers and a shrinkage of from 0.1 to 0.6 percent in the base and all-purpose rubbers.

Any dentist can check the dimensional changes which occur in a denture in service by the following simple procedure. Make an artificial stone model of the bearing surface of the denture to serve as a record of its important dimensions. If the denture, after being worn for some time, will not seat on the stone model, a change has occurred. This change in dimension is reflected by the fit of the denture on the model more than one may realize, as is shown in figure 86 . These dentures were treated according to the following schedule: (1) The

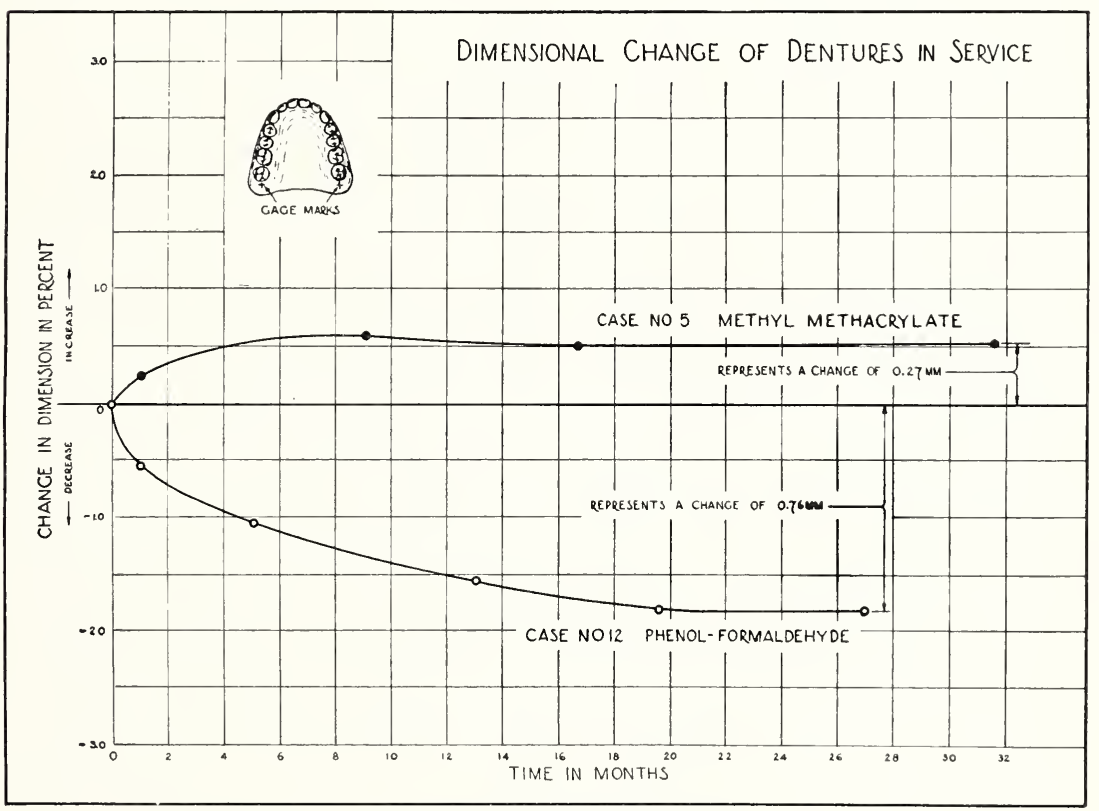

Figure 85.-Dimensional change of dentures in service.

dentures were processed to nearly identical size and shape. They were made from a master model, in some instances in duplicate, by two commercial laboratories according to the directions which accompanied the respective materials, (2) gypsum models of the bearing surfaces were poured when the dentures were received, (3) the dentures were then stored for 15 days in water at $37^{\circ} \mathrm{C}\left(99^{\circ} \mathrm{F}\right)$. They were then placed upon the gypsum models as shown in figure 86 .

Shrinkage during curing.-The actual shrinkage occurring in a denture base material during processing in a dental technic has never been measured because of the many obvious difficulties therein encountered. Even if the total volumetric shrinkage could be determined it would not necessarily give the information desired, as the linear change would not be the same in all directions because of the restraining action of the mold over which the denture is formed. To 
demonstrate this make a cross-section of a flasked case just after processing, as has been frequently done by many experimenters. A view of such a cross-section shows that the denture will conform fairly well to the bearing surface of the model but will appear to have pulled away from the flasking plaster on the lingual and buccal surfaces.

How much this condition will affect the dimension across the posterior was determined in a series of tests using a stainless steel die which simulates an upper arch form (fig. 87, item $A$ ). Two reference cross lines, $B$, were ruled on the crest of the alveolar ridge portion of the die about 1 centimeter from the posterior border. Cases were waxed on the steel model and were carried through the conventional

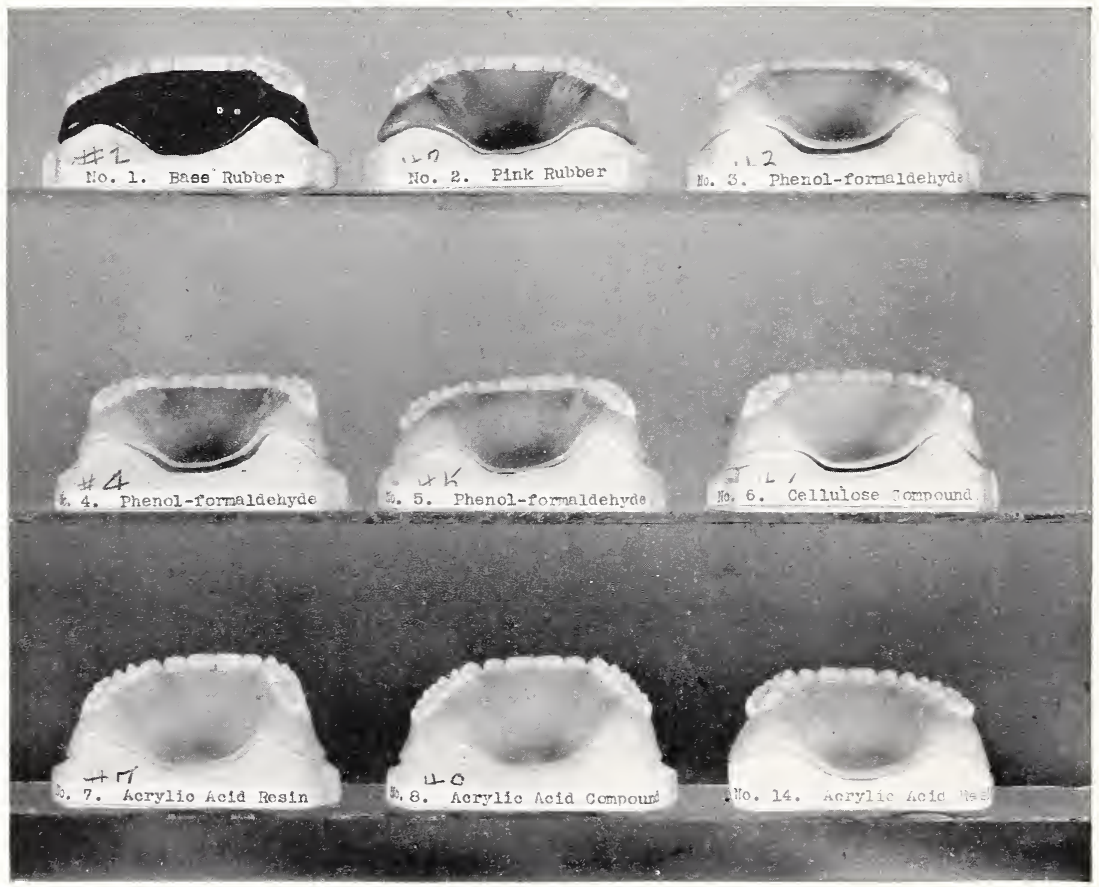

FIGURE 86.-Fit of dentures on gypsum models after the dentures were immersed in water at $37^{\circ} \mathrm{C}\left(99^{\circ} \mathrm{F}\right)$ for 15 days.

dental technic, using the steel die instead of a gypsum replica of it. In all cases the details of processing were carried out as directed by the manufacturer of each material. After the flask came to room temperature the denture form and die were removed. The fit of the form on the die could be used as a qualitative measure of shrinkage. The apparent linear shrinkage (table 58, column 6) was computed from measurements of the distance between reference marks (fig. 87, item B) on the model and between the same marks on the resin, which were transferred to it during processing. The measurements were made immediately after the resin form was removed from the flask. No temperature corrections were made for the differential thermal expansion of the metal die and the various resins or rubbers. 
The data (table 58, column 6) show that the methyl methacrylates may have shrinkages as low as 0.25 percent and as high as 0.45 percent. These values appear difficult to explain when one takes into consideration the differential thermal expansion of the die and resin from the curing temperature of $100^{\circ} \mathrm{C}\left(212^{\circ} \mathrm{F}\right)$ to room temperature. Methyl methacrylate resin for instance should have a linear thermal shrinkage of 0.65 percent over the temperature range $100^{\circ}$ to $20^{\circ} \mathrm{C}$ $\left(212^{\circ}\right.$ to $\left.68^{\circ} \mathrm{F}\right)$. Yet as before stated the combined curing and thermal shrinkage of methyl methacrylate resin amounted to no more than 0.45 percent at the most. It would appear that the resin adapts itself to the die during cooling. This adaptation temperature for one of the methyl methacrylate resins was found by calculation from the thermal expansion data to be near $90^{\circ} \mathrm{C}\left(194^{\circ} \mathrm{F}\right)$.

The linear curing shrinkages of rubber and of acrylic-vinyl copolymer are appreciably less than that of the methyl methacrylate resins.

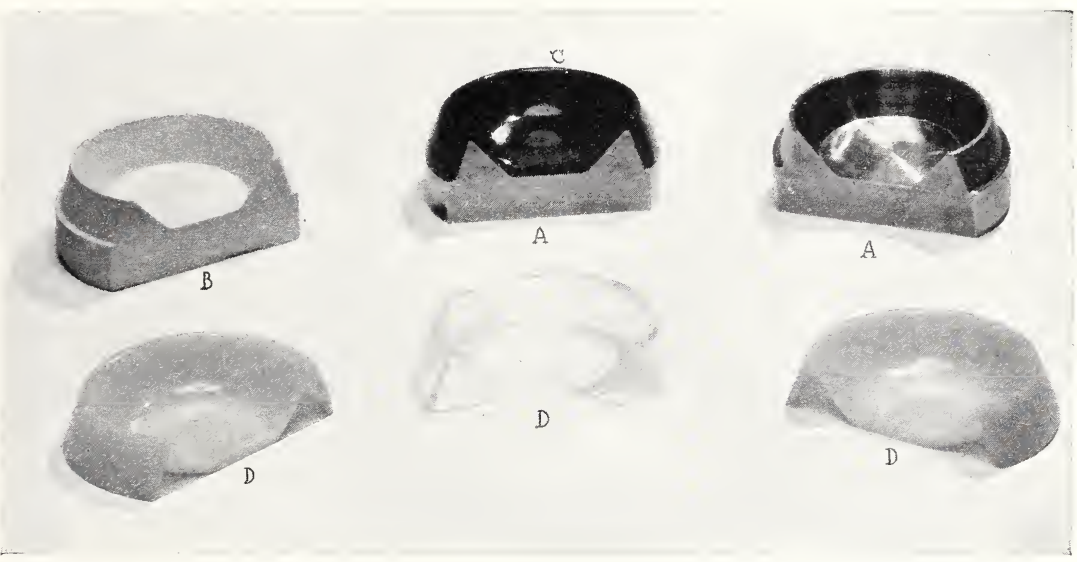

FIGURE 87.- Stainless-steel die and specimens of resins used in determining linear shrinkage during curing.

$A$, Stainless-steel dies; $B$, gypsum replica of $A ; C$, olive base rubber form; $D$, acrylic resin forms; forms $C$ and $D$ were molded on dies $A$, which had fine cross-line reference marks on the crest of the ridge. These marks were transferred to the forms $C$ and $D$ during molding. The difference in distance between the reference marks on the die and resin forms represented the shrinkage of the resin during processing.

However in evaluating the various types of denture base materials in terms of shrinkage, it is convenient to add algebraically the curing shrinkage (table 58, column 6) to the expansion caused by water absorption (table 58, column 5). This indicates the relative change and its direction, both of which are given in table 58, column 7 . The acrylic-vinyl copolymers have the least permanent change, roughly one-third that of the methyl methacrylates or rubber.

Shrinkage caused by prolonged curing after denture is placed in service.-The phenol-formaldehyde resins continue to shrink with time as will be seen by referring to cases 3,4 , and 5 in figure 86 . These changes on the experimental dentures occurred within a 15-day period. In addition to these laboratory cases the shrinkage of some practical cases was followed for over 2 years. An example of the data obtained in case 12 is shown in figure 85 . This denture continued to shrink for about $1 \frac{1}{2}$ years; the shrinkage amounting to almost 2 percent. Subsequently the denture changed very little in dimensions. 
The individual who wore this particular denture did not complain of the change even though it amounted to almost 1 millimeter across the posterior section. Evidently his tissues adjusted themselves to the changing dimensions, otherwise the plate would not have been retained well.

Expansion or contraction with change in temperature.-All of the organic denture base materials have high coefficients of thermal expansion. This ranges from about 56 parts per million per degree centigrade for rubber to 135 parts for celluloid (table 2). Methyl methacrylate resin falls in between having a coefficient of approximately 81 parts per million per degree centigrade. Even with this large coefficient the actual change in a denture under service conditions is very small. If it is assumed that the temperature of a denture may, when in contact with hot foods, rise to $50^{\circ} \mathrm{C}\left(122^{\circ} \mathrm{F}\right)$ the actual linear change then from $37^{\circ} \mathrm{C}$ to $50^{\circ} \mathrm{C}\left(99^{\circ}\right.$ to $\left.122^{\circ} \mathrm{F}\right)$ would amount to only 50 microns over a posterior dimension of 50 millimeters. This is only 0.1 percent, a figure of no consequence practically. The tissues would also swell with the increase in temperature and would probably more than cancel the slight expansion of the resin.

Comparison of mechanical properties.-The mechanical properties of materials are frequently of singular importance in predicting the expected service of the material. They are probably the greatest single aid outside of clinical or practical tests, which obviously are the best criteria. In this connection let it always be remembered that physical and clinical tests supplement each other. Neither can be used alone to measure the worth of a denture base. For example the thermoplastic vinyl resin, which a few years ago was extensively used as a denture base, has good mechanical properties (table 60), which are certainly comparable to those of rubber, yet in clinical use it failed well-nigh universally. Here clinical tests disclosed an unsuitable material. One might say also that this discovery was made fairly rapidly yet at an enormous cost. The clinical tests however did not disclose why the material was unsatisfactory. The Bureau's laboratory investigations of the physical and chemical properties revealed: (1) Nonuniformity in composition; (2) internal strain in the blank as supplied; (3) internal strain in the denture caused by using too low a pressing temperature; and (4) a low endurance limit in flexure fatigue tests. All of these contributed to the failure of the material in service. If adequately controlled clinical cases are carefully conducted prior to the wholesale use of a material much of the misfortune and discredit attending its use can be avoided.

Phenol-formaldehyde resin dentures have been used for years. Yet this long clinical service did not disclose that the dentures were contracting as much as 2 percent linear in less than 2 vears.

These two illustrations will serve as examples of the necessity of using both laboratory and clinical experience and of not relying on either alone to measure the suitability of a denture base or any other dental material or technic.

Hardness.- The hardness of the surface of the materials was determined at $25^{\circ}$ to $30^{\circ} \mathrm{C}\left(77^{\circ}\right.$ to $\left.86^{\circ} \mathrm{F}\right)$ by the Knoop indentation method [107] using a 50-gram load in contact with the specimen for 5 seconds. The ratio of the load applied to the area of the indentation, expressed in kilograms per square millimeter is shown in table 60 , column 3. The lower the number, the softer the material. 


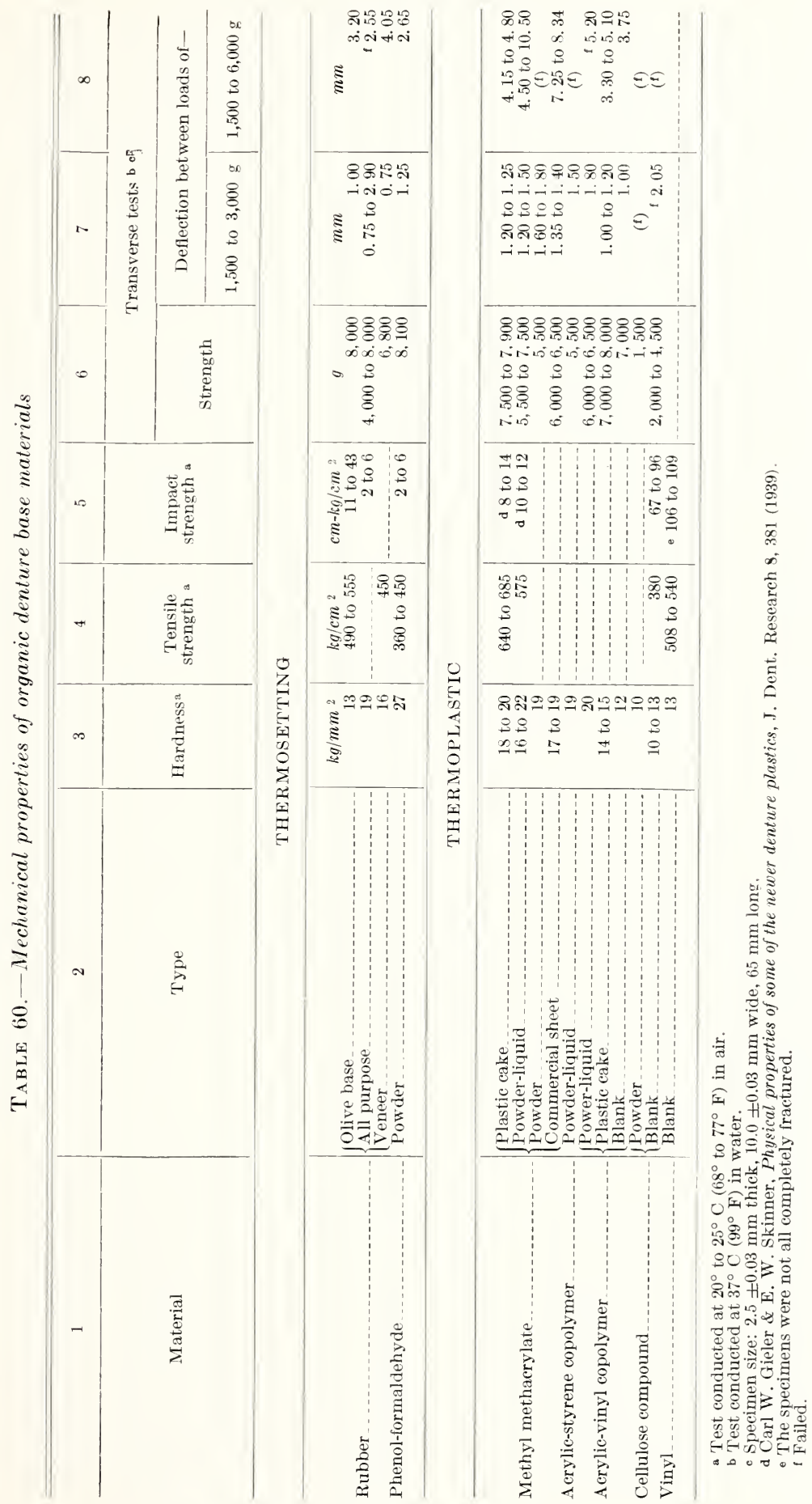


The cellulose compounds are the softest and the phenol-formaldehrde resins are the hardest of the materials tested. The harder materials may retain a polish better than the softer ones; that is, if other factors such as softening point, solubility, uniformity, and so forth, are equal. Brinell numbers of over 200 have been reported in the dental literature [128] for phenol-formaldehyde denture base materials. Such hardness values are obriously in error as ther approach those of hard gold alloys. In fact, the data in table 60 . column 3 are more representative of Brinell numbers than many reported ralues.

Lltimate tensile strength.- Tensile strength is one of the important properties of materials from an engineering standpoint and offers a very useful criterion for comparing materials. It is computed on the original cross-sectional area of the specimen rather than on the area at the instant of breaking. As some of the denture materials neck down to a great extent, that is, the cross-sectional area of the specimen is greatly reduced prior to rupture, the tensile strength for the narrowed

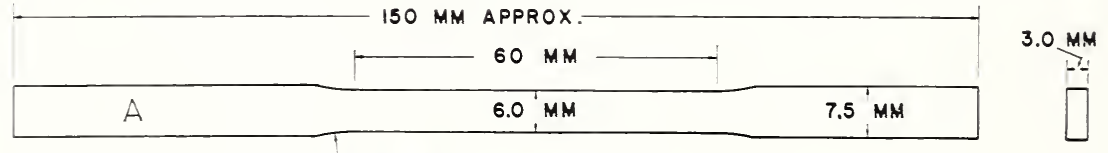

25 MM
RADIUS

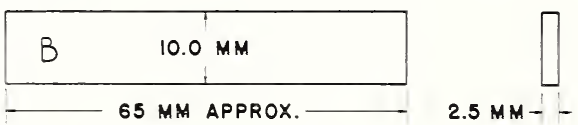

FIGLRE S8.-Specimens used in testing denture base materials.

A, tensile specimen; B, specimen used in impact, fatigue, and transcerse tests.

section is much greater than the conventional values reported in table 60 , column 4 .

These values were obtained on an Amsler testing machine (fig. 25). An averaging extensometer (fig. 26) was used to obtain measurements of strain. All the measurements were made at $20^{\circ}$ to $25^{\circ} \mathrm{C}\left(68^{\circ}\right.$ to $\left.77^{\circ} \mathrm{F}\right)$. The indicated loading of the machine was at the rate of 10 pounds a minute. Details of the size and shape of the specimen are shown in figure 88 . The specimens were machined from sheets or plates (250 $\mathrm{mm}$ long, $125 \mathrm{~mm}$ wide, and $4 \mathrm{~mm}$ thick) prepared according to the manufacturers' directions.

The values obtained under the foregoing conditions (table 60 , column 4) rate the materials from the strongest to the weakest in the following order; methyl methacrylate resin, rinyl resin and base rubber, phenol-formaldehyde resin, and cellulose compounds.

Stress-srtain relationship.-During the tensile tests observations were taken to determine the stress-strain relationships over the lower stress ranges. These relationships afford information regarding the elongation of the materials at various stresses and offer a risual representation of their beharior when subjected to stresses. Representative stress-strain curves for eight classes of denture materials are shown in figure 89. These curves all have about the same general shape with the exception of the curve for the cellulose nitrate compound, wlich 
shows a greater deformation for a given load than do the other materials. The curves are concave toward the strain axis, which means that the higher the load, the greater the deformation produced by a given increment of load. In other words there is no part of the curve where the stress-strain relationship is strictly proportional. This means that the materials shown in figure 89 have no true proportional limit as do some metals. One can define an arbitrary proportional limit but this would be of little value practically.

Impact strength.- Impact tests were made on a small Schopper machine (fig. 90) using the hammer in the 40 centimeter-kilogram position. The specimens (fig. 88) were placed on the horizontal supports in such a manner that the smallest dimension $(2.5 \mathrm{~mm})$

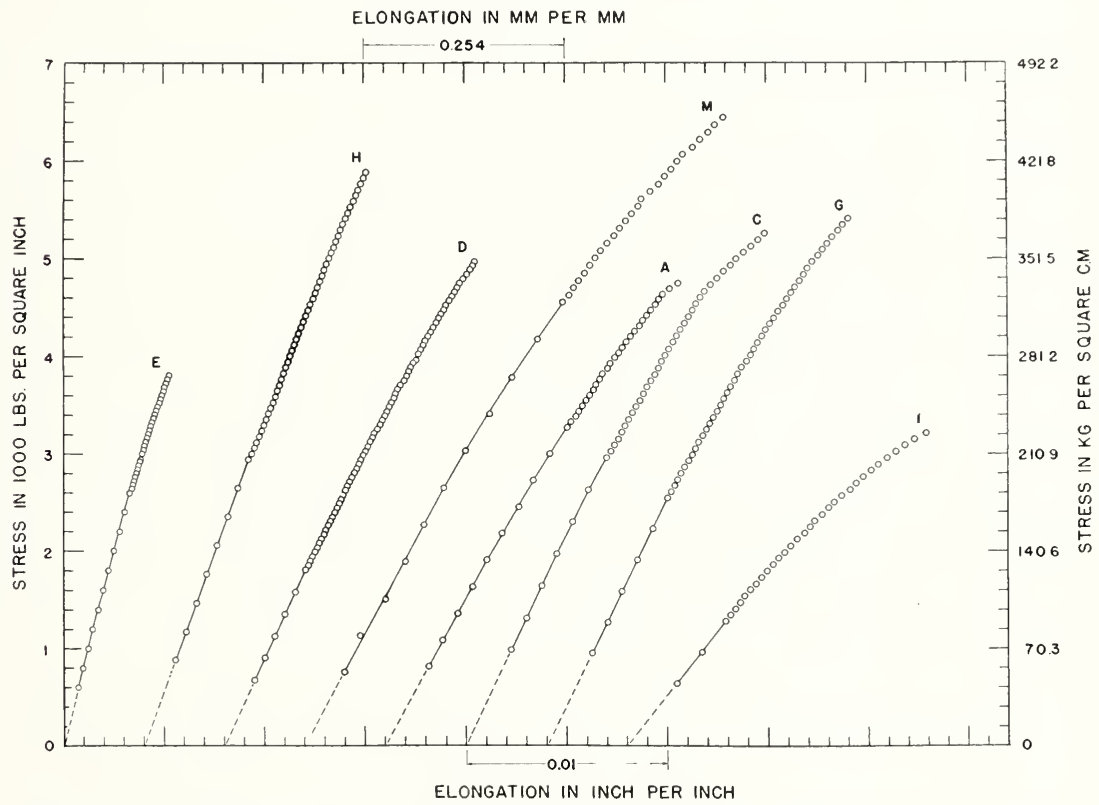

FIGURE 89.-Representative stress-strain curves for eight classes of organic denture base materials

$E$, pink veneer rubber; $H$, phenol-formaldehyde resin; $D$, maroon rubber; $M$, methyl methacrylate resin; $A$, olive base rubber; $C$, metal-filled base rubber; $G$, vinyl resin; $I$, cellulose nitrate compound.

lay in the direction of the hammer blow. The energy absorbed by the specimens is shown in table 60, column 5 . Other things being equal the material having the highest impact strength should be the least liable to fracture when dropped or given rough treatment. The rating of the materials on the basis of impact strength places vinyl resin far in the lead, followed in descending order by cellulose compounds, base rubber, methyl methacrylate, and all-purpose rubber, with phenol-formaldehyde resins in last place.

Transverse bending tests.- The transverse bending of five classes of denture base materials was measured at various temperatures. In these tests the specimen (fig. 88) was mounted on flexible selfaligning supports which were spaced 50 millimeters apart. A 50- 


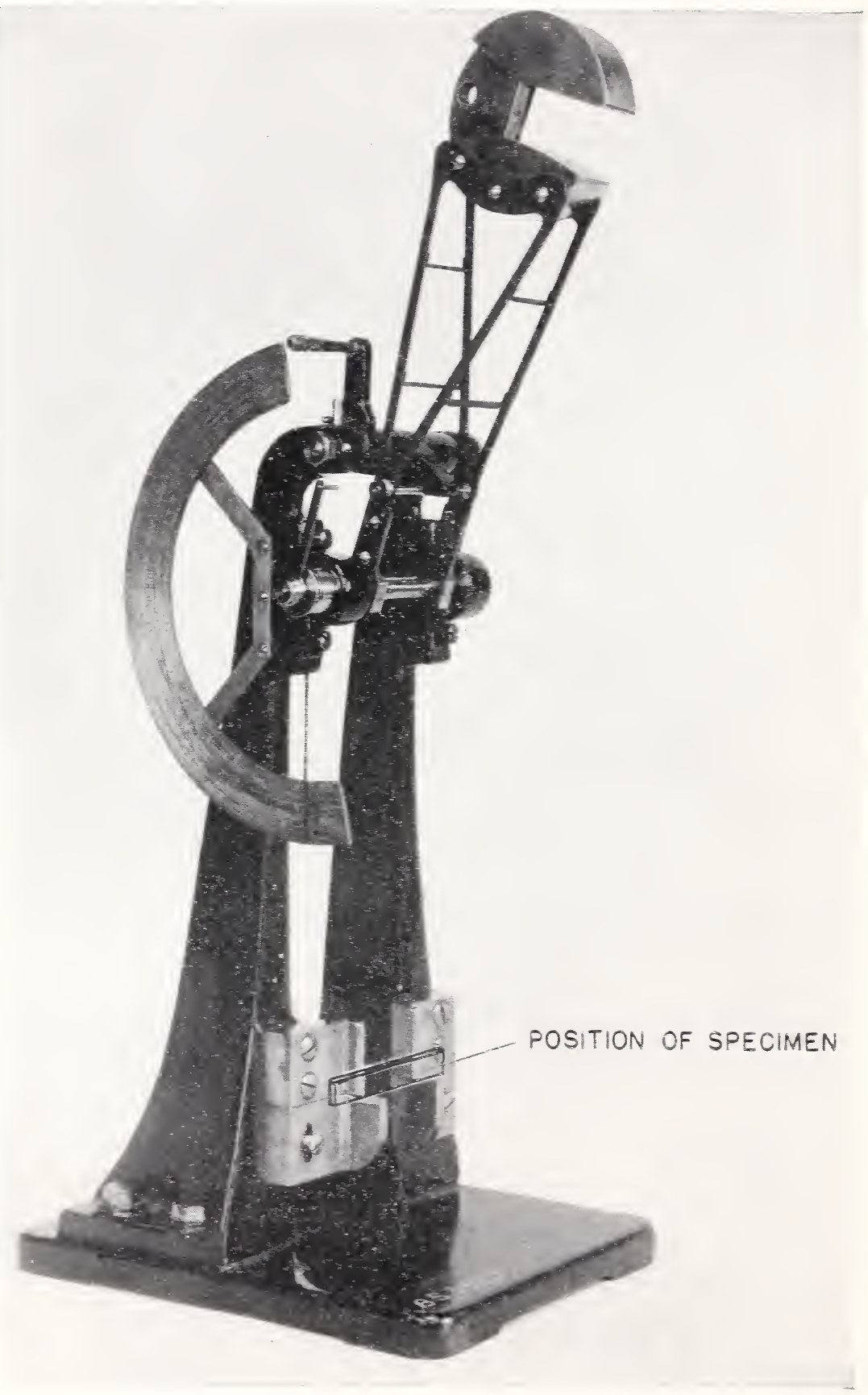

FIGURE 90.-Charpy-type impact machine. One-third actual size 
gram weight was suspended from the center of the specimen. The deflection of the specimen was measured with a dial gage. The temperature of the water bath in which the specimen was immersed was raised approximately $1.5^{\circ} \mathrm{C}\left(2.7^{\circ} \mathrm{F}\right)$ a minute. The test results, graphically shown in figure 91, indicate the softening range of each class of material. Certainly the possibility of deforming dentures while chewing hot foods or while being scrubbed in hot water

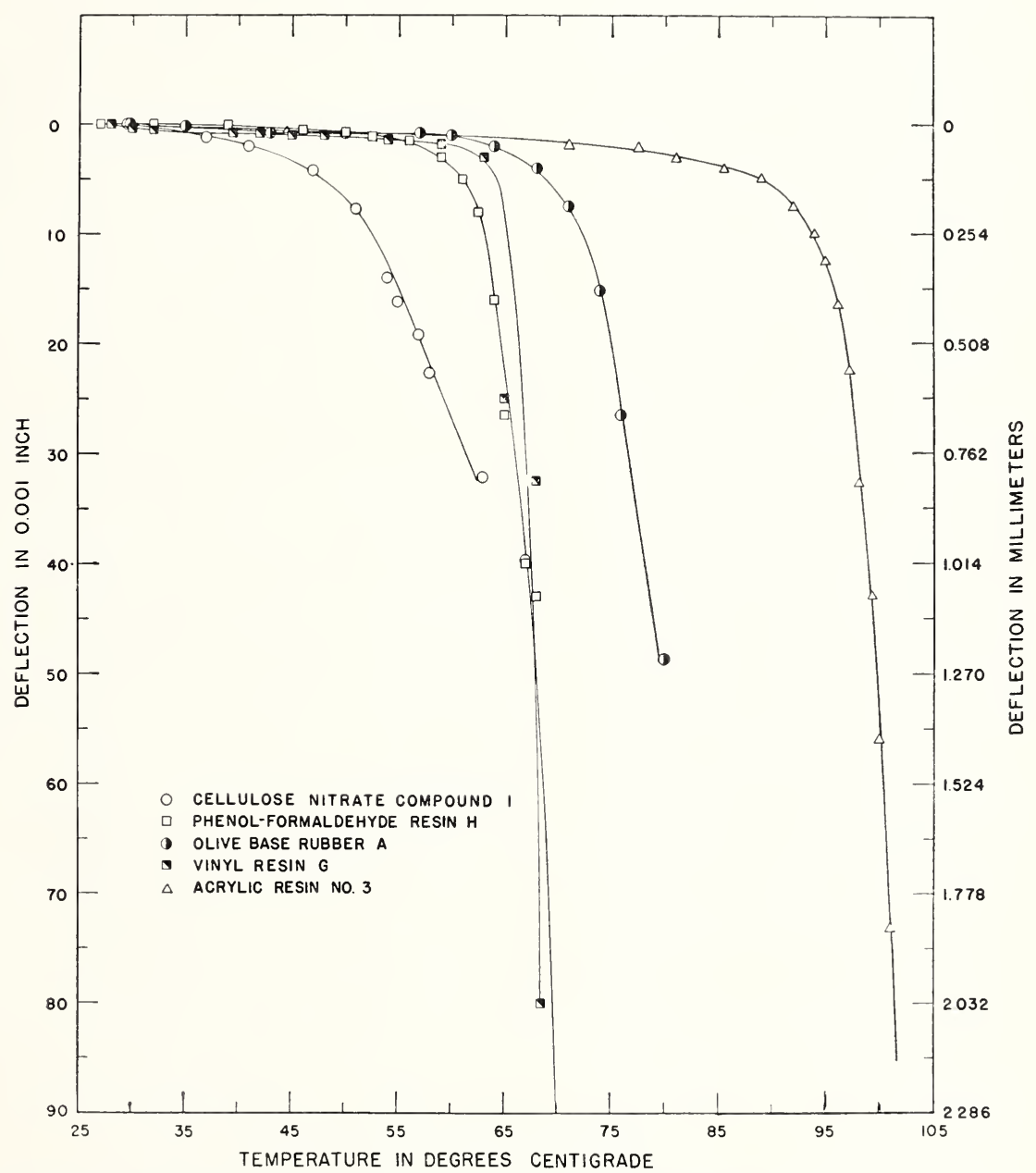

FIGURE 91.- The transverse bending of denture base materials versus temperature.

is clearly shown. The cellulose nitrate compound softened at such a low temperature range that dangerous distortions undoubtedly could occur under conditions of service. The high softening range of methyl methacrylate makes it far superior to the other materials in this regard.

Other tests were conducted by the transverse loading of a specimen, where the load was varied, but the temperature of the water immersion 
bath was held at $37^{\circ} \mathrm{C}\left(99^{\circ} \mathrm{F}\right)$. A drawing of the instrument used in this type of testing is presented in figure 92. An initial load of 1,500 grams was applied to the specimen (fig. 88). The bending of the specimen under this load was taken as the initial or base line deflection. Then a load increment of 500 grams was gradually applied during a 30-second interval. Thirty seconds later the deflection was recorded. This procedure was repeated until the specimen broke or bent sufficiently to force it through the 50-millimeter span. The loads required to do this are listed in table 60 , column 6 . Where only one brand of a material of a given type was tested a single average value is given. When more than one brand of material

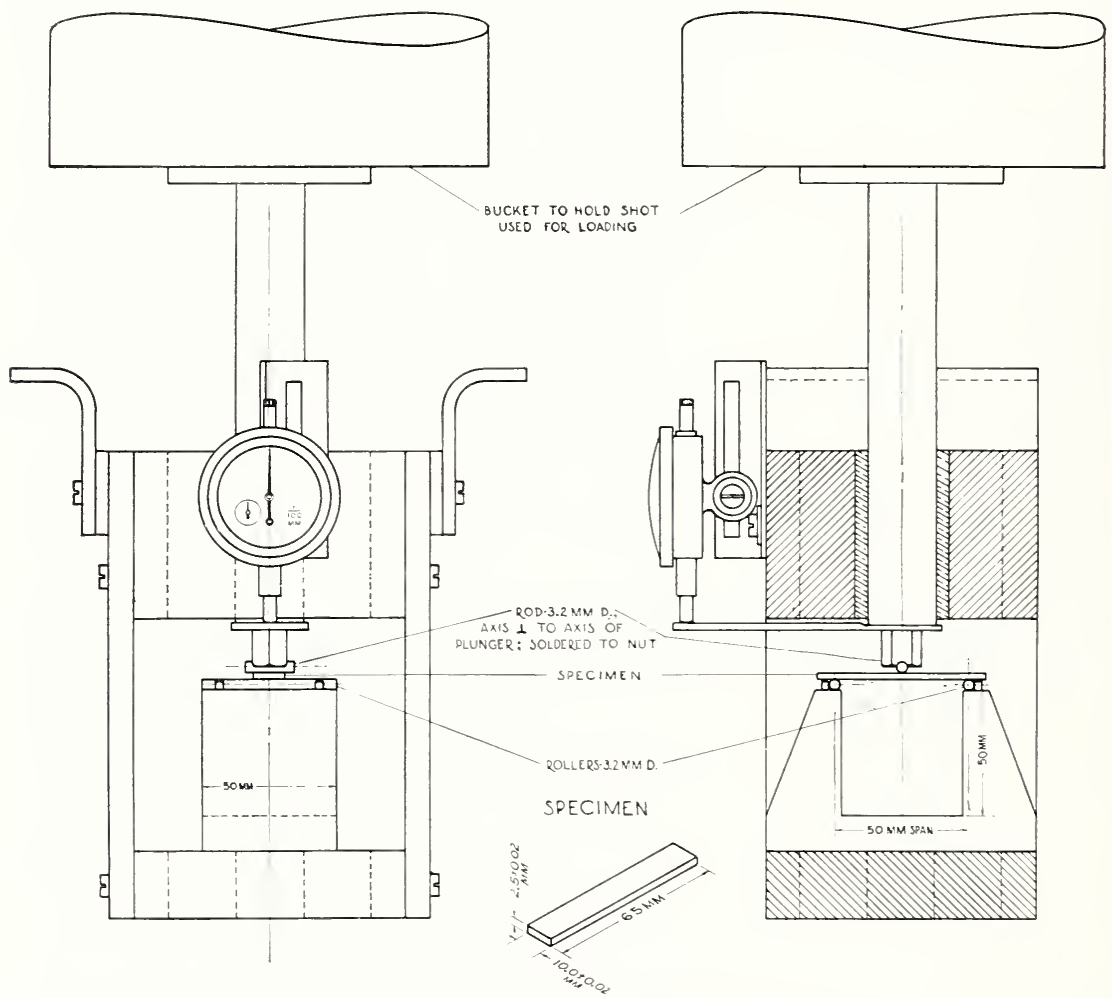

Figure 92.-Transverse-testing apparatus.

within a given type was tested the arerage values of the weakest and strongest material are given. As the width and thickness of the specimen were held at narrow tolerances, the values represent the relative strengths. Base rubber, phenol-formaldehyde resin, methyl methacrylate (plastic cake type) and the acrylic-vinyl copolymer are all of about the same high strength. Individual materials in each class required a load of roughly 8,000 grams to cause failure.

The deflections of the materials over two selected load ranges $(1,500$ to $3,000 \mathrm{~g}$ and 1,500 to $6,000 \mathrm{~g})$ are given in table 60 , columns 7 and 8 . In attempting to correlate the deflections with the strengths, it should be noted that usually the weak material had the largest 
deflection. For instance, consider the so-called all-purpose rubbers with strengths running from 4,000 to 8,000 grams. The weakest brand of all-purpose rubber tested failed at 4,000 grams, the strongest at 8,000 grams. The weakest material usually had the largest deflection at a given load, and conversely.

The combination of strength (load) and bending (deflection) may be considered as an index of the toughness of the material. The toughest material can, therefore, be considered as the one having the highest strength and at the same time having a relatively large deflection before failure. Such a material will absorb a comparatively large amount of energy before fracturing. A brittle material would be equally strong but would have a comparatively small defiection.

Flexural fatigue.-Dentures are subjected to repeated stress cycles in chewing. The magnitude and the number of such stress cycles are not known but a simple calculation indicates that it is not unreasonable for a denture to undergo several million cycles during its life. Therefore the endurance limit or the maximum stress that a material will withstand for many millions of cycles of stress may be of importance in judging its usefulness. To determine the endurance limits of a resin is indeed a very slow and tedious process. Consequently, no attempt was made to determine the actual endurance limits of any of the denture base materials. However, some flexural fatigue testing was done. The results indicated that rubber and phenol-formaldehyde resin had definitely higher endurance limits than did vinyl resin. This inability of the vinyl resin to withstand low repeated stresses was probably one of the causes of the failure of these resins as a denture base material. The comparatively low endurance limit may not necessarily be inherent in the material but may be due to the large amount of internal strain which was in the vinyl resin specimens.

As the acrylic-vinyl copolymers are giving better service than the first vinyl denture resins did it can be assumed that the copolymers have higher endurance limits or less internal strain or both. At any rate dentures made of the copolymers continue to give satisfactory service.

Conclusion.-At the present time (1942) methyl methacrylate resin and some of its copolymers appear to be, all things considered, the most satisfactory available denture base materials.

\section{DENTIFRICE}

Much has been claimed for the different types of dentifrice, but the chief service rendered by a dentifrice is as a mechanical or chemical cleansing agent. There seems to be no justification whatever for claims that any one brand of dentifrice will prevent the decay of teeth to a greater degree than any other brand, nor has it been demonstrated that any dentifrice will prevent or retard decay.

The tooth paste problem, for the public, need not become complicated. Exhibits are before us daily wherein normal oral health has been maintained for years by the use of extremely simple materials. Common table salt and baking soda are the standard tooth-cleaning materials for thousands.

There are, however, frequently discovered evidences that serious damage can be done to the exposed surfaces of the teeth, especially to dentine and cementum, when they are brushed with materials 
containing grit or tooth-dissolving chemicals. Irritations and painful afflictions of the oral tissues are not uncommon where defective dentifrices are used.

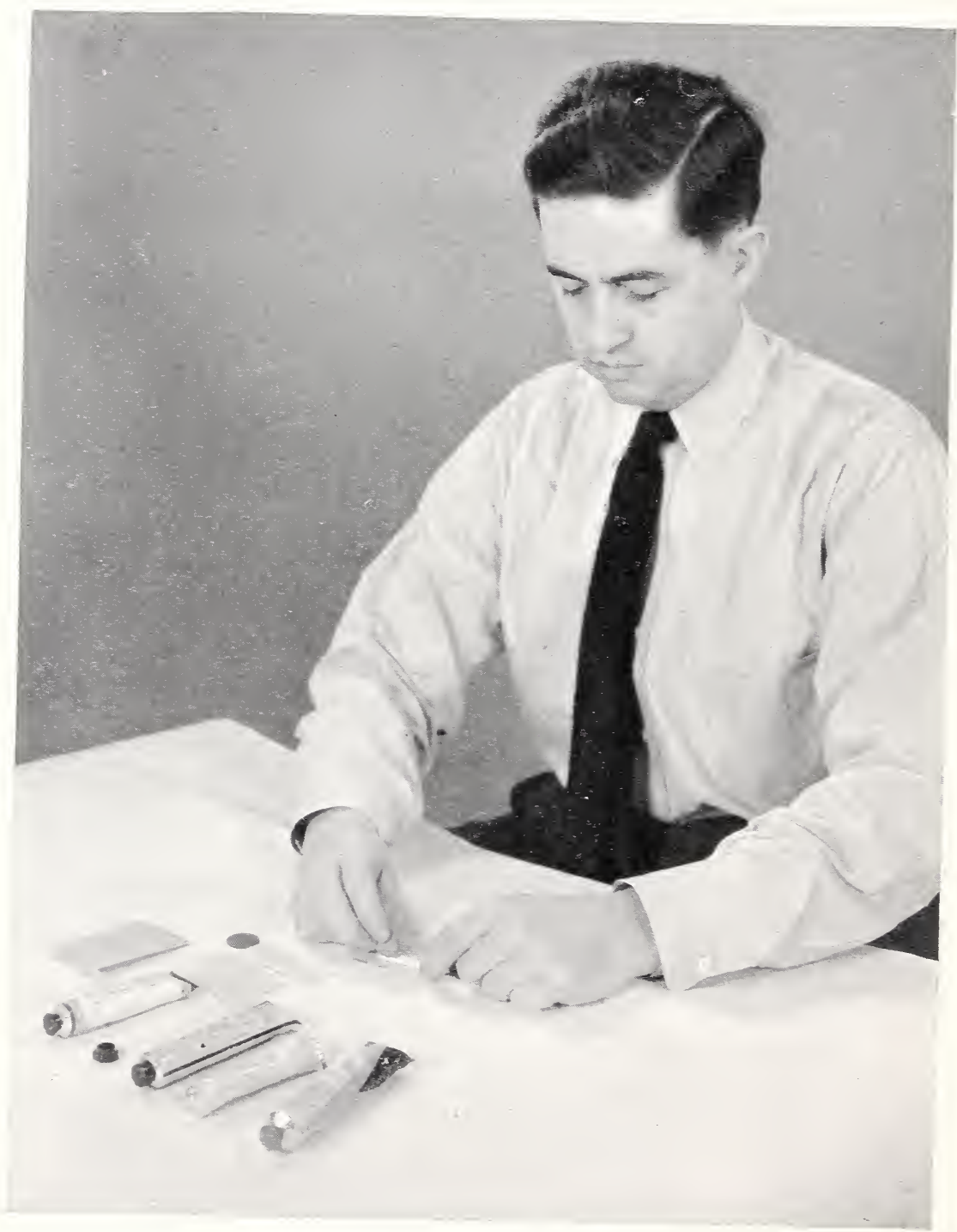

FIGURE 93. - Scratch test for tooth paste.

Grit and similar impurities will, when rubbed with the metal disk, scratch the glass plate.

The question whether tooth paste is to be regarded as a medicine or as a cosmetic can be disposed of without extended discussion. It must be admitted that in certain instances, a medicated preparation is necessary in treating a definite oral pathologic condition. Such a condition, demanding a medicated dentifrice, also requires medical or dental inspection and obserration. Specifications for a medicated 
dentifrice should be written by the attending dentist or physician who assumes responsibility for the therapeutic effects of the special dentifrice.

Specifications. - The Federal specification which was developed for general use by the Government and the public at large, covers only the paste type of dentifrice (p. 199). However, certain of the sections relating to acidity, abrasion and safe ingredients may be applied to liquids and powders.

The consistency or viscosity of the paste must be within a range which will deliver a uniform product under normal climatic and storage conditions. The demand for a solid detergent (minimum arbitrarily set at 40 percent) arises from the recognized efficiency of powder for removing films like those formed on the teeth.

The solid detergents which are permitted by the specification are, in their pure state, known to be practically nonabrasive to teeth. The specification scratch test (fig. 93) is made to detect impurities in these detergents or the presence of other abrasives which may have been introduced in the manufacturing process. The method of testing for abrasive material is very sensitive. The presence of 0.01 percent of emery in a paste is readily revealed [72]. It is doubtful whether any type of abrasion machine now available is capable of revealing this small quantity of grit in tooth paste. Manufacturers have found that the dust which collects in the folds of paper containers of the powder detergents may, if dumped into the mixing bins, cause a rejection of the paste when tested by the scratch test outlined in the specification.

Guaranteed brands.--It is thought that the consumer will be adequately protected when he purchases a tooth paste guaranteed by the manufacturer to comply with the Federal specification.

Most of the tests outlined in the Federal specification can be made in the high school laboratory. In fact some can be made in the home. There is little excuse for the presence of defective tooth pastes on the market or their continued use by the public when simple tests will reveal the more serious defects.

\section{METHODS OF PURCHASING}

\section{CERTIFIED PRODUCTS}

At no time during the Bureau's participation in programs of dental research has any plan for the manufacturing of dental materials, by the Bureau or by the American Dental Association, been given more than passing attention. There has always been a feeling that the services of specialized manufacturers are necessary. They have consistently improved their products to meet the needs of an advancing profession. In many instances manufacturers have given too much cooperation in attempting to produce an item which represented the wants of a dentist, and later have found that these wants of the individual could not be regarded as the needs of the profession.

With the added attention and efforts being given to sales technique the dentist found difficulty in making wise selections from the many brands of supplies submitted for his approval. He found it unsafe to assume that "newest" was synonymous with "best." Anxious to give his patients the benefit of all the developments in dental science 
and art he frequently found himself puzzling over the question which brand to purchase. "The fact that a brand was sold "on approval" might make him suspicious that the item was an experimental product which had not been approved clinically. Neither was the product highest in price always found to be highest in quality.

The evolution of a method whereby dentists may now purchase products guaranteed to meet a standard of quality is an interesting development in the cooperative program with the American Dental Association, and a brief rehearsal of the events leading up to its establishment may be of interest.

In 1928 the American Dental Association rated 26 allovs against the Federal specification of that date [16]. Six passed the specification. In 1929 forty-four alloys (including those tested in 1928) were tested [19]. Eighteen met the specification requirements. While this discloses a definite improvement in the average quality of amalgam alloys over that of 1928, it also shows that less than half of the alloys purchased and tested in 1929 complied with the specification.

In the above procedure over 50 percent of the time, for this phase of the research, was spent in testing inferior products. The cooperative research was definitely heading for an increasing amount of free service to indifferent amalgam manufacturers. Neither the Bureau nor the Rescarch Commission of the American Dental Association felt justified in permitting this research to develop into a wholesale testing program. In fact, there was the danger that an unearned and in fact an unfair advantage might be given to some one or more products, where one package of a brand might by chance pass the specification and consequently be placed on a list of certified materials.

The Research Commission and the Bureau developed therefore a restricted procedure which appears to be much nearer to a correct solution of this problem. This procedure eliminates the responsibility of the Commission or the Bureau to procure and test all brands of alloy, gold, or other dental materials on the market. A product is now tested only after the manufacturer has submitted evidence that the product was tested by himself or his agents and found to comply with the specification, and that these tests will be continued during further production. A description of the testing equipment, the name of the operator, and copies of the test data are demanded before a sample will be procured (on the open market) for test at the Bureau. (This procedure applies to all certified products.) While this plan has not reduced the total amount of testing, it has decreased the amount of time spent in testing defective materials. The 1938-41 tests included 79 brands of amalgam alloy. Sixty-four of these passed the specification. Thus 81 percent of the testing was on alloys which had been correctly rated by the manufacturers. The names of the satisfactory alloys were placed on the lists of certified products which are published by the Association [101].

The lists of certified products published periodically by the Research Commission of the American Dental Association constitute a direct and valuable consumer service. The dentist may select his restorative materials from the certified lists and thus be assured of securing materials of high quality. The patient is thus assured that no defective materials will be used. The manufacturer of products of 
high quality finds himself in an advantageous position when his brands are placed on the certified lists. Products will not appear on these lists unless they are up to the standards set by the specification and assurance is given that they will be kept up to the standard.

These lists of dental materials include all the items for which specifications are available. The tests and listings are made without cost to the manufacturer. The procedure is not complicated. It does not permanently injure, individually, the manufacturer of a defective product as the names of brands which fail to meet the standards set by the specifications are not listed. Failure to comply does not disqualify a manufacturer from again certifying, after he has remedied the defect in his product. This plan has virtues and should find applications in those markets where high-quality materials are necessary for the welfare of a profession or the public.

\section{TESTING GOVERNMENT PURCHASES}

An entirely different procedure is followed in making purchases of amalgam alloy or other materials supplied under specifications for use in the Government dental services. Manufacturers and dealers are invited to name a price at which they are willing to deliver to the Government a certain quantity of the desired material. The individual making the bid must guarantee that the item will meet all the requirements of the Federal specification. Samples of the delivery are tested. If these samples meet the specification, the purchase is completed by the payment of the contract price.

If the delivered material is not up to the standard demanded in the specification, the bidder may be given an opportunity to replace it with acceptable material. Should he fail in this attempt, the award is made to the next higher firm on the list of bidders at its bid price. The firm which delivered the substandard material is, according to purchase regulations, required to pay the difference in price between its bid and the bid on the acceptable material, plus the costs incurred in testing the defective material. In this manner the Government actually gets the item at the lowest bid price. A manufacturer who repeatedly attempts to deliver substandard materials may be denied the privilege of bidding on future orders.

The testing of each purchase is not feasible on the small-quantity orders of individual dentists. The certification method adopted by the American Dental Association seems best suited to their needs. This requires the constant testing of samples from the shelves of dealers throughout the country if the highest standards of quality are to be maintained. 'This testing is being done and the quality is being maintained.

The National Bureau of Standards cooperates in both methods of purchasing and gives such suggestions as are necessary to enable dental agencies to secure the best materials for their individual needs. In a similar manner, the Bureau has always been willing to cooperate with manufacturers and aid them in developing or improving their products. It cannot, however, attempt to take over the functions of a production testing laboratory, which the manufacturer should have before attempting to guarantee a definite standard of quality for his product. 


\section{SPECIFICATIONS}

\section{FEDERAL SPECIFICATIONS}

Eight Federal specifications for dental materials are reprinted here for the conrenience of readers of this Circular. The dental amalgam specification is printed in full. The others hare been abstracted, omitting certain details of packaging and formalities not inrolring quality of the item.

\section{$\mathrm{U}-\mathrm{A}-451 \mathrm{a}$ APRIL 23, 1937 \\ SUPERSEDING \\ Fed. Spec. $\mathrm{C}-\mathrm{A}-151$ \\ March 31,1931}

FEDERAL STANDARD STOCK CATALOG

Section IV

Part 5

FEDERAL SPECIFICATION

FOR

\section{ALLOY; DENTAL, AMALGAM}

This specification was approred br the Director of Procurement, for the use of all departments and establishments of the Gorernment, and shall become effectire not later than Norember 15, 193\%. It may be put into effect, howerer, at any earlier date after promulgation.

\section{A. APPLICABLE FEDERAL SPECIFICATIONS.}

A-1. There are no other Federal specifications applicable to this specification.

B. TYPES.

B-1. Dental amalgam alloy shall be of the following types as specified:

Type A.-Shavings.

Type B.-Filings.

C. MATERIAL.

C-1. Material.-The comminuted allor shall be free of foreign materials and shall be uniform throughout the package.

\section{GENERAL REQUIREMENTS.}

D-1. Amalgams shall possess the following features, known as satisfactory working qualities:

D-1a. Smooth plastic amalgamation in three minutes.

D-1b. Susceptibility to carring for at least 15 minutes after amalgamation.

D-1c. Susceptibility to receiring and retaining a polish 24 hours after amalgamation.

E. DETAIL REQLTREMENTS.

E-1. Chemical composition.-The chemical composition shall comply with the following requirements:

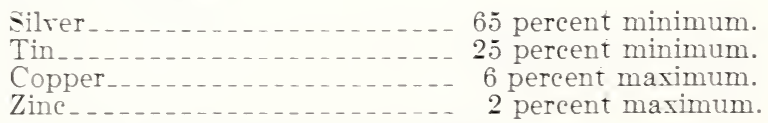

The allor mar contain gold and platinum.

E-2. Flow.-Specimens subjected to a constant pressure of 250 kilograms per square centimeter (approximately 3,550 pounds per square inch) shall not show more than 1 percent flow (that is, more than 1 percent shortening in length of specimen) in a period of 21 hours. 
E-3. Setting changes.-Twenty-four hours after amalgamation the length shall have increased between 3 and 13 microns per centimeter.

\section{F. METHODS OF SAMPLING, INSPECTION, AND TESTS.}

F-1. Sampling. - At least 1 ounce shall be taken at random from every 500 ounces or fraction thereof for test at time of delivery.

F-2. Inspection and tests.-

F-2a. Flow. - Specimens shall be cylinders 4 millimeters in diameter and 8 millimeters long. These shall be prepared by condesning the amalgam into a eavity of these dimensions in a rigid block, using a reasonable technique (approximately that given in the sheet of instructions accompanying the alloy). The ends of the cylinder shall be surfaced plane at right angles to the axis. Three hours after condensing, the specimens shall be subjected to a constant pressure of 250 kilograms per square centimeter (approximately 3,550 pounds per square inch). This pressure shall be maintained 21 hours. During this test the specimens shall be maintained at a temperature between $20^{\circ}$ and $25^{\circ} \mathrm{C}$.

F-2b. Setting changes. - Specimens shall be prepared by condensing into a cavity or matrix. These shall be removed as soon as condensation is completed and shall not be subject to restraint during the test. Measurements shall begin 15 minutes after amalgamation. The specimen shall be placed in the measuring instrument and adjusted within 12 minutes after amalgamation is started. (Time spent in mulling and condensing to be included as a part of the 12 and 15 minutes.)

\section{g. Packaging, PaCking, and marking.}

G-1. Packaging.-Dental amalgam alloy shall be furnished in glass containers having either 1 or 5 ounces troy as specified.

G-2. Packing.-Unless otherwise specified, the subject commodity shall be delivered in standard commercial containers, so constructed as to insure acceptance by common or other carriers, for safe transportation, at the lowest rate, to the point of delivery.

G-3. Marking.-

G-3a. Packages shall bear the regular trade label, stating the contents, name of maker or distributor, weight of contents, and directions for use.

G-3b. Unless otherwise specified, shipping containers shall be marked with the name of the material, the type, and the number of units contained therein, as defined by the contract or order under which shipment is made, the name of the contractor, and the number of the contract or order.

\section{H. REQUIREMENTS APPLICABLE TO INDIVIDUAL DEPARTMENTS}

$\mathbf{H}-\mathbf{1}$. The following departmental specifications of the issue in effect on date of invitation for bids shall form a part of this specification:

H-1a. Army.-U. S. Army Specification No. 100-2, Standard Specification for Marking Shipments.

H-1b. Navy. - Navy Department General Specification for Inspection of Material, copies of which may be obtained without cost upon application to the Bureau of Supplies and Accounts, Navy Department, Washington, D. C.

\section{NOTES.}

I-1. It is believed that this specification adequately describes the characteristics necessary to secure the desired material, and that normally no samples will be necessary prior to award to determine compliance with this specification. If, for any particular purpose, samples with bids are necessary, they should be specifically asked for in the invitation for bids, and the particular purpose to be served should be definitely stated, the specification to apply in all other respects.

I-2. Equipment suitable for making these tests is deseribed in National Bureau of Standards Technical Paper No. 157. (For sale by Superintendent of Documents, Washington, D. C. Price, 10 cents. Reprinted in Dental Cosmos, March 1920, page 305.)

I-3. An index of Federal specifications may be obtained upon application as noted in paragraph next below at a cost of 10 cents.

I-4. Copies of this specification may be obtained upon application, accompanied by money order, or coupon, or cash to the Superintendent of Documents, Government Printing Office, Washington, D. C. Price, 5 cents.

NOTICE.-When Government drawings, specifications, or other data are used for any purpose other than in connection with a definitely related Government procurement operation, the United States Government thereby incurs no responsibility nor any obligation whatsoever; and the fact that the Government may have formulated, furnished, or in any way supplied the said drawings, specifications, or other data is not to be regarded by implication or otherwise as in any manner licensing the holder or any other person or corporation, or conveying any rights or permission, to manufacture, use, or scll any patented invention that may in any way be related thereto. 
[ABSTRACT]

FEDERAL SPECIFICATION

FOR

\section{INVESTMENT; CASTING, INLAY, DENTAL}

B. TYPES AND GRADES.

B-1. Investment; inlay, casting, shall be of two types and one grade, as follows:

Type I. Medium expanding.

Type II. High expanding.

\section{MATERIAL AND WORKMANSHIP.}

C-1. Material.- Shall be a powder composed essentially of plaster of paris and silica or material of these types which when mixed with water in proper ratio, applied to the dental wax pattern and heated in the usual mamner, will be found satisfactory for use in casting dental restorations.

C-2. Workmanship. - Shall be first class in every respect and finished product shall be dry, uniform, and free of foreign material, partly set or caked lumps. Coloring material as such will not be regarded as foreign material.

\section{GENERAL REQUIREMENTS.}

D - 1. The material shall not crack in heating.

D-2. The material shall not contaminate the alloy cast into it and shall not cause pitting, rough surfaces or voids, in the alloy.

D-3. When heated, the material shall not give off poisonous or offensive odors.

\section{E. DETAIL REQUIREMENTS.}

E-1. Setting expansion.- Shall be not less than 0.05 percent at the end of 24 hours.

E-2. Thermal expansion.-

E-2a. Type I-Medium expanding. - Shall be not less than 0.7 percent when heated from room temperature to $700^{\circ} \mathrm{C}$.

E-2b. Type II-High expanding.-Shall be 1.25 (plus or minus 0.25) percent at all temperatures between $400^{\circ} \mathrm{C}$. and $700^{\circ} \mathrm{C}$.

E-2c. A thermal expansion curve or sufficient data shall be supplied to enable the purchaser to make proper use of the material.

E-3. Compressive strength. - Shall be not less than 350 pounds per square inch.

E-4. Setting time. - Shall not be less than 5 minutes nor more than 30 minutes. Shall be shown on the package and shall not vary more than 20 percent, plus or minus, from the time indicated thereon.

E-5. Fineness.-

E-5a. Eighty-five percent shall pass a No. 200 sieve.

E-5b. Ninety-five percent shall pass a No. 100 sieve.

E-5c. One hundred percent shall pass a No. 30 sieve.

F. METHODS OF SAMPLING, INSPECTION, AND TESTS.

F-1. Sampling.-Not less than 10 pounds of material, taken at random, shall be submitted for test. If taken from original packages, the material shall be submitted in moisture-proof containers bearing the name of the contractor, and the number of the contract or order.

$\mathrm{F}-2$. Inspection and tests.-

F-2a. Testing consistency.-The investment used in making all test specimens shall be mixed with sufficient distilled water, at room temperature $\left(68^{\circ}-77^{\circ} \mathrm{F}\right.$.), to produce a mix of "testing consistency" in accordance with the following directions to give a "slump" within the following limits:

1. The powder shall be added to the water.

2. Mixes shall be spatulated mechanically by 100 turns of a stiff blade in approximately 15 seconds.

3. A cylindrical mold 2 inches long with an internal diameter of $13 / 8$ inches shall be placed on a dry glass plate and filled.

4. Two minutes from the time of starting the mix, the mold shall be lifted and the mixture allowed to slump or spread over the plate. 
5. The average of the maximum and minimum diameters of spread of the slumped mixture shall come between the limits of 2.25 and 3 inches.

6. These measurements shall be made 1 minute after the cylinder is lifted.

F-2b. Setting expansion.-The change in length on setting shall be determined on a specimen approximately 30 centimeters long by observing the change with a micrometer microscope comparator or equipment of equal accuracy. (See par. I-4.)

F-2c. Thermal expansion.-Shall be measured on a specimen approximately 1.2 centimeters in diameter by approximately 20 centimeters in length by the "Fused quartz expansion apparatus" method, or by the use of equipment of equal accuracy. The specimen shall be gradually heated from room temperature to $700^{\circ} \mathrm{C}$. $\left(1,292^{\circ} \mathrm{F}\right.$.) in 180 minutes. The heating of the specimen shall approximate the following schedule:

\begin{tabular}{|c|c|c|}
\hline $\begin{array}{c}\text { Time } \\
\text { (minutes) }\end{array}$ & \multicolumn{2}{|c|}{ Temperature } \\
\hline 0 & ${ }^{\circ} C$. & ${ }^{\circ} \mathrm{F}$. \\
\hline 60 & 200 & 392 \\
\hline 120 & 500 & 932 \\
\hline 180 & 700 & 1,292 \\
\hline
\end{tabular}

The fiducial observation shall be taken 120 minutes after the beginning of the mix. Subsequent observations shall be taken at 10 minute intervals. (See par. I-5.)

F-2d. Setting time.-The time of setting shall be determined with a vicat needle on a specimen made from not less than 200 grams of powder. Setting is considered complete when the needle no longer penetrates to the bottom of the specimen. (See par. I-6.)

F-2e. Fineness. - The sample shall be spread out in a thin layer and dried at $45^{\circ}$ C. $\left(113^{\circ} \mathrm{F}\right.$.) for 2 hours, and then cooled in a moisture free atmosphere. Fineness shall be determined by screening not less than 100 grams (31/2 ounces) of the dried sample on the sieves specified, and determining the amount of material remaining on each sieve. The material shall be shaken and brushed through the sieve with as little abrasion as possible. The operation shall be continued until not more than 1 gram passes through in 1 minute of sieving.

F-2f. Compressive strength.- Shall be determined on five cylindrical specimens, not less than 1.3 inches in diameter and not less than 2 inches high. The vessel containing the mix shall be moved back and forth over the mold while pouring. The specimen shall be worked slightly to remove air bubbles and struck off level. The cylinders shall be removed from the molds as soon as they are hard enough to handle, and stored in air at a temperature of not less than $15^{\circ} \mathrm{C}$. (59 $9^{\circ} \mathrm{F}$.) nor more than $38^{\circ} \mathrm{C}$. $\left(100^{\circ} \mathrm{F}.\right)$. The specimens shall be crushed when they are 7 days old.

F-2f (1). In computing the average strength, any cylinder whose strength varies more than 15 percent from the average shall be discarded. In case three or more cylinders vary more than 15 percent from the average, the lot shall be discarded and the test repeated.

\section{G. PACKAGING PACKING, AND MARKING FOR SHIPMENT}

G-1. Packaging.- Material shall be packaged in moisture resisting containers.

G-1a. Accompanying each package shall be accurate and adequate instructions for proportioning and manipulating. These shall include:

1. The testing consistency recommended by the manufacturers.

2. The setting time.

3. The setting expansion curve.

4. The thermal expansion curve.

G-3. Marking.-Each package shall be marked with a serial number or a combination of letters and numbers which shall refer to the manufacturer's records for the particular lot or batch of material. The date of manufacture (year and month) shall be indicated on the package as a separate item, or as a part of the serial number. Minimum net weight of the contents shall be marked on each package.

G-3a. Shipping containers.-Unless otherwise specified, shipping containers shall be marked with the name of the material, serial number, or a combination of letters and numbers which shall refer to the manufacturer's records for the 
particular lot or batch of material; quality contained therein, as defined by the contract or order under which shipment is made, and the gross weight.

\section{H. REQUIREMENTS APPLICABLE TO INDIVIDUAL DEPARTMENTS.}

$\mathrm{H}-1$. The following departmental specifications of the issue in effect on date of invitations for bids shall form a part of this specification.

H-1a. Army.- U. S. Army specification No. 100-2, Standard Specifications for Marking Shipments.

H-1b. Navy.-Nary Department General Specifications for Inspection of Material, copies of which may be obtained without cost upon application to the Bureau of Supplies and Accounts, Nary Department, Washington, D. C.

\section{NOTES.}

I-1. Purchasers should exercise any desired options offered herein. See paragraph $\mathrm{C}-1, \mathrm{E}-2 \mathrm{c}, \mathrm{G}-2$ and $\mathrm{G}-3 \mathrm{a}$.

I-2. It is believed that this specification adequately describes the characteristics necessary to secure the desired material, and that normally no samples will be necessary prior to award to determine compliance with this specification. If, for any particular purpose, samples with bids are necessary, they should be specifically asked for in the invitation for bids, and the particular purpose to be served should be definitely stated, the specification to apply in all other respects.

I-3. This specification covers only the trpes, classes, grades, sizes, etc., of the commodity as generally purchased by the Federal Government, and is not intended to include all the trpes, etc., which are commercially available.

I-4. Reference: Dental Cosmos, page 746, August 1926; Bureau of Standards Journal of Research, December 1928. (Research paper No. 32.)

I-5. Reference: Bureau of Standards Research Paper No. 29, Norember 1928 .

I-6. Reference: Federal Specification SS-G-901.

I-7. An index of Federal Specifications may be purchased as noted in the paragraph below, price to be obtained from the Superintendent of Documents.

I-8. Copies of this specification may be obtained upon application, accompanied by money order, or coupon, or cash to the Superintendent of Documents, Government Printing Office, Washington, D. C. Price, 5 cents.

\section{U-M-506 \\ OCTOBER 2. 1940}

[ABSTRACT]

FEDERAL SPECIFICATION

FOR

\section{MODELING-COMPOUND; DENTAL}

\section{A. APPLICABLE SPECIFICATION.}

A-1. There are no other Federal specifications applicable to this Specification.

B. TYPES AND GRADE.

B-1. Modeling compound shall be of but one grade and the following types. Type I. Impression compound.

Trpe II. Tray compound.

B-2. Shall be furnished in cakes, sticks, wafers, or cones as specified in the invitation for bids.

C. MATERIAL AND WORKMANSHIP.

C-1. Type I. Shall be uniform and suitable for taking impressions in the oral cavity. Mixture shall be free from ingredients injurious to the mouth.

C-2. Type II. - Shall be uniform and suitable for forming trays to be used in the oral cavity. Mixture shall be free from ingredients injurious to the mouth. 


\section{GENERAL REQUIREMENTS.}

D-1. Modeling compound shall have the following properties:

D-1a. Homogeneity throughout.

D-1b. A smooth, glossy surface after flaming.

D-1c. Firm, smooth margins after trimming at room temperature.

D-2. Instructions, including method of softening, working temperature, and curve or data showing the shrinkage of the compound from $40^{\circ} \mathrm{C}$. $\left(104^{\circ} \mathrm{F}\right.$.) to $20^{\circ}$ C. $\left(68^{\circ}\right.$ F.) shall be supplied with each package.

D-3. Color shall be as specified in invitation for bid.

\section{E. DETAIL REQUIREMENTS.}

\section{E-1. Flow.-}

\begin{tabular}{|c|c|c|c|}
\hline \hline \multicolumn{2}{|c|}{ Temperature } & \multicolumn{2}{|c|}{ Flow (percent) } \\
\cline { 1 - 3 } C. & $($ F.) & Type I & Type II \\
\hline $37.0^{\circ}$ & $\left(98.6^{\circ}\right)$ & 6 (max.) & $(2$ (max.) \\
$40.0^{\circ}$ & $\left(104.0^{\circ}\right)$ & 20 (min.) & 15 (max.) \\
$45.0^{\circ}$ & $\left(113.0^{\circ}\right)$ & 85 (min.) & 90 (min.) \\
$50.0^{\circ}$ & $\left(122.0^{\circ}\right)$ & $-\cdots$ & \\
\hline
\end{tabular}

E-2. Type I (impression compound). - Shall record accurately the complete surface detail of the test block (See fig. 1.)* at $45^{\circ}$ C. $\left(113.0^{\circ} \mathrm{F}\right.$.).

\section{F. METHODS OF INSPECTION AND TEST.}

F-1. Preparation of specimens.-

F-1a. Flow specimens.- The mold used in forming the cylindrical flow specimens shall be flat metal plate $6.0 \mathrm{~mm}$. (0.236 in.) thick, containing one or more holes $10.0 \mathrm{~mm}$. (0.394 inch) in diameter. The mold shall be warmed and placed upon a smooth flat surface. Sufficient compound which has been heated to just above its melting range shall be poured into the mold until it is "over-filled." A smooth flat plate shall then be placed on top of the mold and pressed down until the compound becomes rigid. After cooling, the ends of the specimens shall be made plane and parallel. The specimens shall be at least 24 hours old before testing.

F-1b. Impression specimen.-The impression specimen shall be a disk $40 \mathrm{~mm}$. (1.57 inches) in diameter and between $4 \mathrm{~mm}$. $(0.16 \mathrm{inch})$ and $7 \mathrm{~mm}$. $(0.28$ inch) in thickness. The cake of compound shall be warmed in water and the disk cut. If the cake is thinner than $4 \mathrm{~mm}$. $(0.16 \mathrm{inch})$, two cakes shall be flamed and pressed together before cutting the disk.

F-2. Methods of test.-

F-2a. Flow test.- The length of each specimen shall be measured at room temperature $20^{\circ}-25^{\circ} \mathrm{C}$. $\left(68^{\circ}-77^{\circ} \mathrm{F}\right.$.). Twenty minutes shall be allowed prior to testing for the specimen to come to the required temperature. A thin sheet of cellophane shall be placed between the instrument and each end of the specimen, which shall then be subjected to a constant axial load of $2,000 \mathrm{gm}$. (4.4 pounds) for 10 minutes. The specimen shall then be removed and, after it is cooled to room temperature and the cellophane stripped out, the final length shall be determined.

F-2a (1). The flow, as evidenced by the change in length, shall be reported as percentage of the original length. The value for flow at any temperature shall be the average value for two specimens and shall be reported to the nearest 0.1 percent.

F-2b. Impression test. - A water bath shall be adjusted to $45.0^{\circ} \mathrm{C} .\left(113.0^{\circ} \mathrm{F}\right.$.). A flat plate (to support the specimen while it is coming to the required temperature), a test block (fig. 1) and a weight having a base approximately $50 \mathrm{~mm}$. (1.97 inches) in diameter and weighing $1,000 \mathrm{gm}$. (2.2 pounds) in air, shall be placed in the bath and allowed to come to the temperature of the bath. (The water level in the bath shall be 30 plus or minus $5 \mathrm{~mm}$. (1.18 plus or minus 0.19 inches) above the top surface of the test block.)

$\mathbf{F}-2 \mathbf{b}(\mathbf{1})$. The impression specimen shall then be placed in the water bath on the flat plate. Twenty minutes later, the specimen shall be centered on the test block, a sheet of cellophane shall be placed over the specimen and the weight shall be placed on the specimen. Ten minutes later, the weight shall be removed, the

*This illustration is printed as figure 65 of the Circular, see page 141. 
test block and specimen shall be taken from the bath and chilled and the specimen shall be removed from the test block.

F-2b(2). The impression shall be considered satisfactory if the ridges corresponding to the large cross grooves (B, fig. 1) of the test block are sharp, and the ridges corresponding to the fine grooves (C, fig. 1) are complete and visible to the unaided eye for at least $30 \mathrm{~mm}$. (1.18 inches) of their length.

\section{G. PACKAGING, PACKING, AND MARKING FOR SHIPMENT.}

G-3. Marking.-

G-3a. Package.-Unless otherwise specified, each package shall be marked with the name and type of material contained therein, the net weight of the contents, a serial number or a combination of letters and numbers which refer to the manufacturer's records for the particular lot or batch of compound, and the name or trademark of the contractor. The date of manufacture (year and month) shall be indicated on each package as a separate item or as a part of the serial number.

I-2. It is believed that this specification adequately describes the characteristics necessary to secure the desired material, and that normally no samples will be necessary prior to award to determine compliance with this specification. If, for any particular purpose, samples with bids are necessary, they should be specifically asked for in the invitation for bids, and the particular purpose to be served by the bid sample should be definitely stated, the specification to apply in all other respects.

I-3. This specification covers only the types, classes, grades, sizes, etc., of the commodity as generally purchased by the Federal Government, and is not intended to include all of the types, etc., which are commercially available.

I-4. An index of Federal specifications may be purchased as noted in the paragraph below, price to be obtained from the Superintendent of Documents.

I-5. Copies of this specification may be obtained upon application, accompanied by money order, coupon, or cash to the Superintendent of Documents, Government Printing Office, Washington, D. C. Price 5 cents.

\section{$\mathrm{QQ}-\mathrm{G}-\mathbf{5 4 0}$ \\ MARCH 7, 1940}

[ABSTRACT]

FEDERAL SPECIFICATION

FOR

\section{GOLD; CASTING, INLAY, DENTAL}

\section{A. APPLICABLE SPECIFICATION.}

A-1. The following Federal Specification of the issue in effect on date of invitation for bids, shall form a part of this specification.

$\mathrm{U}-\mathrm{I}-546$. Investment; Inlay, Casting, Dental.

\section{B. TYPES.}

B-1. Dental casting gold shall be of the following types, as specified in the invitation for bids:

Type I. Soft.

Trpe II. Medium.

Trpe III. Hard.

Type IV. Extra hard.

\section{MATERIAL AND WORKMANSHIP.}

C-1. Material.- Shall be as specified hereinafter for each type.

C-2. Workmanship.-Each ingot shall be of uniform composition and color throughout.

\section{GENERAL REQUIREMENTS.}

D-1. Color.- Shall be the color specified in invitation for bids.

D 2. Castings.- The molten gold shall fill the mold completely when cast into dental casting investment. 
E. DETAIL REQUIREMENTS.

E-1. Detail requirements shall be as given in table below:

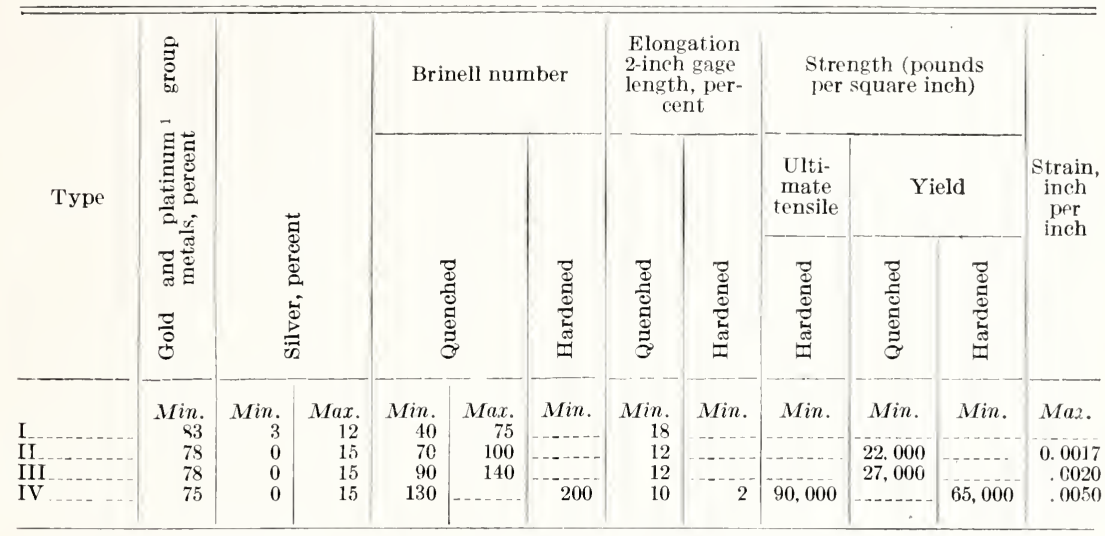

1 Palladium is not permitted in excess of 4 percent in any of thes: alloys.

\section{F. METHODS OF INSPECTION AND TESTS}

F-1. Examination for compliance with this specification.

F-2. Composition.- The determined values for metallic constituents shall be recorded at the nearest 0.5 percent. When a determined value falls midway between a half and a whole number, the whole number shall be recorded.

F-3. Physical properties.-Physical properties, other than fusion temperatures, shall be determined on cast samples placed in a furnace at $1,290^{\circ} \mathrm{F}$. for 10 minutes and quenched in water at room temperature. Where hardened specimens are demanded these shall be prepared by placing quenched specimens in an oven heated to $840^{\circ} \mathrm{F}$. After they have been in the oven 2 minutes the temperature shall be uniformly reduced to $480^{\circ} \mathrm{F}$. in 30 minutes. Cast samples shall be prepared by casting into a dental casting investment which complies with Federal Specification U-I-546, by any dental casting method. The use of a wax pattern is not required.

F-3a. An alloy complies with this specification when all of the recorded values for the properties of three of more of a series of six castings meet the requirements. The recorded value for each property shall be obtained by averaging the determined values for all samples meeting the requirements of the specification.

F-4. For determining compliance with this specification, the successful bidder shall be required to supply six cast specimens with sprue and button attached for types I, II, and III, and 12 specimens with sprue and buttons attached for type IV at the time of delivery. These specimens shall be not less than $5 \frac{1}{2}$ inches long and not less than 0.07 inch nor more than 0.09 inch in diameter. Agreement of the cast specimens in composition, purity, etc., with delivered material shall be determined by chemical analysis or such other methods as may be necessary.

F-5. Brinell number.-The Brinell number shall be determined by applying a load of 27.8 pounds $(12.6 \mathrm{~kg}$.) on the sample through a $1 / 16$ inch hardened steel ball for 30 seconds. The diameter of the depression shall be determined by measuring two diameters perpendicular to each other and the average diameter used in the calculation of the hardness number. The determined value shall be recorded as the nearest whole number. When the determined number falls midway between two numbers, the even number shall be recorded. See par. I-3.

F-6. Yield strength.

F-6a. The yield strength shall be determined on cast samples whose diameters are between 0.07 and 0.09 inch. The value for yield strength shall be determined on a gage length of not less than $50 \mathrm{~mm}$. (approximately 2 inches). An averaging extensometer shall be used.

F-6b. An initial load calculated to produce a stress of 5,000 pounds per square inch shall be applied to the sample and the extensometer read. The load shall then be increased to the minimum values for the yield strength (type II, 22,000 pounds per square inch; type III, 27,000 pounds per square inch; and type IV, 65,000 pounds per square inch) and a second reading taken. The maximum $406035^{\circ}-42-13$ 
strain permitted between the limits specified is for type II, 0.0017 inch per inch; type III, 0.0020 inch per inch; and type IV, 0.005 inch per inch. The determined value for strain shall be recorded to the nearest 0.0001 inch per inch. When the determined strain falls midway between two numbers, the nearest even number shall be recorded.

F-6c. As as alternate method, loads above and below the two limits specified may be applied provided they do not vary the stress over 500 pounds per square inch from the specified load. The recorded strain may be determined graphically.

F-7 Elongation.-Elongation shall be determined on the samples used in the test for yield strength. The load shall be applied slowly (not more than 20 minutes between initial load and rupture) and continuously after the extensometer is removed until rupture occurs. Castings which break outside the gage marks may be repulled. Elongation shall be determined on a $50 \mathrm{~mm}$. (approximatel 2 inches) gage length. The determined value shall be recorded as the nearest 0.5 percent. When the determined value falls midway between a half and a whole number, the whole number shall be recorded.

F-8. Fusion temperature wire method.-The fusion temperature is the temperature at which a wire 0.70 to $0.80 \mathrm{~mm}$. (0.028 to 0.032 inch) in diameter and approximately $2 \mathrm{~mm}$. (0.08 inch) long, supported at both ends, will break when subjected to a cross bending load of 85 grams (approximately 3 ounces). The heating rate within $100^{\circ} \mathrm{F}$. of the breaking point shall be between 5 and $28^{\circ} \mathrm{C}$. $\left(10\right.$ and $50^{\circ} \mathrm{F}$.) per minute.

\section{G. PACKAGING. PACKING, AND MARKING FOR SHIPMENT.}

G-3a. Package.- The name of the contractor or manufacturer, name of the material, type, and minimum net weight of contents, shall be marked on each envelope, together with serial number or combination of letters and numbers which shall refer to the manufacturer's records for the particular lot or batch of alloy.

G-3b. Shipping container.- - Unless otherwise specified, shipping containers shall be marked on one end with the name of the material, the type and the number of units contained therein, as defined by the contract or order under which shipment is made, the name of the contractor, the number of the contract or order, and the gross weight.

\section{NOTES.}

I-1. Types.-Requirements given cover only those types of gold primarily used for inlays.

I-2. Uses.- The usual uses for the four trpes of allors specified are:

Type I. Soft inlays - easily burnished and subject to very slight stress.

Type II. Inlars subject to moderate stress; $3 / 4$ crowns, abutments, pontics, full crowns, and sometimes soft saddles.

Type III. Inlays subject to high stress; thin $3 / 4$ crowns, thin cast backings, abutments, pontics, full crowns, and saddles.

Type IV. Inlays subject to very high stress, saddle bar, and clasps, and unit castings.

I-3. Hardness number.- The use of a 13.9 pound $(6.3 \mathrm{~kg})$ load for the determination of hardness numbers below 50 is permissible.

I-8. Copies of this specification and of U-I-546 may be obtained upon application, accompanied by money order, coupon, or cash to the Superintendent of Documents, Government Printing Office, Washington, D. C., price 5 cents each.

\section{LINGUAL BARS}

General Specification

There is at this time no approved Federal or American Dental Association specification for lingual bars.

A number of Departmental purchases have been made, using tentative specifications. These have been based on tests reported in 1928 [13] and include requirements approximating the following:

Optional items.-The color, size, length, shape, and weight shall be as specified by the purchaser.

Chemical composition.-The gold and platinum group metals shall total not less than $66^{2} / 3$ percent or 75 percent by weight, as specified by the purchaser.

Fusion temperature.-The fusion temperature shall be $875^{\circ} \mathrm{C}$ or more.

Hardness.-The Brinell hardness of oren-cooled specimens shall be 185 or more.

Cold bends. Quenched specimens shall withstand two or more cold bends over mandrels having radii of 0.05 inch. 
Methods for testing and details for chemical composition, fusion temperature, hardness, quenching, and oven cooling are to be found on page 189 (Specifications for gold alloys). Twenty pounds tension shall be applied to the specimen while making the cold bend tests. From vertical to horizontal (09 degrees) is called one bend. Back through vertical and to horizontal in the other direction gives a total of two bends.

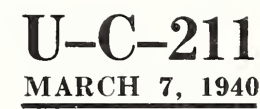

[ABSTRACT]

FEDERAL SPECIFICATION

FOR

\section{CEMENT; ZINC-PHOSPHATE, DENTAL}

\section{A. APPLICABLE SPECIFICATIONS.}

A-1. There are no other Federal Specifications applicable to this specification.

B. TYPE AND GRADE.

B-1. Dental zinc phosphate cement shall be of one type and one grade.

\section{MATERIAL AND WORKMANSHIP.}

C-1. Material-

C-1a. Cement shall consist of a powder and a liquid which, when mixed as directed, will harden or set to a condition satisfactory for dental use.

c-1b. Colors for the set cement shall be as specified in the invitation for bids or purchase orders.

C-2. Workmanship.- The powder and liquid shall be uniform and free from poisonous and foreign materials.

D. GENERAL REQUIREMENTS.

D-1. The liquid shall be free from cloudiness, precipitates, deposits, or sediments.

D-2. Cements when spatulated shall not:

D-2a. Form lumps or granules.

D-2b. Evolve gas.

D-2c. Discolor tooth structures.

\section{E. DETAIL REQUIREMENTS.}

E-1. Time of setting. - Shall be not less than four nor more than 10 minutes.

E-2. Ultimate compressive strength. - Shall not be less than 840 kilograms per square centimeter (12,000 pounds per square inch) for specimens crushed 7 days after mixing.

E-3. Film thickness. - Shall not exceed $0.04 \mathrm{~mm}$. (0.0016 inches). See paragraph F-5.

E-4. Disintegration.-The disintegration of the cement shall not exceed 0.30 percent by weight after immersion for 7 days in distilled water. See paragraph $\mathrm{F}-6$.

E -5. Arsenic.-The cement shall not contain more than one part of arsenic in 500,000 parts of cement ( 0.0002 percent) mixed to standard testing consistency. (See F-7.)

\section{F. METHODS OF INSPECTION AND TESTS.}

F-1. Examination for compliance with specification.

F-2. Preparation of test specimens. - The manufacturer or contractor shall furnish the powder liquid ratio for obtaining the standard testing consistency. (See par. I-4.) This ratio shall be used for all test purposes. The preparation of the test specimens shall be conducted at a temperature between $65^{\circ} \mathrm{F}$. and $75^{\circ} \mathrm{F}$. and at a relative humidity between 55 and 75 percent. The mixing technies employed in the preparation of all test specimens shall be those which accompany the packages of the cement except that the temperature and humidity may vary within above limits. All apparatus and instruments shall be clean, dry, and free from particles of hardened cement. 
F-3. Time of setting. - A ring $5 \mathrm{~mm}$. (0.2 inches) high and $10 \mathrm{~mm}$. (0.4 inches) in diameter is placed on a flat plate and filled with cement of standard consistencr. Three minutes after starting the mix. the specimen is transferred to an atmosphere of 100 percent relative humidity at $37^{\circ} \mathrm{C}$. $99^{\circ} \mathrm{F}$. A standard Gillmore needle weighing 454 grams 1 pound and having an end $1.06 \mathrm{~mm}$. (0.0417 inches in diameter is lowered vertically until the surface of the cement is touched. This is repeated at frequent intervals. The time of setting shall be the number of minutes elapsed from the starting of the mix to the time when the needle fails to make a perceptible circle on the surface of the specimen. The setting time shall be reported to the nearest minute.

F-4. Lltimate compressive strength. -A crlindrical mold $12 \mathrm{~mm}$. 0.172 inches high and $6 \mathrm{~mm}$. 0.236 inches in diameter is placed on a flat plate and slightly overfilled with cement of standard consistencr. A second flat plate is pressed on top of the mold to remore excess cement. The molds shall be made of hard rubber, glass, or other substance that will not be corroded br the cement. (Painting the molds with a thin solution of a hard was in benzene will facilitate removal of the specimens.) Three minutes after starting the mix, the molds are transferred to an atmosphere of 100 percent relative humidits at $37^{\circ} \mathrm{C}$. $\left(99^{\circ} \mathrm{F}\right.$.). Thirts minutes later the specimens are immersed in distilled water at room temperature.

F-4a. The ends of the crlinder shall be surfaced plane at right angles to the axis. The ends of the specimens mar be ground flat br the use of a small amount of carborundum powder $200 \mathrm{mesh}$ ) and water. The molds containing the specimens are drawn back and forth across a glass plate coated with the abrasive and water. Ther should be rotated about ${ }_{t}$ turn ererr fer strokes. The test specimens shall be kept wet during the grinding and until after crushing. The machine used in crushing the test specimens shall be operated at a rate of speed which will more the crushing head $0.25 \mathrm{~mm}$. 0.01 inches per minute.

F-4b. The value for compressive strength shall be reported as the average of 3 or more from a lot of 5 specimens and shall be rounded off to the nearest 150 pounds per square inch. If the values for individual specimens rars more than 15 percent below the average ther shall be discarded and the average of the remaining specimens shall be reported. In case more than 2 of the specimens are eliminated, the test shall be repeated.

$\mathbf{F}$-5. Film thichness. - A portion of a mix of standard consistener is placed between 2 flat square plates of uniform thickness. The surface of the plates between which the cement is spread shall be approximately 2 square centimeters (0.31 square inch). Three minutes after the mix is started a load of 15 kilograms (3.3 pounds shall be applied rertically on the top plate.

F-5a. Ten minutes after the mix is started the thickness of the two plates with the cement film between them shall be determined. The difference in the thickness of the plates with and without the cement film shall be considered as the film thichness. An average of three tests shall be reported to the nearest $\check{\jmath}$ microns (0.0002 inches).

F-6. Disintegration. - The disintegration of a cement is a measure of the erosion plus the extraction of soluble material from the cement br the action of water.

F-6a. One-half cubic centimeter $(0.5 \mathrm{cc}$.) of cement of standard consistency is pressed between two flat plates until the cement is $20 \mathrm{~mm}$. $(0.79$ inches) in diameter a piece of fine platinum wire placed in the soft cement before the specimens are formed provides a convenient method of holding the specimens). Three minutes after the mix is started the plates and cement are placed in an oren at $37^{\circ} \mathrm{C}$. $\left(99^{\circ} \mathrm{F}\right.$. for 1 hour. Two such specimens shall be used for each determination.

F-6b. After 1 hour the specimens are withdrawn from the oren placed into a tared weighing bottle or flask. and quickly weighed. The combined weight of the two specimens and the weighing bottle. less the weight of the weighing bottle and the platinum wire, shall be taken as the weight of the specimens of cement. The specimens are immediately submerged by pouring $50 \mathrm{cc}$. of distilled water into the reighing bottle. which is stored for 7 dars at $37^{\circ} \mathrm{C}$. $\left(99^{\circ} \mathrm{F}\right.$.). The specimens are then removed from the water. There shall be no evidence of crrstal growth or extensions from the surface of the specimen. The water is eraporated from the flask at a temperature just below $100^{\circ} \mathrm{C}$. $212^{\circ} \mathrm{F}$.). The flask is then dried at $149^{\circ} \mathrm{C}$. $300^{\circ} \mathrm{F}$.) to constant weight. The flask and contents are weighed. The difference between the final weight of the flask and its initial weight is the amount of disintegration. The gain in weight divided br the weight of the specimens times 100 . gives the percentage of disintegration. The average of duplicate tests two flasks containing two specimens each), shall be reported to the nearest 0.1 percent. 
F-7. Arsenic test. - The test for arsenic shall conform to that designated by the American Chemical Society recommended specification for reagent phosphoric acid (see par. I-5), and shall be made on samples of cement mixed to standard testing consistency.

\section{G. PACKaging, PACKing, and MARKing FOr SHipMent.}

G-1. Packaging.-Unless otherwise specified, the cement powder and liquid shall be supplied in glass containers with cork stopper and viscose seal. Unless otherwise specified, the cement powder shall be supplied in 1-ounce containers, and the liquid in an amount 20 percent in excess of that necessary to combine with the specified amount of powder when mixed to standard testing consistency. One bottle each of powder and liquid shall be packed, with a suitable dropper, in a cardboard carton or equal.

G-1a. Adequate and accurate instructions for proportioning and manipulation shall accompany each package. These instructions shall include the temperature of the slab, the powder-liquid ratio, the rate of powder incorporation and the time of mixing.

G-3a. Package.-Each package of powder and liquid shall be marked with the name of the manufacturer and with a serial number or a combination of letter and number, which shall refer to the manufacturer's records for that particular lot or batch of cement powder and liquid. The date of manufacture (year and month) shall be indicated on the package as a separate item or as a part of the serial number.

I-4. Reference: Journal, American Dental Association, volume 24, page 2019, December 1937.

I-5. Reference: Industrial and Engineering Chemistry 19: 1369, December, 1927.

I-7. Copies of this specification may be obtained upon application, accompanied by money order or coupon, or cash, to Superintendent of Documents, Government Printing Office, Washington, D. C. Price 5 cents each.

[ABSTRACT]

FEDERAL SPECIFICATION

FOR

\section{RUBBER; DENTURE}

A. APPLICABLE SPECIFICATIONS.

A-1. There are no other Federal Specifications applicable to this specification.

B. TYPES, GRADE, AND CLASS.

B-1. This specification covers three types, one grade, and one class of denture, rubber, as follows, as specified in the invitation for bids:
Type I. Base, Rubber.
Type II. General Purpose, Rubber.
Type III. Veneer, Rubber.

\section{MATERIAL AND WORKMANSHIP.}

C-1. Material.-Material shall be a high grade rubber, combined with sulfur, suitable fillers, and pigments. None of the ingredients shall be toxic or irritating to the mouth tissues, after vulcanizing.

C-2. Workmanship. - Shall be first class in every respect. The unvulcanized rubber compound shall be free from dirt, grit or other objectionable foreign materials. Coloring matter shall not be considered a foreign material.

\section{GENERAL REQUIREMENTS.}

D-1. Adhesion to mold.-The material shall adhere to dry set dental plaster at room temperature. 
D-2. Size.- Tnless otherwise specified, sheets shall conform to the following dimensions:

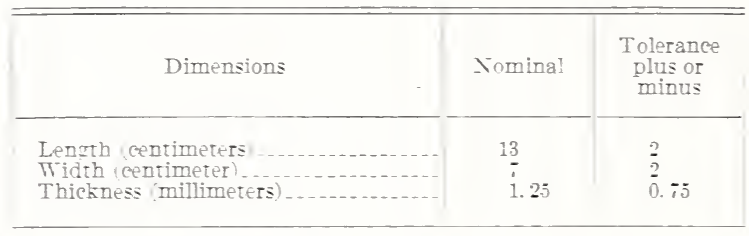

D-3. Satisfactory working qualities. - The rubber when vulcanized according to instructions furnished by the manufacturer shall rield a satisfactory denture material. The rulcanite shall display the following general properties.

D-3a. A smooth gloss surface when vulcanized against tin or aluminum foil. D-3b. A smooth surface when polished according to the usual dental methods.

D-3c. A smooth unchipped surface when trimmed at room temperature.

\section{E. DETAIL REQUTREMENTS.}

E-1. Unvulcanized compound.-The unvulcanized rubber compound shall meet the following requirements.

E-1a. Cohesive or packing test. - The material shall be cohesive at $37^{\circ} \mathrm{C}$.

E-1b. Adhesion to fabric. - The Holland cloth shall strip easily and cleanly from the rubber compound at room temperature $\left(25^{\circ} \mathrm{C}\right.$. plus or minus $5^{\circ} \mathrm{C}$.).

E-1c. Density.-The density, in grams per cubic centimeter, shall be stated on the package or in the instructions furnished with each package. Density stated shall be accurate within plus or minus 5 percent.

E-1d. Plasticity.-The plasticity of the unvulcanized compound, as measured br the reduced thickness of a solid crlinder having a volume of two cubic centimeters shall be as follows:

\begin{tabular}{|c|c|c|c|c|}
\hline \multirow{2}{*}{ Trpe } & \multicolumn{4}{|c|}{ Thickness of specimen in millimeters } \\
\hline & \multicolumn{2}{|c|}{$\begin{array}{l}\text { After } 5 \text { minutes under } \\
\text { load }\end{array}$} & \multicolumn{2}{|c|}{ Aiter 30 minutes under } \\
\hline $\begin{array}{l}\text { I. Base ... } \\
\text { II. General purpose } \\
\text { III. Teneer................ }\end{array}$ & $\begin{array}{r}\text { Minimum } \\
1.5 \\
1.5 \\
2.5\end{array}$ & $\begin{array}{r}\text { Maximum } \\
3.0 \\
3.5 \\
4.5\end{array}$ & $\frac{\text { Minimum }}{2.0}$ & $\begin{array}{r}\text { MrImum } \\
2.0 \\
2.5 \\
1.0\end{array}$ \\
\hline
\end{tabular}

E-2. Instructions for vulcanization.-Adequate and accurate instructions for rulcanization shall accompany each package. These shall be such that they can be carried out with the equipment generally available in the laboratory of the dental practitioner. These instructions shall include the following:

(a) Temperature of flask when rubber is packed.

(b) Time to heat to $100^{\circ} \mathrm{C}$.

(c) Time to raise from $100^{\circ}$ C. to recommended vulcanization temperature.

(d) Time to hold at rulcanization temperature.

(e) How to cool flask.

(f) When to release pressure from flask.

E-3. Tulcanized rubber. - Shall meet the following requirements:

E-3a. Transierse test qulcarized rubber). - The deflection of specimens tested at $37^{\circ} \mathrm{C}$. shall meet the following requirements:

\begin{tabular}{|c|c|c|c|c|c|}
\hline \multirow{3}{*}{ Tspe } & \multicolumn{5}{|c|}{ Deflection for various loads : } \\
\hline & 4.000 grams & \multicolumn{2}{|c|}{5.500 grams } & \multicolumn{2}{|c|}{6.500 grams } \\
\hline & $\begin{array}{l}\text { Marimum } \\
\text { mm. }\end{array}$ & Minimum. & $\begin{array}{l}\text { Marimum. } \\
\qquad \mathrm{mm}\end{array}$ & Minimum. & $\begin{array}{l}\text { Sarimum, } \\
\text { mm }\end{array}$ \\
\hline $\begin{array}{l}\text { I or II } \ldots \\
\text { III }\end{array}$ & $\begin{array}{l}2.0 \\
2.0\end{array}$ & 2. 5 & 5.0 & 3.0 & 5.0 \\
\hline
\end{tabular}

I Deflection shall be measured from an initisl losd of 1,500 grams to load indieated. 
E-4. Color.- Unless otherwise specified colors of the vulcanized rubber shall be as follows:

Type I. Base

Light red.

Type II. General purpose ................... Pink.

Type III. Veneer........................ Granular pink.

E-5. Porosity.-Cross sectioned vulcanized specimens (six $\mathrm{mm}$. in thickness) shall not show porosity by visual inspection.

\section{F. METHODS OF INSPECTION AND TESTS}

$\mathbf{F}-1$. Preparation of test specimens.

F-1 a. Specimens of unvulcanized rubber compound shall be made from material as received.

F-1b. Specimens of vulcanite shall be made from materials processed in accordance with the directions accompanying the package.

F-2. Cohesion or packing test. - Strips $10 \mathrm{~mm}$. wide and $35 \mathrm{~mm}$. long shall be cut from the sheets after removing the cloth. The strips shall be stored in air at 37.0 plus or minus $0.5^{\circ} \mathrm{C}$. for at least 30 minutes. One strip shall be placed flat on a smooth glass plate. A second strip shall be placed across the first at right angles forming a cross. A glass plate (weight 20 grams) and a 500 gram weight shall be placed on the intersection of the strips for five minutes. The strips shall then be removed from the plates, and shall cohere at their intersection so that they cannot be separated at the original surface when slowly pulled apart by hand. All equipment used shall be at $37^{\circ} \mathrm{C}$. before and during the testing.

F-3. Adhesion to fabric.- The sheet shall be separated about $2 \mathrm{~cm}$. at one end and shall then be torn apart by holding the fabric in one hand, the rubber sheet in the other, and subjecting the fabric and the rubber to a continuous pull between the hands. The maximum time allowed (after starting the ends) for the separation of one side of the sheet shall be 5 seconds. This test shall be conducted at room temperature $\left(25^{\circ}\right.$ plus or minus $5^{\circ} \mathrm{C}$.) .

F-4. Plasticity. - The plasticity of the unvulcanized rubber compound shall be determined on a parallel plate plastometer at $70^{\circ}$ plus or minus $1^{\circ} \mathrm{C}$. on a specimen having a volume of 2 cubic centimeters, subjected to a 5,000 gram load, by measuring the thickness of the specimen in millimeters at various intervals of time. The volume of the test specimen shall be computed from its weight and density. The specimen shall be prepared by cutting disks approximately $19 \mathrm{~mm}$. $(0.75$ inch) in diameter from a sheet of the material. These disks shall be stacked to form a short cylinder which shall be adjusted to the proper volume $(2 \mathrm{cc}$.) by trimming the top disk. The cylinder shall be mounted between two sheets of bond paper and placed in the oven containing the plastometer. Sixty minutes later the specimen shall be placed in the instrument and compressed to 5 millimeters between the plates. This shall be accomplished by placing a 5-millimeter stop on the machine and subjecting the specimen to a 5,000 gram load for 10 minutes. The stop shall then be removed and the load allowed to press on the specimen. The initial time shall be taken when the stop is removed and the thickness of the specimen shall be recorded at 5 minutes and at 30 minutes. (Correction shall be made for the thickness of the paper.) The thickness of the specimen shall be recorded to the nearest $0.01 \mathrm{~mm}$. and the average of three tests shall be reported to the nearest $0.1 \mathrm{~mm}$. When the determined number falls midway between two numbers the even number shall be reported.

F-5. Density.-The apparent density shall be determined by weighing a specimen of the unvulcanized rubber compound in air and in water at room temperature $\left(20^{\circ}\right.$ to $25^{\circ} \mathrm{C}$.). The density shall be reported in grams per cubic centimeter.

F-6. Transverse test.-Transverse tests shall be made on specimens $2.50 \mathrm{~mm}$. thick, $10.00 \mathrm{~mm}$. wide and $65 \mathrm{~mm}$. long at 37 plus or minus $5^{\circ} \mathrm{C}$. The specimens may be either molded or machined to dimension. The tolerance on the thickness and the width shall be plus or minus $0.03 \mathrm{~mm}$. The prepared specimen shall be stored for at least 48 hours at $37^{\circ} \mathrm{C}$. before testing. The specimen mounted in an appropriate instrument shall be placed over a $50 \mathrm{~mm}$. span and the load applied in the center of the span. The bearing surfaces shall be $3.2 \mathrm{~mm}$. $(0.125$ inch $)$ in diameter. The deflection shall be measured at the center of the span by means of an indicator accurate to at least $0.01 \mathrm{~mm}$. An initial load of 1,500 grams shall be placed on the specimen, the deflection recorded, the additional loads (see E-4) applied at the rate of 500 grams per minute. The deflection shall be read one-half minute later. The deflection shall be recorded to the nearest $0.01 \mathrm{~mm}$. The difference between the deflections at the initial load and the total load shall be taken as the deflection of the specimen. The average of the recorded deflections for three specimens shall be reported to the nearest $0.1 \mathrm{~mm}$. When the determined number falls midway between two numbers the even number shall be recorded. (See par. I-4.) 


\section{g. PACKAging, PACKING, AND MARKING FOR SHIPMENT}

G-1. Packaging.-Unless otherwise specified, each sheet of rubber shall be placed between Holland cloth and packed one-half pound, net weight, and sealed, in a suitable cardboard carton.

G-1a. Adequate and accurate instructions for vulcanization shall accompany each package.

G-3a. Packages.-Unless otherwise specified, each package shall be marked with the name or trade mark of the manufacturer or contractor. The date of manufacture (year and month) shall be indicated on the package as a separate item.

I-6. Copies of this specification may be obtained upon application accompanied by money order, or coupon, or cash to the Superintendent of Documents, Government Printing Office, Washington, D. C. Price 5 cents.

[ABSTRACT]

FEDERAL SPECIFICATION

FOR

\section{IMPRESSION-MATERIAL; HYDROCOLLOIDAL, DENTAL}

\section{A. APPLICABLE SPECIFICATIONS.}

A-1. There are no other Federal Specifications applicable to this specification.

B. TYPE, GRADE, AND CLASS.

B-1. This specification covers one type, one grade, and one class of impression material, hydrocolloidal.

\section{MATERIAL AND WORKMANSHIP.}

C-1. Material.-Shall be a mixture of ingredients, combined in such proportions, that the resulting material shall be uniform and suitable for taking impressions in the oral cavity or for reproducing dental models. Material may or may not contain fibers as specified. Material shall not irritate oral tissues and shall have a pleasant odor and flavor.

C-2. Workmanship.-Shall be first class in every respect.

\section{GENERAL REQUIREMENTS.}

D-1. The material shall impart a glossy surface to, and separate cleanly from, the hardened gypsum model.

D-2. Material shall not contain poisonous ingredients in sufficient concentrations to cause bodily injury by the ingestion of $30 \mathrm{ml}$. of the packaged material.

\section{E. DETAIL REQUIREMENTS.}

E-1. The material shall become sufficiently plastic when heated five minutes in a metal mixing syringe in boiling water, or ten minutes in the original container, to permit removal from the syringe or container and to permit adaptation to the impression tray. After softening and during hardening of the material, the ingredients shall not segregate. The heated material shall be homogeneous; shall have a smooth surface and be free from lumps or granules. The original container shall be such that it and the contained material can be boiled for 15 minutes without rupture of container.

E-2. Material, maintained 1 week at $20^{\circ}-25^{\circ} \mathrm{C}$., shall not support mold growth. (See par. F-2.)

E-3. Impression material shall not rupture during withdrawal from a model of which an impression has been taken. Surface of a model prepared in the impression shall be smooth upon separation. (See par. F-3.)

E-4. Temperature of gel formation.- The temperature at which the plastic mass sets to a gel shall be not less than $35^{\circ} \mathrm{C}$. $\left(95^{\circ} \mathrm{F}\right.$.) nor more than $45^{\circ} \mathrm{C}$. $\left(113^{\circ} \mathrm{F}\right.$.) (See par. $\mathrm{F}-4$.)

E-5. Strain in compression.

E-5a. The strain shall be not less than 4.0 nor more than 20.0 percent between 
a stress of 100 grams per square centimeter (1.42 pounds per square inch) and a stress of 1,000 grams per square centimeter (14.2 pounds per square inch). (See par. F-5a.)

E-5b. The set shall not exceed 3.0 percent when stresses of 100 grams per square centimeter (1.42 pounds per square inch), 1,000 grams per square centimeter (14.2 pounds per square inch), 0 grams per square centimeter $(0$ pounds per square inch), and 100 grams per square centimeter (1.42 pounds per square inch) are applied for 1 minute intervals in the foregoing sequence. (See par. $F-5 b$.)

E-5c. The compressive strength shall be not less than 2,000 grams per square centimeter (28.45 pounds per square inch). (See par. F-5c.)

E-6. Direction for mixing Impression Material, Hydrocolloidal shall be included in each package. (See par. G-1a.)

\section{F. METHODS OF INSPECTION AND TEST.}

F-1. Preparation of test specimens.-The specimens shall be prepared in accordance with the mixing directions which accompany the package.

F-2. Test for mold growth.- Not less than $25 \mathrm{ml}$. of the test specimen shall be placed in the petri dish or similar container and cooled to $20^{\circ}-25^{\circ} \mathrm{C}$. $\left(68^{\circ}-77^{\circ} \mathrm{F}\right.$.) Mold obtained from stale bread or similar substance shall be used to inoculate the material by making three parallel lines through the material with a needle which shall have been previously drawn through the bread mold.

F-3. Test for impression taking.-An impression of a specified type of metal model (fig. 1)* shall be taken with the impression material prepared as per instructions accompanying the package in a tray. The impression shall be chilled in water at $10^{\circ} \mathrm{C}$. $\left(50^{\circ} \mathrm{F}\right.$.), plus or minus $3^{\circ} \mathrm{C}$. $\left(5^{\circ} \mathrm{F}\right.$.) for fifteen minutes after which the impression and model shall be withdrawn from the water and the impression pulled from the metal model. A gypsum model shall be immediately prepared in the impression by gently vibrating the unset gypsum mixture into it and allowing it to set for 30 minutes before removal.

F-4. Test for temperature of gel formation.-Approximately $50 \mathrm{ml}$. of the material which has been softened according to the mixing directions, shall be ejected into a small metal tray (fig. 2). $\dagger$ As the material cools, a metal tube shall be pressed vertically into it until the floor of the metal tray is contacted. The tube shall then be immediately withdrawn. Near the critical point, trials shall be made every $0.5^{\circ} \mathrm{C}$. The final trials shall be made in that portion of the material lying near the thermometer bulb. The temperature of the gel formation shall be the highest temperature at which the two concentric circles caused by the inside and outside surfaces of the indenting tube are clearly and sharply outlined and the material does not cling to the polished surfaces of the tube. The rate of cooling of the specimen from $50^{\circ} \mathrm{C}$. $\left(122^{\circ} \mathrm{F}\right.$.) to the temperature of gel formation shall be $1.5^{\circ} \mathrm{C}$., plus or minus $0.5^{\circ} \mathrm{C}$., per minute. An average of three tests on the temperature of the gel formation shall be reported to the nearest degree centigrade. When the determined number falls midway between two numbers, the even number shall be recorded. (See par. I-4.)

F-5. Test for strain in compression.-A ring shall be placed on a flat glass plate and shall be slightly more than one-half filled with the heated plastic material. A mold, 1/2-inch inside diameter, 1-inch outside diameter, and 3/4-inch high, shall immediately be placed inside the ring and shall be forced into the material until the mold comes into contact with the glass plate and the material has exuded on top of the mold. A flat metal plate shall be pressed on top of the mold to remove excess material. One-half hour later the ends of the specimen shall be made flat and parallel, if necessary, by drawing the mold containing the specimen across No. 00 abrasive paper. The specimen shall then be removed from the mold and placed in an atmosphere of 100 percent relative humidity at $20^{\circ}-25^{\circ} \mathrm{C}$. $\left(68^{\circ}-77^{\circ} \mathrm{F}\right.$.) for approximately $1 / 2$ hour.

F-5a. The specimen shall then be transferred to an appropriate instrument and shall be subjected to a load calculated to produce a stress of 100 grams per square centimeter (1.42 pounds per square inch). Thirty seconds later the dial indicator shall be read. This value shall be designated as reading "A." Sixty seconds after applying a stress of 100 grams per square centimeter (1.42 pounds per square inch), an additional load calculated to produce a total stress on the specimen of 1,000 grams per square centimeter (14.2 pounds per square inch) shall be gradually applied during an interval of 10 seconds. Thirty seconds after the beginning of the stress test of 1,000 grams per square centimeter $(14.2$ pounds per square inch), a reading of the dial indicator shall be taken. This reading shall

-This illustration is printed as figure 71 of the Circular, see p. 148

†This illustration is printed as figure 67 of the Circular, see p. 144. 
be designated as reading "B." The difference between readings " $A$ " and " $B$ " divided br the original length of the specimen the original length of the specimen shall be considered as the heirht of the mold used in forming it times 100 , shall be considered as the percentage of strain between the stresses of 100 grams per -quare centimeter 1.42 pounds per square inch and 1.000 srams per square centimeter $1 \pm .2$ pounds per square inch.

F-5b. Sirty seconds after beginning the application of the stress of 1.000 gram = per square centimeter 14.2 pounds per square inch the specimen shall be released of all stress for a period of 60 seconds. Then a load calculated to produce a stress of 100 grams per square centimeter 1.12 pounds per square inch shall be applied on the specimen for 30 seconds. when a reading of the dial indicator shall be taken. This reading shall be designated as reading "C." The difference between readings " $A$ " and " $C$ " divided by the original length of the specimen, times 100 , shall be considered as the set in percent.

$F-5 b$ 1. The specimen shall be tested at $20^{\circ}-25^{\circ} \mathrm{C}$. During the test the specimen shall be protected br moistened cloth qauze to prevent excessive moisture losses. The canze shall be wrapped loosely about the specimen so as not to support it. After the test, the specimen shall be returned to an atmosphere of 100 percent relative humidity and stored there until the test on compressive strength is started.

$F-5 b$ 2. The value for strain $E-5 a$ and for set $E-5 b$ shall be reported as the arerage of tests on three specimens and shall be recorded to the nearest 0.1 percent.

F-5c. Compressive strength. - Then the specimens which were used in the tests for strain and set (F-5 are 2 hours old. ther shall be subjected to the test for compressive strength. Succesite loads calculated to produce a stress of 400 srams per square centimeter 5.65 pounds per square inch shall be applied at 50 -second intervals until rupture occurs. Each stress increment shall be gradually applied during a 10 -second interval.

F-5c 1 . The environment of the specimen during the test shall be the same as that specified in $\mathrm{F}-5$.

F-5c 2. At least two of the three specimens shall support a stress of 2.000 grams per square centimeter 28.1 pounds per square inch) without rupturing.

\section{G. PACKAGIYG. PACKING. AND MAREING FOR SHIPMENT}

G-1. Packaging.- Tnless otherwise specified the material shall be supplied in sealed airticht. collapsible tubes which shall be made of substances that shall not have a chemical affinity for. nor contaminate the impression material and which shall be sufficiently flexible to permit extrusion of the heated material. If metal tube is used. it shall have a clip securely attached. A package shall consist of 12 tubes packed in a suitable cardboard carton.

G-1a. Adequate and accurate instructions for manipulation shall accompant each package. These instructions shall include:

G-1a 1. Time and temperature requirements for softening the material in the original container and in a mixing syinge.

G-1a 2. The temperature of the material when inserted in the mouth.

G-1 a 3. The technic for chilling the impression in the mouth.

G-1a 4 . The treatment of the impression between the interval of withdrawal from the mouth and preparation of the grpsum model.

G-3a. Packages.- Tnless otherwise speciffed, packages shall bear the regular trade label, stating the contents, name of the manufacturer or contractor. net weight of contents: shall be marked with a serial number or combination of letters and number which shall refer to the manufacturer's records for the particular lot: the date of manufacture rear and month shall be indicated on the package as a separate item or as a part of the serial number.

I-4. Reference: Joturnal, American Dental Association. 27.373 (1940).

I-6. Copies of this specification may be obtained upon application, accompanied by moner order. coupon. or cash to the Superintendent of Documents, Gorernment Printing Offee, Washington, D. C. Price, 5 cents. 
[ABSTRACT]

\section{FEDERAL SPECIFICATION}

FOR

\section{DENTIFRICE; TOOTH PASTE}

\section{A. APPLICABLE SPECIFICATIONS.}

A-1. There are no other Federal Specifications applicable to this specification.

\section{B. TYPE.}

B-1. Tooth paste shall be of the paste or cream type.

\section{MATERIAL AND WORKMANSHIP.}

C-1. The tooth paste shall be free from materials other than those specified and shall be uniform in composition.

\section{GENERAL REQUIREMENTS.}

D-1. The paste shall be free of lumps or particles which are palpable in the mouth as separate or discrete particles.

D-2. The tooth paste shall, when used in the normal manner, assist in the removal of the usual daily accumulations of debris and deposits from the exposed surfaces of the teeth without injury to the teeth, mucous membrane of the mouth, or body in general.

D-3. The tooth paste, when applied undiluted to the mucous membrane of the cheeks and gums for a period of two minutes, shall not produce irritation or unpleasant symptoms.

D-4. The flavor shall be distinct and pleasant or shall be as specified in the invitation for bids.

D-5. The color shall be (A) white, (B) cream, or (C) pink, as specified in the invitation for bids.

D-6. The tooth paste shall extrude from the tube in a continuous mass at a temperature of $10^{\circ} \mathrm{C}$. $\left(50^{\circ} \mathrm{F}\right.$.) without the application of excessive force which would cause injury to the tube.

D-7. Paste extruded from the tube (orifice down) to a length of $10 \mathrm{~mm}$ at a temperature of $20^{\circ} \mathrm{C}$. $\left(68^{\circ} \mathrm{F}\right.$.) shall remain attached to the tube for at least 15 seconds.

D-8. The tooth paste shall not segregate, ferment or deteriorate when cooled to a temperature of $-15^{\circ} \mathrm{C} .\left(5^{\circ} \mathrm{F}\right.$.) for one hour or when heated to a temperature of $45^{\circ} \mathrm{C} .\left(113^{\circ} \mathrm{F}\right.$.) for 72 hours.

D-9. The formula shall accompany the bid proposal.

D-10. Bid Sample.-Each bid shall be accompanied by a 2-ounce sample of the tooth paste, for the purpose of determining flavor and color, only, which the bidder proposes to supply if awarded the contract. (The size of this tube and the label need not be in conformity with this specification.)

D-11. All deliveries shall conform in all respects to the provisions of the Federal Food, Drug, and Cosmetic Act of June 25, 1938, and to amendments and subsequent decisions thereto, all in effect on date of invitation for bids.

\section{E. DETAIL REQUIREMENTS.}

E-1. Composition. - Tooth paste shall be made from combinations of two or more of the following ingredients and within the limits specified:

E-1a. Forty percent or more (by weight) shall be from the following detergents: Calcium Carbonate, Dicalcium Phosphate, Tricalcium Phosphate, Magnesium Carbonate, Magnesium Hydroxide.

E-1b. The following detergents, preservatives and flavors are limited in their use (if used) as follows: Soap (hard or soft) U. S. P. XI, Federal Specifications $\mathrm{P}-\mathrm{S}-612, \mathrm{P}-\mathrm{S}-616, \mathrm{P}-\mathrm{S} 621$ (not over 20 percent), Sodium Benzoate (not over 2.5 percent), Thymol (not over 0.2 percent). 
E-1c. Sugars and Saccharin are permitted, except as limited by flavor or other tests.

E-1d. The use of one or more of the following detergents, plasticity and acidity regulators in proper amount shall be permitted:
1. Sodium Bicarbonate.
2. Sodium Borate.
3. Sodium Carbonate.
4. Sodium Chloride.
5. Boric Acid.
6. Citric Acid.
7. Acetic Acid.
8. Cream of Tartar.
9. Gelatine.

10. Gum Karaya.

11. Gum Tragacanth.

12. Irish Moss.

13. Petroleum Jelly.

14. Mineral Oil.

15. Alcohol.

16. Glvcerine.

17. Water.

18. Starch.

E-1e. The use of flavors and colors, permitted by the U. S. Food and Drug Administration for use as food dyes and flavors, in proper amounts, shall be permitted.

E-2. Tooth paste shall not contain appreciable amounts of the commonly recognized poisonous elements such as arsenic and heavy metals.

E-3. The $\mathrm{pH}$ value for the tooth paste, when diluted with four parts of water to one part of tooth paste (by weight) shall be greater than the number 4.9 and less than the number 10.1 , when measured at $25^{\circ} \mathrm{C}$.

$\mathbf{E}-4$. The tooth paste shall not scratch glass.

\section{F. METHODS OF INSPECTION AND TESTS.}

\section{F-1. Tests.-}

F-1a. Flavor and Color.-Inspections for flavor and color shall be made on the bid sample prior to awarding the contract. Material differences in flavor or color of the tooth paste delivered on contract shall be sufficient cause for rejection.

F-1b. Purity.- The methods specified in the U. S. P. XI shall be used for the detection of poisons and impurities. To test for the presence of inferior soaps: Extract with boiling Ethyl Alcohol (94\% or higher). Dry the residue. Extract with solvents in which soap is not soluble. Examine the residue and the fatty acids (after separating them from the soap) for odors, rancidity or other evidences of the use of an inferior grade of soap.

F-1 c. $p H$ Values.-The glass electrode and potentiometer shall be used for the determination of $\mathrm{pH}$ values.

F-1d. Abrasion. - The paste shall be placed on glass and rubbed with a metal instrument having a surface similar to the curved surface of a 5 cent coin. The glass shall be chemically clean and of the usual sodalime grade such as is used in non-corrosive microscope slides. The metal instrument shall be approximately the same hardness as the 5 cent coin. 100 double strokes shall be made. A thrust of 16 ounces shall be applied during the test. A control test of the metal instrument and glass shall be made using a lubricant such as Glycerine, Petroleum Jelly, or a known non-abrasive paste. Make this control test on the glass near the spot where the primary test was made. After both tests are completed, place the glass in hot Nitric Acid to remove particles of alloy adhering to the glass. View the glass in transmitted and reflected light without the use of a microscope. If the tooth paste test shows more scratching on the glass than does the control test, repeat the test to eliminate the possibility of accidental defective spots in the glass surface. If the repeat test shows excessive scratching by the tooth paste, the tooth paste shall be rejected.

F-1d (1). Ignore apparent polishing effects which may in some illuminations appear to be changes in surface, but which are not line scratches.

F-1e. Segregation and Fermentation.- The tooth paste shall be placed in a glass test tube stoppered and heated at $45^{\circ} \mathrm{C}$. for 72 hours after which it shall be observed for homogeneity and fermentation.

\section{G. PACKAGING, PACKING, AND MARKING FOR SHIPMENT.}

\section{G-1. Packaging.-}

G-1 a. The containers shall be of the usual collapsible tube having non-corrosive screw caps. The cap shall have a diameter at some point of $15 \mathrm{~mm}$ or over. The container including the cap shall not be attacked, chemically, by the tooth paste. Tubes shall be of tin or aluminum. Copper or similar alloying elements will be permitted as hardening agents provided they do not react with the paste or introduce dangers of poisoning. Wax lined tube will not be accepted. The area of the orifice through which the paste is to be extruded shall be greater than 13 square 
millimeters and less than 36 square millimeters. Orifices shall not have minor dimensions less than one-third the major dimension. Paint on the fold or erimp end of the tube shall not extend nearer than 3 millimeters to the end of the tube when unfolded.

I-3. Copies of this specification as well as the soap specifications P-S-612, $\mathrm{P}-\mathrm{S}-616$, and $\mathrm{P}-\mathrm{S}-621$, referred to in paragraph $\mathrm{E}-1 \mathrm{~b}$, may be obtained upon application, accompanied by money order, coupon, or cash, to the Superintendent of Documents, Government Printing Office, Washington, D. C. Price 5 cents each.

\section{AMERICAN DENTAL ASSOCIATION SPECIFICATIONS}

The American Dental Association has 12 specifications for dental restorative materials, namely, dental amalgam alloy [50], inlay casting investment [26], impression compounds [90], inlay casting wax [93], inlay casting gold alloys [34], dental mercury [35] [37], wrought gold wire alloys [40], zinc phosphate cement [73], silicate cement [74], denture rubber [94], hydrocolloidal impression material [88] and acrylic resin [99]. In most instances the Federal and the American Dental Association specifications are identical in physical and chemical requirements and differ only in details of packaging and so forth. Where no Federal specification is available the $\mathrm{ADA}$ specification is here included.

\section{AMERICAN DENTAL ASSOCIATION SPECIFICATION NO. 4 FOR INLAY CASTING WAX [93]}

A. 'Type.

A-1. This specification is for inlay casting wax used in making patterns which are to be used in the production of inlays. It consists essentially of waxes and hydrocarbons of the paraffin series.

A-2. The wax shall be furnished as sticks or cones, as specified by the purchaser.

B. Material.

B-1. The wax shall be uniform and free of foreign materials.

C. General Requirements.

$\mathrm{C}-1$. The color of the wax shall be such as to facilitate the carving of patterns through contrast with the colors of the hard and soft tissues of the mouth.

C-2. The wax shall soften without becoming flaky.

$\mathrm{C}-3$. The wax shall not show appreciable chipping or flaking when trimmed to a fine margin at room temperature.

$\mathrm{C}-4$. The melted wax when vaporized at $500^{\circ} \mathrm{C}$. $\left(932^{\circ} \mathrm{F}\right.$.) shall leave no solid residue other than carbon.

C-5. The temperature to which the wax should be heated for most satisfactory use in taking direct impressions in the dental cavity shall be indicated on each package.

C-6. A curve or data sufficient to show the thermal expansion of the wax from room temperature to the temperature at which warpage or softening of the test. specimen occurs shall be included in each package.

D. Detail Requirements.

D-1. Flow.

D-1a. The flow at $37.5^{\circ} \mathrm{C}$. $\left(99.5^{\circ} \mathrm{F}\right.$.) shall not be more than 1 per cent.

D-1b. The flow at $38.0^{\circ} \mathrm{C}$. $\left(100.4^{\circ} \mathrm{F}\right.$.) shall not be more than 5 per cent.

D-1e. The flow at $42.0^{\circ} \mathrm{C} .\left(107.6^{\circ} \mathrm{F}\right.$.) shall not be less than 5 per cent.

D-1d. The flow at $43.0^{\circ}$ C. $\left(109.4^{\circ} \mathrm{F}\right.$.) shall not be less than 50 percent or more than 75 per cent.

E. Methods of Test.

E-1. Flow.

E-1a. Specimens.-The mold used in forming the cylindrical flow specimens shall be a flat metal plate $6.0 \mathrm{~mm}$. (0.236 inch) thick, containing one or more holes $10.0 \mathrm{~mm}$. (0.394 inch) in diameter. This mold shall be warmed and placed on a smooth flat surface, which shall also be warmed slightly. Wax that has been heated to just above its melting range shall be poured into the mold until it 
is "orerfilled." As the wax freezes and a shrinkage void or pipe appears, liquid wax shall be added. When the wax has lost its "mirror-like" surface, pressure shall be applied to it and maintained until the wax becomes rigid. After cooling, the excess was shall be removed, the ends of the specimens being carred flush with the surface of the mold. The ends of the specimens shall be made plane and parallel. The specimens shall be more than 24 hours old and less than 1 week old when tested.

E-1b. Testing. - The specimen shall be placed in a bath (air or water) held at testing temperature for twenty minutes prior to testing. Thin sheets of cellophane shall be placed between the ends of the specimen and the instrument used for loading. The specimen shall then be subjected to a constant load of 2,000 $\mathrm{gm}$. for ten minutes at testing temperature. Change in length during the test shall be calculated as percentage of the original length, the specimen being measured at room temperature before and after test with a micrometer caliper. The change in length, in percentage. shall be reported as the flow.

E-2. Thermal expansion.

E-2a. The linear thermal expansion characteristics of the material shall be determined by methods which will insure an accuracy such that the expansion at any temperature is correct to \pm 0.05 per cent of the original length of the test specimen from room temperature to the temperature at which warpage occurs. This accuracy is easily obtained through the use of a specimen 200 to $300 \mathrm{~mm}$. in length.

\section{F. Packing.}

F-1. The minimum net weight of the contents shall be indicated on all pachages.

F-2. Each package shall be marked with a serial number or combination of letters and numbers which shall refer to the manufacturer's records for the particular lot or batch of wax.

F-3. The date of manufacture (rear and month) shall be indicated on the package as a separate item or as a part of the serial number.

\section{AMERICAN DENTAL ASSOCIATION SPECIFICATION NO. 6 FOR DENTAL MERCURY [35, 37]}

(Approved October 18, 1931)

I. This specification is to cover the properties of mercury for use in the produc tion of dental amalgams.

II. General requirements.

1. The mercury shall have a bright mirror-like surface free from film or scum. Under certain conditions of storage, mercury may develop a slight film. Such mercurr should readil r be separated from this film by filtration through chamois skin or some similar filtration medium, and when filtered, the mercury should remain bright after agitation with air.

2. The mercury shall pour freely and in entirety from a thoroughly clean glass container.

III. Detail requirement.

The mercury shall have a nonvolatile residue of not more than 0.02 percent when the mercury is evaporated from a porcelain crucible at a temperature below its boiling point and the crucible then ignited at a dull red heat.

IV. Methods of inspection and test.

The determination of nonvolatile residues shall be made on samples having a weight of from 10 to $15 \mathrm{gm}$.

T. Packing

1. The minimum net weight of the contents shall be marked on each pachage.

2. Mercury shall be packed in clean, clear. glass containers.

AMERICAN DENTAL ASSOCIATION SPECIFICATION NO. 7 FOR DENTAL WROUGHT GOLD WIRE ALLOYS [40]

I. Wrought gold wire alloys which are used in prosthesis and orthodontia are considered in this specification. 
Detail requirements for dental wrought gold alloys

\begin{tabular}{c|c|c|c|c|c}
\hline \hline $\begin{array}{c}\text { Gold and } \\
\text { platinum } \\
\text { group metals } \\
\text { percent }\end{array}$ & $\begin{array}{c}\text { Fusion tempera- } \\
\text { ture wire method }\end{array}$ & $\begin{array}{c}\text { Ultimate tensile } \\
\text { strength pounds } \\
\text { per square inch }\end{array}$ & $\begin{array}{c}\text { Yield strength } \\
\text { pounds per } \\
\text { square inch }\end{array}$ & $\begin{array}{c}\text { Elongation 2 inch gage length } \\
\text { per cent }\end{array}$ \\
\hline $\begin{array}{c}\text { Minimum } \\
75\end{array}$ & $\begin{array}{c}\text { Degrees F. } \\
\text { minimum } \\
1,750\end{array}$ & $\begin{array}{c}\text { "Oven-cooled" } \\
\text { minimum } \\
150,000\end{array}$ & $\begin{array}{c}\text { "Oven-cooled" } \\
\text { minimum } \\
125,000\end{array}$ & $\begin{array}{c}\text { Quenched } \\
\text { minimum } \\
15\end{array}$ & $\begin{array}{c}\text { "Oven-cooled" } \\
\text { minimum } \\
4\end{array}$ \\
\hline
\end{tabular}

II. General requirements.

1. Color. The color of the gold alloys shall be the color specified by the purchaser. This specification applies both to the white golds and to the gold-color alloys.

2. Physical properties. These shall be determined on wrought round wire in the quenched (softened) and in the "oven-cooled" (hardened) condition.

III. Detail requirements.

The detailed requirements are given in the accompanying table.

IV. Methods of inspection and test.

1. Composition. The determined values for metallic constituents shall be recorded as the nearest 0.5 per cent. When a determined value falls midway between a half and a whole number, the whole number shall be recorded.

2. Physical properties. These shall be determined on round wrought wire samples: (a) quenched: placed in a furnace at $1290 \mathrm{~F}$. for ten minutes and immediately quenched in water at room temperature; (b) "oven-cooled": placed in a furnace at $1290 \mathrm{~F}$. for ten minutes and immediately quenched in water at room temperature, then placed in the furnace at $840 \mathrm{~F}$. for two minutes and uniformly slow cooled to $480 \mathrm{~F}$. in thirty minutes.

An alloy complies with this specification when the values of the physical properties of the average of three or more out of a series of five samples meet the requirements.

3. Yield strength.

(a) The yield strength shall be determined on round wrought samples whose diameters are between 0.038 and 0.042 inch. The gage length used shall not be less than 2 inches. An averaging strain gage shall be used.

(b) An initial load calculated to produce a stress of 20,000 pounds per square inch shall be applied to the "oven-cooled" sample and the strain gage read. The load shall then be increased to the minimum value for yield strength $(125,000$ pounds per square inch) and a second reading taken. The maximum strain permitted between the limits specified is 0.0085 inch per inch. The determined value for strain shall be recorded to the nearest 0.0001 inch per inch. When the determined value falls midway between two numbers, the even number shall be recorded.

(c) As an alternate method, loads above and below the two limits specified may be applied provided they do not vary the stress by more than 1,000 pounds per square inch from the specified loads.

4. Elongation.

This shall be determined on the samples used for the test for yield point. The load shall be applied slowly (not more than twenty minutes between initial load and rupture) and continuously after the strain gage is removed until rupture occurs. Samples which break outside the gage length may be repulled. Elongation shall be measured on a 2 -inch gage length. The determined value shall be recorded to the nearest 0.5 per cent. When the determined value falls midway between a half and a whole number, the whole number shall be recorded.

5. Fusion temperature, wire method.

The fusion temperature is the lowest temperature at which a wire from 0.028 to 0.032 inch in diameter and approximately onesixteenth inch long will break when subjected to a cross bending 
V. Packing.

load of 3 ounces aroirdupois. The heating rate within $100 \mathrm{~F}$. of the breaking point shall be between 10 and 50 degrees per minute. The test is made by fusing or welding the sample under test, between two wires of a platinum, platinum-rhodium thermocouple so that the two welds or fused balls are separated by approximately one-sixteenth inch of wire. The 3-ounce weight is attached to the sample by means of a hook of high fusing noble metal nr noble metal alloy. "The hook shall have approximately the same diameter as the test sample.

1. The minimum net weight of the contents shall be marked on each package.

2. Each package shall be marked with a serial number or combination of letters and numbers which shall refer to the manufacturer's records for the particular lot or batch of alloy.

\section{AMERICAN DENTAL ASSOCIATION SPECIFICATION NO. 9 FOR DENTAL SILICATE} CEMENT [74]

\section{A. General Specification.}

(Effective July 1, 1938)

This specification is for dental cement which is to be used for restorations primarily in the anterior teeth.

B. Types.

Only one type of cement is specified.

\section{Material.}

$\mathrm{C}-1$. The cement shall consist of a powder and a liquid which when mixed in the usual dental manner will harden or set and yield a satisfactory restoration.

$\mathrm{C}-2$. The powder and liquid shall be uniform and free from poisonous foreign materials.

$\mathrm{C}-3$. Shades for the set cement shall be specified by the purchaser.

D. General Requirements.

D-1. The liquid shall be free from cloudiness, precipitates, deposits or sediment.

D-2. Cements when spatulated in the usual dental manner shall not:

D-2a. Form lumps or granules.

D-2b. Erolve gas.

D-2c. Discolor tooth structures after insertion in a tooth.

\section{E. Detail Requirements.}

$\mathrm{E}-1$. Time of setting. The time of setting shall not be less than three nor more than eight minutes.

E-2. Ultimate compressive strength. The ultimate compressive strength shall be more than $1260 \mathrm{~kg}$. per square centimeter (approximately 18,000 pounds per square inch) for specimens crushed seren dars after mixing."

E-3. Opacity. The opacity represented by the contrast ratio $\mathrm{C}_{0.70}$ shall not be less than 0.35 nor more than 0.55 . The contrast ratio $\left(\mathrm{C}_{0 \cdot 70}\right)$ is the ratio between the daylight apparent reflectance of the cement specimen $(1 \mathrm{~mm}$. in thickness) when backed by a black backing and the darlight apparent reflectance of the specimen when backed by a white backing having a daylight apparent reflectance of 70 per cent relative to magnesium oxide ( $\mathrm{MgO}$ ).

E-4. Solubility and disintegration. The solubility and disintegration of the cement shall be less than 2.0 per cent by weight when immersed for seren dars in distilled water at $37^{\circ} \mathrm{C}$. $\left(99^{\circ} \mathrm{F}\right.$.).

E-5. Arsenic content. The water soluble arsenic content of the mixed cement shall not exceed one part in 500,000 (0.0002 per cent by weight).

\section{F. Methods of Inspection and Test.}

F-1. Preparation of test specimens. The preparation of the test specimens shall be conducted at a temperature between 18 and $24^{\circ} \mathrm{C} .\left(64\right.$ and $75^{\circ} \mathrm{F}$.) and at a relative humidity between 55 and 75 per cent. The powder-liquid ratio shall be determined by the consistency test. The mixing technics employed in the preparation of all test specimens shall be according to the directions which are in the packages of the cement, except that the temperature and humidity may vary within the foregoing limits. 
All apparatus and instruments shall be clean, dry and free from particles of hardened cement.

F-2. Testing consistency. One type of apparatus for measuring consistency is shown in Figure 2 [74]. This apparatus consists of two flat glass plates, a weight and a glass tube (inside diameter approximately $10 \mathrm{~mm}$. [0.39 in.]) which will deliver $0.5 \mathrm{cc}$. of mixed cement. The combined weight of the top plate and the weight shall be $2,500 \mathrm{gm}$. (5.51 pounds).

$\mathrm{F}-2 \mathrm{a}$. Trial amounts of powder shall be mixed with 0.4 cc. of liquid. Then 0.5 cc. of mixed but unset cement shall be delivered from the glass tube on a flat glass plate. Two minutes after the mix is started, another glass plate (weighing approximately $20 \mathrm{gm}$.) and the additional weight shall be carefully placed on the soft cement. Trials shall be made until the average of the major and minor diameters of the slumped mass of cement is $25 \pm 1 \mathrm{~mm}$. (0.98 inch) ten minutes after starting the mix. The average weight of powder used in three such determinations shall be the amount of powder (combined with $0.4 \mathrm{cc}$. of liquid) necessary to produce a mix of standard consistency.

\section{G. Trme of Setting.}

G-1. A ring $5 \mathrm{~mm}$. (0.2 inch) high and $10 \mathrm{~mm}$. $(0.4$ inch) in diameter shall be placed on a flat plate and filled with cement of standard consistency. Two minutes after starting the mix, the specimen shall be transferred to an atmosphere of 100 per cent relative humidity at $37^{\circ} \mathrm{C}$. $\left(99^{\circ} \mathrm{F}\right.$.). A standard Gillmore needle, weighing $454 \mathrm{gm}$. (1 pound) and having an end $1.06 \mathrm{~mm}$. (0.0417 inch) in diameter, shall be lowered vertically until the surface of the cement is touched. This shall be repeated at frequent intervals. The time of setting is the number of minutes elapsed from the starting of the mix to the time when the needle fails to make a perceptible circle on the surface of the specimen. The setting time shall be reported to the nearest minute.

\section{H. Ultimate Compressive Strength.}

$\mathrm{H}-1$. A cylindrical mold $12 \mathrm{~mm}$. (0.472 inch) high and $6 \mathrm{~mm}$. (0.236 inch) in diameter shall be placed on a flat plate and slightly overfilled with cement of standard consistency. A second flat plate shall be pressed on top of the mold. The molds shall be made of hard rubber, glass or other substance which will not react with the cement. Three minutes after starting the mix, the molds shall be transferred to an atmosphere of 100 per cent relative humidity at $37^{\circ} \mathrm{C} .\left(99^{\circ} \mathrm{F}\right.$.). One hour later, the specimens shall be immersed in distilled water at room temperature.

$\mathrm{H}-2$. The ends of the cylinder shall be surfaced plane at right angles to the axis. The ends of the specimens may be ground flat by the use of a small amount of carborundum powder $(200$ mesh) and water. The molds containing the specimens shall be drawn back and forth across a glass plate coated with the abrasive and water. They shall be rotated about one fourth turn every few strokes. The test specimens shall be kept wet during the grinding and until after crushing. The machine used in crushing the test specimens shall be operated at a rate of speed which will move the crushing head $0.25 \mathrm{~mm}$. $(0.01 \mathrm{inch})$ a minute.

$\mathrm{H}-3$. The value for compressive strength shall be reported as the average of three or more from a lot of five specimens and shall be rounded off to the nearest $10 \mathrm{~kg}$. per square centimeter. If the values for individual specimens fall more than 15 per cent below the average, they shall be discarded and the average of the remaining specimens shall be reported. In case more than two of the specimens are eliminated, the test shall be repeated.

\section{Opacity.}

I-1. A sufficient amount of cement of standard testing consistency shall be pressed between two flat glass plates to form a disk of cement approximately $3 \mathrm{~cm}$. $(1.2 \mathrm{inch})$ in diameter and $1 \mathrm{~mm} . \pm 0.025 \mathrm{~mm} .(0.039 \pm 0.001$ inch) thick. Three minutes after the mix is started, the plates and cement shall be stored for one hour in an atmosphere having a relative humidity of 100 per cent at $37^{\circ} \mathrm{C}$. $\left(99^{\circ} \mathrm{F}\right.$.). The specimen shall then be removed from the plates and stored for one week in distilled water at $37^{\circ} \mathrm{C}$. $\left(99^{\circ} \mathrm{F}\right.$.).

I-2. A comparison of the opacities of the cement specimen and two opal glass standards with $\mathrm{C}_{0.70}$ values of 0.35 and 0.55 respectively shall be made by placing them (specimen and standards) against a variegated black and white background. A film of distilled water shall cover the cement specimens and the standards and also the space between them and the black and white backing during observations.

$406035^{\circ}-42-14$ 
In comparing the opacity $\left(\mathrm{C}_{0 \cdot 70}\right)$ of a cement with that of a glass standard, the uncertainty should not exceed \pm 0.02 . If the opacity of the specimen is between the opacities of the standards, the cement complies with this requirement.

Summary of detail requirements of A D A specification No. 9 for dental silicate cement

\begin{tabular}{|c|c|c|c|c|c|c|c|}
\hline \multirow{2}{*}{$\begin{array}{l}\text { Consistency } \\
\text { of mix }\end{array}$} & \multicolumn{2}{|c|}{$\begin{array}{c}\text { Time of setting at } 37^{\circ} \\
\text { C. }\left(99^{\circ} \mathrm{F} .\right)\end{array}$} & \multirow{2}{*}{$\begin{array}{c}\text { Ultimate } \\
\text { compressive } \\
\text { strength }\end{array}$} & \multicolumn{2}{|c|}{ Opacity } & \multirow{2}{*}{$\begin{array}{c}\begin{array}{c}\text { Solubility } \\
\text { and dis- } \\
\text { integration }\end{array} \\
\text { Maximum }\end{array}$} & \multirow{2}{*}{$\begin{array}{c}\begin{array}{c}\text { Arsenic } \\
\text { eontent }\end{array} \\
\text { Maximum }\end{array}$} \\
\hline & Minimum & Maximum & & Minimum & Maximum & & \\
\hline \multirow[b]{2}{*}{$\begin{array}{l}\text { Disk } 25 \pm 1 \\
\text { mm. in di- } \\
\text { ameter. }\end{array}$} & Minutes & Minutes & 7 days & \multicolumn{2}{|c|}{$\mathrm{C}_{0.70}$} & 7 days & $\begin{array}{c}\text { Percentage by } \\
\text { weight }\end{array}$ \\
\hline & 3 & 8 & $\begin{array}{c}\mathrm{Kg} . / \mathrm{Cm} .{ }^{2} \\
1,260 \\
\left(L b s . / I_{2} .^{2}\right) \\
(18,000)\end{array}$ & 0.35 & 0.55 & $\begin{array}{r}\text { Percentage } \\
\text { by weight } \\
2.0\end{array}$ & $\begin{array}{l}0.0002 \text { (1 part } \\
\text { in } 500,000) \text {. }\end{array}$ \\
\hline
\end{tabular}

\section{J. Solubility and Disintegration.}

$\mathrm{J}-1$. The disintegration of a cement is a measure of the erosion plus the extraction of soluble material from the cement by the action of water.

J-2. One-half cubic centimeter of cement of standard consistency shall be pressed between two flat plates until the specimen is $20 \mathrm{~mm}$. $(0.79 \mathrm{inch})$ in diameter. A piece of fine platinum wire placed in the soft cement as the specimens are formed provides a convenient means of holding the specimens. Three minutes after the mix is started, the plates and cement shall be placed in an oven at $37^{\circ} \mathrm{C}$. $\left(99^{\circ} \mathrm{F}\right.$.) in a relative humidity of 100 per cent and left for one hour.

$\mathrm{J}-3$. After one hour, the specimens shall be withdrawn from the oven and two specimens shall be placed in each tared weighing bottle and weighed. The combined weight of the two specimens and the weighing bottle, less the weight of the weighing bottle and the platinum wire, shall be taken as the weight of the specimens of cement. The specimens shall immediately be submerged by pouring 50 cc. of distilled water into the weighing bottle, which shall be stored for seven days at $37^{\circ} \mathrm{C}$. $\left(99^{\circ} \mathrm{F}\right.$.). The specinens shall then be removed from the water. There shall be no evidence of crystal growth or extensions from the surface of the specimens. The water shall be evaporated from the weighing bottle at a temperature just below $100^{\circ} \mathrm{C}$. $\left(212^{\circ} \mathrm{F}\right.$.). The weighing bottle shall then be dried at $149^{\circ}$ C. $\left(300^{\circ} \mathrm{F}\right.$.) to constant weight. The weighing bottle and contents shall be weighed. The difference between the final weight of the weighing bottle and its initial weight shall be the amount of disintegration. The gain in weight divided by the weight of the specimens times 100 gives the percentage of disintegration. The average of duplicate tests (two weighing bottles containing two specimens each) shall be reported to the nearest 0.1 per cent.

\section{K. Arsenic Content.}

$\mathrm{K}-1$. One gram of hardened cement, powdered to pass a No. 200 sieve, shall be digested in $100 \mathrm{cc}$. of distilled water on a steam bath for one hour. The filtrate shall be used in the test for water-soluble arsenic.

$\mathrm{K}-2$. The test for arsenic shall conform to that designated by the American Chemical Society recommended specification for reagent phosphoric acid. (Indus. \& Eng. Chem., 19: 1369, December 1927.) For detailed description of test, see Hillebrand and Lundell: Applied Inorganic Analysis. New York: John Wiley \& Sons, 1929, p. 217.

\section{Packaging.}

L-1. The cement powder and liquid shall be supplied in properly stoppered glass containers. The net weight of the powder shall be indicated on the container. The liquid shall be supplied in an amount 20 per cent in excess of that necessary to combine with the total amount of powder when mixed to testing consistency.

L-2. Adequate and accurate instructions for proportioning and manipulation shall accompany each package. These instructions shall include the temperature of the slab, the powder-liquid ratio, the rate of incorporating the powder and the time of mixing.

L-3. Each package of powder and liquid shall be marked with a serial number or a combination of letters and numbers which shall refer to the manufacturer's records for that particular lot or batch of cement powder or liquid. 
L-4. The date of manufacture (year and month) shall be indicated on the package as a separate item or as a part of the serial number.

REVISED AMERICAN DENTAL ASSOCIATION SPECIFICATION NO. 12 FOR DENTURE BASE MATERIAL, ACRYLIC RESIN, OR MIXTURES OF ACRYLIC AND OTHER RESINS

\section{A. General Specification.}

(Effective January 1, 1942)

This specification is for denture base material composed of polyesters of acrylic acid or substituted acrylic acids or copolymers of these with vinyl esters or styrene.

B. Types and Classes.

B-1. Types.-Denture base material shall be of the following three types:

Type I. Powder and liquid.

Type II. Plaster cake (5 $\pm 3 \mathrm{~mm}$. thick).

Type III. Powder.

B-2. Classes.-Denture base material shall be furnished in the following two classes:

Class A.-Pink.

Class B.-Clear.

C. Material and Workmanship.

C-1. Toxicity and Irritation.-No ingredient of the resins shall, after curing, be toxic or irritating to the mouth tissues.

C-2. Impurities.- The material shall be free from dirt, grit, or other objectionable foreign materials. Coloring matter shall not be considered a foreign material.

D. General Requirements.

D-1. Translucency.-A specimen (see F-4) of the cured pink resin $1 \mathrm{~mm}$. thick shall be translucent.

D-2. Satisfactory Working Qualities.-The resin when cured according to instructions furnished by the manufacturer shall yield a satisfactory denture. The cured resins shall display the following general properties:

D-2a. A smooth glossy surface.

D-2b. A smooth surface when polished.

D-2c. A smooth unchipped surface when trimmed at room temperature.

D-2d. Cured denture base shall be compatible with uncured denture base material, and a strong union shall result when additions or repairs are properly made.

D-3. Porosity.-Cross-sectioned specimens $(6 \mathrm{~mm}$. in thickness and $25 \mathrm{~mm}$. square) of the cured resin shall not show bubbles or voids by visual inspection.

D-4. Color.- The color of the cured resins shall be as specified by the purchaser.

D-4a. Class A.-The color shall be evenly distributed or uniformly mottled.

D-4b. Class B.-Clear resin shall be crystal clear.

E. Detail Requirements.

E-1. Uncured Material.- The uncured material shall meet the following requirements:

E-1a. Packing Test.-The material shall have sufficient plasticity to mold as specified in $\mathrm{F}-2$.

E-2. Cured Resin.-The cured resin shall meet the following requirements:

E-2a. Transverse Test.-The deflection of specimens (see F-3) tested in air at $37^{\circ} \mathrm{C}$. shall meet the following requirements:

\begin{tabular}{|c|c|c|c|}
\hline \multirow{2}{*}{ TYPE } & \multicolumn{3}{|c|}{ Deflection for loads $1,500 \mathrm{~g}$ to.-- } \\
\hline & $4,000 \mathrm{~g}$ & 6,00 & $0 \mathrm{~g}$ \\
\hline I, II, or III & $\underset{2.6}{\text { Maximum }}$ & $\begin{array}{r}\text { Minimum mm. } \\
3.0\end{array}$ & $\begin{array}{r}\text { Maximum }{ }_{8.0} \\
8.0\end{array}$ \\
\hline
\end{tabular}

-Deflection shall be measured from an initial load of $1,500 \mathrm{~g}$ to the load indicated.

E-2b. Sorption. - The increase in the weight of the resin shall not be more than $0.7 \mathrm{mg}$. per square centimeter of surface after immersion in water for twentyfour hours at $25^{\circ} \mathrm{C}$. (see $\mathrm{F}-4$ ). 
E-2c. Solubility.-The loss in weight of the specimen used in $E-2 b$ shall not be more than $0.07 \mathrm{mg}$. per sq. $\mathrm{cm}$. of surface.

$\mathrm{E}-2 \mathrm{~d}$. The color of the cured resin shall be stable (see $\mathrm{F}-6$ ).

F. Methods of Inspection and Test.

F-1. Preparation of Specimens.-Specimens of the cured resin shall be made from samples processed in accordance with the directions accompanying the package $(\mathrm{G}-1)$.

F-2. Packing Test.-The apparatus used in the packing test consists of: (A) A flat smooth brass die $(5 \mathrm{~cm}$. square and $1 \mathrm{~cm}$. thick) containing holes $0.75 \mathrm{~mm}$. (0.029 inch; using No. 69 drill) and $1.00 \mathrm{~mm}$. (0.040 inch; using No. 60 drill) in diameters. The holes shall be arranged around the center of the block in four concentric circles, the radius of the smallest circle being $5 \mathrm{~mm}$. The holes shall be spaced at $5 \mathrm{~mm}$. intervals on radii 22.5 degrees apart. Those of the inner circle shall be $0.75 \mathrm{~mm}$. in diameter. All others shall be $1.00 \mathrm{~mm}$. in diameter. (B) A device for applying a load of 5,000 g. (C) An air chamber, the temperature of which shall be adjusted to $\pm 5^{\circ} \mathrm{C}$ of the manufacturer's specified temperature (see $\mathrm{G}-1$ ). All of the equipment shall be brought to this temperature before the specimen is inserted.

The material shall be handled as directed by the instructions accompanying the package up to the point of packing the case. In type I material, a suitable plasticity shall be obtained within $10 \pm 5$ minutes after the start of the mix of the powder and liquid. Then $8 \pm 2 \mathrm{~g}$ of the material shall be placed on the metal die to a depth of approximately $5 \mathrm{~mm}$. The die and specimen shall be quickly transferred to the air chamber and the 5,000-g load immediately applied. Ten minutes later, the die and specimen shall be removed from the oven and the resin stripped from the die.

The material complies with the packing test if it is intruded into at least two of the smaller holes to a depth of more than $0.5 \mathrm{~mm}$.

F-3. Transverse Test. - Transverse tests shall be made on specimens $2.50 \mathrm{~mm}$. thick, $10.00 \mathrm{~mm}$. wide, and $65 \mathrm{~mm}$. long. The specimens shall be machined to dimension and finished to a smooth surface. The tolerance on the thickness and the width shall be $\pm 0.03 \mathrm{~mm}$. The prepared specimen shall be stored in water at $37^{\circ} \mathrm{C}$. for from two to four days immediately before testing in air at $37^{\circ} \mathrm{C}$. The specimen mounted in an appropriate instrument, such as is shown in Figure $1, *$ shall be placed over a $50-\mathrm{mm}$. span and the load applied in the center of the span. The bearing surfaces shall be $3.2 \mathrm{~mm}$. $(0.125 \mathrm{inch})$ in diameter. The deflection shall be measured at the center of the span by means of an indicator accurate to at least $0.01 \mathrm{~mm}$. An initial load of $1,500 \mathrm{~g}$ shall be placed on the specimen, the deflection recorded, and the additional loads (see E-2a) applied at the rate of $500 \mathrm{~g}$ per minute. The deflection shall be read one-half minute later. The deflection shall be recorded to the nearest $0.01 \mathrm{~mm}$. The difference between the deflections at the initial load and the total load shall be taken as the deflection of the specimen. The average of the recorded deflections for three specimens shall be reported to the nearest $0.1 \mathrm{~mm}$. When the determined number falls midway between two numbers, the even number shall be recorded.

F-4. Water Sorption.-The water sorption test shall be made in duplicate on disks $50 \pm 5 \mathrm{~mm}$. in diameter and $1 \pm 0.2 \mathrm{~mm}$. thick. All surfaces of the disks shall be smooth, and the top and bottom shall be flat. The specimens shall be conditioned by drying to a constant weight in an oven at $75 \pm 3^{\circ} \mathrm{C}$, cooled in a desiccator for one hour, and weighed to $0.2 \mathrm{mg}$. Constant weight shall be considered as attained when the specimen loses no more than $0.5 \mathrm{mg}$. in weight after any 24 -hour period in the oven at $75^{\circ} \mathrm{C}$.

The specimens are then immersed for 24 hours in water at $25 \pm 2^{\circ} \mathrm{C}$. At the end of this time, they are wiped with a dry cloth and weighed immediately.

The value of water sorption shall be calculated as follows for each speimen:

$$
\left.\frac{\text { wet weight-conditioned weight (mg.) }}{\text { surface area (sq. cm.) }}=\text { sorption (mg. per sq. } \mathrm{cm} .\right) \text {. }
$$

The average of the determined values for the two specimens shall be reported to the nearest hundredth milligram per square centimeter. The final value (average of two determinations) shall be rounded to the nearest $0.1 \mathrm{mg}$. per sq. $\mathrm{cm}$. When the final value falls midway between two numbers, the even number shall be recorded.

\footnotetext{
* This illustration is printed as figure 92 of the Circular, see p. 176.
} 
$\mathrm{F}-5$. Solubility. - The specimens used in $\mathrm{F}-4$ shall be used in determining solubility. After the final weighing (in $\mathrm{F}-4$ ), they shall be reconditioned to constant weight in the oven precisely as was done in $\mathrm{F}-4$. The soluble matter lost during immersion shall be determined to the nearest hundredth of a milligram per square centimeter as follows for each specimen:

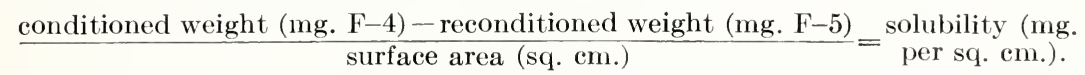

The final value (average of two determinations) shall be rounded to the nearest $0.01 \mathrm{mg}$. per sq. $\mathrm{cm}$. When the final value falls midway between two numbers, the even number shall be recorded.

F-6. Color Stability.- Smooth flat specimens of cured resin shall be exposed to the radiation of a sunlamp BM12 (General Electric) with S-1 bulb which has been in use for not less than 50 hours nor for more than 400 hours. The light source is a combination tungsten-filament mercury-arc enclosed in Corex D glass which filters out the ultraviolet light below $2800 \mathrm{~A}$. The lamp is rated at 450 watts. The specimens are carried on an aluminum disk which is centered under the $\mathrm{S}-1$ bulb and rest on a phonograph turntable operated at 33 revolutions per minute. The specimens are held approximately $5 \mathrm{~mm}$. above the disk and 5 inches from the center by screws. The plane of the specimen is 7 inches from the bottom of the S-1 bulb. Specimens the size of those used in F-4 are satisfactory. The specimens shall not show more than a slight change in color (perceptible with difficulty) after twenty-four hours of exposure, when compared with an unexposed duplicate specimen. The comparison shall be made by visual inspection in daylight.

\section{G. Packaging.}

G-1. Direction for Curing.--Adequate and accurate instructions for storing and processing shall accompany each package. These shall be such that they can be carried out with the equipment generally available in the laboratory of the dental practitioner. These instructions shall include the following: (a) temperature of flask when the resin is packed, (b) time to bring to recommended curing temperature, (c) time to hold at curing temperature, (d) how to cool flask, and (e) when to release flask.

G-2. Package Marking.--Each package of material shall be marked with a serial number or a combination of letters and numbers which shall refer to the manufacturer's records for that particular lot or batch. The resin content shall be stated on the outside of each package. For example, if the resin is a mixture of methyl and ethyl methacrylate, it shall be so stated. Names of all of the resins present in the material shall be given.

G-3. The minimum net weight of the contents shall be indicated on all packages. In type I the minimum net volume of the liquid shall be indicated.

Noтe. Federal Specification U-D-226, Acrylic Resin, is available from the Superintendent of Documents, U. S. Government Printing Office, Washington, D. C., at 5 cents a copy.

\section{BIBLIOGRAPHY}

Letters with serial numbers at the extreme right are used to designate Bureau publications. Thus $\mathrm{S}=$ Scientific Paper ; $\mathrm{T}={ }^{\prime}$ Technologic Paper; RP = Research Paper; and FS=Federal Specification. 'These may be purchased from the Superintendent of Documents, Washington, D. C. at the indicated prices. In the several congressional districts certain libraries have been designated as "Government depository libraries." In these libraries the Bureau publications may be consulted.

\section{REPORTS FROM THE NATIONAL BUREAU OF STANDARDS}

[1] Wilmer Souder and Chauncey G. Peters, Physical properties of dental materials. (Amalgam and testing equipment). Reprinted in Dental Cosmos 62, 305 (1920). T157; 10c.

[2] Dental Research. (Outline of program). J. Am. Dental Assn. 11, 249 (1924).

[3] Wilmer Souder, Physical properties of dental materials. (Problems and possibilities). J. Am. Dental Assn. 12, 509 (1925). 
[4] R. L. Coleman, Jr., Physical properties of dental materials. (Wrought gold alloys). J. Am. Dental Assn. 12, 520 (1925).

[5] Wilmer Souder, Possibilities of a specification for dental amalgams. Bul. Chicago Dental Soc. 5 (July 24, 1925).

[6] Wilmer Souder, Physical properties of dental materials. (Amalgam). Dental Dig. 32, 16 (1926).

[7] R. L. Coleman, Jr., Physical properties of dental materials. (Analysis of problems in casting gold alloys). Dental Cosmos 68, 743 (1926).

[8] Wm. H. Swanger, Analysis of dental gold alloys. Sci. Pap. BS 21, 209 (1926). Reprinted in J. Dental Research $\%, 373$ (1927). S532; 10c.

[9] Wilmer Souder, Selection of dental materials. (Casting to dimensions). J. Am. Dental Assn. 14, 189 (1927).

[10] Wilmer Souder, Dental amalgam. (Specification.) J. Dental Research 7 , 173 (1927). Latest Federal Specification April 1937. FS U-A-451a; 5c.

[11] R. L. Coleman, Jr., Casting gold alloys. (Compositions and properties). Dental Cosmos 69, 1007 (1927).

[12] George K. Burgess, Problems of research. Proc. Am. Assn. Dental Sch. 5, 76 (1928).

[13] Wilmer Souder, Dental gold alloys. (Tentative specification). J. Am. Dental Assn. 15, 627 (1928).

[14] R. L. Coleman, Jr., Physical properties of dental materials. (Summary of tests on gold alloys and accessory materials). BS J. Research 1, 867 (1928). RP32; 35c.

[15] N. O. Taylor, Mechanical amalgamation: Progress report of research on dental materials. J. Am. Dental Assn. 16, 583 (1929).

[16] N. O. Taylor, Survey of amalgam alloys: Report to the Research Commission of the American Dental Association. (See later reports for changes in this list). J. Am. Dental Assn. 16, 590 (1929).

[17] National Bureau of Standards, A statement in relation to the utilization of the name of the Bureau in advertising. J. Am. Dental Assn. 16, 1108 (1929).

[18] Wilmer Souder, Physical properties of dental materials. (Some laboratory experiments for the dental schools). J. Am. Dent. Assn. 16, 1829 (1929).

[19] N. O. Taylor, Specification for dental amalgam alloys: Report to the Scientific Foundation and Research Commission of the American Dental Association. J. Am. Dental Assn. 17, 112 (1930).

[20] N. O. Taylor, Progress report on research on dental materials (II). The research program. J. Am. Dental Assn. 17, 775 (1930).

[21] Wilmer Souder and W. T. Sweeney, Tentative specifications for dental casting investment. J. Am. Dental Assn. 1\%, 780 (1930).

[22] Wilmer Souder, Value of dental research appreciated by the profession. Iowa Dental Bul. 16, 81 (1930).

[23] Wilmer Souder, Problems in dental research. J. Dental Research 10, 547 (1930).

[24] N. O. Taylor, Amalgam technic: Dangerous and dependable practices. J. Am. Dental Assn. 17, 1880 (1930).

[25] N. O. Taylor and G. C. Paffenbarger, Survey of current inlay casting technics. J. Am. Dental Assn. 17, 2058 (1930).

[26] N. O. Taylor, G. C. Paffenbarger, and W. T. Sweeney, Dental inlay casting investments: Physical properties and a specification. J. Am. Dental Assn. 17, $2266(1930)$. FS U-I-546; 5c.

[27] N. O. Taylor, W. T. Sweeney, and G. C. Paffenbarger, Specification for inlay casting wax. J. Am. Dental Assn. 18, 40 (1931). FS U-W-141; 5c.

[28] N. O. Taylor, W. T. Sweeney, and G. C. Paffenbarger, Specification for dental impression compound. J. Am. Dent. Assn. 18, 53 (1931). FS U-M-506; 5c.

[29] N. O. Taylor, Progress report: Research on dental materials, Research Program, Cooperative work on inlay casting technic. J. Am. Dent. Assn. 18, 294 (1931).

[30] N. O. Taylor, Standards for dental materials. Iowa Dental Bul. 17, 89 (1931). Michigan State Dental Soc. Bul. 13, 26 (1931).

[31] G. C. Paffenbarger and W. T. Sweeney, Dental casting technic: Theory and practice. J. Dental Research 11, 681 (1931).

[32] N. O. Taylor, Problems involved in the study of wrought gold alloys for orthodontia. Int. J. Orthodontia 17, 1033 (1931).

[33] Wilmer Souder and W. T. Sweeney, Is mercury poisonous in dental amalgam restorations? Dental Cosmos 73, 1145 (1931). 
[34] N. O. Taylor, G. C. Paffenbarger, and W. T. Sweeney, Inlay casting golds: Physical properties and specifications. J. Am. Dental Assn. 19, 36 (1932). FS QQ-G-540; $5 c$.

[35] Aaron Isaacs, Mercury for dental amalgams. J. Am. Dental Assn. 19, 54 (1932).

[36] R. H. Volland and G. C. Paffenbarger, Cast gold inlay technic as worked out in the cooperative research at the National Bureau of Standards and applied by a group of practicing dentists. J. Am. Dental Assn. 19, 185 (1932).

[37] N. O. Taylor and G. C. Paffenbarger, Progress report on research on dental materials (1931). J. Am. Dental Assn. 19, 404 (1932).

[38] N. O. Taylor, G. C. Paffenbarger, and W. T. Sweeney, Study of wrought gold wire alloys: Preliminary report. J. Am. Dental Assn. 19, 410 (1932).

[39] G. C. Paffenbarger, Dental research at the National Bureau of Standards. Xi Psi Phi Quart. 30, 386 (1932).

[40] G. C. Paffenbarger, W. T. Sweeney, and Aaron Isaacs, Wrought gold wire alloys: Physical properties and a specification. J. Am. Dental Assn. 19, 2061 (1932). FS QQ-G-555; 5c.

[41] W. T. Sweeney, Cristobalite for dental investment. J. Am. Dental Assn. 20, 108 (1933)

[42] G. C. Paffenbarger and W. T. Sweeney, Third survey of amalgam alloys (1932-33). J. Am. Dental Assn. 20, 649 (1933).

[43] Wilmer Souder, Science aids in improving dental restorations. J. Dental Research 13, 154 (1933)

[44] G. C. Paffenbarger and W. T. Sweeney, Progress report on restarch on dental materials (1932). J. Am. Dental Assn. 20, 885 (1933).

[45] Wilmer Souder, Time required to cast dental restorations from molten alloy. J. Am. Dental Assn. 20, 1010 (1933).

[46] Research Commission, Dental Research Fellowship at the National Bureau of Standards. J. Am. Dental Assn. 20, 1040 (1933).

[47] G. C. Paffenbarger, W. T. Sweeney, and Aaron Isaacs, Preliminary report on the zinc phosphate cements. J. Am. Dental Assn. 20, 1960 (1933).

[48] Wilmer Souder, Fifteen years of dental research at the National Bureau of Standards. J. Am. Dental Assn. 21, 58 (1934).

[49] G. C. Paffenbarger and W. T. Sweeney, Second survey of dental impression compounds and of inlay casting waxes. J. Am. Dental Assn. 21, 657 (1934).

[50] G. C. Paffenbarger and W. T. Sweeney, Specifications and certifications for dental materials. (1934 revision of amalgam alloy specification). J. Am. Dental Assn. 21, 658 (1934).

[51] G. C. Paffenbarger, W. T. Sweeney, and Aaron Isaacs, Zinc phosphate cements: Physical properties and a specification. J. Am. Dental Assn. 21, 1907 (1934). FS U-C-211; 5c.

[52] Ronald Barber, Preliminary tests of some of the newer denture materials. J. Am. Dental Assn. 21, 1969 (1934).

[53] C. T. Messner, Revised list of dental materials certified to the Research Commission of the American Dental Association. J. Am. Dental Assn. 21, 2026 (1934).

[54] G. C. Paffenbarger and W. T. Sweeney, Dental research at the National Bureau of Standards in relation to orthodontia. Int. J. Orthodontia 20, 1166 (1934).

[55] Research Commission, Investigation of "Chief" White Gold "Castloy." J. Am. Dental Assn. 22, 348 (1935).

[56] R. H. Volland, American Dental Association's affliation with the National Bureau of Standards. J. Am. Dental Assn. 22,618 (1935).

[57] Research Commission, Dental research at the National Bureau of Standards. J. Am. Dental Assn. 22, 625 (1935).

[58] Research Commission, Certified amalgam alloys. A. D. A. Specification No. 1. J. Am. Dental Assn. 22, 1028 (1935).

[59] R. H. Volland, G. C. Paffenbarger, and W. T. Sweeney, Study of zinc phosphate cement by a group of practicing dentists under the direction of the A. D. A. Research Fellowship at the National Buieau of Standards. J. Am. Dental Assn. 22, 1281 (1935).

60] Research Commission, Certified inlay casting investments. A. D. A. Specification No. 2. J. Am. Dental Assn. 22, 1384 (1935).

[61] Research Commission, Certified impression compounds. A. D. A. Specification No. 3. J. Am. Dental Assn. 22, 1742 (1935).

[62] Wilmer Souder, Standards for dental materials. (Advantages). J. Am. Dental Assn. 2\%, 1873 (1935). 
[63] Wilmer Souder, Standards for orthodontic materials. Int. J. Orthodontia 21, 1003 (1935).

[64] Research Commission, Certified zinc phosphate cemonts. J. Am. Dental Assn. 23, 299 (1936).

[65] W. T. Sweeney and I. C. Schoonover, Progress report on denture base materials. J. Àm. Dent. Assn. 23, 1498 (1936).

[66] G. C. Paffenbarger and Wilmer Souder, Physical properties of the zinc phosphate cements. Proc. Ninth Int. Dental Cong. 1, 347 (1936).

[67] Wilmer Souder, Research on dental materials brings improved dental service. Proc. Ninth Int. Dent. Cong. 1, 1231 (1936).

[68] Research Commission, Report to the American Dental Association. (List of certified products). J. Am. Dent. Assn. 24, 269 (1937).

[69] Research Commission, List of certified products (1936-3\%). J. Am. Dental Assn. 24, 1355 (1937).

[70] Research Commission, Certified wrought gold wire alloys. J. Am. Dental Assn. 24, 1702 FS (1937).

[71] Wilmer Souder, Dentists rely on standards. (Certification plan.) Ind. Standard and Commer. Standards Monthly 8, 275 (1937).

[72] Wilmer Souder and I. C. Schoonover, A specification for toothpaste. J. Am. Dental Assn. 24, 1817 (1937). FS FFF-D 191a; 5c.

[73] G. C. Paffenbarger and J. R. Beall, American Dental Association No. 8 for dental zinc phosphate cements-First Revision (effective July 1, 1938). J. Am. Dent. Assn. 24, 2019 (1937). FS U-C-211; 5c.

[74] G. C. Paffenbarger, I. C. Schoonover, and Wilmer Souder, Dental silicate cements: Physical and chemical properties and a specification. J. Am. Dental Assn. 25, 32 (1938).

[75] Research Commission, List of certified products (1937). J. Am. Dental Assn. 25, 475 (1938).

[76] Research Commission, Survey of certified amalgam alloys. J. Am. Dental Assn. 25, 981 (1938).

[77] G. C. Paffenbarger and J. R. Beall, An investigation of four gypsum materials used to prepare indirect inlay models. J. Am. Dental Assn. 25, 1146 (1938).

[78] I. C. Schoonover and W. T. Sweeney, Some properties of two types of resins used for dentures (phenol and vinyl). J. Am. Dental Assn. 25, 1487 (1938).

[79] Research Commission, List of certified dental materials (as of October 1, 1938). J. Am. Dental Assn. 25, 1857 (1938).

[80] Raleigh Gilchrist, New procedure for the analysis of dental gold alloys. J. Research NBS 20, 745 (1938). RP1103; 10c.

[81] American Dental Association Research Fellowship at the National Bureau of Standards, Annual report. J. Am. Dental Assn. 26, 128 (1939).

[82] Research Commission, List of certified impression compounds. J. Am. Dental Assn. 26, 285 (1939).

[83] G. C. Paffenbarger, An investigation of a supposedly nontarnishing amalgam. J. Am. Dental Assn. 26, 990 (1939).

[84] Wilmer Souder and I. C. Schoonover, Probable chemical reactions in silicate cements (abstract). New York J. Dent. 9, 239 (1939).

[85] Research Commission, List of certified dental materials. J. Am. Dental Assn. 26, 1197 (1939).

[86] American Dental Association Research Fellowship at the National Bureau of Standards, Annual report. J. Am. Dental Assn. 26. 1728 (1939).

[87] W. T. Sweeney, Denture base material: acrylic resins. J. Am. Dent. Assn. 26, 1863 (1939).

[88] G. C. Paffenbarger, Hydrocolloidal impression materials: physical properties and a specification. J. An. Dental Assn. 27, 373 (1940). FS U-I-496; $5 c$.

[89] Research Commission, List of certified inlay casting waxes. J. Am. Dental Assn. 27, 451 (1940).

[90] W. T. Sweeney and John R. Beall, American Dental Association Specification No. 3 for dental impression compounds. J. Am. Dental Assn. 27, 713 (1940).

[91] Research Commission, List of certified dental materials. J. Am. Dental Assn. 27, 791 (1940).

[92] Research Commission, Acrylic resins. J. Am. Dental Assn. 27, 960 (1940).

[93] John R. Beall, Revision of American Dental Association Specification No. 4 for inlay casting wax. J. Am. Dental Assn. 27, 1140 (1940). FS $\mathrm{U}-\mathrm{IV}-141 ; 5 \mathrm{c}$. 
[94] W. T. Sweeney and H. J. Caul, Denture rubber: composition, properties and a specification. J. Am. Dental Assn. 27, 1446 (1940). FS ZZ-R-696; 5c.

[95] Research Commission, List of certified inlay casting investments. J. Am. Dental Assn. 2\%, 1518 (1940).

[96] G. C. Paffenbarger and H. J. Caul, Dental cements. Proceedings Dental Centenary Celebration, pages 232-237 (The Waverly Press, Baltimore, Md.)

[97] G. C. Paffenbarger, Silicate cement: an investigation by a group of practicing dentists under the direction of the A. D. A. Research Fellowship at the National Bureau of Standards. J. Am. Dental Assn. 2\%, 1611 (1940).

[98] G. C. Paffenbarger, Dental research at the National Bureau of Standards, Science 92, 527 (1940).

[99] W. T. Sweeney and G. C. Paffenbarger, Tentative American Dental Association Specification No. 12 for denture base material, acrylic resin or mixtures of acrylics and other resins. J. Am. Dent. Assn. 28, 325 (1941). FS UD-226; 5 c.

[100] I. C. Schoonover and Wilmer Souder. Corrosion of dental alloys. J. Am. Dent. Assn. 28, 1278 (1941).

[101] Research Commission, List of certified dental materials. J. Am. Dent. Assn. 28, 477 (1941).

[102] W. T. Sweeney, G. C. Paffenbarger, and John R. Beall, Comparison of acrylic resins. J. Am. Dent. Assn. 28, (1941).

\section{OTHER REFERENCES}

[103] M. L. V. Gaylor, The constitution of the alloys of silver, tin, and mercury. J. Inst. Metals, 60, 379 (1937).

[104] A. F. Romnes and E. W. Skinner, Report of a study concerning post-operative pain following restoration with amalgam. Northwestern Univ. Bul. 38, 19 (1938).

[105] Paul D. Foote, C. O. Fairchild, and T. R. Harrison, Pyrometric Practice. BS. Tech. Pap. T170 (1921); 60c.

[106] N. Kurnakow, S. Zemezuzy, and M. Zasedatelev, The transformations in alloys of gold with ooper. J. Inst. Metals. London 15, 305 (1916).

[107] F. Knoop, C. G. Peters, and W. B. Emerson, Sensitive Pyramidal diamond tool for indentation measurements. J. Research NBS 23, 39 (1939) RP1220; 10c.

[108] W. A. Price, The laws determining the behavior of gold in fusing and casting, Dental Cosmos 53, 265 (1911).

[109] W. Souder and P. Hidnert, Measurements on the thermal expansion of fused silica, Sci. Pap. BS 21, 1 (1926-27). S524; $10 \mathrm{c}$.

[110] C. H. Scheu, A new precision casting technic, J. Am. Dent. Assn. 19, 630 (1932).

[111] P. J. Brekhus and W. D. Armstrong, Civilization-a disease, J. Am. Dent. Assn. 23, 1459 (1936).

[112] Blair S. Luckie, Oxide of zinc and eugenol, Dent. Items of Interest 20, 490 (1898).

[113] D. A. Wallace and H. L. Hansen, Zinc oxide-eugenol cements, J. Am. Dent. Assn. 26, 1536 (1939).

[114] W. F. Hillebrand and G. E. F. Lundell, Applied Inorganic Analysis (John Wiley \& Sons, New York, N. Y., 1929).

[115] Chas. B. Hurd, Theories for the mechanism of the setting of silicic acid gels, Chem. Reviews 22, 403 (1938).

[116] A. D. Black, Progress in operative dentistry in recent years, J. Am. Dent. Assn. 15, 1187 (1928).

[117] W. S. Crowell, Physical chemistry of dental cements, J. Am. Dent. Assn. 14, 1030 (1927).

[118] I. G. Priest, Priest-Lange reflectometer applied to nearly white enamels, J. Research NBS 15, 529 (1935) RP847; 5c.

[119] Alphons Poller, Improved material for moulding articles of all kinds, more particularly parts of living bodies, Brit. Pat. No. 252, 112, September 4, 1925.

[120] Paul Gross, New negative mass for making accurate plastic reproductions, Arch. Path. 16, 867 (1933).

[121] T. Yanagawa and Y. Nishida, Study of agar-agar II, Reprints, Imper. Ind. Research Inst., Osaka, Japan, 11, No. 14, 1930.

[122] C. S. Van Horn, Casting: A review and commentary, including a technique, Dent. Cosmos 5\%, 873 (1910). 
[123] J. G. Lane, The casting process as applied to inlays of gold and other dental uses, Dent. Digest 15, 497, 1909.

[124] S. D. Douglas and W. N. Stoops, Polymer distribution in vinyl ester resins, Ind. Eng. Chem. 28, 1152 (1936).

[125] R. H. Gerke, Temperature coefficient of vulcanization, Ind. Eng. Chem. 31, 1481 (1939).

[126] M. S. Van Deusen, Thermal conductivity of heat insulators, Tran. Am. Soc. Heating Ventilating Engrs. 26, 385 (1920).

[127] P. B. Taylor, Factors in porosity in vulcanite, J. Am. Dent. Assn. 27, 564 (1940).

[128] H. D. Kimball, Further determinations on the strength of denture materials: condensites and vulcanites: a progress report, J. Am. Dent. Assn. 23, 1904 (1936).

[129] Howard K. Worner, Some aspects of dental significance from recent research in the dental metallographic research laboratory. 10th National Dental Congress (Melbourne) 1939, p. 232.

[130] E. M. Wise, W. S. Crowell, and J. T. Eash. The role of the platinum metals in dental alloys, Trans. Am. Inst. Mining Met. Engrs. 99 (1932).

[131] C. D. Clarke, Molding and Casting. (John D. Lucas Co., Baltimore, Md., 1939.)

[132] H. W. Gillett and A. J. Irving, Gold Inlays, by the Indirect System, p. 28 (Dental Items of Interest Publishing Co., New York, N. Y., 1932.)

[133] S. M. Shelton, Thermal conductivity of some Irons and Steels over the Temperature Range $100^{\circ}$ to $500^{\circ} \mathrm{C}$, BS J. Research 12, 441 (1934) RP669; 5c.

\section{APPENDIX}

\section{CONVERSION TABLES}

The following relations of units are added for the convenience of those wishing to evaluate data in units other than those given in the text.

The standard of length is in some instances referred to the International Prototype Meter and in others to the wavelength of light. The following equation includes this relation: 1 meter $=1,000$ millimeters $=1,000,000$ microns $=$ $1,553,164.13$ wavelengths (cadmium red). The yellow helium light, frequently used with the interferometer, has a wavelength of approximately 0.5876 micron.

A liter may be defined as a unit of capacity equal to a volume occupied by the mass of 1 kilogram of pure water at its maximum density. It is equivalent in volume to 1.000028 cubic decimeters. A milliliter $(\mathrm{ml})$ is equal to 0.001 liter, or to 1.000028 cubic centimeters $\left(\mathrm{cm}^{3}\right)$.

\section{LENGTH}

\begin{tabular}{c|c|c}
\hline \hline Millimeters & Inches & Feet \\
\hline 1 & 0.03937 & 0.00328 \\
25.4 & 1 & 1.0833 \\
304.8 & 12 & 1 \\
\hline
\end{tabular}


MASS

\begin{tabular}{|c|c|c|c|c|c|c|}
\hline \multirow[b]{2}{*}{ Grams } & \multirow[b]{2}{*}{ Kilograms } & \multicolumn{2}{|c|}{ Ounces } & \multicolumn{2}{|c|}{ Pounds } & \multirow[b]{2}{*}{ Grains } \\
\hline & & $\begin{array}{l}\text { Avoir- } \\
\text { dupois }\end{array}$ & $\begin{array}{l}\text { Troy and } \\
\text { apoth- } \\
\text { ecary }\end{array}$ & $\begin{array}{l}\text { Avoir- } \\
\text { dupois }\end{array}$ & $\begin{array}{l}\text { Troy and } \\
\text { apoth- } \\
\text { ecary }\end{array}$ & \\
\hline $\begin{aligned} 1 & \\
1000 & \\
28 . & 349 \\
31 . & 103 \\
453 . & 59 \\
373 . & 24 \\
0 . & 06480\end{aligned}$ & $\begin{array}{l}0.001 \\
1 \\
0.028349 \\
.031103 \\
.45359 \\
.37324 \\
.00006480\end{array}$ & $\begin{array}{c}\text { 0. } 03527 \\
35.274 \\
1 \\
1.0971 \\
16 \\
13.166 \\
0.002285\end{array}$ & $\begin{array}{c}0.03215 \\
32.151 \\
0.91146 \\
1 \\
14.583 \\
12 \\
0.002083\end{array}$ & $\begin{array}{l}0.002205 \\
2.2046 \\
0.0625 \\
.068571 \\
1 . \\
0.8229 \\
.0001428\end{array}$ & $\begin{array}{l}\text { 0. } 002679 \\
\text { 2. } 679 \\
0.07596 \\
.08333 \\
\text { 1. } 2153 \\
1 \\
0.0001736\end{array}$ & $\begin{array}{c}15.432 \\
15432.4 \\
437.5 \\
480 \\
7000 \\
5760 \\
1\end{array}$ \\
\hline
\end{tabular}

PRESSURE

\begin{tabular}{|c|c|c|}
\hline $\begin{array}{l}\text { Grams per square } \\
\text { millimeter }\end{array}$ & $\begin{array}{l}\text { Kilograms per square } \\
\text { centimeter }\end{array}$ & Pounds per square inch \\
\hline $\begin{array}{r}1 \\
10 \\
0.703\end{array}$ & $\begin{array}{l}0.1000 \\
1 \\
0.0703\end{array}$ & $\begin{array}{l}\text { 1. } 4223 \\
\text { 14. } 223 \\
1\end{array}$ \\
\hline \multicolumn{3}{|c|}{ AREA } \\
\hline Square millimeters & Square centimeters & Square inches \\
\hline $\begin{array}{c}1 \\
100 \\
645.2\end{array}$ & $\begin{array}{l}0.01 \\
1 \\
6.45\end{array}$ & $\begin{array}{l}0.00155 \\
0.155 \\
1\end{array}$ \\
\hline
\end{tabular}

\section{DENSITY}

\begin{tabular}{|c|c|c|}
\hline \multicolumn{2}{|c|}{ Grams per cubic centimeter } & Pounds per cubic foot \\
\hline $\begin{array}{l}1 \\
0.0\end{array}$ & & $\begin{array}{c}\text { 62. } 428 \\
1\end{array}$ \\
\hline \multicolumn{3}{|c|}{ CAPACITY-LIQUID MEASURE } \\
\hline Minims & Fluid ounces & Milliliters \\
\hline $\begin{array}{r}1 \\
480 \\
16.2311\end{array}$ & $\begin{array}{l}0.002083 \\
1 \\
0.033814\end{array}$ & $\begin{array}{l}0.06161 \\
29.5729 \\
1\end{array}$ \\
\hline
\end{tabular}

The apparently indiscriminate mixing of units (metric and English) throughout this publication will be found, upon a more careful study, to be justified upon the following conditions: (a) Approved methods of testing the material under consideration; (b) commercial practices in sales listings; and (c) convenience in the selection of testing equipment.

It is thought that the above conversion tables will be sufficient for the needs of all research workers interested in the subjects treated in the publication. 


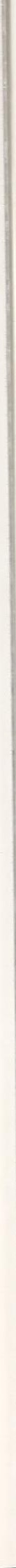




\section{N D E X}

Abrasion, dentifriee

Absorption. See Sorption.

A eidity, silieate eement

Aerylie resin. See also Methyl methaerylate. Speeifieation

Adhesiveness:

Zine phosphate eements

Apparatus for testing

Agar impression materials. See Hydrocolloid. Alloys:

Base metal

Fusing points

Melting range

Amalgam

Adaptation to cavity

Allergy

Composition of old and new

Compressive strength

Cooperator's tests

Corrosion

Dimensional ehange, influence of variables

Disintegration by heat

Effeet of meehanieal amalgamation

Eleetrode potentials

Flow

Flow meter

Improvements

Mereury vapor

Mulling in hand

Nontarnishing

Palming .

Polishing of, neeessary

Qualitative tests

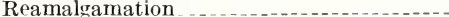

Reinforeement

Setting ehanges

Soiling of hand

Solubility

Speeifieation

Strength, eompressive

Strength, tensile

Tarnishing

Teehnie

Thermal expansion--

Amalgam alloy:

Chemieal eomposition

Silver eontent

Amalgamation, meehanieal

Amalgamators, meehanieal

Ameriean Dental Assoeiation

Lists of materials certified

Speeifieations

Amsler testing maehine

Angell, R.

Apparatus:

Casting shrinkage

Color stability

For easting specimens

For deteeting mereury vapor

For hydroeolloid testing

For measuring amalgam flow

For testing amalgam in tension

Gelation point, hydroeolloids

Heat treating

Thermal expansior

Transverse testing

Arsenie content:

Silieate eement

Zinc phosphate cement

Asbestos lining in easting ring

Associates, research.

Barber, $\mathrm{R}$

Base metal alloys:

Chemieal eomposition

Investments
$\mathbf{B}$

Page

Beall, J. R $\ldots \ldots \ldots$

Berger, $\mathrm{H}$

120 Blaek, A. D .

207 Black, G, V

Brinell hardness:

103 Instrument

104 Number

78

47 Casting ring, asbestos lining in $\ldots 91$

44 Casting to dimension, gold alloys .......... 76

3 Casting shrinkage:

Apparatus

Caul, H. J

Cavity lining:

A malgam

Silicate eement 128

Cellulose denture material

Cement:

Classifieation 93

Combination, silicate-zine phosphate....-. 136

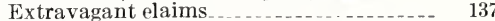

Physieal properties. 136

Copper phosphate

Oxyehloride of zine

Physieal properties ............... 96, 100, 116

Silieate:

Aeidity

Arsenie eontent _.. 116

Cavity lining _ _ _

Chaining reaetion _................... 110

Chemieal eomposition of liquid

Chemieal eomposition of powder

Chemieal reaetions in ... 111

Compressive strength . . . $\quad 117$

With time 118

Consisteney _ _ _ n

Dimensional change _....... 124

$\begin{array}{ll}\text { Discoloration } & 129 \\ \text { Dye test } & 130\end{array}$

$\begin{array}{ll}\text { Dye test } & 130 \\ \text { Effect of hydrogen sulfide } & 129\end{array}$

Effeet of size and shape of specimen upon 126

$\begin{array}{ll}\text { dimensional ehange } & 126 \\ \text { Effeet of varying technie } & 136\end{array}$

$\begin{array}{ll}\text { Effeet of varying technie } & 136 \\ \text { Effeet of water } & 128\end{array}$

Etehed surfaee.

Gel structure - ..... 110

$\begin{array}{ll}\text { Gel structure } & 122 \\ \text { Hardness } & \end{array}$

Hypothetical reaction

Index of refraetion ...... 121

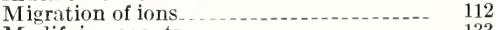

Modifying agents

Opaeity _. _ .

$\mathrm{pH}$

$\begin{array}{lr}\text { Physieal properties } & 116 \\ & 118,135\end{array}$

116,205

Powder-liquid ratio

Pulp irritation
Solubility

$\begin{array}{lr}\text { Solubility } & 119 \\ \text { Solubility of pow der } & \end{array}$

Speeifieation _. 204

Speetrochemieal analysis _._._____ 115

Staining _....... 129

Standard eonsisteney

Storage media

Teehnie ............... 116, 136

Thermal expansion

$\begin{array}{ll}\text { Time of setting } & 116 \\ \text { Variation in eonsistency } & 134\end{array}$

Variation in liquid. 132

Variations in lots 
Cement-Continued.

Silicate-Continued.

Variation in powder

Volume change

X-ray diffraction pattern

Substitute for amalpattern

Zine oxide-eugenol:

Chemical composition

Zinc oxychloride

Zinc phosphate:

Adhesiveness

Arsenic content

Chemical composition:

Liquid.

Powder

Compressive strength

Compressive strength and color

Compressive strength and powder-liquid ratio

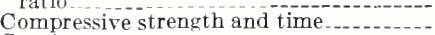

Consistency

Contact with water

Density of powders

Dilution of liquid and setting time---

Disintegration ....

Effect of hydrogen sulfide

Effect of rate of addition of pow der

Effect of storage media

Film thickness

Opacity.

Particle size of pow der

Powder-liquid ratio and compressive strength

Powder-liquid ratio and setting time-..-

Shrinkage

Specification

Technic

Temperature rise on setting

Thermal conductivity

Time of setting

X-ray diffraction pattern

Cement liquid:

Change in water content

Effects of humidity

Exposure to air

Methods of protecting

Certification policy, Research Commission, A. D. A

Certified products, Research Commission,

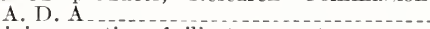

Chaining reaction of silicate cement

Chemical composition:

Amalgam

Amalgam alloy

Base metal alloys

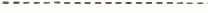

Gold alloys:

After remelting

Denturc casting

Inlay casting

Solders

Wrought wire

Uercury expressed from mix --

Liquid

Powder

Silicate-zine phosphate combination cements

Zinc oxide-eugenol cements

Zine phosphate cements Liquid

Powder

Chemical reactions of silicate cement

Chromium, alloys containing

Classification by type:

Denture base materials

Impression matcrials

Colcman, R. L

Colloidal gel. See Gel structure.

Color of zinc phosphate cement and compres. sive strength

Color stability:

Apparatus for testing

Denture base matrials

Comparater, length, for wax, compound, and investment

Compressive strength:

Amalgam
Page Compressive strength-Continued.

Page

Dentin _............. 101

Investment_......... 87

Plaster of paris

Plaster of paris

$\begin{array}{ll}\text { Effect of pow der-liquid ratio on } & 117 \\ & \end{array}$

Effect of storage media on

Effect of time on 118

Zine phosphate cement _._.

Effect of pow der-liquid ratio on

Effect of storage media on

Relation to color -101

Conductivity, thermal, of zine phosphate cements

Consistency:

Silicate cement

Variations in

Relation to powder-liquid ratio-s.

Cooling curve of gold alloy

Cooperators:

Amalgam tests

Silicate cement tests

Copper phosphate cements............. 996

Copolymer resin denture base

Corrosion:

Amalgam

Prevention in amalgam

Theorics
Cristobalite investment, thermal expansion---

Cristobalite investment, thermal expansion $-8_{--} 80,83$
Crowell, W. S

Curing shrinkage of denture base materials.-. 167

D

Defective castings of gold alloys_.._-_._._._. 42, 77

Defective materials-1919 _..._._._._._. 30

Defects in eastings.

Deformation. See Flow and elongation.

Density:

Denture base materials _._._._._._._._. 157

Zinc phosphate cement powder.......- 109

Dental casting, porosity

Dental cements, classification

Dental materials, thermal expansion.-...-. 13

Dentrifrice ......... 177

Abrasion

Scratch test_........

Specification

Tests

179 Dentin:

110 Compressive strength

Index of refraction

Opacity

3 Dentures:

80
154
 Dimensional change in service

Practical tests

38 Denture base materials

Denture hase materials
Classification

Color stahility

Confusion in field

Density

Dimensional changes

Flexural fatigue

Hardness

Ideal properties

Impact strength

Internal strain _._._._-_._- 165

Mechanical properties.-...- 171

Packing qualities

Plasticity

Porosity -160

Shelf life

$\begin{array}{ll}\text { Shelf life } & 156 \\ \text { Shrinkage during curing } & \end{array}$

Sorption

Stiffness

$\begin{array}{ll}\text { Strain pattern } & 165 \\ \text { Stress-strain relationship_...- } & 172\end{array}$

$\begin{array}{ll}\text { Stress-strain relationshlp_- } & 172 \\ \text { Tensile strength } & \end{array}$

Test specimens

Thermal conductivity

Thermal expansion

Transverse tests

Variations in properties

Denture rubber:

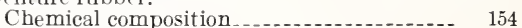


Denture rubber-Continued.

Packing test

Porosity

Specification

Vulcanization rate

Vulcanization temperature

Die-steel, for testing technic

Dimensional change:

A malgam

Influence of variables on

Dentures:

Long time tests on

Water sorption and loss

Denture base materials.

Investment

Silicate cement

Instrument for measuring

Zinc phosphate cement
Discoloration of silicate cemen

Disintegration:

Silicate cement

Zine phosphate cement

Distortion in dentures

Dye test for silicate cement

\section{E}

Elastic impression materials Elastic limit:

Definition of

Gold alloys

Relation to hardness

Electrode potentials:

A malgam

Metals

24-carat gold

Electromotive force, changes with temperature

Elongation:

Gold alloys

Relation to hardness

Enamel:

Estimate of compressive strength

Indentation hardness

Index of refraction.

Opacity

Solubility

Etched surface of silicate cement

Expansion. See Dimcnsional change or Thermal expansion.

Exposure of cement liquid, change in water content

Extensometer

Extravagant claims for hybrid or combination cement

\section{$\mathbf{F}$}

Fatigue, flexural, denture base material

Federal specifications

Film thickness, zine phosphate cement

Flexural strength. See Transverse strength.

Flexure machine

Flow:

Amalgam

Control of amalgam

Plastic impression compotond

Flow measuring instrument for wax and compound

Flow meter, amalgam

Flow specimens, inlay wax

Flow test, impression compounds

Furnace for heat treating

Fusion temperature, gold alloys

\section{G}

Galvanic action

Gayler, Marie

Gel structure:

Hydrocolloids

Silicate cement

Silicic acid

Gieler, C. W

Gold

Analytical methods

Casting to dimension

Casting shrinkage
Page | Gold alloys: Page

Chemical composition ..... 36

Comparison of casting methods

Composition, change in

Cooling curve

Defects in castings

Denture:

Chemical composition...... 38

Physical properties

Specification 188

Effects of excessive heating _........... 40

Elastic limit _........ 56

Elongation .........

Fusion temperatures.

Hardness

Hardening heat treatment

Heat treatment

Inlays:

Chemical composition_........ 37

Relation between hardness and elastic

limit

Physical properties._. 57

Specification

Life tests....... 66

Mechanical properties, interrelation...... 64

Melting.

Melting ranges

Methods of heat treating

Microstructure

Modulus of elasticity

Modulus of resiliency

Porosity from gases

Porosity from shrinkage._._._.

$\begin{array}{ll}\text { Segregation } & 39 \\ \text { Softening heat treatment. }\end{array}$

Solders:

Chemical composition

Melting range. 48

Tarnish... 41

Technic for casting

Tensile strength

Test specimens _._._.

Thermal contraction

Time required to cast.

22-carat:

Properties

Composition

Types_...

Wrought:

Chemical composition...... 38

Physical properties

Specification ......... 202

Stress-strain curves

Technics _..._........ 77

Gold foil:

Hardness

Properties

Micrograph

Technic

Government purchases

107 Gross, Paul, hydrocolloid formula

67

Gypsum

H

Hardening of metals, three methods _........ 34 Hardness:

Denture base materials . . . _........... 170

Gold alloys _............. 53

Gold foil

Knoop, indentation marks

Meaning of

Vickers

Relation to elastic limit

Relation to elongation... 66

Relation to tensile strength

Silicate cement............ 122

Table. 124

24 Hawkins, III, N. D

$\begin{array}{ll}\text { Heat treating, methods } & 76 \\ \text { Heat-treating furnace. } & \end{array}$

Heat treatment:

Apparatus for
Gold alloys
Gold alloys, effect on life test

$\begin{array}{rr}\text { Gold alloys, effect on life test } \ldots & 69 \\ \text { Hickson, E. F } & \end{array}$

Hidnert, $\mathrm{P}$.

Humidity, effects on cement liquids ..... 106, 131

69 Hurd, C. B 
Page

Hybrid cement, extravagant claims for-_._-_ 137 Mechanical properties. See Physical properHydrocal

Hydrocoll

81 ties.

Melting points of metals

Agare of

Gel structure

Gelation point apparatus

Hysteresis.

Physica

Practical tests

Specification

Stress-strain curve

Testing apparatus

143 Melting range:

149 Alloys

144 Gold alloys

144 Gold solder

Metals:
Flectrode potentials

143 Flectrode potentials _.......... 24

145 Melting points _.

Mercurochrome test

145 Mercury:

145, 196

Dental . . 33

Expressed, composition

Poisoning . .

$\begin{array}{lr}\text { Specification } & 202 \\ \text { Vapor } & \end{array}$

\section{I}

Impact inachine, Charpy type

Methyl methacrylate resin:

Denture base material_....._._._._._._. 154, 171

Impact strength of denture base materials...-

Impression compound:

Flow.

Flow-measuring instrument

Practical tests.

Test block

Thermal expansion

-

Impression materials

Technic

Types.

Index of refraction:

Dentin

(12

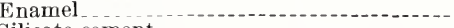

Silicate cement
Inlay casting:

Technic chart

Inlay wax:

Flow

Flow curve

Flow specimens

Practical tests

Specification

Thermal expansion

Instrument. See Apparatus.

Effect of water

Porosity 162

140 Powder-liquid and plastic cake.........

139 Specification

138 Migration of ions in silicate cements....... 112

140 Mixing technic. Sep Technic.

137 Modifying agents, silicate cements

137 Modifying agents, silicate cements $14 \ldots \ldots \ldots \ldots$

Mulling amalgam

\section{o}

121 Opacity:

Dentin

Enamel

Silicate cement

Zine phosphate cement

150 Opacity standards for silicate cements ........ 122

151 Oxychloride of zinc cement. See Cement, oxychloride of zine.

149 Oxyphosphate of zinc cement. See Cement, 201 zine phosphate.

Interferometer

Investment:

Base metal alloys

Compressive strength

Compressive strength, effect of temperature

Cristobalite, thermal expansion

Expansion, effect of powder-liquid ratio....

Hygroseopic expansion

Mold and specimen

Powder-liquid ratio

Quartz, thermal expansion

Specification

Surface defects

Technic

Test methods

Testing at elevated temperature

expansion

J

\section{J}

Jarabak, J. R

6 Packing qualities of denture base material....

Palladium:

92 In gold alloys

87

86

86
184

184
90
89

\section{K}

Knoop, F

Knoop liardness indenter

\section{$\mathbf{L}$}

Lane, J. G.

Liesegang rings

Life tests, gold alloys

Lingual bar:

Tests

Specification

Liquid, cement, method of protecting

Lists of certified materials, American Dental Association.

\section{M}

Manufacturers, not charged for certification.. Mechanical amalgamation

use of, in alloys

Palming amalgam

Peters, C. G

Petrolatum in silicate cement 133

$\begin{array}{lll}\text { pH changes in silicate cement } & 120 \\ \text { Phenol-formaldehyde resin. See Denture } & \end{array}$ base material or resin.

Physical propertics:

Amalgam

Cements of different types.

Denture base materials ............ 171

Gold alloys, denture

Gold alloys, inlay .......... 57

Gold alloys, wrought wire

Hydrocolloidal impression materials _.... 143

Impression compound ... . . . . . . 138

Inlay wax _..

Investment . . .

Silicate cements

Varying powder-liquid ratio_.

Silicate-zine phosphate cements _..._._._. 137

Stainless steel _... 79

54 Zine phosphate cements

54

Plaster of paris:

Compressive strength

Impression material

Thermal expansion _....... 85

150 Warpage of models _.__ _ 149

$\begin{array}{rll}112 & \text { Plastic impression material } & 138 \\ 66 & \text { Plasticity of denture base material } & 157\end{array}$

Poisoning:

$65 \quad$ Mercury
$190 \quad$ Vapor

190 Polarized light for detecting strains 165

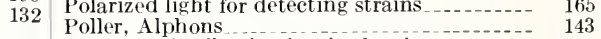

$\begin{array}{ll}\text { Poller, Alphons } & 143 \\ \text { Polymer distribution in vinyl resin } & 154\end{array}$

180 Polymer distribution in vinylresin_...... 154

Porosity:

Dental casting _._.

Denture base material

1,32 Denture rubber. 
Porosity-Continued.

Gold alloys

Methyl methacrylate resin

Reservoir to eliminate

Powder-liquid ratio:

Effect on compressive strength of zinc phosphate cement

Effect on investment expansion

Investment

Silicate cement

Zine phosphate cement, relation to consis tency.

Powder size, zinc phosphate cement

Price, IV

Proportional limit, defined

Protection of cement liquid

\section{Q}

Quartz, investment ingredient

\section{$\mathbf{R}$}

Reinforcement of amalgam

Remelting of casting alloys

Research associates of American Dental Association

Research Commission of American Dental Association

Resiliency, modulus of

Resin:

Acrylic

Methyl methacrylate

Phenol-formaldehyde

Vinyl.

Rigid impression material

Roeser, W. F

Rubber. See Denture rubber.

\section{S}

Schoonover, I. C

Scratch test for dentifrice

Segregation in gold alloys

Setting expansion. See Dimensional change.

Setting time:

Silicate cement

Zinc phosphate cement

thelf life of denture base material

Shrinkage:

Cast gold alloy

See also Dimensional change.

Shrinking investment, demonstration.......

Silica gel, theoretical reactions

silicate cement. See Cement, silicate.

Silicate-zinc phosphate combination cements

Skinner, E. W

Snover, Dorothy

Soap-like modifiers for silicate cements

Solder, gold:

Chemical composition

Physical properties

Solubility:

Amalgam

Enamel

Silicate cement:

Powder

Sorption of denture base materials 157,16

Spatulators for investments

specifications:

Acrylic resin

Amalgam

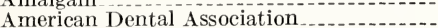

Casting gold alloys

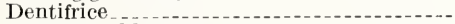

Denture rubber

Federal

Hydrocolloidal impression material

Inlay casting wax

Investment .

Mercury

Methyl methacrylate resin

Modeling compound

Silicate cement

Wrought gold wire alloy

Zinc phosphate cement

Spectrochemical analysis of silicate cement $406035^{\circ}-42$

Page |

Page

Stainless steel, mechanical properties _..... 79

72 Standard consistency of silicate cement_.... 205

Stone cements. See silicate-zinc phosphate combinations.

101 Storage media:

84 Effect on silicate cement _.....

84 Effect on zinc phosphate cements

Strader, K. H

Strain:

99 Denture base materials

terials ....... 165

Detection of by polarized light

Pattern in denture resin . . .

Vinyl resins......

32 Strength. See tensile, compressive, trans-

verse, impact.

Stress-strain curves:

Denture base materials _..._._._._._._. 173

Gold alloys, wrought wire

82

Sulfide:

Effect on zine phosphate cement_..._..... 129

Effect on silicate cement

2 Surface injury of silicate cement

Swanger, $W$. H

Sweeney, W. T $\ldots \ldots \ldots \ldots \ldots$

III, 2 Tarnish:

Amalgam ........... 4, 24

Cooperators' test of

Gold alloys

Taylor, $\mathrm{N}$ O

Taylor, P. B

Technic:

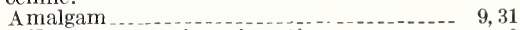

Effect of excessive trituration

Casting gold alloys

Gold foil

Impression materials . .

Investment

Silicate cement

Wrought gold alloys

Zinc phosphate cement

Technic casting in plaster of paris....... $\quad 85$

Technic chart for inlay casting

116 Teeth, thermal expansion_.............. 12

98 Temperature rise in zinc phosphate cement.-- 106

156 Tensile strength:

Amalgam

Denture base materials $\ldots . . . \ldots \ldots$

Gold alloys

86 Relation to hardness . . .

110 Tests:

A ir pressure-amalgam ................. 20

Amalgam, long time

Cooperators', on amalgam $\ldots \ldots$

Dentifrice........................... 178, 200

Gold alloys, irregular shapes

Hydrocolloidal impression materials

Qualitative amalgam

39

Test methods:

Dimensional change in silicate cement _._. . 124

Investments

Test, packing, denture rubber

Test, practical:

Denture base material $\ldots \ldots \ldots$

Denture resins

Dentures

Hydrocolloidal impression material _..... 145

Impression compound _._._._._._... 138

Inlay wax

Thermal conductivity:

Table _._. 103, 160

Zine phosphate cement

Thermal expansion:

Amalgam
Apparatus

Apparatus

Denture base material

Dental materials _.................... 13

Effect of powder-liquid ratio _._._._. 84

Impression compound _.............. 140

Inlay wax

Investments

Plaster of paris . _._.

Silicate cement

Teeth..... 12 
Page Page

Thermoplastic resin denture base

154 WTarpage of plaster of paris models

Thermosetting resin denture base

154 Water:

Time required to fill mold for gold alloys ......

Tooth paste. See Dentifrice.

Transverse testing apparatus

Transverse tests on denture base materials.

Tray impression compound

V

Van Horn, C. S

Effect on silicate cement _._._............ 128

176 Wax:

zinc phosphate cement

Flow-measuring instrument $-2=-139$

139 Inlay 149

Inlay casting specification

Weight changes in dentures

Variations in silicate cement

150 Theinstein Research Laboratories.

Vickers hardness, instrume

Number.

55 chemical composition _............... 60,38

Vinyl resin:

Internal strain

Polymer distribution

$\mathbf{X}, \mathbf{Y}, \mathbf{Z}$

Vulcanite. See Denture rubber.

Vulcanization of denture rubber

Rate

W

Walker, P. H

163

154

127

159

159

(2)

155

Wrought gold wire, specification

X-ray diffraction pattern for silicate cement _. 94, 111

X-ray diffraction pattern for zinc phosphate _._ 94, 95

Yield strength of gold alloys _.___ 189, 203

Zinc oxide-eugenol cement. See Cement.

Zinc oxychloride cement. See Cement.

Zinc phosphate cement. See Cement, zinc phosphate. 



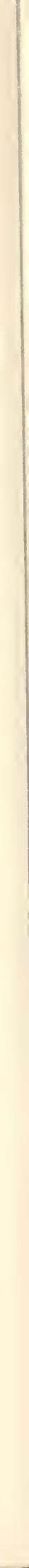


